GEAP-5722

AEC Research and

Development Report

January 1969

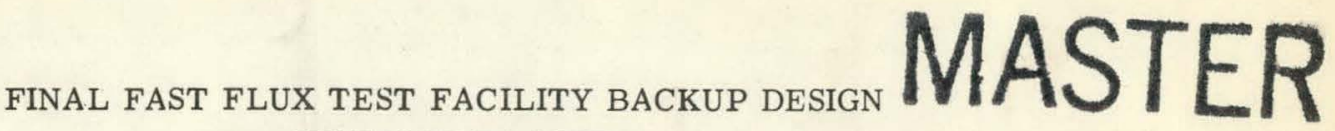 SUMMARY REPORT
}

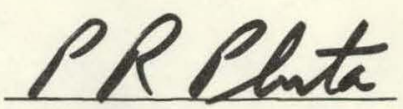

P.R. Pluta

Project Engineer

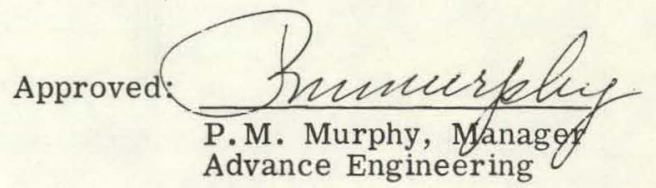

Prepared for the

U.S. Atomic Energy Commission Under Contract Number BDR-341

Between Pacific Northwest Laboratory and the General Electric Company

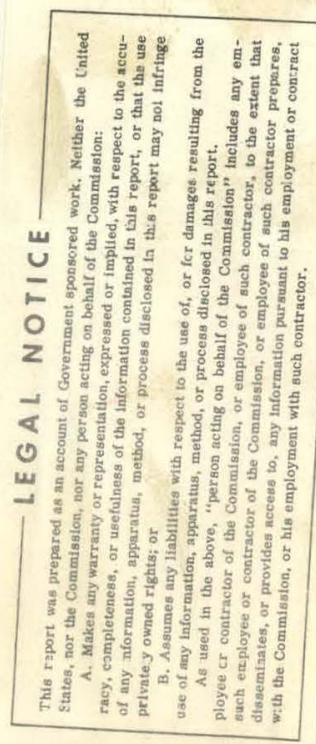

Printed in U.S.A. Available from the

Clearing House for Federal Scientific and Technical Information

National Bureau of Siandards, U.S. Department of Commerce

Springfield, Virginia

Price: $\$ 3.00$ per copy 


\section{DISCLAIMER}

This report was prepared as an account of work sponsored by an agency of the United States Government. Neither the United States Government nor any agency Thereof, nor any of their employees, makes any warranty, express or implied, or assumes any legal liability or responsibility for the accuracy, completeness, or usefulness of any information, apparatus, product, or process disclosed, or represents that its use would not infringe privately owned rights. Reference herein to any specific commercial product, process, or service by trade name, trademark, manufacturer, or otherwise does not necessarily constitute or imply its endorsement, recommendation, or favoring by the United States Government or any agency thereof. The views and opinions of authors expressed herein do not necessarily state or reflect those of the United States Government or any agency thereof. 


\section{DISCLAIMER}

Portions of this document may be illegible in electronic image products. Images are produced from the best available original document. 


\section{LEGAL NOTICE}

This report was prepared as an account of Government sponsored work. Neither the United States, nor the Commission, nor any person acting on bebalf of the Commission:

A. Makes any warranty or representation, expressed or implied, with respect to the accuracy, completeness, or usefulness of the information contained in this report, or that the use of any information, apparatus, metbod, or process disclosed in this report may not infringe privately owned rights; or

$B$. Assumes any liabilities with respect to the use of, or for damages resulting from the use of any information, apparatus, metbod, or process disclosed in this report.

As used in the above, "person acting on behalf of the Commission" includes any employee or contractor of the Commission, or employee of such contractor, to the extent that such employee or contractor of the Commission, or employee of such contractor prepares, disseminates, or provides access to, any information pursuant to bis employment or contract with the Commission, or bis employment with such contractor. 


\section{TABLE OF CONTENTS}

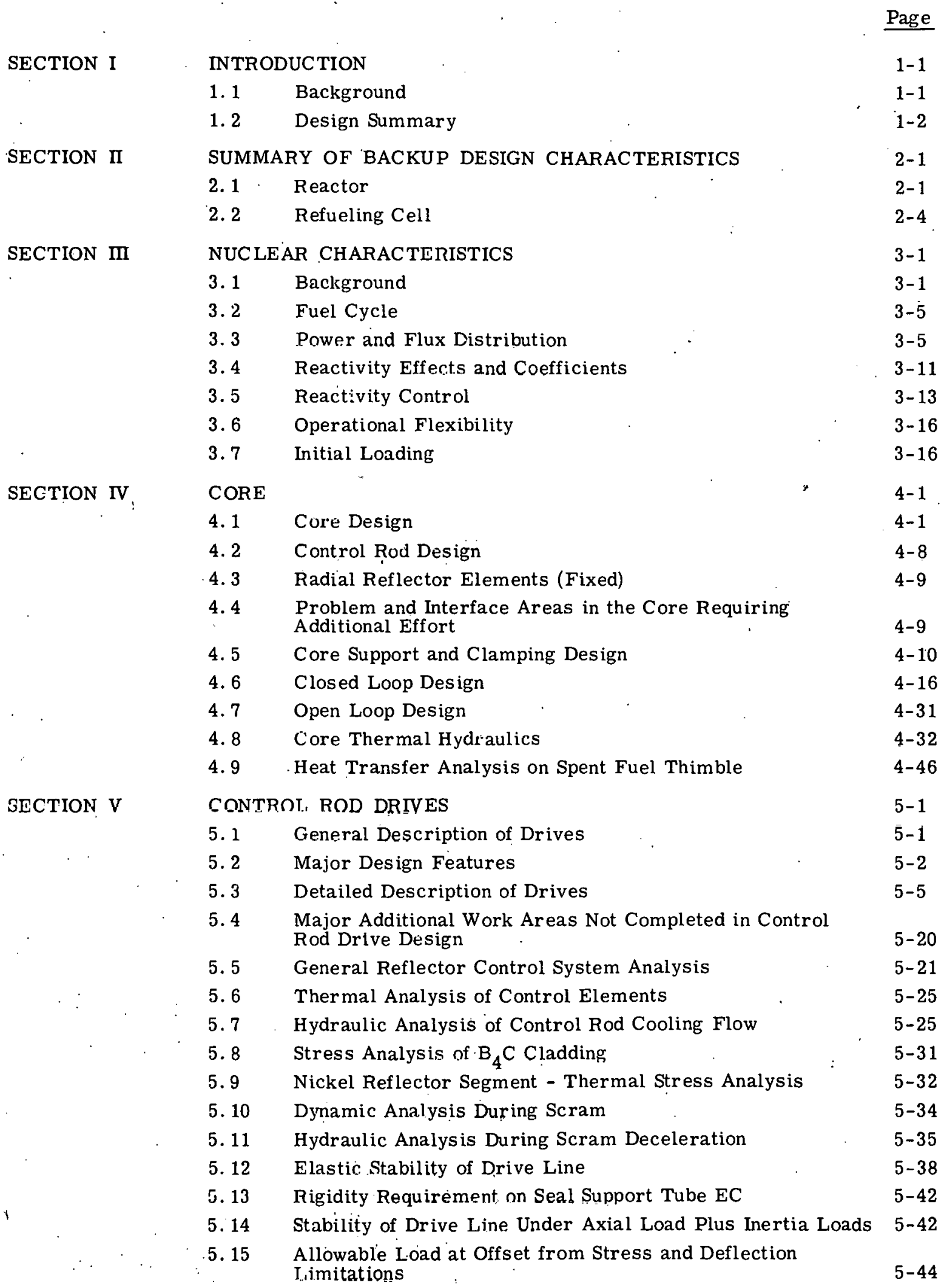


TABLE OF CONTENTS (Continued)

5.16 Allowable Impact Velocity of Control Rod

Page

5.17 Analysis of Pneumatic Cylinder during Scram

DRIVER FUEL INSTRUMENTATION FACILITIES 6-1

6.1 General Description 6-1

6.2 Temperature Measurement 6-2

6. 3 Availability-Driver Fuel Instrumentation 6-3

6. 4 Flow Measurement $\quad 6-15$

$\begin{array}{ll}6.5 \text { Acoustic Sensor } & 6-15\end{array}$

6. 6 Instrument Modules 6-15

6. 7 FEDAL System 6-21

6. 8 Instrument Module Exchange 6-21

SECTION VII

HEAD DESIGN FOR THE FFTF BACKUP REACTOR 7-1

7.1 Introduction and Functional Requirements 7-1

7.2 Head Design Description 7-2

7. 3 Structural Design . 7-9

7.4 Thermal Analysis and Cooling Requirements 7-31

7.5 Biological Shield Design $\quad$ 7-35

7.6 Plug Guidance Concepts 7-43

7. 7 Conclusions and Recommendations on Head Design 7-48

SECTION VIII SHIELDING AND RADIATION LEVELS - 8-1

. 8.1 Introduction $8-1$

8. 2 Primary Shielding $\quad$ 8-1

8. 3 Total Neutron Flux and Thermal Neutron Flux 8-8

8. 4 Gamma Dose Rate $8-8$

8.5 Refueling Cell Shield Design 8-8

8. 6 Primary Heat Exchanger and Pump Cell 8-12

8. 7 Closed Loop Cells 8-13

8. 8 Sodium Coolant Activation 8-14

8.9 Heat Generation Outside of the Reactor Vessel 8-15

8. 10 Fission Product Decay Energy 8-16

8. 11 Shielding Design Methods 8-24

SECTION DX VESSEL

9. 1 Vessel-to-Closure Interface Loading Analyses 9-1

9. 2 Vessel Height Considerations $9-2$

SECTION $\mathrm{X} \quad$ S SYSTEM DYNAMIC ANALYSIS $\quad \cdot \quad 10-1$

10.1 Introduction $10-1$

10.2 Model of Transient System $\quad 10-2$

10.3 Summary of Mild Transients Results 10-6

10.4 Summary of Severe Transients Results 10-6

10.5 5 Sodium Temperature Response to Mild Transients,
Results for Parameter Study

10.6 Results for Response to Specific Accidents Followed
by Normal Scram and Coastdown Curve 1

10.7 Sodium Temperature Response to Severe Transients 10-16 
TABLE OF CONTENTS (Continued)

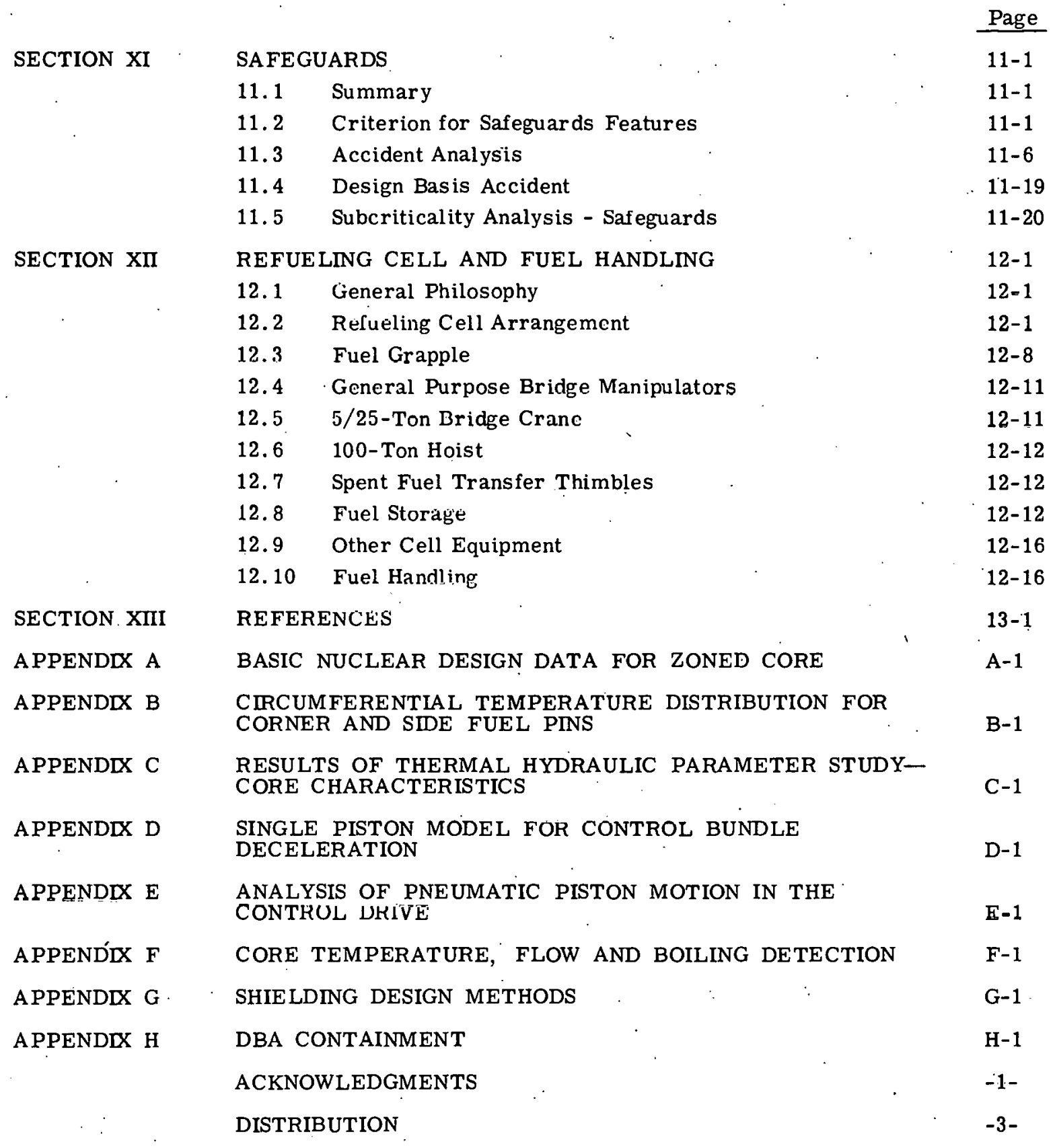




\section{LIST OF ILLUSTRATIONS}

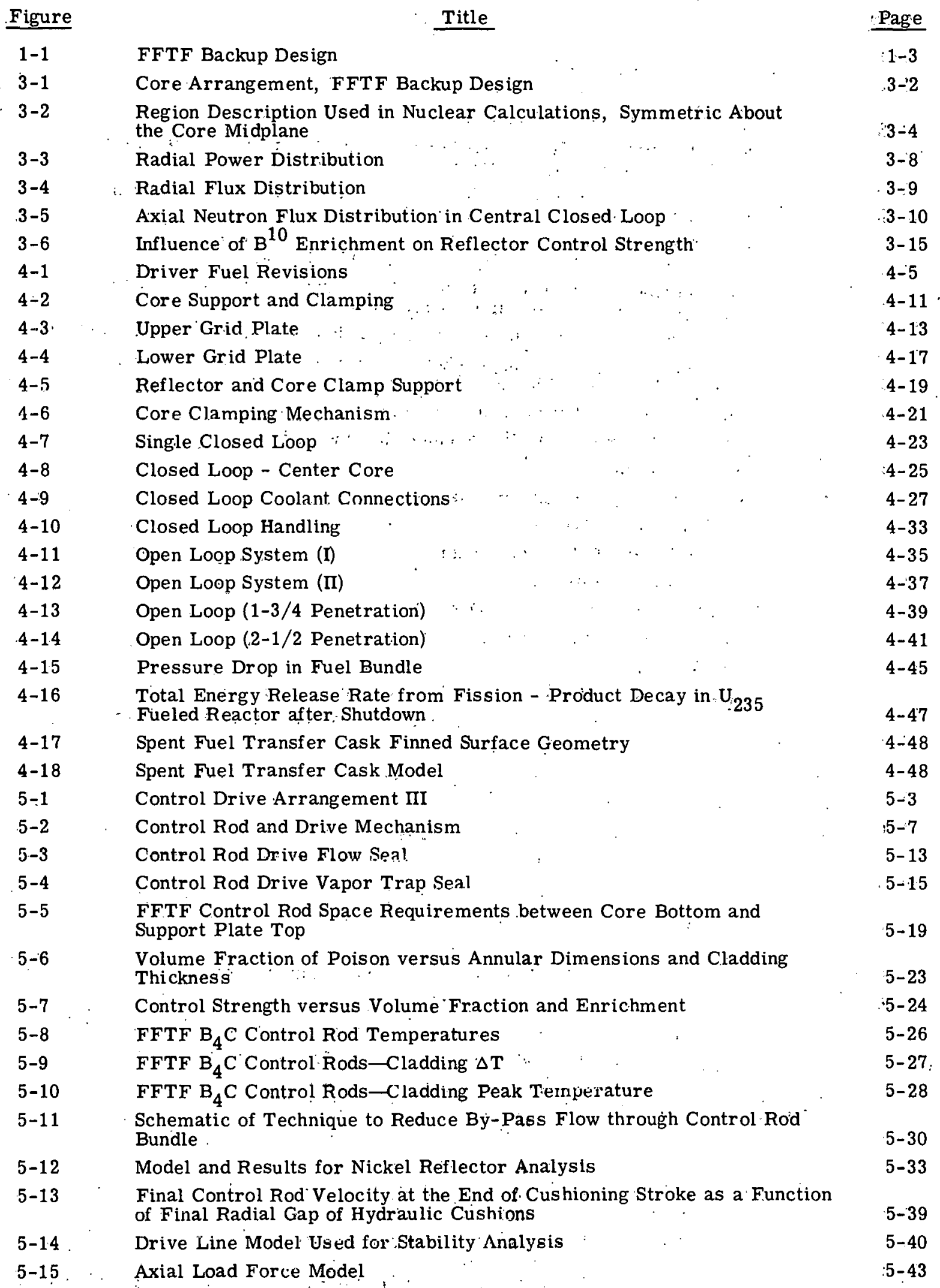




\section{LIST OF ILLUSTRATIONS (Continued)}

\begin{tabular}{|c|c|c|c|}
\hline Figure & Title & & Page \\
\hline $5-16$ & Control Element Flexure & : & $5-45$ \\
\hline $5-17$ & Spring Cushion Characteristics & & $5-49$ \\
\hline $6-1$ & Core Temperature Sensing-General & & $6-4$ \\
\hline $6-2$ & $\begin{array}{l}\text { Core Temperature Sensing-Scheme A, One Thermocouple per Channe } \\
\text { Scram on Any High Temperature }\end{array}$ & & $6-5$ \\
\hline $6-3$ & $\begin{array}{l}\text { Core Temperature Sensing-Scheme B, } 3 \text { Thermocouples per Channel } \\
\text { with Majority Logic in Fach Channel }\end{array}$ & & $6-5$ \\
\hline $6-4$ & $\begin{array}{l}\text { Core Temperature Sensing-Scheme C, } 3 \text { Thermocouples per Channel, } \\
\text { "OR", in } 3 \text { Groups, Majority Logic in Each Channel }\end{array}$ & & $6-6$ \\
\hline $6-5$ & $\begin{array}{l}\text { Core Temperature Sensing Scheme D, } 4 \text { Thermocouples per Channel, } \\
\text { (One Spare), Otherwise Same as Scheme C }\end{array}$ & & $6-6$ \\
\hline $6-6$ & Core Temperature Sensing-Scheme E, Scheme C Plus Failure Detect & ion & $6-7$ \\
\hline $6-7$ & $\begin{array}{l}\text { Core Temperature Sensing-Scheme F, Scheme E Plus Protection } \\
\text { Against Failures of } 120 \text {-Input "OR" 's }\end{array}$ & & $6-7$ \\
\hline $6-8$ & Consequences of Thermocouple Failure & & $6-8$ \\
\hline $6-9$ & Paths to Thermocouple Replacement in Scheme D & & $6-14$ \\
\hline $6-10$ & Instrumentation Module & & $6-17$ \\
\hline $6-11$ & Refueling Plug and Instrumentation. & & $6-19$ \\
\hline $7-1$ & Vessel Head - Plan View & & $7-5$ \\
\hline $7-2$ & Vessel Head - Reference Design & & $7-7$ \\
\hline $7-3$ & Vessel Head - Alternate & & $7-11$ \\
\hline $7-4$ & Head Structure (Reference Design) & & $7-13$ \\
\hline $7-5$ & Vessel Head - Penetrations & & $7-15$ \\
\hline $7-6$ & Vessel Head & & $7-17$ \\
\hline $7-7$ & Reference Head Design, Solid Plate Equivalent: Moments & & $7-20$ \\
\hline $7-8$ & Reference Head Design, Solid Plate Equivalent: Shear and Stress & & $7-21$ \\
\hline $7-9$ & Flat Plate: Design Moments & & $7-23$ \\
\hline $7-10$ & Flat Plate Design: Shear and Stress & & $7-24$ \\
\hline $7-11$ & Taper Plate No. 1: Moments & & $7-25$ \\
\hline $7-12$ & Taper Plate No. 1: Shear and Stress & & $7-26$ \\
\hline $7-13$ & Taper Plate No. 2: Moments & & $7-27$ \\
\hline $7-14$ & Taper Plate No. 2: Shear and Stress : & & $7-28$ \\
\hline $7-15$ & Taper Plate No. 3: Moments $\because$ & & $7-29$ \\
\hline $7-16$ & Taper Plate No. 3: Shear and Stress & & $7-30$ \\
\hline $7-17$ & Effective Thermal Conductivity for Honeycomb Structure & & $7-36$ \\
\hline $7-18$ & Effect of Sodium Deposition on Honeycomb Conductivity & . & $7-37$ \\
\hline $7-19$ & Gamma Dose Rate* Versus Height Above Core Midplane & & $7-38$ \\
\hline $7-20$ & $\begin{array}{l}\text { Total Neutron Flux and Thermal Neutron Flux Verșus Height Above } \\
\text { Core Midplane }\end{array}$ & & $7-39$ \\
\hline $7-21$ & Instrument Lead Penetration in the Top Head & & $7-42$ \\
\hline $7-22$ & Guide Structure & & $7-45$ \\
\hline $8-1$ & Core Shielding Schematic-Elevation & & $8-2$ \\
\hline $8-2$ & $\begin{array}{l}\text { Fast Neutron Fluence: nvt }>1.0 \mathrm{MeV} \text { and nvt }>0.1 \mathrm{MeV} \text { Versus } \\
\text { Radial Distance from Center of Core }\end{array}$ & & $8-4$ \\
\hline $8-3$ & $\begin{array}{l}\text { Fast Neutron Fluence: nvt }>1.0 \mathrm{MeV} \text { and nvt }>0.1 \mathrm{MeV} \text { Versus } \\
\text { Height Above Core Midplane }\end{array}$ & & $8-5$ \\
\hline $8-4$ & Fast Neutron Fluence: nvt $>1.0 \mathrm{MeV}$ Versus Depth Below Core Midpl & & $8-6$ \\
\hline
\end{tabular}




\section{LIST OF ILLUSTRATIONS (Continued).}

Figure

8-5

8-6

$8-7$

8-8

$8-9$

8-10

8-11

9-1

9-2

9-3

$9-4$

$9-5$

9-6

$9-7$

10.-1

$10-2$

10-3

$10-4$

$10-5$

$10-6$

10-7

10-8

10-9

$10-10$

10-11

10-12

$10-13$

$10-14$

$10-15$

10-16
Title

Total Neutron Flux and Thermal Neutron Flux Versus Radial Distance from Core Center

Gamma Dose Rate Versus Radial Distance from Core Center

Absorbable Energy Released by Fission Products Following Infinite Reactor Operation

Absorbable Energy Released by Fission Products Following Infinite Reactor Operation

Absorbable Energy Released by Fission Products for Operating Times Varying from One Hour to $\infty$ Versus Cooling Time

Absorbable Energy Released by Fission Products for Operating Times Varying from One Hour to $\infty$ Versus Cooling Time

8-9

8- 10

8-18

$8-19$

$8-20$

8-21

8-22 (6 to 16 months)

9-3

$9-4$ : and Flange

Temperature Gradient after Scram-Vessel Upper Wall Between Sodium Outlet and Flange

$9-5$

Vessel Flange Transient Temperatures $\left(50^{\circ} \mathrm{F} / \mathrm{h}\right)$, Sodium Temperature Transient $450^{\circ} \mathrm{F}-1200^{\circ} @ 50^{\circ} \mathrm{F} / \mathrm{h}$, Time $=900$ Minutes

Vessel Flange Transient Temperatures $\left(100^{\circ} \mathrm{F} / \mathrm{h}\right)$, Sodium Temperature Transient $450^{\circ}-1200^{\circ} @ 100^{\circ} \mathrm{F} / \mathrm{h}$, Time $=450$ Minutes

Maximum Length Vessel

$9-7$

9-8

$9-9$

$10-3$

$10-5$

Flow Coastdown Characteristics

Comparis on of the Effect of the Coastdown Curves on the Sodium-

Temperature Response. Conditions: Scram and Coastdown at Time, $\mathbf{t}=\mathbf{0}$

$10-10$

Coastdown with Curve No. 1 Channel Outlet Sodium Versus Time

Effect of Time Between Scram Signal and Start of Rod Drop, Scram

Signal at Time, $t=0$, Coastdown with Curve No. 1 at Time, $t=0$, Channcl. Outlet Sodium Versuls Time.

$10-11$

$10-13$

$10-14$

$10-15$

Mild Accident Sodium Temperature Response at Vessel Outlet

$10-17$

$10-18$

$10-21$

$10-22$

$10-23$

No Scram-Full Flow

$10-24$

10-25

Coastdown Curve No, 1

$10-26$ 


\section{LIST OF ILLUSTRATIONS (Continued)}

\begin{tabular}{|c|c|c|c|c|}
\hline igure & & Title & & Page \\
\hline $10-17$ & & $\begin{array}{l}\text { Sodium Temperatures Above Core-All Pumps Trip Without Scram. } \\
\text { Coastdown Curve No. } 2\end{array}$ & & $10-27$ \\
\hline $0-18$ & & $\begin{array}{l}\text { Core Temperatures-All Pumps Trip W'ithout Scram. Coastdown } \\
\text { Curve No. } 2\end{array}$ & & \\
\hline $1-1$ & & Control Reactivity & & $1-10$ \\
\hline $1-2$ & & Pump Coastdown (FERMI-12000 gpm) & & $1-11$ \\
\hline $1-3$ & & Percent Melting at Core Hot Spot Reactivity Transients ... & & $11-12$ \\
\hline $1-4$ & & Peak Cladding Temperature During. Reactivity Transients" & & $11-1$ \\
\hline $1-5$ & . & Peak Coolant Outlet Temperature Reactivity Transients & & $1-1$ \\
\hline $1-6$ & & $\begin{array}{l}\text { Peak Coolant and Cladding Temperatures Normal Scram With Flow } \\
\text { Coastdown }\end{array}$ & & $1-1$ \\
\hline $1-7$ & & Coolant Temperature Response to Blockage & & $11-1$ \\
\hline $1-8$ & & Time to Reach Boiling in Hot Channel as Function of Blockage & & $1-1$ \\
\hline $1-9$ & $\therefore$ & $\begin{array}{l}\text { Schematic Diagram of Two Detector Two Channel Cross Correlation } \\
\text { Measurement }\end{array}$ & & $11-2$ \\
\hline $1-10$ & & $\begin{array}{l}\text { Modulus of Zero Power Transfer Function for FFTF as a Function } \\
\text { of Subcriticality }\end{array}$ & & $11-26$ \\
\hline $11-11$ & & FFTF Backup Deșign Core and Reflector Arrangement $(\mathrm{cm})$ & & $11-29$ \\
\hline $1-12$ & & Detector Efficiency vs Radial Distance & & $11-31$ \\
\hline $1-13$ & $\therefore$ & Detector Efficiency vs Height & & $11-3$ \\
\hline $1-14$ & & $\begin{array}{l}\text { Reactivity Uncertainty vs Radius ( } 1 \mathrm{gm} \mathrm{B}{ }^{10} \text { Detector, FFTF Backup } \\
\text { Design) }\end{array}$ & & $11-:$ \\
\hline $1-15$ & & ity Uncertainty vs Height $\left(1 \mathrm{gm} \mathrm{B}{ }^{10}\right.$. Detector, FFTF Backup & & $11-3$ \\
\hline $1-16$ & & $\begin{array}{l}\text { ty } Y^{\prime} \text { rsus Reactivity for Several Detectors } \\
\text { at Radial Reflector-Support Structure Boundary }\end{array}$ & & $11-3$ \\
\hline $2-1$ & & Reactor Systems Arrangement-Plan (Similar to GE Drawing 153F674) & & $12-3$ \\
\hline $2-2$ & & Reactor System Arrangement-Elevation (Similar to GE Drawing 153 F674 & & $12-5$ \\
\hline $2-3$ & & Fuel Grapple $\quad \therefore \quad \cdots$ & & $12-9$ \\
\hline $2-4$ & & Transfer Thimble (Similar to GE' Drawing 153 F668) & & $12-13$ \\
\hline $2-5$ & & orage Tanks : : & & $12-1$ \\
\hline $2-6$ & & Fuel Transfer Sequence (Similar to GE Drawing 919D493) & & $12-19$ \\
\hline B-1 & & Typical 127-1 & & B-2 \\
\hline$B-2$ & & 1 Pin Geometry & & $B-5$ \\
\hline B-3 & & Model for Velocity Distribution Calculations & & B-7 \\
\hline B-4 & & Momentum Balance on Elemental Volume $\mathrm{dA} \cdot \mathrm{dz}$ & & B-7 \\
\hline $3-5$ & & Forces on Elemental Volume $\Delta \mathrm{A}$ df & & B-10 \\
\hline$B-6$ & & for Temperature Distribution Calculations & & B-15 \\
\hline$C-1$ & & Driver Fuel $A$ & & $\mathrm{C}-2$ \\
\hline $\mathrm{C}-2$ & & Velocity of Sodium Coolant Through the Fuel Bundle. & & $\mathrm{C}-3$ \\
\hline$C-3$ & & $\begin{array}{l}\text { Variation of (a) Peak Linear Power and (b) Average Linear Power } \\
\text { with Pitch/Diameter Ratio }\end{array}$ & & $\mathrm{C}-4$ \\
\hline$C-4$ & & Integral of $\cdot \mathbf{K d} \theta$ & & $\mathrm{C}-5$ \\
\hline$C-5$ & & Total Pressure Loss from Plenum to Plenum & & $C-6$ \\
\hline$C-6$ & & $\begin{array}{l}\text { Pressure Loss from Frictional, Entrance, and Exit Effects for Fuel } \\
\text { and Gas Plenum Section Only }\end{array}$ & & $C-7$ \\
\hline-1 & & Dynamic Control Drive Model Schematic $\quad . \quad$. & & E-1 \\
\hline
\end{tabular}




\section{LIST OF ILLUSTRATIONS (Continued)}

Figure

F-1

F-2

F-3

G-1

G-2

G-3

G-4

$\mathrm{H}-1$

$\mathrm{H}-2$
Title

Page

Simplified Thermocouple Electrical Circuit

F-4

Power Versus Time for Water Boiling With Frequency, $\mathrm{Hz}$, as a Parameter

F-20

$F-21$

$\mathrm{Hz}$, as a Parameter

Comparison of the Results from a 31-Group Calculation and a 15-Group

Calculation: Tntal Neutron Flux Versus Height Above Core Midplane

G-2

Comparison of the Results from a 31-Group Calculation and a 15-Group

Calculation: Thermal Neutron Flux Versus Height Above Core Midplane

Comparis on of the Results of a 31-Group Calculation and a 15-Group Calculation: Gamma Dose Rate* Versus Height Above Core Midplane

Comparison of the Results from a 31-Group Calculation Versus a 15-

Group Calculation: $n v t\left(\mathrm{E}_{\mathrm{n}}>1.0 \mathrm{MeV}\right)$ Versus Height Above Core Midplane

Deflection of Vessel and Blast Cylinders

$\mathrm{H}-10$

$\mathrm{H}-11$ 


\section{LIST OF TABLES}

Table

$3-1$

$3-2$

3-3

$3-4$

$3-5$

$3-6$

3-7

3-8

$3-9$

4-1

4-2

4-3

4-4

5-1

5-2

5-3

$5-4$

5-5

5-6

$5-7$

$5-8$

5-9

6-1

7-1

7-2

7-3

7-4

8-1

8-2

$8-3$

$8-4$

8-5

8-6

$8-7$

$8-8$

10-1

10-2
Title

Core Arrangement and Description of a Driver Fuel Bundle

Energy Structure of FFTF Backup Design 16 Group Cross Section File

Energy Produced per Fission

Region Dependent Batch Loading and Fuel Isotopic Atom Fractions

Power Peaking Factors at Beginning of Cycle

U-238 Doppler Coefficient

Temperature Reactivity Effect for the FFTF Backup Zoned Core at the End of an Equilibrium Burnup Cycle Assuming No Control Inserted

Assumed Material Temperatures and Average Linear Expansion

Control Requirements

is

Des ign Parameters for the FFTF Backup Design Fuel Element Assembly

Design Criteria and Data for the In-Core Safety Rods

Thermal Hydraulic Parameters Used to Calculate Peak Allowable Power Generation

Temperature Distribution in Finned Transfer Thimble

Control Drive Valve Characteristics

Parameters Selected for Calculation of $\mathrm{B}_{4} \mathrm{C}$ Control Rod Temperatures

Summary of Control Bundle Bypass Flow Characteristics

Control Rod Deceleration Using the Control Rod Channel Hydraulic Piston

Control Rod Channel Hydraulic Cushion With Eccentricity

and Tolerance Effects

Critical Load as a Function of Assumed Drive Geometry

Allowable Moment from Deflection - Clearance Compatibility

Section Modulus and Allowable Bending Moment for Various Control Rod Configurations

Allowable Moment from Stress Limits

Plant Unavailabilities of Various Instrumentation Schemes

Summary of Head Heat Loads

Heat Transfer Analys is for FFTF Head

Dose Rates at the Upper Surface of the Top Head: Radiation Streaming Through Annular Plug Gaps

Dose Rates at the Upper Surface of the Top Head: Radiation Streaming Through Specific Types of Top Head Penetrations

Material Compositions for the Radial Shield

Material Compositions for the Upper Axial Shield

Material Compositions for the Lower Axial Shield

Calculated Formation Rate in FFTF Primary Coolant Sodium

Saturated Specific Activity of Sodium in the Primary Coolant Sodium

FFTF Backup Design, 400 MW Thermal, Gamma Heat Generation Rate in the Components Located Externally Adjacent to the Reactor Vessel

Energy Release Rate from Fission Product Decay in a U-235 - Fueled Reactor after Shutdown

Fission Product and Np-239 Decay Heat Absorbed (kW) in an FFTF Fuel Bundle and Fuel Transfer Thimble Versus Irradiation Period and Shutdown 'T'ime

Maximum Negative Sodium Temperature Gradients for Simultaneous Coastdown and Scram Gradient $\left({ }^{\circ} \mathrm{F} / \mathrm{sec}\right)$
Page

3-3

3-3

3-5

3-6

3-7

3-11

3-11

3-12

3-14

4-2

4-9

4-43

4-50

5-6

5-25

5. -29

5-37

5-37

5-41

5-46

5-47

$5-47$

6-15

7-31

7-32

7-11

7-41

8-3

8-7

8-7

8-14

8-15

8-16

8-23

10-7 


\section{LIST OF TABLES (Continued)}

Table

Title

Page

11-1

Fuel Overpower Damage Severity Criteria

11-4

11-2

Cladding Overtemperature Criteria

$11-5$

11-3

Design Transients for Consideration

$11-8$

A-1

Assumed Temperatures for Expansion Effects and Linear Expansion from Room Temperature

A-1

$A-2$

Calculation of Atom Densities

A-2

A-3

Bundle Type Volume Fractions

A-3

Material Densities and Dimensions.

A-4

A-4

Volume Fractions by Composition

A -5

A-6

Composition ky hiex Type

A-6

$\mathrm{F}-1$

Normal Instrumentation Requirements

$\mathrm{F}-2$

$\mathrm{F}-2$

Statement of Requirements for $\vec{F} F \mathbf{F}$ Fuel Channe! Flowmeter

$F-8$ 


\section{SECTION I}

\section{INTRODUCTION}

\subsection{BACKGROUND}

The objective of the FFTF backup design was to provide the capability for replacing the reference FFTF dispersed core design at any point in its evolution with an open latiice vertical core, and associated handling system, instrumentation, control rod and head configuration making use of the reference design vessel, hot cell, coolant system, etc. Contract BDR-341 and its attached Statement of Work between Pacific Northwest Laboratories and the General Electric Company authorized that the backup design be developed witn sufficient design deiai!s and design specifications to establish its feasibility when coupled with the required engineering development program. Layout drawings were to be completed in sufficient design detail to obtain cost estimates, establish feasibility, and allow development of shop fabrication drawings from the basic information contained.

The General Electric Company was advised by Pacific Northwest Laboratories in October 1968, that a new reference FFiF concept had been selected. PNL requested that all design activity on the GE backup design be terminated anc' the completed work be summarized in a Final Design Report. In addition, PNL requested that a document describing the development programs to support the bacliup design concept be prepared. Reports which describe the GE work and complement this backup design summary report are:

1. GEAP-4470 - An Engineering Review of the Fast Flux Test Facility-Phase I; J. H. Field (May 1966).

2. GEAP-5290 - Fast Flux Test Facility Functional Requirements; C.N. Spalaris (Octobe: 1966).

3. GEAP-5422 - Fast Flux Test Facility Phase II-Study-A Conceptual Design of the Fast Flux Test Facility Reactor System; W. J. Clabaugh (December 1966).

4. GEAP-5551 - The Selection of a Pipe Loop System for the Fast Flux Test Facility; W. W. Kendall and G. B. Kruger (October 1967).

5. GEAP-5552 - Conceptual Design of the Backup Reaçtor System for the Fast Flux Test Facility; D. R. Riley (August 1967).

6. GEAP-5660 - Sodium Temperaturc Response to Transients in the Fast Flux Test Facility Conceptual Backup Design and Description of Dynamics Model; A. B. Reynolds and P. C. Vaughan (September 1968).

7. GEAP-5550 - Fast Flux Test Facility Backup Design Project-First Quarterly Report, May-August 1967.

8. GEAP-5614 - Fast Flux Test Facility Backup Design Project-Second Quarterly Report, September-November 1967. 
9. GEAP-5641 - Fast Flux Test Facility Backup Design Project-Third Quarterly Report, December-February 1968.

10. GEAP-5650 - Fast Flux Test Facility Backup Design Project-Fourth Quarterly Report, March-May 1968.

11. GEAP-5684 - Fast Flux Test Facility Backup Design Project-Fifth Quarterly Report, June-August 1968.

12. GEAP-5715 - Fast Flux Test Facility Backup Design Development Report; P.R. Pluta (January 1969).

13. GEAP-5721 - Fast Flux Test Facility Backup Design Interface Definition, Discussion of System Requirements; G. Kruger. W.W. Kendall and D. Mitome (January 1969).

\subsection{DESIGN SUMMARY}

A pictorial of the backup design concept is shown in Figure 1-1. The major features of this design follow:

1. open lattice, vertical core

2. peak neutron flux in excess of $1 \times 10^{16}$

3. fuel pins 0.210 inch in diameter

4. primary control by means of reflector control rods around the core periphery; drives have a 10 -inch off set from rods

5. six closed loop test locations in the core

6. twelve open loop test locations in the core

7. torsion bar core clamping system

8. open head refueling through a large refueling plug to increase plant availability

9. refueling by direct access of fuel grapple to increase plant availability

10. most control rods connected during refueling

11. an annular plug (around the refueling plug) that may be removed for vertical access to the control rods and reflector to increase plant availability and testing capability

12. driver fuel transported to storage in the refueling cell in natural convection cooled finned transfer thimbles

13. the head is cooled to provide a minimum cover thickness and ambient temperature base for mounting service equipment

14. the head, cell and containment are designed to accommodate a DBA which releases $1500 \mathrm{MW}-\mathrm{sec}$ of available work 


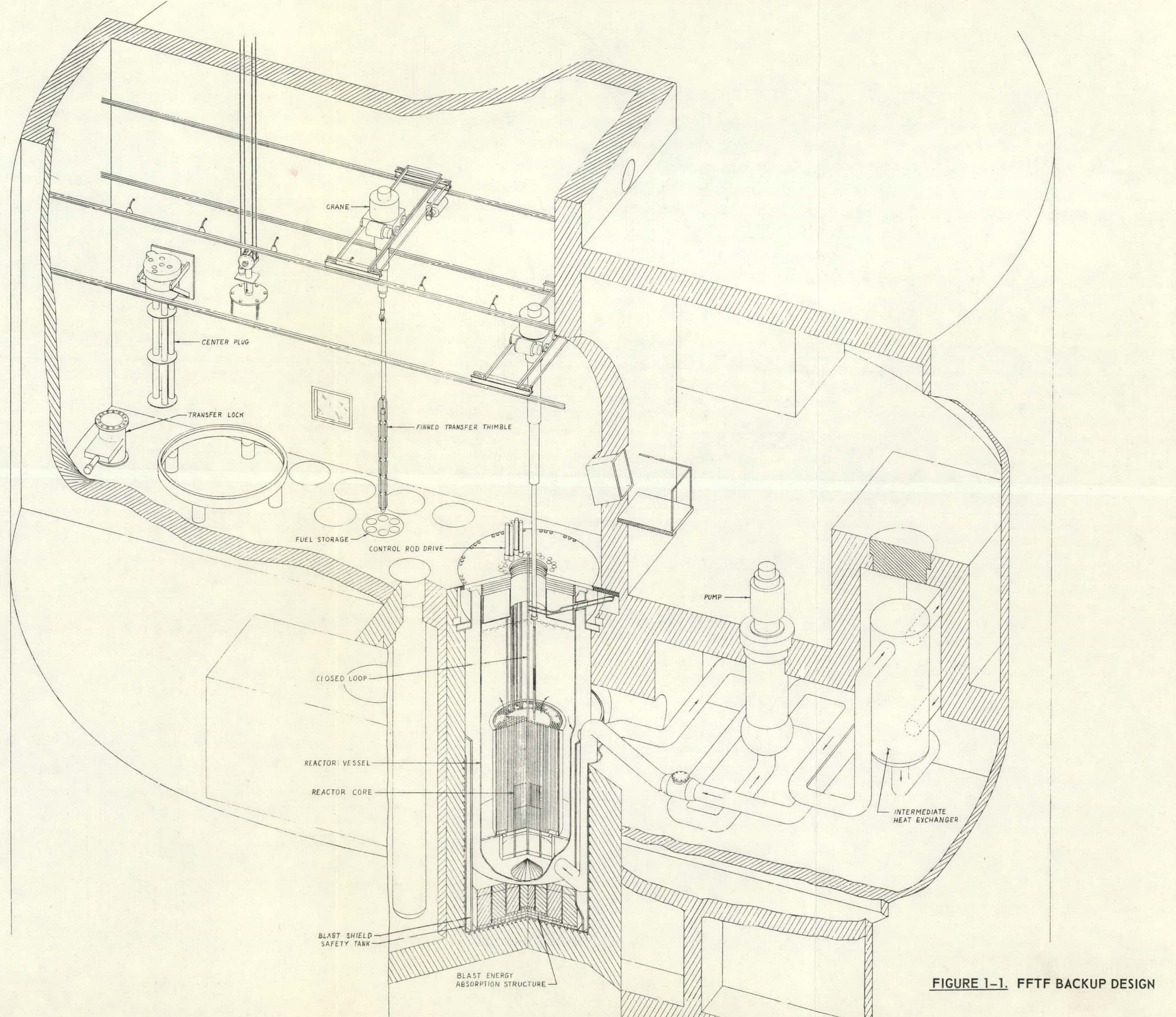


15. instrumentation capability for all in-core locations.

16. a refueling cell above the core with argon atmosphere designed for manned suited access during full power operation

17. three primary coolant loops

18. elevated coolant loops are recommended to enhance safety and provide redundant natural circulation decay heat removal during normal as well as accident conditions. 


\section{SUMMARY OF BACKUP DESIGN CHARACTERISTICS}

\subsection{REACTOR}

Type

Power

Coolant

\subsubsection{Test Loops}

Closed loops

Closed lonp shannels

Double channel central closed loop

Open loops

Total closed and open loops open lattice, vertical

$400 \mathrm{MWt}$

sodium

\subsubsection{Nuclear}

Peak neutron flux at beginning of an equilibrium fuel cycle without fuel shuffling

$0.95 \times 10^{16}$

Peak neutron flux at beginning of an equilibrium fuel cycle with fuel shuffling

$1.01 \times 10^{16}$

Peak neutron flux at the end of an equilibrium fuel cycle without fuel shuffling

Number of enrichment zones

Fissile enrichment $\left(\mathrm{Pu}^{239}+\mathrm{Pu}^{241}\right)$

Zone 1

Zone 2

Average discharge exposure

Full power days operation during cycle

U-238 Doppler Coefficient, $\mathbf{T} \frac{\mathrm{dlk}}{\mathrm{dT}}$

Beginning of cycle

End of cycle
6

7

1

12

18
2

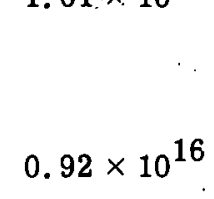

20.67

29.02

57, $000 \mathrm{MWd} / \mathrm{Te}$

60

$-0.0047$

$-0.0054$ 
Control Requirements

Primary reflector control

$6.5 \% \Delta \mathrm{k} / \mathrm{k}$

In-core backup control

$2.9 \% \Delta \mathrm{k} / \mathrm{k}$

Control Available

Primary reflector control

$>6.5 \% \Delta \mathrm{k} / \mathrm{k}$

In-core backup control

$>2.9 \% \Delta \mathrm{k} / \mathrm{k}$

Delayed neutron fraction $\beta$ eff

0.0028

\subsubsection{Driver Fuel}

Number of driver channels

Zone 1

63

Zone 2

42

Total

105

Fuel

Cladding

Pins per channel

$\mathrm{PuO}_{2}-\mathrm{UO}_{2}$

Type 316 stainless steel

127

Pin outside diameter

0.21 inch

Cladding thickness

$0.015 \mathrm{inch}$

Pin, $P / D$

1.286

Spacer

Wire wrap diameter

Wire wrap pitch

Pellet density

Pellet cold smeared density

Active fuel length

End reflector length

Axial shield. length

Gas plenum length

Swelling

\section{1.4 Driver Fuel Channel}

Material

Incoloy 800

Shape

hexagonal

Channel wall thickness

0.100 inch

Distance across flats

3. 360 inches

Clearance between channels

0.022 inch 
2.1.5 Thermal Hydraulic

Coolant flow

Inlet temperature

Nominal outlet temperature

Core $\Delta \mathrm{P}$ (nominal plenum to plenum)

Average pin power

Peak calculated pin power $(120 \%$

overpower)

Maximum allowable pin power $(120 \%$

overpower)

Average heat flux

Total zone 1 power peaking factor

Maximum allowed cladding temperature (120\% overpower)

Peak velocity within channel

Heat generation fraction

Fuel

Structural

All others
$15.1 \times 10^{6} \mathrm{lb} / \mathrm{h}$

$700^{\circ} \mathrm{F}$

$1000^{\circ} \mathrm{F}$

$108 \mathrm{psi}$

$8.24 \mathrm{~kW} / \mathrm{ft}$

$17.3 \mathrm{~kW} / \mathrm{ft}$

$18.0 \mathrm{~kW} / \mathrm{ft}$

$0.5 \times 10^{6} \mathrm{Btu} / \mathrm{h}-\mathrm{ft}^{2}$

1.77

$1215^{\circ} \mathrm{F}$

$32.5 \mathrm{ft} / \mathrm{sec}$

0.91

0.04

0.05

\subsubsection{Reflector Control}

Number

Material

Volume fraction $\mathrm{B}_{4} \mathrm{C}$

$\mathrm{B}_{4} \mathrm{C}$ rods per bundle

Rod outside diameter
38

$35 \%$ enriched $\mathrm{B}_{4} \mathrm{C}$

0.292

37

0.406 inch

2. 1. 7 In-Core Backup Control

Number

Number of in-core channels

Material

Rods per bundle
3

3

enriched $\mathrm{B}_{4} \mathrm{C}$

19

\subsubsection{Total In-Core Channels}

In-core control

Closed loops

Open loops

Driver fuel

$$
\text { Zone } 1
$$

Zone 2

Total
7

12

63

42

127 


\subsubsection{Radial Reflector}

Material

2. 1.10 Cover Gas

Type

Pressure, operating

2.1.11 Head

Refueling

Plugs

Temperature

\subsection{REFUELING CELL}

\subsubsection{Size}

Length

Width

Height

\subsubsection{Fuel Handling}

Means of removal from core

Means of transfer

Fuel storage

\subsubsection{Refueling Cell Atmosphere}

Atmosphere

Design temperature, accident

Design operating temperature
Nickel

argon

\pm 0.5 in. water gage

open head-direct

rèfueling plug and annular control plug

cooled

84 feet

30 feet

78 feet

grapple

closed, finned thimble, natural circulation in-cell, natural circulation pools

argon

$250^{\circ} \mathrm{F}$

$150^{\circ} \mathrm{F}$

\subsubsection{Major Equipment}

Bridge crane mounted telescoping tube hoists with fuel grapple mechanisms 2

Bridge crane mounted general

purpose manipulators

$$
2
$$

Master slave manipulators

3

Traveling hoist

100 tons

Bridge crane

$5 / 20$ ton 
GEAP-5722

Decay and storage tanks

Transfer thimbles

\subsubsection{Radiation Levels}

Operating floor

Refueling cell floor
7

50

$0.5 \mathrm{mR} / \mathrm{h}$

$50 \mathrm{mR} / \mathrm{h}$ 
GEAP- 5722

\section{SECTION III}

\section{NUCLEAR CHARACTERISTICS}

\subsection{BACKGROUND}

The FFTF Backup Design consists of 127 total in-core hexagonal channels of which 105 are driver fuel locations. Two radial core zones with different fissile enrichments are used to flatten the power distribution. Twelve in-core positions are assumed to be open loops containing $75 \%$ of the fuel content of a driver bundle. A double channel closed lonp is assumed at the core center with 5 single channel closed loops located near the core periphery. The backup safety system occupies 3 in-core locations with the primary control system located in the first row of channels outside the core. The core arrangement is shown in Figure 3-1 and is described in Table 3-1. Table 3-1 also includes a description of a driver fuel bundle.

\subsubsection{Geometrical and Analytical Models Used in Nuclear Calculations}

The geometric model assumed in nuclear analysis calculations is described. in Figure 3-2. This represents the reactor at full power condition $(400 \mathrm{MWt})$. The reactor is assumed to be symmetrical about the core midplane. For simplicity and because of axial symmetry, it was assumed that only the core was influenced by temperature, i.e., expanded or contracted due to temperature changes.

Appendix A contains all data necessary to describe the various reactor regions indicated in Figure 3-2. Included in Appendix A are the following:

- material density, temperatures, and expansion coefficients

- material volume fractions for all bundle types

- region compositions by bundle type

- material volume fractions for all region compositions

The RISYN computer code ${ }^{1}$ (multi-group, two-dimensional synthesis diffusion theory) was used in all nuclear analysis calculations.

\subsubsection{Cross Sections}

Sixty group fuel cross sections were generated for the two enrichment zones in the FFT F Backup Design. U-238, Pu-239, and Pu-240 were self shielded for each enrichment zone. These cross sections were generated from the General Electric BAS03 fuel cross section data. Nickel crose sections were obtained for the ENDF/B cross section library and appropriately self shielded by the ENDRUN code for the radial nickel reflector.

The sixty group cross sections were condensed to 16 energy groups for use in 2-D synthesis calculations. The condensation was performed in several reactor regions and several reactor conditions (control in, control out, and sodium voided) to include spatial variations in the neutron energy spectrum. The energy structure of the 16 group cross section set (listed in Table 3-2) was established using a flux, adjoint flux, and $\Delta v_{\text {cap }}$ in U-238 (due to Doppler) weighting as described in Reference 2. 


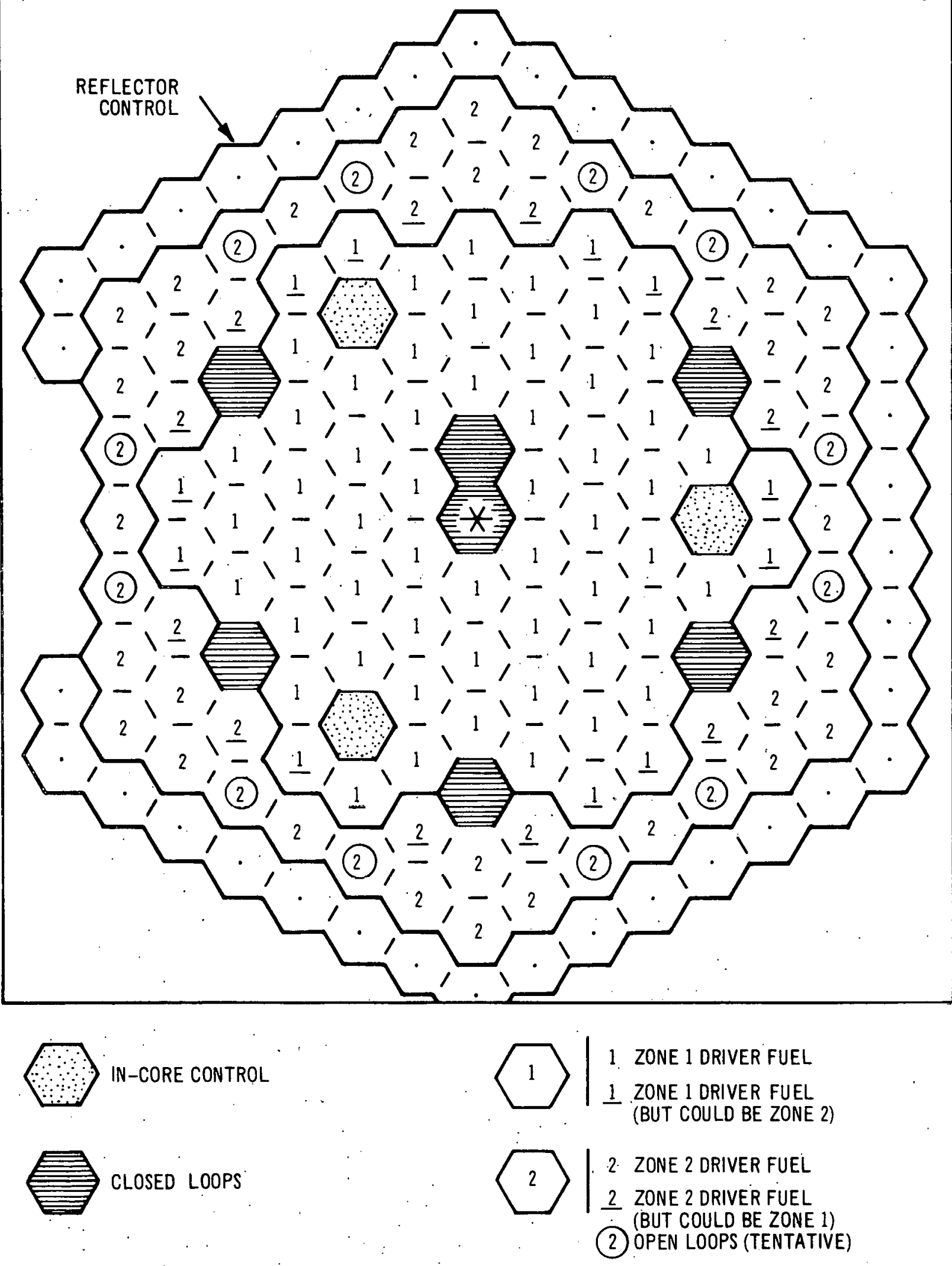

FIGURE 3-1. CORE ARR ANGEMENT, FFTF. BACKUP DESIGN 
TABLE 3-1.

CORE ARRANGEMENT AND DESCRIPTION

OF A DRIVER FUEL BUNDLE

\author{
Core Thermal Power \\ Core Height \\ Core Composition \\ Secondary Control \\ Closed Loops \\ Open Loops \\ Driver Fuel \\ Enrichment Zone 1. \\ Enrichment Zone 2 \\ Total \\ Driver Fuel \\ No. Fuel Pins Per Bundle \\ Fuel Pin o.d. \\ Fuel Pin Cladding Thickness \\ $\mathrm{P} / \mathrm{D}$ \\ Channel Wall 'Thickness \\ Bundle Size (flat to flat) \\ Cell Size *
}

$400 \mathrm{MW}$

36 inches

3 channels

7 channels

12 channels

63 channels

$\frac{42 \text { channels }}{127 \text { channels }}$

127

0.21 inch

0.015 inch

1.286

0.100 Inch

3.360 inches

3.382 inches

* A gap between channel walls of 0.022 inches is expected to exist in the core when the reactor is at full power. This 0.022 inch gap is also assumed at the cold condition.

TABLE 3-2

ENERGY STRUCTURE OF FFTF BACKUP DESIGN

16 GROUP CROSS SECTION FILE

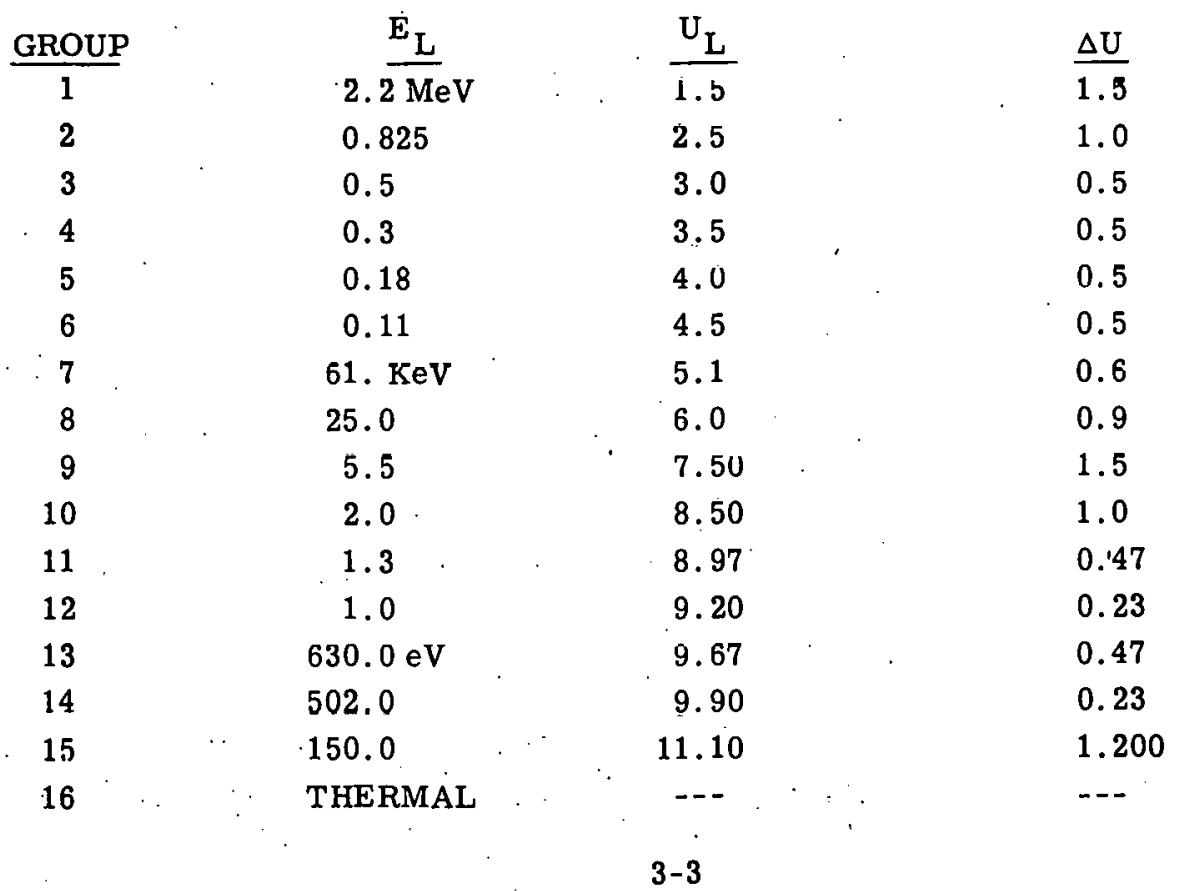




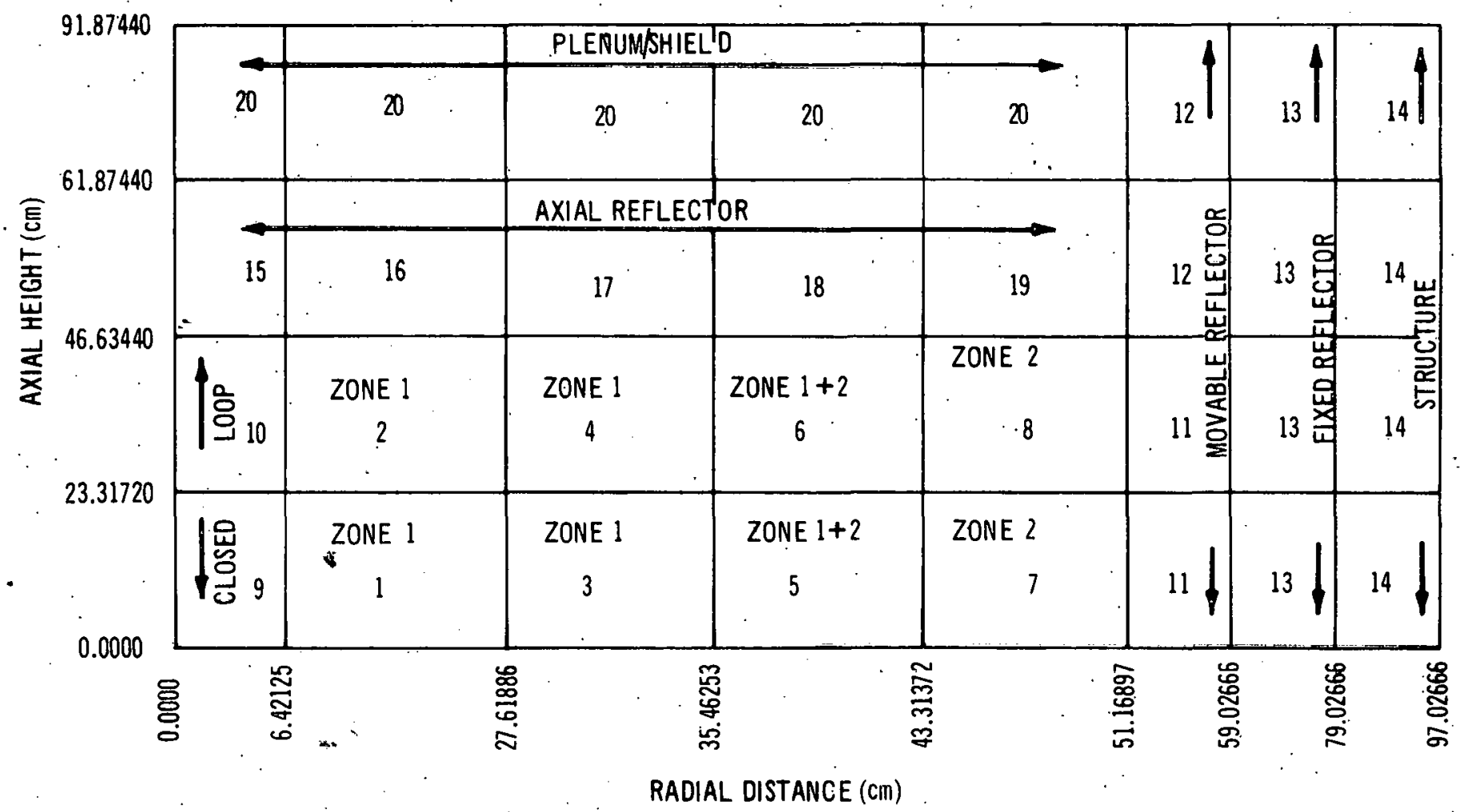




\subsubsection{Energy Produced per Fission}

The calculated energy production per fission in the FFTF Backup Design is $215 \mathrm{MeV}$. The contributions are listed in Table 3-3. For a given reactor power level, the neutron flux is inversely proportional to the $\mathrm{MeV} /$ fission.

It was assumed in calculating maximum neutron flux for the $400 \mathrm{MWt}$ power level that all energy (including gamma energy) is absorbed within the vessel and is, therefore, carried away by sodium. It was further assumed that of the neutrons leaking beyond the reflector $90 \%$ were absorbed in boron and $10 \%$, in steel.

Values for energy production per event were obtained from ANL-5800, Reactor Physics Constants, Second Edition, 1963.

TABLE 3-3

ENERGY PRODUCED PER FISSION

\section{SOURCE}

Kinetic energy of fission fragments

Kinetic energy of neutrons

Beta (fission products)

Gamma (other than inelastic scattering gammas)

Prompt fission

Fission products

$\mathrm{n}, \gamma$ reactions

Alpha ( $n, \alpha$ reactions in boron)

Total
$\mathrm{MeV} /$ Fission

171.3

5.8

9.0

7.8

7.2

12.8

1.0

214.9

\subsection{FUEL CYCLE}

Fuel cycle analysis assumes that an equilibrium fuel cycle has been achieved. A peak fuel burnup of $80,000 \mathrm{MWd} / \mathrm{Te}$ is assumed for the FFTF Backup Design with the average discharge burnup of $\sim 57,000 \mathrm{MWd} / \mathrm{Te}$. The refueling interval is 60 full power days with a burnup reactivity of $2.35 \% \Delta \mathrm{k} / \mathrm{k}$. The region dependent batch loading (i.e., one per the fraction of fuel replaced at each reload) and isotopic fuel atom fractions for the two enrichment zones are listed in Table 3-4.

\subsection{POWER AND FLUX DISTRIBUTION}

The peak linear power density allowable is $18.0 \mathrm{~kW} / \mathrm{ft}$ including an overpower allowance of 1.2. Since the, peak power density in both zones 1 and 2 is at its highest at the beginning of an equilibrium burnup cycle (b.o.c.), when the greatest amount of peripheral control is inserted, the zoned core must be designed such the the b.o.c. condition satisfies the peak linear power density limit. This limit has been met in the present zoned core design assuming that no fuel 
TABLE 3-4

REGION DEPENDENT BATCH LOADING

(Refer to Figure 3-2 for location pf regions.)

\begin{tabular}{clcc}
\multirow{3}{*}{ Region } & & $\frac{\text { Zone 1 }}{4.00}$ & $\frac{\text { Zone 2 }}{\sim}$ \\
& 1 & 4.74 & $\sim$ \\
& 2 & 5.54 & 4.04 \\
& 3 & $\sim$ & 5.27
\end{tabular}.

* The 12 open loops are included in the refueling scheme for region 4 .

\section{FUEL ISOTOPIC ATOM FRACTIONS}

Initial Clean Bundle:

$\mathrm{U}-238$

$\mathrm{Pu}-239$

$\mathrm{Pu}-240$

$\mathrm{Pu}-241$

Discharged Bundle

(Average for Zone):

$$
\begin{aligned}
& \mathrm{U}-238 \\
& \mathrm{Pu}-239 \\
& \mathrm{Pu}-240 \\
& \mathrm{Pu}-241 \\
& \mathrm{Pu}-242 \\
& \text { F.P.P. }
\end{aligned}
$$

Beginning of Equilibrium

Burnup Cycle

(Average for Zone):

$$
\begin{aligned}
& \mathrm{U}-238 \\
& \mathrm{Pu}-239 \\
& \mathrm{Pu}-240 \\
& \mathrm{Pu}-241 \\
& \mathrm{Pu}-242 \\
& \text { F.P.P. }
\end{aligned}
$$

End of Equilibrium Burnup Cycle

(Average for Zone):

$$
\begin{aligned}
& \mathrm{U}-238 \\
& \mathrm{Pu}-239 \\
& \mathrm{Pu}-240 \\
& \mathrm{Pu}-241 \\
& \mathrm{Pu}-242 \\
& \text { F.P.P. }
\end{aligned}
$$

\begin{tabular}{lr} 
Zone 1 & Zone 2 \\
\hline 0.7651 & 0.6702 \\
0.2043 & 0.2869 \\
0.0282 & 0.0396 \\
0.0024 & $\underline{0.0033}$ \\
\hline 1.0000 & 1.0000
\end{tabular}

0.7269

0.1722

0.0370

0.0031

0.0002

0.0606

1.0000

0.6436

0.2387

0.0493

0.0040

0.0002

0.0642

1.0000
0.7506
0.6599
0.1914
0.2663
0.0318
0.0438
0.0026
0.0036
0.0001
0.0001
0.0235
$\underline{0.0257}$
1.0000
1.0000

\begin{tabular}{lll}
0.7420 & 0.6546 \\
0.1842 & 0.2574 \\
0.0338 & 0.0457 \\
0.0028 & 0.0037 \\
0.0001 & 0.0001 \\
0.0371 & $\quad$ & $\mathbf{0 . 0 3 8 5}$ \\
\hline 1.0000 & $\mathbf{1 . 0 0 0 0}$
\end{tabular}


bundle is moved from its initial loaded location. The shuffling of partially burned ffuelito the icore center would, of course, reduce the peak linear power density.

The radial power distribution at the beginning and end of an equilibrium burnup cycle is shown in Figure 3-3. The plutonium enrichment is distributed ibetween the two enrichment:zones such that the peak linear power density in a fresh, newly loaded fuel:bundle is the same in reach zone at the beginning of an equilibrium fuel cycle. This is the limiting power density condition. The power peaking factors for the beginning of cycle condition are listed in Table $3-5$.

TABLE 3-5

POWER PEAKING FACTORS AT BEGINNING OF:CYCLE

\begin{tabular}{|c|c|c|c|}
\hline & ZONE 1 & & ZONE 2 \\
\hline Radial & 1.30 & & 1.28 \\
\hline Axial & 1.21 & & i1.21 \\
\hline New to Average & $1 . .06$ & & 1.08 \\
\hline Fabrication & 1.035 & & .1 .035 \\
\hline Experiment Compensation & 1.025 & & $\sim 1.00$ \\
\hline Total & $1: 77$ & & \\
\hline Average Linear Power Density & $8.16 * 1$ & $\mathrm{~kW} / \mathrm{ft}$ & \\
\hline Peak Linear Power Density & 14.4 & $\mathrm{~kW} / \mathrm{ft}$ & . \\
\hline Over Power Factor & 1.2 & & \\
\hline $\begin{array}{l}\text { Peak Linear Power Density including } \\
\text { Over Power Factor }\end{array}$ & 17.3 & $\mathrm{~kW} / / \mathrm{ft}$ & $\because$ \\
\hline Peak Linear Power Density Allowable & 18.0 & $\mathbf{k W} \cdot / \mathbf{f t}$ & \\
\hline
\end{tabular}

*Value Based on $91 \%$ of total energy absorbed in fuel.

It is the intention that zone 1 and zone 2 fuel bundles can be interchanged at the boundary between the two zones to compensate for experimental reactivity changes. Interchanging 12 fuel bundles causes a reactivity change of $\sim 1.0 \% \Delta \mathrm{k} / \mathrm{k}$. When 12 zone 2 fuel bundles are replaced with zone 1 fuel, the power density near the core center increases about $2.5 \%$. Hence, the 1.025 experimental compensation power peaking factor.

The peak linear power density including the 1.2 overpower factor is calculated to be $17.3 \mathrm{~kW} / \mathrm{ft}$ while the maximum allowable value is $18.0 \mathrm{~kW} / \mathrm{ft}$. Since the calculated peak linear power density is not yet limiting, this allows for possible uncertainties in analytical techniques.

The radial neutron flux distribution in the core is shown in Figure 3-4 for the beginning and end of cycile conditions. The peak neutron flux is $0.95 \times 10^{16}$ at beginning of cycle and $0.92 \times 10^{16}$ at the end of cycle. These values assume that no fuel shuffling occurs.

The axial neutron flux in the central closed loop.at the end of cycle is shown in Figure 3-5. 


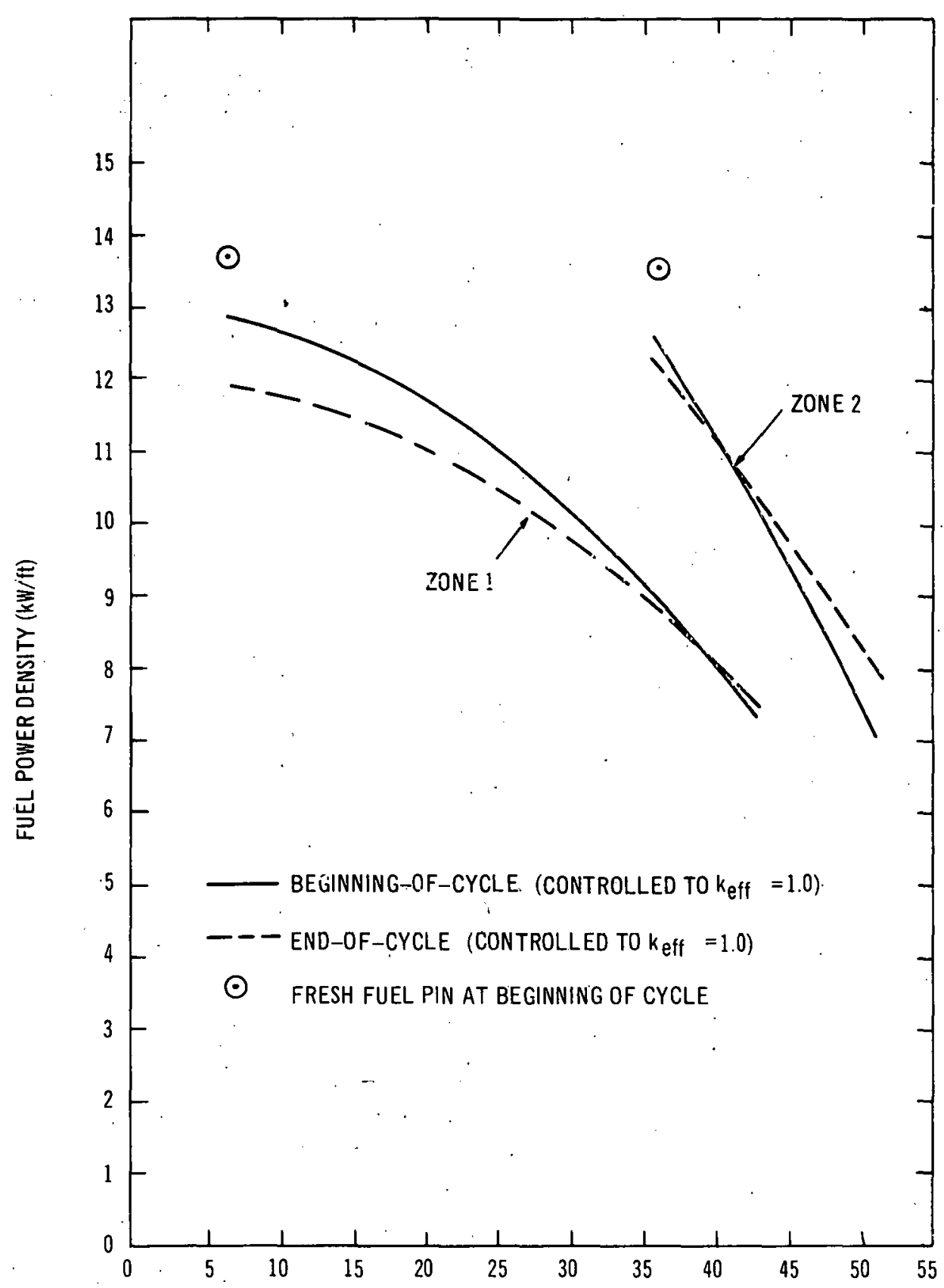

RADIUS (CM) 


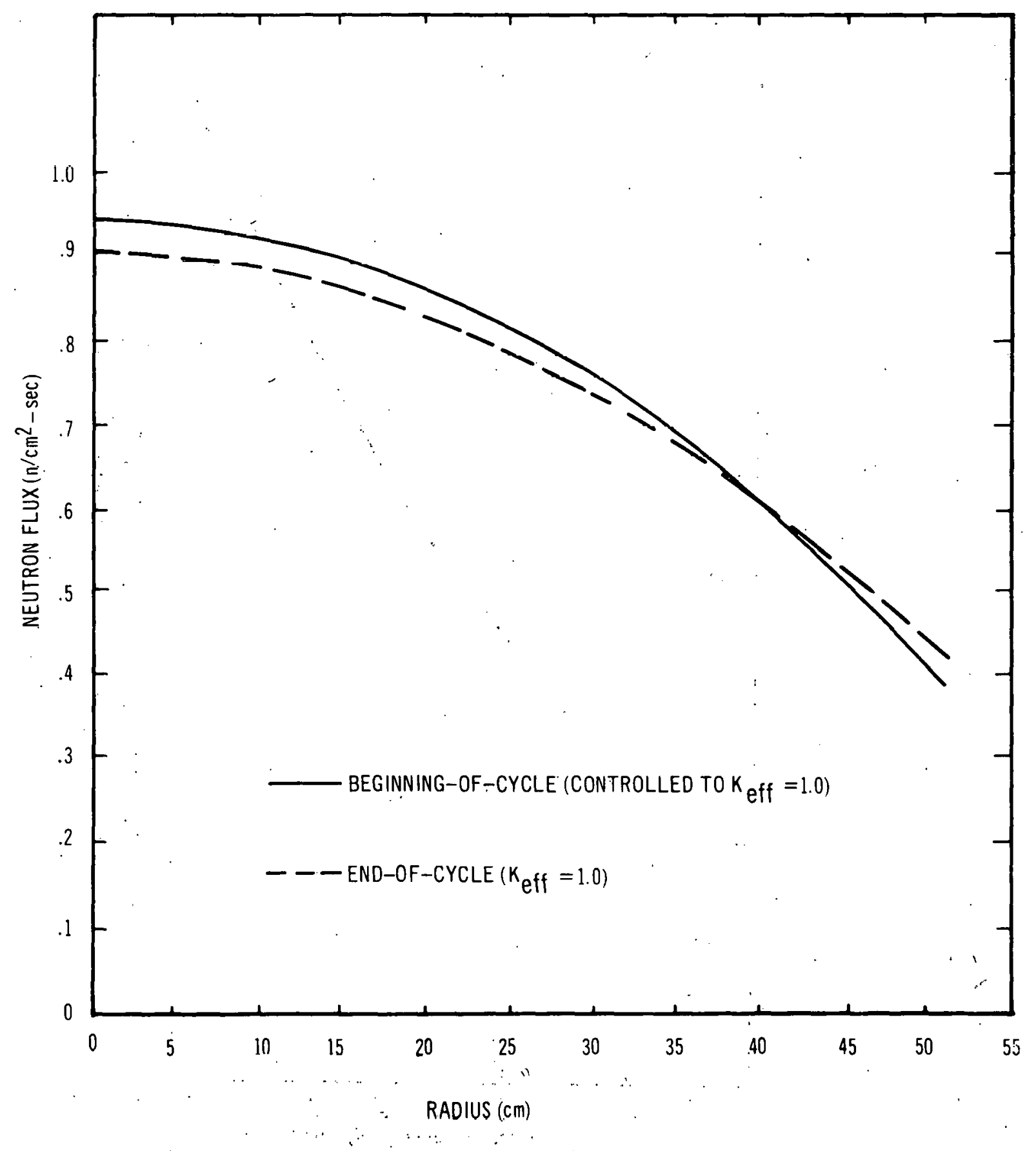

FIGURE 3-4. RADIAL FLUX DISTRIBUTION 


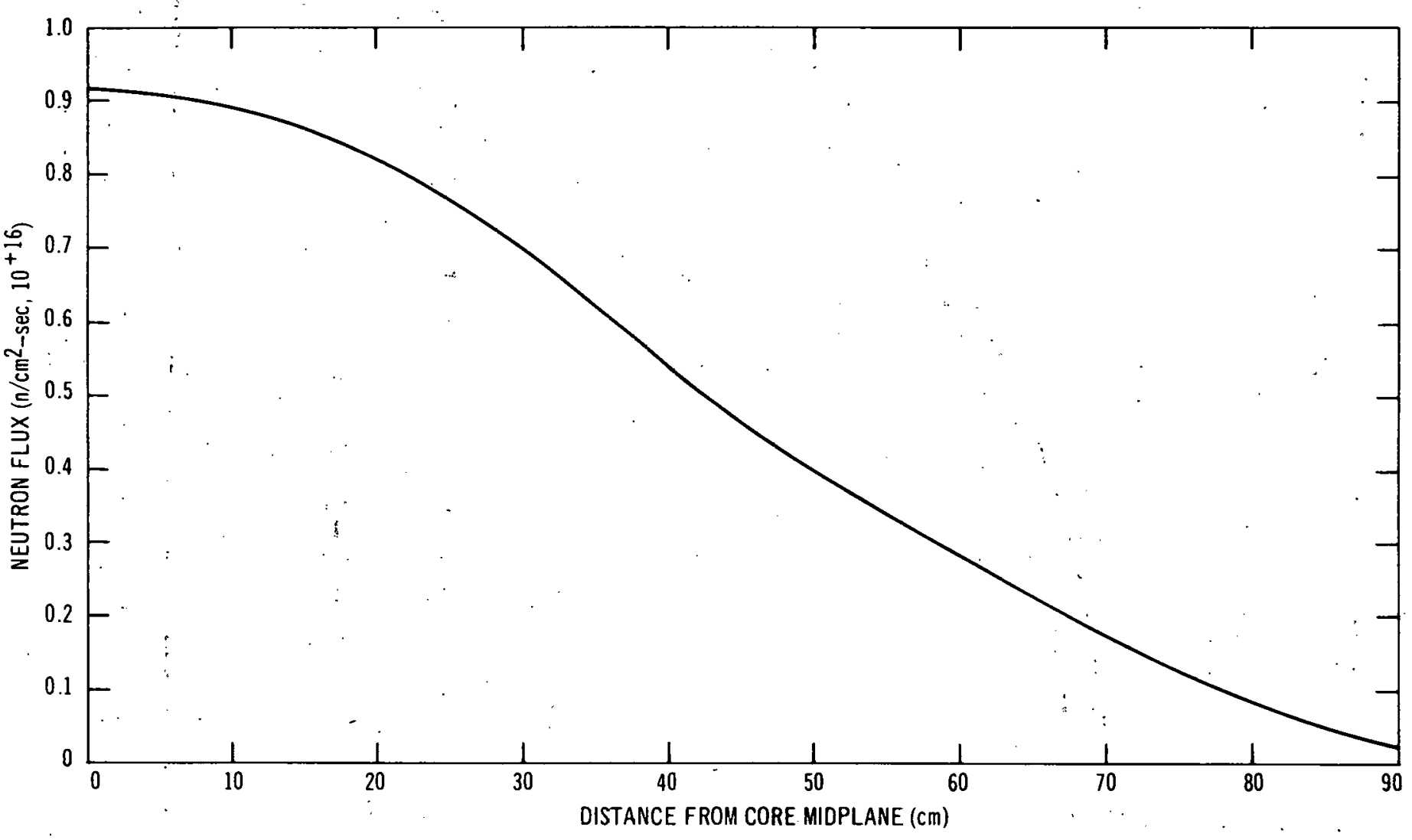

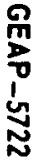

FIGURE 3-5. AXIAL NEUTRON FLUX DISTRIBUTION IN CENTRAL CLOSED LOOP 


\subsection{REACTIVITY EFFECTS AND COEFFICIENTS}

\subsubsection{Temperaturc Rcactivity Effects}

The U-238 Doppler coefficient, $\mathrm{T} \frac{\mathrm{dk}}{\mathrm{dT}}$, has been calculated at beginning and end of cycle conditions and listed in Table 3-6. The calculations used the 16 group cross section file described in Section 3.1 .

TABLE 3-6

\section{U-238 DOPPLER COEFFICIENT}

$\begin{array}{ll}\text { Reactor Condition } & \mathrm{T} \mathrm{dk} / \mathrm{dT} \\ \text { Beginning of cycle, } & -0.0047 \\ \quad 2.35 \% \Delta \mathrm{k} / \mathrm{k} \text { control inserted } & \\ \text { End of cycle, no control } & -0.0054 \\ \text { End of cycle, no control, } & -0.0034 \\ \quad \text { sodium voided in core } & \\ \text { Beginning of cycle, 2.35\% } \Delta \mathrm{k} / \mathrm{k} & \sim-0.0027 \text { (estimated) } \\ \quad \text { control inserted with sodium } & \\ \quad \text { voided in core } & \end{array}$

Calculations have been performed for the FF? zoned core design to evaluate the reactivity effect of changing the reactor condition from cold reîuling temperature $\left(400^{\circ} \mathrm{F}\right.$ isother mal) to full power $(400 \mathrm{MWt})$. The total temperature reactivity effect was calculated to be $-1.35 \% \Delta \mathrm{k} / \mathrm{k}$, cold refueling to full power operation.

In addition, the reactivity effect from $700^{\circ} \mathrm{F}$ isothermal to full power was calculated. The results of these calculations are shown in Table 3-7. The material temperatures assumed and the corresponding average linear expansions at each temperature state are given in Table 3-8.

TABLE 3-7

TEMPERATURE PEACTIVITY EFFECT FOR THE FFTF BACKUP ZONED CORE AT THE END OF AN EQUILIBRIUM BURNUP CYCLE ASSUMING NO CONTROL INSERTED

\begin{tabular}{|c|c|c|c|}
\hline Case & $\begin{array}{l}\text { Expansion and } \\
\text { Density Effects } \\
\end{array}$ & $\begin{array}{c}\text { Doppler } \\
\text { Effect } \\
\end{array}$ & Total \\
\hline $\begin{array}{l}400^{\circ} \mathrm{F} \text { Isothermal } \\
\rightarrow 400 \mathrm{MWt}\end{array}$ & $-0.77 \% \Delta \mathrm{k} / \mathrm{k}$ & $-0.58 \% \Delta \mathrm{k} / \mathrm{k}$ & $-1.35 \% \Delta \mathrm{k} / \mathrm{k}$ \\
\hline $\begin{array}{l}700^{\circ} \mathrm{F} \text { Isothermal } \\
-400 \mathrm{MWl}\end{array}$ & $-0.56 \% \Delta \mathrm{k} / \mathrm{k}$ & $-0.41 \% \Delta \mathrm{k} / \mathrm{k}$ & $-0.97 \% \Delta \mathrm{k} / \mathrm{k}$ \\
\hline $\begin{array}{l}400^{\circ} \mathrm{F} \text { Isothermal } \\
-700^{\circ} \mathrm{F} \text { Isothermal }\end{array}$ & $-0.21 \% \Delta \mathrm{k} / \mathrm{k}$ & $-0.17 \% \Delta \mathrm{k} / \mathrm{k}$ & $-0.38 \% \Delta \mathrm{k} / \mathrm{k}$ \\
\hline
\end{tabular}


TABLE 3-8

\section{ASSUMED MATERIAL TEMPERATURES AND AVERAGE LINEAR EXPANSION}

$(1+\alpha \Delta \mathrm{T}$ from Room Temperature)

$400^{\circ} \mathrm{F}$ Isothermal

Temperature

$\underline{(1+\alpha \Delta \mathrm{T})}$

$700^{\circ} \mathrm{F}$ Isothermal

Temperature $\quad \underline{(1+\alpha \Delta \mathrm{T})}$

Fuel :

Average ccnterline temp.

(for axial fuel expansion)

$400^{\circ} \mathrm{F}$

1.0010

$700^{\circ} \mathrm{F}$

1.0022

$700^{\circ} \mathrm{F}$

$w$
1
$N$ $400^{\circ} \mathrm{F}$

$400^{\circ} \mathrm{F}$

$400^{\circ} \mathrm{F}$

$400^{\circ} \mathrm{F}$ $700^{\circ} \mathrm{F}$

$700^{\circ} \mathrm{F}$

$700^{\circ} \mathrm{F}$

$\rho \curvearrowright 400^{\circ} \mathrm{F}$

1. 00316

1. 00290
Sodium, average temp.

Channels, average temp.
$=0.906 \mathrm{gm} / \mathrm{cc}$

$\begin{array}{cc}400^{\circ} \mathrm{F} . \quad & \rho 400^{\circ} \mathrm{F} \\ & =0.906 \mathrm{gm} / \mathrm{cc}\end{array}$

$400 \mathrm{MWt}$

Temperature $\quad \underline{(1+\alpha \Delta \mathrm{T})}$ 
The calculations were performed assuming fuel compositions for the end of an equilibrium burnup cycle. The total temperature reactivity effect (expansion and density changes plus Doppler) at the beginning of the burnup cycle is nearly equal to the end of cycle temperature effect.

The axial fuel expansion reactivity effect at the hot operating condition was found to be $\frac{\Delta \mathrm{k} / \mathrm{k}}{\Delta \mathrm{h} / \mathrm{h}}=-0.29$, where $\mathrm{h}$ is fuel height. Other individual temperature reactivity effects were not calculated.

\subsubsection{Delayed Neutron Fraction}

The effective delayed neutron fraction, $\beta_{\text {eff }}$, in the FFTF Backup Design is 0.0028 . The two enrichment zone FFTF Backup Design has a $\beta$ eff substantially lower than the 0.003 previously quoted for the one zone design. This reduction in $\beta_{\text {eff }}$ is primarily due to the increased plutonium ${ }^{-}$ enrichment and, hence, higher fraction of fissions in plutonium for the two-zone design. $\epsilon_{\text {eff }}$ was calculated for both the beginning and end of an equilibrium fuel cycle: Calculations indicate that $\beta_{\text {eff }}$ is essentially constant during the fuel cycle.

The delayed neutron fraction, $\beta_{\mathrm{k}}$, was calculated for each core region using the one group cross sections and material balance from BISYN output and delayed neutron fractions from Keepin ${ }^{(3)}$. A delayed neutron spectrum was obtained from Keepin and delayed neutron chi values, $x_{d, i}$, determined for the FFTF 16-energy group cross section set where $\sum_{i} x_{d, i}=1$. A BISYN perturbation was made where $X$ was perturbed in each region $k$ and energy group $i$ by the amount $\delta \mathrm{X}_{\mathrm{k}, \mathrm{i}}=\beta_{\mathrm{k}} \mathrm{x}_{\mathrm{d}, \mathrm{i}}$, yielding the value of $\beta_{\text {eff }}$.

\subsubsection{Maximum Fuel Bundle Worth}

The maximum worth of a single fuel bundle has been calculated for the FFTF Backup Design. A fresh fuel bundle is inserted into a sodium filled hole at the center of the core with the core at beginning of cycle conditions. The worth of a zone 1 fuel bundle is $\$ 2.3$, and the worth of a zone 2 fuel bundle is $\$ 3.7$ at this location for $\beta_{\text {eff }}=0.0028$.

\subsection{REACTIVITY CONTROL}

\subsubsection{Control Requirements}

The requirements of the primary control system and the Backup Safety System are listed in Table 3-9. It is assumed that both the primary and backup systems must control the temperature reactivity effect, some undefined accident, and provide a shutdown margin. In deining the requirements the combined effect of shutdown margin and accident are assumed to be $1 \% \Delta \mathrm{k} / \mathrm{k}$. The primary control system must also control a $2.35 \% \cdot \Delta \mathrm{k} / \mathrm{k}$ burnup reactivity and provide a $0.5 \% \Delta \mathrm{k} / \mathrm{k}$ allowance for experiment uncertainty.

Since uncertainties exist in the calculated control requirements and the calculated worth of the control system, a $25 \%$ contingency is added to the control requirements to allow for uncertainties. Thus the control requirement for the primary and backup control systems are $6.5 \% \Delta \mathrm{k} / \mathrm{k}$ and $2: 9 \% \Delta \mathrm{k} / \mathrm{k}$. 
TABLE 3-9

CONTROL REQUIREMENTS

$\begin{array}{llc} & \frac{\text { Primary }}{1.35 \%} & \frac{\text { Backup }}{1.35 \%} \\ \text { Temperature Effect } & 2.35 \% & -- \\ \text { Burnup } & 0.5 \% & -- \\ \text { Experimental Allowance } & 1.0 \% & 1.0 \% \\ \text { Shutdown and Accident } & \overline{5.2 \%} & \overline{2.35 \%} \\ \quad \text { Total } & 1.3 \% & 0.59 \% \\ \text { 25\% contingency } & \overline{6.5 \% \Delta \mathrm{k} / \mathrm{k}} & \overline{2.9 \% \Delta \mathrm{k} / \mathrm{k}} \\ \quad & \end{array}$

\subsubsection{Reflector Control Strength}

The reflector control strength calculations are based on a control system with the material composition described in Appendix A $\left(29 \mathrm{v} / \mathrm{oB}_{4} \mathrm{C}\right)$. Of the 42 reflector locations adjacent to the radial core boundary, 38 contain reflector control. The other four are located in the area of the refueling cask and are not available as reflector control locations. The two dimensional synthesis calculations assume all 42 locations are used and the calculated control strength is reduced by $38 / 42$ to obtain the worth of the control system. The worths of a natural $\mathrm{B}_{4} \mathrm{C}$ and $\mathrm{B}_{4}{ }^{10} \mathrm{C}$ control system are $5.4 \% \Delta \mathrm{k} / \mathrm{k}$ and $9.4 \% \Delta \mathrm{k} / \mathrm{k}$, respectively. The influence of $\mathrm{B}^{10}$ enrichment on the reflector control strength is seen in Figure 3-6 for two different reflector control designs. As indicated in Figure 3-6, boron containing $\sim 35 \% \mathrm{~B}^{10}$ is required in the primary control system to satisfy the control requirements of $6.5 \% \Delta \mathrm{k} / \mathrm{k}$.

\subsubsection{Boron Burnup and Helium Generation in Reflector Control Strength}

The reactivity loss due to boron-10 burnup in the reflector control system is $\sim 20 \%$ a year assuming $75 \%$ operating efficiency. This results in the destruction of $4.20 \times 10^{25}$ boron-10 atoms $\left(\sim 2 \%\right.$ of all $\mathrm{B}^{10}$ atoms in the reflector control system) and the creation of an equivalent amount of He atoms or $\sim 1565$ liters of $\mathrm{He}$ at standard conditions $\left(0^{\circ} \mathrm{C}\right.$ and one atmosphere pressure).

Calculations indicate that a neutron capture rate in $\mathrm{B}^{10}$ of $3.6 \times 10^{18}$ captures a second is required at the beginning of an equilibrium fuel cycle to control the burnup reactivity. It is assumed that the capture rate decreases linearly to zero at the end of cycle. Since the burnup cycle is $\sim 60$ full power days, the total number of captures in $B^{10}$ is

$$
\frac{3.60 \times 10^{16} \mathrm{capt} / \mathrm{sec}}{2} \times 5.184 \times 10^{6} \mathrm{sec} / 60 \text { days }=9.34 \times 10^{24} \mathrm{capt} / \mathrm{cycle}
$$

If an operating efficiency of $75 \%$ is assumed, the fuel cycle length is 80 calendar days with $\sim 4.5$ cycles year. Thus the total number of $\mathrm{B}^{10}$ atoms destroyed per year is $4.2 \times 10^{25}$ atoms. Using $\mathrm{B}_{4} \mathrm{C}$ with the boron enriched to $35 \% \mathrm{~B}^{10}$, the total $\mathrm{B}^{10}$ inventory for the reflector control system is $2.09 \times 10^{27}$ atoms. Thus the fraction of $\mathrm{B}^{10}$ destroyed per year is $=\frac{4.2 \times 10^{25}}{2.09 \times 10^{27}}=2.0 \%$. This is equivalent to a reduction in the reflector control strength of about $20 \not$. 


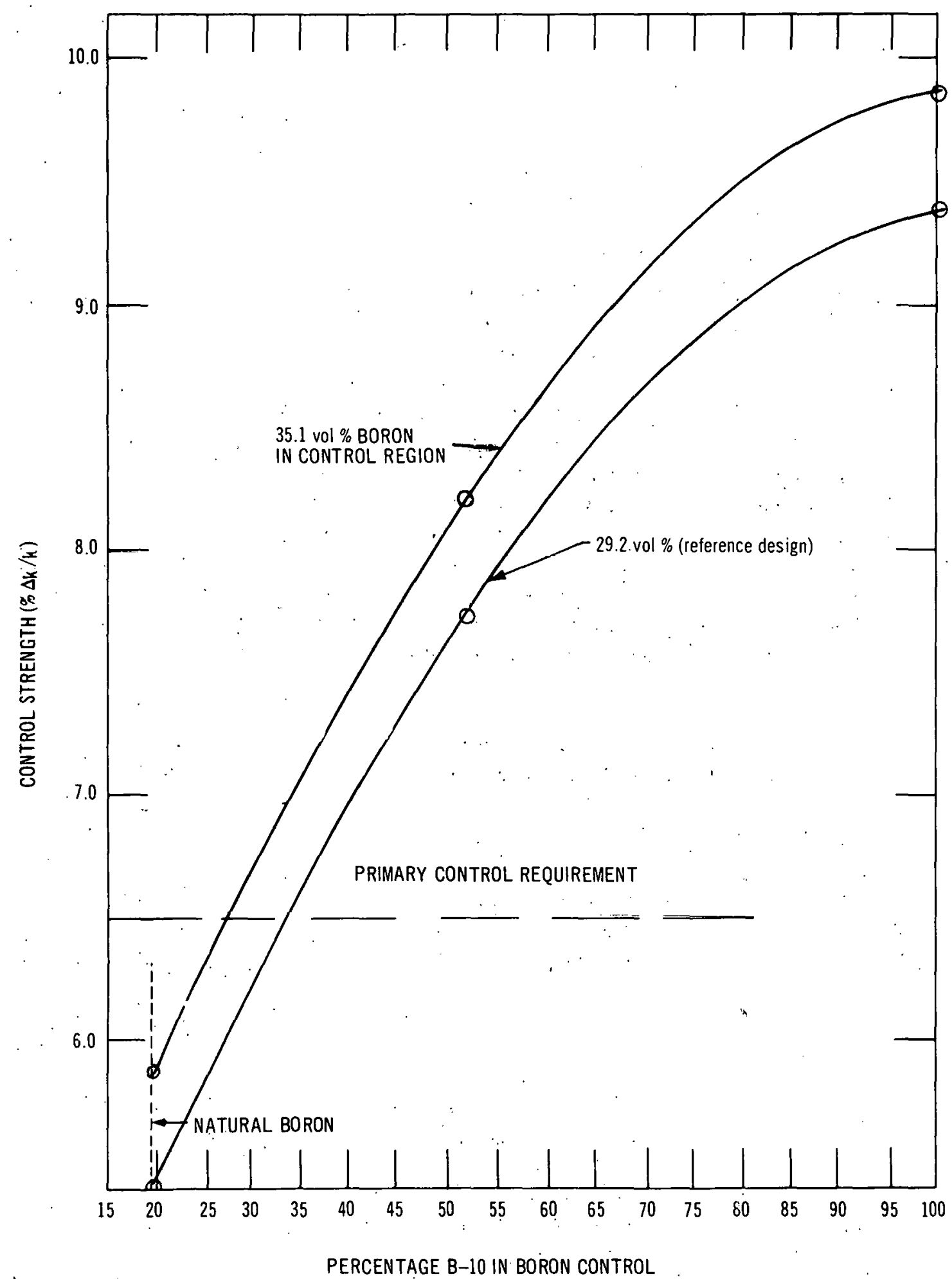

FIGURE 3-6. INFLUENCE OF B ${ }^{10}$ ENRICHMENT ON REFLECTOR CONTROL STRENGTH 
The destruction of a $\mathrm{B}^{10}$ atom, by the $\mathrm{n}, \alpha$ reaction, results in the creation of a $\mathrm{He}^{4}$ atom and $\mathrm{Li}^{7}$ atom. So for every $\mathrm{B}^{10}$ atom destroyed, a He atom is created. In one year's time (assume $75 \%$ operating efficiency) $4.20 \times 10^{25}$ atoms of helium are created or $\sim 1565$ liters of He at standard conditions $\left(0^{\circ} \mathrm{C}\right.$ and one atmosphere pressure).

\subsection{OPERATIONAL FLEXIBILITY}

A significant advantage of the zoned core is that it offers much more operational flexibility than an unzoned core. Some of the options available to the reactor operator are the following:

Fuel shuffling to increase the peak neutron flux. By not loading new fuel bundles into the first two rows of zone 1 driver fuel ( $\sim 17$ bundles), it is possible to increase the peak neutron flux by $\sim 6 \%$. Fuel shuffling requires that partially burned fuel from other zone 1 locations be loaded into the first two rows instead of fresh bundles. This means that the enrichment at the peak power density location is lower and, hence, a higher flux is required to reach the peak linear power density limit. Fuel shuffling in zone 2 is also.a possibility.

Compensation of experimental reactivity by fuel loading. It is possible to compensate for changes in the experimental reactivity by changing the number of zone 2 bundles. For example, the addition of 12 zone 2 bundles (and removal of 12 zone 1 bundles) increases the, core reactivity by $\sim 1 \% \Delta \mathrm{k} / \mathrm{k}$. Conversly, the removal of 12 zone 2 bundles (and addition of 12 zone 1 bundles) decreases the core reactivity by $\sim 1 \% \Delta \mathrm{k} / \mathrm{k}$. Examination of Figure 3-3 shows that the addition of 12 zone 2 bundles will not significantly change the peak power density of zone 2 . This is possible since the bundles can be added in the same row as the bundles in which the peak power density for zone 2 occurs.

Relatively simple adjustments in the zoned fuel loading are possible to correct for errors in operational reactivity or power distribution predictions.

\subsection{INITIAL LOADING}

The nuclear design of the FFTF Backup Design assumes that the reactor has achieved an equilibrium fuel cycle. Many different methods and strategies are possible to approach the equilibrium cycle from the initial loading. The preliminary analysis of one possible strategy is outlined below.

This strategy uses fuel (i.e., fissile enrichment) which is designed for the equilibrium fuel cycle. The core reactivity is detcrmined by the number of zone 2 fuel bundles loaded in the core. For example, if 18 zone 2 fuel bundles are loaded at the core periphery in the initial loading, an uncontrolled $\mathrm{k}_{\text {eff }}$ of 1.025 results, i.e., a burnup reactivity of $2.5 \% \Delta \mathrm{k} / \mathrm{k}$ is possible. As the fission product inventory in the core increases with burnup or the number of experiments increase, the number of zone 2 fuel bundles are increased to maintain criticality. This allows the reactor operator a certain degree of flexibility in approaching the equilibrium fuel cycle. 
This strategy has several disadvantages, however. The power peaking is such that $400 \mathrm{MWt}$ probably cannot be achieved with the initial loading previously described (18 zone 2 fuel bundles). This may not be much of a disadvantage since the reactor will probably operate at reduced power for some time after start up. Another disadvantage is that the reflector control strength is reduced for the initial loading. With only 18 zone 2 fuel bundles loaded, the reflector control strength is $\sim 6.0 \% \Delta \mathrm{k} / \mathrm{k}$ instead of the $6.5 \% \Delta \mathrm{k} / \mathrm{k}$ achieved with the equilibrium fuel cycle. The reflector control strength can be increased for the initial loading by using dummy bundles and, thereby, increasing the number of zone 2 fuel bundles loaded. 


\section{SECTION IV}

\section{CORE}

\subsection{CORE DESIGN}

The core is composed of 127 hexagon channels on 3.390 inch center-to-center pitch as shown in Figure 3-1. Each core element is contained within a hexagonal structure 3.360 inches across flats with a nominal 0.022 -inch clearance between channels. Three channel positions contain in-core safety rods, 105 positions contain driver fuel elements, 7 positions are used for 6 closed loops (center loop occupies 2 core positions), and open loops occupy 12 positions.

Surrounding the core are 38 combination shim-safety rods, each with nickel reflector followers. The next 2 rows radially outward contain 102 stationary reflector rods. The remaining hexagon positions contain 198 shield elements and 54 core clamping mechanisms. Axial reflectors are located above and below the core and are an integral part of the fuel elements.

Driver fuel elements are composed of 127 fuel rods on a triangular pitch of 0.270 -inch with wire wrap spacers on each fuel rod. Coolant inlet temperature is $700^{\circ} \mathrm{F}$ and the outlet temperature is $1000^{\circ} \mathrm{F}$. The fuel elements are orificed to provide a uniform outlet temperature across the core. Two zones of enrichment in the core are used to achieve radial power flattening.

\subsubsection{Driver Fuel Description}

The driver fuel element consists of an assembly of fuel, reflector, and shielding in a hexagon channel. A drawing of the fuel element is shown in Figure 4-1. A tabulation of design data is presented in Table $4-1$.

The basis for the FFTF Backup Design fuel element assembly is intended to agree will those used for the PNL, FFTF Reference Design except for those parameters dictated by nuclear design considerations. The FFTF Backup Fuel Element Design was to rely heavily on the technical data derived from the PNL, FFTF Development Program. Constant updating of the design was to occur as new data became available.

\subsubsection{Nose Piece}

The nose piece extends through the upper and lower core support plates. The reglon between the two plates is the high pressure inlet plenum. Coolant flows into the nose piece radially through multiple holes. The nose piece performs the following functions:

- it locates the channel within the core

- it provides orificing

- it acts as a coarse screen to help prevent total channel flow blockage

- it provides hydraulic hold down for the fuel element assembly 
TABLE 4-1

DESIGN PARAMETERS FOR THE FFTF BACKUP DESIGN FUEL ELEMENT ASSEMBLY

\section{Parameter}

General

Reactor Power

Heat Generation Fraction

Fuel

Structural

Everything Else

Coolant

Flow Direction

Plenum-to-Plenum Pressure Drop

Inlet Temperature

Outlet Temperature

Nominal

Local Hot-Channel

Fuel Element Pitch, Center-to-Center at $70^{\circ} \mathrm{F}$

Zoned Core

Fuel Subassembly

Channel (cooling duct)

Material

Size

Wall Thickness

Orifice

Fuel Bundle

Number of Fuel Pins per Bundle

Active Fuel Length

Pin Pitch

$\mathrm{P} / \mathrm{D}$

Nominal Pin Separation

Separation Method

Wire Wrap Pitch

Peak Velocity in the Fuel Pin Region

Fixed Support

Fúel Pin Gas Plenum

End Reflectors (each)

Channel Pitch
Backup Design

400 MW (does not include closed loops)
0.91
0.04
0.05

$\mathrm{Na}$

Up

$<120$ psi

$700^{\circ} \mathrm{F}$

$1000^{\circ} \mathrm{F}$

$1060^{\circ} \mathrm{F}$

3.382 ( 0.022 in. between channels)

2 zones

Incoloy 800

Hexagon, $3.360 \pm 0.005$ in. across flats $0.100 \mathrm{in}$.

Individual channels orificed to achieve $1000^{\circ} \mathrm{F}$ bulk temperature outlet

127

36 in.

0.270 in.

1.283

0.060 in.

Wire wrap

12 in. (tentative)

$32.5 \mathrm{ft} / \mathrm{sec}$

Bottom

$\sim 30$ in.

$6.0 \mathrm{in}$.

3.390 in. 
TABLE 4-1 (Continued)

\section{Parameter}

Backup Design

Fuel Pin Cladding

Material

Cladding o. d.

Cladding i. d.

Wall Thickness

Length

Fabrication

Condition

Filler Gas

Fuel Pellet

Fuel Composition

Oxygen/Uranium.Plus Plutonium Ratio

Pellet Density

Pellet Diameter

Pẹllet Length

Fuel Column .Length

Cold Smeared Density
Type 316 Stainless Steel

0.210 in. nominal

$0.180 \pm 0.001$ in.

$0.015 \pm 0.001 \mathrm{in.}$.

80 in.

Seamless

Fully annealed

Helium at $1 \mathrm{~atm}$.

Fuel Operating Conditions

Cladding.Internal Surface Temperature

Nominal

Maximum

Fission Gas Release

Internal Pressure

Stress Limit

Maximum Burnup

Swelling

Thermo-Hydraulics
Mixed oxide, $\sim 21$ to 29 vol. \% fissile plutonium (239 and $241 \mathrm{Pu}$ ) 23.5 to 33 vol. \% total plutonium $(12 \% 240 \mathrm{Pu})$; the remainder is $\mathrm{UO}_{2}$

1.97 to 1.98

$94 \pm 2-1 / 2 \%$ TD

$0.175 \pm 0.001 \mathrm{in}$.

$\sim 0.20$ in.

36 in.

$89 \%$ TD

Pin Linear Power

Average

Maximum, New Fuel

Maximum Allowed (OPF + local peaking factor)

$700^{\circ}$ to $1050^{\circ} \mathrm{F}$

$.1215^{\circ} \mathrm{F}$ at $120 \%$ power

$100 \%$ at all burnup levels

- 760 psi at $70,000 \mathrm{MWd} / \mathrm{Te}$ average exposure for peak pin and an end-of-life effective wall thickness of $0.010 \mathrm{in}$. $6950 \mathrm{psi}$ at $1200^{\circ} \mathrm{F}$ (Based on allowable limit, ASME Code, Section I)

$80,000 \mathrm{MWd} / \mathrm{Te}$

$1 \% \Delta \mathrm{D} / \mathrm{D}$ at $84,000 \mathrm{MWd} / \mathrm{Te}$ (tentative)

Heat Flux

Average

Maximum

Maximum with OPF'

$8.24 \mathrm{~kW} / \mathrm{ft}$

$13.6 \mathrm{~kW} / \mathrm{ft}$

$18 \mathrm{~kW} / \mathrm{ft}$

$0.5 \times 10^{6} \mathrm{Btu} / \mathrm{h}-\mathrm{ft}^{2}$

$0.917 \times 10^{6} \mathrm{Btu} / \mathrm{h}-\mathrm{ft}^{2}$

$1.1 \times 10^{6} \mathrm{Btu} / \mathrm{h}_{\mathrm{L}}-\mathrm{fl}^{2}$ 
TABLE 4-1 (Continued)

Parameter

Backup Design

Thermo-Hydraulics (Continued)

Power Peaking Factors

Nuclear

Axial

1.21

Radial

1. 3 total

New Fuel per Average Fuel

1.06

Engineering

Local Peaking Factor

1.1

Enrichment, Density, and

Pin Tolerances

1.035

Local Peaking Due to Experiments

1.025

Overpower Factor (OPF)

1.20

Fuel Melting Range

Zero Burnup

With Burnup (estimated)

Fuel Thermal Conductivity, $\int_{\mathrm{kd} \theta}$

$5200^{\circ} \mathrm{F}$

$4850^{\circ} \mathrm{F}$ at $80,000 \mathrm{MWd} / \mathrm{Te}$

$18.7 \mathrm{~W} / \mathrm{cm}$ at $1100^{\circ} \mathrm{C}$

$54.3 \mathrm{~W} / \mathrm{cm}$ at $2700^{\circ} \mathrm{C}$

Fuel to Cladding Heat Transfer Coefficient

$1500 \mathrm{Btu} / \mathrm{h}-\mathrm{ft}^{2}-{ }^{\circ} \mathrm{F}$

\subsubsection{Channel}

The channel is a hexagon tube with 0.1 -inch thick walls. It serves two functions: first it is the structural member for the fuel element; second it serves as the coolant duct.

The channel material is Incoloy 800 . The use of Incoloy 800 allows thinner walls as compared to 304 stainless steel tubing due to its greater strength (design stress at $1200^{\circ} \mathrm{F}=$ $28,500 \mathrm{psi}$ ) and its high nickel content which enhances the Doppler effect. Extrapolating from data at $3 \times 10^{21}$ nvt, it appears it will also possess relatively high residual ductility at FFTF exposures of $\sim 10^{23}$ nvt.

\subsubsection{Lower Shield and Reflector Rods}

The six 0.875 o. d. rods in the lower section of the fuel element are combination shieldreflector rods. Bare nickel rods are shown for the reference design lower reflector but austenitic steel cladding could be used if future corrosion studies warrant it. High nickel allows are also candidates for reflector material.

The shield rods are solid 304 stainless steel tubing rods. A combination of stainless steel next to the reflector followed by a few inches of stainless steel clad $\mathrm{B}_{4} \mathrm{C}$ is an alternate design if additional shielding. should be required to decrease fluence in the core support plate. 

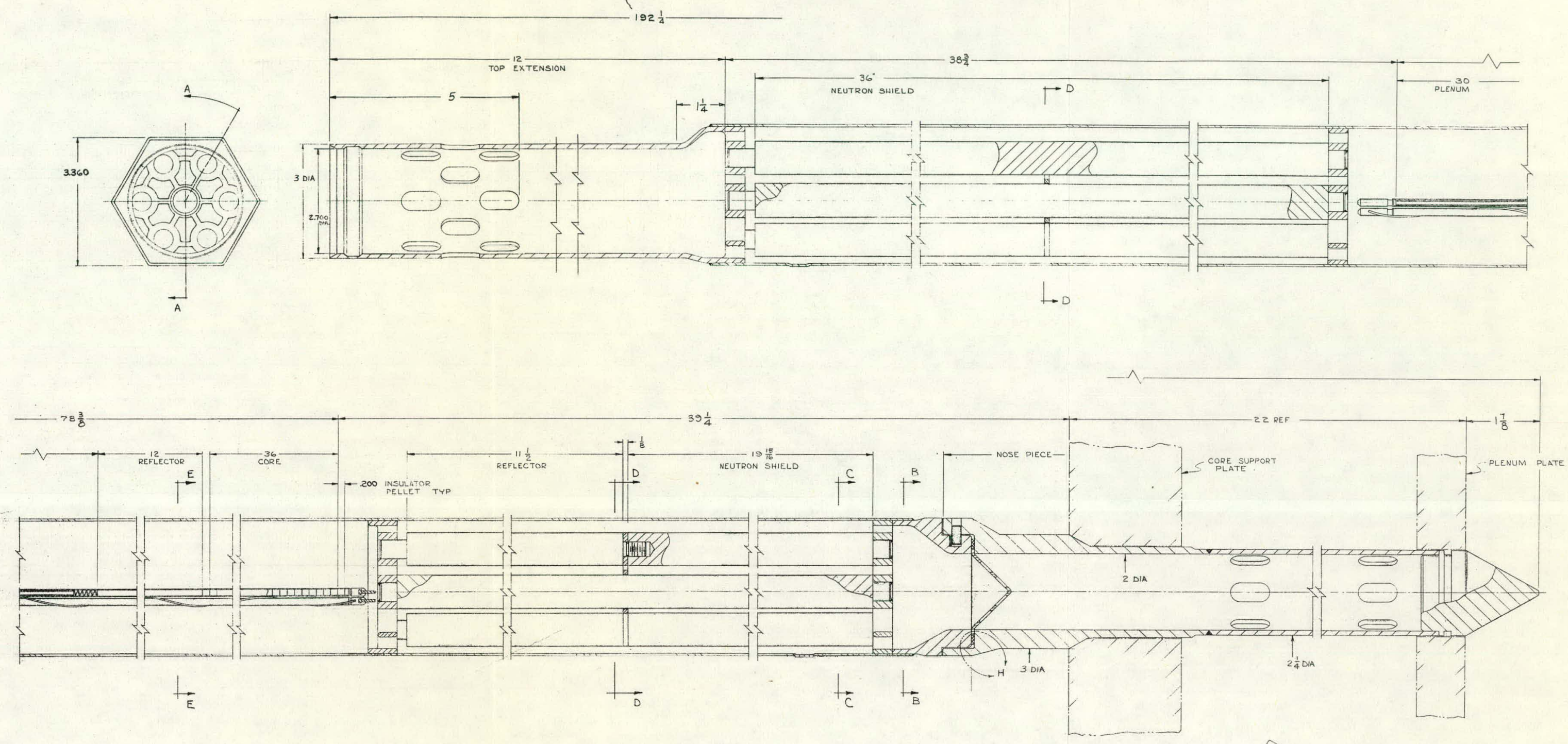

SECT-AA

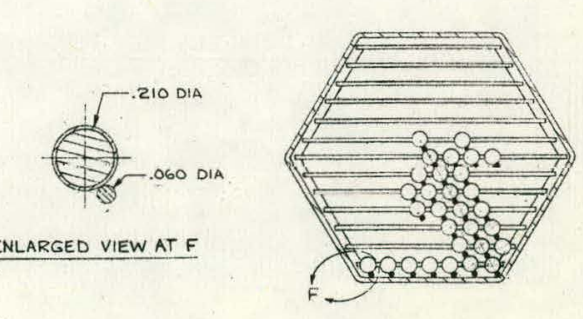

SECT-EE

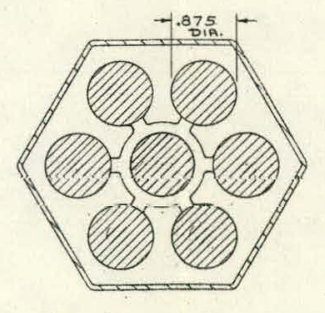

SECT:DD

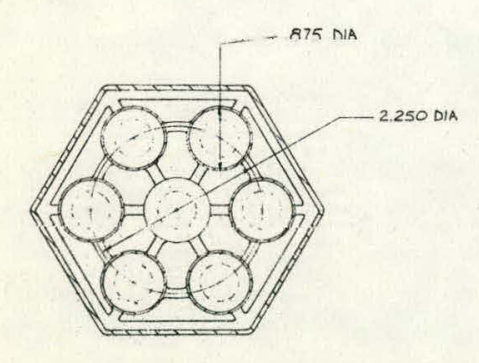

SECT-CC

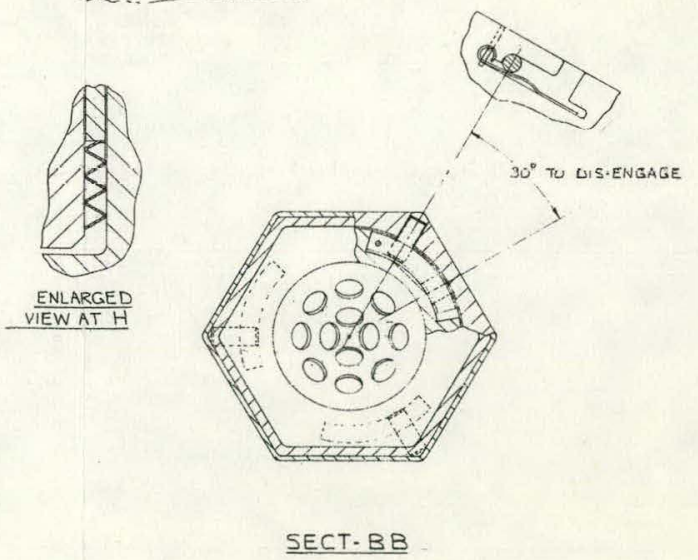

FIGURE 4-1. DRIVER FUEL REVISIONS 


\subsubsection{Fuel Rods}

The fuel rods are 79.5-inches long. Fuel pellets occupy the lower 36 inches. Above and below the fuel column is a 0.2 -inch long depleted $\mathrm{UO}_{2}$ insulator pellet. The upper insulation is followed by a 6 -inch long nickel reflector. Above the reflector is a 30-inch long gas plenum. The gas space contains a short spring and a spring support tube to prevent fuel pellet movement during handling prior to irradiation.

A fuel pin diameter of 0.21 inch was selected for the FFTF Backup Core Design. The 0.21-inch diameter fuel pin yields higher neutron flux and reflector control strength than the larger fuel pin diameter, while maintaining an adequate Doppler coefficient. A parameter study performed on 0.21 -inch and 0.25 -inch fuel pin designs indicates that the 0.21 -inch design has the following:

- A peak neutron flux $\sim 14 \%$ higher than the 0.25 inch design.

- Reflector control strength $\sim 140 \%$ of the 0.25 inch design

- The Doppler coefficient $\left|\mathrm{T} \frac{\mathrm{dk}}{\mathrm{dT}}\right|, 0.0007$ less than the 0.25 inch design

\subsubsection{Fuel Rods Spacing}

Fuel rod spacing is provided by a 0.060 -inch diameter wire-wrap on each fuel rod. Analysis has indicated that the greater flow around the bundle edges might cause undesirable thermal bowing and stress. However, since its effects had not yet been fully assessed no design change was made to the bundle assembly.

\subsubsection{Fuel Pellets}

Fuel pellets are $\mathrm{PuO}_{2}-\mathrm{UO}_{2}$ prepared by cold-pressing and sintering coprecipitated powder. Fuel composition for the two-zone core is discussed in Section 3.3. The fuel pellets have a $94 \%$ TD and are $U .1 \%$-inch in dlameter by approximately 0.20 -inch in length,

\subsubsection{Upper Axial Shield Rods}

The six upper axial shield rods are solid 304 stainless steel tubing, 0.875 -inch in diameter by 36 -inches in length. This design gives a $1 \times 10^{16}$ fast neutron fluence at the top of the fuel element over the life of the plant. Removing the neutron shielding and placing it in the top head was considered. Fast neutron fluence would be increased by a factor of 30,000 at the top of the fuel element to $3 \times 10^{20}$ nvt.

\section{1:9 Top Extension}

A 12-inch long cast section extends above the neutron shield region which accommodates the fuel element grapple during fuel insertion and removal and also provides a flow tube for the fuel element instrumentation package, which is suspended from the refueling head. 


\subsection{CONTROL ROD DESIGN}

\subsubsection{Reflector Control Rod}

A concentrated analysis effort was undertaken to develop a detailed design criteria for the dual purpose shim-safety rods for the primary control system. Extensive kinetic studies were in process at the time of contract redirection to develop the design requirements relating to the offset design. The results of this analysis are given in above in this section. Nuclear and mechanical design considerations had established a reference design with the following volume percent composition:

\begin{tabular}{lc}
\multicolumn{1}{c}{ Material } & Volume \% \\
$\mathrm{B}_{4} \mathrm{C}$ & $29.2^{\circ}$ \\
$\mathrm{Na}$ & 32.8 \\
Stainless Steel Tubing & 26.6 \\
Incoloy 800 & 11.4
\end{tabular}

The chosen reference design is a 37 rod bundle with $\mathrm{B}_{4} \mathrm{C}$ cladding in 0.406 -inch o.d. , 0.042 -inch wall austenitic stainless steel tubing. Tantalum was considered, but because of its lower worth it was not chosen for the reference design poison.

The main features of the design include an outer channel similar to the fuel channel (3. 36-in. flat-to-flat with a 0.1-inch wall), a movable hexagon carriage (2.71-inch flat-to-flat with a 0.1 -inch thick wall), the $\mathrm{B}_{4} \mathrm{C} \cdot \mathrm{rod}$ bundle contained within the carriage and a 30 -inch to 36 -inch long follower reflector region. The detailed design was to be accomplished within the coming contract year. A scope design is shown in Figure 5-1 (disrussed fully in Section 5) which, although not reflecting the current reference dimensions or snubbing features resulting from the current analysis, shows the salient features of the design.

\subsubsection{In-Core Safety Rod}

Three in-core safety rods are used as backup control in case the primary control fails. The drives for this system are separate and independent from the primary control drive system. As with the reflector control design, the current effort had been aimed at determining the design criteria. Detailed design was to be completed later in the contract period. Table 4-2 shows the design criteria selected for the in-core safety rods.

The major features of the as-scoped design are an outer stationary hexagon channel, an inner movable hexagon carriage, a bundle of $19 \mathrm{~B}_{4} \mathrm{C}$ rods, a follower section composed of $1 / 3$ steel and $2 / 3$ sodium, and a remote disconnect between the drive extension and carriage to permit removing the backup safety control drives with the refueling plug.

One of the major analytical and mechanical problems remaining is the design of an orificing arrangement that will minimize the amount of coolant bypassing the core, especially when the rod is in the full out position. 
TABLE 4-2

DESIGN CRITERIA AND DATA FOR THE IN-CORE SAFETY RODS

$\mathrm{B}_{4} \mathrm{C}$ (natural) v/o

Calculated $\% \delta \mathrm{k} / \mathrm{k}$

Average Heat Generation

Peak Heat Generation

Poison Column Length

Channel Geometry

Channel Size - o. d.

Channel Size - i. d.

Carriage Geometry

Carriage Size - o. d.

Carriage Size - i.d.

Gap between Channel and Carriage

$\mathrm{B}_{4} \mathrm{C}$ Rods per Bundle

$\mathrm{B}_{4} \mathrm{C}$ Rod Diameter

$\mathrm{B}_{4} \mathrm{C}$ Rod Wall Thickness

Inlet Temperature

Outlet Temperature

Cladding o.d. Temperature

Cladding i.d. Temperature

$\mathrm{B}_{4} \mathrm{C}$ Center Line Temperature

Coolant Flow

Bypass Flow (no orificing)
35

2.8

$62 \mathrm{~W} / \mathrm{gm}$

$75 \mathrm{~W} / \mathrm{gm}$

36 in.

Hexagon tube

3.36 in.

$3.16 \mathrm{in.}$

Hexagon tube

2.96 in.

2.56 in.

$0.1 \mathrm{in}$.

19

$0.535 \mathrm{in.}$

0.025 in.

$700^{\circ} \mathrm{F}$

$1000^{\circ} \mathrm{F}$

$860^{\circ} \mathrm{F}$

$885^{\circ} \mathrm{F}$

$1450^{\circ} \mathrm{F}$

$12,300 \mathrm{lbm} / \mathrm{h}$

$12,000 \mathrm{lbm} / \mathrm{h}$

\subsection{RADIAL REFLECTOR ELEMENTS (FIXED)}

Two rows of channels beyond the row of primary control rods contain 102 radial reflector elements as shown in Figure 3-1. Each reflector element fits into a fuel element type channel. The nickel section of the reflector element is approximately 4 feet in length and extends 6 inches above and 6 inches below the reactor core. The channel above and below the nickel section contains tubes filled with $\mathrm{B}_{4} \mathrm{C}$ shielding. Coolant is supplied from the reflector element nose piece which extends into the high pressure plenum below the core support plate. The fuel channel holddown system is also used to hold the reflector elements in place against the upward flowing sodium.

\subsection{PROBLEM AND INTERFACE AREAS IN THE CORE REQUIRING ADDITIONAL EF FORT}

The redirection of the work effort was premature relative to the completion of work planned As a result, many areas remain to be integrated. Some of these special areas follow: 
a. Core Elevation

Consideration was being given to raising the core elevation to accommodate possible length requirements for a control rod deceleration device at the bottom of the reflector control channels. Several possibilities exist for raising the core elevation:

(1) Recent analysis shows that the upper axial reflector region can be decreased 6 inches (from the reference 12 -inch height).

(2) The upper axial shield could be relocated in the top head.

(3) The upper axial shield could be a combination of stainless steel tubing and $\mathrm{B}_{4} \mathrm{C}$ to reduce its length.

(4) A combination of $a, b$, or $c$.

b. Fuel Element Tolerances

Both fabrication and material property tolerances consistent with state-of-the-art testing methods requires further consideration.

c. Structural Material Swelling

The effect of cladding and channel material swelling upon the core design tolerances needs to be further assessed.

\subsection{CORE SUPPORT AND CLAMPING DESIGN}

The major function of the core support and clamping sysiem is to provide primary structure for support of the reactor internals. The detailed design of the mair components of the core support vessel interface structure will depend on the design of the reference pressure vessel. The detail design of the pressure vessel must include the necessary reatures to allow for an efficient means of removing the reference core support structure at any point in time, including after initial operation.

\subsubsection{Core Support and Inlet Plenum}

A proposed design for the interface betwecn the core support structure for the backup design and the reference pressure vessel has been established and is shown in Figurc 4-2. The inlet plenum for the backup design consists of two perforated plates which would be bolted to the reference design core structure replacing the two perforated plates that form the inlet plenum for the reference design. Core bypass leakage that might occur at the junction of the perforated plates and the reference structure will be controlled by metallic seals at each of the junctions. The seals will be compressed by the plate hold-down bolts. The upper plate is bolted directly to the reference structure while the lower plate is held down by a set of special fasteners located just inside the circle of bolts that fasten the upper plate to the zeference structure.

The upper plate of the inlet plenum as shown in Figure 4-3 has an outside diameter of 70 inches, a thickness of 6 inches and is perforated with 1272.390 -inch diameter holes on a 


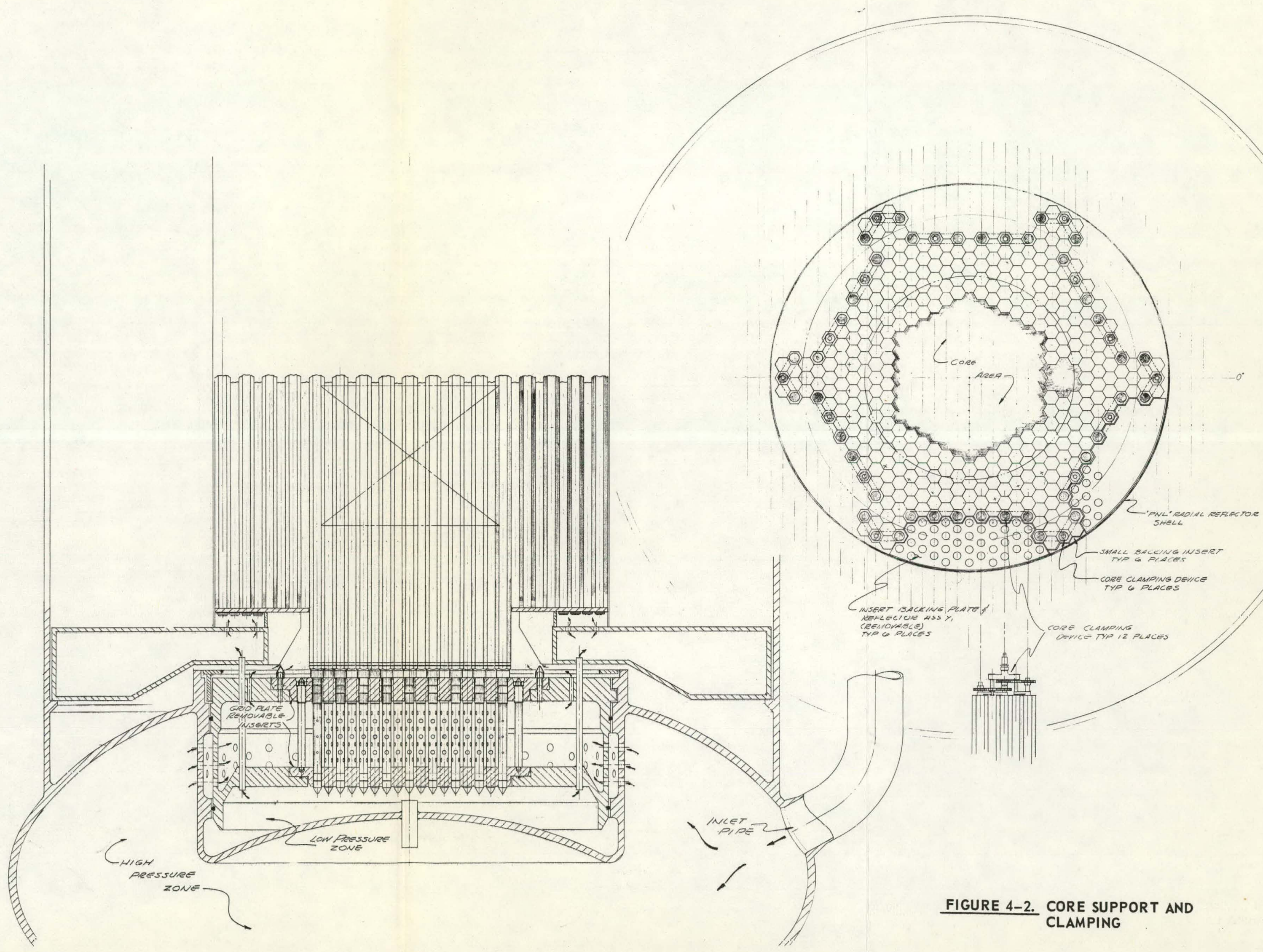




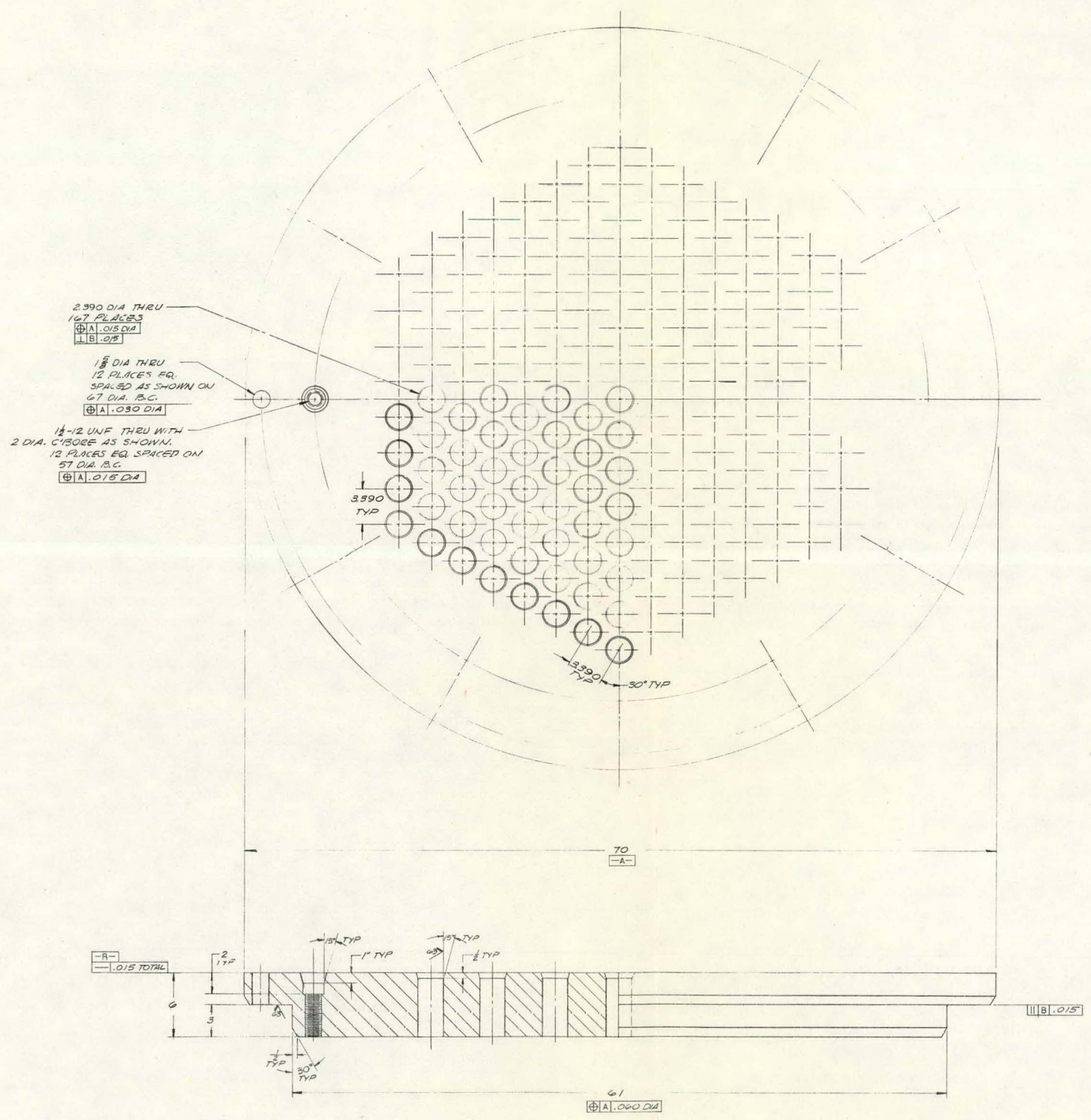


3. 39-inch equilateral triangular spacing. The lower plate of the inlet plenum as shown in Figure 4-4, has an outside diameter of 59 inches, a thickness of 6 inches and is perforated with 1272.265 -inch diameter holes on the same pitch and pattern as the upper plate. The alignment of the hole patterns between the upper and lower grid plates is very important since the nose piece of the fuel assemblies must penetrate both plates to be properly installed. The hole pattern alignment will be controlled by machining the holes in both plates at the same time while they are clamped together. During reactor shutdown conditions; the upper grid plate will support the dead weight of the entire core which includes the driver fuel bundles, closed.loops, open loops, and control rod shrouds. During: operating conditions the core components will be held down to the upper grid plate against the hydraulic forces by a combination of their weight and utilization of the hydraulic holddown effect created by the high pressure within the inlet plenum acting over the projected area of the lower end of the assemblies. As the coolant pressure within the inlet plenum increases, the load on the upper grid plate will change from a downward force to a net upward force at a point when the hydrostatic force from the inlet.plenum pressure exceeds the weight of the core components. The pressure difference across the upper grid plate during operating conditions will produce a load on the plate which will exceed the dead weight load on the plate and is the most important factor in the determination of the thickness of the plate. Also the lower grid plate will be subjected to the same hydrostatic pressure and must be of a strength equal to that of the upper grid plate. At installation, the hole patterns of the two plates will be kept in alignment by the use of several specially sized keys that will extend through the upper plate and into the holes of the lower plate, holding them in proper position until the bolts are fastened, after which the keys would be removed.

The lower end of the fuel assemblies and other core components will extend through the upper plate into and through the lower plate forming a seal at each of the plates as shown in Figure 4-2. A piston ring type of seal will be used to reduce the amount of core bypass flow that will occur at the penetration into the high pressure plenum. The coolant pressure difference between the inside and outside of the lower end of the fuel assembly acting over the cross-sectional area of the lower end will produce a force which will in addition to the weight of the fuel assembly be sufficient to keep the fuel assembly -seated on the upper grid plate. The coolant pressure in the region just beneath the lower plate of the inlet plenum is maintained at a low value relative to the pressure within the inlet plenum by means of tubes connecting this region to the area above the inlet plenum. These tubes pass through the outer edge of the inlet plenum as shown on Figure 4-2. The bolted-in grid plate in the reference design would have the advantage of providing a relatively simple means of replacing the upper grid plate at any time over the life of the plant should this become necessary because of radiation damage or other reasons. Actual remnval $\mathrm{or}$ installation of the grid plates could be accomplished by remote means and would require only the rotation of the two sets of screws and a means to grapple the two plates. The proposed joint between the reference and vertical core structure would be located at a radius great enough to allow for a change of the core size of the reference core as well as the vertical core.

Figure 4-5 shows a conceptual design of the structure that provides support for the reflector and shielding material which surrounds the core as well as providing a rigid structure to back up the core clamping system. 


\subsubsection{Core Clamping}

The core clamping system which has been established for the FFTF backup design utilizes a torsion rod type of clamping mechanism similar to the type installed in the SEFOR reactor. The clamping device is shown in Figure 4-6. In the proposed system a clamping device would be installed within each of a set of reflector assemblies which form a complete ring around the fuel assemblies. The locations of the 54 clamping devices are shown in the plan view of Figure 4-2. The ring of clamping devices is located radially beyond the outside diameter of the reflector plug. The clamping devices are actuated by an actuating tool that is inserted through access holes located in the reactor outer head.

The clamping devices are connected by roller chains, as shown in Figure 4-6, in groups of three so 18 access holes are necessary to actuate the 54 clamping mechanisms required to form the complete ring of clamping force around the reactor core. The actuating tool rotates the torsion rods of the clamping mechanisms to some determined torque value by means of the helical drive socket, sprockets, and roller chains at the top of the clamp assembly. The torque is then locked in the torsion rods by means of a splined connection. The reaction to the torque stored within the torsion rods is used to force the hexagonal channel, in which the clamping mechanism is installed, radially inward. The tightening process is repeated at 18 locations around the periphery of the core creating a complete ring of radially inward directed force which will hold the fuel assemblies in a compact rigid array. The lower transition piece of the clamp assemblies is designed to allow a small amount of relative motion in any direction between the clamping device and the grid plate which supports it. Relative motion between the clamping mechanism and the clamp support plate is provided to ensure that the core can be tightly compacted by the core clamps without causing bending of the clamping assemblies. Differential thermal expansion between the core and surrounding reflector region is ascommndater by rotation of the torsion rod of the clamps which functions as a torsional spring. The above method of clamping the core has the major advantages of not interfering with refueling or experiment handling since the clamping mechanisms are located outside of the core. Also, the core can be tightened before startup since no temperature changes or hydraulic pressure are required for clamp actuation.

\subsection{CLOSED LOOP DESIGN}

The closed loops are designed to provide an isolated test region within the reactor core complete with an independent coolant system and means for installation and removal of the test hardware without removal of the vessel refueling plug. There are a total of six closed loops proposed for installation within the FFTF core. Five of the six closed loops are of the reentrant or counterflow type, as shown in Figure 4-7, and are located at the same radial position within the core, approximately 13.5 inches from the core center. The sixth closed loop, shown in Figure 4-8, is to be installed at the center of the core. It differs from the other five closed loops in occupying two adjacent hexagonal channel positions in the core. One of the hexagonal channels is used for the inlet flow to the test region and the other is used to house the test region, thus allowing for a larger diameter test assembly and more coolant flow than can be accommodated in the five re-entrant type closed loops. Both types of closed loops are connected to the coolant inlet and outlet lines by means of remotely operable couplings. The remotely operable couplings and the inlet and outlet coolant lines are shown in Figure 4-9. 


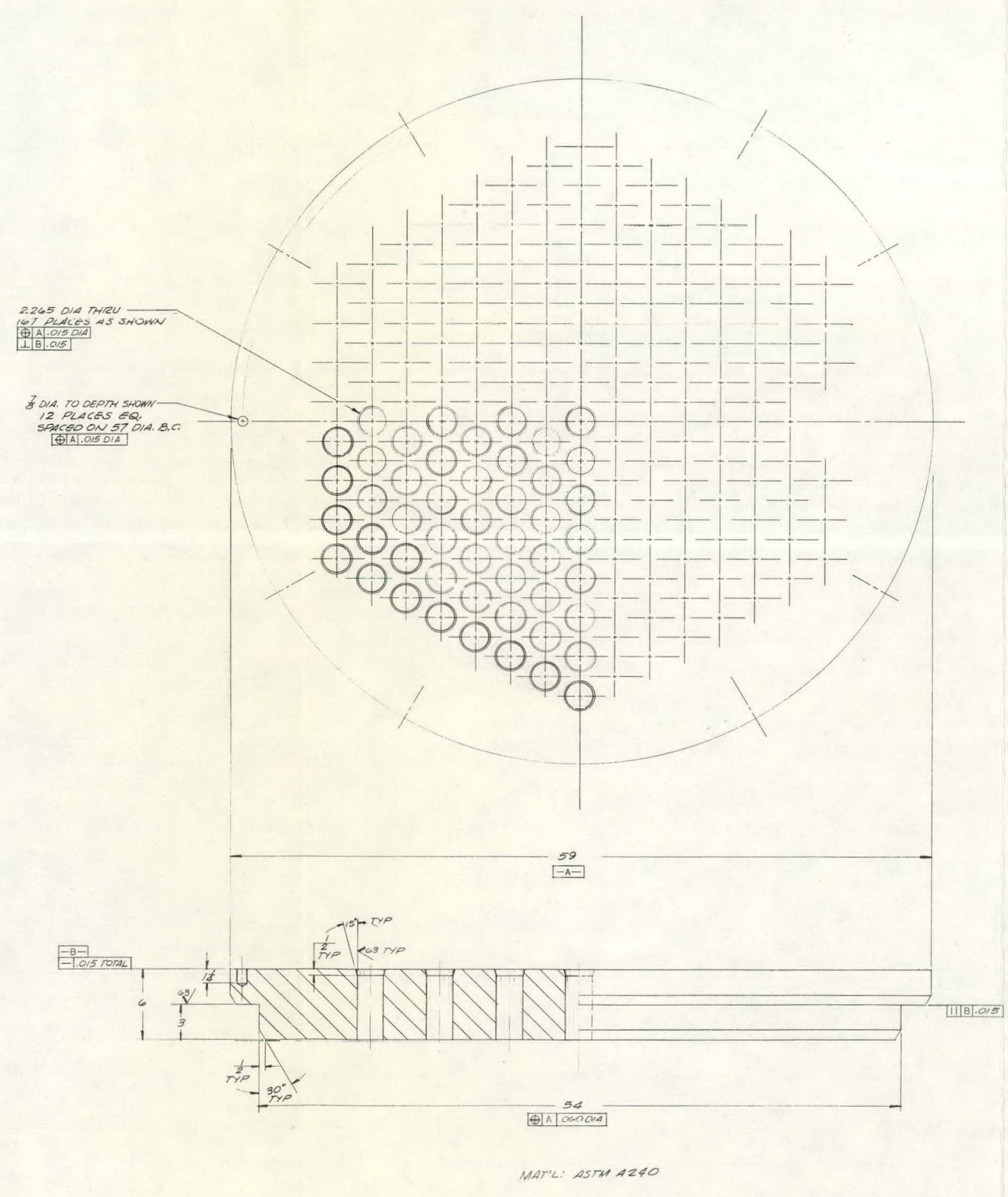

FIGURE 4-4. LOWER GRID PLATE

$4-17 / 4-18$ 


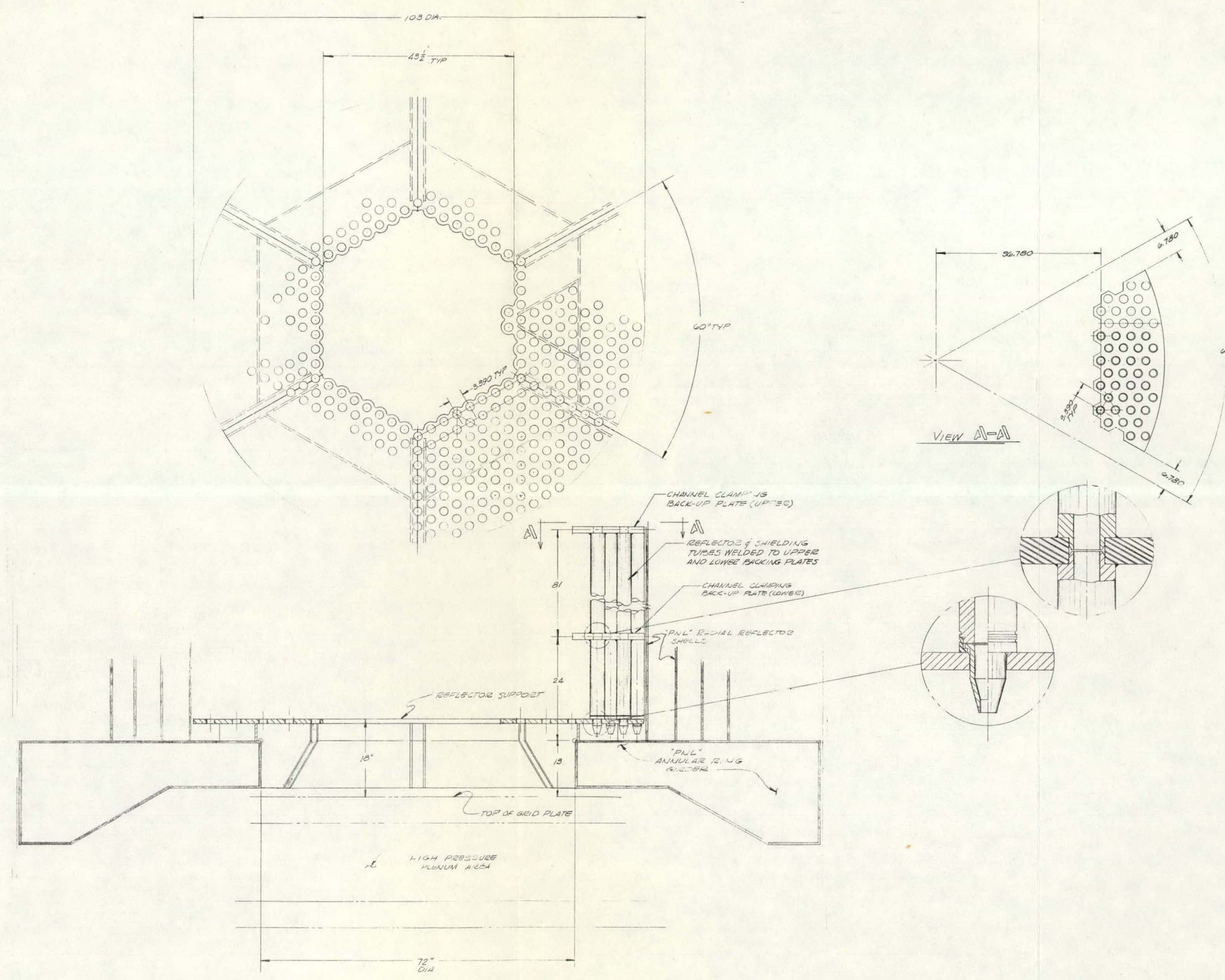

FIGURE 4-5. REFLECTOR AND CORE 


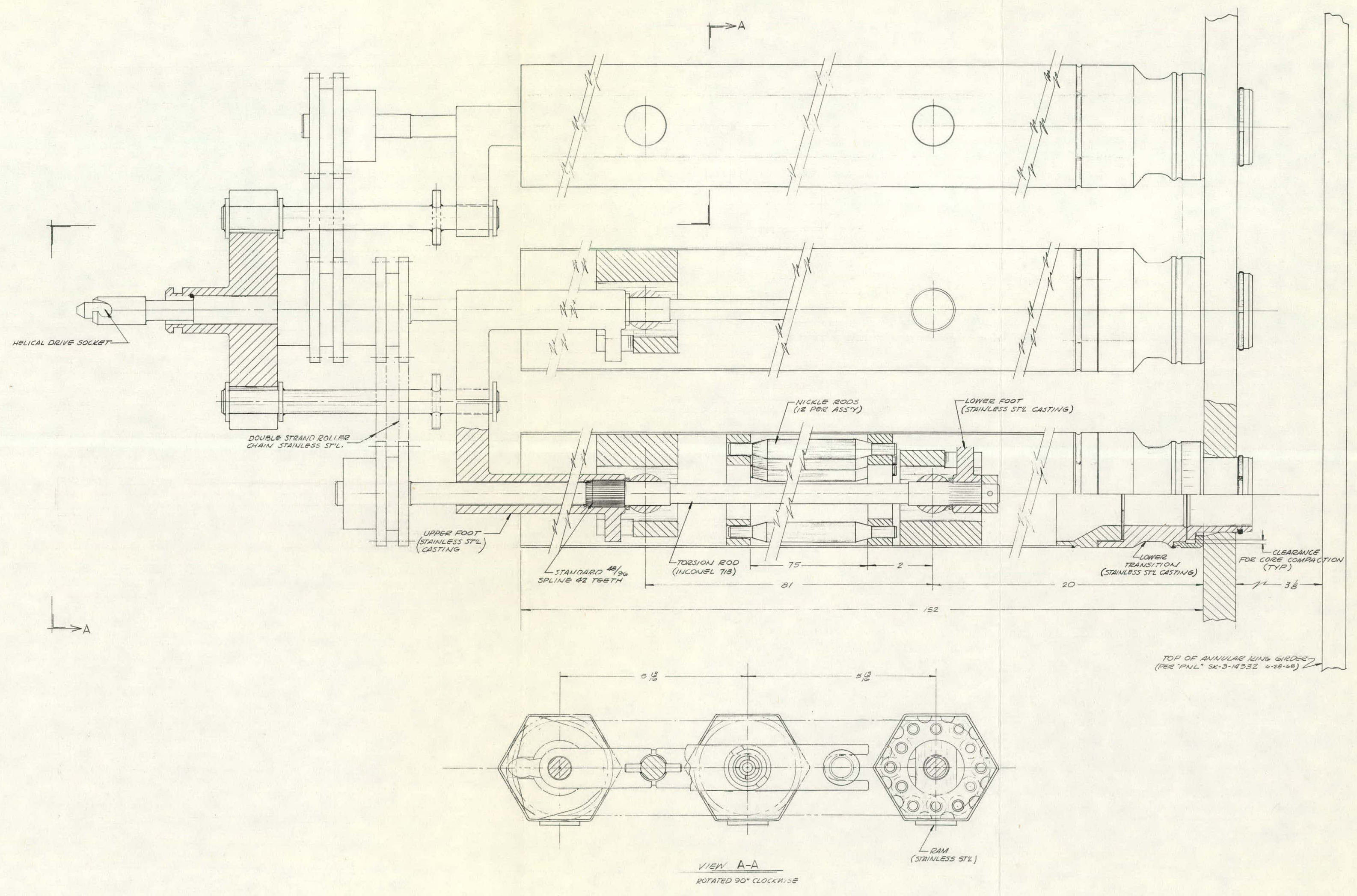

FIGURE 4-6. CORE CLAMPING MECHANISM 


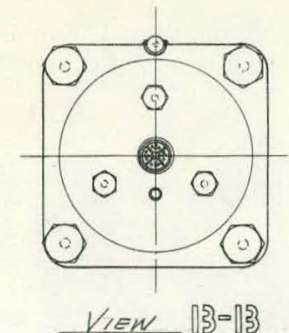
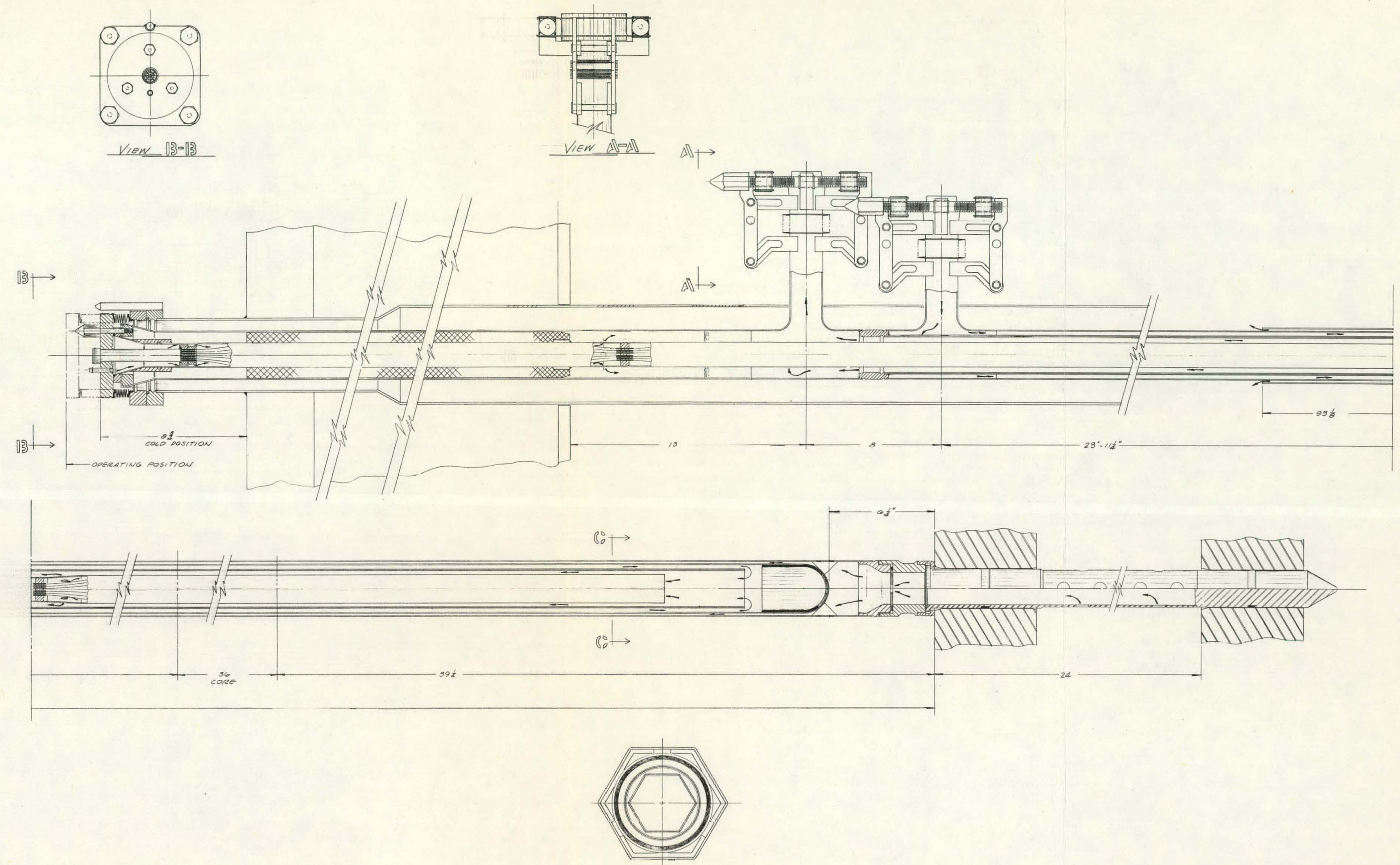

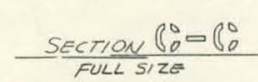




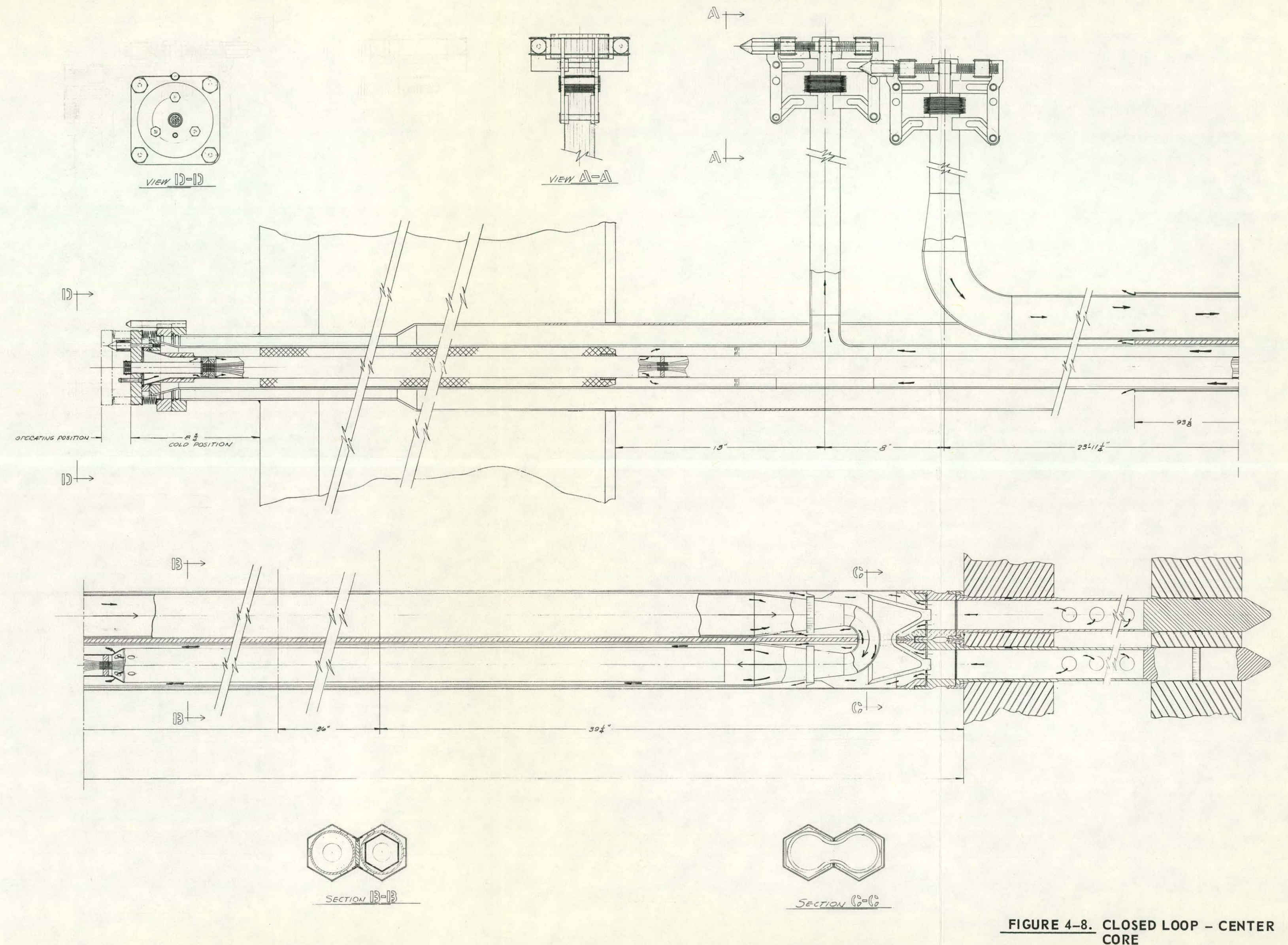



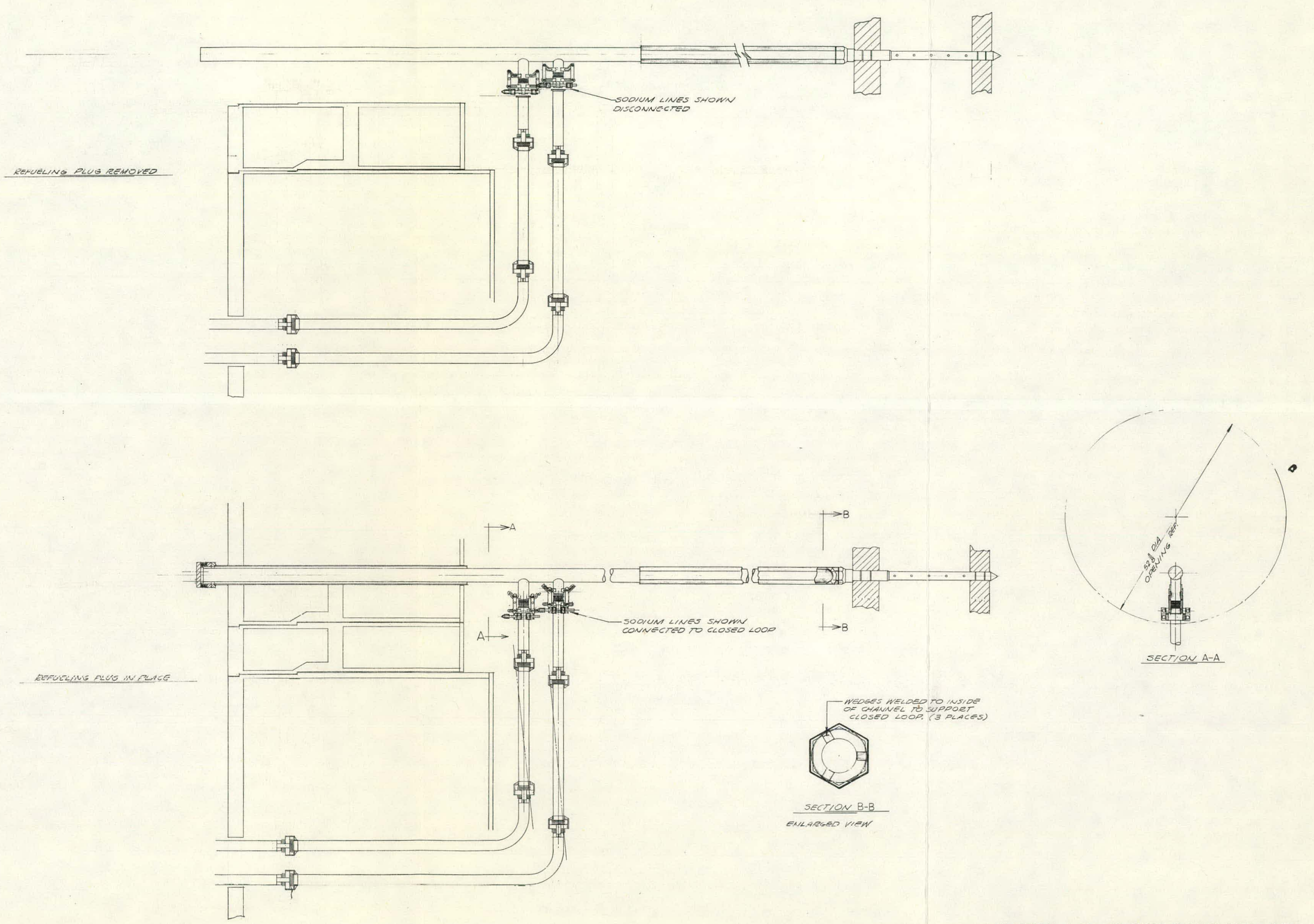
FIGURE 4-9. CLOSED LOOP COOLANT
CONNECTIONS 
The couplings are located at an elevation just below the refueling plug and at a radial position above the reflector-control channels which surround the fuel assemblies. The remotely operable couplings are accessible when the refueling plug has been removed since they are located within the refueling plug opening. The upper end of both types of closed loops is essentially identical above the elevation of the point of attachment of the closed loops to the inlet and outlet piping crossing over the core. Shielding will be provided as a part of the closed loop over the length of closed loop that passes through the refueling plug. The lower end of the closed loops will be similar to the nose piece of the driver fuel elements and will extend through the upper and lower perforated plates which form the inlet plenum to take advantage of the hydraulic holddown effect. Differential expansion of the closed loops with respect to the refueling plug will be accommodated by having the closed. loops connected to the refueling plug by means of a bellows which will allow the required axial motion of the closed loop relative to the refueling plug.

The lower end of the closed loops is designed similar to that of a driver fuel element that can be installed in a closed loop position if it is desired to operate the reactor with less than six closed loops installed.

\subsubsection{Re-Entrant Type Closed Loop}

The re-entrant or single hexagonal position type closed loop is shown in Figure 4-7. The overall length of the single closed loop is approximately 33 feet extending from 1 inch below the lower grid plate of the inlet plenum to 8-3/4 inches above top surface of the refueling plug when installed in the reactor. The extreme lower end of the closed loop will be designed similar to the lower end of the driver fuel assembly so that special holes in the upper and lower grid plates of the inlet plenum will not be required for the closed loops; also, the closed loops will be able to take advantage of the hydraulic holddown effect created by the high pressure within the inlet plenum acting over the projected area of the lower end of the closed loop. Another advantage of designing the lower end of the closed loop similar to that of the driver fuel assemblies is the possibility that a typical driver fuel assembly could be installed in a closed loop position if it was desired to operate the reactor without some of the closed loops installed. The lower end of the closed loop contains a number of holes that allow some of the reactor inlet coolant to flow up through the hexagonal channcl shroud in which the closed loop is installed. 'I'his core bypass flow will provide cooling along the outside surface of the outer tube of the closed loop, thereby eliminating a high thermal gradient across the outer tube since the inside surface is in contact with the inlet flow of the closed loop which will be near the same temperature as the reactor inlet flow. The above flow paths are indicated by the arrows in Figure 4-7. Orificing of this bypass cooling flow will be provided by an orifice located at the lower end of the hexagonal shroud surrounding the closed loop as indicated in Figure 4-7. The lower end of the closed loop shroud is designed to allow a small amount of relative motion in any direction between the closed loop shroud and the core support plate. Relative motion between the closed loop shrouds and the core support plate is provided to ensure that the core can be tightly compacted by the core clamps. without causing bending of the closed loop shrouds. A melt down cup made of tantalum or other suitable material is installed in the closed loop beneath the test region to serve as a container for the test material in the event of a melt down or other damage to the test region. 
The test region itself is suspended within the core by means of a hanger rod or handle which extends from the top of the closed loop above the refueling plug. The test region may be removed from the core by means of the handle after removal of several bolts and a cap at the top of the closed loop.

The inlet coolant flow to the closed loop enters the closed loop at an elevation 21 inches below the underside of the refueling plug and then flows downward through an outer annular path to the bottom of the closed loop as shown by the arrows in Figure 4-7. At the bottom of the closed loop the coolant turns 180 degrees and flows vertically upward through the test region to the outlet pipe located 8 inches above the inlet pipe. The level of the outlet coolant within the closed loop is controlled by a cover gas pressure to maintain the level within the closed loop at the same level as the coolant level in the reactor. The tube which keeps the cooler inlet flow separated from the hot outlet flow within the closed loop will be constructed of several concentric tubes in layers to reduce the thermal stress in this part. The instrumentation leads from the test region are routed through the tube or handle which supports the test region. A seal is provided within the handle just above the test region to prevent the coolant from entering the handle. The instrumentation leads from the test region terminate at the upper end of the handle in a plug-in type of electrical connector that can be separated to allow removal of the loop internals. Additional shielding will be included as a part of the closed loop over the elevation that corresponds to thickness of the refueling plug. The couplings which connect the closed loop to the coolant inlet and outlet lines are remotely operable by rotation of two screws that hold the two halves of each coupling together. Rotation of the two.screws also causes the joint to separate in a horizontal direction through a cam and follower to free the closed loop from the piping and allow removal. Figure 4-9 shows a typical re-entrant type closed loop connected to the external coolant lines with the reactor refueling plug in place and also in the disconnected condition ready for removal, with the refueling plug removed.

\subsubsection{Center of Core Closed Loop}

The center of the core closed loop as shown in Figure 4-8, differs from the re-entrant type by occuping two hexagonal channel positions in the core. One of the hexagonal channels is used for the inlet flow and the other is used to house the test region, thus allowing for a larger diameter test assembly and more coolant flow than can be accommodated in the re-entrant type closed loops. The portion of the center closed loop above the couplings to the coolant inlet and outlet lines and the couplings themselves are identical to the re-entrant type closed loop and the description given for this portion of the re-entrant loop applies also to the center loop. The flow path through the conter loop is indicated by the arrows shown in Figure 4-8. The lower end of the center loop terminates in two nose pieces which are similar to the lower ends of a driver

fuel assembly and which penetrate holes of the same spacing and size as the driver fuel assemblies to preserve the uniform pattern of holes in the upper grid plate and allow the installation of two driver fuel assemblies in place of the center closed loop if it was desired to operate the reactor without the center closed loop. As in the case of the re-entrant closed loop, the center closed loop utilizes the hydraulic holddown effect of the high pressure within the inlet plenum. Bypass inlet coolant is allowed to flow from the inlet plenum through an orifice into the double-hexagonal shroud surrounding the center closed loop. This bypass coolant will be used to reduce thermal gradients in the structure of the closed loop. Other features of the center loop are similar to those described above for the re-entrant type closed loop. 


\subsubsection{Closed Loop Experiment Handling}

A conceptual design has been established for a method and equipment for removing and replacing the test region of a closed loop while the closed loop remains in the reactor connected to the external piping. Figure 4-10 shows in sequence the steps required in the closed loop experiment removal scheme using the proposed equipment. In the proposed system, the instrumentation lines and the inert gas lines are first disconnected from the top of the closed loop and the expansion seal cap is then removed. Next, the handling machine is bolted to the top flange of the closed loop as shown in stage 1 of Figure 4-10. The handle of the test region is grappled, and the test region is withdrawn from the closed loop by a cable operated lifting mechanism. An enlarged view of the grapple and of the lifting mechanism is also shown on Figure 4-10. As the experiment is raised within the closed loop and into the handling machine, the sodium level within the handling machine is also raised by creating a vacuum at the top of the machine, thus keeping the test section under sodium at all times. Stage 2 of Figure 4-10 shows the experiment raised to a sufficient height that a finned pot or thimble can be rotated into a position directly beneath the suspended experiment. In stage 3 the experiment is lowered into the finned pot. At this point the vacuum above the experiment is released allowing the sodium within the handling machine to flow back into the closed loop except for that trapped in the finned pot surrounding the experiment. The handing machine can now be unfastened from the closed loop flange, as shown in stage 4, and moved away to carry the experiment to its destination.

\subsection{OPEN LOOP DESIGN}

The design provides for 12 open loop assemblies located around the periphery of the core region in a flux of $0.65-0.75 \mathrm{n} / \mathrm{cm}^{2}-\mathrm{sec}$. The plan view locations in the inner shield plug are discussed in Section 7. The open loop assemblies are straight and descend vertically into the core below. The instrumentation leads are routed out of the vessel through this vertical pipe stalk that penetrates the central refueling plug: Refer to Figures 4-11 and 4-12.

The vessel head penetration design for the open loop which had been proposed initially is shown in Figure 4-13. The penetration design allows the refueling plug to be lifted vertically with llie slalionary open loop stalks slipping through the penetration. The sealing cap is first removed using a remote tool that engages the spur gear shown. When the open loop is installed in place, the sealing cap is tightened on its thread to draw a tight contact seal at the bottom side of the vessel head. The intended function of the contact seal was to prevent sodium vapor deposits from clogging the annular clearance between the head guide lube and the open loop assembly. A bellows seal just below the contact seal provides for thermal expansion of the open loop stalk with respect to the refueling plug. The reference design is shown in Figure 4-14.

After the above penetration design was proposed more investigation into vessel penetrations has been made, and this information has indicated that the sodium vapor deposits in the annulus of a guide tube not sealed at the bottom are probably not a problem. At Argonne Laboratory the shaft seal vessel penetrations for the EBR-II control drives and the FARET test model have performed successfully with no sodium vapor deposit problems, and those designs have a bellows seal at the top of the head with an annulus gap extending through the head. The annulus gap recommended should be in the order of $1 / 4$ inch: Because of the proven success of these penetrations, a design for the open loops using the concept of a bellows seal top side of the head with an annular gap extending through the head should be given serious consideration. 
A cable connection is provided at the top of the stalk. An array of 19 paired leads, each pair in an 1/8-inch diameter sheath, was selected as the number of instrument leads for each open loop. This selection was based on the number of wires that would be accommodated by a connector that would fit into the size of the cross-sectional area available for each open loop penetration. This selection also was reasonable for the amount of instrumentation provided. The limiting factor in the number of instrumentation leads that can be provided is in the number of pins possible for a connector size that will fit through the hole that can be provided in the vessel structure. As the vessel head is raised for refueling and the open loop assemblies remain stationary, the connector must slip through the vessel hole. The density of leads in the connector is much lower than the density of leads in sheaths bundled together.

The basic parameters to be measured are assembly outlet temperature, flow, and inlet temperature. The number of paired leads allocated for each of these is listed below:

$\begin{array}{lll}\text { - } & \text { Outlet Temperature } & 5 \text { (thermocouples) } \\ \text { - } & \text { Flowmeter } & 1 \\ \text { - } & \text { Inlet Temperature } & 3 \text { (thermocouples) }\end{array}$

This leaves a remainder of 10 paired leads to be utilized for additional instrumentation requirements as needed for the particular experiment design. Additional discussion of instrumentation is given in Section 6 and Appendix F.

\section{8 CORE THE RMAL HYDRAULICS}

\subsubsection{Thermal Hydraulic Constraints}

The main constraints from thermal hydraulic considerations are as follows:

- Peak centerline fuel temperature does not exceed the safety limits of Table 10-1. This is interpreted that there shall be no fuel melting at the local hot spot at $120 \%$ core power: i.e., the fuel centerline temperature shall be $\leq 5200^{\circ} \mathrm{F}$.

- Peak cladding temperature - local hot spot on the cladding inside diameter shall be $<1200^{\circ} \mathrm{F}$.

- Core pressure drop plenum-to-plenum shall be approximately 100 psi.

A detailed fuel management program has not been completed, but the reference scheme assumed that the core would be orificed. A tolerance on orificing is incorporated in the hot channel flow factor in which the flow per channel is considered to be up to $10 \%$ below the normal flow to give a nominal temperature rise of $300^{\circ} \mathrm{F}$ across the bundle. The allowable peak power density in the fuel is calculated to be $17.8 \mathrm{~kW}$ per foot based upon centerline melting at the core hot spot at $120 \%$ core power. This along with the pressure drop constraint was used as the basis for a parameter study to determine the relationship between pin diameter, pin spacing, and pin length from which the core geometry was established to optimize neutron flux at the test locations. The reference core parameters selected are given in Table 4-1. 

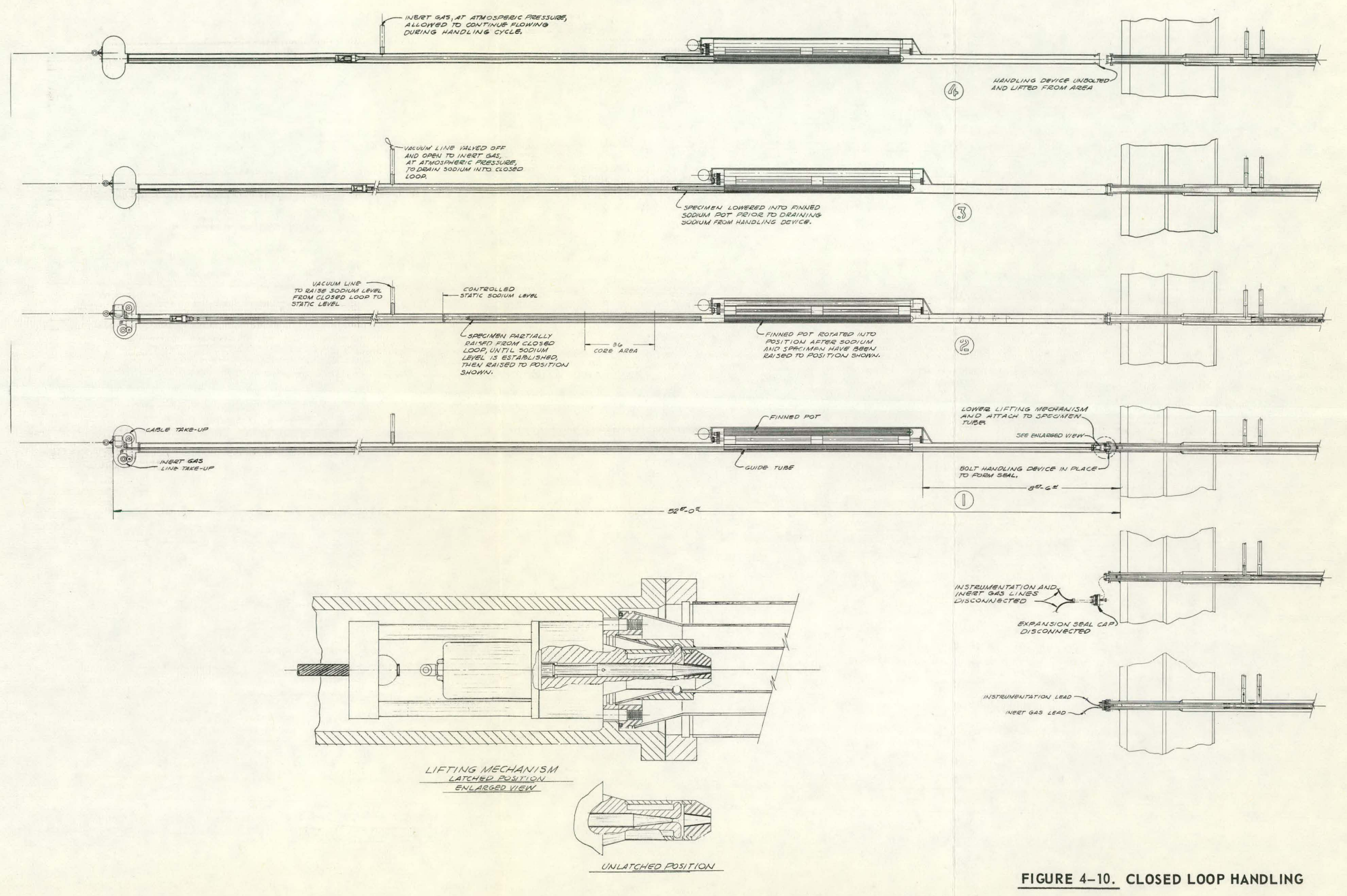

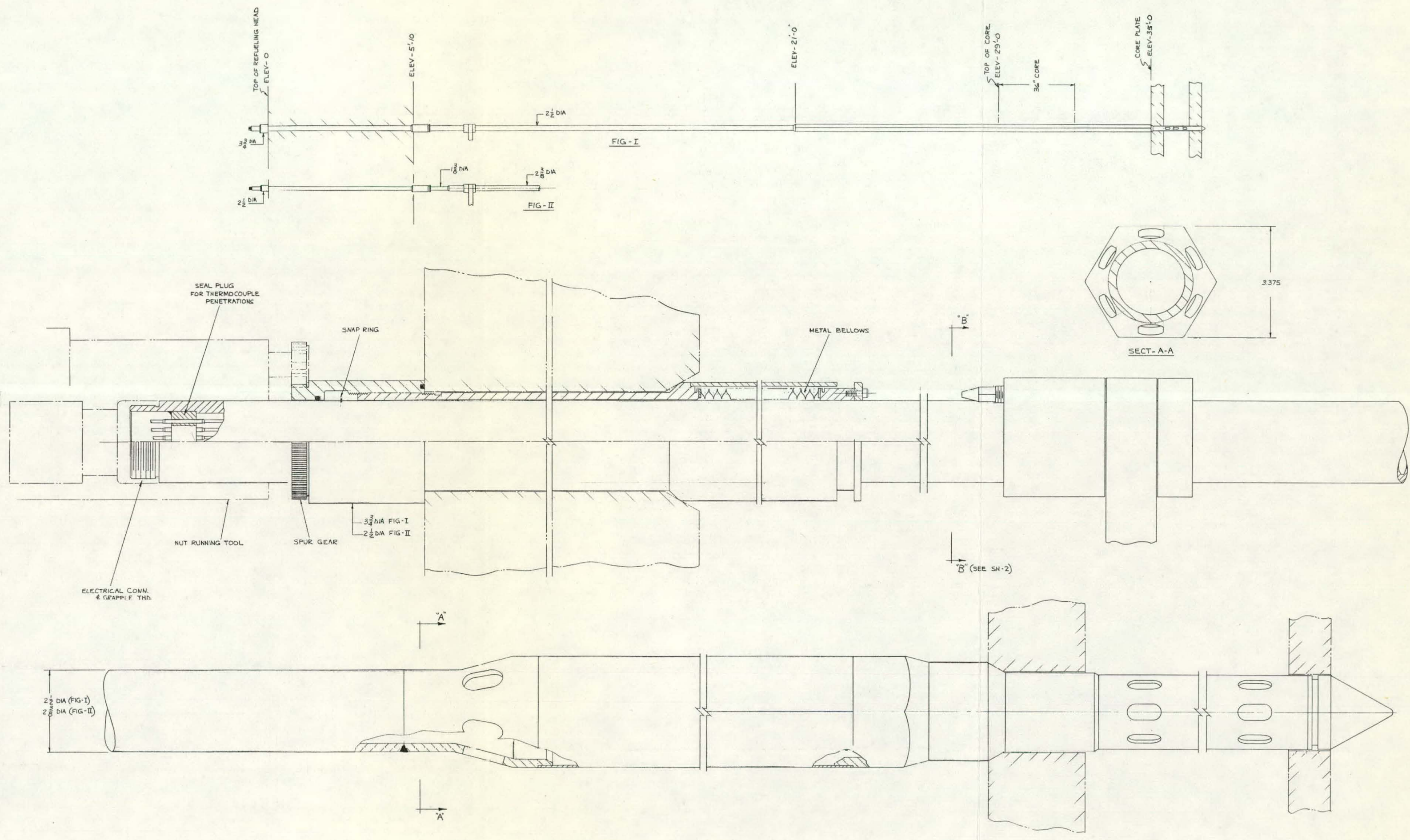

FIGURE 4-11. OPEN LOOP SYSTEM (I) 
GEAP-5722

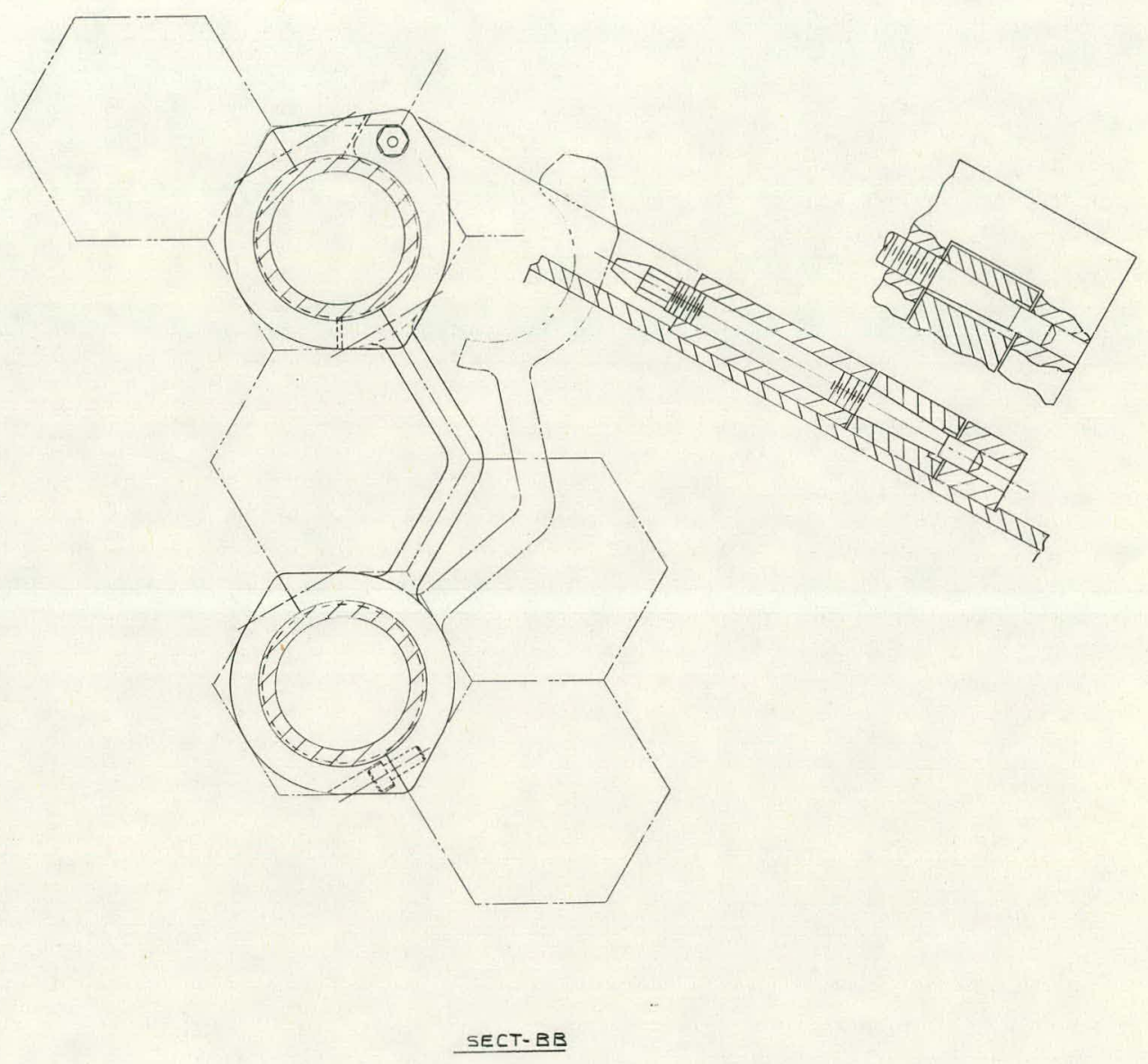

FIGURE 4-12. OPEN LOOP SYSTEM (II) 


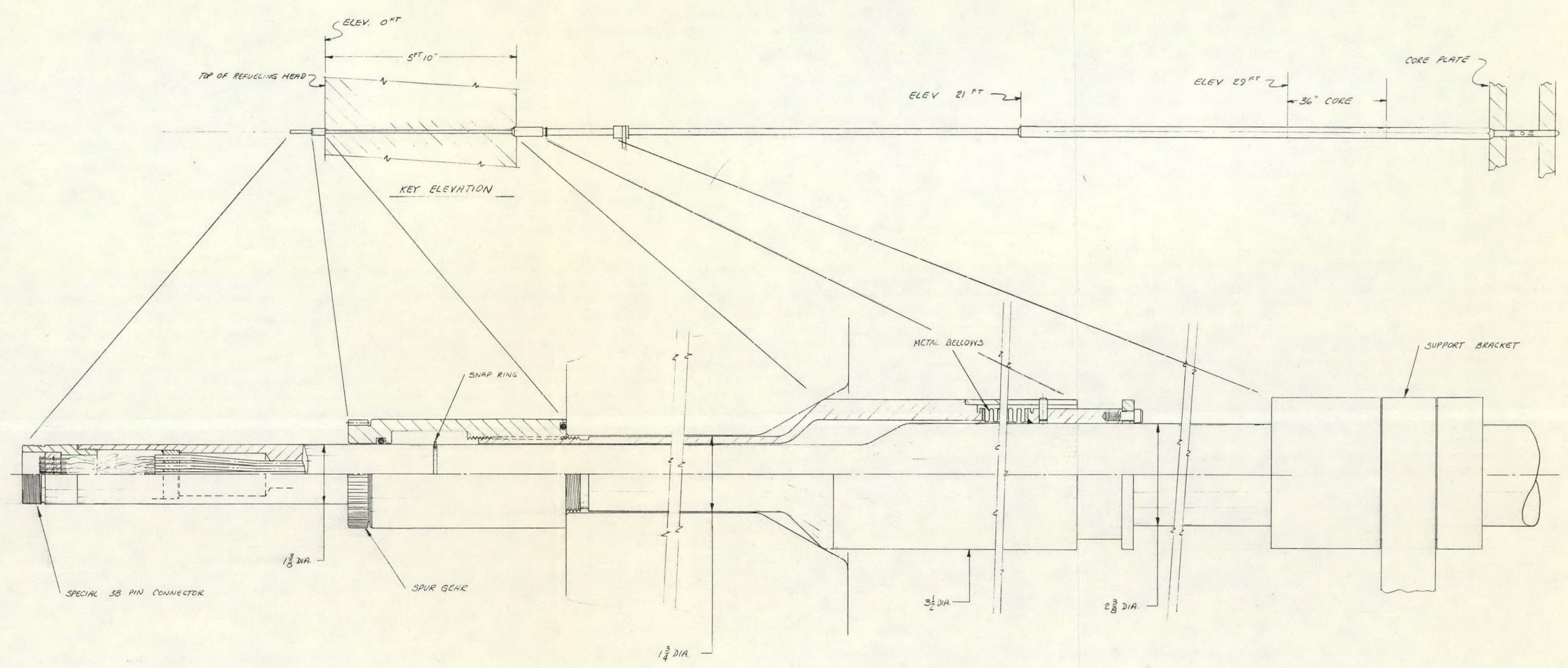




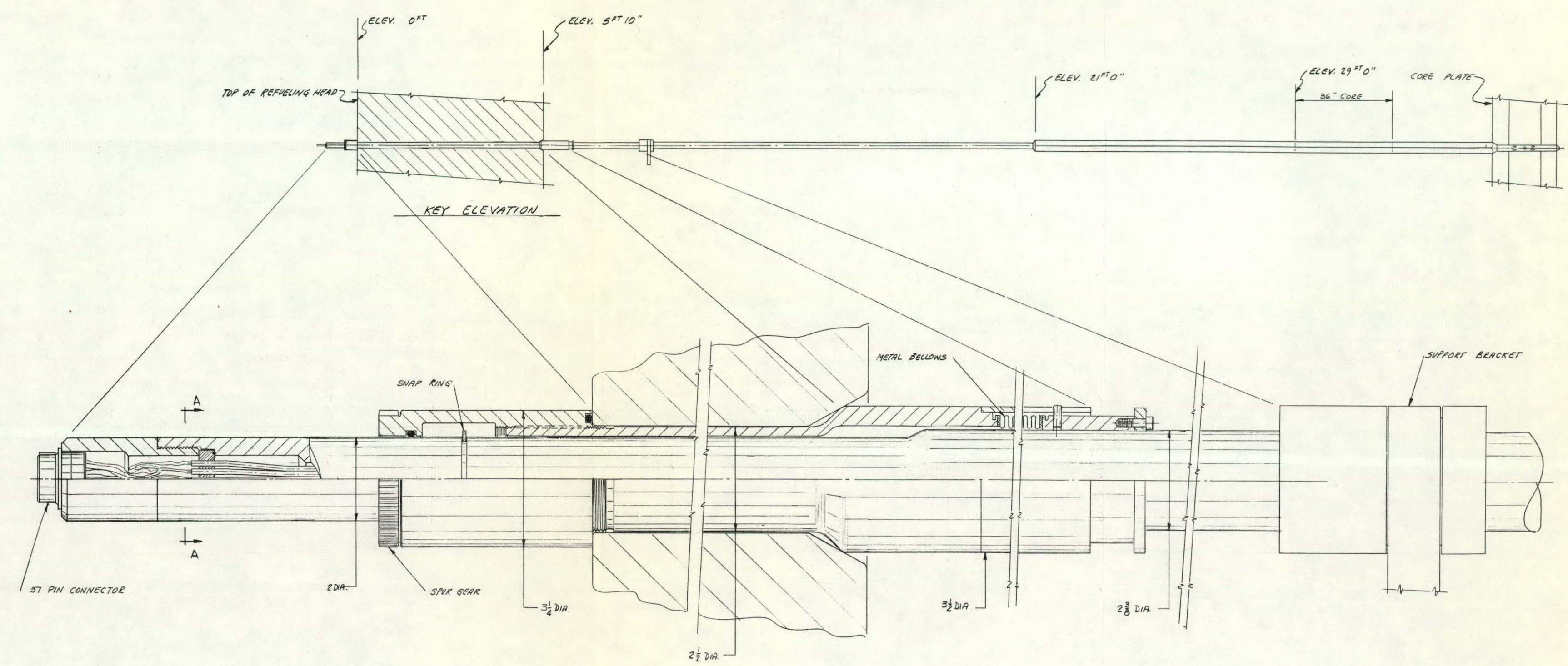

FIGURE 4-14. OPEN LOOP (2-1/2 PENE. TRATION) 


\section{8.2 Allowable Peak Power Generation in Fuel Pin}

The peak cladding temperatures in the fuel are estimated and presented in the following discussion. A detailed method of analysis of circumferential temperature in the cladding for edge pins in the bundle is presented in Appendix B.

The peak power generation which occurs at the centerline and mid-height of the core is computed on the basis that the peak fuel centerline temperature is less than $5200^{\circ} \mathrm{F}$ at $120 \%$ full power. The local bulk coolant temperature is computed assuming the peak power generating pin has a power peaking factor of 1.035 to cover tolerance variations on enrichment, density, and diameter, and the local coolant channel has a hot channel flow factor of 1.12 to cover reductions of local flow due to geometric tolerances and inlet orifice tolerances. The bulk core $\Delta T$ is $300^{\circ} \mathrm{F}$. The resulting coolant temperature rise through the hot channel at overpower is $1.12 \times 1.035 \times 1.2 \times 300=416^{\circ} \mathrm{F}$.

Coolant temperature at the mid-plane of the hot channel is $700+416 / 2=908^{\circ} \mathrm{F}$.

The peak allowable power generation is calculated using the parameters shown in Table 4-3.

TABLE 4-3

THERMAL HYDRAULIC PARAMETERS USED TO CALLCULATE PEAK ALLOWABLE POWER GENERATION

Fuel centerline temperature

Coolant temperature

Coolant to cladding heat transfer coefficient

Cladding to fuel heat transfer coefficient

Thermal conductivity of fuel

Thermal conductivity of cladding

Axial power peaking factor

Local power peaking factor

Fluw = hot ehanncl faotor

Pin o.d.

Cladding thickness

Bulk coolant inlet temperature

Bulk coolant outlet temperature

Allowable power generation in fuel pin $5200^{\circ} \mathrm{F}$

$908^{\circ} \mathrm{F}$

27, $700 \mathrm{Btu}$ per $\mathrm{h} / \mathrm{ft}^{2}$ per ${ }^{\circ} \mathrm{F}$

1,500 Btu per $h / \mathrm{ft}^{2}$ per ${ }^{\circ} \mathrm{F}$

See Figure $\mathrm{C}-4$

$12 \mathrm{Btu}$ per $\mathrm{h} / \mathrm{ft}$ per ${ }^{\circ} \mathrm{F}$

1.21

1.035

1.12 ,

0.210

0.015

$700^{\circ} \mathrm{F}$

$1000^{\circ} \mathrm{F}$

$17.8 \mathrm{~kW} / \mathrm{ft}$

'In sizing the core the allowable generation rate used was $17.3 \mathrm{~kW} / \mathrm{ft}$ which provides for an approximately $5 \%$ variation to cover errors in analytical techniques and adjustments to basic property data used in the analysis. The core has been sized on the basis of generation $400 \mathrm{MW}$ with $91 \%$ of this generated in the fuel and $4 \%$ in channel structure. The remaining $5 \%$ is assumed to be generated in the radial reflector and carried away by leakage flow between channels in the core. This selected design is an array of 127 bundles ( 127 pins per bundle), of which 105 are fuel bundles and 12 are open loops containing $75 \%$ as much fuel as a full bundle. 


\subsubsection{Coolant Flow and Pressure Drop}

The total coolant flow to give a $300^{\circ} \Delta \mathrm{T}$ at $400 \mathrm{MW}$ total power is $15.02 \times 10^{6} \mathrm{lb} / \mathrm{h}$.

Coolant flow through the bundles is $14.27 \times 10^{6} \mathrm{lb} / \mathrm{h}$. Normal coolant flow through the hottest bundles is (average coolant flow) $\times$ (radial power factor): i.e., $\frac{14.27}{117} \times 10^{6} \times 1.30=$ $15.9 \times 10^{4} \mathrm{lb} / \mathrm{h}$.

For the reference geometry of 127 pins, 0.21 -inch pin diameter and 0.060 -inch wire diameter, the total flow area is 4.20 square inches. The average velocity in the bundle $=29.2 \mathrm{ft} / \mathrm{sec}$. Maximum velocity along channel wall $=32.5 \mathrm{ft} / \mathrm{sec}$. The resulting pressure drop is 9.2 psi per foot along the fuel pins giving $60 \mathrm{psi}$ frictional drop along the 6.5-foot-long fuel pin. The analytical method used in calculating the pressure drop through wire wrapped fuel pin bundles is described in ASME paper No. 68-WAHT-35-"Calculation of Rod Bundle Pressure Loss" by W. A. Sangster. The overall pressure drop through the hot bundle is 108 psi assuming sharp corners at section changes. Rounding these will reduce the pressure drop at these locations. The detailed pressure drop profile is shown in Figure 4-15.

\subsubsection{Peak Cladding Temperature}

A reference of $1200^{\circ} \mathrm{F}$ has been selected for the local hot spot at the $\mathrm{i}, \mathrm{d}$, of the cladding under steady state operation. It is assumed that in controlling the reactor to operate at $100 \%$ power and that due to tolerances on instrumentation and heat balances, the reactor could in actuality be above this power level. The design reference of $110 \%$ is selected for the steady state peak cladding temperature evaluation. With a hot channel flow factor of 1.12 and local power peaking factor of 1.035 , the hot channel $\Delta \mathrm{T}^{\prime}$ at $110 \%$ power is $1.1 \times 1.12 \times 1.035 \times 300=383^{\circ} \mathrm{F}$ and the corresponding coolant outlet temperature is $1083^{\circ} \mathrm{F}$. The fuel rod power at the outlet is $0.654 \times$ power at core midplane.

For the hottest fuel rod this is $0.654 \times \frac{1.1}{1.2} \times 17.8=10.6 \mathrm{~kW} / \mathrm{ft}$.

The temperature difference between coolant and cladding o. d, with $\mathrm{h}=27,000 \mathrm{Btu}$ per $\mathrm{h} / \mathrm{ft}^{2}$ $-{ }^{\circ} \mathrm{F}=2.07^{\circ} \mathrm{F} / \mathrm{kW}$ per $\mathrm{ft}$.

The temperature rise through the 0.015 -inch cladding with $\mathrm{k}=12 \mathrm{Btu} / \mathrm{h}-\mathrm{ft}^{2}$ is $6.43^{\circ} \mathrm{F} / \mathrm{kW}$ per ft.

Excluding circumferential variations, the temperature at the cladding i.d.

$=1083+10.6(2.07+6.43)$

$=1083+90$

$=\underline{1173^{\circ} \mathrm{F}}$

The circumferential variation around the cladding caused by the non axisymmetric geometry of cooling in a hexagonal array of pins is estimated as $5.0^{\circ} \mathrm{F} / \mathrm{kW}$ per ft for internal pins in the bundle. This is based upon a model assuming slug flow and no mixing. The variation on edge pins in the bundle will be greater, but since these are over cooled on the outside sectors, the peak cladding temperature will not be limiting. 


$$
\begin{aligned}
& \text { POSITION } \\
& 1 \text { - OUTSIDE ENTRANCE } \\
& 2 \text { - AT CORE SUPPORT PLATE } \\
& \text { 3-AT TRANSITION PIECE } \\
& \text { 4.-AT SHIELD SPACER } \\
& 5 \text { - AFTER SHIELD SPACER } \\
& 6 \text { - AT SECOND SHIELD SPACER } \\
& 7 \text { - AFTER SECOND SHIELD SPACER } \\
& 8 \text { - AFTER FUEL SPACER } \\
& 9 \text { - AT END OF FUEL PINS } \\
& 10 \text { - AFTER THIRD SHIELD SPACER } \\
& 11 \text { - AT TRANSITION PIECE } \\
& 12 \text { - AFTER TRANSITION PIECE } \\
& 13 \text { - UPPER PLENUM } \\
& \Delta \mathrm{P}_{2-3}=0.228 \mathrm{psi} \\
& \Delta \mathrm{P}_{3-4}=2.860 \mathrm{psi} \\
& \Delta P_{4-5}=1.295 \mathrm{psi} \\
& \Delta \mathrm{P}_{5-6}=6.880 \mathrm{psi} \\
& \Delta \mathrm{P}_{6-7}=1.295 \mathrm{psi} \\
& \Delta \mathrm{P}_{7-8}=1.935 \mathrm{psi} \\
& \Delta \mathrm{P}_{8-9}=60.00 \mathrm{psi} \text {. } \\
& \Delta \mathrm{P}_{9-10}=3.930 \mathrm{psi} \\
& \Delta \mathrm{P}_{10-11}=9.750 \mathrm{psi} \\
& \Delta \mathrm{P}_{11=12}=3.285 \mathrm{psi} \\
& \Delta \mathrm{P}_{12-13}=4.580 \cdot \mathrm{psi} \\
& \Delta P \text { TOTAL }=\Delta P_{1-13}=108 p s i
\end{aligned}
$$

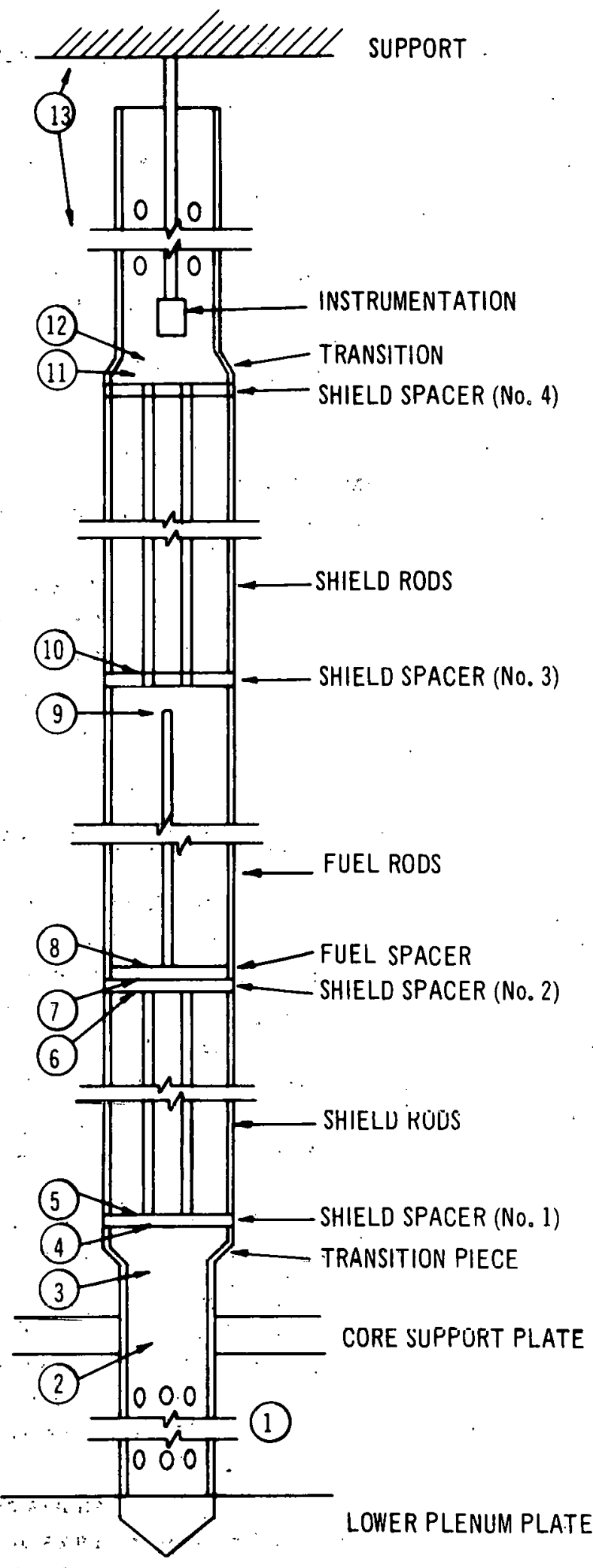


Circumferential variation $=5.0 \times 10.6=53.0^{\circ} \mathrm{F}$.

Peak cladding temperature $=1173+53.0=1226^{\circ} \mathrm{F}$ at $110 \%$ power .

For fuel pins in channels at the inner edge of the outer zone the contributions from local power generation is approximately the same as at the center of the core, but a variation due to the steep radial gradient will cause an increase in the coolant and cladding temperature.

Assuming no mixing between inter-fuel flow streams in the bundle, the hot stream in this channel will be approximately $25^{\circ} \mathrm{F}$ above the mean stream in the channel. This will result in a calculated peak cladding temperature of $1225^{\circ} \mathrm{F}$. This can be reduced to the $1200^{\circ} \mathrm{F}$ limit by adjustment of the inlet orifice and still meet the pressure drop limit.

For bundles at the edge of the core, the reduction in the local power density offsets the radial gradient effect such that orificing to a nominal $1000^{\circ} \mathrm{F}$ outlet temperature at $100 \%$ power is satisfactory. For fuel rods at the inner edge of the outer bundle:

$\begin{array}{ll}\text { Coolant Temperature } & =1083^{\circ} \mathrm{F} \\ \Delta \mathrm{T} \text { Coolant to Cladding at } 6.5 \mathrm{~kW} / \mathrm{ft} & =13^{\circ} \mathrm{F} \\ \Delta \mathrm{T} \text { through Cladding } & =42^{\circ} \mathrm{F} \\ \text { Circumferential Gradient } & =32^{\circ} \mathrm{F} \\ \text { Radial Gradient } & =\frac{23^{\circ} \mathrm{F}}{1195^{\circ} \mathrm{F}}\end{array}$

\subsubsection{Thermal Hydraulic Parameter Study}

In order to permit an evaluation of the effect on nuclear characteristics of variations in core geometry parameters, a study was performed in which the pressure drop versus pitch to diameter ratio was determined for two pin sizes, two core heights, and two cladding thicknesses. A plenum to plenum pressure drop of 100 psi was selected as a reference and the resulting geometries defined the input to the physics studies. The reference core was selected as a result of the parameter study. Appendix $\mathrm{C}$ gives the results of this study.

\subsection{HEAT TRANSFER ANALYSIS ON SPENT FUEL THIMBLE}

The feasibility of removing spent driver fuel shortly after reactor shutdown from the core to decay storage tanks located in the refueling cell was investigated and established.

This transfer is accomplished with the use of a sodium filled transfer thimble. The analysis presented indicates that adequate cooling can be provided by natural circulation alone, resulting in a cooling method which is entirely independent of external equipment and will provide safe transfers, even during abnormalities which may delay the transfer sequence:

The decay heat load has been conservatively calculated as $25 \mathrm{~kW}$. This is the level of the hottest fuel channel 24 hours after shutdown with a $30 \%$ increase for margin (refer to Figure 4-16). A plan view schematic of the finned transfer thimble is given in Figure 4-17. A digital computer code was written based on modeling the transfer cask into 16 axial nodes with a heat balance made on each node (refer to Figure 4-18). The methods of internal heat transfer in the cask are 


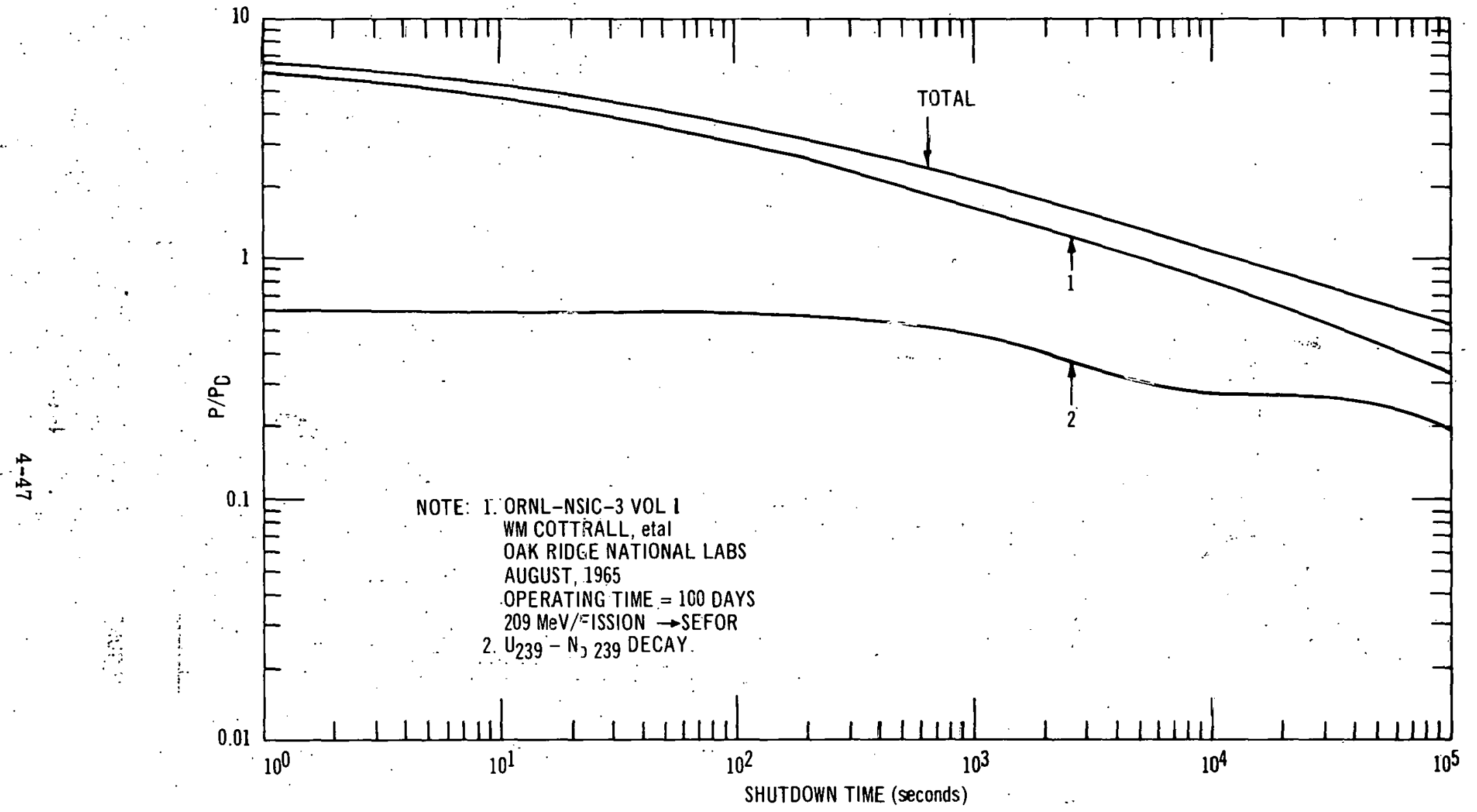


GEAP -5722

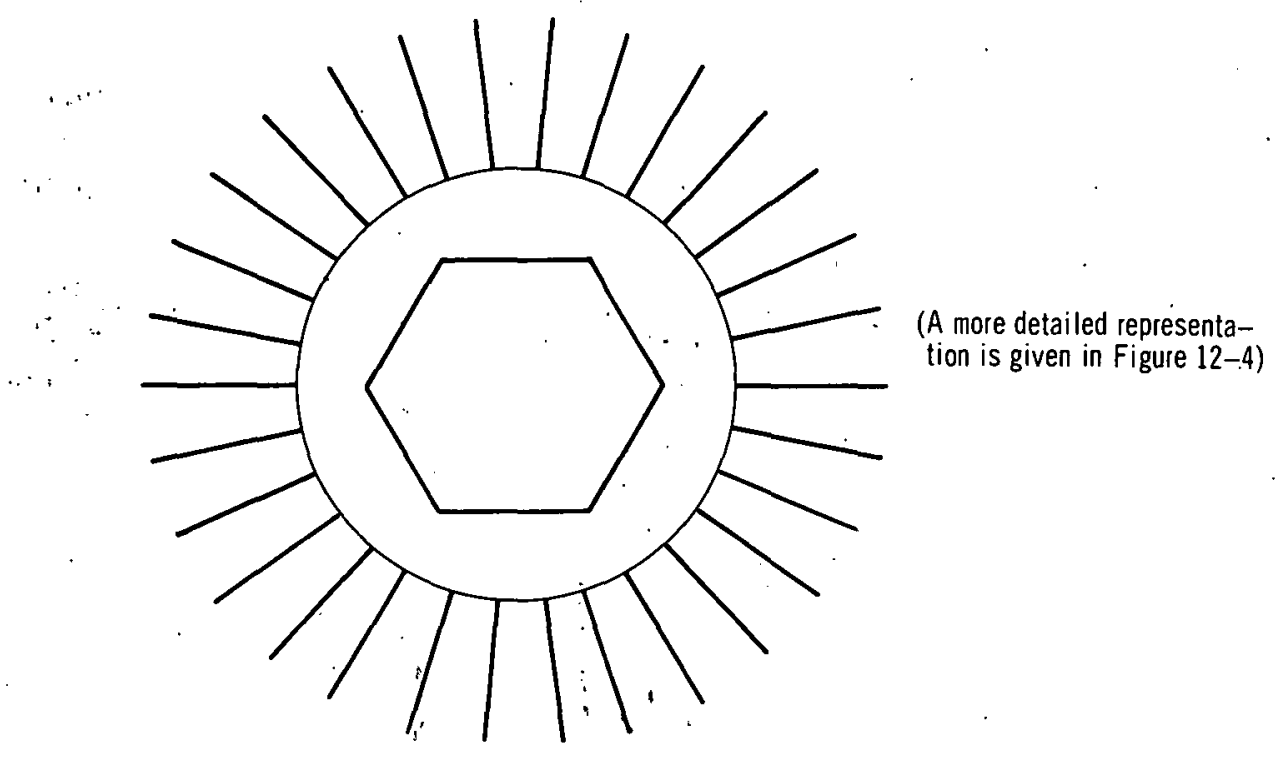

FIGURE 4-17. SPENT FUEL TRANSFER CASK FINNED SURFACE GEOMETRY

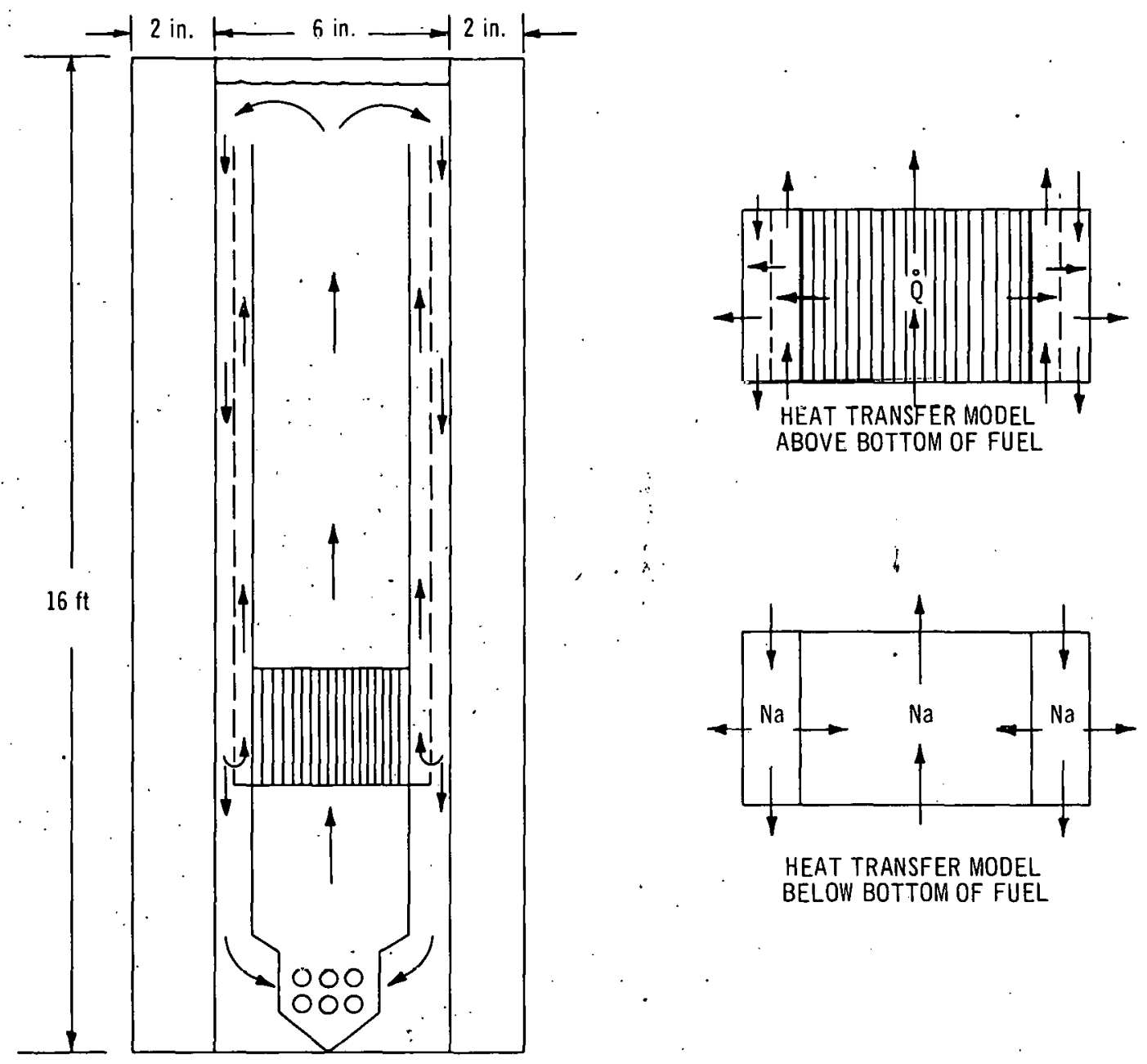

FIGURE 4-18. SPENT FUEL TRANSFER CASK MODEL 
assumed to be by mass transfer axially and by conduction radially. The heat is dissipated by vertical fins to an argon atmosphere at $100^{\circ} \mathrm{F}$. The following assumptions, material properties, and equations were used:

\section{Assumptions and Model}

- The decay heat rate is conservatively $25 \mathrm{~kW} 25$ hours after shutdown.

- Two natural circulation loops of sodium are set up in the cask as shown in Figure 4-18.

\section{Material Properties}

- Thermal conductivity of stainless steel $=12$ Btu per $\mathrm{h}-\mathrm{ft}-{ }^{\circ} \mathrm{F}$.

- Heat transfer coefficient of stainless steel to argon gas $=1$ Btu per $\mathrm{h}-\mathrm{ft}^{2}-{ }^{\circ} \mathrm{F}$.

\section{Equations}

Heat transferred through one fin is given by the following:

$$
Q=2 \delta \mathrm{KNLT} \tanh (\mathrm{Nw}+\sqrt{\mathrm{Nu}})
$$

where:

$\delta=0.1$ in., $1 / 2$ thickness of fin

$\mathrm{K}=12 \mathrm{Btu}$ per $\mathrm{h} / \mathrm{ft}-{ }^{\circ} \mathrm{F}$, thermal conductivity of fin

$\mathrm{N} \quad=\quad 3.16 \mathrm{ft}^{-1}, \frac{\mathrm{h}}{\mathrm{K} \delta} \quad\left(\mathrm{h}=1 \mathrm{Btu}\right.$ per $\left.\mathrm{h} / \mathrm{ft}^{2}-{ }^{\circ} \mathrm{F}\right)$

$L=16 \mathrm{ft}$, length of fin

$\mathrm{T}_{\mathrm{O}}=\mathrm{T}_{\mathrm{S}}-\mathrm{T}_{\infty}$, temperature difference between base of fin and"argon atmosphere

$\mathrm{W}=2$ in., width of fin

$\mathrm{Nu} \cdot=6.95\left(10^{-4}\right), \frac{\mathrm{h} \delta}{\mathrm{K}}$

The optinum fin spacing is given by the following:

$$
\frac{b_{\text {opt }}}{L}=\frac{50}{G_{\mathrm{b}_{\text {opt }}} \operatorname{Pr}}
$$

where:

$\mathrm{b}_{\text {opt }}=$ uptimum fin spacing

$\mathrm{L}=16 \mathrm{ft}$, length of fin

$\operatorname{Pr}=0.654$, Prandtl number of argon:

$\mathrm{Gr}_{\mathrm{b}}=\frac{\rho^{2} \beta \mathrm{gt} \Delta \mathrm{T} \cdot\left(\mathrm{b}_{\mathrm{opt}}\right)^{3}}{\mu^{2}}$, Grashof number

$\rho=0.05 \mathrm{lb} / \mathrm{ft}^{3}$, density of argon:

$\mu=0.0955 \mathrm{lb} / \mathrm{h}-\mathrm{ft}$, viscosity of argon $\because$ 


$\mathrm{C}_{\rho}=0.1243 \mathrm{Btu} / \mathrm{lb}-{ }^{\circ} \mathrm{F}$, specific heat of argon
$\mathrm{g}=32.3 \mathrm{ft} / \mathrm{sec}$, acceleration due to gravity
$\Delta \mathrm{T}=670-100=570^{\circ} \mathrm{F}$, average temperature difference
$\beta \quad 1.92\left(10^{-3}\right) \mathrm{ft}^{-1}$, coefficient of thermal expansion

Radiation is initially neglected in the analysis because of the low emissivity anticipated due to sodium wetting of the outer surface. The splitting of the downward flow in the natural circulation loop requires the two slightly different configurations of axial nodes as shown in Figure 4-18.

For a 0.2 -inch thick and 16 foot long fin, the optimum fin spacing is 10.87 inch center to center. A 21 fin design provides $\sim 0.896$ inch centers for the fins.

Table 4-4 shows the temperature distribution in the 21 fin transfer thimble. Total heat loss is $25 \mathrm{kWt}$. The natural circulation flow up through the fuel bundle is $1100 \mathrm{lb} / \mathrm{h}$, up through the annulus is $1100 \mathrm{lb} / \mathrm{h}$, and down next to the wall is $2200 \mathrm{lb} / \mathrm{h}$. Steady state equilibrium conditions are assumed.

TABLE $4-4$

\section{TEMPERATURE DISTRIBUTION IN FINNED TRANSFER THIMBLE}

\begin{tabular}{|c|c|c|c|}
\hline $\begin{array}{c}\begin{array}{c}\text { Distance } \\
\text { Up Thimble } \\
\text { (ft) }\end{array} \\
\end{array}$ & $\begin{array}{c}\operatorname{Temperature~}^{\circ} \mathrm{F} \\
\text { (bundle) }\end{array}$ & $\underset{\text { (annulus) }}{\text { Temperature }^{\circ} \mathrm{F}}$ & $\begin{array}{c}\text { Temperature }{ }^{\circ} \mathrm{F} \\
\text { (next to wall) }\end{array}$ \\
\hline $\begin{array}{r}0 \\
1 \\
2 \\
3 \\
4 \\
5 \\
6 \\
7 \\
8 \\
9 \\
10 \\
11 \\
12 \\
13 \\
14 \\
15 \\
16\end{array}$ & $\begin{array}{r}770 \\
774 \\
786 \\
808 \\
838 \\
878 \\
976 \\
1041 \\
1086 \\
1042 \\
1007 \\
977 \\
953 \\
934 \\
920 \\
911 \\
908\end{array}$ & $\begin{array}{r}0 \\
0 \\
0 \\
0 \\
0 \\
+950 \\
957 \\
989 \\
991 \\
971 \\
945 \\
926 \\
911 \\
902 \\
889 \\
900 \\
906\end{array}$ & $\begin{array}{l}770 \\
787 \\
813 \\
848 \\
893 \\
950 \\
969 \\
984 \\
975 \\
952 \\
930 \\
914 \\
902 \\
896 \\
895 \\
899 \\
909\end{array}$ \\
\hline
\end{tabular}

The calculations are based upon holding the cask in the ambient argon until steady state conditions are attained. During the normal refueling procedure, the temperature rise of the cask and fuel channel is anticipated to be of the order of $200^{\circ} \mathrm{F}$. Neglecting surface heat losses and heat capacity of the fuel channel the initial temperature rise based upon the time required to bring the sodium and cask up to temperature is $14^{\circ} \mathrm{F}$ per minute. Under normal refuleing conditions the transfer will be completed well before equilibrium conditions are attained ( 15 to 20 minutes).

For the off-normal conditions, in which the cask would be held in the argon atmosphere for a prolonged period, consideration must be given to both the fuel temperature and cask temperature limits and also the sodium vapor generation. To cover this situation, the cask may have to be handled in a manner which controls sodium vapor generation. This will most probably introduce 
forced convective cooling of the cask surface. Calculations to date have been directed toward computing the temperature levels in the cask and fuel assuming natural circulation. Cooling of the surface may be required to answer safeguard questions in which cooling may be lost. It may be possible to answer this question in other ways, but a cask with such capability appears desirable. A 21 fin arrangement appears to meet this requirement with ample margin against sodium boiling. Further analytical evaluation is required to obtain an optimum cask configuration..

The analysis to date has assumed 16 feet length available for fins, however, it is possible to increase the length by several feet to obtain significantly more external heat transfer surface.

Proof testing of the eventual design will be desirable to assure that the design of this key hardware item is completely adequate. Closer fin spacing with means of tripping the boundary layer is an alternate to be evaluated if a greater margin of safety is desired or if the experiment does not confirm the present analysis. 
GEAP-5722

\section{CONTROL ROD DRIVES}

\subsection{GENERAL DESCRIPTION OF DRIVES}

The primary control is a reflector control system with control rod positions filling the next row out from the core except for two locations next to the refueling transfer pot (refer to Figure 5-1). A single control rod drive mechanism operates a pair of adjacent control rods; 20 drives operate 40 reflector control rods. This configuration results in a close center to center drive mechanism spacing of 6.780 inches.

The back-up safety control system consists of 3 in-core control rod locations with the drive mechanisms mounted on the inner shield plug. Section VII describes the head design and arrangement of plugs and penetrations in detail. These drives will be uncoupled and removed prior to the removal of the inner shield plug. The same control rod drive mechanism design is proposed for both primary reflector and back-up safety systems.

A major objective of the reactor design is to be able to achieve the refueling of the core without uncoupling and removal of the reflector control drives. This also leaves the reflector control drives operable during refueling which reduces the safeguard hazard of uncoupled control rods, and provides a method if needed for determining the degree of subcriticality. An inner shield plug with a diameter that encloses the outer periphery of the core permits access during refueling to the fuel assemblies immediately adjacent to the reflector control channels.' The drive mechanisms are mounted on the outboard edge of the hole occupied by the inner shield plug and from that location require an offset between the axis of the drive mechanisms and the axis of the reflector control rods in their hexagonal guide channels. An offset of 10.0 inches has been used in the design (refer to Figure 5-1).

The main element of the primary reflector control drive is a vertically mounted double shaft pneumatic cylinder. Connected to the lower shaft of the pneumatic cylinder is an extension rod shaft which extends down into the reactor and carries the load of the reflector control rod pair. The upper shaft of the pneumatic cylinder extends up into a cylindrical housing mounted in line with the pneumatic cylinder. An attachment to the upper shaft engages slots in the cylindrical housing to achieve an antirotation feature that is required to prevent disengagement of the rotary breech-block coupling between the extension shaft and the reflector control rod. The coupling is engaged or disengaged by 45-degree rotation of the drive and extension shaft; thus to prevent uncoupling; the antirotation feature of the drive shaft is required. The control rod assembly is prevented from rotation in its guide channel by being captured within the limits of the hexagonal channel.

Mounted at the top of the cylindrical housing is a gear motor which drives a lead screw that positions a stop nut at any desired position along the full stroke length of the drive. This nut provides a stop for the cylinder. Gas pressure is applied to the lower end of the pneumatic cylinder which carries the load of the control rod and holds the control rod and piston assembly firmly in contact with the stop nut engaged on the lead screw. The position of the control rod is then determined by positioning the stop nut with the lead screw. 
A control rod scram is produced by pressurizing the top side of the pneumatic cylinder from a remote accumulator. The support pressure on the lower side of the piston is simultaneously vented.

The stroke length of the drive consists of three components.

- With the control rod in its normally down position, the poison rod section of the control rod matches end for end the core section height which is 36 inches.

- An additional 4 inches of stroke is added so that the poison rod section can be removed from the core and provide a 4 -inch gap between the top of the core and the bottom of the poison rod to reduce the burn-up in the poison rod. Therefore, the basic stroke consists of 40 inches:

- The control rod in the down position rests on a spring assembly which provides the final cushion of the scram stroke following an initial dashpot cushion. A maximum 6 -inch deflection is allocated for the spring cushion stroke. Therefore, the total drive stroke including cushion overtravel is 46 inches.

\subsection{MAJOR DESIGN FEATURES}

A. The control rod drive mechanisms of the primary reflector control system remain operable and connected to the control rods during refueling.

B. The primary reflector control drives are combination shim and scram drives. The same drive design is proposed for the back-up safety system, being used as a two pnsition scram drive.

C. The control rods scram downward on signal from any position in the stroke under all operating conditions.

D. An electrical power failure results in scram.

E. No energy is required to be applied to the system to obtain a scram.

F. No delatching is required to initiate a scram. Pressure reversal in pneumatic cylinder changes force direction to cause the separation of control rod drive line from support structure.

G. Position indication system follows scram motion.

H. A positive holddown force is maintained on the control rod after scram.

I. A coupling is provided for the drive assembly to be disconnected at the control rod assembly.

J. A disconnect joint for maintenance disassembly is provided between the extension shaft and the drive mechanism. 


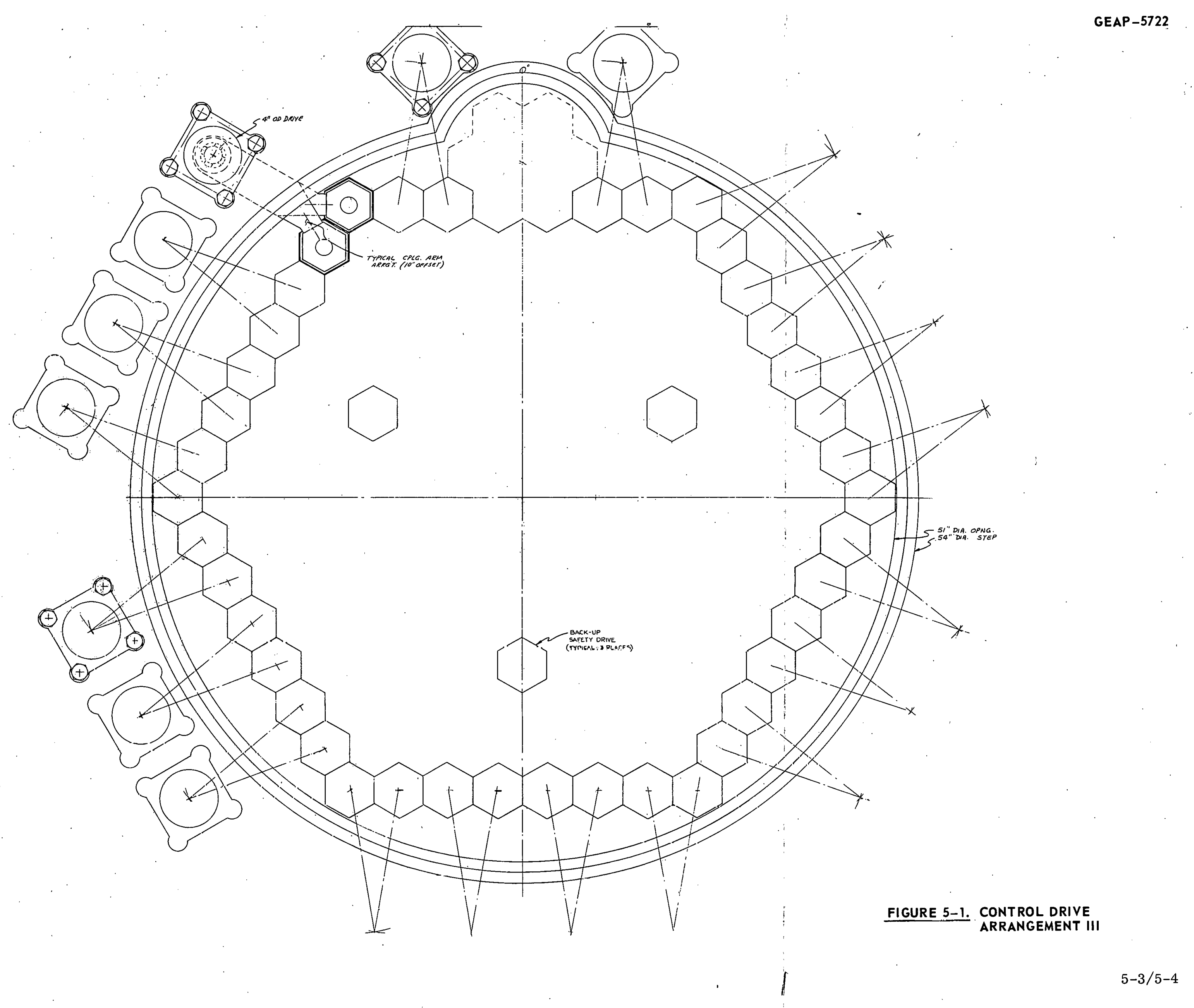




\subsection{DETAILED DESCRIPTION OF DRIVES}

\subsubsection{Outline of Description Approach}

To present the detailed description of the control drive system the following sequence of presentation will be followed. The discussion will start with the drive mechanism mounting at the top of the head, proceed upward through the components to the top of the drive, then return to the shaft seal vessel penetration below the top of the head and proceed downward through the control rod.

\subsubsection{Drive Mounting Flange}

The drive mechanism is clamped to the vessel head by a captive four sided flange with four bolts which thread into the vessel head. Refer to section C-c of Figure 5-2. The flange clamps the drive securely to the vessel head and provides the antirotation required to keep the control rod coupling engaged. Loosening the flange and rotating the drive mechanism disengages the control rod coupling.

\subsubsection{Pneumatic Cylinder and Control Valves}

The pneumatic cylinder is the main force generating element of the drive mechanism. It is a double rod cylinder mounted vertically above the top of the vessel head with its lower end attached to the mounting flange described in the above section. For normal operation, gas pressure is applied to the lower side of the cylinder piston. This pressure can lift the weight of the reflector control rod and the assembly of its driveline parts upward and into contact with a stop-nut located in a housing mounted above the pneumatic cylinder. Positioning the control rod is achieved by positioning the adjustable stop-nut which can override the pneumatic cylinder lifting force for downward positioning. For scram operation, high pressure gas is applied to the upper side of the cylinder piston and at the same time the gas pressure on the lower side of the piston is vented.

The estimated lifting pressure required is 140 psi based on lifting a control rod and driveline assembly weight of 750 pounds, a net piston area of 8.39 sq. inches (3.5-inch bore, 1.25-inch shaft), and approximately $50 \%$ added for margin.

The stroke length required for the cylinder is the sum of the drive stroke length plus the final spring cushion overtravel. The values for these quantities were a 40 -inch stroke and 6 -inch maximum overtravel totaling 46 -inch pncumatic piston travel.

The design as shown in Figure 5-2 has the packing seal of the pneumatic cylinder also providing the shaft seal for the vessel penetration. This would be the desirable approach provided the seal development program for drive shaft penetrations confirmed a seal useable in this manner. Less frictional drag on the drive shaft is the advantage of using one seal. However, independent sealing for the vessel and pneumatic cylinder might be required. Argon would be the working gas of the pneumatic cylinder.

No cushion would be requirer as part of the pneumatic cylinder since the scram stroke is cushioned within the vessel. 
Control valves for the pneumatic cylinder have tentatively been selected as a possible choice. The valves have a large capacity coefficient to provide rapid exhaust and input during scram. Computations on the required flow rates during scram were not completed, and these valves are not known to meet the scram requirements; however, they are large capacity valves and were considered a promising candidate. The valves are electrical solenoid controlled. Two valves would be used connected electrically in parallel, one for the cylinder inlet and one for the exhaust. The basic description is given in Table 5-1.

\section{TABLE 5-1}

\section{CONTROL DRIVE VALVE CHARACTERISTICS}

$\begin{array}{ll}\text { Vendor: } & \begin{array}{l}\text { Parker-Hannifin Corp. } \\ \text { Hannifin Pneumatic Division } \\ \text { Des Plaines, Illinois }\end{array} \\ \text { H2000 } \\ \text { Valve Series } & \begin{array}{l}\text { Inlet: } 1-1 / 4 \text { inch NO, (normally open) } \\ \text { Exhaust: } 1-1 / 4 \text { inch NC, (normally closed) }\end{array} \\ \text { Valve Size: } & \begin{array}{l}\text { Inlet: } \text { Cy }=17.24 \\ \text { Exhaust: Cy }=19.74\end{array} \\ \text { Valve Capacity Coefficients } & 1-1 / 4 \text { inch } \\ \text { Pipe Size: } & 4 \times 5 \text { inch base, } 7-1 / 2 \text { inch high } \\ \text { Approximate Size: } & 3-\text { way } 2-\text { position } \\ \text { Porting: } & 15 \text { to } 150 \text { psi } \\ \text { Pressure: } & 115 / 120 \text { volt, } 50 / 60 \text { cycle, continuously rated } \\ \text { Solenoid: } & \end{array}$

The design for mounting the valves and providing the supply piping to the cylinder was not completed. The concept that was considered would mount the valves on a framework structure above the electric motor. The $1-1 / 4$ inch ports of the valves that connect with the pneumatic cylinder would be initially ducted into a small manifold which would branch into several $1 / 2$ to $3 / 4$ inch tubes that would route the gas down the side of the drive in parallel flow to the pneumatic cylinder. Several inlet ports at each end of the cylinder would be required.

Both valyes for normal operation are electrically energized so that a power failure results in switching to the scram mode.

\subsubsection{Upper Housing}

The upper housing is a cylindrical shaped unit which is bolted by a rabbet mounting in-line to the upper end of the pneumatic cylinder and as a structure provides the antirotation function for the drive shaft. It also houses the positioning lead screw with stop-nut and the position indication system.

\subsubsection{Drive Shaft Antirotation}

The antirotation feature of the drive shaft is required to prevent the coupling to the control rod from disengaging. The antirotation is provided by an attachment to the end of the upper shaft 


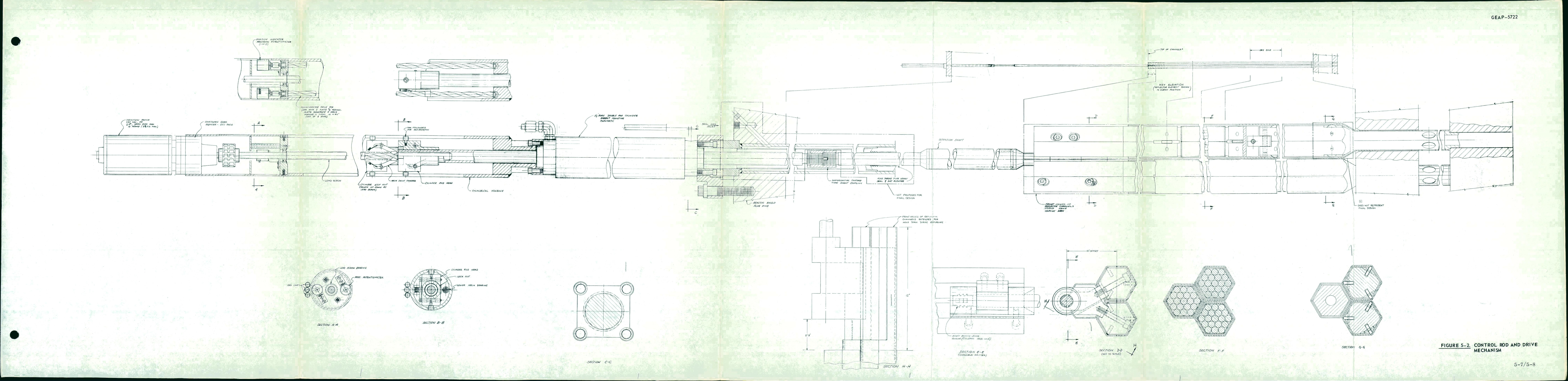


of the pneumatic cylinder. The attachment is referred to as a cylinder rod head in Figure 5-2, section B-B. The cylinder rod head has two protrusions shown as cam followers which engage long slots cut in the wall of the upper housing structure.

\subsubsection{Lead Screw and Stop-Nut}

A lead screw is located on the centerline of the drive mechanism and housed within the upper housing. The lead screw is supported by a thrust bearing at the upper end of the housing, and driven by a gear motor mounted at the upper end of the upper housing. The stop-nut limits the upward motion of the pneumatic linder, and the lead screw driving the stop-nut positions the control rod by overriding the pnerimatic cylinder lifting force for downward positioning or increasing the limit for upward positioning.

Approximately 500 pounds is the planned axial load required to move the rod downward. No design detail has been devoted to the screw design and Figure 5-2 only diagrammatically shows a lead screw and threaded member. Serious consideration should be given to incorporating a ball screw into the design. The column loading requirements for the lead screw can be approximated from the technical handbook of a ball screw manufactured as follows. A factor of $10 \times$ applied to the nominal 500 pound load to cover column loading contingencies results in a 5000 pound design load. At 5000 pounds with with a 40 -inch column (for 40-inch stroke) a 0.875 -inch diameter screw is required. The tentative pitch had been selected at 6 threads per inch.

Some method is required of sensing the contact between the stop-nut and the cylinder rod head at the end of the pneumatic cylinder. The sensed contact signal would be used to interlock with the application of gas lift pressure of the pneumatic cylinder to prevent a rod jump and final impact if contact was not initially made with the stop-nut, and the signal would also be used to initiate the motor drive follow up of the stop-nut immediately after scram. The proposed position indication system can measure the separation between the stop-nut and cylinder rod head; however, when the separation becomes small, the accuracies of position measurement will result in a tolerance zone where actual contact or some small separation is not knuwn. If this tolerance zone is too large (its magnitude has not been determined at this point), a more precise measurement of contact, such as a switch may be required.

\section{3. 7 Position Indication System}

The proposed position indication system utilizes two long lead screw rods with flats ground for the full stroke length on two sides. The flats take the shape of a long lead helix with several revolutions or helix cycles within the stroke length. These helix rods are positioned axially within the antirotation housing between the housing wall and the upper shaft of the pneumatic cylinder. Refer to Figure 5-2, section B-B, and elevation views at section A-A.

A helix rod is located on each side of the housing at $90^{\circ}$ to the centerline between the antirotation slots. Directly comected to the upper end of each helix rod is an angular transducer. Engaging the flats on the helix rods are sliders which as a result of their axial travel along the rod cause it to rotate. One slider pair is attached to the upper end of the pneumatic piston shaft, and the other slider pair to the stop-nut. The sliders are pivoted to allow for slight misalignments between the helix rods, lead screw, and piston shaft. With this system the positiun of the reflector control rod is measured through a direct linkage, and the separation between the stop nut and 
the upper end of the piston shaft can be measured by the difference between the two transducers. Because of the long lead helix, the sliders do not require disengagement during scram.

The number of helix cycles within the stroke length would have to be determined in the final design. The more helix cyles used, the more sensitive are the helix rods to axial control rod motion. Too many turns result in the sliders not being able to force the helix to follow their alignment during the scram stroke. For discussion purposes, 10 helix cycles could be a reasonable choice for the 46 -inch stroke ( 40 -inch basic plus 6 -inch cushion overtravel); this choice results in an approximate $1600 \mathrm{rpm}$ angular velocity of the helix rod for a control rod scram speed of $10 \mathrm{ft} / \mathrm{sec}$. A major contribution to the error of the mechanical system would be the small amount of rotation of the main drive shaft due to the clearance with the cam followers in the antirotation slots; see section B-B of Figure 5-2. This rotation directly rotates the helix rod and results as an error. A clearance gap of 0.060 inch in the antirotation slots results in approximately \pm 1 degree rotation of the main drive shaft and therefore \pm 1 degree error on the helix rod. For a 10 turn helix rod this results in \pm 0.013 -inch error in axial position. Another source of error would be any deviation of the helix flats true position shape as a result of manufacturing error, or also any deviation of perfect alignment between the helix flats and the slider surfaces. The deviation from true position or misalignment of \pm 0.003 inch would result in \pm 0.006 -inch error in axial position. Allowing some contingency for other errors, it appears reasonable that a mechanical system could be developed in which the mechanical error would be within approximately \pm 0.040 -inch error in axial position. Some of the contribution to the mechanical error would be systematic error which would be reduced through calibration. In addition the electrical error of the annular transducer and read out must be considered, and for this function there is a wide variety of systems available with a wide range of accuracies. A straight forward $\pm 0.1 \%$ full. scale resistance potentiometer would result in \pm 0.046 -inch axial error.

\subsubsection{Gear Reducer}

The lead screw is rotated by coupling it to a motor driven gear reducer. Power transmission components with characteristics as follows had been tentatively selected; these components result in approximately a 1.5 minute 40 -inch stroke travel time:

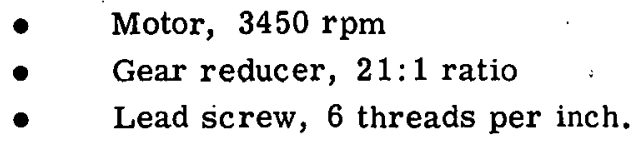

The basic gear reducer tentativcly selected is manufactured by the Ferguson Machine Co., St. Louis, Missouri. HR-16-I is the model number with a 21:1 ratio. The input shaft is in-line with the output.

\subsubsection{Motor}

The motor is mounted in-line with the gear reducer through a transition plate to form a gear motor combination. The motor tentatively selected is manufactured by the specialty Motor Department of the General Electric Co., Fort Wayne, Indiana. The basic specifications follow:

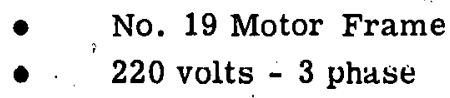


- $\quad 3450 \mathrm{rpm}, 2$-pole

- 0.5 horsepower

- Starting torque $300 \%$ of full-load

- 3.86-inch maximum outside diameter.

\subsubsection{Shaft Seal Vessel Penctration}

The control rod shaft seal penetrating the vessel is one of the more difficult developmental assemblies required in the control rod drive system. Selection of a shaft seal design to be used should be made only after testing and evaluation of a development prototype. At this point in the FFTF backup design work, a reference seal configuration has not been selected; however, several concepts can be proposed which appear promising and warrant further investigation and development work. A description of these concepts follows.

\subsubsection{Flow Seal}

This is the seal concept which has been given in earlier backup design descriptions. It is an assembly which extends through a guide tube in the vessel head, beginning just below the pneumatic cylinder of the drive mechanism. This proposed shaft seal has a constant stream of fresh argon flowing through a labyrinth shaft seal into the vessel cover gas (refer to Figure 5-3). The function of the flowing argon is to maintain an argon region. free of sodium vapor for one stroke length around the shaft that would enter a packing seal, thus keeping the shaft free of sodium deposits. The flow of argon would also prevent the escape of radioactive argon cover gas. The packing seal would preferably be located within the pneumatic cylinder as indicated in section $\mathrm{C}$ above. The packing seal and labyrinth would be, spaced at least one stroke length apart. (46inch full stroke; 40 -inch basic plus 6 -inch overtravel.) The labyrinth would function to reduce the argon flow required.

The level of the sodium pool in the vessel of the FFTF backup design is located near the lower side of the vessel head which is approximately 4 -feet thick. Therefore, if the packing seal is located in the pneumatic cylinder and just a few inches above the top surface of the head, the sodium pool level would be close to the location of the labyrinth seal. With such a configuration (refer to Figure 5-3), a portion of the shaft that is wetted by the sodium pool would pass into the labyrinth seal. Information obtained at Argonne National Laboratory has indicated that passing a shaft which contacts the sodium pool through a seal or bushing should generally be avoided due to the deposits that form on the portion of the shaft wetted by the pool. To overcome this potential problem, the tube that houses the labyrinth seal is extended down into the sodium pool several feet, and the argon flow gas forces the sodium level to the lower end of the tube. The guide tube which is part of the vessel head is extended 2 to 3 feet below the lower end of the labyrinth housing tube so that it catches the bubbles emitted from the labyrinth housing tube. The bubbles are ducted upward within the guide tube to a level above the vessel sodium pool, then ducted into the vessel cover gas, thus preventing the bubbles from entering the vessel sodium system.

This seal concept was discussed at Argonne National Laboratory, and the following comments were received:

The flow of argon, although of high purity, would contain small amounts of oxygen which would form sodium oxide deposits, and for long periods of operation the accumulated amounts 
could cause problems. Also, some method of sodium vapor migration and deposition, either diffusion or some other phenomenon, will cause the plugging of $1 / 4$ inch and even larger pipes that carry a continuous high velocity of pure argon supply into a sodium cover gas region. This phenomenon of the plugging has been observed in the pipelines of experimental equipment several feet from the entrance of the pipe into the cover gas region. Thus keeping the sodium vapor laden argon downstream of the labyrinth seal may not be assured.

Although the above comments tend to de-emphasize the usefulness of the concept they are based on conditions and configurations which are not the same as those of the flow seal and may not be directly applicable to the flow seal configuration. Also, the magnitude of the questionable effects may not be great enough to make a design of the concept unworkable. Further investigation of this concept is recommended in a parallel effort with other seal concepts.

\subsubsection{Refluxing Vapor Trap Seal}

The concept for this shaft seal penetration is somewhat similar to the flow seal in that a region of one stroke length below a packing seal is maintained relatively free of sodium vapor to keep the shaft free of sodium deposits. However, in place of the labyrinth seal a refluxing vapor trap assembly is used to achieve the blockage of sodium vapor, and no argon flow is required.

Argonne has constructed a refluxing vapor trap which has performed successfully and which is based on a principle that has possibilities of being used in a shaft seal. The vapor trap has been used to remove sodium vapor from a flow of argon through the trap, and $99.8 \%$ sodium vapor removal has been measured. The vapor trap has also been demonstrated to be effective in blocking sodium vapor passage in non-flow applications. The trap is constructed with a series of baffels which have a decreasing temperature gradient through the series with the inlet side at the high temperature and the outlet at the lower temperature and maintained at a point above but close

to the freezing point of sodium. Sodium vapor condenses on the baffles and returns by gravity back to the sodium pool.

The proposed concept for a shaft seal using the vapor trap principle is shown in Figure 5-4. To maintain the mounting of the drive mechanism as low and close to the vessel head as possible, and to maintain the packing seal one stroke length from the vapor trap, the vapor trap assembly would have to be located in the high temperature region of the vessel. Thus, it would be required to maintain the upper end of the vapor trap baffles at near the freezing point of sodium insulation and cooling coils. The sodium pool level of the vessel must also be lowered in a similar manner as described in the flow seal section above. No argon flow or bubbles would be present, however, other than to allow for the small leakage past the packing seal. The upper side of the packing seal would be maintained at a pressure higher than the vapor trap side so that any small leakage flow is into the vessel.

This seal concept was also discussed at Argonne and was considered to have a good degree of promise. A packing type of seal, without any vapor trap protection, intended for a grapple shaft application has been constructed at Argonne, tested, and proved very successful. This configuration provided only a few inches of clearance between the sodium wetted portion of the shaft and the packing seal. Successful operation of this type of seal indicates good possibilities also for the proposed shaft seal. 


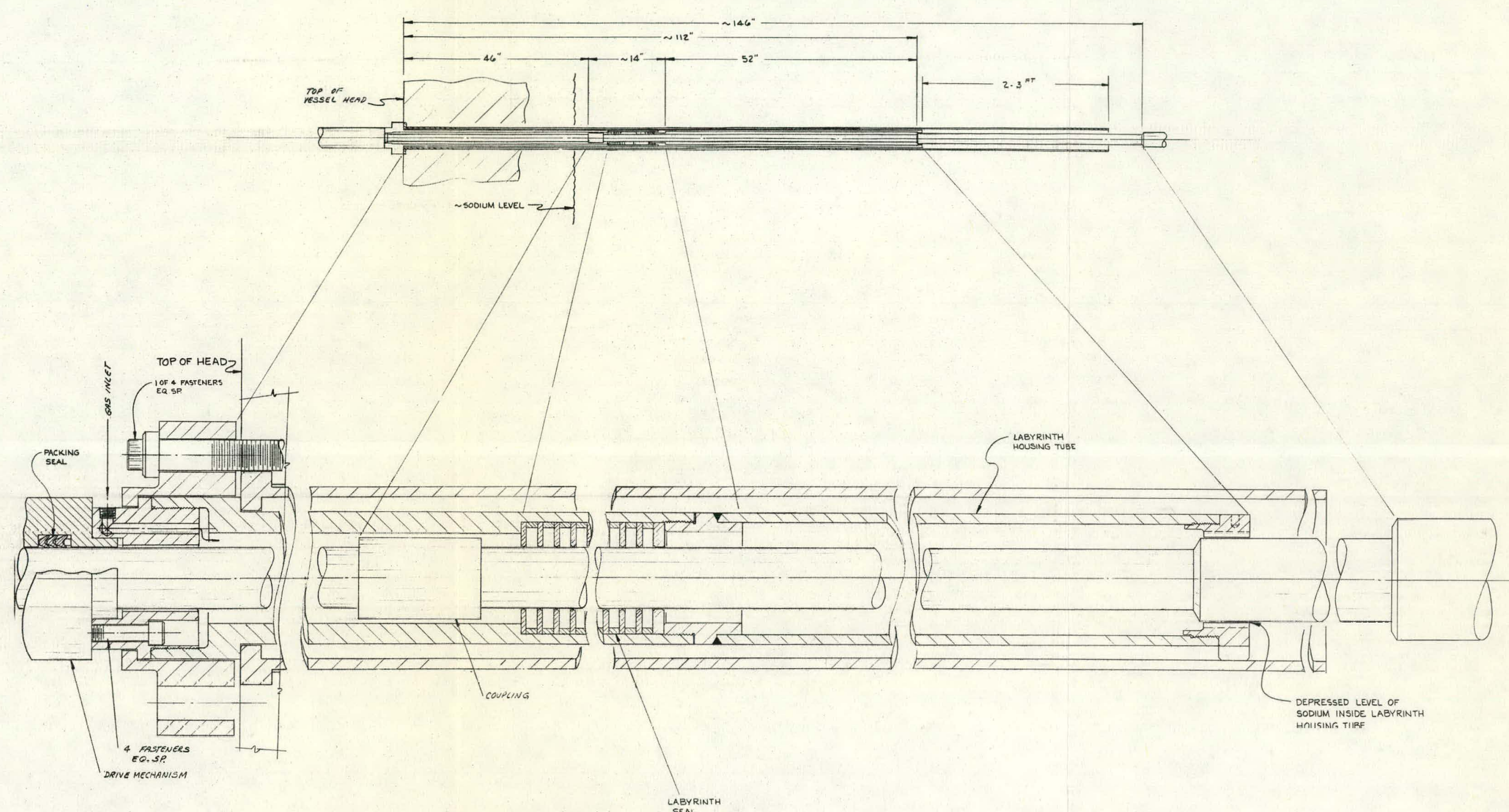

FIGURE 5-3. CONTROL ROD DRIVE FLOW SEAL 

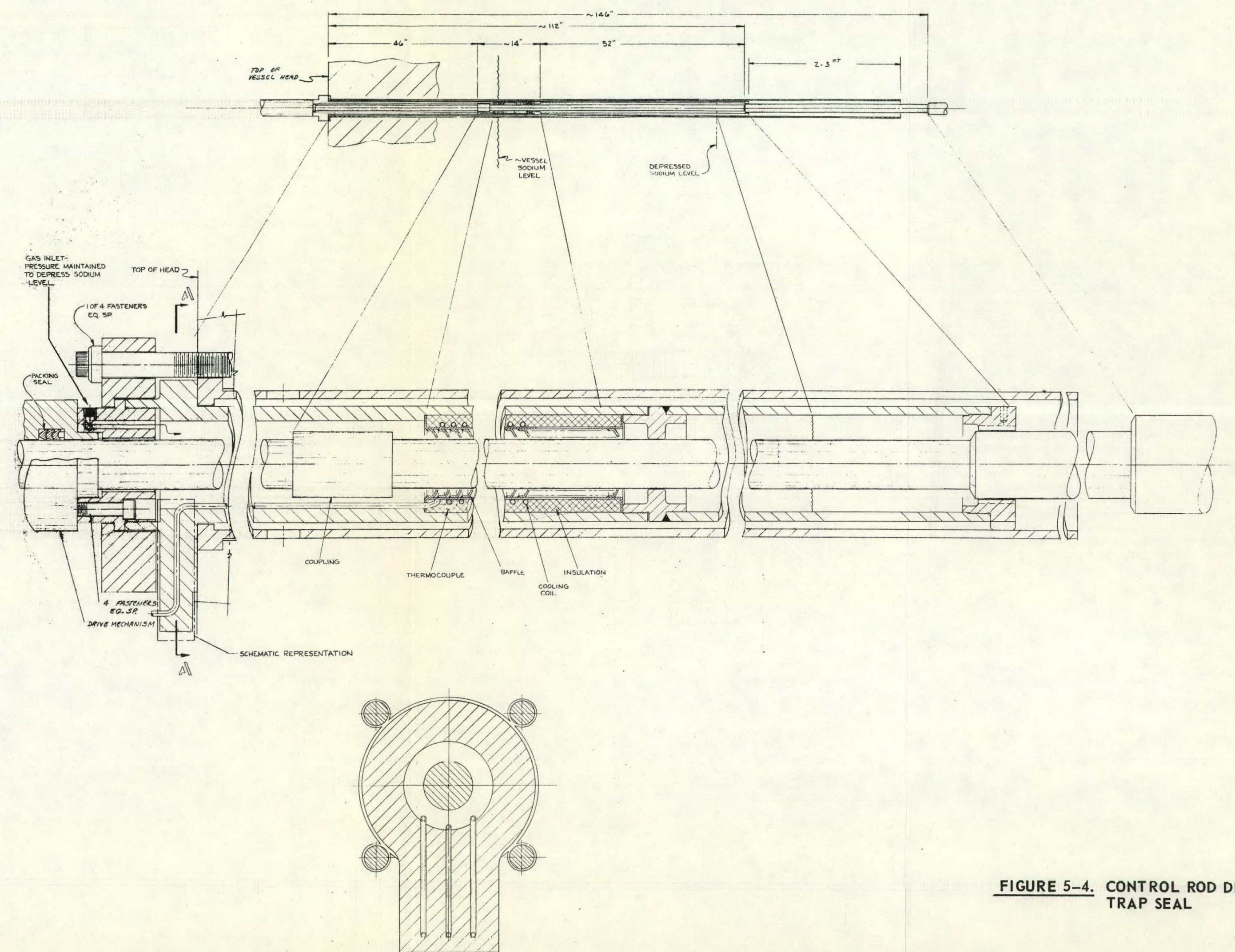

FIGURE 5-4. CONTROL ROD DRIVE VAPOR

SECTION $\mathbb{A}-\mathbb{A}$ 


\subsubsection{Bellows Seal}

The main control rod shaft seals for both EBR-II, FARET prototype testing, and FERMI have had very good in-service results using welded edge metal bellows. With the design configurations used, no problems caused by excessive sodium vapor deposition have-resulted. The control rod stroke requirements for the FFTF backup design are more demanding on a bellows assembly than these examples in that the bellows would have to follow a longer scram stroke, and operate in a higher temperature environment. The long operational success of EBR-II, FARET, and Fermi bellows indicates, however, that a good possibility of developing a successful bellows assembly for the FFTF backup control rod seal might be feasible and should be considered as a possible alternate to other seal designs.

A bellows seal configuration would be attractive for the FFTF backup design if it could follow the scram stroke and be located below the top of the vessel head, thus permitting the drive mechanism to be mounted just above the head. This would place the bellows in the hot region of the reactor. The level of the vessel sodium pool could be lowered within the guide tube by a source of external argon pressure similar to the method proposed for the flow and vapor trap seals.

\subsubsection{Extension Shaft Disconnect}

The extension shaft links the drive mechanism to the reflector control rod. A differential screw type disconnect joint is provided at the end of the pneumatic cylinder shaft to. allow the long extension shaft to be removed from the drive mechanism, thus facilitating handling and maintenance.

\subsubsection{Extension Shaft}

The extension shaft consists of a 1.50-inch diameter solid shaft through the shaft seal vessel penetration, then expanding into a tubular section between the shaft seal and control rod coupling. Early design work was based on a configuration that used an extension shaft essentially unguided for a distance near the bottom of the vessel head to the control rod coupling. This was the result of a short length shaft seal assembly. The current design concept provides an additional guide bushing along the shaft length as a result of the current shaft seal proposals which use a long housing and guide tube to depress the sodium pool level relative to the extension shaft. Column buckling calculations were made for the previous configuration, but have not been made on the current configuration. An improvement in the column loading is expected, however, because of the additional guidance provided.

The lower end of the extension shaft ends with the male portion of the control rod coupling which is described in the following section.

\subsubsection{Control Rod Coupling and Offset}

The offset between the axis of the control rod mechanism and the control rods is achieved at the connection of the drive extension shaft to the control rod. The offset is provided by a rigid bracket structure attached to the top end of the control rod assembly. Since two control rods are carried by one drive mechanism, the brackets require a configuration to permit the assembly of 
two adjacent control rods with the single extension shaft. This is achieved with an assembly that resembles a hinge. The extension shaft is similar to a hinge pin and the bracket structures fit together in a manner similar to the leaves of a hinge. The extension shaft or hinge pin is secured in the assembly by means of a rotary breech-block type of coupling. A $45^{\circ}$ rotation of the drive mechanism and extension shaft is required to engage or disengage the interlocking teeth of the coupling (refer to section E-E of Figure 5-2). To prevent the coupling from disengaging, the antirotation feature of the drive shaft is required.

The effect of this offset on the control drive system has been a significant portion of the analysis work. - Refer to sections $5.11-5.17$ for a description of the analysis.

\subsubsection{Control Rod}

The description of the control rod is covered in section 5.5 .

\subsubsection{Dashpot.Cushion}

The paired control rods and drive line assembly are decelerated at the end of the scram stroke by a dashpot assembly in the lower end of each of the two paired control rod guide channels. Constructed into the guide channel, as shown diagrammatically in Figure 5-5, is a fixed dashpot chamber. There are no outlets to the chamber other than the large diameter at the top of the chamber. A tapered dashram is constructed onto the bottom end of the control rod which enters into the dashpot chamber for the cushion stroke. The outlet to the sodium inside the chamber can only exhaust through the annular orifice formed between the dashpot and tapered dashram. The taper decreases the exit area, thus increasing the pressure in the dashpot which in turn provides the decelerating force. Analysis of this dashpot configuration using a 12 -inch cushion stroke has been performed and reported in subsection 5.11, and the significant $r$ esults presented in Figure 5-13 (page 5-39) which shows the final velocity of the control rod as a function of the final annular orifice gap. The maximum allowable final radial gap was determined to be 0.008 -inch, or in terms of diametral gap, 0.016-inch. This comes from results in Figure 5-13 (page 5-39) and by limiting the final dashram velocity to $4 \mathrm{ft} / \mathrm{sec}$ as determined by analysis for the final spring cushion: The control rod is finally stopped by contacting a spring cushion.

The Fermi reactors safety rods usc a dashpot cushion of a similar configuration, and the Fermi design was investigated to determine the performance, minimum gap clearances used, and materials. Satisfactory and trouble free performance was reported for the Fermi cushions; 774 scheduled and unscheduled scrams have been performed within the reactor with no problems being experienced. Based on the maximum diameter of the taper and using the tolerances given for the diameters, the FERMI cushion at the point of lowest clearance has a minimum diametral gap of 0.004 inch and a maximum of 0.008 inch. This compares with the diametral gap of 0.016 inch considered usable for the FFTF calculations. No special materials were used on the mating surfaces; both the dashram and dashpot were constructed from 304 stainless steel.

Between the two systems, the weight of rod being stopped is quite different however, the FERMI rod being 35 pounds versus approximately 350 for FFTF backup. To compensate for this difference the FFTF backup design proposes a longer cushion stroke, a.larger dashpot-dashram diameter, and the final velocity of the dashpot cushion completely brought to rest by a final spring assembly. 


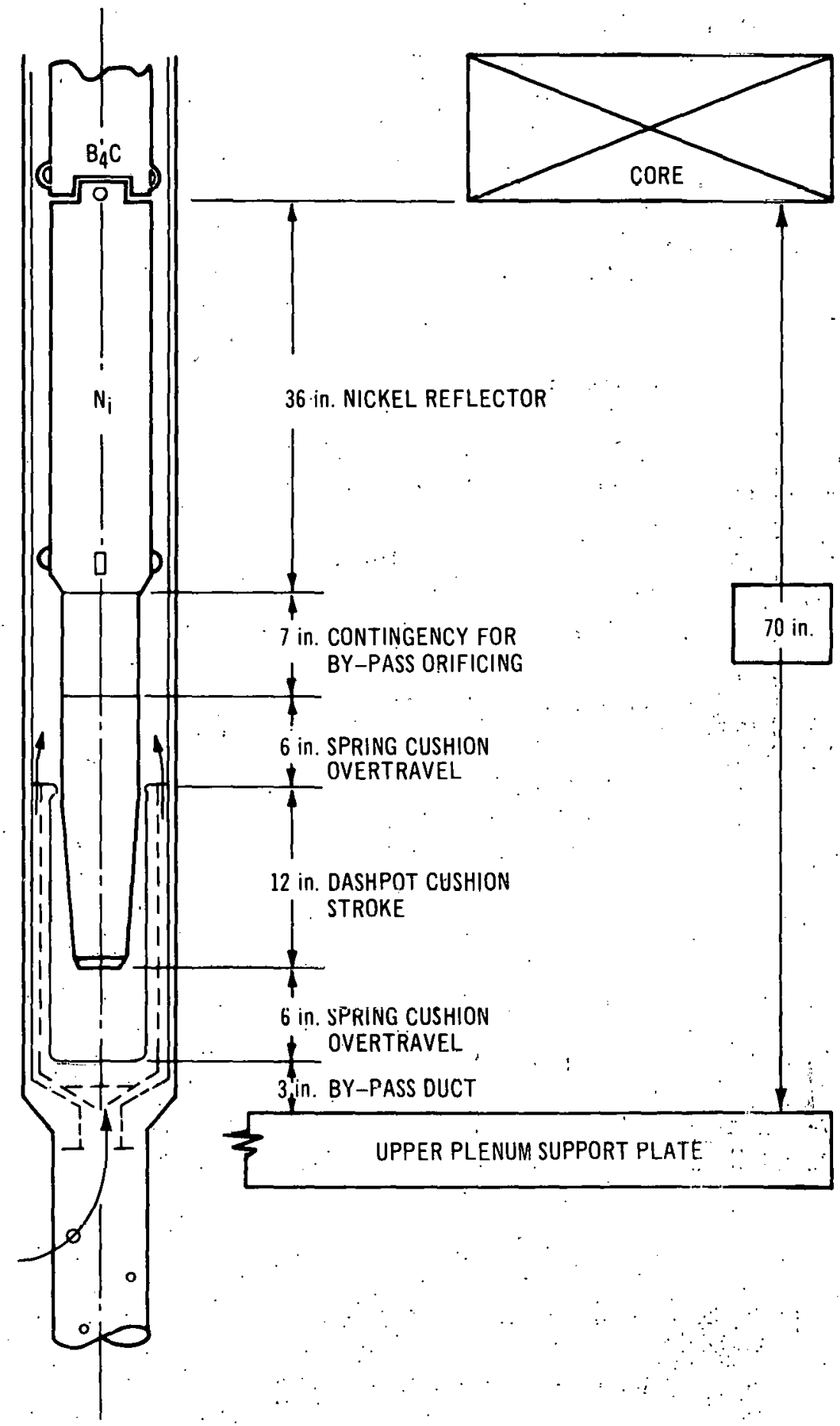

FIGURE 5-5. FFTF CONTROL ROD SPACE REQUIREMENTS BETWEEN CORE BOTTOM AND SUPPORT PLATE TOP 


\subsubsection{Final Spring Cushion}

A spring cushion is proposed to finally stop the control rod after the terminal velocity of the dashpot cushion has been reached. Because of the weight of the control rod assembly and the minimum annular gap of the dashpot, a possible maximum dashpot terminal velocity of $4 \mathrm{ft} / \mathrm{sec}$ could result. Optimization of the final design would hopefully reduce this value, but this contingency is being. allowed for at this point in design.

An attractive location for placing the final cushion spring is in the hexagonal reflector channel adjacent to the two paired control rods and on the side away from the core. Investigative calculations for a spring to provide the final stop have shown that for a spring fitting into a single hexagonal channel location, a helical coil spring is limited by force to a deceleration rate of approximately 3-1/4 g. Belleville spring washers have been considered and found to be possible candidates but fairly stiff in practical stacked heights and offer deceleration of approximately $6 \mathrm{~g}$.

To provide the flexibility to cover the range of decelerations as may be required for the final design selection, it may be necessary to use more than a single reflector hexagonal channel as locations for the springs. A cluster of three reflector channels are available for this purpose which are located directly under the offset from control rod to drive extension shaft.

The analysis of subsection 5.15 indicates that a $6 \mathrm{~g}$ deceleration is the upper limit for the final spring cushion. In considering the spring requirements for the final spring cushion, Figure 5-15 (page 5-43) was developed to show the spring deflection (travel after impact) and spring constant at various final dashpot velocities for selected deceleration rates. The basis for this curve is to equate the compression work on the spring to the kinetic energy of the control rod assembly at spring contact, plus the potential energy obtained from the control rod assembly weight and the additional scram force traveling through the spring stroke. The control rod assembly weight and the additional scram force were taken at 750 pounds and 300 pounds, respectively. At this point in design a maximum spring cushion stroke of 6 inches is being allotted.

\section{3.17 Space Requirements for Cushion System}

Figure 5-5 shows the space allotment required to accommodate the dashpot and spring cushions. The result of 70 inches between the core bottom and the upper grid plate is based on a dashpot stroke of 12 inches, the maximum spring cushion stroke of 6 inches, and a 7 inch contingency for control rod orificing. A method of orificing the control rod bypass flow is required so that the bypass flow is reduced when the control rod is in the full down or up position. The 70 -inch dimension was not incorporated in the other design areas, but would have to be resolved.

\section{4 MAJOR ADDITIONAL WORK AREAS NOT COMPLETED IN CONTROL ROD DRIVE DESIGN}

- Dynamic Scram Analysis:

The performance of the pneumatic cylinder during scram needs to be analyzed.

- Shaft Seal Vessel Penetration Design and Development:

The evaluation of several concepts should be pursued in a parallel effort. 
- Final Spring Cushion Design.

- Remote Handling Methods for Installing and Removing Drives and Control Rods.

- Location and Mounting of Scram High Pressure Argon Tank.

\section{5 GENERAL REFLECTOR CONTROL SYSTEM ANÁLYSIS}

The reflector control system (refer to section 5.1 through 5.3 for details) is comprised of 38 control elements ( 2 singles and 18 pairs) driven by head mounted pneumatically actuated drive mechanisms. A long push rod connects the pneumatic piston to an extension on the control element(s) through a joint located just above the core bundle. To accommodate the small refueling plug, the drive mechanisms are mounted such that their vertical axes are offset radially from the vertical axes of the control elements. This requirement of an offset in the drive line is met by placing a coupling beam between the push rod and control element extension shaft(s) at the joint above the core bundle. The control element is a bundle of 37 stainless cladding $\mathrm{B}_{4} \mathrm{C}$ pins with a sealed gas plenum formed by the cladding tubing being longer than the poison. These pins are mounted as a hexagonal array inside a stainless steel hexagonal wrapper tube. A nickel reflector section hangs below the poison region with axial cooling holes passing through it. The coolant flowing through the nickel feeds the tube bundle. A tapered piston on the lower end of the nickel reflector acts as a damper at the end of the scram stroke by mating concentrically with an orifice in the lower end of the fixed structure. A clearance is maintained between the wrapper tube to minimize viscous resistance during scram and to avoid binding due to flexure, thermal distortion, and mechanical tolerances. Wear pads are located on the reflector segment and above the bundle section to maintain a clearance and guide the control rod. These also provide reactions to the bending moment applied by virtue of the off set in the drive line. The control rod extension above the poison pin bundle section is tapered to increase the clearance between it and the fixed channel wall at the tor of the core bundle, where flexural deflection is a maximum.

Requirements on the system follow:

a. An adequate volume fraction of poison $\left(B_{4} C\right)$ should be provided without going to excessive $\mathrm{B}^{10}$ enrichment such that the design objective control worth of $\$ 20.00$ is aclineved.

b. Cooling of the poison pins when adjacent to the core shall maintain temperature limits on the poison and cladding.

c. Bypass cooling around the rods should not be excessive; $3 \%$ of core flow is desirable; $10 \%$ may be acceptable.

d. Hydraulic forces across the rod at full flow shall be such that rod ejection in the event of a mechanical failure in the drive will not occur, i.e., hydraulic forces to be well below the weight of the rods.

e. The rate of insertion during scram must meet the response requirements from safety considerations. An acceleration rate of approximately $32 \mathrm{ft} / \mathrm{sec}^{2}$ over the first 24 inches has been tentatively established. 
f. Rate of deceleration and final velocity must minimize bounce back at the end of scram stroke, and positive holddown in addition to weight is desirable.

g. Mechanical integrity and freedom from binding must be maintained under all conditions.

The following design parameter interactions were considered in establishing the reference design:

a. Volume fraction of poison and $B^{10}$ enrichment (results shown in Figures 5-6 and 5-7).

1. Increase in clearance between wrapper and channel decreases volume \% poison.

2. Increase in wrapper thickness decreases volume \% poison.

3. Increase in cladding thickness decreases volume $\%$ poison.

b. $\quad \mathrm{B}_{4} \mathrm{C}$ Cladding: Increase in plenum length increases flexibility of control element under bending loads and thus adds to clearance required around wrapper.

c. Plenum Length: Increase in plenum length increases flexibility of control element under bending loads and thus adds to clearance required around wrapper.

d. Magnitude of Offset: Increase in off set limits maximum forces that can be applied during scram acceleration and deceleration for a given clearance around the wrapper.

e. Clearance Around Wrappér:

1. Percentage of bypass flow increases as this gap is increased for rods not in full up or full down position where flow can be restricted.

2. Decrease in this clearance increases viscous resistance during acceleration phase of the scram requiring increased load on the drive line at reduced insertion rate.

The following analyses have been conducted to support selection of the design configuration:

a. Reflector worth versus geometry variables

1. Thermal analysis of control elements

2. Hydraulic analysis of control elements

b. Stress analysis of poison cladding.

c. Thermal stress analysis of nickel segment.

d. Dynamics analysis during scram.

e. Hydraulic analysis during scram deceleration.

f. Elastic stability of drive line.

g. Allowable load at offset from stress and deflection limitations.

h. Allowable impact velocity at end of scram.

i. Analysis of pneumatic cylinder during scram. 


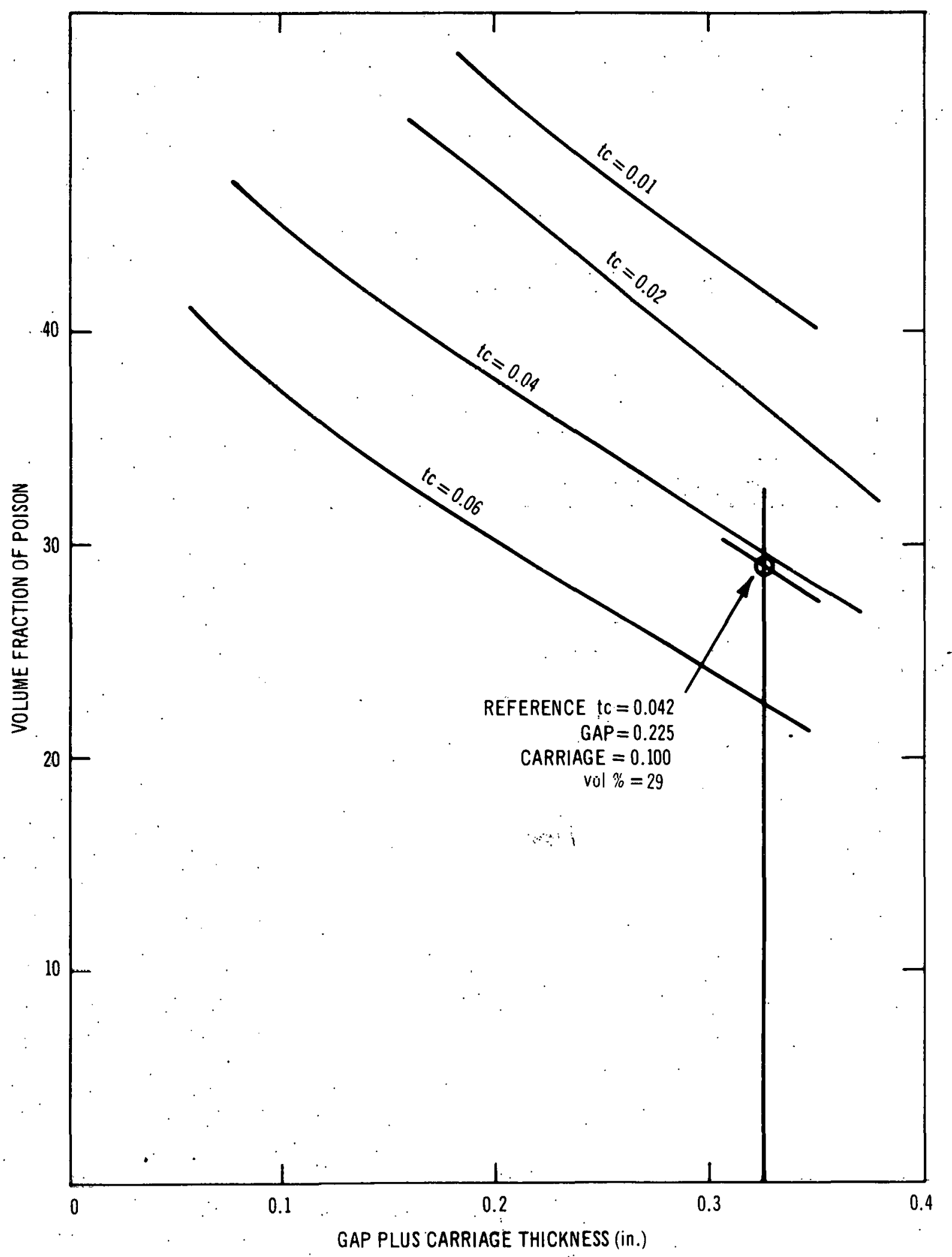

FIGURE 5-6. VOLUME FRACTION OF POISON VERSUS ANNULAR DIMENSIONS AND CLADDING THICKNESS 
GEAP-5722

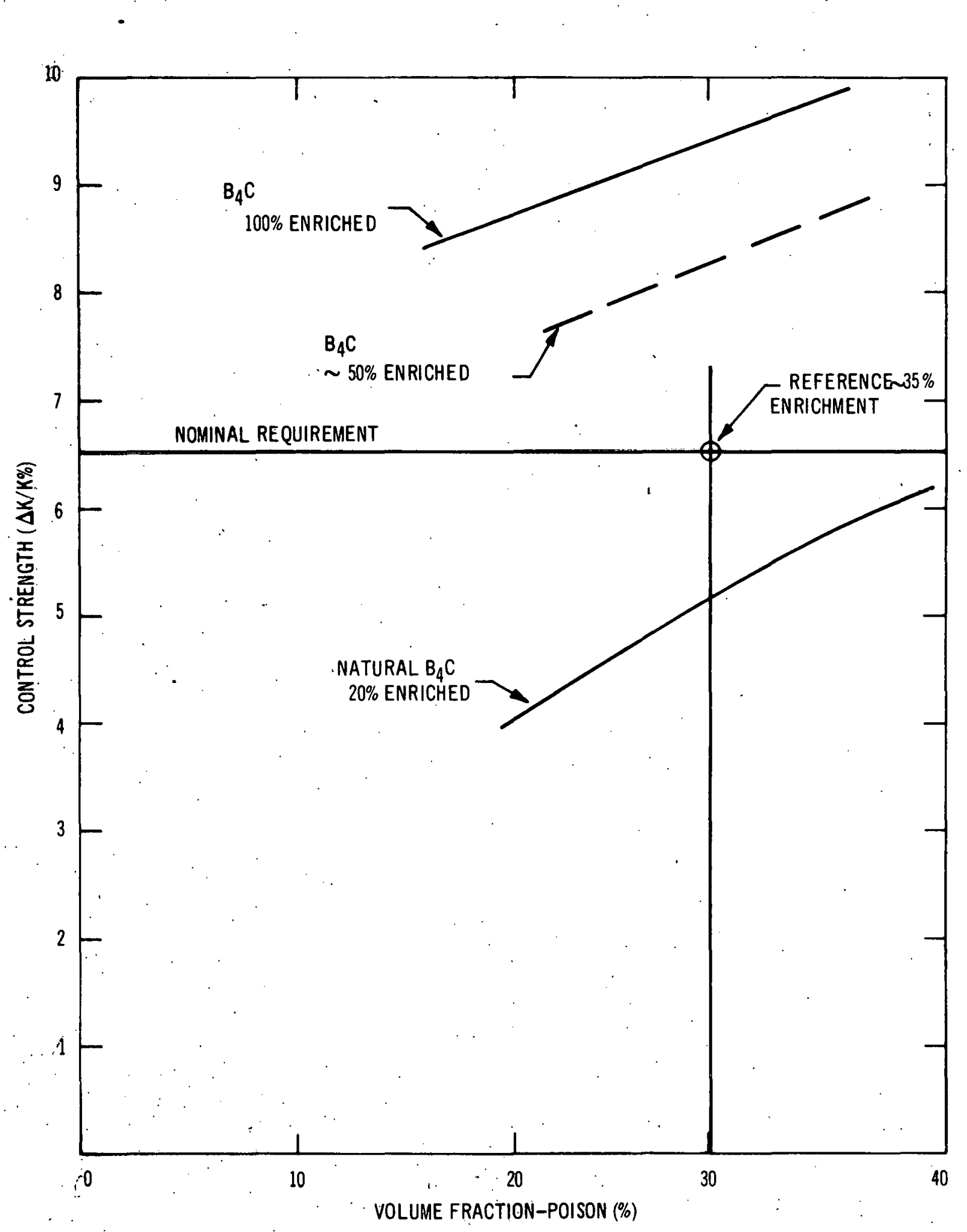

FIGURE 57. CONTROL STRENGTH VERSUS VOLUME FRACTION AND ENRICHMENT 


\section{6 THERMAL ANALYSIS OF CONTROL ELEMENTS}

Thermal calculations were performed in support of the design of the $\mathrm{B}_{4} \mathrm{C}$ control rod. Figure 5-8 is the calculated $\mathrm{B}_{4} \mathrm{C}$ centerline temperature (at the axial midplane) for three heating rates with a cladding thickness of 30 mils. For temperatures greater than $1500^{\circ} \mathrm{F}$, constant conductivity is assumed.

Figure 5-9 adjusts Figure 5-8 curves for selection of cladding thicknesses other than 30 mils. Corrections are for $0.4,0.5$ and 0.6 inch $\mathrm{B}_{4} \mathrm{C}$ o.d. geometries.

Figure 5-10illustrates the maximum cladding temperature for $0.4,0.5$ and 0.6 inch $\mathrm{B}_{4} \mathrm{C}$ diameter rods with several cladding thicknesses. The cladding temperature was calculated at the proper axial location where the maximum temperatures occur and the local conditions have been integrated into the calculations.

The assumptions used in the calculations are listed in Table 5-2.

TABLE 5-2

PARAMETERS SELECTED FOR CALCULATION OF B $_{4}$ C CONTROL ROD TEMPERATURES

$\begin{array}{ll}\text { Sodium temperature at inlet } & 700^{\circ} \mathrm{F} \\ \text { Sodium temperature at axial midplane } & 850^{\circ} \mathrm{F} \\ \text { Sodium temperature at control rod outlet } & 1000^{\circ} \mathrm{F} \\ \text { Film coefficient - sodium to cladding } & 20,000 \mathrm{Btu} / \mathrm{h}-\mathrm{ft}^{2}-{ }^{\circ} \mathrm{F} \\ \text { Film coefficient - cladding to } \mathrm{B}_{4} \mathrm{C} & 1200 \mathrm{Btu} / \mathrm{h}-\mathrm{ft}^{2}-{ }^{\circ} \mathrm{F} \\ \text { Thermal conductivity of statnless sieel } & 12.4 \mathrm{Btu} / \mathrm{h}-\mathrm{ft}{ }^{\circ} \mathrm{F} \\ \text { Density of } \mathrm{B}_{4} \mathrm{C} & 1.9 \mathrm{gm} / \mathrm{cc} \\ \text { Density of stainless steel } & 7.91 \mathrm{gm} / \mathrm{cc} \\ \text { Heat generation of stainless steel due to }(\gamma, \mathrm{n}) & 7.5 \text { watts } / \mathrm{gm}\end{array}$

\subsection{HYDRAULIC ANALYSIS OF CONTROL ROD COOLING FLOW}

Coolant supplied to the lower end of the rod will split into two paths: (1) through the rod and (2) through the annulus surrounding the rod. The flow split between annulus and rod is about 3 to 1 for a 0.1 -inch annulus and about 22 to 1 for an annulus of 0.225 -inch. Flexural analysis of the rod indicates the annular gap required is 0.225 inch. Since required flow through the rod to cool the $\mathrm{B}_{4} \mathrm{C}$.is about $8000 \mathrm{lb} / \mathrm{h}$, the bypass flow in the annulus would be about $7 \times 10^{6} \mathrm{lb}$ m $/ \mathrm{h}$ through all 38 control elements. Nominal flow through the core is $14.3 \times 10^{6} \mathrm{lb}_{\mathrm{m}} / \mathrm{h}$ at full power; hence, it can be seen the bypass flow without some modifications is excessive.

Placing restrictions on the annulus to reduce this introduces the problem of high viscous resistance during scram action. The approach taken is to design restrictions into the annulus which are effective when the control rod is in the full-up or full-down position, but which are ineffective during the scram travel. This can be done by having lands on the extension rod which mate with lands on the channel in the extreme positions but are not mated for the rod in the intermediate position. Operation of the control rods should be such that only two pairs are in the 
GEAP-5722

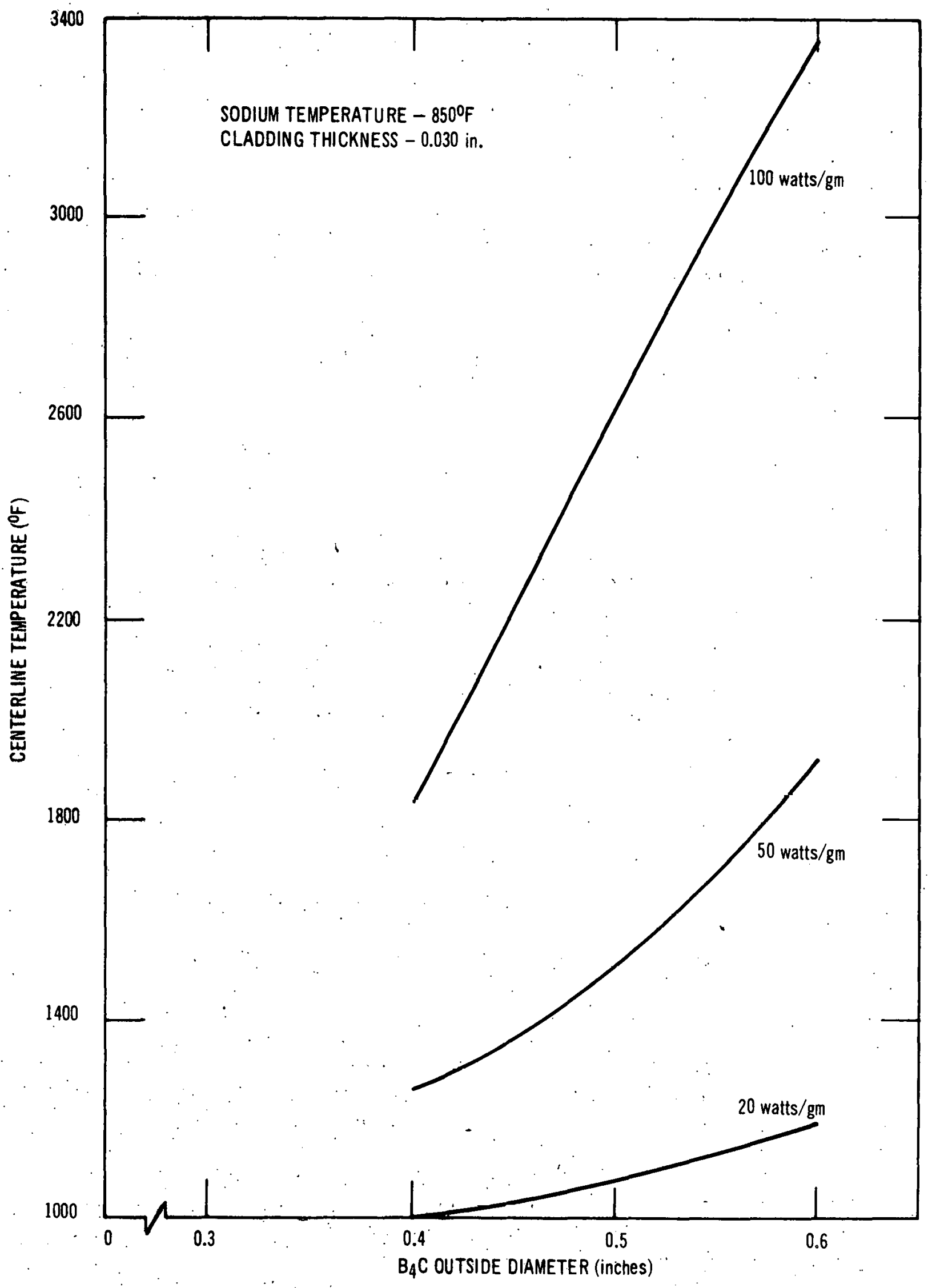

FIGURE 5-8. FFTF $B_{4}$ C CONTROL ROD TEMPERATURES 


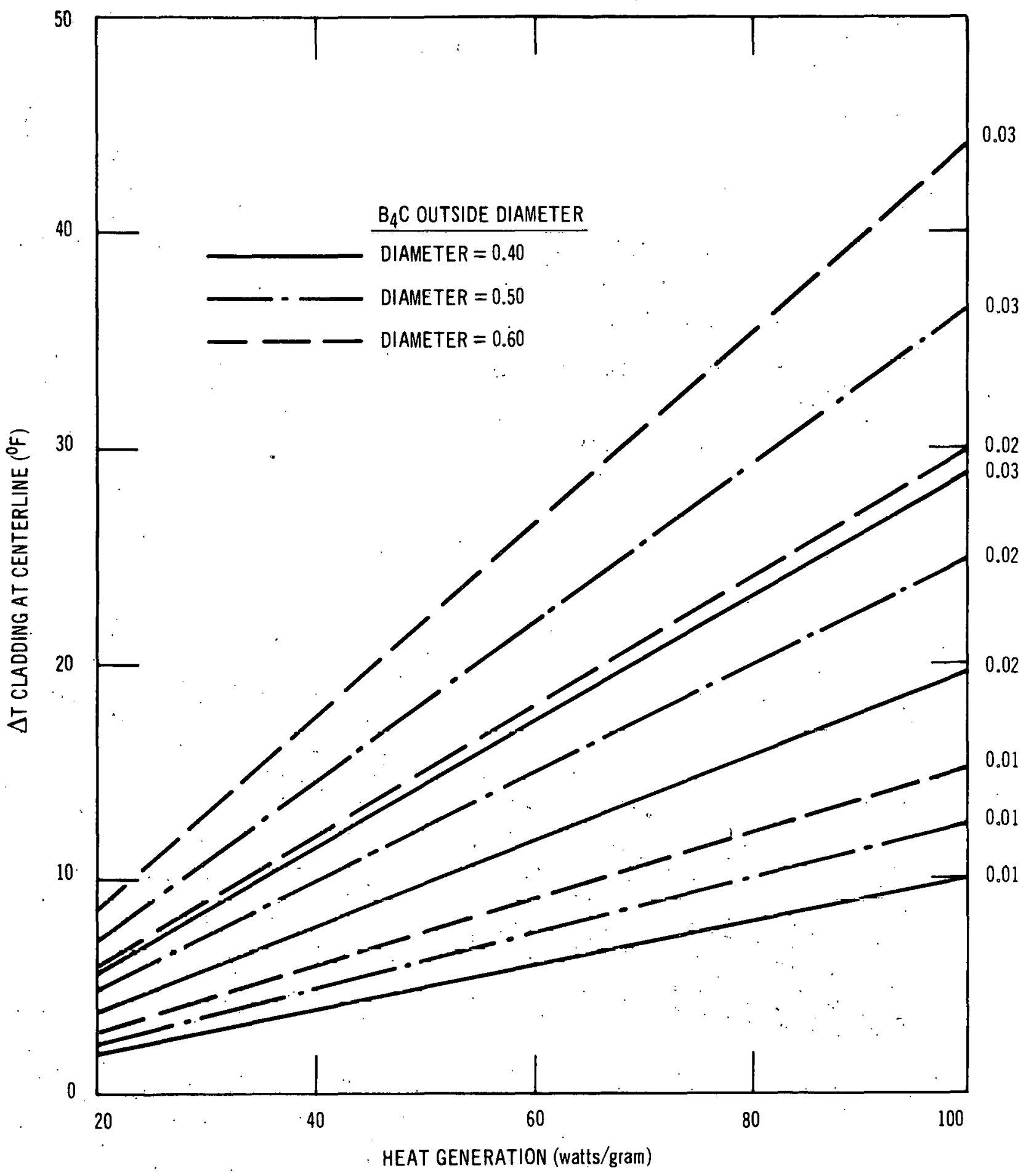

IFIGURE 5-9. FFTF $B_{4}$ C CONTROL RODS;-CLADDING $\triangle T$ 


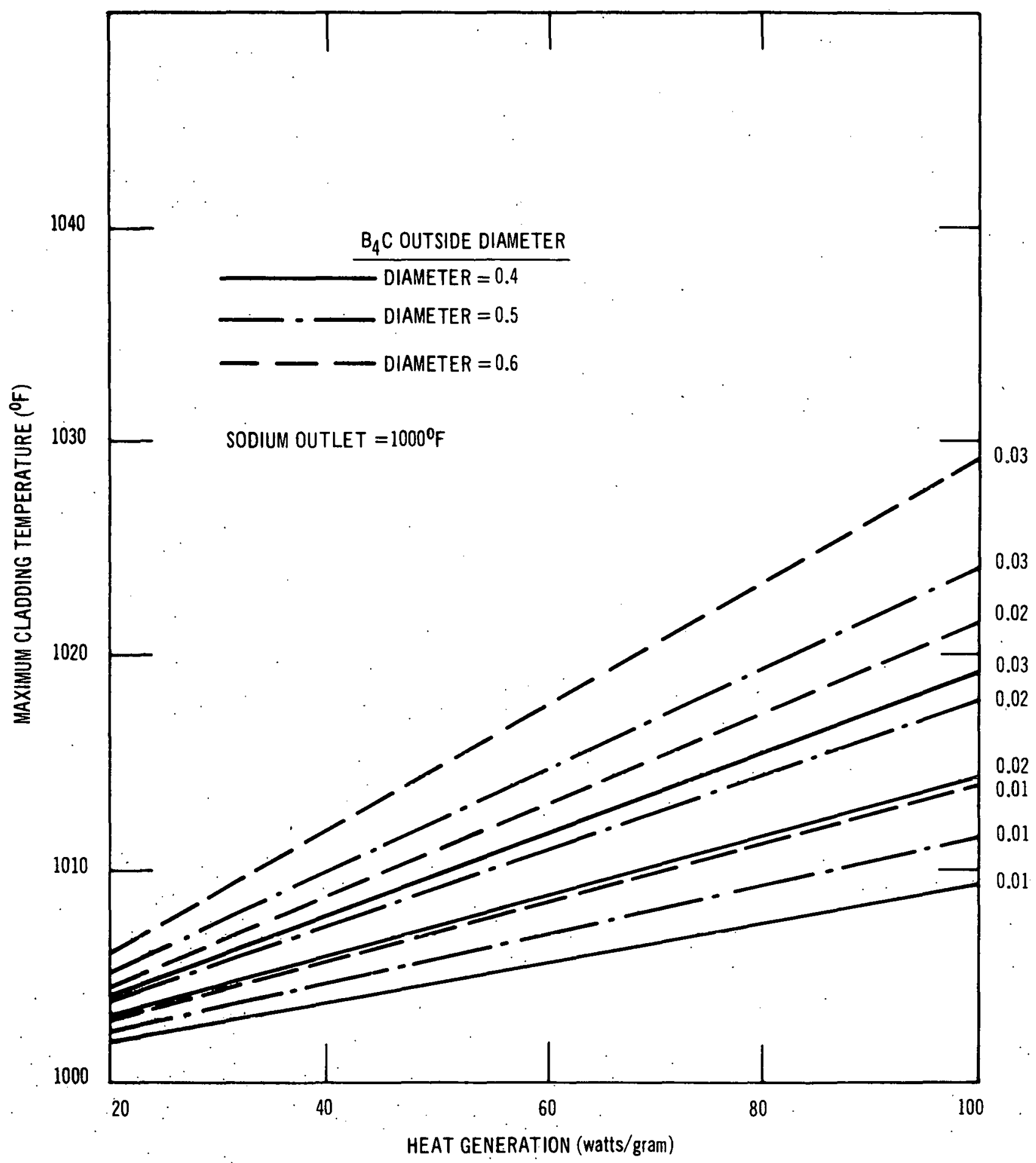

FIGURE 5-10. FFTF $B_{4}$ C CONTROL RODS "- CLADDING PEAK TEMPERATURE 
intermediate position during power operation as shown in Figure 5-11. This would result in bypass flow in annuli around the rods being limited to about $0.9 \times 10^{6} \mathrm{lb} / \mathrm{h}$ or about $6 \%$ of total sodium flow through the core bundles.

A further hydraulic consideration is the safety requirement that the hydraulic loads across the rod do not have the capacity to eject the rod in the event of a failure or malfunction in the drive mechanism or drive line. The weight of a single control element is approximately 250 pounds and the cross-section area is approximately $7.0 \mathrm{sq}$. in. A pressure drop across the rod of $35 \mathrm{psi}$ could eject the rod if resistance from the drive line is accidentally lost.

The flow rate required through the poison section of one control element is approximately $8,000 \mathrm{lb} \mathrm{m} / \mathrm{h}$ for a $300^{\circ} \mathrm{F}$ temperature rise assuming the average heat generation is $40 \mathrm{~W} / \mathrm{gm}$. This is considered a conservatively high estimate of heating rate. Any reduction in the actual heating rate will lower the temperature level of the $\mathrm{B}_{4} \mathrm{C}$ and cladding.

For a flow rate of $8,000 \mathrm{lb} / \mathrm{h}$, the friction pressure drop through the poison pins is $2.0 \mathrm{psi} /$ $\mathrm{ft}$, giving $10 \mathrm{psi}$ through the 5 -foot long bundle. The pressure required at the bottom of the rod is controlled by the above $8,000 \mathrm{lb} / \mathrm{h}$ flow requirement and the flow split between the rod and the annulus. The critical configuration from $\mathrm{B}_{4} \mathrm{C}$ cooling considerations requires the rod to be in a slightly withdrawn position such that there is no restriction in the annulus and heat generation in the rod to be near its maximum. The over-all pressure drop is the sum of the pressure drop through the nickel reflector, the poison section, and the extension rod. The total flow required is controlled by the flow in the annulus which must have the same pressure drop as through the internal path. For a 0.225 -inch annulus, the flow rate to give $2.0 \mathrm{psi} / \mathrm{ft}$ (10 psi along $5 \mathrm{ft}$ pins) is $180,000 \mathrm{lb}_{\mathrm{m}} / \mathrm{h}$. For this flow rate, the pressure drop along the nickel section is approximately $8 \mathrm{psi}$, and the pressure drop along the extension shaft is approximately $5 \mathrm{psi}$. This results in a total of approximately 25 psi which is below that which would have the potential to overcome the weight of the rod. The calculated results are summarized in Table 5-3.

TABLE $5-3$

SUMMARY OF CONTROL BUNDLE EYPASS FLOW CHARACTERISTICS

\begin{tabular}{|c|c|c|}
\hline & Upen Annulus & $\begin{array}{c}\text { Restricted } \\
\text { Aninulus }\end{array}$ \\
\hline Fluw in $\mathrm{B}_{4} \mathrm{C}$ pinss & $0,000 \mathrm{lb}_{\mathrm{m}} / \mathrm{h}$ & $13 ; 100 \mathrm{lb}_{\mathrm{m}} / \mathrm{h}$ \\
\hline$\Delta \mathrm{p}-$ Nickel $(\mathrm{AB})^{*}$ & $\cdot .8 \mathrm{psi}$ & $0.1 \mathrm{psi}$ \\
\hline$\Delta \mathrm{p} \mathrm{B}_{4} \mathrm{C}(\mathrm{BC})$ & $10 \mathrm{psi}$ & $21.3 \mathrm{psi}$ \\
\hline$\Delta p$ Extension $(\mathrm{CD})$ & $\begin{array}{l}2 \text { psi } \\
3 \text { psi }\end{array}$ & $\begin{array}{l}3.5 \mathrm{psi} \\
0.1\end{array}$ \\
\hline $\begin{array}{l}\text { Bypass Flow } \\
\text { Total } \wedge p\end{array}$ & $\begin{array}{c}180,000 \mathrm{lb}_{\mathrm{m}} / \mathrm{h} \\
25 \mathrm{psi}\end{array}$ & $\begin{array}{l}\sim \text { zero } \\
25 \text { psi }\end{array}$ \\
\hline
\end{tabular}

*Refer to Figure 5-11 for definition of symbols.

Total flow, assuming four elements are in intermediate position

$=4 \times 180,000+4 \times 8,000+34 \times 13,400$

$=720,000+32,000+465,000$

$=1.217 \times 10^{6} \mathrm{lb} / \mathrm{h}$

Core Flow is $14.3 \times 10^{6} \mathrm{lb}_{\mathrm{m}} / \mathrm{h}$

Ratio Control Rod Flow: Core Flow $=8.5 \%$

Excess Control Rod Flow $=4 \times 180,000+34 \times 5,400$

$=0.903 \times 10^{6} \mathrm{lb}_{\mathrm{m}} / \mathrm{h}$

Ratio of Excess Control Rod Flow: Core Flow $=6.3 \%$ 


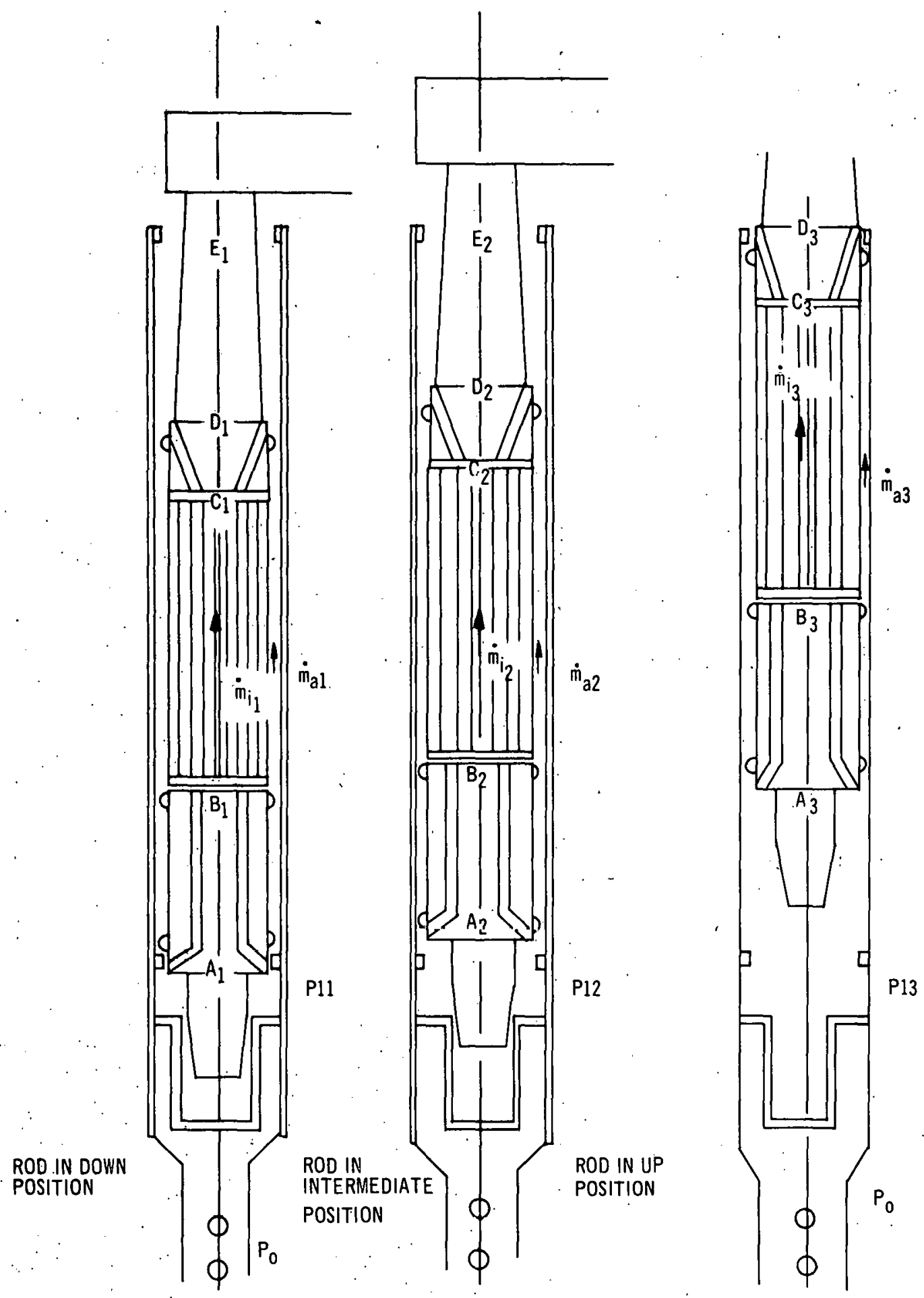

FIGURE 5-11. SCHEMATIC OF. TECHNIQUE TO REDUCE BY-PASS FLOW THROUGH CONTROL ROD BUNDLE 


\subsection{STRESS ANALYSIS OF $\mathrm{B}_{4} \mathrm{C}$ CLADDING}

Evaluation of rate of burnup of control reactivity indicates that this is relatively low (3\% of total reactivity) per full power year; hence; gas pressure buildup in the poison pins is expected to control the residence time of the control rods in the reactor. A 15 -inch long gas plenum has been selected as a reference. It is desirable from structural rigidity of the control blade considerations to keep this as small as possible.

Nomenclature

$$
\begin{aligned}
& \mathrm{g}_{\mathrm{H}}=\text { Helium generation rate in maximum pin (atoms per } \mathrm{gm} / \mathrm{sec} \text { ) } \\
& l_{\mathrm{B}}=\text { Length of pin adjacent to core }(\mathrm{cm}) \\
& \rho_{\mathrm{B}}=\text { Density of } \mathrm{B}_{4} \mathrm{C}\left(2.0 \mathrm{gm} / \mathrm{cm}^{3}\right) \\
& \cdots A_{B}=\text { Cross secliun area of } \mathrm{B}_{4} \mathrm{C}\left(\mathrm{cm}^{2}\right)
\end{aligned}
$$

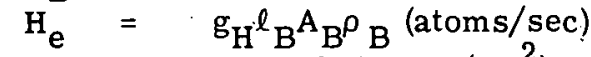

$$
\begin{aligned}
& A_{p}=\text { area of plenum }\left(\mathrm{cm}^{2}\right) \\
& \ell_{p}=\text { length of plenum (cm) } \\
& v_{p}=\text { Volume of plenum }\left(A_{p}{ }_{p} c^{c m}{ }^{3}\right) \text {. } \\
& r=\text { Fraction of helium generated released to the plenum } \\
& \mathrm{H}_{\mathrm{e}_{\mathrm{p}}}=\text {. Helium released to plenum } \\
& \mathrm{H}_{\mathrm{e}_{\mathrm{p}}}=\mathrm{rg}_{\mathrm{H}} \mathrm{\ell}_{\mathrm{B}} \mathrm{A}_{\mathrm{B}}{ }^{\rho} \mathrm{B} \text { (atoms/sec) } \\
& \text { Avogadros No }=6.02 \times 10^{23} \\
& \mathrm{~T}=\text { Time at exposure (days) }
\end{aligned}
$$

Accordingly,

$$
\frac{\mathrm{H}_{\mathrm{e}}}{\mathrm{v}_{\mathrm{p}}}=\frac{\mathrm{rg}_{\mathrm{H}^{\ell} \mathrm{B}^{\mathrm{a}} \mathrm{B}^{\rho_{\mathrm{B}}}}}{\mathrm{a}_{\mathrm{p}}{ }_{\mathrm{p}}} \mathrm{T} \times 8.64 \times 10^{4} \frac{\text { atoms }}{\mathrm{cc}}=\frac{6.02 \times 10^{23}}{22,400}=2.68 \times 10^{19} \frac{\text { atoms }}{\mathrm{cc}} \text { at STP }
$$

Pressure at $1000^{\circ} \mathrm{F}=\left(\frac{1000+400}{520}\right) \times 14.7=41.2 \mathrm{psi}$

The pressure due to gas release is

$$
P=r g_{H} \frac{l_{B}}{l_{p}} \rho_{\mathrm{B}} \mathrm{T} 8.64 \times 10^{4} \times \frac{41.2 \mathrm{psi}}{2.68 \times 10^{10}} \text { at } 1000^{\circ} \mathrm{F}
$$
For a rod fully inserted continuously for one year, $\mathrm{g}_{\mathrm{H}_{\mathrm{av}}}$ has been estimated at $5.0 \times 10^{13}$
atoms per $\mathrm{gm} / \mathrm{sec}$

$$
\begin{aligned}
& \ell_{B}=36 \text { in. } \ell_{p}=15 \text { in. } \ell_{B} / l_{p}=2.4, r=0.25 \\
& \rho_{B}=2 \mathrm{gm} / \mathrm{cc} T=365 \text { days for one year exposure }
\end{aligned}
$$

$P=2920$ psi for $25 \%$ gas release after 365 days exposure over the full length of rod. 
Stress in cladding

$$
\begin{aligned}
& \text { For } 304 \text { stainless steel } \quad S_{\text {Yield }}=14,000 \text { psiat } 1100^{\circ} \mathrm{F} \\
& \mathrm{S}_{\mathrm{M}}=0.9 \mathrm{~S}_{\text {Yield }}=12,600 \mathrm{psi} \\
& \text { Hoop Stress (average) } \quad s_{t}=p \frac{\left(d-t_{c}\right)}{2 t_{c}} \quad \begin{array}{l}
t_{c}=\text { cladding thickness } \\
d=\text { pin o.d. }
\end{array} \\
& \text { For reference pin } d=0.404 \quad t_{c}=0.042 \\
& \text { Allowable } p_{\max }=s_{t} \frac{2 t_{c}}{\left(d-t_{c}\right)}=\frac{12,600 \times 2 \times 0.042}{0.362} \text {. } \\
& 2920 \mathrm{psi} \text {. }
\end{aligned}
$$

Comparing allowable pressure to pressure generated, the reference selected can accommodate $25 \%$ gas release in a pin which remains fully inserted for 400 full power days. The detailed schedule of control rod change out has not been specified. When rods are used to balance out reactivity changes due to temperature, they'accumulate very little burnup. When used to balance fuel burnup reactivity, rods accumulate burnup at approximately half the fully inserted rate. The reference selected has ample flexibility to establish a rod change schedule. Detailed evaluation and analysis will probably permit a thinner cladding, shorter plenum, or higher gas release to be accommodated.

\subsection{NICKEL REFLECTOR SEGMENT - THERMAL STRESS ANALYSIS}

The nickel segment when adjacent to the core has an internal heat generation rate of $4 \mathrm{~W} / \mathrm{gm}$ (or $3.44 \times 10^{6} \mathrm{Btu} / \mathrm{h}-\mathrm{ft}^{3}$ ).

Since flow around the periphery may be choked off to minimize bypass flow through the control drive channels and since the flow to the $\mathrm{B}_{4} \mathrm{C}$ region must be directed into the center of the element, assume cooling is provided by flow in internal passages in the nickel segment and (conservatively) neglect cooling on the outer surface.

To minimize the volume of nickel to be removed, a symmetrical array of seven cooling holes was selected (diameter of $3 / 8$ inch was selected as a reference for this analysis. The final selection depends upon detailed pressure drop requirements.) as shown in Figure 5-12.

The region around each hole was considered as an equivalent thick-walled hollow cylinder of 0.65 inch o.d. and 0.375 inch i.d.

The maximum hoop stress is at the inner diameter and is given by:

$$
\sigma_{\theta \cdot a}=K \frac{E \alpha}{2(1-\nu)} \frac{d}{2 k \rho} \frac{a^{2}}{2}\left(\frac{2 b^{2}}{a^{2}} \ln \frac{b}{a}-\frac{b^{2}}{a^{2}}+1\right)=\frac{K E \alpha}{2(1-\nu)}\left(T_{b}-T_{a}\right)
$$

where,

$$
\begin{aligned}
& \sigma_{\dot{\theta}}=\text { Hoop stress at } \mathrm{i} \cdot \mathrm{d} . \\
& \mathbf{K} \cdot=\ldots \text { Constant }
\end{aligned}
$$



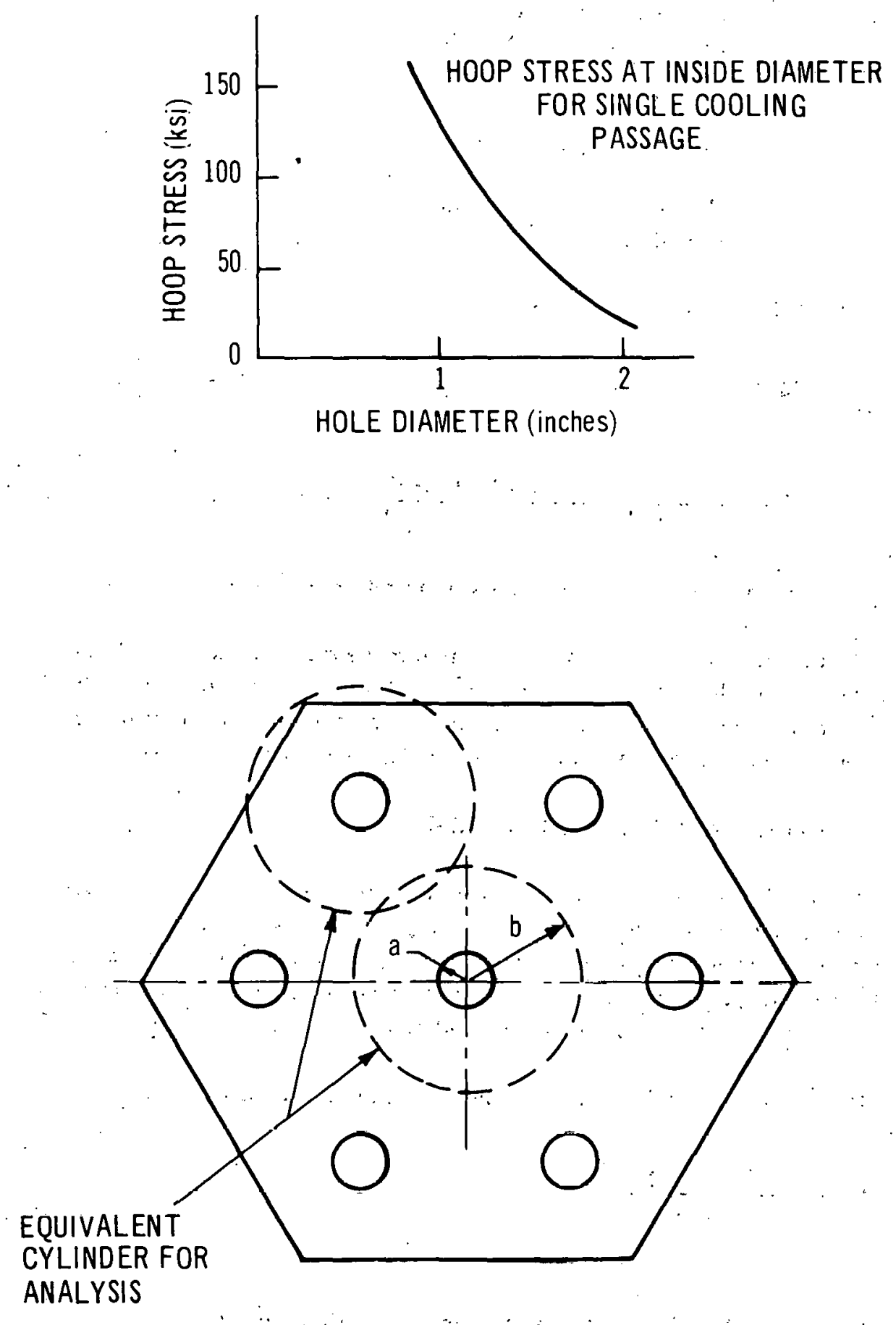

FIGURE 5-12. MODEL AND RESULTS FOR NICKEL REFLECTOR ANALYSIS 


$$
\begin{aligned}
\mathrm{E} & =\text { Modulus of elasticity }=27 \times 10^{6} \mathrm{psi} \\
\alpha & =\text { Coefficient of linear expansion }=8 \times 10^{-6} \mathrm{per}{ }^{\circ} \mathrm{F} \\
\nu & =\text { Poissons ratio }=0.3 \\
\mathrm{Q} & =\text { Internal heating rate }=3.44 \times 10^{6} \mathrm{Btu} / \mathrm{h}^{-\mathrm{ft}^{3}} \\
\mathrm{k} & =\text { Thermal conductivity }=29 \mathrm{Btu} / \mathrm{h}-\mathrm{ft}-{ }^{\circ} \mathrm{F} \\
\mathrm{a} & =\text { Inner radius }=0.188 \\
\mathrm{~b} & =\text { Outer radius }=0.325 \\
\rho & =\text { Density }=0.3 \mathrm{lb} / \mathrm{in}^{3} \\
\mathrm{~T} & =\text { Temperature } \\
& \text { Find. K from Glasstone* } \\
\sigma_{\theta}= & \frac{1000 \mathrm{E} \alpha \mathrm{Qa}{ }^{2}}{16 \mathrm{~K}(1-\nu)} \text { for } \frac{\mathrm{b}}{\mathrm{a}}=10
\end{aligned}
$$

With above equation gives $\mathrm{K}=1.38$

$$
\begin{aligned}
& \frac{\mathrm{Q}}{\mathrm{pk}}=828^{\circ} \mathrm{F} \quad \mathrm{b} / \mathrm{a}=1.73 \ldots \\
& \sigma_{\theta \mathrm{a}}=\frac{27 \times 10^{6} \times 8 \times 10^{-6} \times 1.38^{\prime} \times 0.188^{2}}{2 \times 0.7 \times 4}\left(2 \times 1.73^{2} \ln 1.73+1-1.73^{2}\right)=2000 \mathrm{psi} .
\end{aligned}
$$

Allowable number of fatigue cycles is infinite for such a low stress.

The thermal stress calculation was also made for a single central hole, and it was determined the hole would have to be in the range of 1.5 -inch diameter to keep the thermal stress below the range where fatigue failure would be a potential failure mode. The seven hole configuration is considered to provide a more desirable temperature distribution.

\subsection{DYNAMIC ANALYSIS DURING SCRAM}

From safety considerations, a scram acceleration of $32 \mathrm{ft} / \mathrm{sec}^{2}$ over the first 2 feet of rod travel was selected as a reference. The analysis has assumed a constant downward force is supplied by the pneumatic control system in addition to thêr control rod weight. A constant force of 500 pounds from the pneumatic cylinder has been selected as a reference value sufficiently high to meet the $32 \mathrm{ft} / \mathrm{sec}^{2}$ requirement and provide a positive hold down.

The equation of motion for the control elements and push rod is:

$$
\ddot{x}=\frac{F_{S}+W-F_{B}-F_{R}}{W / g}
$$

where:

$$
\begin{aligned}
& \mathrm{F}_{\mathrm{S}}=\text { Net downward force from pneumatic cylinder } \\
& \mathrm{W}=\text { Weight of moving assembly }
\end{aligned}
$$

* "Introduction to Nuclear Engineering" - S. Glasstone, 1951. 


$$
\begin{aligned}
& F_{B}=\text { Buoyancy force } \\
& F_{R}=\text { Viscous resistance of sodium in the annulus. } \\
& \ddot{X}=\frac{\left(1+F_{S}-F_{B}-\dot{F}_{R}\right)}{W} \mathrm{~g}
\end{aligned}
$$

Assuming control system must scram against full flow:

$$
\begin{aligned}
& \mathrm{F}_{\mathrm{R}}=\quad \begin{array}{l}
25 \mathrm{psi} \times 7 \text { in. } \\
\text { per element }=2 \text { elements }=350 \mathrm{lb} \text { when rod velocity is zero and flow rate }
\end{array} \\
& \text { pe00 } \mathrm{lb}_{\mathrm{m}} / \mathrm{h} \text { in the annulus. }
\end{aligned}
$$

Consider a rod velocity of $10 \mathrm{ft} / \mathrm{sec}$. The displaced flow is:

$$
\frac{7}{144} \mathrm{ft}^{2} \times 10 \frac{\mathrm{ft}}{\mathrm{sec}} \times 3600 \frac{\mathrm{sec}^{2}}{\mathrm{hr}} \times 52 \frac{\mathrm{lb}}{\mathrm{ft}^{3}}=9,100 \mathrm{lb}_{\mathrm{m}} / \mathrm{h}
$$

Since this is small compared to $180,000 \mathrm{lb}{ }_{m} / h$, the value of $F_{R}$ can be taken as essentially constant at 350 pounds.

The buoyance force $F_{B}$ is approximately:

$$
\begin{aligned}
& \frac{\rho_{\mathrm{Na}}}{\rho_{\mathrm{Steel}}} \times \mathrm{W}=\frac{0.03}{0.3} \times 750=75 \mathrm{lb} \\
& \text { For } \ddot{\mathrm{X}} \cong 32 \mathrm{ft} / \mathrm{sec} \\
& \mathrm{F}_{\mathrm{S}}=\mathrm{F}_{\mathrm{B}}+\mathrm{F}_{\mathrm{R}}=350+75=425 \mathrm{lb}
\end{aligned}
$$

Select 150 pounds \pm 50 pounds as net scram force required from pneumatic cylinder.

\section{'5.11 HYDRAULIC ANALYSIS UUTRING SCRAM DECELERATION}

The last 12 inches of the 36 inch travel of the control rod is used to slow the rod down so that the maximum deceleration does not cause excessive inertia loads on the offset and drive line, and the tendency for hnunrehas.k is minimized, Following evaluation of dash pot devices located (a) at the bottom of the control rod, . (b) at the top of the push rod, (c) under the offset arm, and (d) combinations of (a), (b), and (c), a dashpot at the bottom of each rod was selected. This is comprised of a tapered piston on the bottom of the reflector segment which penetrates a circular orifice in the top of a closed ended cylinder. It was considered a requirement to scram with a low pressure in the inlet plenum. Since this source of resistance was not considered to be always available, the closed end cylinder became necessary to provide sufficient resistance. At a low inlet pressure, the acceleration of the moving assembly over the first two feet is:

$$
\ddot{\mathrm{x}}=\frac{F_{\mathrm{S}}+\mathrm{W}-\mathrm{F}_{\mathrm{B}}-\mathrm{F}_{\mathrm{R}}}{\mathrm{W}} \mathrm{g} \text {. }
$$




$$
\begin{aligned}
& \text { For } F_{S}=500 \mathrm{lb} \text { and } F_{R}=\text { zero } \\
& \ddot{X}=\left[\frac{500+750-75}{750}-(\sim 0)\right] \times 32.3=50.5 \frac{\mathrm{ft}}{\mathrm{sec}^{2}}
\end{aligned}
$$

At the end of the 2 feet acceleration, the velocity is $V=\sqrt{2 a s}=\sqrt{2 \times 50.2 \times 2}=14.4$ fps.

Assuming a constant deceleration over the 1 -foot slowing length, the deceleration is:

$$
a_{d_{a v}}=\frac{v^{2}}{2 S}=\frac{14.4^{2}}{2 \times 1}=101 \mathrm{ft} / \mathrm{sec}^{2}=\underline{3.13 \mathrm{~g}} .
$$

At full flow $F_{R}=350 \mathrm{lb}$ and $F_{S}=500 \mathrm{lb}$

$$
\begin{aligned}
& X=\left[\frac{500+750-75-350}{750}\right] \times 32.2=35 \frac{\mathrm{ft}}{\mathrm{sec}^{2}} \\
& v_{\max }=\sqrt{2 \times 35 \times 2} \cong 12 \mathrm{fps} .
\end{aligned}
$$

A constant deceleration over last 1 foot gives:

$$
\mathrm{a}_{\mathrm{av}}=\frac{\mathrm{v}^{2}}{2 \mathrm{~s}}=70 \mathrm{ft} / \mathrm{sec}^{2}=1.18 \mathrm{~g}
$$

Detailed analyses were not performed using the above values. Estimates are made from analyses which were conducted using a velocity of $10 \mathrm{ft} / \mathrm{sec}$ at the end of the 2-foot acceleration phase of the stroke with a scram force of zero and 300 pounds acting on the drive line from the pneumatic cylinder. In these analyses, linear tapers were assumed and the effects of eccentricity also were included. The results of these analyses are given in Tables 5-4 and 5-5. For these cases, the peak deceleration of the moving assembly was calculated to be $3.16 \mathrm{~g}$ and $3.4 \mathrm{~g}$ for concentric and eccentric cases. These correspond to 2.0 and 2.2 times the average deceleration of $1.54 \mathrm{~g}$ for $10 \mathrm{fps}$ to approximately zero in 12 inches.

By using a shaping along the piston other than a straight taper, the peak deceleration can be brought closer to the average. This has not been pursued in detail.

The maximum design load at the offset is 1000 pounds for a 10 inch offset. During scram deceleration, this is made up of the pneumatic scram load plus the inertia load of the upper push rod.

$$
\begin{aligned}
\mathbf{F}_{\mathrm{O}} & =\mathbf{F}_{\mathrm{S}}+\mathrm{NW} \\
\mathbf{F}_{\mathrm{O}} & =\text { Force at offet } \\
\mathbf{F}_{\mathbf{S}} & =\text { Scram force }
\end{aligned}
$$


TABLE 5-4..

CONTROL ROD DECELERATION USING THE CONTROL ROD CHANNEL HYDRAULIC PISTON

\begin{tabular}{|c|c|c|c|c|c|c|c|}
\hline $\begin{array}{c}\text { Diameter } \\
\text { of Piston } \\
\text { (in.) }\end{array}$ & $\begin{array}{l}\text { Piston } \\
\text { Area } \\
\left(\text { in. }{ }^{2} \text { ) }\right. \\
\end{array}$ & $\begin{array}{l}\text { Initial Gap } \\
\text { Clearance } \\
\text { (in.) } \\
\end{array}$ & $\begin{array}{l}\text { Final Gap } \\
\text { Clearance } \\
\text { (in.) } \\
\end{array}$ & $\begin{array}{c}\text { Maximum } \\
\text { Force } \\
\text { (One Piston) } \\
\text { (lb) } \\
\end{array}$ & $\begin{array}{l}\text { Maximum } \\
\text { Force on } \\
\text { Offset } \\
\text { (Total) } \\
\text { (lb) }\end{array}$ & $\begin{array}{c}\text { Initial } \\
\text { Piston } \\
\text { Velocity } \\
\text { (ft/sec) } \\
\end{array}$ & $\begin{array}{c}\text { Final } \\
\text { Piston } \\
\text { Velocity } \\
\text { (ft/sec) } \\
\end{array}$ \\
\hline 2.0 & 3.14 & 0.050 & 0.030 & 660 & 280 & 10 & 9.8 \\
\hline 3.0 & 7.07 & 0.050 & 0.030 & $.930^{\circ}$ & 395 & 10 & 4.2 \\
\hline 2.0 & 3.14 & 0.030 & 0.030 & 520 & 220 & 10 & 8.4 \\
\hline 2.0 & 3.14 & 0.025 & 0.015 & 860 & 370 & 10 & 4.6 \\
\hline 2.5 & 4.91 & 0.020 & 0.005 & 2640 & 1130 & 10 & 0.73 \\
\hline 2.5 & 4.91 & 0.030 & 0.005 & 1280 & 550 & 10 & 0.79 \\
\hline 2.5 & 4.91 & 0.030 & 0.003 & 1310 & 560 & 10 & 0.45 \\
\hline 2.5 & 4.91 & 0.035 & 0.003 & 1200 & 510 & 10 & 0.46 \\
\hline 2.5 & 4.91 & 0.035 & 0.003 & 700 & 300 & 6 & 0.46 \\
\hline 2.5 & 4.91 & 0.035 & 0.003 & 900 & 385 & 8 & 0.46 \\
\hline 2.5 & 4.91 & 0.035 & 0.003 & 1600 & 680. & 12 & 0.46 \\
\hline
\end{tabular}

TABLE 5-5

CONTROL ROD CHANNEL HYDRAULIC CUSHION WITH ECCEN'LICITY AIND TOLERANCE EFFECTE

Maximum Hydraulic Force Maximum

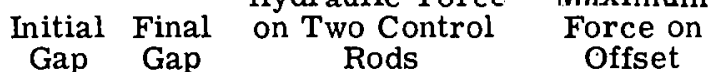
Gap Gap (in.) (in.) (lb)

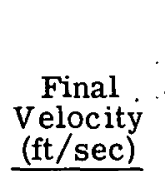

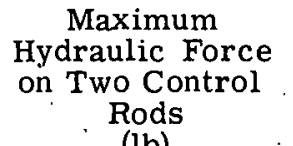

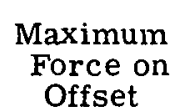
(lb)
Final Velocity (ft/sec)

\begin{tabular}{|c|c|c|c|c|c|c|c|}
\hline \multicolumn{5}{|c|}{ Concentric Case } & \multicolumn{3}{|c|}{ Eccentric Case } \\
\hline & & & & Force $=0$ & & & \\
\hline $\begin{array}{l}0.035 \\
0.035 \\
0.035\end{array}$ & $\begin{array}{l}0.003 \\
0.005 \\
0.007\end{array}$ & $\begin{array}{l}2220 \\
2140 . \\
2060\end{array}$ & $\begin{array}{l}475 \\
460 \\
440\end{array}$ & $\begin{array}{l}0.61 \\
1.08 \\
1.59\end{array}$ & $\begin{array}{l}2380 \\
2250 \\
2140\end{array}$ & $\begin{array}{l}510 \\
485 \\
460\end{array}$ & $\begin{array}{l}0.90 \\
1.73 \\
2.64\end{array}$ \\
\hline
\end{tabular}

Scram Force $=300 \mathrm{lb}$

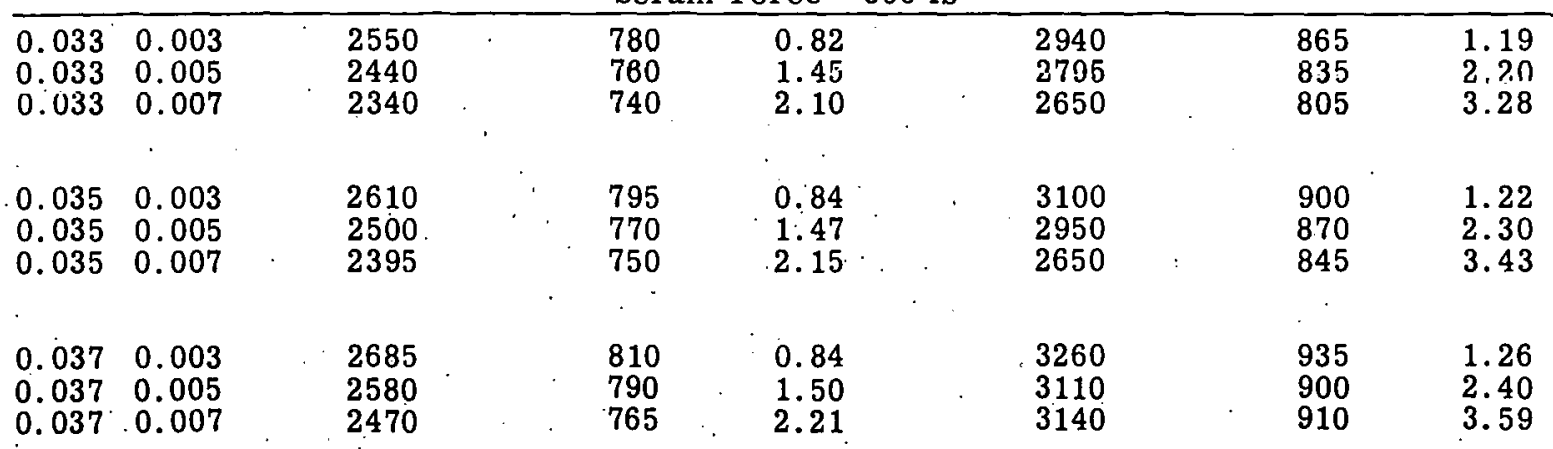




$$
\begin{aligned}
& \mathrm{N}=\text { Maximum deceleration in } \mathrm{g}^{\prime} \mathrm{s} \\
& \mathrm{W}^{1}=\text { wt of assembly above the offset } \\
& \text { For } \mathrm{F}_{\mathrm{O}}=1000 \mathrm{lb} \quad \mathrm{F}_{\mathrm{S}}=500 \mathrm{lb} \quad \mathrm{W}^{1}=150 \mathrm{lb} \quad \mathrm{N}=\frac{1000-500}{150}=3.3 \mathrm{~g} .
\end{aligned}
$$

Comparing this to the decelerations quoted above, it can be seen that the rod can be slowed from $10 \mathrm{ft} / \mathrm{sec}$ without overloading the offset. By shaping the piston it is reasonable to expect slowing from $12 \mathrm{ft} / \mathrm{sec}$ to be attained. Further consideration is required for the case where no pressure exists in the lower plenum. The exhaust orifice(s) of the pneumatic cylinder may be designed and located to reduce the net scram force after the 2 feet of acceleration travel.

It is apparent from the analyses conducted that the velocity at the end of the 12 -inch deceleration is independent of the velocity at the start of deceleration and depends entirely on the final clearance between piston and orifice.

Figure 5-13 indicates the relationship between velocity and final clearance. The minimum gap that can be provided which does not introduce problems is an item in the design for which experimental evaluation is required. It is considered unlikely that the velocity can be reduced to the point where an impact can be tolerated (see section 5.17 ) so a spring energy absorber is mounted in the adjacent channels under the off set beam to bring the rod to final rest.

Appendix D presents the formulation of the deceleration analysis. The acceptability of the above analysis depends upon an evaluation on the pneumatic cylinder showing the net force on the piston during the scram phase can be maintained reasonably constant between 400 and 500 pounds and during the deceleration phase can be decreased slightly.

\subsection{ELASTIC STABILITY OF DRIVE LINE}

The drive line is loaded as a column during scram. The column is comprised of two sections, $A B$ and $B D$, of different cross sections (see Figure 5-14), $A B$ being a 2 inch to 3 inch pipe and $B D$ being a 1-1/4 inch to $1-3 / 4$ inch solid shaft. The upper section (BD) is restrained at the gas seal (c) against lateral movement by the cylinder EC which is cantilevered down from the top head.

Assuming EC is sufficiently rigid, the column can be considered as a pin-ended strut at A and $\mathrm{C}$. To maximize the critical buckling load, the small diameter section BC should be as short as possible, i.e., the stroke length of the drive plus clearance. For calculational purposes this is taken as 50 inches. It may be as short as 40 inches in the actual design. The seal $\mathrm{C}$ must be above the normal sodium level which is about 70 inches below the top of the head. EC has been selected as 50 inches.

The vapor seal located at $C$ in this evaluation can be moved down about 50 inches by redesign resulting in $A B$ being shorter and $C D$ being longer by this amount. Since additional supports will also be provided for section $C D$, the overall buckling resistance will be increased if the same sizes (cross sectional) are maintained. Re-evaluation of this change will permit a reduction in size and weight of section $A B$. 


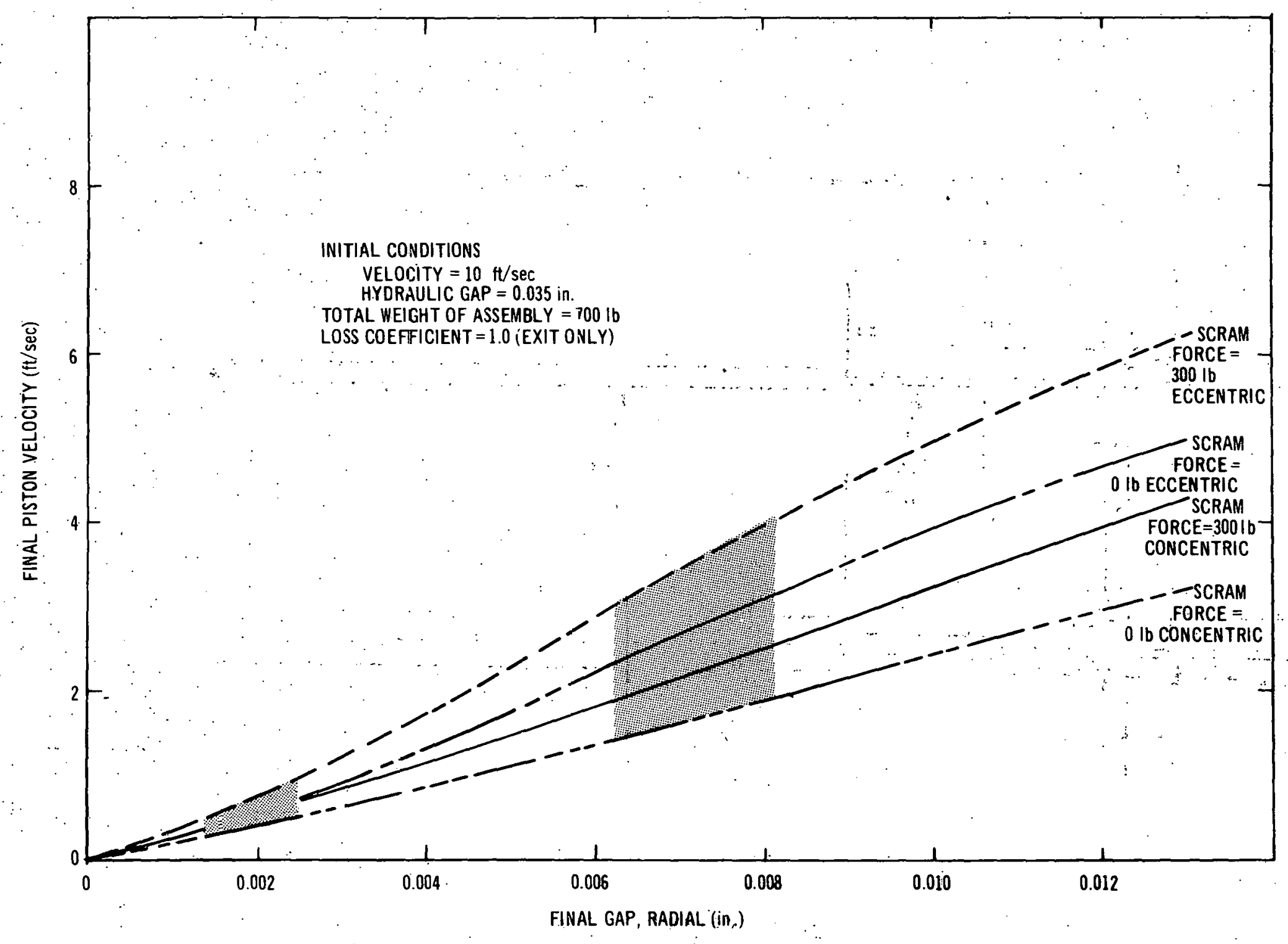

变

FIGURE 5-13. IFINAL CONTROL RID VELOCITY AT THE END OF CUSHIONING STROKE AS A FUNCTION OF FINAL RADIAL. GAP OF HYDRAULIC CUSHIONS. 
GEAP-5722

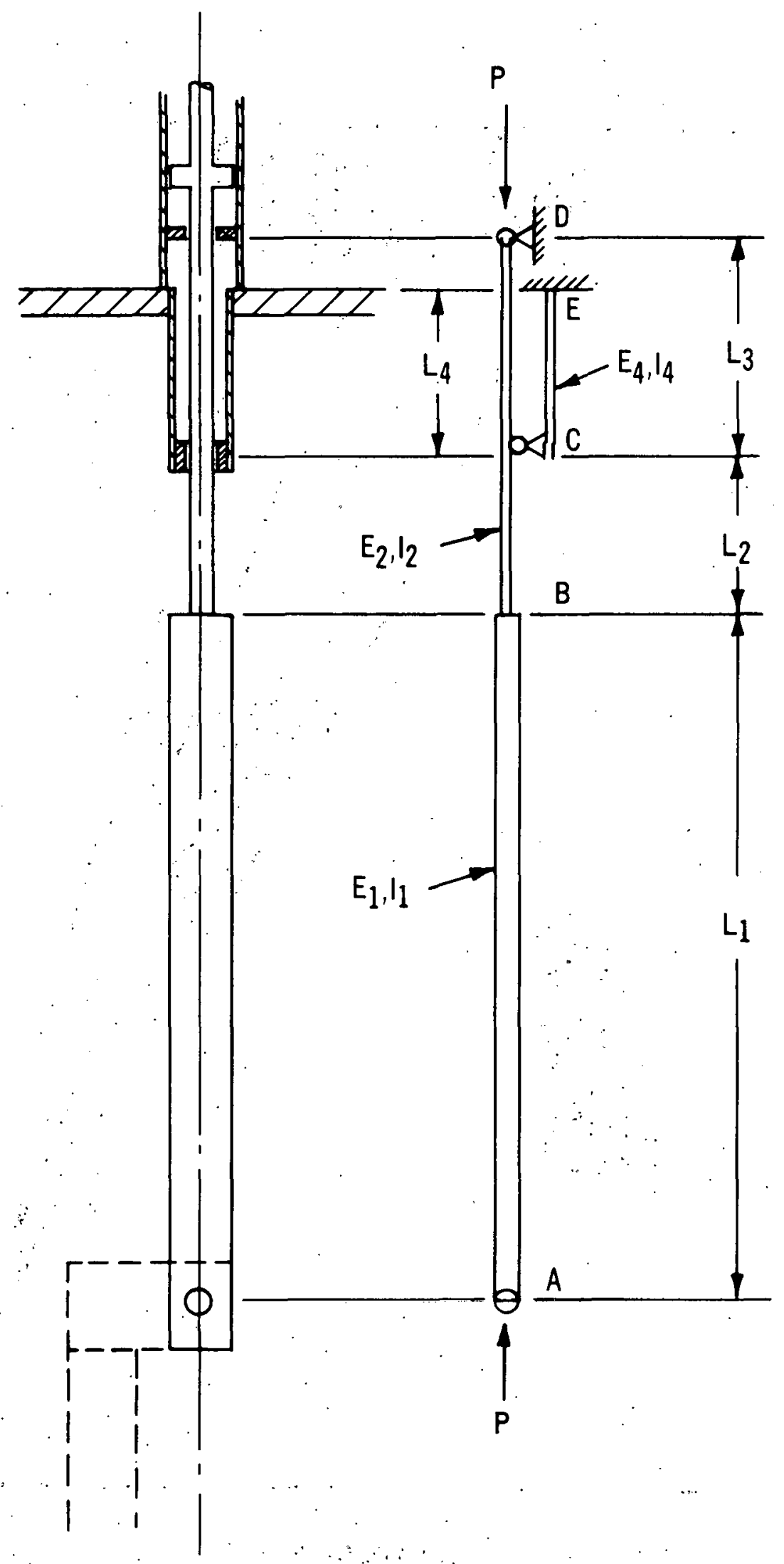

FIGURE 5-14. DRIVE LINE MODEL USED FOR STABILITY ANALYSIS

- . $5-40$ 
The critical buckling load was computed using the conventional Rayleighs Method. A deflection shape was assumed and the critical load found when the change in external work done by the load for a small increment in deflection exceeded the change in internal strain energy for the deflection increment.

$$
\text { Assuming a sinusoidal deflection shape, i.e., } y=\bar{y} \sin \frac{\pi x}{L}
$$

where,

$$
\begin{aligned}
& \bar{y} \quad=\quad \text { maximum deflection } \\
& \mathrm{x}=\text { distance frum one end } \\
& \mathrm{L}=\text { length of the strut }
\end{aligned}
$$

resulted in the following expression for critical load:

$$
P_{c r}=\frac{\pi^{2} E I_{1}}{L^{2}} \frac{1}{\frac{L_{1}}{L}+\frac{L_{2} I_{1}}{L I_{2}}+\frac{1}{2 \pi} \frac{I_{1}-I_{2}}{I_{2}} \sin \frac{2 \pi L_{1}}{L}} .
$$

Table 5-6 shows the critical load for various size rods for $A B$ and $B C$ with $L_{1}=150$ inches and

\begin{tabular}{|c|c|c|c|c|}
\hline Section 1 & Section 2 & $\mathrm{I}_{1}$ & $\mathrm{I}_{2}$ & $P_{\mathrm{cr}}$ \\
\hline $\begin{array}{l}2.25 \text { in. } 0 . d .-1.75 \text { in, } i_{\text {i. }} d \text {, } \\
.\end{array}$ & $\begin{array}{l}1.25 \text { in. diam. } \\
1.5 \text { in. } \\
1.75 \text { in. }\end{array}$ & $\begin{array}{l}0.8 \\
0.8 \\
0.8\end{array}$ & $\begin{array}{l}0.12 \\
0.25 \\
0.46\end{array}$ & $\begin{array}{l}2,140 \\
3,740 \\
6,900\end{array}$ \\
\hline 3.0 in. 0. d. -2.5 in. i. d. & $\begin{array}{l}1.25 \text { in. } \\
1.5 \text { in. } \\
1.75 \text { in. }\end{array}$ & $\begin{array}{l}2.05 \\
2.05 \\
2.05\end{array}$ & $\begin{array}{l}0.12 \\
0.25 \\
0.46\end{array}$ & $\begin{array}{l}2,400 \\
4,600 \\
7,580\end{array}$ \\
\hline $\begin{array}{c}3.0 \text { in. } 0 . \text { d. }-2.0 \text { in. i. d. } \\
\ddots\end{array}$ & $\begin{array}{l}1.25 \mathrm{in} . \\
1.5 \mathrm{in.} \\
1.75 \mathrm{in.}\end{array}$ & $\begin{array}{l}3.2 \\
3.2 \\
3.2\end{array}$ & $\begin{array}{l}0.12 \\
0.25 \\
0.46\end{array}$ & $\begin{array}{r}3,100 \\
6,100 \\
10,300\end{array}$ \\
\hline
\end{tabular}
$\mathrm{L}_{2}=50$ inches. $\mathrm{E}$ is assumed constant at $20 \times 10^{6}$ psi.

TABLE 5-6

CRITICAL LOAD AS A FUNCTION OF ASSUMED DRIVE GEOMETRY

(Nomenclature defined in Figure 5-14)

The above procedure was repeated for $y .=\bar{y} \sin \frac{\pi x}{2 L_{1}} 0<x<L_{1}$ and $y=\bar{y} \cos \pi \frac{\left(x-L_{1}\right)}{L_{2}}$ for $\mathrm{X}>\mathrm{L}_{1}$ with results within $10 \%$ of those tabulated.

Since Rayleigh's Method, which is approximate, under-predicts buckling loads, the above values are conservative. 
As discussed below, the design scram load will be in the 300 to 700 pound range. A 3-inch o.d. to 2.5-inch i.d. pipe for Section $A B$ and 1.5-inch diameter shaft for $B C$ will result in a margin of safety in the 7 to 10 range. This has been tentatively selected as a balance between drive line weight and drive line stiffness.

\subsection{RIGIDITY REQUIREMENT ON SEAL SUPPORT TUBE EC}

Give the point $C$ in Figure 5-14 an arbitrary lateral deflection $\delta$.

Let the reaction of $\mathrm{C}$ of the cantilever $\mathrm{EC}$ on the strut be $\mathrm{H}_{1}$,

From equilibrium of the strut $H=\frac{P \delta}{L}$,

For adequate restraint at $\mathrm{C}, \mathrm{H}_{1}$ must be $>\mathrm{H}$ or deflection of $\mathrm{C}$ relative to $\mathrm{E}$ due to $\mathrm{H}$ must be less than $\frac{\mathrm{HL}_{1}}{\mathrm{P}}$,

For the cantilever EC:

$\delta_{c}=\frac{\mathrm{H} \mathrm{L}_{2}^{3}}{3 \mathrm{EI}}<\frac{\mathrm{HL}_{1}}{\mathrm{P}}$ or $\quad \mathrm{I}>\frac{\mathrm{P} \mathrm{L}_{2}^{3}}{3 \mathrm{EI}_{1}}$

For: $\mathbf{P} \sim 5000 \mathrm{lb}$ (critical load for strut)

L $\sim 200$ inches

$\mathrm{L}_{2} \sim 50$ inches

E. $\sim 25 \times 10^{6} \mathrm{psi}$

I required $=\frac{5000 \times 50^{3}}{3 \times 25 \times 10^{6} \times 200}=0.04 \mathrm{in}^{4}$

Current reference for EC is a cylinder 3 in. o.d., 2.5-in. i.d.

$I=2.06$.

For initially straight rod, I is ample.

\subsection{STABILITY OF DRIVE LINE UNDER AXIAL LOAD PLUS INERTIA LOADS}

Formulae for Stress and Strain, by R.J. Roark, gives the required relationship on this subject following the schematic shown in Figure 5-15:

$\mathbf{p}^{\prime}+0.5 p^{\prime} L=\frac{\pi^{2} E I}{L^{2}}$ 


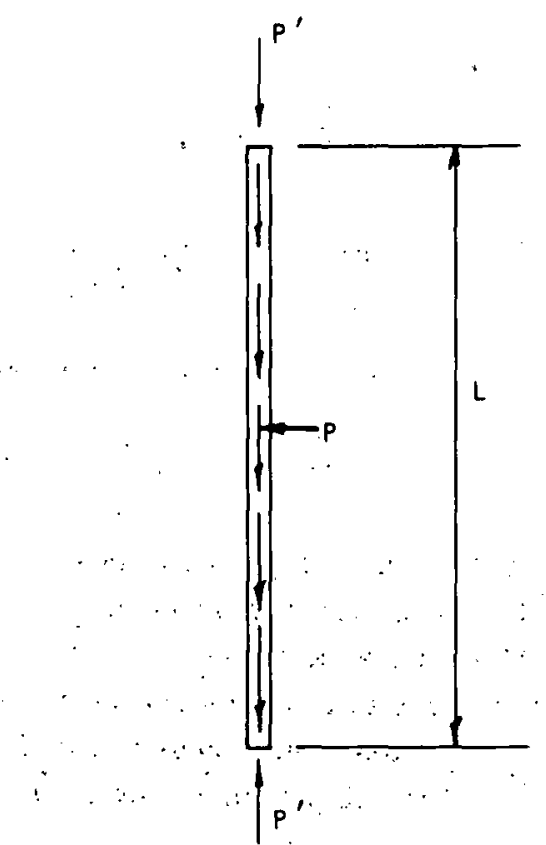

FIGURE 5-15. AXIAL LOAD FORCE MODEL

Under deceleration $\mathrm{Ng}$ :

$\mathrm{pL}=\mathrm{WN}$

$P^{\prime}+0.5 W N^{\prime}=\left(\frac{\pi^{2} E I}{L^{2}}\right)$

For: 3-in. o.d., 2-1/2-inch i. d., for Section. 1

\section{5-inch diam for Section 2}

$$
\rightarrow \frac{\pi^{2} \mathrm{EI}}{\mathrm{L}^{2}}=4600
$$

Area of 3 -inch o.d. section $=\pi \cdot\left(1.5^{2}-1.25^{2}\right)=2.16$ in. $^{2}$

$$
\mathrm{w}=2.16 \times 0.3=0.65 \mathrm{lb} / \mathrm{in} \text {. }
$$

$150 \mathrm{in.} \rightarrow 150 \times 0.65=\dot{9} 7.5 \mathrm{lbs}$.

1,5 in. diam area $=1.76$ in. $2 \times 0.3=0.53 \mathrm{lb} /$ in.

50 in. $\times 0.53=26.5 \mathrm{lbs}$.

Total $=97.5+26.5=124 \mathrm{lbs}$.

Use 200 poun ds to include shaft and piston above top support point.

$\mathbf{P}=\mathrm{F}_{\mathrm{S}}+0.5 \mathrm{WN}$

$=\mathbf{F}_{\mathbf{S}}+100 \mathrm{~N}^{\prime}$ 
For: $F_{S}=300$

$P=300+100 \mathrm{~N}^{\prime}$

Using a safety factor of 5 for instability

$P=\frac{4600}{5}=920,300+100 \mathrm{~N}^{\prime}=920, \mathrm{~N}^{\prime}=\frac{920-300}{100} \cong \underline{6 \mathrm{~g}}$.

Maximum deceleration of drive should be limited to $6 \mathrm{~g}$ from stability considerations.

\subsection{ALLOWABLE LOAD AT OFFSET FROM STRESS AND DEFLECTION LIMITATIONS}

This analysis was made to determine the optimum location of bearing pads on the control rod and the beam stiffness and clearance required between rod and channel. The allowable bending moment on the drive at the offset, because of pneumatic scram actuation forces in the mechanism and inertia loads during deceleration, establishes the maximum offset that can be accepted. The following analysis indicates from stress and deflection considerations that 5000 in. $-1 b$ per control rod or 10,000 in. $-1 b$ per assembly of two rods is both practical and feasible.

Three locations of F (Figure 5-16: AF at 45 in., 60 in., and 75 in.) were considered along with 3 degrees of taper of FA (2.76-inch diameter with F at 2.76 in., 2.26 in., and 1.76 in. diameter at $\mathrm{A}$ ). Two wall thicknesses, 0.1 inch and 0.2 inch, for the wrapper around the poison pins were considered.

Table 5-7 shows the allowable offset moment at the top of one control rod based upon limiting the deflection to the available clearance. In the poison carriage region $\mathrm{JG}$, an allowance for tolerance and thermal bow of 0.116 inch was taken off the nominal gap, and at the top, point A, 0.050 inch allowance for tolerance and alignment was used.

Table 5-8 shows the allowable bending moment for various control rod configurations as a function of section modulus.

In addition to the above clearance limitations, the allowable moment from stress limits was considered. The allowable moment from stress considerations is shown in Table 5-9 for various rod configurations.

An allowable bending stress of $5000 \mathrm{psi}$ was selected as a conservative value to permit accommodation of stress risers and thermal stresses which have been neglected. The yield strength of 304 stainless steel at $1200^{\circ} \mathrm{F}$ is $15,000 \mathrm{psi}$, and Incoloy is $20,000 \mathrm{psi}$.

\subsection{ALLOWABLE IMPACT VELOCITY OF CONTROL ROD}

From the evaluation of the hydraulic damper (section 5.11), it is seen that the clearance limitations on the damper result in a minimum velocity in the range of 2 to $4 \mathrm{ft} / \mathrm{sec}$. To bring the rod to final rest without a sudden impact which would result in damaging dynamic loads, a spring 


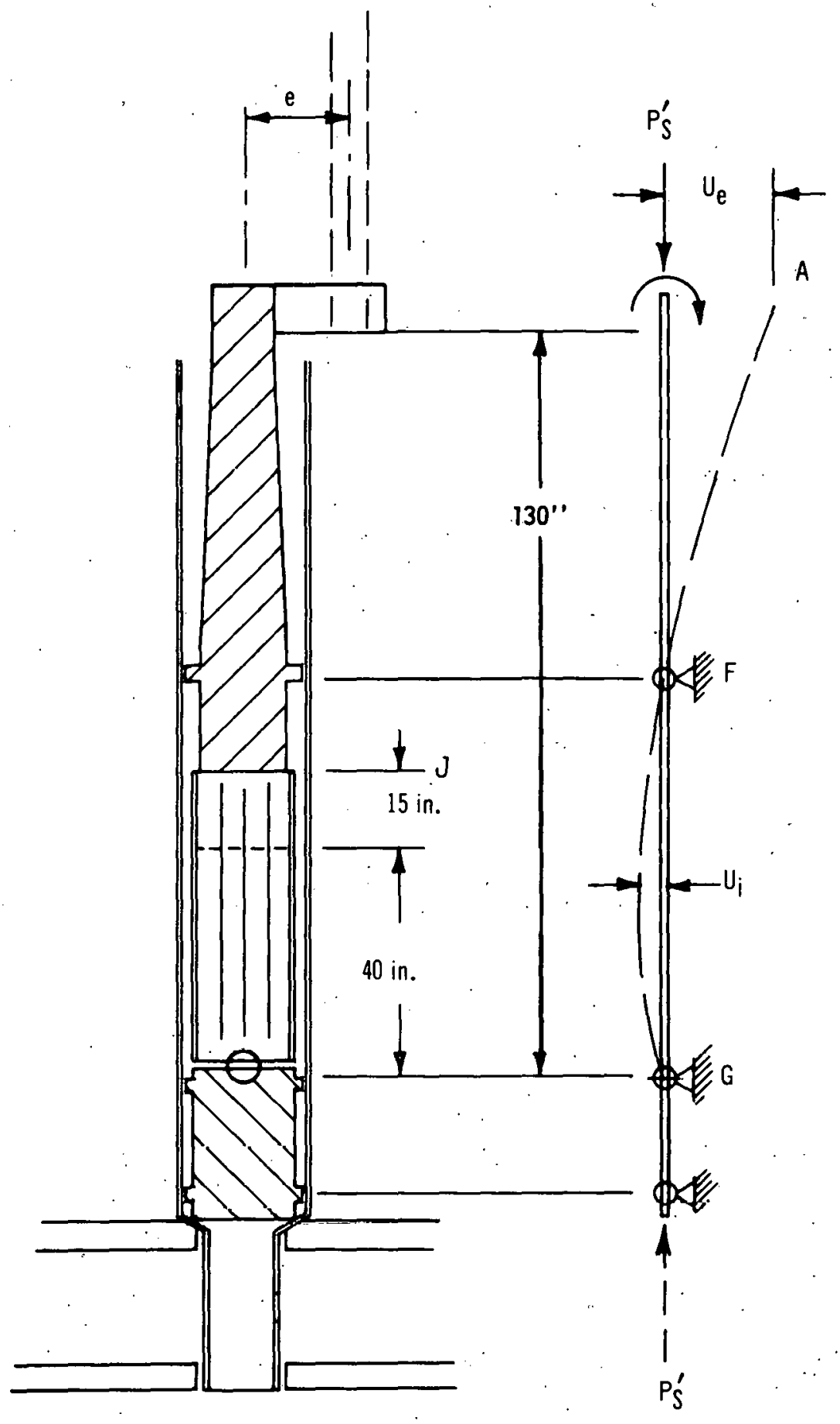

FIGURE 5-16. CONTROL ELEMENT FLEXURE 
TABLE 5-7

ALLOWABLE MOMENT FROM DEFLECTION - CLEARANCE COMPATIBILITY

\begin{tabular}{|c|c|c|c|c|c|c|c|c|c|c|c|c|c|}
\hline FJ & ${ }^{t}$ Carr & Gapj $_{\mathrm{JG}}$ & $\delta_{\text {flex JG }}^{*}$ & $\begin{array}{r}M_{\text {Allowable }}^{* *} \\
\text { (in. -lb.) }\end{array}$ & & $\underline{\mathrm{AF}}$ & Diameter $_{\mathrm{F}}$ & Diameter $_{A}$ & & Clearance $_{A}$ & & $\delta_{\text {Allowable A }}^{* * *}$ & $\begin{array}{c}\mathrm{M}_{\text {Allowable FA }}^{* *} \text { (in. -lb.) } \\
\end{array}$ \\
\hline 0 & 0.1 & 0.15 & 0.034 & 3550 & & 75 & 2.76 & 2.76 & & 0.2 & & 0.15 & 1300 \\
\hline 0 & 0.2 & 0.15 & 0.034 & 6300 & & 75 & 2.76 & 2.76 & & 0.2 & & 0.15 & $\overline{1800}$ \\
\hline$\therefore 0$ & 0.1 & 0.15 & 0.034 & 3550 & & 75 & 2.76 & 2.26 & & 0.45 & & 0.40 & $\overline{2670}$ \\
\hline 0 & 0.2 & 0.15 & 0.034 & 6300 & & 75 & 2.76 & 2.26 & $\cdot$ & 0.45 & & 0.4 & $\overline{3250}$ \\
\hline 0 & 0.1 & 0.15 & 0.034 & 3550 & - & $75:$ & .2 .76 & 1.76 & $\because$ & 0.7 & & 0.65 & $\overline{2800}$ \\
\hline 0 & 0.2 & 0.15 & 0.034 & 6300 & : & 75 & 2.76 & 1.76 & & 0.7 & & 0.65 & 3180 \\
\hline 15 & 0.1 & 0.15 & 0.034 & 2520 & & 60 & 2.76 & 2.76 & & 0.2 & & 0.15 & 1920 \\
\hline 15 & 0.2 & 0.15 & 0.034 & 4250 & & 60 . & 2.76 & 2.76 & & 0.2 & & 0.15 & $\overline{2340}$ \\
\hline 15 & 0.1 & 0.15 & 0.034 & 2520 & & 60 & 2.76 & 2.26 & & 0.45 & & 0.4 & $\overline{3900}$ \\
\hline 15 & 0.2 & 0.15 & 0.034 & $\overline{4250}$ & & 60 & 2.76 & 2.26 & & 0.45 & & 0.4 & 4650 \\
\hline 15 & 0.1 & 0.15 & 0.034 & $\overline{2520}$ & & 60 & 2.76 & 1.26 & & 0.7 & & 0.65 & 4250 \\
\hline 15 & 0.2 & 0.15 & 0.034 & $\overline{4250}$ & & 60 & 2.76 & 1.26 & & 0.7 & & 0.65 & 4670 \\
\hline 30 & 0.1 & 0.15 & 0.034 & 2020 & & 45 & 2.76 & 2.76 & & 0.2 & & 0.15 & 2580 \\
\hline 30 & 0.2 & 0.15 & 0.034 & 3100 & & 45 & 2.76 & 2.76 & & 0.2 & & 0.15 & 3560 \\
\hline 30 & 0.1 & 0.15 & 0.034 & $\overline{2020}$ & . & 45 & 2.76 & 2.26 & & 0.45 & & 0.40 & 6350 \\
\hline 30 & 0.2 & 0.15 & 0.034 & 3100 & & 45 & 2.76 & 2.26 & & 0.45 & & 0.40 & 7000 \\
\hline 30 & 0.1 & 0.15 & 0.034 & 2020 & & 45 & 2.76 & 1.76 & & 0.7 & & 0.65 & $7000^{\circ}$ \\
\hline 30 & 0.2 & 0.15 & 0.034 & $\overline{3100}$ & & 45 & 2.76 & 1.76 & . & .0 .7 & 2 & 0.65 & 7580 \\
\hline 15 & 0.1 & 0.2 & 0.084 & $\overline{6200}$ & & & & & & & & & \\
\hline 15 & 0.2 & 0.2 & 0.084 & 10500 & & & & & & & & $"$ & \\
\hline 30 & 0.1 & 0.2 & 0.084 & 5000 & & & & & & & & & \\
\hline 30 & 0.2 & 0.2 & 0.084 & 7700 & & & & & & & & & \\
\hline 30 & 0.1 & 0.25 & 0.134 & 10000 & & & & & & & & & \\
\hline
\end{tabular}

* Gap-0.116 in. (tolerance + thermal bow $=0.070+0.046=0.116$ in.)

*** Use clearance ${ }_{A}=0.050$ in. 
cushion is provided. This is located under the offset beam near the center of gravity of the moving assembly to avoid large moments on the offset. This location is also attractive since space is available in the reflector positions outboard of the control positions.

The analytical method to determine the spring characteristics and travel requirements is to equate the kinetic and potential energy of the moving assembly at impact to the potential energy and spring strain energy at the maximum deflection position (zero velocity condition). The assembly weight and scram force were taken as 750 pounds and 300 pounds, respectively. The restraint on the system is that the maximum deceleration does not cause excessive inertia loads on the drive line. Stability. of the push rod is considered the limiting item and paragraph 5.14 shows that $6 \mathrm{~g}$ is a conservative maximum deceleration that can be tolerated.

TABLE 5-8

SECTION MODULUS AND ALLOWABLE BENDING MOMENT FOR VARIOUS CONTROL ROD CONFIGURATIONS

Configuration

2.76 in. diam shaft

2.26 in. diam shaft

1.76 in. diam shaft

Hexagonal carriage $\mathrm{H}=2.76$ in., $t=0.1$ in.

Hexagonal carriage $\mathrm{H}=2.76$ in., $t=0.2$ in.
$\underline{I / C} \quad M($ in. - lb. $)$

$2.06 \quad 10,000$

$1.135,700$

$0.535 \quad 2,700$

$0.72 \quad 3,600$

1.28 . 6,400

TABLE 5-9

\section{ALLOWABLE MOMEN'T FROM STRESS LIMITS}

\begin{tabular}{|c|c|c|c|}
\hline $\begin{array}{l}\text { FJ } \\
\text { (inches) }\end{array}$ & $\begin{array}{c}\mathrm{T}_{\text {Carr }} \\
\text { (inches) }\end{array}$ & $\begin{array}{l}\mathrm{M}_{\mathrm{J}} \text { allowable } \\
\text { (in.-lb.) }\end{array}$ & $\begin{array}{c}\mathrm{M}_{\text {allowable }}\left(={ }^{\mathrm{M}} \mathrm{A}_{\text {allowable }}\right) \\
\text { (in.-lb.) }\end{array}$ \\
\hline 0 & $\begin{array}{l}0.1 \\
0.2\end{array}$ & $\begin{array}{r}3600 \\
6400\end{array}$ & $\begin{array}{l}3600 \\
6400\end{array}$ \\
\hline 15 & $\begin{array}{l}0.1 \\
0.2\end{array}$ & $\begin{array}{l}3600 \\
6400\end{array}$ & $\begin{array}{l}4650 \\
.8250\end{array}$ \\
\hline 30 & $\begin{array}{l}0.1 \\
0.2\end{array}$ & $\begin{array}{l}3600 \\
6400\end{array}$ & $\begin{array}{l}5550 \\
9900\end{array}$ \\
\hline
\end{tabular}

The following reference configuration is selected:

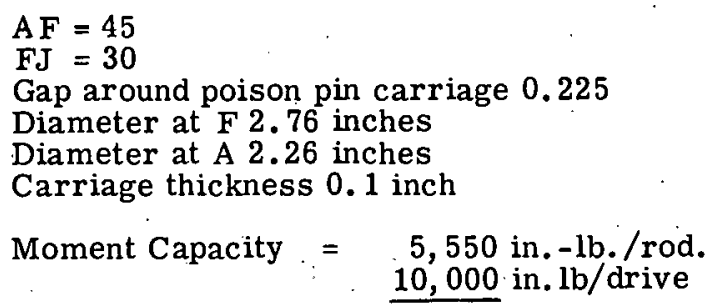




\subsubsection{Analysis for Allowable Impact}

Equating kinetic plus potential energy at impact to potential plus spring energy at the bottom of the spring stroke gives:

$$
\frac{1}{2} \frac{\mathrm{W}}{\mathrm{g}} \mathrm{v}^{2}+\mathrm{F}_{\mathrm{S}} \mathrm{S}+\mathrm{WS}=\frac{1}{2} \mathrm{KS}^{2}
$$

where,

$$
\begin{aligned}
& \mathrm{W}=\text { wt of moving assembly (lb) } \\
& \mathrm{V}=\text { Velocity of impact (in./sec) } \\
& \mathrm{F}_{\mathrm{S}}=\text { Scram force (lb) } \\
& \mathrm{S}=\text { Maximum compression of spring (in.) } \\
& \mathrm{K}=\quad \text { Spring constant (lb/in.) }
\end{aligned}
$$

Rewriting:

$$
\mathrm{s}^{2}-2 \frac{\left(\mathrm{F}_{\mathrm{S}}+\mathrm{W}\right)}{\mathrm{K}}-\frac{\mathrm{Wv}^{2}}{\mathrm{Kg}}=0
$$

The maximum deceleration occurs at the end of travel and from Newton's Law is:

$$
\frac{d^{2} S}{d t^{2}}=-\frac{\left(F_{K}-F_{S}-W\right)}{W / g}=-\left[\frac{K_{g S}}{W}-\frac{\left(F_{S}+W\right)}{W} g\right] \text {. }
$$

From these two equations, Figure 5-17 is generated relating allowable deceleration, spring constant, and maximum travel for a system with $W=750$ pounds and $F_{S}=300$ pounds.

\subsubsection{Height of Control Rod Rebound}

Assuming a perfectly elastic spring, the height of rebound is $\frac{\mathrm{v}^{2}}{2 \mathrm{~g}}$.

For no down force on top of control drive line,

$$
\begin{aligned}
\mathrm{h}=\frac{\mathrm{v}^{2}}{2 \mathrm{~g}} & =1.7 \text { in. for } \mathrm{V}=3 \mathrm{ft} / \mathrm{sec} \\
& =3 \text { in. for } \mathrm{V}=4 \mathrm{ft} / \mathrm{sec}
\end{aligned}
$$

These are sufficiently small that reactor safety is not compromised.

\subsection{ANALYSIS OF PNEUMATIC CYLINDER DURING SCRAM}

The function of the pneumatic cylinder in the control drive mechanism is to move the control rods up and down by pneumatic forces on the piston which is attached to the drive line. Shim control is effected by having a pressure on the underside of the piston which reacts the weight of the 


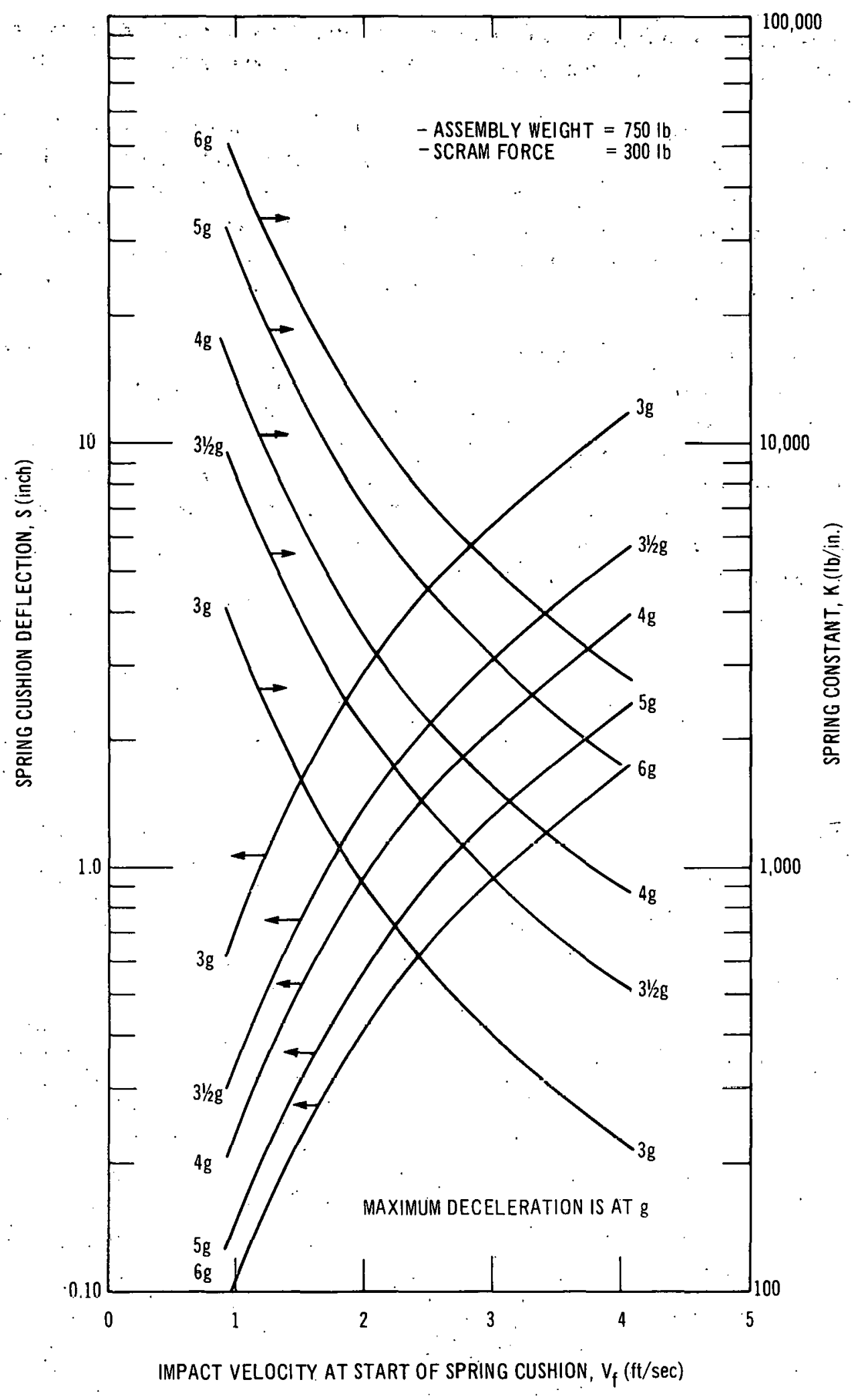

FIGURE 5-17. SPRING CUSHION CHARACTERISTICS 
moving assembly and holds it against an adjustable stop. Scram is effected by connecting the upper end of the cylinder to a high pressure gas source and venting the volume below the piston.

For shim operation, the force on the underside of the piston must be greater than the buoyant weight of the rod plus an allowable for friction. It is assumed that shim control is required at low primary sodium flow, i.e., the lift due to pressure drop across the control section is neglected in setting the pressure on the lower side of the piston. Since the fressure on top of the piston is 0 psig during shim, pressure on underside of piston of 100 psig actir.g on $3.4 \mathrm{sq}$. in. gives a force of 840 pounds to counteract 675 pouids of buoyant weight plus frictional resistance.

During scram, a net pneumatic force on the piston of 400 to 500 pounds downwards is required during the first two feet of tzavel. It is desirable to reduce this during the last one foot of travel so that the forces on the cffset are decreased. Thə force on the piston and the velocity response of the piston are controlled ty pressure of gas source conrected to top of piston, resistance of line between gas source and upper cylinder, and resistance of vent line connected to lower end of cylinder. The mathematical formulation of the problem is presented in Appendix $E$. This has been set up for computer solution using the DYNASAR code, but had not been debugged at the termination of the Backup Design effort. 
SECTION VI

\section{DRIVER FUEL INSTRUMENTATION FACILITIES}

\section{1 GENERAL.DESCRIPTION}

Instrumentation to each fuel position is required for continuous surveillance of reactor operating conditions. Protection of the core integrity, and prevention or detection of unsafe operation or malfunction is considered the overriding objective of the core instrumentation. Another important objective is to be able to determine the characteristics of the reactor under operating conditions so test conditions may he more accurately assessed. These objectives are met by supplying each fuel position with an instrument package to continuously monitor flow and temperature at the channel outlet and to detect fuel failures. Reactor operation is dependent on the sensor output and it is essential that they be designed for reliability and ease of maintenance.

The instrumentation for the driver fuel assemblies is designed to be an integral part of the refueling plug. The instrumentation is built in modules that can be attached and removed from the instrument structure. The feature allows for the convenient replacement of defective instrumentation.

The modules are intended to be fabricated and tested to ensure they are working properly before being brought into the refueling cell. The structure of the modules provides protection to the sensors and leads during its assembly to the refueling plug.

The modules consist of a connector, head penetration, instrument lead support, and sensor package. The main lead support tube extends through the head to a few feet above fuel element handles. At this elevation, a series of small tubes fan out to the various core positions. The instrumentation to positions beneath the closed loop piping must be moved before the refueling plug can be raised. The modules with instrumentation to these positions are designed to allow the required movement with minimum handling problems.

Sample lines are included in the refueling plug structure. These lines extend from the fuel element handles to a foot or so into the refueling plug and terminate around the periphery. These sample lines are not mechanically connected at either end and add no complications to the plug handling. Reactor pressure drives the sodium with sufficient force to jump the gap to the corresponding line in the annular plug.

Repair work or modifications to the refueling plug and instrumentation is done with the plug in the refueling cell storage position. This area will be accessible for both remote and manual operations. It may prove desirable to have two refueling plugs to minimize shutdown time. Maintenance or repair work to the plug not in use would be done at the convenience of the operating personnel during the next operating cycle.

\section{1. 1 Instrumentation}

Protection of the core integrity and prevention or detection of unsafe operation or malfunction is considered the overriding objective of the driver fuel instrumentation. Nearly all of 
the instrumentation considered for the driver fuel can be construed to contribute to this objective, some more effectively than others. There are other objectives which must be considered, such as determining the characteristics of the reactor under operating conditions so that test conditions can be more accurately assessed, but these functions can, in general, be served by the types of instrumentation used for reactor safety.

Protection of the core integrity is defined as preventing a fuel meltdown in one fuel assembly from propagating to an adjacent assembly. A conservative approach to meet this requirement is to prevent sodium boiling and be able to shut the reactor down before the sodium boils in the event there is a loss of coolant flow. Generally it will be sufficient to measure the temperature at the outlet of a fuel element to sense an over temperature and then shut down the reactor before the sodium boils. It is questionable that for a sudden flow loss of $70 \%$ or more that the outlet thermocouples will see the.increased temperature in sufficient time to prevent boiling. A fast responding flow meter would be required to detect the loss of flow and shut the reactor down for this case.

During a startup it is desirable to monitor both flow and temperature to detect abnormal conditions. At this time any mishap that occurred during the shutdown would most likely be detected.

\subsubsection{Driver Fuel Instrumentation Package}

Instrumentation sensors to be included in each channel are:

- Temperature (required)

- Flow (required)

- Acoustic (optional)

\subsection{TEMPERATURE ME ASUREMENT}

It is anticipated that the temperature sensors will be commercially available thermocouples. The system response is expected to have a system response time $\leq 0.7$ second. Attachment methods will be investigated to achieve the desired accuracy and response time.

The choice of four thermocouples per instrument package is based on the results of the availability study, given below. A majority logic integrated circuit will be connected to three of the four couples in each channel for scram purposes, the fourth being utilized as a redundant spare. : The study considers only thermocouples since sufficient information is not available on other type sensors. The study is based on assumptions applicable at the time and should be reviewed to determine if they are still applicable with the current design. The assumption of 300 hours to replace a thermocouple appears excessive with the current instrument replacement scheme, although it would be very difficult to estimate a time for this operation.

A general discussion of thermocouple characteristics is given in Appendix $\mathbf{F}$. 


\subsection{AVAILABILITY-DRIVER FUEL INSTRUMENTATION}

Eight schemes for core temperature sensing have been conceived, ranging from a scheme with no redundancy whatever to an elaborate scheme using four thermocouples per channel and extensive failure-detecting circuitry. The unavailability of each scheme has been predicted, and on this basis the arrangement called "Scheme $D$ " is recommended. In brief, this scheme uses four thermocouples per channel, with three of them actively connected and one as a spare. One thermocouple from each channel is connected to each of three "or" circuits, and then the three "or"s are connected to two-out-of-three majority logic to provide the scram signal.

\subsubsection{Assumptions}

Results of this study should be viewed in light of the assumptions used. They are listed below.

1. It is necessary to instrument each driver fuel channel. A thermocouple in one channel is not used to sense overheating in an adjacent channel.

2. Integrated electronic circuits will be used throughout. All electronics will be located in a nonradioactive environment, with suitable air conditioning and access for repair.

3. The failure rate of an integrated-circuit chip is assumed to be 0.3 per million hours, based upon experience with semi-conductor devices in "benign", environments.

4. The failure rate of thermocouple joints is 0.1 per million hours, and the failure rate of thermocouple leads is also 0.1 per million hours. This is based upon sodium-cooled reactor history, adjusted for design inıprovements.

5. Fuel channel meltdowns occur at the rate of 0.002 meltdowns per channel per year (reactor experience).

6. Mean repair times, including time to diagnose failure and to restart the reactor, are as follows:

False scram -8 hours

Replace thermocouple- 300 hnurs

Repair after channel meltdown -4 months longer than repair of plugging.

7. At intervals of 1 year, all thermocouples and electronics will be rigorously tested, and any failures not detected during operation will be repaired.

8. All electronic circuits have two equally likely failure modes: false output (leading to false scram), and malfunction (inability to scram when requested).

9. All thermocouple and lead failures result in an abnormally high or low output that can be sensed as a failure. 


\subsubsection{Schemes for Core Temperature Sensing}

Schematic representations of the eight basic schemes, A through $F$, are shown generally and respectively. in Figures $6-1$ through 6-7.

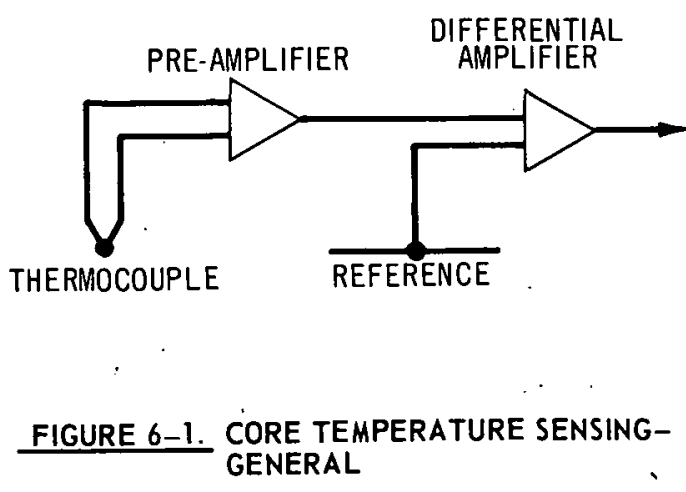

\subsubsection{Scheme A}

Each channel is provided with one thermocouple. As with all schemes each thermocouple output is fed to a temperature-stabilized preamplifier and thence to a differential amplifier, which compares the thermocouple output to a reference temperature limit (see Figure 6-8). Whenever any thermocouple output exceeds the temperature limit, its differential amplifier changes to the alarm state.

Assuming 120 channels to be instrumented, there will be 120 amplifier outputs. These are connected to a 120-input "or" circuit, which outputs a scram signal whenever any one of its inputs is in the alarm state. As an optional feature, the preamplifier or differential amplifier outputs may be connected to individual recorders.

Scheme A is the simplest way to instrument every channel, and thus it is the cheapest from the standpoint of capital cost. However, it incorporates no redundancy, and it is susceptible to both false-output failures and malfunctions.

\subsubsection{Scheme B}

In this scheme, each channel is provided with three thermocouples. Each thermocouple output is fed through a temperature-stabilized preamplifier, and then compared with a reference in a differential amplifier. For each channel, the three amplifier outputs are connected to a two-outof-three majority gate (see diagram for Scheme B, Figure 6-3).

For 120 channels, there will thus be 120 majority gates. The outputs of these majority gates are shown connected to a 120 -input "or" circuit, which provides a scram signal whenever any one of the 120 majority gates indicates an alarm.

Scheme B is the most straightforward extension of Scheme A. This protects against failures in thermocouples or in thermocouple amplifiers. It does not, however; protect against failures in the 120 majority gates or in the 120-input "or". A second problem is that one thermocouple or amplifier failure in each channel will go undetected until the yearly inspection.

\subsubsection{Scheme C}

The scheme is a rearrangement of the electronic logic of Scheme B. As with B, each channel is provided with three thermocouples and associated amplifiers. "There are three 120-input "or" 
GEAP-5722

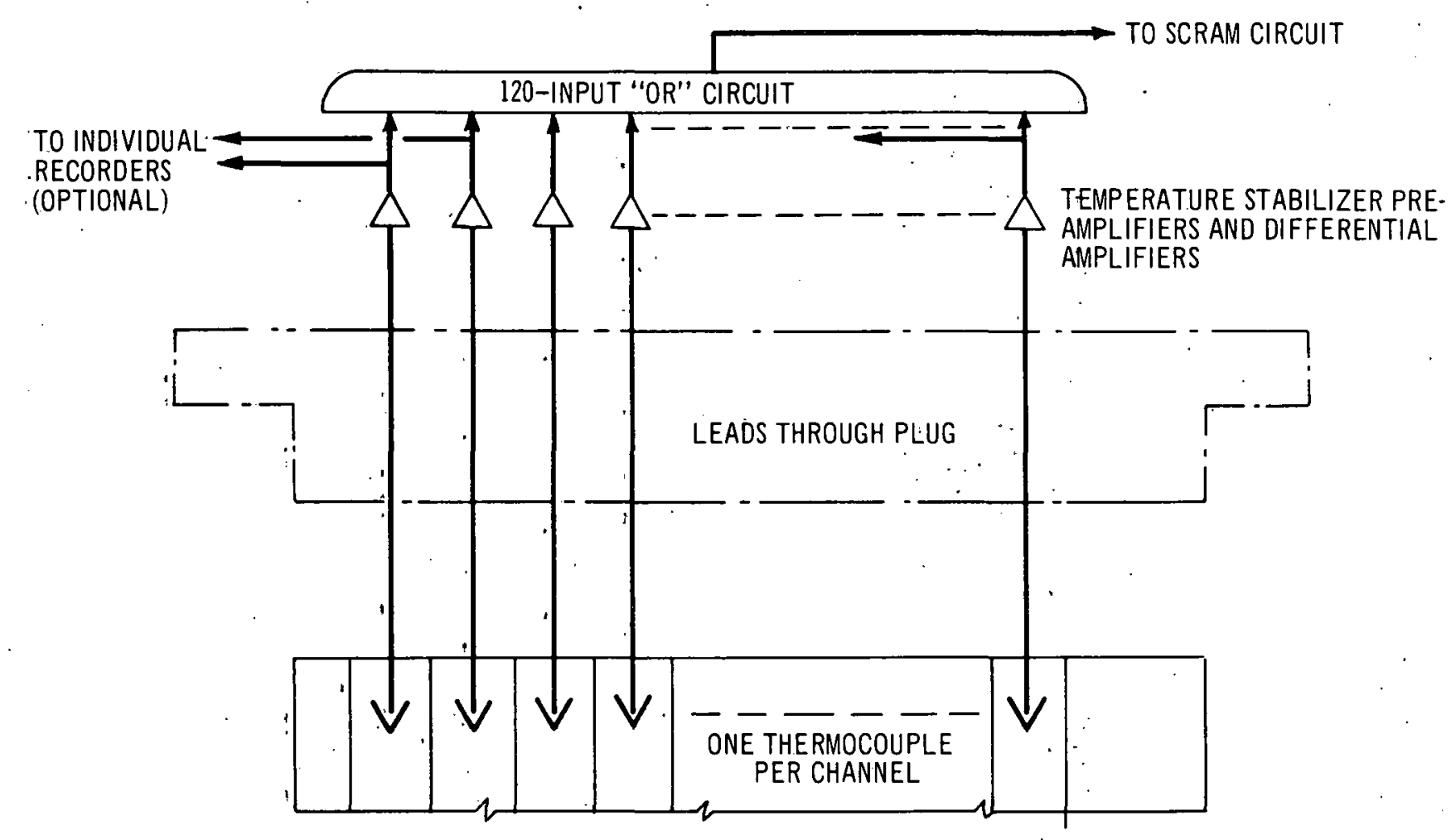

FIGURE 6-2. CORE TEMPERATURE SENSING-SCHEME A, ONE THERMOCOUPLE PER.CHANNEL, SCRAM ON ANY HIGH TEMPERATURE

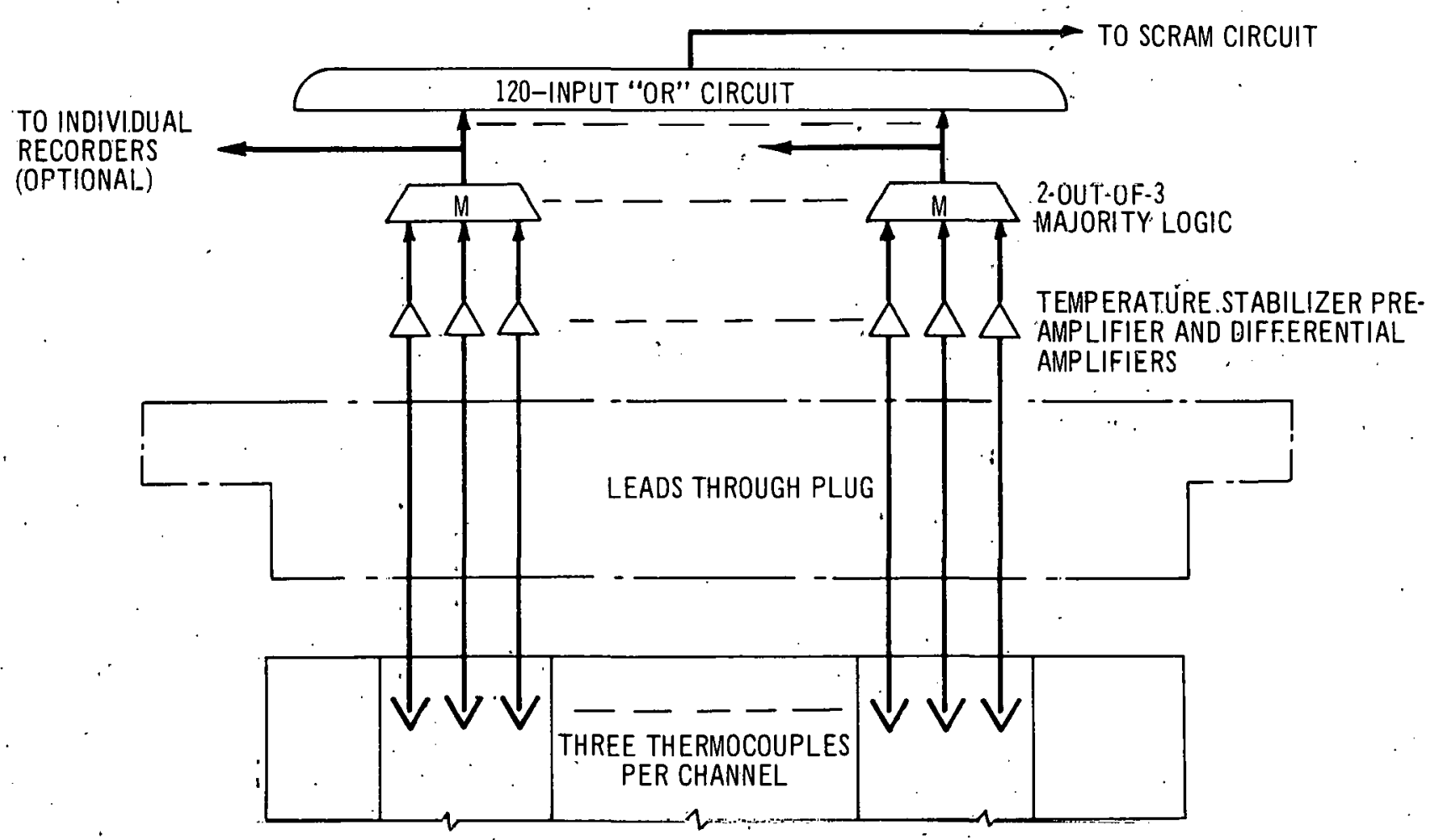

FIGURE 6-3. CORE TEMPERATURE SENSING-SCHEME B, 3 THERMOCOUPLES PER CHANNEL WITH MAJORITY LOGIC IN EACH CHANNEL 


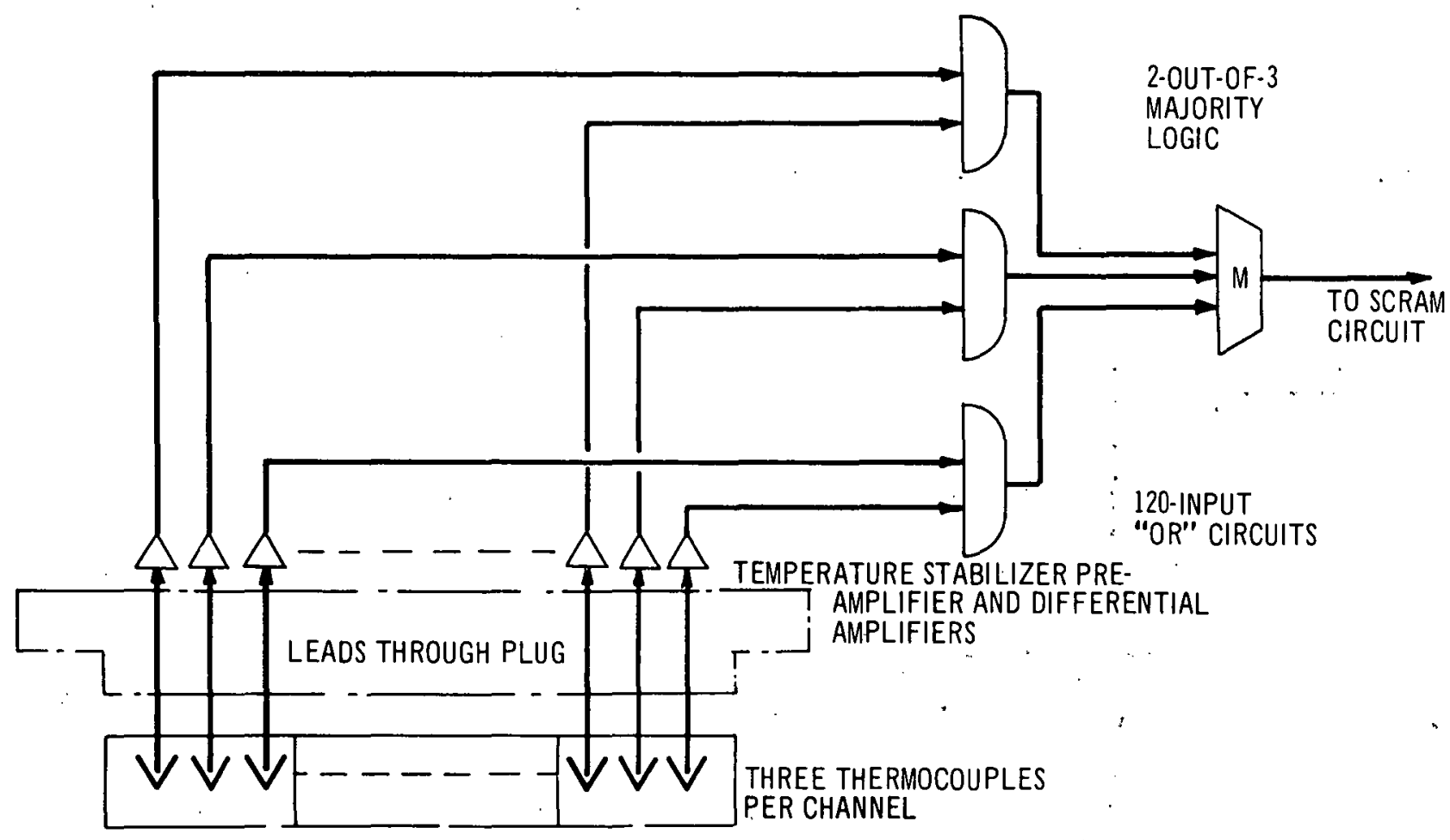

FIGURE 6-4. CORE TEMPERATURE SENSING-SCHEME C 3 THERMOCOUPLES PER CHANNEL, "OR", IN 3 GROUPS, MAJORITYY LOGIC IN EACH CHANNEL

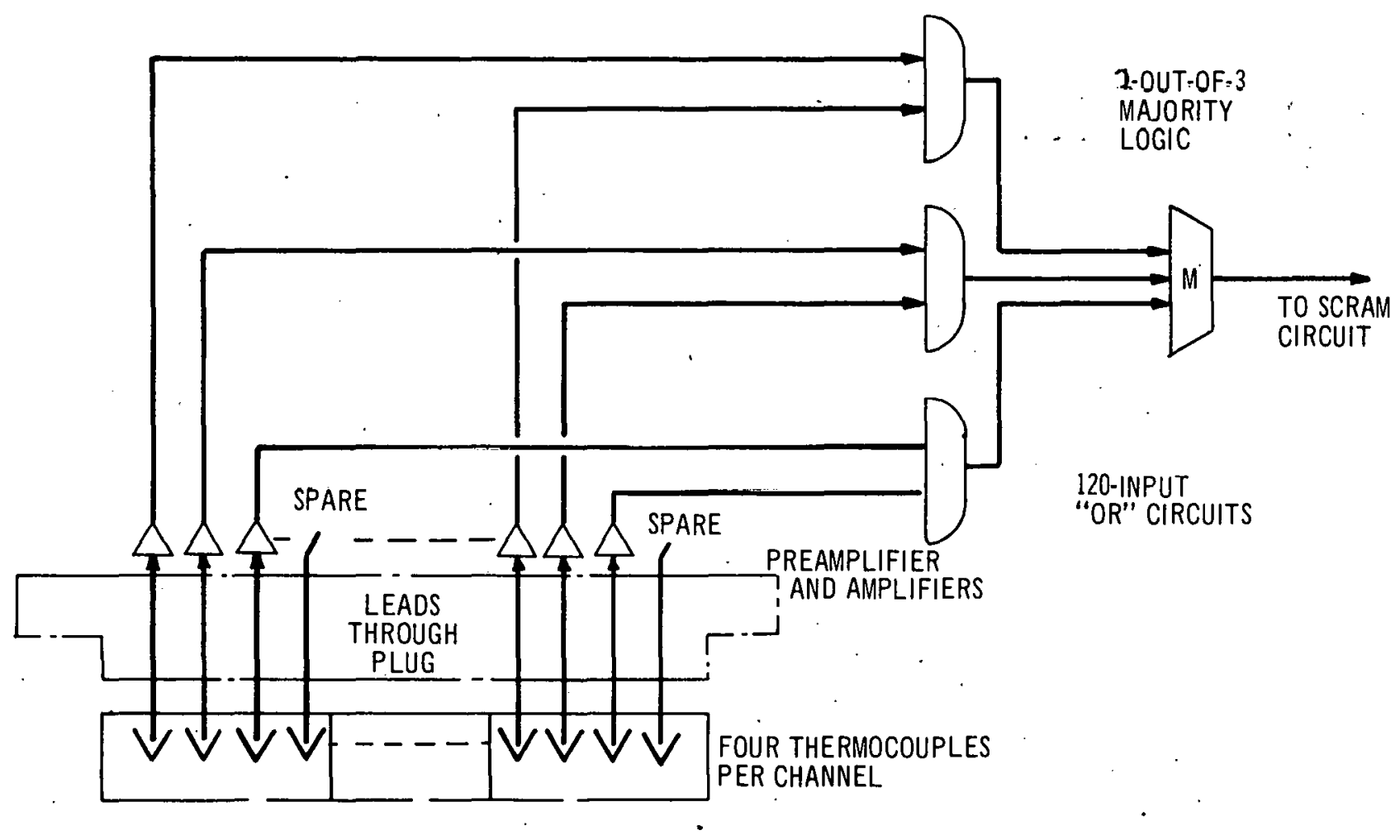

FIGURE 6-5. CORE TEMPERATURE SENSING-SCHEME D, 4 THERMOCOUPLES PER CHANNEL, (ONE SPARE), OTHERWISE SAME AS SCHEME C 


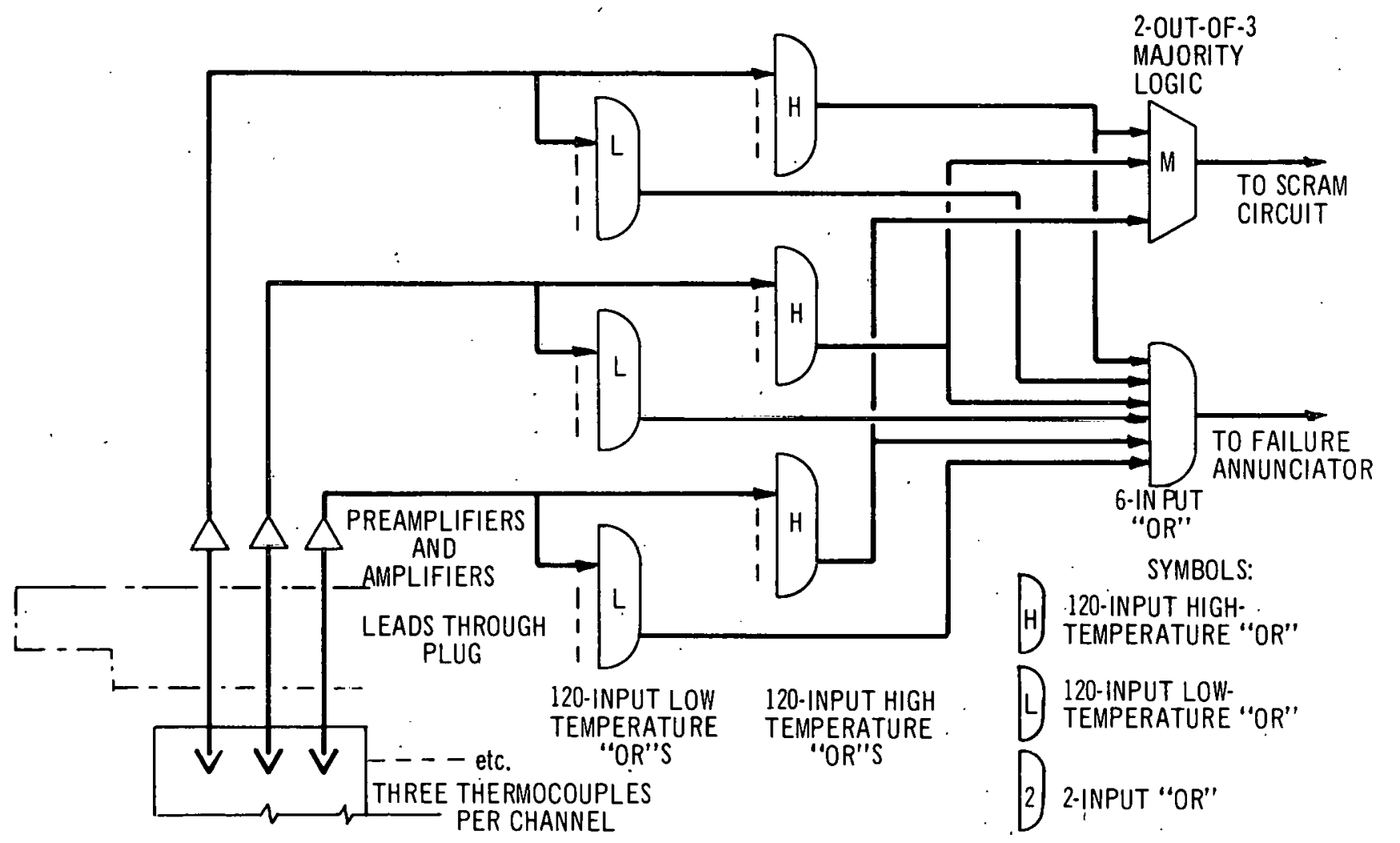

FIGURE 6-6. CORE TEMPERATURE SENSING-SCHEME E, SCHEME C PLUS FAILURE DETECTION

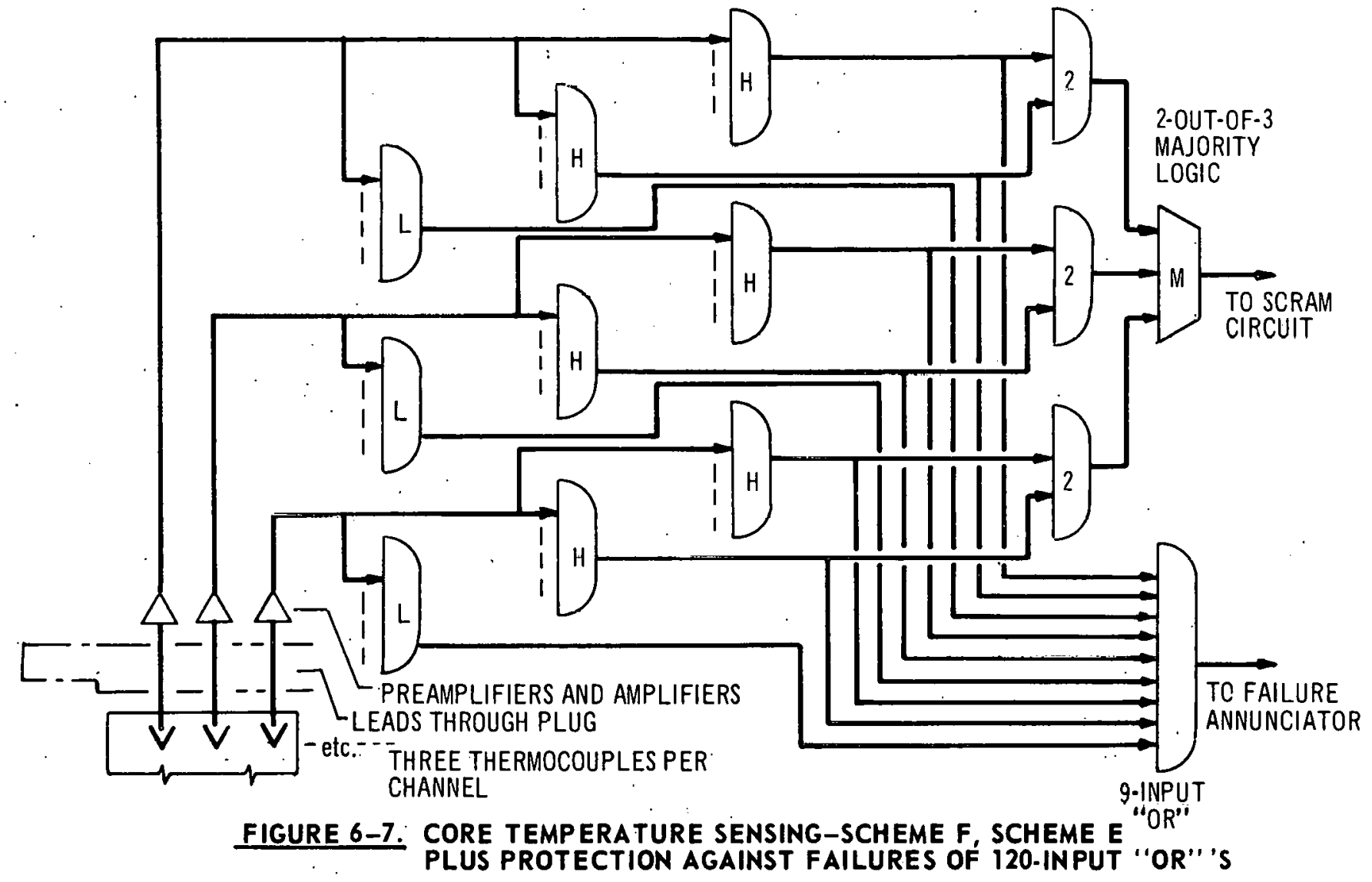




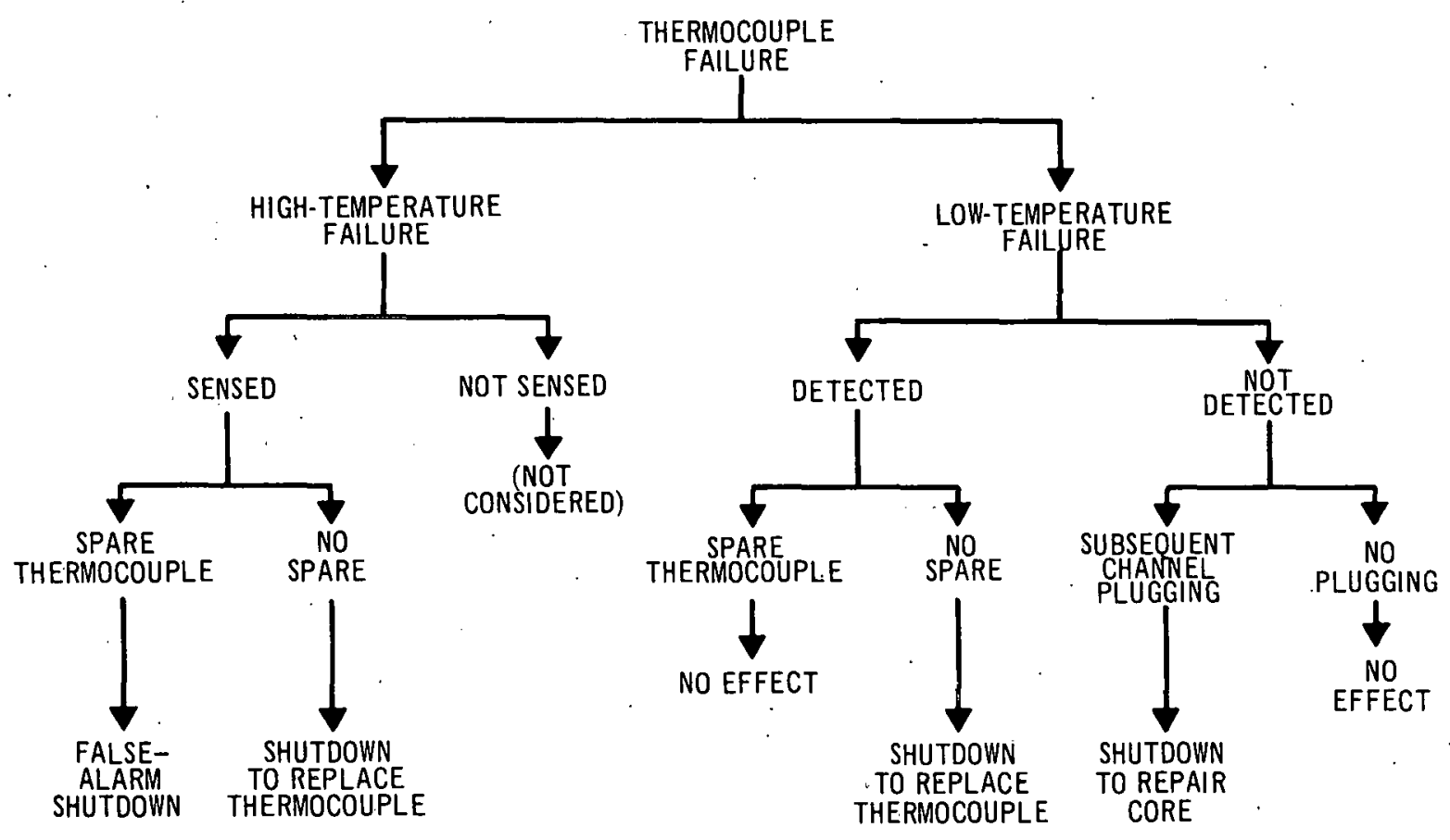

FIGURE 6-8. CONSEQUENCES OF THERMOCOUPLE FAILURE

circuits; one of the amplifier outputs from each of the 120 channels is connected to each "or" (see the schematic diagram, Figure 6-4, for Scheme C). The outputs of the three "or"s are connected to a two-out-of-three majority gate, which provides the scram signal.

In Scheme B, there are 120 majority gates and one 120-input "or", none of which are protected by redundance. In Scheme C, by comparison, the only circuit not protected by redundancy is one majority gate. Scheme C requires three 120 -input "or"s while Scheme B requires only one of them, but in $\mathrm{C}$ they are protected by redundancy.

Scheme C should be less expensive. Its "or" circuits and majority gate require an estimated 46 integrated-circuit chips, while the corresponding circuits in Scheme B will require about 105 chips.

\section{3. 2. 4. Scheme D}

This is a variation of Scheme $C$, the difference being that a spare thermocouple is provided in each channel for Scheme $D$.

It is assumed that operating policy will be to shut down the reactor for repair whenever a thermocouple failure is known to exist. - With Schemes B, C, and D, a single thermocouple failure in any channel will not be known until a second failure occurs in the same channel. The second failure may be either another thermocouple failure or a thermocouple amplifier failure. Because amplifier failures will probably be more likely than thermocouple failures (see assumed failure 
rates), it is appealing to have a spare thermocouple in each channel. Thus, the time to replace a bad thermocouple is reduced greatly, from the estimated 300 hours to allow for decay and lift the cover, to an estimated 8 hours for changing leads externally.

\subsubsection{Scheme E}

This is a different variation of Scheme $C$, where failure detection is provided.

Referring to the diagram for Scheme E, Figure 6-6, note that it uses three 120-input "high-temperature or" circuits. These are identical to the 120-input "or"s of Scheme C, and it . will be noted that they are connected to a two-out-of-three majority gate as in Scheme C. The added equipment in Scheme E consists of three 120-input "low-temperature or" circuits, plus a 6 -input "or" which provides failure annunciation. Whenever any one of the 360 thermocouple . amplifier outputs is faulty, either high or low, it will be sensed by one of the six 120-input "or"s.

Scheme $E$ will announce failure in any thermocouple or any thermocouple amplifier. Presumably such a failure can be repaired with a short downtime, or perhaps with no downtime at all if its repair can be deferred until refueling (there would still be two good sensors in the affected channel). This scheme does not detect malfunction-type failures in the "or" circuits or the majority gate, but most of the electronics is in the thermocouple amplifiers.

\subsubsection{Scheme F}

This is an extension of Scheme E, designed to provide protection against malfunction-type failures in the 120-input "or" gates which feed the majority gate.

Referring to the diagram for Scheme F, Figure 6-7, note that three more 120-input "hightemperature or" gates have been added. Each thermocouple amplifier output feeds two "hightemperature or" circuits, as well as one "low-temperature or." There are three sets of "high-temperature or" gates with common inputs (two gates per set), and the diagram shows the outputs from the two gates of each set fed to a two-input "or." The three 2-input "or"s provide the signals for the two-out-of-three majority gate, which in turn provides the scram signial.

With this scheme, any three of the "high-temperature or" gates can fail without subverting the scran function. It is truc that only one failure can be tolerated in the 2 -input "or"s, but these are much simpler than the 120-input "high-temperature or" gates.

Scheme $F$ has the most complicated electronic logic of all schemes (except $\mathrm{H}$, which is similar to F). It requires about 138 integrated-circuit chips for the logic ("or" gates and the majority gate). This is relatively small, even so, when it is considered that about 720 chlps will be needed for the thermocouple amplifiers of all schemes except Scheme A.

\subsubsection{Scheme G}

No diagram for Scheme $G$ is given in the appendix; it is a straightforward variation of Scheme E. The only difference is that Scheme.G has a spare thermocouple in edich clidumel, similar to Scheme D. 


\subsubsection{Scheme H}

This scheme also lacks a diagram because it is a straightforward variation of Scheme $F$. Scheme $\mathrm{H}$ uses a spare thermocouple in each channel; otherwise it is identical to F.

\subsubsection{Amount of Electronic Circuits}

To predict failure rates for the various schemes, it was necessary to estimate the amount of electronic circuits in each. The following first-order estimates for the circuits required were made.

\section{Majority Gate (three inputs)}

This will be presumed mechanized as three "and" gates with "wired or" outputs. Threefourths of one integrated-circuit chip will be required.

\section{Thermocouple Amplifiers}

Each thermocouple must be provided with a temperature-stabilized preamplifier, a differential amplifier to compare with reference, and fan-out circuitry. The preamplifier corresponds to two transistor stages plus temperature-controlling circuitry, all of which occupies one IC chip. The differential amplifier corresponds to 8 or 10 transistors, and it also occupies one IC chip. The fan-out circuitry corresponds to two transistors, occupying only $1 / 6$ IC chip. Thus, each thermocouple will require a total of $2-1 / 6$ IC chips.

This estimate assumes use of chromel-constantin in thermocouple junctions, which have a . sensitivity of 80 microvolts per degree $\mathrm{C}$ at a temperature of $450^{\circ} \mathrm{C}$. Thermocouples with different sensitivities would require re-examination of the amplifier stabilization circuitry.

\section{"Or" Gates}

A 16 -input "or" can be constructed from a 4-input "nand" circuit (1/2 IC chip), an inverter (1/6 chip), and a 12 -input input expander $(1 \mathrm{chip})$. Thus, a 120 -input "or" will require $8 \times(1+1 / 2+1 / 6)$ chips, plus 1 chip to combine the eight outputs; a total of 15 chips.

Estimates have also been made of the amount of discrete-circuit hardware needed. Assuming failure rates of $\lambda=0.3$ per million hours per chip or per active element group (discrete), the following results are obtained:

\section{$\underline{\text { Circuit }}$}

Thermocouple preamplifiers and amplifiers 120 -input. "or" gate 3 -input majority gate

$$
\begin{array}{r}
\left(\text { per } 10^{6} \mathrm{~h}\right) \\
\lambda . \text { discrete } \\
\hline
\end{array}
$$

$$
\text { 4. } 0
$$$$
25.0
$$$$
\text { 1. } 8
$$

$$
\underline{\lambda^{\left(\text {integrated } 10^{6} \mathrm{~h}\right)}}
$$

0.6

4. 5

0.3

It is seen that the predictions for integrated circuits are, in general, about six times better. than for discrete circuits. 


\subsubsection{Formulas for Unavailability}

Unavailability is a dimensionless quantity, defined as the ratio of expected downtime per period to total desired operating time per period:

$\mathrm{U}=\frac{\mathrm{E} \text { (downtime) }}{\mathrm{T}}$

Using this definition, it may be readily shown that a suitable approximation for nonredundant systems is

$\mathrm{U} \cong \lambda \mu$

where $\lambda$ is the system failure rate and $\mu$ is its mean repair time. This also applies to the "i"th system component:

$$
\mathrm{U}_{\mathrm{i}} \cong \lambda_{\mathrm{i}} \mu_{\mathrm{i}}
$$

and the system unavailability may be closely approximated by the sum of the component unavailabilities:

$$
\mathrm{U} \cong \sum_{\mathbf{i}} \mathrm{U}_{\mathrm{i}}
$$

Suitable approximations can also be derived for redundant systems. For example, with two-out-of-three najority logic the unavailability is

$$
\mathrm{U} \cong 3 \lambda^{2} \mu \mathrm{T}_{\mathrm{I}}
$$

where $T_{I}$ is the interval between inspections (assuming that single failures are not detected until periodic inspection). If a system is a serial combination of redundant subsystems, the unavailabilities of the subsystems may be directly summed to approximate the system una vailability.

For the unavailability formulas used for the eight schemes following, the following numenclature will be used.

$\mathrm{U}_{\mathrm{FS}}=$ unaviailability because of false scrams.

$\mathrm{U}_{\mathrm{TR}}=$ unavailability because of thermucuüple replacement

$\mathrm{U}_{\mathrm{ND}}=$ unavailability because of nondetected failures and subsequent channel plugging

${ }^{\mu} \mathrm{FS}^{\mu} \mathrm{TR}^{\mu} \mathrm{ND}=$ respective mean repair times

$N=120=$ number of channels

$\lambda$ amp, $F=$ failure rate for false-output mode of thermocouple preamplifiers and amplifiers

$\lambda_{\text {amp, }} \mathrm{M}=$ failure rate for malfunction (no output) mode of thermocouple preamplifier $\bar{s}$ 
$\lambda$ or, $\mathrm{F}^{\text {and } \lambda}$ or, $\mathrm{M}=$ failure rates for 120 -input "or" gates

$\lambda_{\mathrm{TC}, \mathrm{F}}$ and $\lambda \mathrm{TC}, \mathrm{M}=$ failure rates for thermocouples

$\lambda_{\text {lead, }} \mathrm{F}$ and $\lambda$ lead, $M=$ failure rates for thermocouple leads*

$\lambda_{M L, F}$ and $\lambda \mathrm{ML}, \mathrm{M}=$ failure rates for 3 -input majority gates

$\lambda_{2, \mathrm{~F}}$ and $\lambda_{2, \mathrm{M}}=$ failure rates for 2-input "or" gates

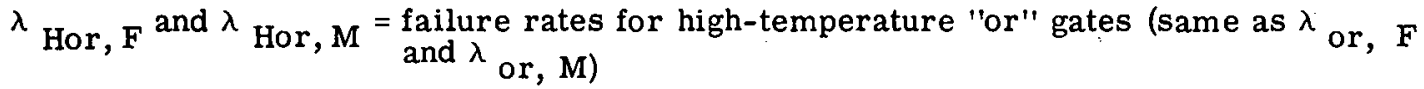

$\lambda_{\text {Lor, } F}$ and $\lambda$ Lor, $M=\underset{\text { failure rates for low-temperature "or" gates (also same as }}{\lambda \text { or, } M \text { ) }}$

$\lambda_{\text {plug }}=$ channel plugging rate

$\mathrm{T}_{\mathrm{I}}=$ inspection interval

Scheme A:

$$
\begin{aligned}
& \mathrm{U}_{\mathrm{FS}}=\left(\mathrm{N} \lambda \text { amp, } \mathrm{F}+\lambda_{\text {or }, \mathrm{F}}\right) \mu \mathrm{FS} \\
& \mathrm{U}_{\mathrm{TR}}=\mathrm{N}\left(\lambda_{\mathrm{TC}, \mathrm{F}}+\lambda_{\text {lead, } \mathrm{F}}\right) \mu_{\mathrm{TR}} \\
& \mathrm{U}_{\mathrm{ND}}=\mathrm{N}\left(\lambda_{\text {amp, } \mathrm{M}}+\lambda_{\text {or }, \mathrm{M}}+\lambda_{\mathrm{TC}, \mathrm{M}}+\lambda_{\text {lead, }}\right) \lambda_{\text {plug }} \mu_{\mathrm{ND}} \mathrm{T}_{\mathrm{I}}
\end{aligned}
$$

Scheme B:

$$
\begin{aligned}
& \mathrm{U}_{\mathrm{FS}}=\left(3 \mathrm{~N} \lambda_{\text {amp, }}{ }^{2} \mathrm{~T}_{\mathrm{I}}+\mathrm{N} \lambda_{\mathrm{ML}, \mathrm{F}}+\dot{\lambda}_{\text {or, } \mathrm{F}}\right)^{\mu} \mathrm{FS} \\
& \mathrm{U}_{\mathrm{TR}}=3 \mathrm{~N} \lambda_{\mathrm{TC}, \mathrm{F}}\left(\lambda_{\mathrm{TC}, \mathrm{F}}+\lambda_{\text {amp, F }}\right) \mu_{\mathrm{TR}} \mathrm{T}_{\mathrm{I}} \\
& \mathrm{U}_{\mathrm{ND}}=\left(3 \lambda_{\text {amp }, \mathrm{M}^{2}}+3 \lambda_{\mathrm{TC}, \mathrm{M}}{ }^{2}+\lambda_{\mathrm{ML}, \mathrm{M}}+\lambda_{\text {or }, \mathrm{M}}\right)\left(\mathrm{N} \lambda_{\mathrm{plug}}{ }^{\mu} \mathrm{ND}_{\mathrm{I}} \mathrm{T}_{\mathrm{I}}\right.
\end{aligned}
$$

Scheme C:

$\mathrm{U}_{\mathrm{FS}}=\left[3\left(\mathrm{~N} \lambda \text { amp, } \mathrm{F}+\lambda_{\text {or }, \mathrm{F}}\right)^{2} \mathrm{~T}_{\mathrm{I}}+\lambda_{\mathrm{ML}, \mathrm{F}}\right]^{\mu} \mathrm{FS}$

$\mathrm{U}_{\mathrm{TR}}$ as for Scheme $\mathrm{B}$

$\mathrm{U}_{\mathrm{ND}}=\left[3 \lambda_{\mathrm{amp}, \mathrm{M}^{2}} \mathrm{~T}_{\mathrm{I}}+3 \lambda_{\text {or, }, \mathrm{M}^{2}} \mathrm{~T}_{\mathrm{I}}+\mathrm{N} \lambda_{\mathrm{ML}, \mathrm{M}}+3 \lambda_{\mathrm{TC}, \mathrm{M}}{ }^{2} \mathrm{~T}_{\mathrm{I}}\right] \cdot \mathrm{N} \lambda_{\text {plug }}{ }_{\mathrm{ND}} \mathrm{T}_{\mathrm{I}}$

Scheme D:

$\mathrm{U}_{\mathrm{FS}}=\left[3 \mathrm{~N} \lambda_{\mathrm{TC}, \mathrm{F}}\left(\lambda_{\mathrm{TC}, \mathrm{F}}+\lambda_{\mathrm{amp}, \mathrm{F}}\right)^{\prime} \mathrm{I}_{\mathrm{I}}+3\left(\mathrm{~N} \lambda_{\text {amp }, \mathrm{F}}+\lambda_{\text {or }, \mathrm{F}}\right)^{2} \mathrm{I}_{\mathrm{I}}+\lambda_{\mathrm{ML}, \mathrm{F}}\right] \mu \mathrm{FS}$

$\mathrm{U}_{\mathrm{TR}}=\frac{9}{4} \lambda_{\mathrm{TC}, \mathrm{F}}^{2} \lambda_{\mathrm{amp}, \mathrm{F}}\left(\lambda_{\mathrm{TC}, \mathrm{F}}+\lambda_{\mathrm{amp}, \mathrm{F}}\right) \mathrm{N} \mu_{\mathrm{TR}} \mathrm{T}_{\mathrm{I}}^{3}$

$\mathrm{U}$, as for Scheme C

\footnotetext{
${ }^{*} \lambda_{\text {lead, }} F^{\text {and } \lambda}$ lead; $M$ are included with $\lambda$ TC, $F$ and $\lambda$ TC, $M$ except for Scheme A.
} 
Scheme E:

$\mathrm{U}_{\mathrm{FS}}$ as for Scheme C

$$
\mathrm{U}_{\mathrm{TR}}=3 \mathrm{~N} \lambda_{\mathrm{TC}}\left(\lambda_{\mathrm{TC}}+\lambda_{\mathrm{amp}}\right) \mu_{\mathrm{TR}} \mathrm{T}_{\mathrm{I}},
$$

where $\lambda_{\mathrm{TC}}=\lambda_{\mathrm{TC}, \mathrm{F}}+\lambda \mathrm{TC}, \mathrm{M}=$ total $\mathrm{TC}$ failure rate and similar for $\lambda$ amp, since any failure is now detected.

$$
\begin{aligned}
& \mathrm{U}_{\mathrm{ND}}=\left[3 \left(\lambda_{\mathrm{amp}, \mathrm{M}^{2}}+\lambda_{\left.\mathrm{TC}, \mathrm{M}^{2}\right) \cdot \lambda}{ }^{2}, \mathrm{M}^{\mathrm{T}} \mathrm{I}+\lambda_{\text {Hor }, \mathrm{M}^{2}}+3\left(\lambda_{\mathrm{amp}, \mathrm{M}^{2}}{ }^{2}+\lambda_{\mathrm{TC}, \mathrm{M}}{ }^{2}\right)\right.\right. \\
& \left.\lambda_{\text {Lor, }} \mathrm{M}^{2} \mathrm{~T}_{\mathrm{I}}^{2}\right] \cdot \mathrm{N} \lambda \text { plug } \mu_{\mathrm{ND}} \mathrm{T}_{\mathrm{I}}^{2}
\end{aligned}
$$

Scheme F:

$$
\begin{aligned}
& \mathrm{U}_{\mathrm{FS}}=3\left(\mathrm{~N} \lambda \text { amp, } \mathrm{F}+2 \lambda \text { or, } \mathrm{F}+\lambda_{2, \mathrm{~F}}\right)^{2} \mu_{\mathrm{FS}} \mathrm{T}_{\mathrm{I}} \\
& \mathrm{U}_{\mathrm{TR}} \text { as for Scheme } \mathrm{E} \\
& \mathrm{U}_{\mathrm{ND}}=3 \mathrm{~N} \lambda{ }_{\text {Hor, } \mathrm{M}^{4} \lambda_{\text {plug }}{ }^{\mu} \mathrm{ND}_{\mathrm{I}} \mathrm{T}_{\mathrm{I}}^{4}}
\end{aligned}
$$

Schemes G and H:

$\mathrm{U}_{\mathrm{FS}}$ as for Schemes $\mathrm{E}$ and $\mathrm{F}$, respectively, with an additional term

$$
\begin{aligned}
& 3 \mathrm{~N} \lambda_{\mathrm{TC}}\left({ }{ }_{\mathrm{TC}}+\lambda_{\mathrm{amp}}\right) \mu \mathrm{FS} \mathrm{T}_{\mathrm{I}} \cdot
\end{aligned}
$$

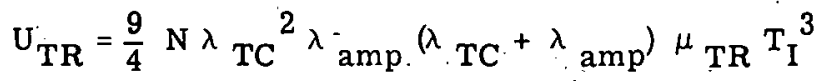

$$
\begin{aligned}
& \mathrm{U}_{\mathrm{ND}} \text { as for Schemes } \mathrm{E} \text { and } \mathrm{F} \text {, respectively. }
\end{aligned}
$$

\subsubsection{Consequence Analysis}

The preceding formulas were derived by considering the possible paths to each type of system failure. The "consequence analyses" will not be discussed in detail, but two examples will be shown.

Figure 6-8 shows the consequence analysis tree for thermocouple failures. This is general and applies to any scheme, because it has branches where failures are detected or not, and where spare thermocouples are available or not. This figure shows how thermocouple failure can lead to any of the three types of unavailability (false alarm, shutdown to replace thermocouple, or shutdown to repair core).

Figure 6-9 shows, for the spec if ic case of Scheme D, the fault tree leading to the event "shutdown to replace thermocouple." This tree was used to derive the expression for $\mathrm{U}_{\mathrm{TR}}$ of Scheme D. Note that the upper half of this tree is traversed with probability $\frac{3}{2} \lambda \mathrm{TC}, \mathrm{F}$ amp, $\mathrm{F}_{\mathrm{I}}{ }^{2}$; the factor of $1 / 2$ arises because a specific order is required for the "and"ed events. Likewise, the lower half of this tree is traversed with probability $\frac{3}{2} \lambda_{\mathrm{TC}, \mathrm{F}}\left(\lambda_{\mathrm{TC}, \mathrm{F}}+\lambda_{\text {anip, } \mathrm{F}}\right) \mathrm{T}_{\mathrm{d}}^{2}$. 


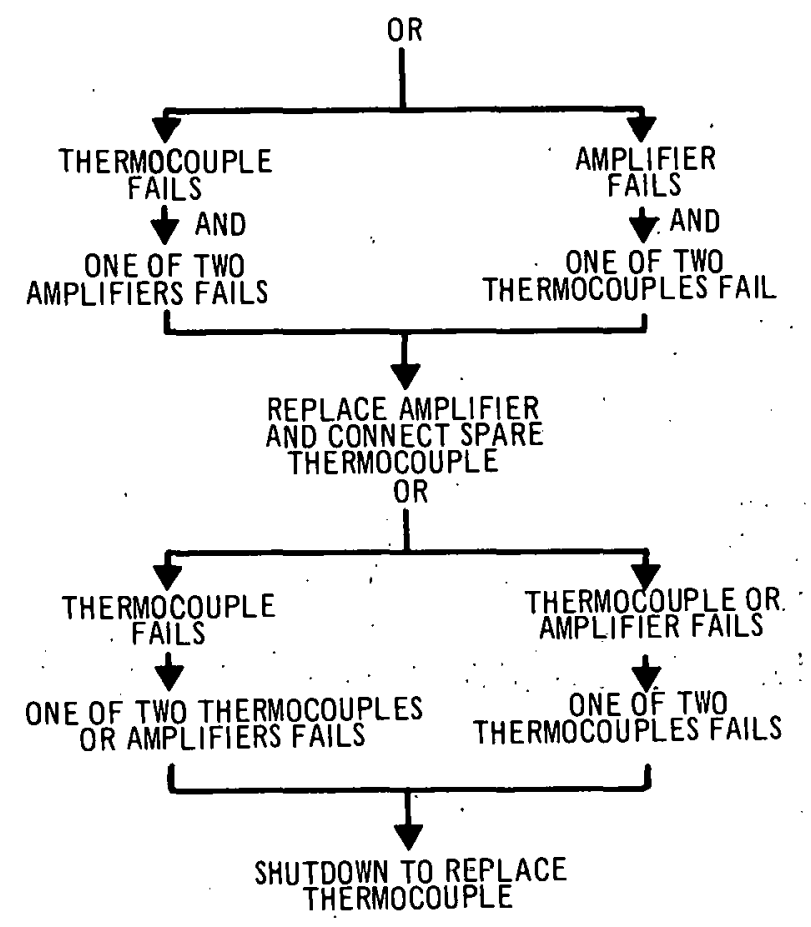

FIGURE 6-9. PATHS TO THERMOCOUPLE REPLACEMENT IN SCHEME D

\subsubsection{Results-Driver Fuel Instrumentation Availability}

By inserting assumed numerical values in the preceding formulas, the unavailabilities for the various schemes were calculated. Results are shown in Table 6-1.

The following conclusions may be drawn:

1. Any of the redundant schemes is better than Scheme A, the nonredundant scheme.

2. Scheme $C$ is a much better way of applying redundance than Scheme B. Because C is slightly less complex, B should receive no further consideration.

3. Schemes D through $\mathrm{H}$, which are more complex than Scheme C, offer little improvement, if any.

On the basis of these results, one would select Scheme C. However, there remains a lingering doubt that the thermocouple failure rate may be higher than assumed here. To satisfy this doubt, 'one might consider Scheme $D$, which differs from Scheme $C$ only in adding a spare thermocouple to each channel. 
TABLE 6-1

\section{PLANT UNAVAILABILITIES OF VARIOUS INSTRUMENTATION SCHEMES}

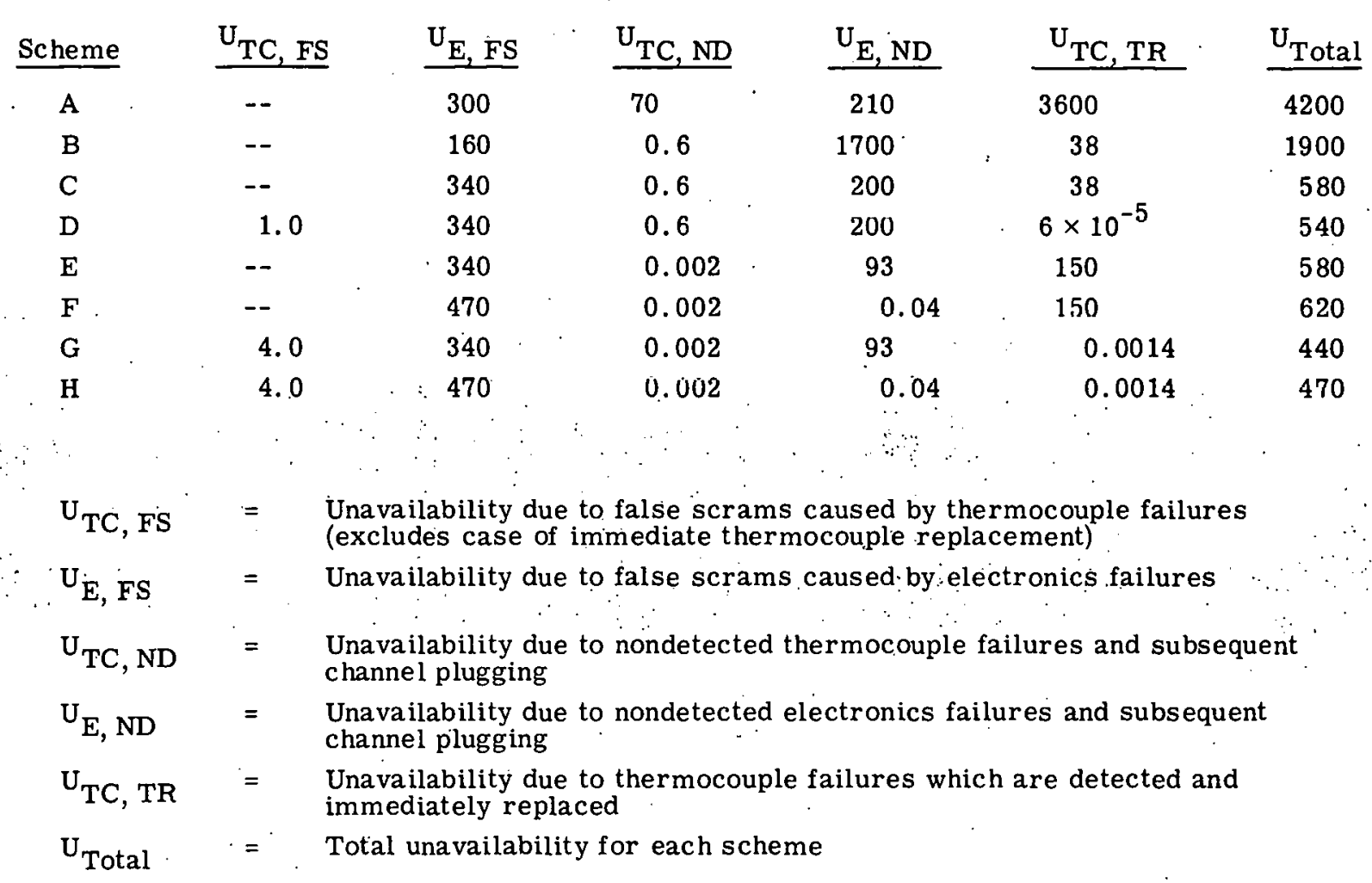

All unavailabilities are to be multiplied by $10^{-6}$.

\section{4. FLOW MEASUREMENT}

There will be one fluid flow sensor per channel. The flow sensor will be a go-no-go gage sensing a loss of flow to $70 \%$ or $80 \%$ of rated channel flow. Simplicity and reliability of operation will be stressed in the design. The capabilities of a variety of flow sensors are evaluated in Appendix F.

\subsection{ACOUSTIC SENSOR}

The primary purpose of the acoustir. sensor is to detect liquid boiling in the channel and, perhaps, cracking of the fuel cladding. Estimates are made of the required acoustic sensitivity, frequency range, and directionality in Appendix F. The characteristics of the Backup Design Fast Flux Test Reactor as a source of flow noise and other background noise must be determined. Environmental effects of the liquid sodium, high temperature, and the neutron density will be considered and factored into the selection of candidate sensor.

\section{6 INSTRUMENT MODULES}

Figure 6-10 shows typical examples of individual instrument modules and Figure 6-11 shows how they are included with the instrument support structure. Two styles of modules are used to 
supply instrumentation to the entire core. The majority of the core positions can be accommodated by the modules shown in group 1. The core positions obstructed by the closed loop pipes are accommodated in a slightly different manner by the modules shown in group 2 . The current design shows 14 instrument modules used, although other numbers and configurations might be considered. The number of modules is based on core arrangement, refueling plug penetration arrangement, and the number of channels to be reached by each module. Eight of the modules each supply instrumentation to 10 to 12 core positions, and one module is associated with the positions obstructed by each closed loop.

The modules accommodating 10 to 12 core positions consist of a multi-contact connector and a central support tube extending through the head to an elevation slightly above the fuel elements. At the bottom of the central support tube, a series of smaller tubes fan out to the fuel positions. A sensor package is connected to the end of the tubes. Sheathed instrument leads are routed along the small tubes to the central support tube which carries the leads through the refueling plug to the connector accessible from the refueling cell. The sheaths are brazed to a tube sheet in the support tube at an elevation near the bottom of the refueling plug. This brazed section forms the penetration seal for the instrument leads and a barrier for the shielding material above this section.

It is anticipated that each instrument package will have from 12 to 15 leads requiring a connector with up to 180 contacts. The connector visualized for this purpose uses spring loaded contact buttons rather than the conventional pin and socket type. It is felt that the contact button type will result in an equally effective but more rugged connector. The ruggedness is of particular importance because of the remote handling requirements.

Figure 6-11 shows the combination shielding stop and sealing surface for this type instrument unit. The reduced diameter of center support tubes corresponds with a reduction of the head penetration diameter forming a step. A metal O-ring on the step makes the seal between the sodium and the refueling cell. The sealing force is applied by the tightening handle which extends through the connector at the top of the module. Rotation of the tightening handle causes the tightening latch to expand and move axially to bear against the penetration nozzle as shown in Figure 6-11. The tightening latch supports the weight of the instrument module and forces the seal against the step in the head. The lower end of the modules are held firmly against support structure by the guide pins and clamping device as shown in Figure 6-11. The lower clamping device is for the purpose of reducing vibrational problems but is designed to support the weight of the module.

Figure 6-10 shows an example of an instrument module for the fuel positions obstructed by the closed loop piping. These modules must allow the instrument packages to be moved from under the closed loop pipes before the refueling plug can be raised. The instrumentation to the positions obstructed by the peripheral closed loops are simply raised about 2 feet and rotated to the position shown in section $c-c$ of Figure $6-11$. The 2 foot lift raises the instrumentation out of the fuel assemblies and above the tight network of support tubes, sample lines, and structural members.

To allow the instrument module to be raised, the shielding step is arranged with the large diameter on top. The shield step is made from two half cylinders that are attached to the module 


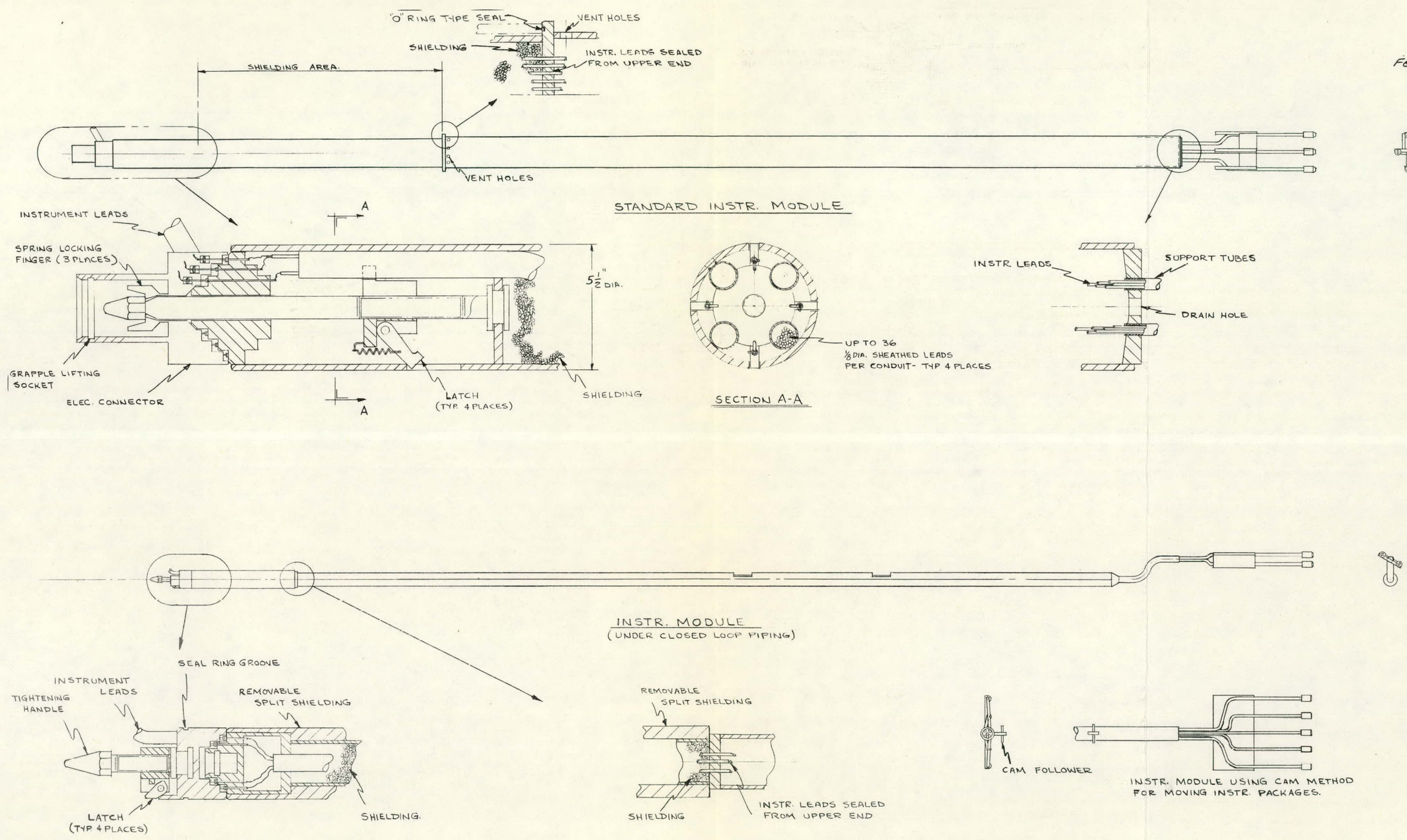

fef $-296 \times 146$

(1) 


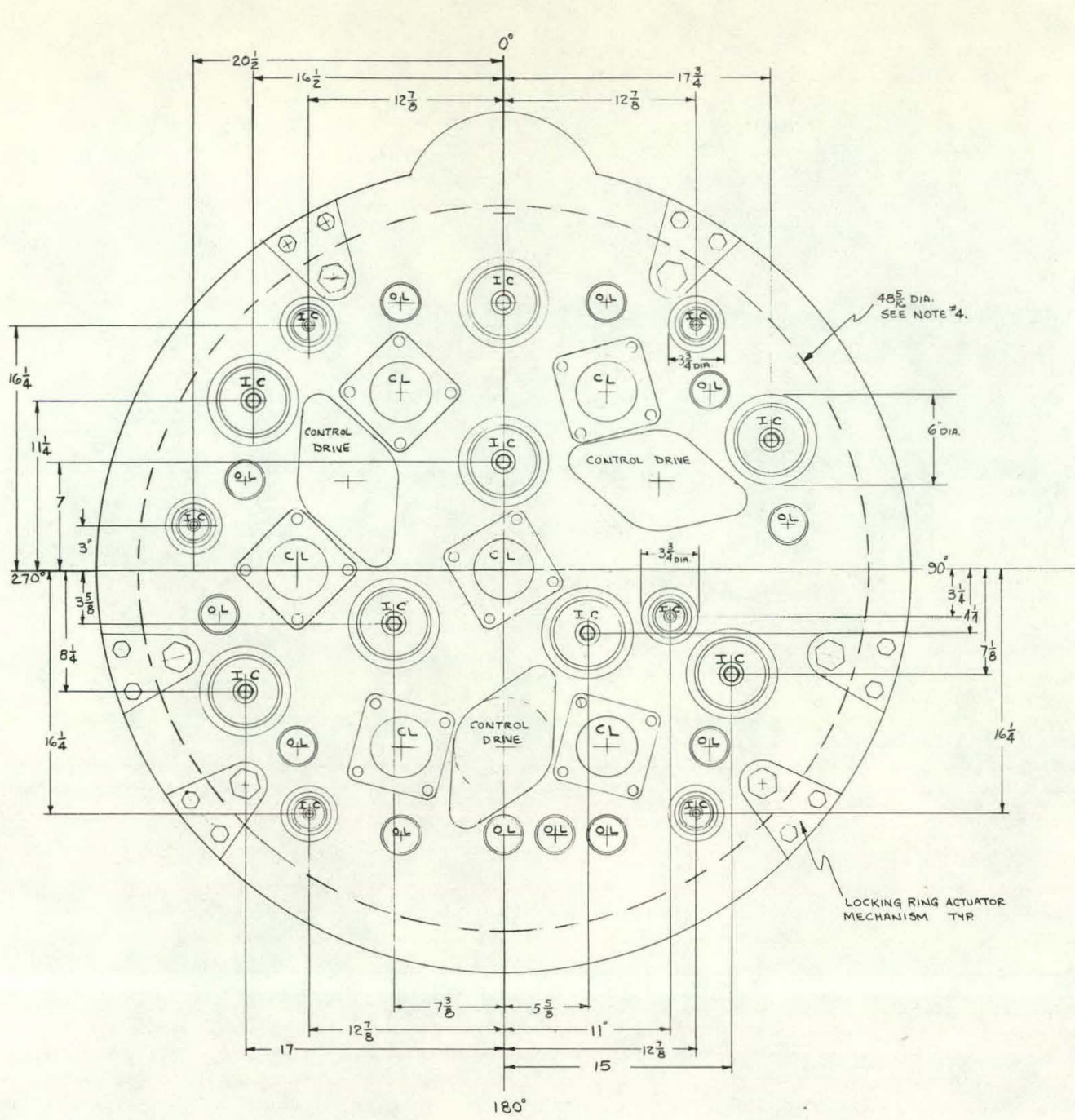

iste
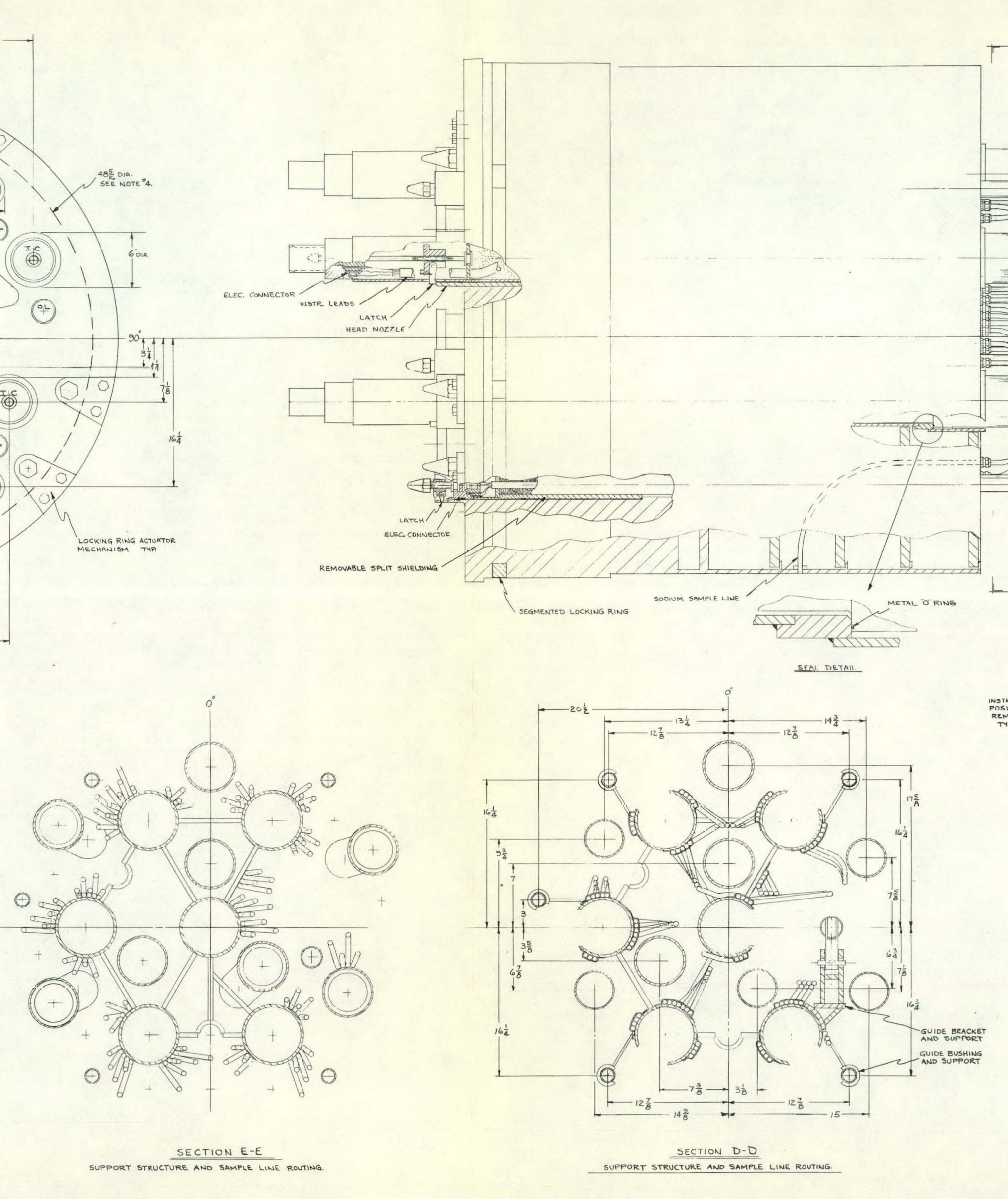

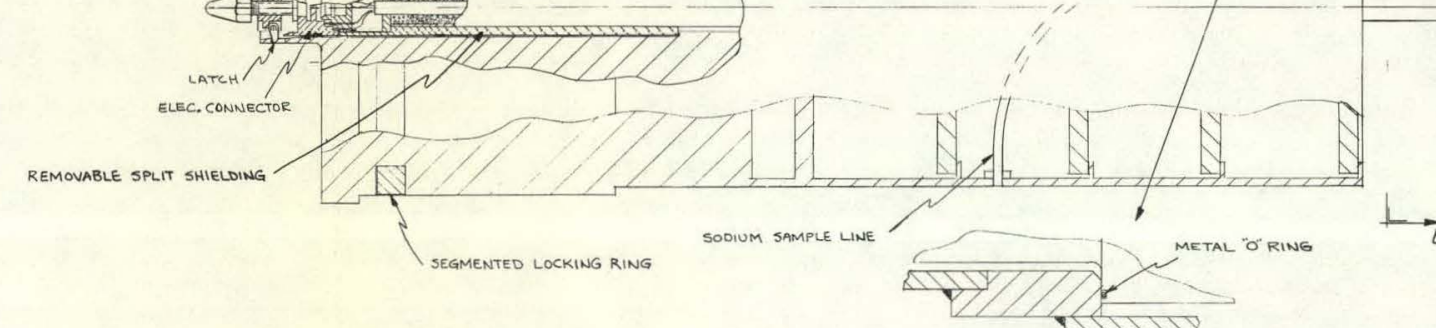

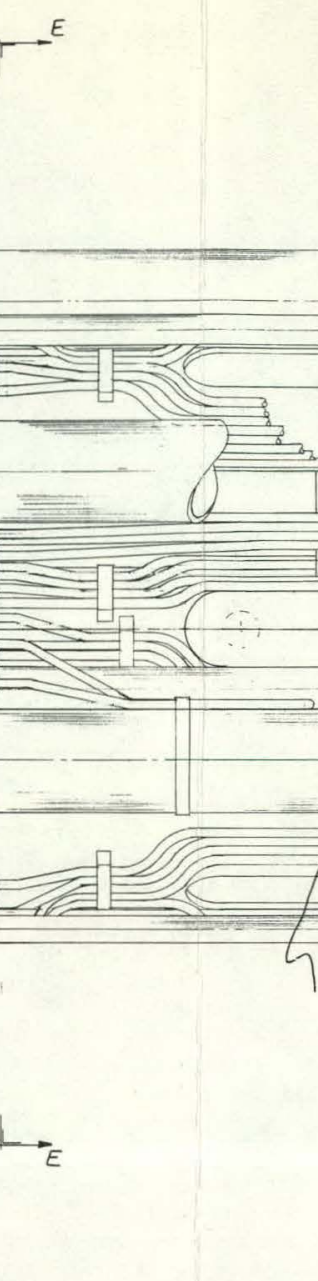

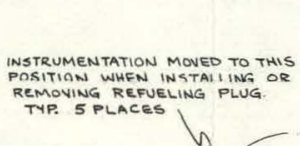

$\left\{\frac{0}{0}=\right.$ (3) $(3)=$ (3)

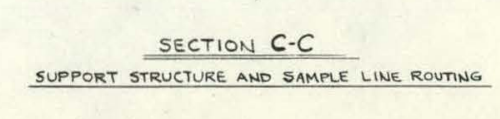

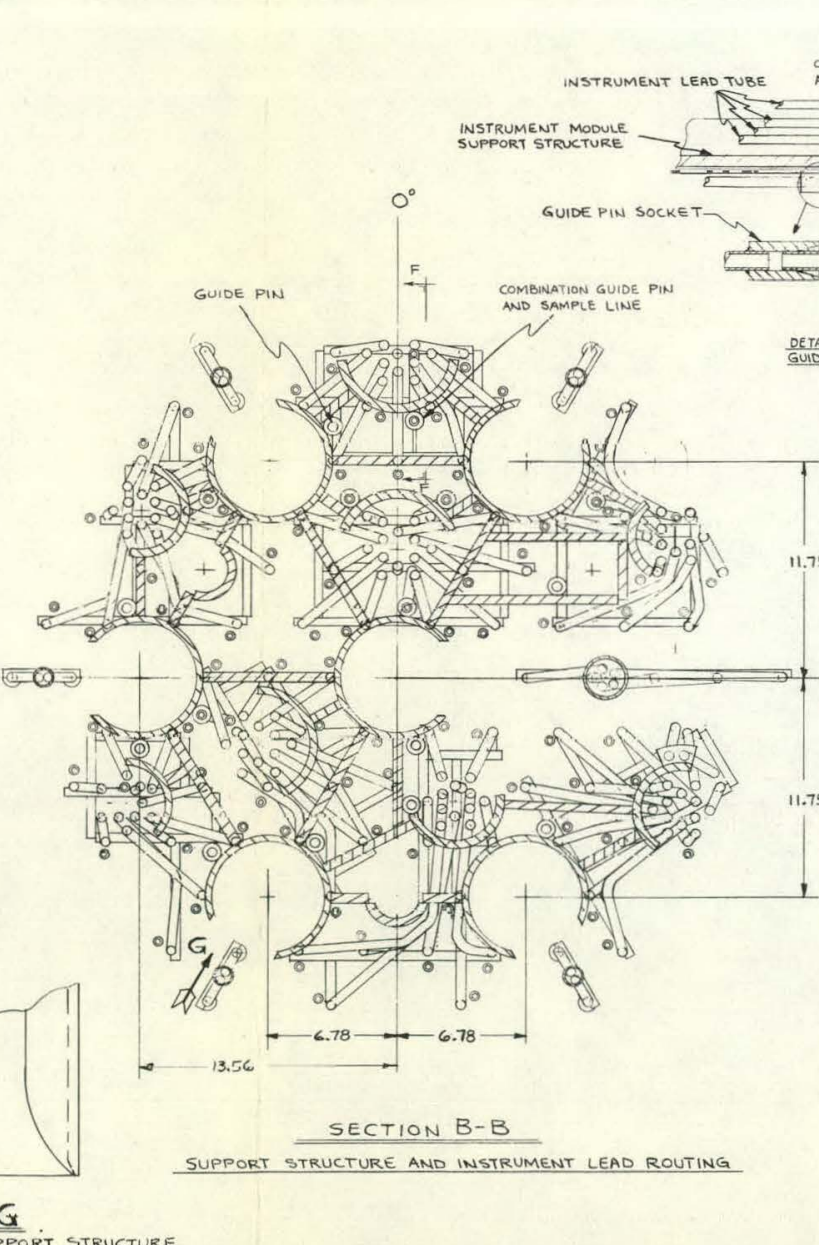

1
2

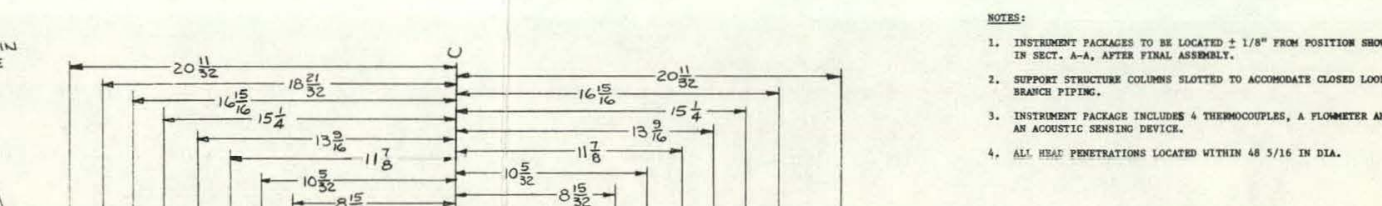

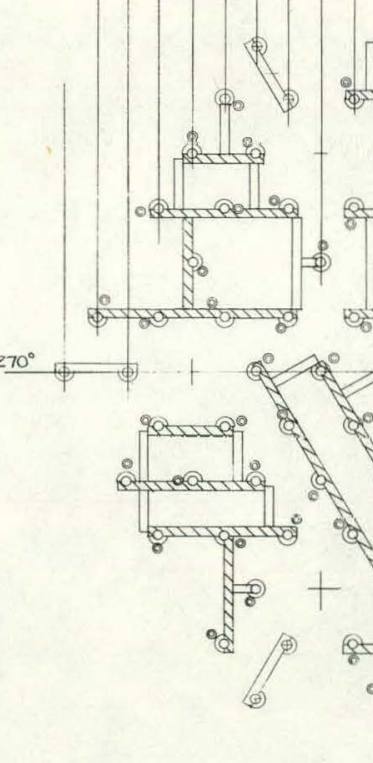
Lem

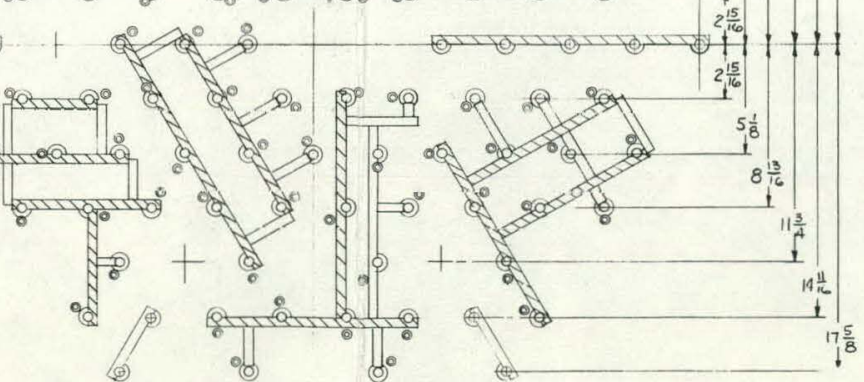

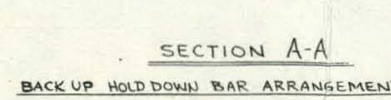


after it has been installed through the head penetration. The instrument module rests on the shield step with the latch fingers providing sufficient downward force to keep it in place. A radial seal in the top half of the connector provides the pressure barrier between the sodium and refueling cell. The seal in this position prevents the possibility of damaging it when the module is being installed.

Because of the number of fuel elements involved, it is not practical to use the rotational method for the instrumentation to the positions obstructed by the central closed loop. The instrument module must be raised about 2 feet to avoid obstructions when it moves. In the raised position the module can be tilted moving the instrument package from beneath the pipes. The tilting action is guided by a cam slot on the refueling plug structure and a cam follower on the instrument module (Figure 6-11). The axial arrangement of the shielding step is such that the 2-foot vertical lift results in a radial clearance between the module and head pentetration. This clearance establishes the angle the module can tilt. About a $1 / 2$-inch clearance will result in the required movement for the instrument packages.

\section{7 FEDAL SYSTEM}

Figure 6-11 shows the arrangement of sodium sample lines in the instrument support structure. With the refueling plug in place on the vessel, these lines will protrude to inside the fuel element handles. The sample lines extend to about a foot into the refueling plug and terminate around its periphery. No mechanical connector is made between these sample lines and the corresponding lines in the annular plug. Sodium is forced through the tubes with sufficient velocity to jump the gap between the two plugs. A pressure drop in the neighborhood of 5 psi is required to maintain the necessary flow for monitoring for delayed neutrons. A flow restrictor in the tops of the fuel elements may be required to develop the pressure drop required.

Section F-F of Figure 6-11 shows how sample lines are provided to positions directly beneath the body of the instrument modules. A sample line attached to the structure would prevent the instrument module from being installed or removed. The section view shows how a short section of the sample line is included with the instrument module and is used as a guide pin. When the instrument unit is installed, the hollow guide-pin mates with its socket to complete the sample line.

\section{8 INSTRUMENT MODULE EXCHANGE}

Exchanging defective instrumentation is a major design consideration for the instrumentation scheme. The ability to replace instrumentation in a minimum time and with minimum complications will help in maintaining a high plant operating factor.

The instrument modules are designed to be replaced when the refueling plug is hanging in the cell storage position. If two plugs are utilized, the repair work can be done at the convenience of the operator during the next operating cycle. The storage position will be accessible with remote handling equipment at several elevations. Man access to this region is also possible, if requircd.

The eight larger instrument modules are attached to the support structure at both top and bottom. The top connection is loosened by a rotary motion such as an impact wrench. With the 
top connection loosened, the entire weight is supported by the lower connection. A grapple attached to the module supports the weight when the lower connection is loosened. The module is then free to be lowered from the structure into a transport device. The grapple must be small enough in diameter to pass through the head penetration.

Installing a new module is done in the reverse order of that described above. A module is positioned beneath the refueling plug in line with a head penetration. The grapple is attached to the module, pulling it into position, and the connections to the refueling plug are made.

The instrument modules to positions obstructed by the closed loop pipes are exchanged in a slightly different manner. With the top half of the connector removed, there is nothing physically connecting the module to the refueling plug. The module is raised, the shielding step removed, and the module lowered out of the refueling plug. In the lowered position, two necked-down sections of support tube will be aligned with the support collars and allow the module to be moved laterally. New modules are installed in reverse of the above procedure. 


\section{SECTION VII}

HEAD DESIGN FOR THE FFTF BACKUP REACTOR

\subsection{INTRODUCTION AND FUNCTIONAL REQUIREMENTS}

The objective of the conceptual design of the head for the FFTF Backup reactor is to describe a replacement head (or cover) compatible with service activities for the invessel experiments, the vertical reactor core, and the access for the open vessel refueling system of the Backup design. The design compatibility with the vessel for the reference dispersed core reactor design and numerous control and instrumentation leads was to be developed as the reference design became more firm. The reference vessel was assumed to be 15 feet 6 inches in inside diameter with the full opening flange face located at the Refueling Cell floor level. $\mathrm{C}$ and I connectors and utility connections to the head were assumed to be modified, if necessary, from the reference design when the head was installed.

The present design is the result of many engineering design compromises. From the beginning provisions were made for all experimental facility leads and coolant system connections, driver fuel instrumentation (including the FEDAL system conduits), control and safety extension rods and access ports to penetrate the head in addition to access ports for refueling and other incore activities. As anticipated, this approach initially produced many difficult design decisions, but as the design developed; all penetration requirements were met. Any deletion or rerouting of these conduits outside of the head would simplify the head design.

The arrangement of the various penetrations was an attempt to group facilities so they could be properly shielded for immediately-after-shutdown manned access to the top of the head for emergency maintenance. They were also grouped radially from the center of the head with respect to frequency of removal. The most frequently moved facilities were located in the central refueling plug.

The structural requirements for the head were determined primarily by the design concept that the head and its pertinences should be designed to remain intact during the Design Basis Accident (DBA). The energy imparted to the head would be absorbed in stretch hold-down bolts. At this time, it was assumed that some reaction products, cover gas, and sodium would be released to the inerted refueling cell during the DBA. The impact to the head was estimated to be about $3 \%$ of the $1500 \mathrm{MW}-\mathrm{sec} \mathrm{DBA}(45 \mathrm{MW}-\mathrm{sec})$ which would give the head an initial acceleration of 50 to $100 \mathrm{~g}$ (depending on the mass of the head). The stiffness of the structure to accommodate this impact is much greater than would normally be required to support the plugs and the head attachments such as the control drives and $C$ and I lead connectors. 
To summarize, the vessel head functional requirements include provisions for:

a. Rapid access to driver fuel, instrumentation, and incore experimental facilities.

b. Adequate biological shielding for personnel access immediately after shut down to the top of the head.

c. Containment of primary sodium coolant and vapor (except during a DBA).

d. Adequate structure to support test facilities, the control drives and to minimize DBA effects of impact energy, internal pressure, and sodium (water) hammer effects on the head.

e. Access to all invessel reactor and experimental facility component parts.

f. Cooling (and heating) the head structure, vessel flange and numerous head penetrations.

g. Adjustment of the head location to realign the center of the head and the core after the plant has been operated.

The conceptual design and supporting analyses presented in the following sections indicate the feasibility of providing a head design that will provide the preceding functional requirements. This design consists of three major concentrically nested components plus numerous individual penetrations for the experimental, control, and instrumentation system leads. The three major components are the box-girder fabricated-ring head (20 feet o.d., 7 foot i.d. $\sim 150$ tons), the solid-plate annular reflector plug (7 foot o.d., $4 \mathrm{ft} 5$ in. i.d. $\sim 15$ tons), and the solid-plate refueling plug ( $4 \mathrm{ft} 4 \mathrm{in} .0 . \mathrm{d}$. $\sim 8 \mathrm{tons}$ ). Each of these head structures have about 30 inches of thermal insulation and the head has a sodium (water) hammer resistant structure attached below the insulation.

Two variations of the head design were being considered at the time of the premature termination of this conceptual design. Although both designs utilized many identical components, the major difference was the cross-section of the head structure. The "reference" design is deeper at the annular reflector plug interface and then tapers to a thinner structure above the vessel flange while the alternate design is a flat box girder ring. The advantage of the alternate design is structural design simplicity while the reference design permits the top of the reflector and refueling plugs to be about 20 inches closer to the core. Many design trade offs in the plug penetrations are insufficiently detailed at this time to conclude which of the head designs are preferable, but it appears that both are feasible and suitable for continued design.

\subsection{HEAD DESIGN DESCRIPTION}

The vessel head for the FFTF Backup Design consists of three concentric nested annular and disk structures. With the exception of the primary coolant system and auxiliaries, all sodium and electrical conduits, access ports, and control drive extension rods that service the experiments and core, penetrate the head. These conduits and rods are sealed in the head 
region to prevent leakage of sodium vapor into the refueling cell. Most of the seals are applications of mechanical and freeze (or vapor trap) type seals.

Forty-eight stretch bolts are located at the periphery of the head and are anchored in the building structural frame (and/or the vessel foundation). All head penetration gear and the two plugs are mechanically fastened to the head structure. This provides an integral cover for the vessel during a DBA. (Reaction products, vapor and sodium leakage are permitted only during the DBA).

To provide as thin (less thick) and as light a head as possible, cooling coils are installed about 3 feet above the high temperature sodium pool and below the steel head structure. Thus, the structural steel operates at a temperature where its physical properties are high. Other advantages of the cool head structure include minimum vessel foundation allowances for temperature, a cool base to mount control drives, and many connectors for the leads penetrating the head, and to provide cooling for the sodium vapor freeze seals. The shape temperature gradient between the pool and the structure is controlled by the installation of thermal insulation.

Biological shielding is provided by adding steel shot to fill the spaces within the head structures and by adding high density materials or mechanical steps and filler pieces to attenuate the radiation in streaming paths. The principal source of radiation is the activated sodium coolant in the pool below the head. The core radiation leakage is partially attenuated by the material between the core and the sodium surface. In this 18 foot space, the attenuation is provided by the reflector, fission gas storage portion of the fuel pins, 4 feet of steel shielding, assembly handles, plus 11 feet of sodium. Initial shielding calculations indicate that this source and the sodium pool source can be attenuated to tolerable levels by 2 feet of steel or the equivalent in the head.

The refueling plug has many design requirements since it provides the driver fuel instrumentation structure which extends about 15 feet below the plug structure as well as the other plug requirements. Because of the inherent fragile nature of the driver fuel instrumentation packages at the lower extremity of the plug, the necessity of locating the instrument packages within the fuel subassembly handles and a relatively close fit of the plug for shielding and vapor sealing, a mechanical guidance system is proposed. In addition to locating and guiding the plug, this system also protects the control drive units (which remain operative during refueling) from mechanical damage. This system is described in more detail later in this section.

The head design is described in the following six drawings which implement the following analysis sections. Significant items in each figure are noted below.

\subsubsection{Figure 7-1: Plan View of the Top of the Head}

- This drawing applies to both the reference and alternate head designs.

- Six branch piping and sodium fuel leak detector line shield covers and pipe routing. The six shields weigh almost as much as the head. At present they are supported by the head. 
- Dotted lines indicate typical locations of the closed loop branch piping and the FEDAL system sodium sample lines. The branch piping is separated below the reflector plug to implement pipe support when the reactor tube is disconnected. Shield holddown structures are not shown, but are required.

- The number and diversity of mechanical operators and instrumentation leads that penetrate the central refueling plug $(\sim 4 \mathrm{ft}$ diam) and the annular reflector plug $(\sim 7 \mathrm{ft}$ diam).

- Twelve plug access holes in the reflector plug for core tightening and general access.

- Six access holes (larger than necessary for clamping) in the head for core tightening and auxiliary purposes such as invessel lighting and viewing.

- The twelve largest circles near the branch piping shields represent spring hangers for the piping and do not penetrate the head.

- The equally spaced holddown bolt location near the periphery of the head. Closed loop piping shields are removed for covered bolt maintenance.

- The circumferential broken line at about $3 / 4$ of the head diameter indicates the vessel diameter.

\section{2.2 Figure 7-2: Elevation B-B of the Reference Head - Sodium Sample Lines}

- Nonuniform cross-section of the head structure is apparent:

- ' Fuur lnches uf cumpartmentized wall type insulation and 11 inches oi lead̃ snieiding are shown around the branch and FEDAL system piping.

- Note location and route of FEDAL system sodium sample lines from the driver fuel elements. Fluid jump connectors are used in both plug interfaces. All lines are disconnected when the plugs are removed.

- The refueling and reflector plug structures are solid steel. The cooling ducts near the bottom of the structure are recessed therein. The 18-inch thickness is required for bulk shielding requirements. Structurally the refueling.plug requires only about 8 inches of steel. The surface of the plugs are below $(\sim 3-1 / 2$ in.) the flange datum level.

- The shear rings that transmit DBA impact energy from the plugs to the head are shown on either side of the control drive rod penetration near the upper plate. They are located as high as possible for convenient access or maintenance. 


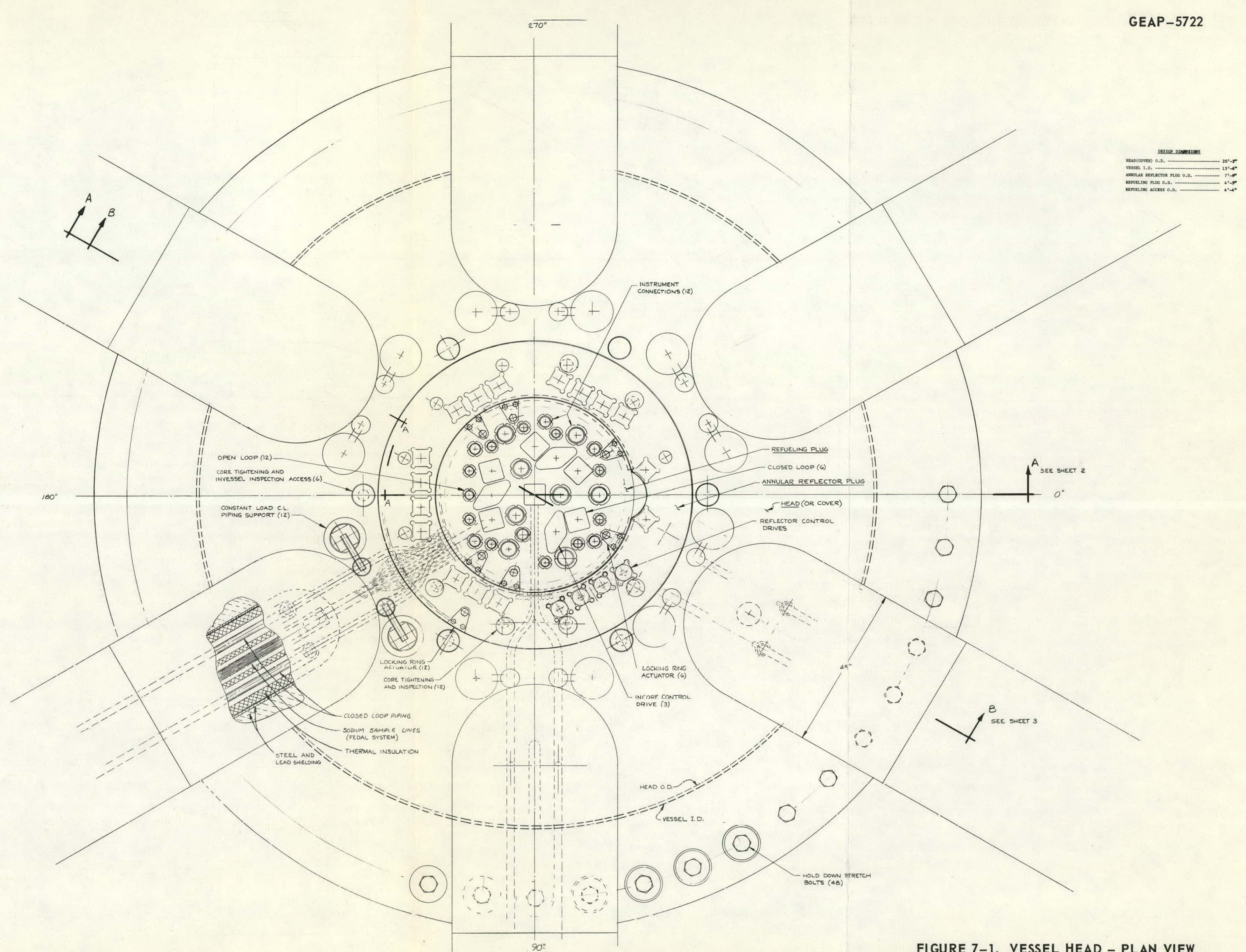




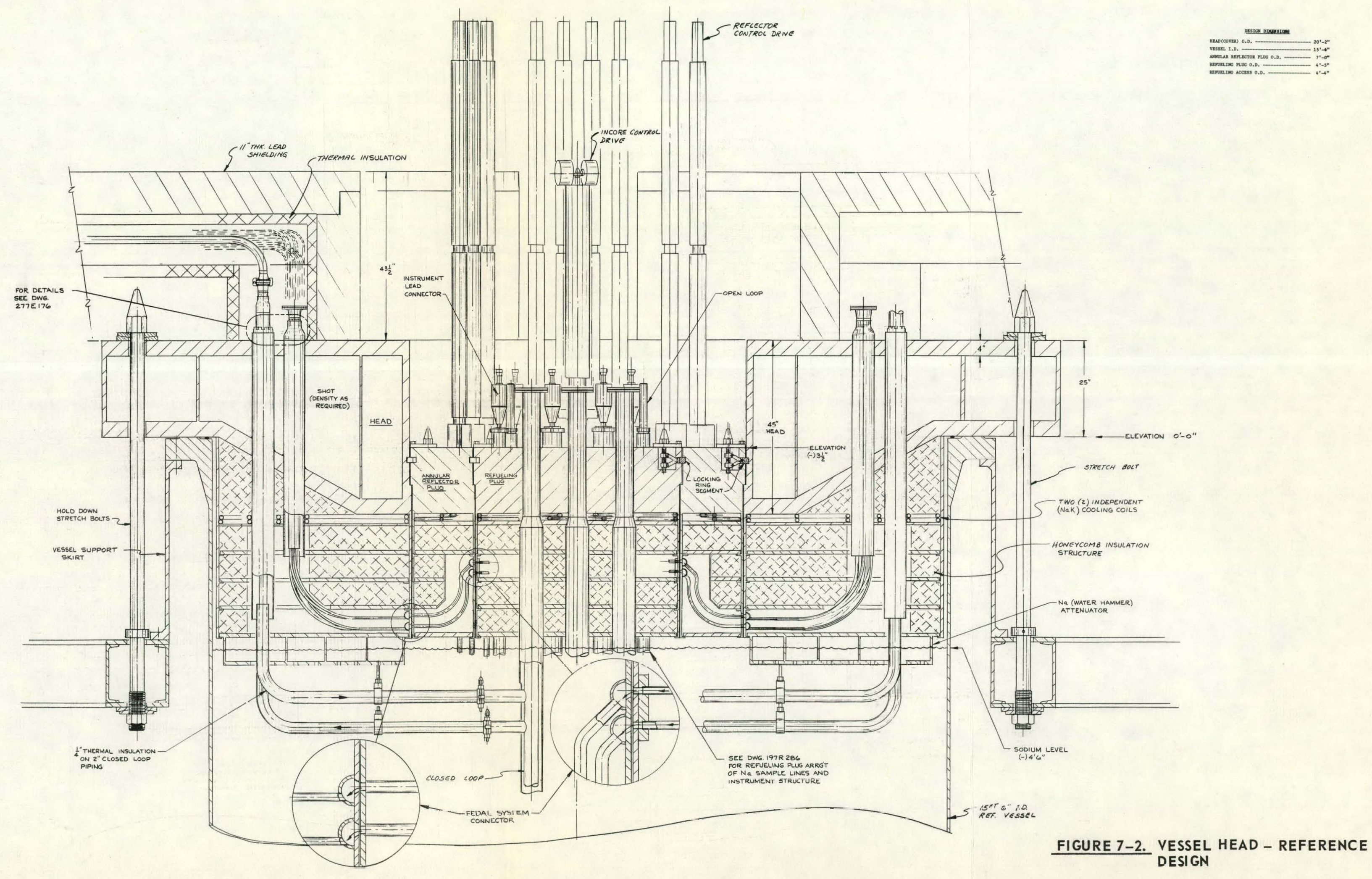




\subsubsection{Figure 7-3: Elevation of the Alternate Head}

- Uniform cross-section, flat head structure

- Additional insulation or energy absorption material between head structure and the cooling coils.

- Elevation of the top of the plug is above $(\sim 18 \mathrm{in}$.$) the vessel flange level.$

\subsubsection{Figure 7-4: Reference Head Structure}

- Structural details of the reference head.

- Additional details of the closed loop branch piping and FEDAL system sodium line penetrations and mechanical seals.

- Below the head structure are four layers of metallic thermal insulation (and/or energy absorbing) material and below this is the sodium (water) hammer attenuator. The coolant to structure temperature gradient occurs across the insulation layers.

\subsubsection{Figure 7-5: Head Penetrations}

- Typical elevation cross-section of each type of plug penetration. Alternate head penetrations are similar except for length.

- Typical plan cross-section of each type of plug penetration indicates relative size and attempts to adequately shield the streaming paths.

\subsubsection{Figure 7-6: Plug Cooling Coils}

- Elevation of this figure is at (-) $18 \mathrm{in.}$ for both the reference and the alternate head drawings .

- This section shows a conceptual layout of the plug cooling coils. A redundant system is shown in each plug. Head cooling is not shown yet.

- Plug penetration sizes and locations are not apparent.

- Location of the two branch pipes for each closed loop and the sample lines are shown at ahout mid-radius of the head. Note proximity of vessel and head circumferences. Clearance shown allows 1 inch head adjustment to recenter core and head.

\subsection{STRUCTURAL DESIGN}

\subsubsection{Loading}

A number of configurations have been investigated on the closure for the pressure vessel (heads and plugs). The investigations were limited to the thermal and structural analyses 
required to demonstrate feasibility and are not to be construed as complete or final. In some cases, the investigation is very preliminary in nature, carried only far enough to indicate a conclusion on feasibility.

The loading on the heads from the design basis accident is so severe that it dwarfs the other sources of loading, and the feasibility primarily is determined from resistance to the loading from the DBA. The design basis accident has been determined as the explosive release of $1500 \mathrm{MW}-\mathrm{sec}$ of energy. Of this release it is estimated that $3 \%$ of the energy $(45 \mathrm{MW}-\mathrm{sec})$ will reach the head (refer to Section XI for details). If this energy is delivered as impulsive loading to the estimated head weight of 530,000 lbs (including shielding weight), the instantaneous velocity of the head, by an energy balance, would be $63.5 \mathrm{fps}$ :

$$
\begin{aligned}
\mathrm{E}= & 45 \mathrm{MW}-\mathrm{sec}=33.17(10)^{6} \mathrm{ft} \mathrm{lb}\left(\text { or } 398 \times 10^{6} \mathrm{in} . \mathrm{lb}\right)=\frac{1}{2} \frac{\mathrm{W}}{\mathrm{g}} \mathrm{V}^{2} \\
= & \frac{1}{2} \frac{5.3(10)^{5}}{32.2}(\mathrm{~V})^{2} \\
& \mathrm{~V}=\sqrt{\frac{33.17(10)^{6}(2)(32.2)}{5.3(10)^{5}}} \sim 63.5 \mathrm{fps}
\end{aligned}
$$

The weight of the head has been estimated from the shielding required for the vessel content ( 2 feet thickness of steel), plug the shielding required for the piping to the closed loop test positions ( 11 inches thickness of lead). The respective weights are 320,000 pounds for the steel and 210,000 pounds for the lead for a total weight of 530,000 pounds for the head and appurtenances. The diameters and other geometrical features are shown in Figures 7-1, 7-2, and $7-4$.

The loads occasioned by nonuniform distribution of both impulse and mass will occasion loads between separate components of the head which must be transmitted by deformable shear ties in order to absorb energy and balance the energy distribution within the head. Development and firmer design preferably based on experimental model information must precede the final concept for these shear elements. The principal loading for the head will be deceleration from the initial velocity by the stretch bolts used to absorb the energy of the impulse. For preliminary design, these bolts have been estimated as forty-eight $3-1 / 2$ inch diameter upset bolts with a shank area of $9.62 \mathrm{sq}$. in., an ultimate strength of 60,000 psi, a yield strength of $30,000 \mathrm{psi}$, and a elongation of $40 \%$. Using the ultimate strength of the bolt to achieve maximum deceleration, the ultimate bolt load is computed to be:

$$
\begin{aligned}
& \mathrm{B}=\sigma_{\mathrm{u}} \mathrm{A}=60,000(9.62)=577,200 \text { pounds each. } \\
& \text { from } \mathrm{F}=\mathrm{ma}, 48(577,200)=\frac{5.3(10)^{5} \mathrm{a}}{\mathrm{g}} \\
& \text { or } \quad \mathrm{a}=\frac{48(577,200)}{530,000} \mathrm{~g}=52.3 \mathrm{~g} .
\end{aligned}
$$

A loading of $53 \mathrm{~g}$ has been used to design the head, the plugs, component hold downs, and stresses as compared to the yield strength of $30,000 \mathrm{psi}$, for adequacy. Therefore, the principal loading is the deceleration loading amounting to 660 psi equivalent on the outer head and $375 \mathrm{psi}$ on the inner disk and intermediate ring. This loading is considered common to all concepts. 


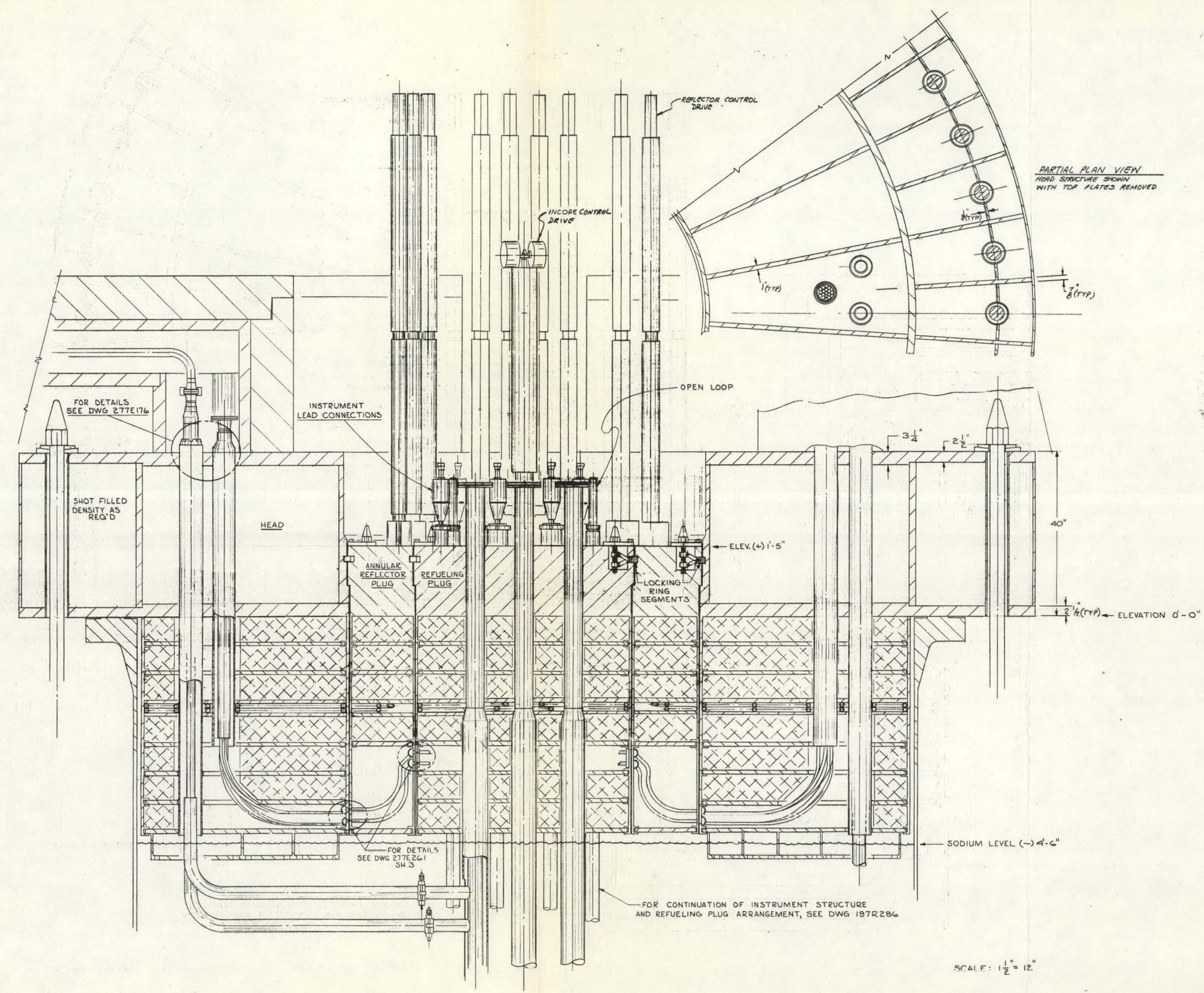



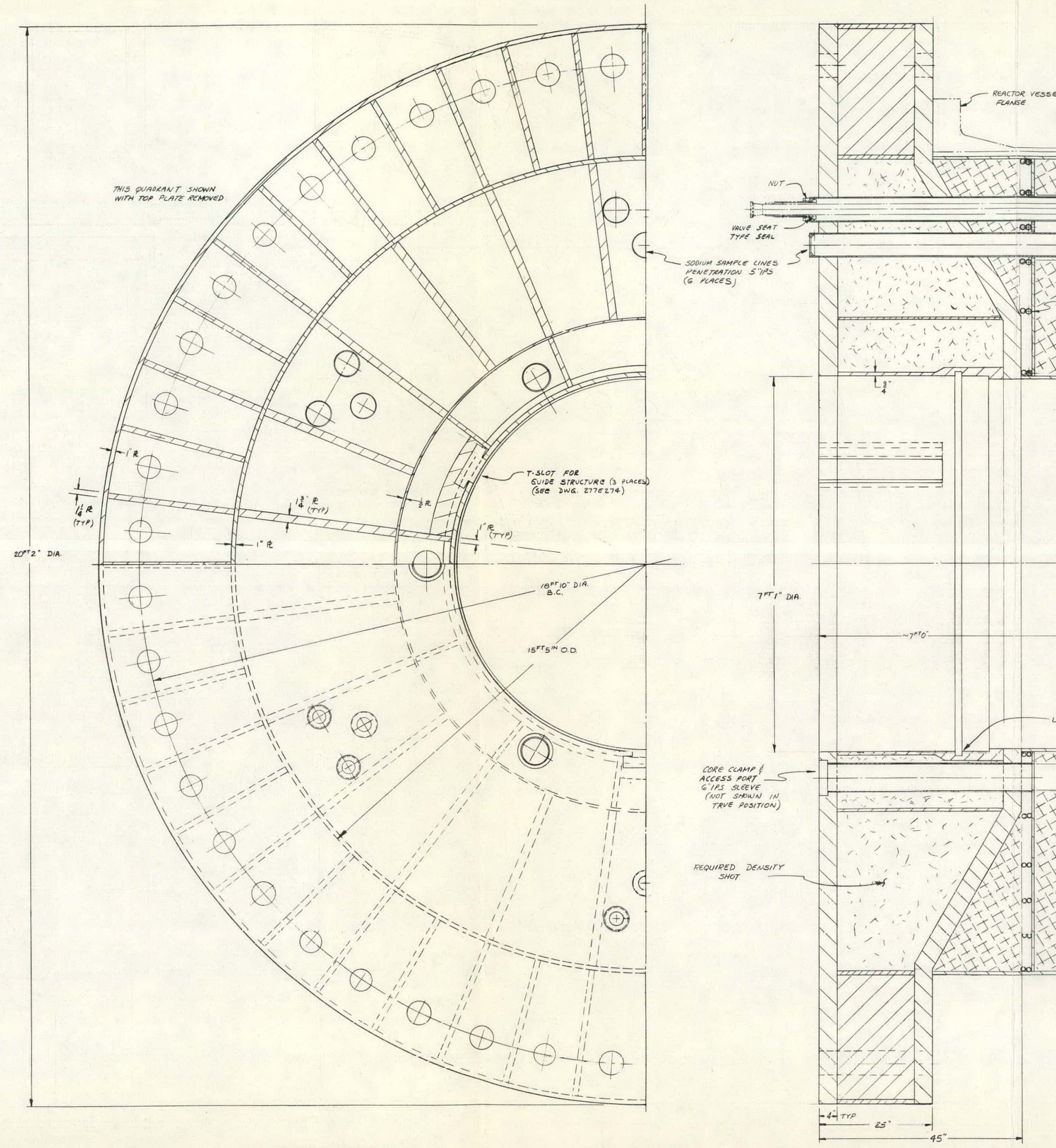


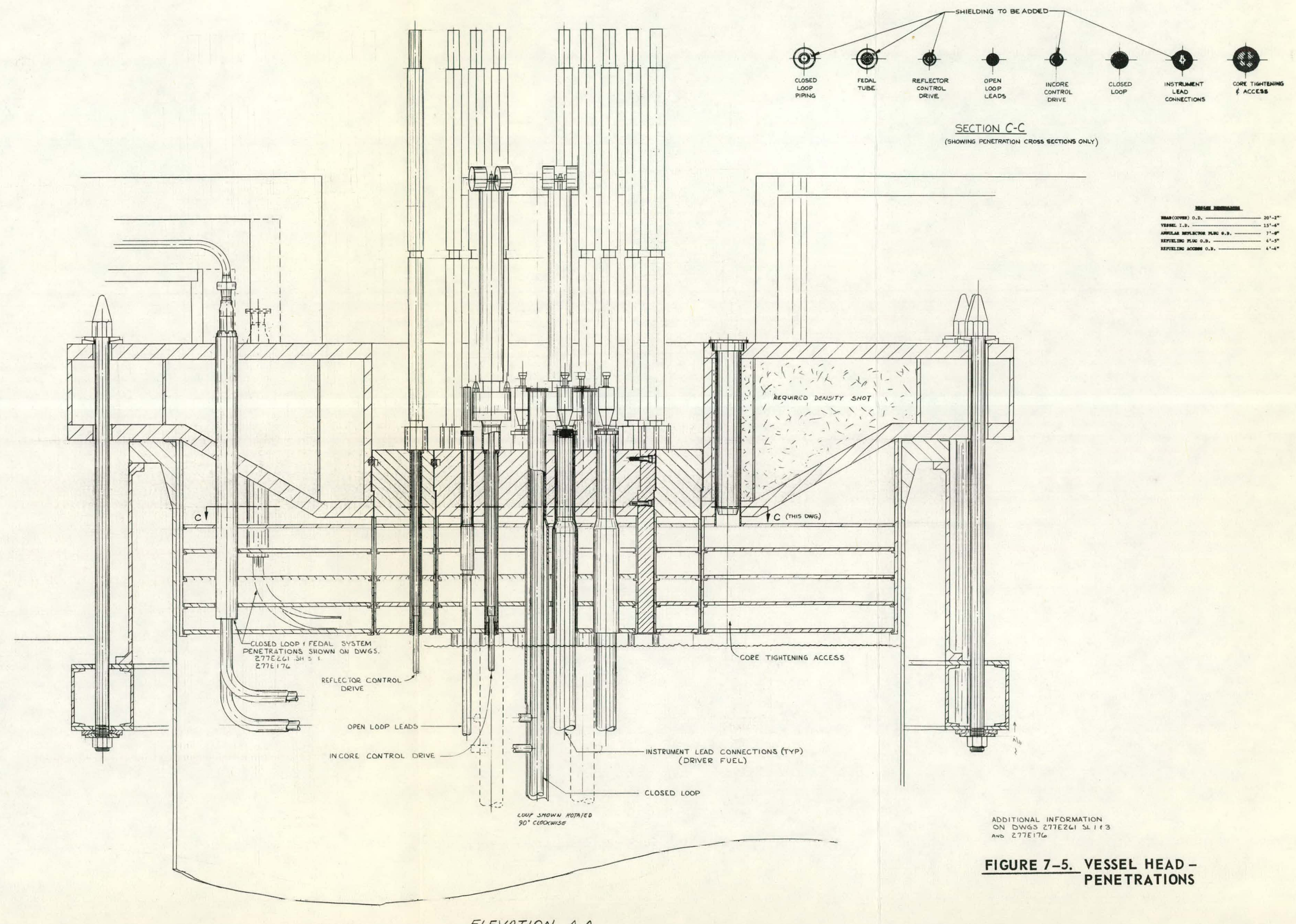




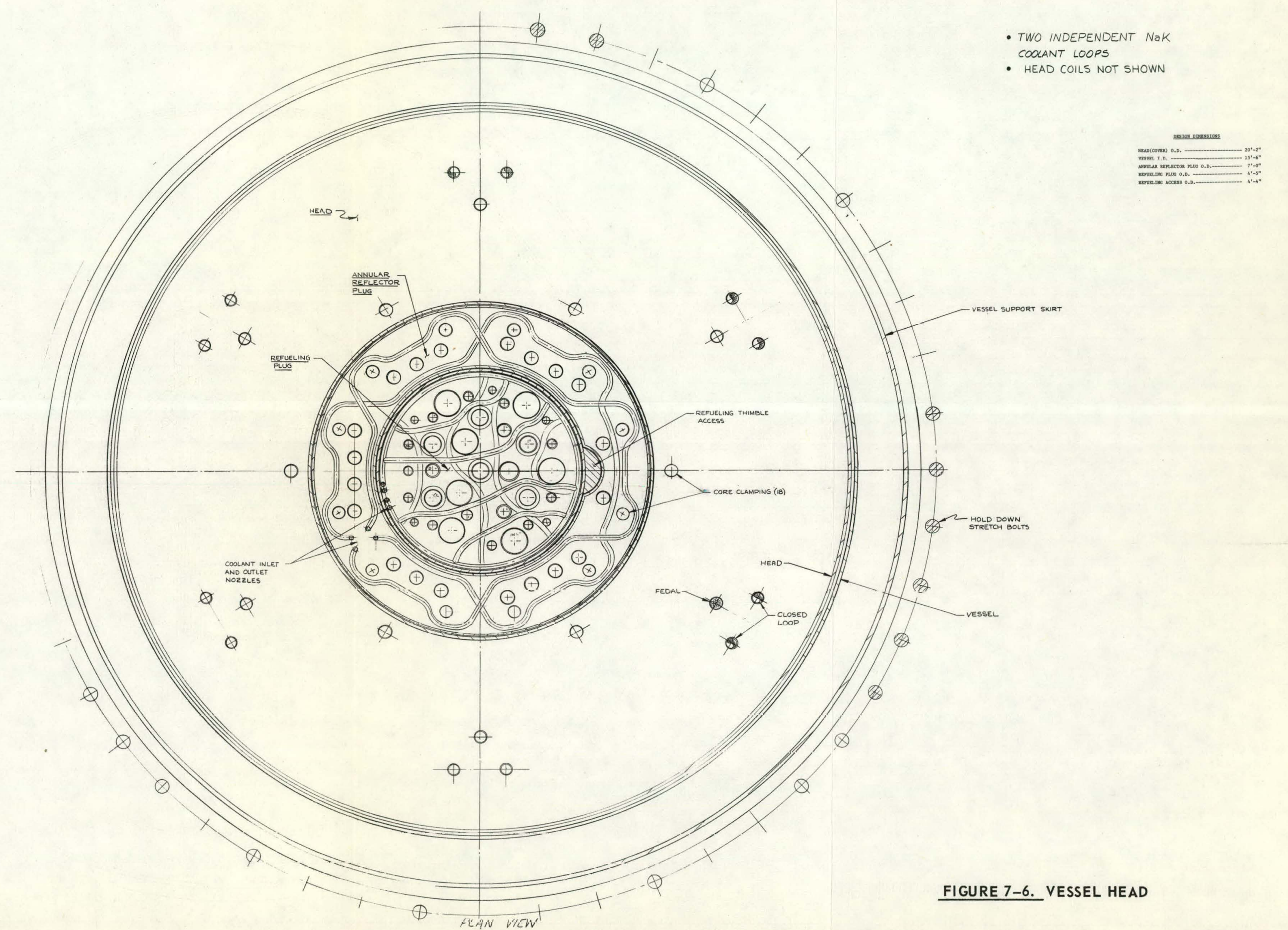


Using average between yield and ultimate strength for the plastic work of the bolts, and equating the plastic work to the energy of the head, results in elongation of the bolts:

$$
\begin{aligned}
& L \in \sigma A=E \\
& \text { or } \quad \in L=\frac{E}{\sigma A}=\frac{398(10)^{6}}{\left(\frac{60,000+30,000}{2}\right)(9.62)(48)}=19.15 \mathrm{in} .
\end{aligned}
$$

Using an elongation of $20 \%$, the stretch length of the bolt must equal:

$$
\frac{19.15}{0.20}=96 \text { inches. }
$$

\subsubsection{Reference Design}

The reference design is shown in Figures 7-1 and 7-2 and consists of three major components: the refueling plug, the annular reflector plug, and the head. The three components must be connected by deformable shear members in order to balance the energy distribution between the differing mass-to-impulse ratios for uniform initial velocity. This feature has not been investigated thoroughly. The refueling plug and annular plug have been analyzed as edgesupported, flat, pierced, solid plates by conventional means. The requirement for shielding mass does not permit weight reduction and this represents a simple and straightforward structure. These two elements are common to all the alternates reviewed and will be assumed unchanged with alternate schemes.

The head is a fabricated box girder plate of variable depth, with radial and circumferential shear webs, that supports the other components as well as furnishing the major area of closure. A computer program was available that is suitable for the solution of solid axisymmetrical plates of variable thickness and loading. Approximating the head by a solid plate of the same section modulus and same radial geometry with the same loading will result in equivalent stresses and moments in the two plates, even though the deflection will not be similar. The shcar etresses will also be dissimilar. These differences will not affect the moment distribution of the equivalence, thus the principal moments and the principal stresses other than shear should equate equal between the plates.

It is therefore possible to analyze the head structure for the moments obtained from the equivalent solid plate. Figures 7-7 and 7-8 show the solid plate equivalent of the reference design with graphs of moment, shear, and effective stress versus radius for the equivalent plate. Analysis indicates that the structure does not exceed yield stress for these moments, and because of the greater thickness, should have deflections smaller than the equivalent solid plate.

Radial and circumferential shear webs have been added and sized to distribute the shear loading shown on Figure 7-8 without exceeding the shearing stress which would cause yielding in the material (304 SS). In computing the webs, the radial webs are sized to carry the shear load for their tributary area minus the contribution made by nonparallel flanges, if any. The circumferential webs must distribute the shear load in radial webs that are discontinuous, the 

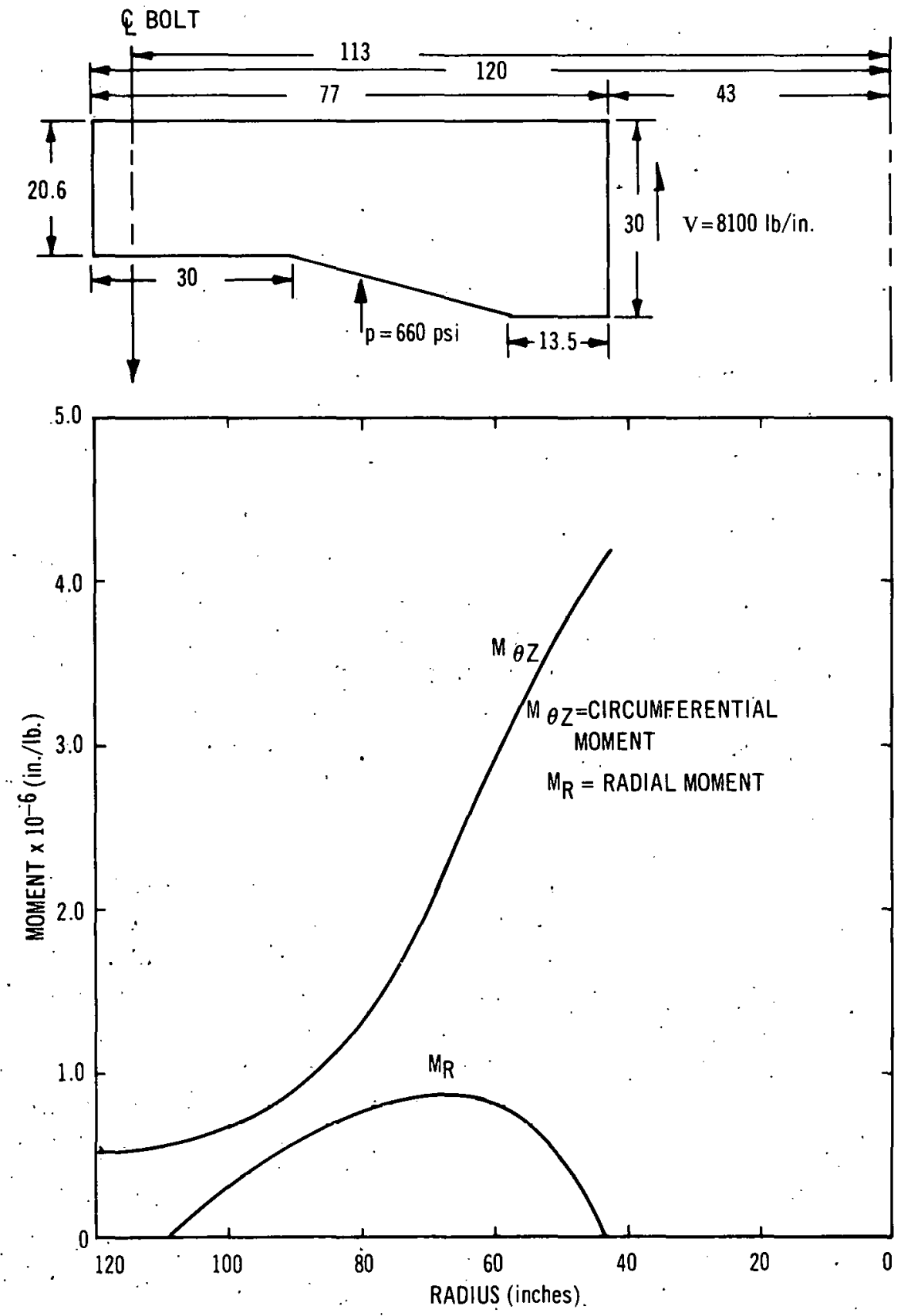

FIGURE 7-7. REFERENCE HEAD DESIGN, SOLID PLATE EQUIVALENT: MOMENTS 

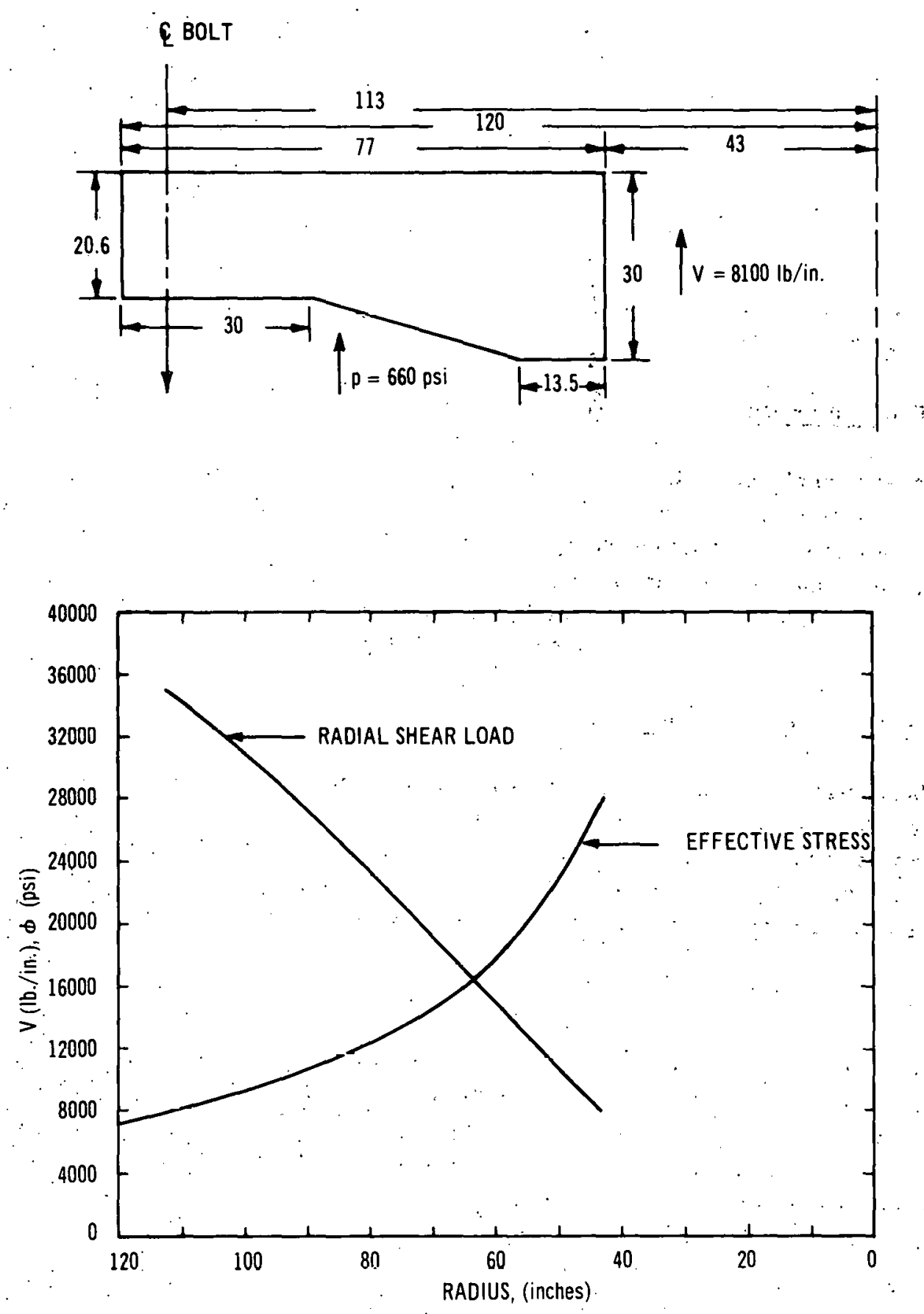
shears being carried by nonparallel flange material where a change of slope occurs and by any nonuniform loading. In addition, they must resist the vertical component of flange load as a column at any point where the slope of the flange material changes. The stresses in the flange plates caused by local bending as a result of distributing load to the shear webs have been added to the primary bending stresses prior to comparison of the combined stress with yield stress of the material.

The refueling plug and the annular reflector plug were analyzed as edge-supported solid but pierced plates. The stresses were computed from the minimum geometry (ligament width divided by pitch of holes) as though a uniform pattern existed, and the required thickness was less than the minimum required for shielding. Thus, there was no incentive for reducing the weight of these elements.

\subsubsection{Flat Plate Head}

A design employing a flat fabricated box-girder plate head is shown in Figure 7-3. The inner components would be unchanged from the reference design. Figures 7-9 and 7-10 show the solid plate equivalent with graphs of moment and deflection versus radius. The translation from this solid equivalent to the fabricated plate was accomplished in a manner similar to that employed for the reference design. In this concept, local additional shear members to distribute the bolt loads would be required as shown on Figure 7-3.

\subsubsection{Additional Head Concepts}

There were additional concepts investigated to attempt optimization of geometry, but these are of principal interest only to illustrate that the moments seek to follow the rigidity of the plate. As a portion of the plate is increased in stiffness (thickness), the moment for this section also increases. The solid plate equivalents are shown in Figures 7-11 to 7-16 with the moment diagrams and illustrate the relationship between stiffness and relative moment of a section.

\subsubsection{Dished Head Design}

For a conventional spherically dished head (with the radius equal to the diameter of the vessel), the thickness of head required is approximately 4 inches with about a 12 -inch thick flange. The plug elevation with this concept must necessarily be raised above the flange of the vessel. For a reversed dished head (concave side up), the thickness required is approximately 15 inches to resist the compressive loading.

\section{3.6 Conclusion of Loading Analyses}

The head configuration choice is not clear between the reference design and the alternate concept. Each have desirable features as well as disadvantages, and the final choice will probably have to probe deeper than structural advantage. The dished head would be economical of material for concave side down (toward pseudo-pressure) but has the disadvantage of increasing the overall height. The reversed dish does not offer any clear structural advantage. It seems that the choice is limited to the first two concepts. 

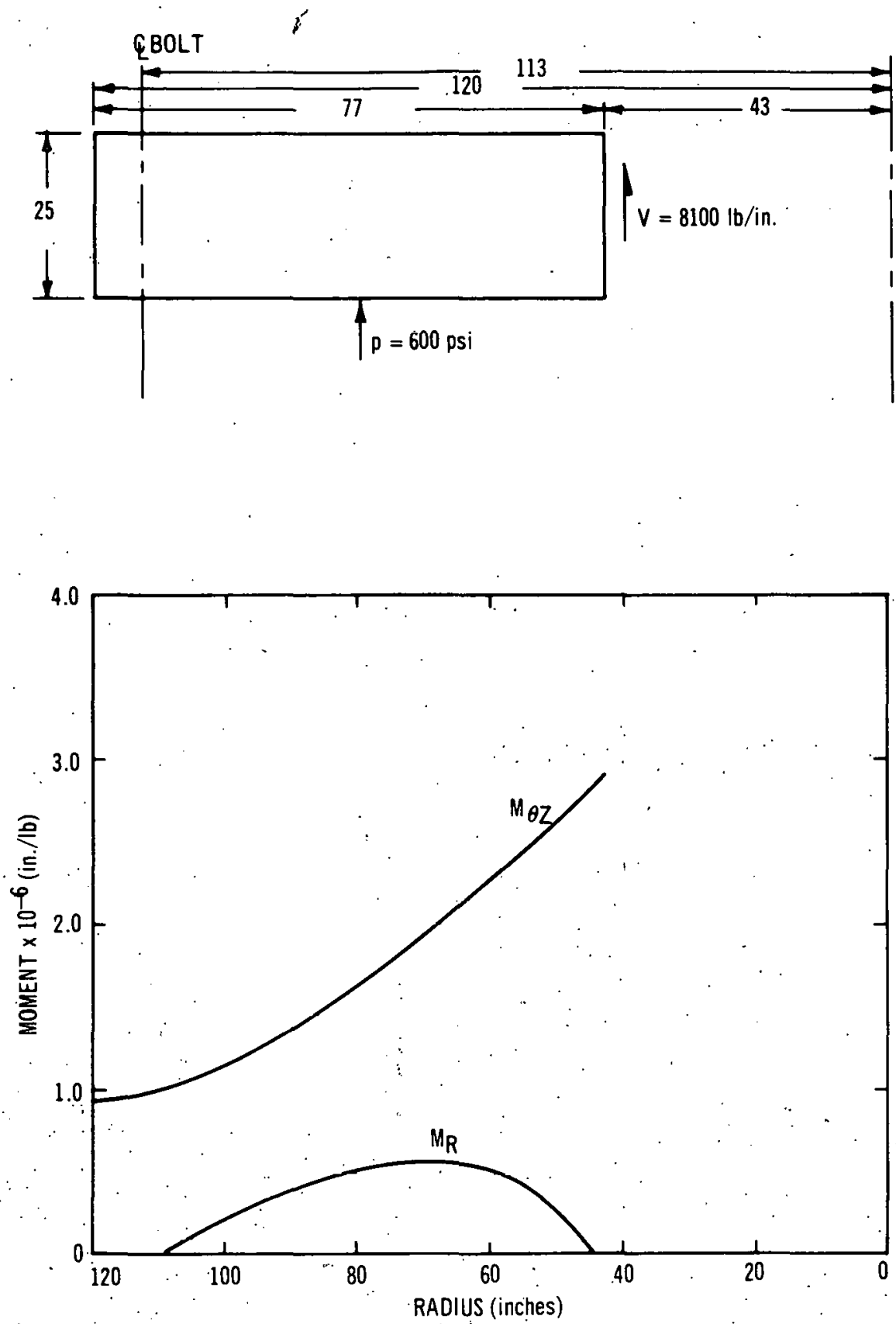

FIGURE 7-9. FLAT PLATE: DESIGN MOMENTS 

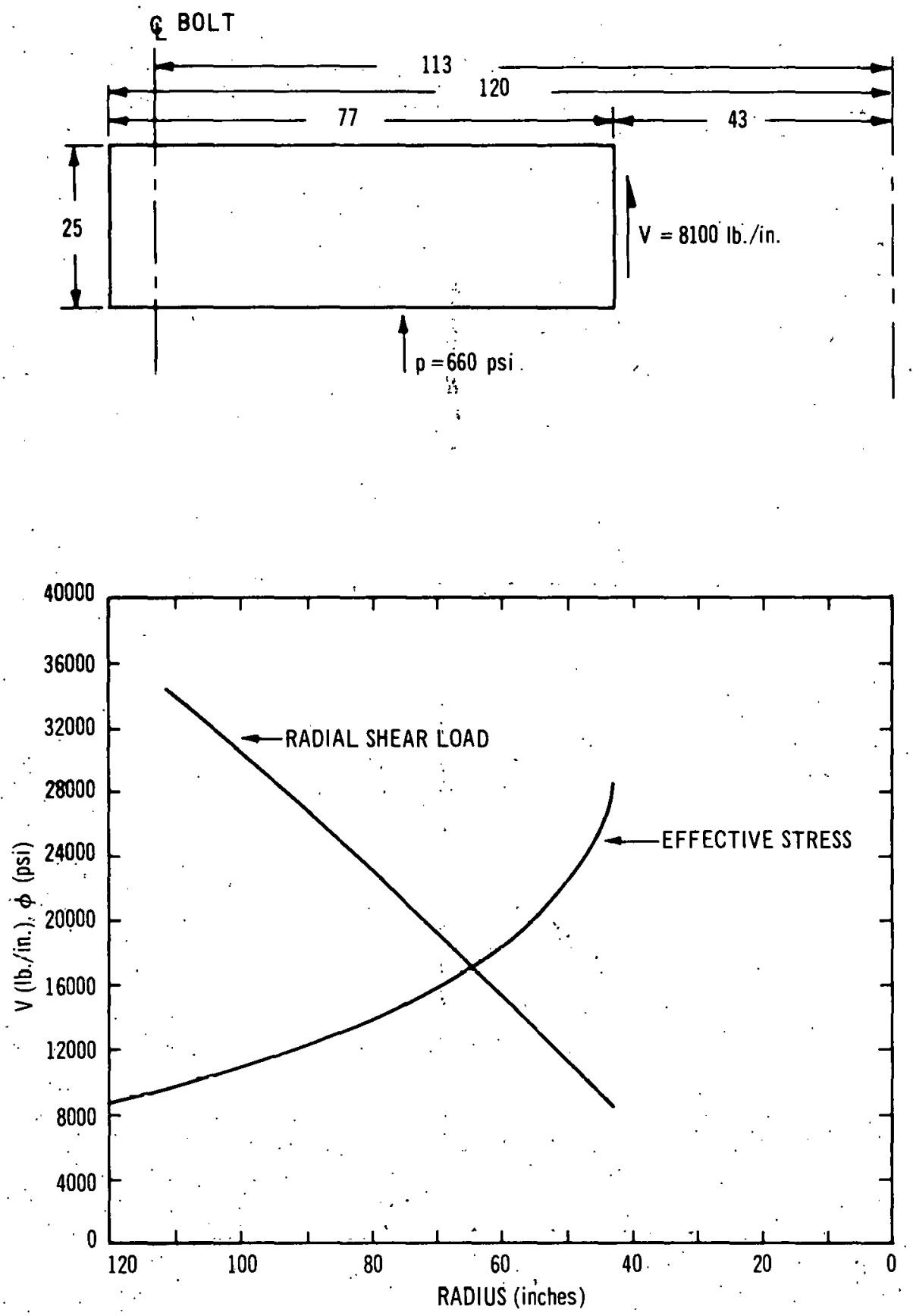

FIGURE 7-10. FLAT PLATE DESIGN: SHEAR AND STRESS 

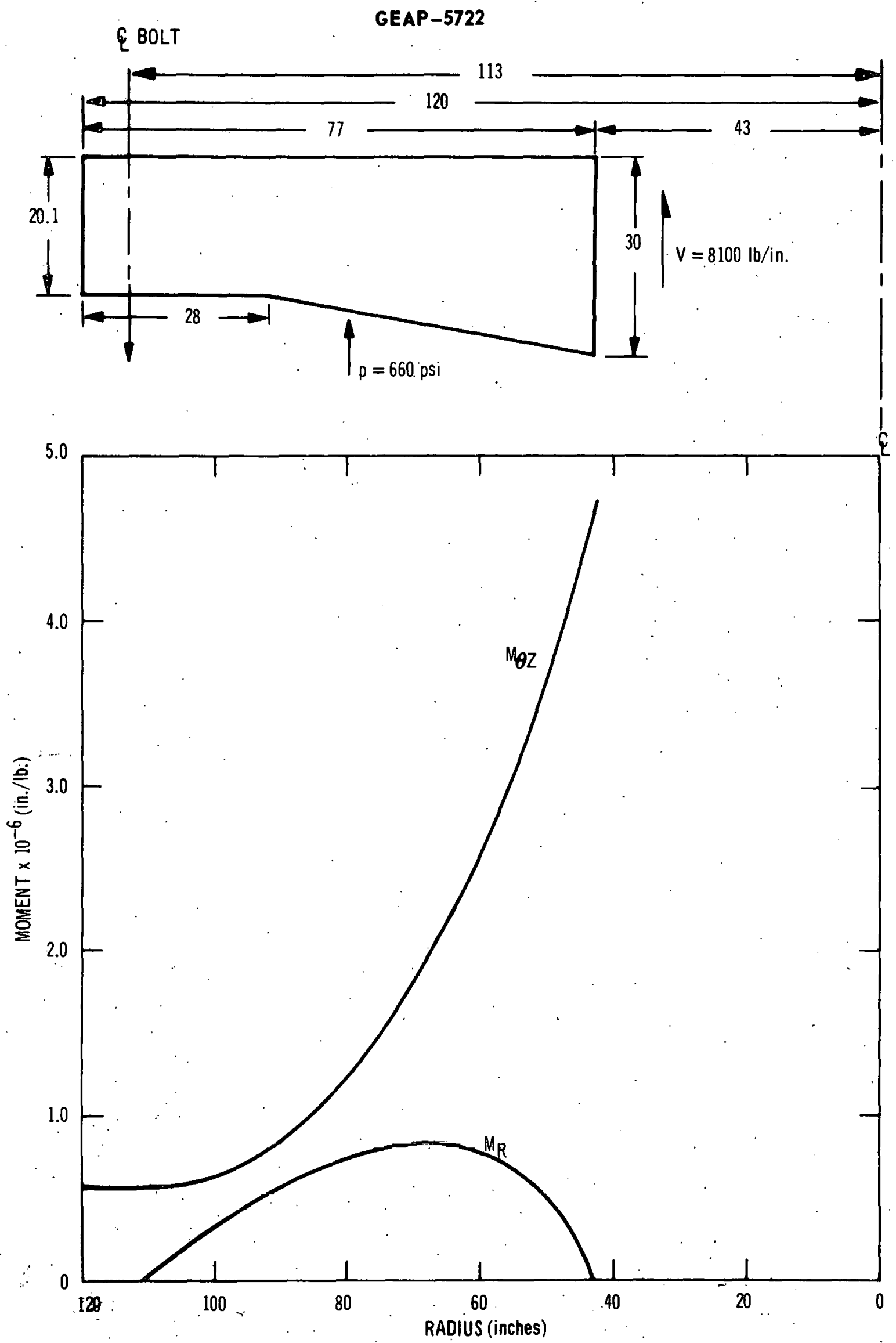

FIGURE 7-11. TAPER PLATE No. 1: MOMENTS 

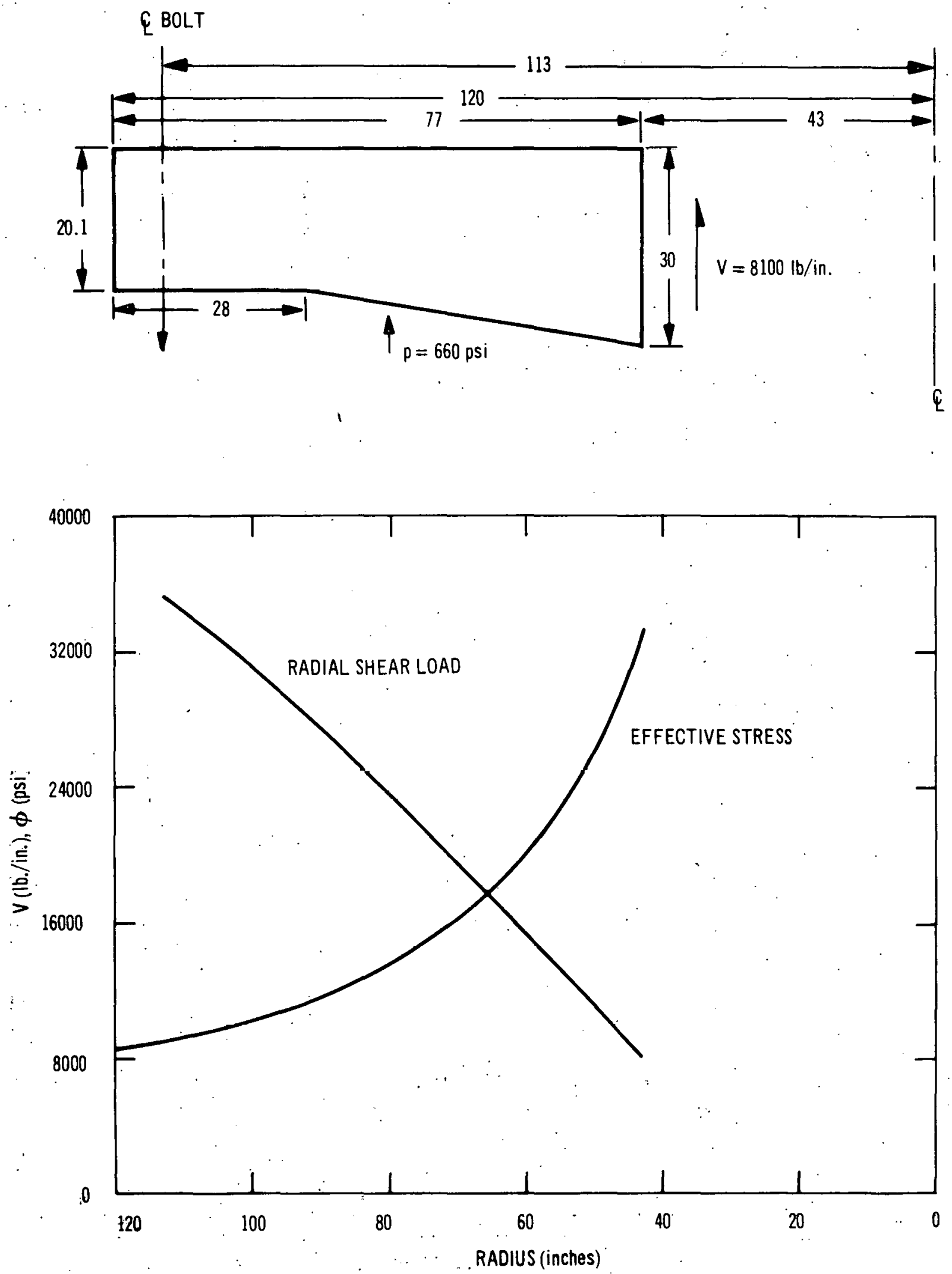

FIGURE 7-12. TAPER PLATENo. 1: SHEAR AND STRESS 

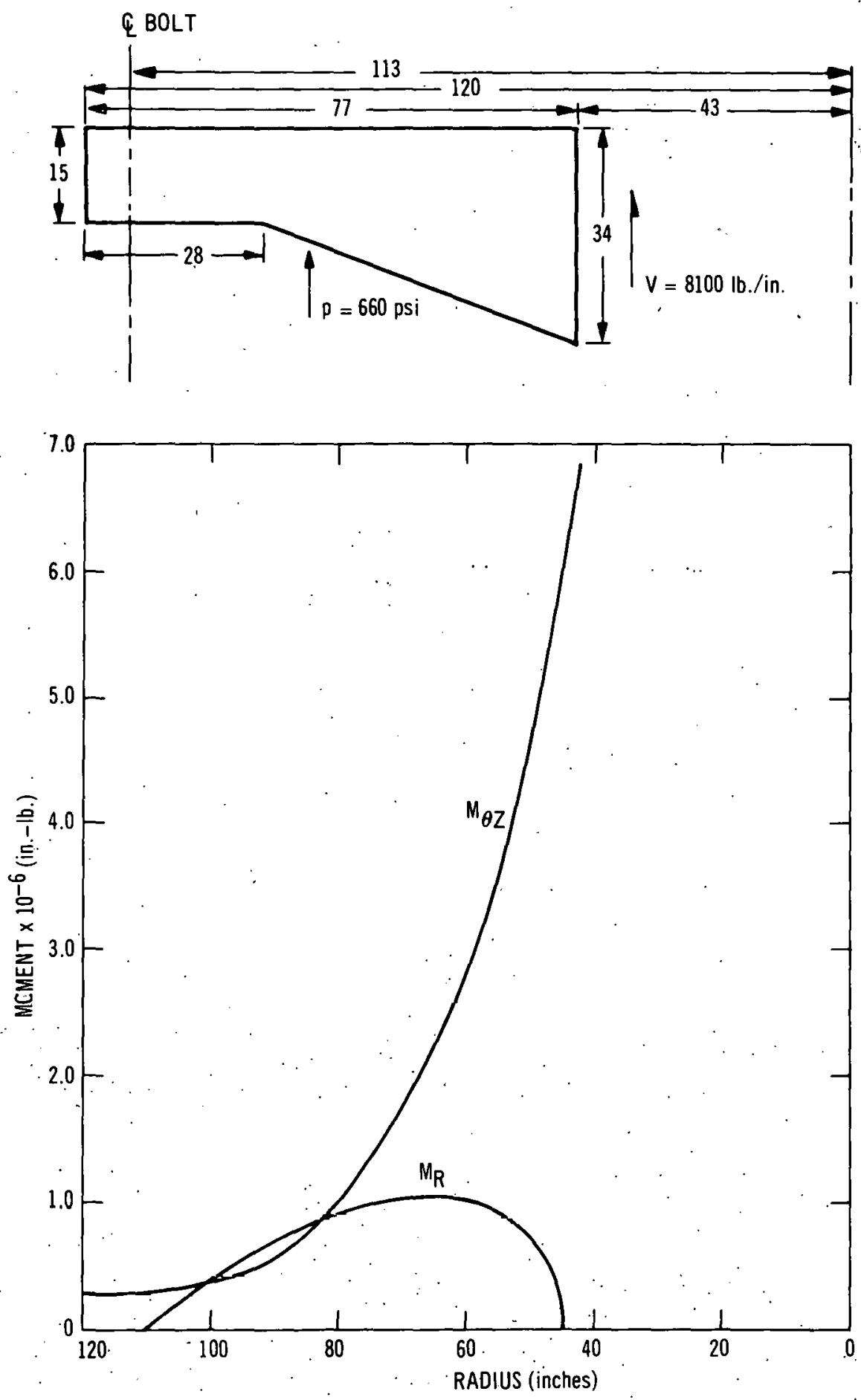

FIGURE 7-13. TAPER PLATE NO. 2: MOMENTS 
GEAP-5722
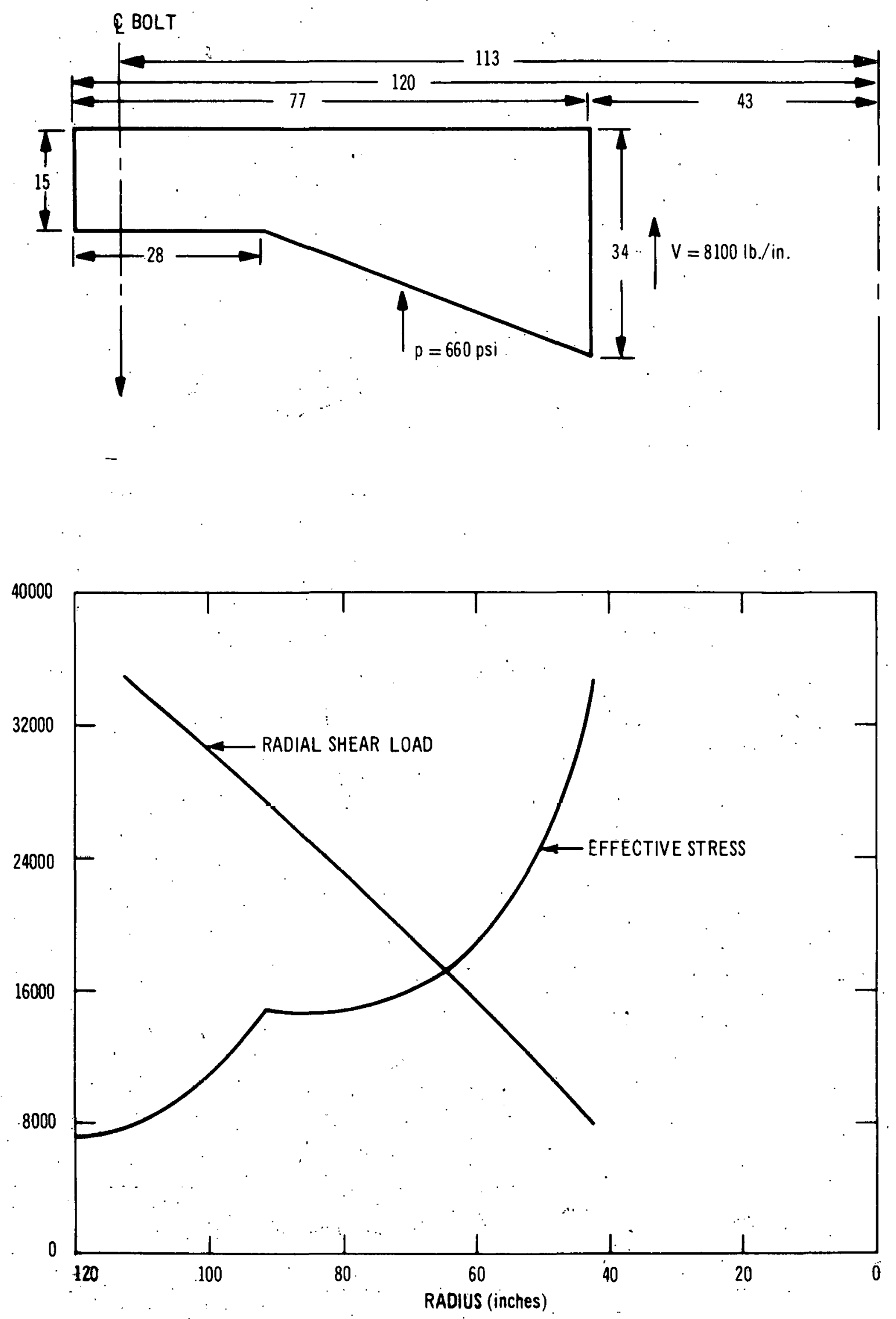

FICURE 7-14. TÁPER PLATEE No. 2: SHEAR AND STRESS

$$
7-28 \text { ! }
$$



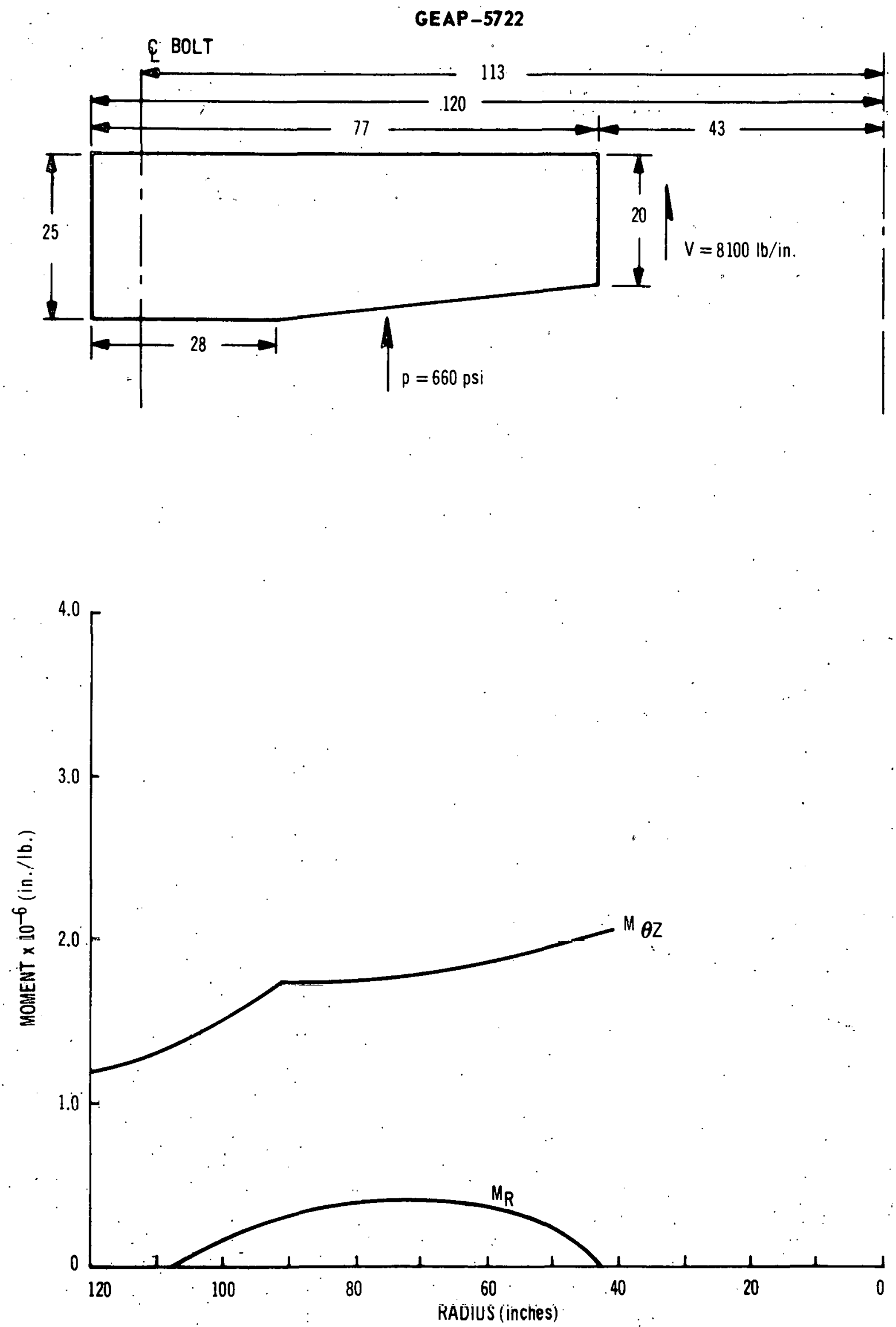

FIGURE 7-15. TAPER PLATE No. 3: MOMENTS 

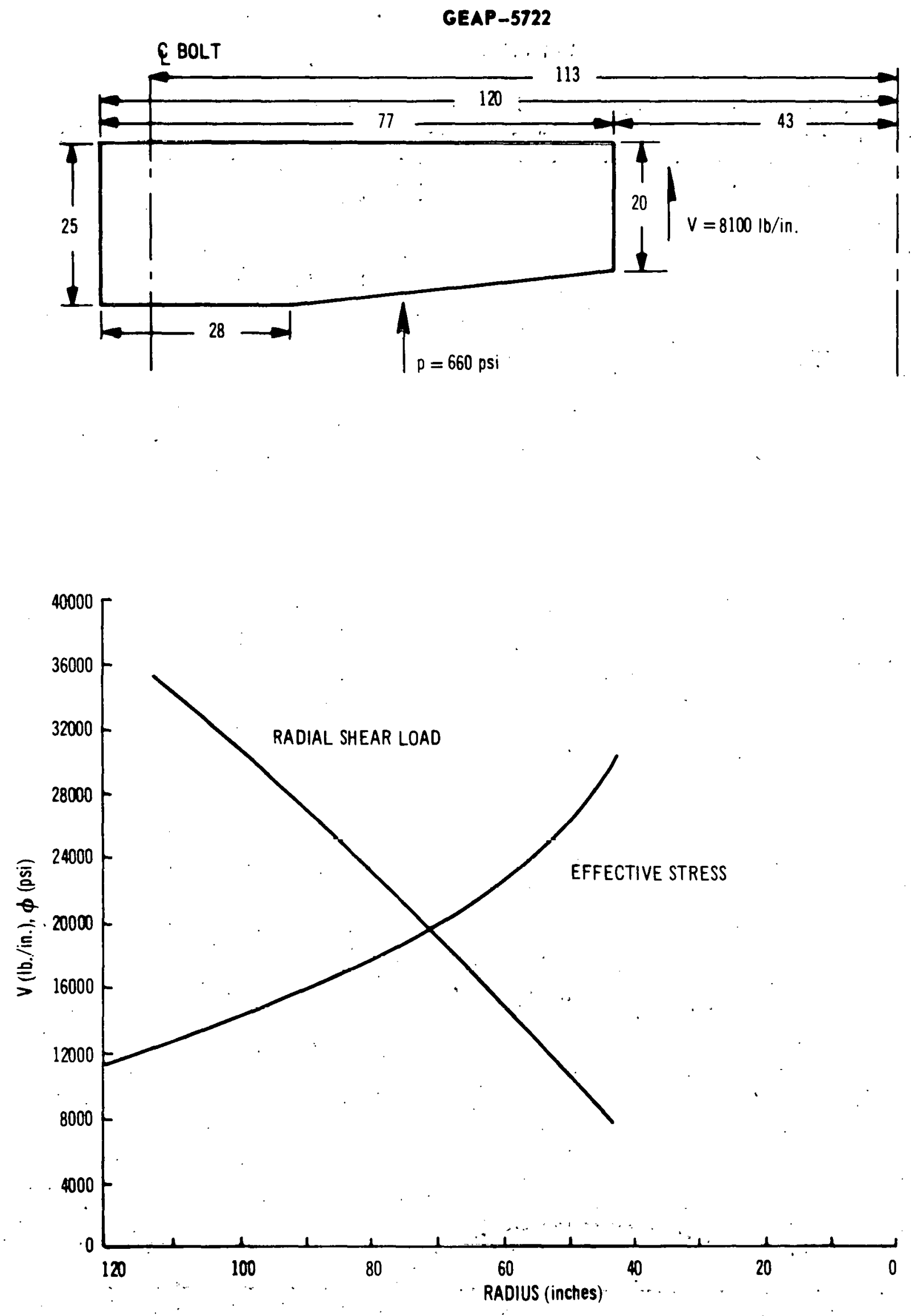

FicuRE 7-16. TAPER plate Mo. 3: SHEAR AMD StRESS

7-30 


\subsection{THERMAL ANALYSIS AND COOLING REQUIREMENTS}

The objective in the design of the vessel head cooling system is to cool the shield and provide a reasonable temperature gradient in the structure, a temperature gradient such that the reactor vessel wall and components penetrating the biological shielding would not undergo adverse thermal stresses, and, in addition, that would reduce the head surface temperature to such a low level to permit access to the area above the head during reactor.operation.

The heat source was divided into (a) conduction from the components submerged in the sodium pool, (b) gamma heat generation from the attenuation of the $\mathrm{Na}_{24}$ activity, and (c) the bulk heat transfer by radiation and convection through the head insulation. A summary of the heat loads of the reference design is presented in Table 7-1. The table itemizes the major components constituting the reactor head. Table 7-1 does not include the heat load from the FEDAL system sodium sample lines. Preliminary calculations assuming convection and radiation heat transfer from the sample lines to the honeycomb panel indicate that the heat load is of such magnitude that insulation of the lines to minimize the transferred heat will be required.

TABLE 7-1

\section{SUMMARY OF HEAD HEAT. LOADS}

\section{Component}

Refueling Plug

Reflector Plug

Reactor Head and Vessel

Total

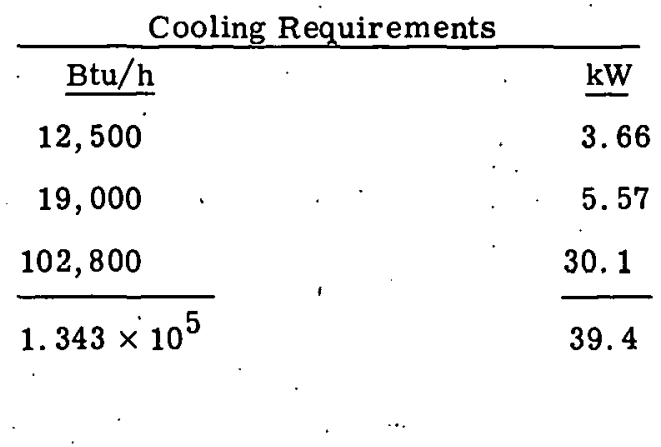

The detailed analysis of the heat conducted from the sodium through the various components penetrating the head is summarized in Table 7-2.

\subsubsection{Internal Heat Generation.}

The heat generation in the head structure due to gamma heating from the $\mathrm{Na} 24$ activity has been estimated to be represented by the following equation: $P=6.0 \times 10^{-4}, e^{-0.733 \chi}(\mathrm{W} / \mathrm{gm})$, where $\chi=$ thickness of steel above the sodium in inches. The total heat generated is a small fraction of the conducted heat transfer.

\subsubsection{Heat Transfer in Honeycomb Insulation Panels}

The amount of heat transmitted through the honeycomb insulation panels was estimated by using the standard heat-conduction equation for steady state analysis of

$$
q=\frac{K_{e} A}{L} \Delta T_{f}
$$


TABLE $7-2$

\section{HEAT TRANSFER ANALYSIS FOR FFTF HEAD}

\section{Penetration}

Type

Refueling Plug

Plug Wall

Closed Loop

outer Tube

Inner Tube

Thermocouples

Open Loop

Outer Tube

Inner Cylinder

Thermocouples

In-Core Safety Rod

Internal Heat Gen.

Búlk Heat Transf.

Polished Surface

Oxidized Surface

Instrument Package

Support Tube

Support Tube

Support Tube

Support Tube

Thermocouple

\section{Cross-Sectional}

\begin{tabular}{c} 
Area \\
Each (in. ) \\
\hline
\end{tabular}

Characteristic
Dimension Size (in.)

Height

(in.)

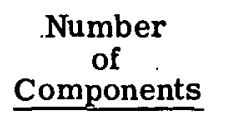

Btu/h

Heat Load (each)

$\mathrm{kW}$

$\frac{\begin{array}{c}\text { Heat Load } \\ \text { (total) }\end{array}}{\mathrm{Btu} / \mathrm{h} \cdot \mathrm{kW}}$ $\%$

Total

$3 / 8$ in. thick 53 in.

62.5

30 diam

3 in. o.d. $\times 1 / 8$ in.

1. 13 thick.

1 in. 0. d. $\times 3 / 32$ in. thick

$1 / 8$ in o.d. $\times 0.010$

in. thick

0. 2675

0.0722

$(20 \mathrm{~T} / \mathrm{C})$

$1-3 / 4$ in. o.d.

$1-3 / 8$ in. i. $d$.

$1-3 / 8$ in. o.d.

$5 / 8$ in. i.d.

$1 / 8$ in. o.d. $x$

$0.010 \mathrm{in.}$

1.50 o.d.

53 in. diam

53 in. o.d.

1.179
0.919
0.0687
$(19 \mathrm{~T} / \mathrm{C})$
1.767
05
05

5 in. Sch 40

4 in. Sch 40

2 in. Sch 40

1-1/4 in. $\operatorname{Sch} 40$.

0.125 in. diam $x$

0.010 .

$\begin{array}{lrr}4.30 & 30 & 3 \\ 3.17 & \quad 30 & 5 \\ 1.074 & 30 & 1 \\ 0.668 & 30 & 5 \\ 0.00361 & 30 & 630\end{array}$

\begin{tabular}{|c|c|c|c|c|}
\hline 54.2 & 0.0159 & 162.8 & 0.0477 & 0.1 \\
\hline 949 & 0.278 & 949 & 0.278 & 0.7 \\
\hline 7060 & 2.07 & & & \\
\hline 7250 & 2.125 & 7250 & 2.125 & 5.4 \\
\hline 131.4 & 0.0385 & 394.2 & 0.116 & 0.3 \\
\hline 96.9 & 0.0284 & 484.3 & 0.142 & 0.4 \\
\hline 32.8 & 0.0096 & 32.8 & 0.0096 & - \\
\hline 20.4 & 0.006 & 102.1 & 0.030 & 0.1 \\
\hline 0.110 & 3. $22 \times 10^{-5}$ & 69.6 & 0.0204 & - \\
\hline
\end{tabular}


TABLE 7-2, (Continued)

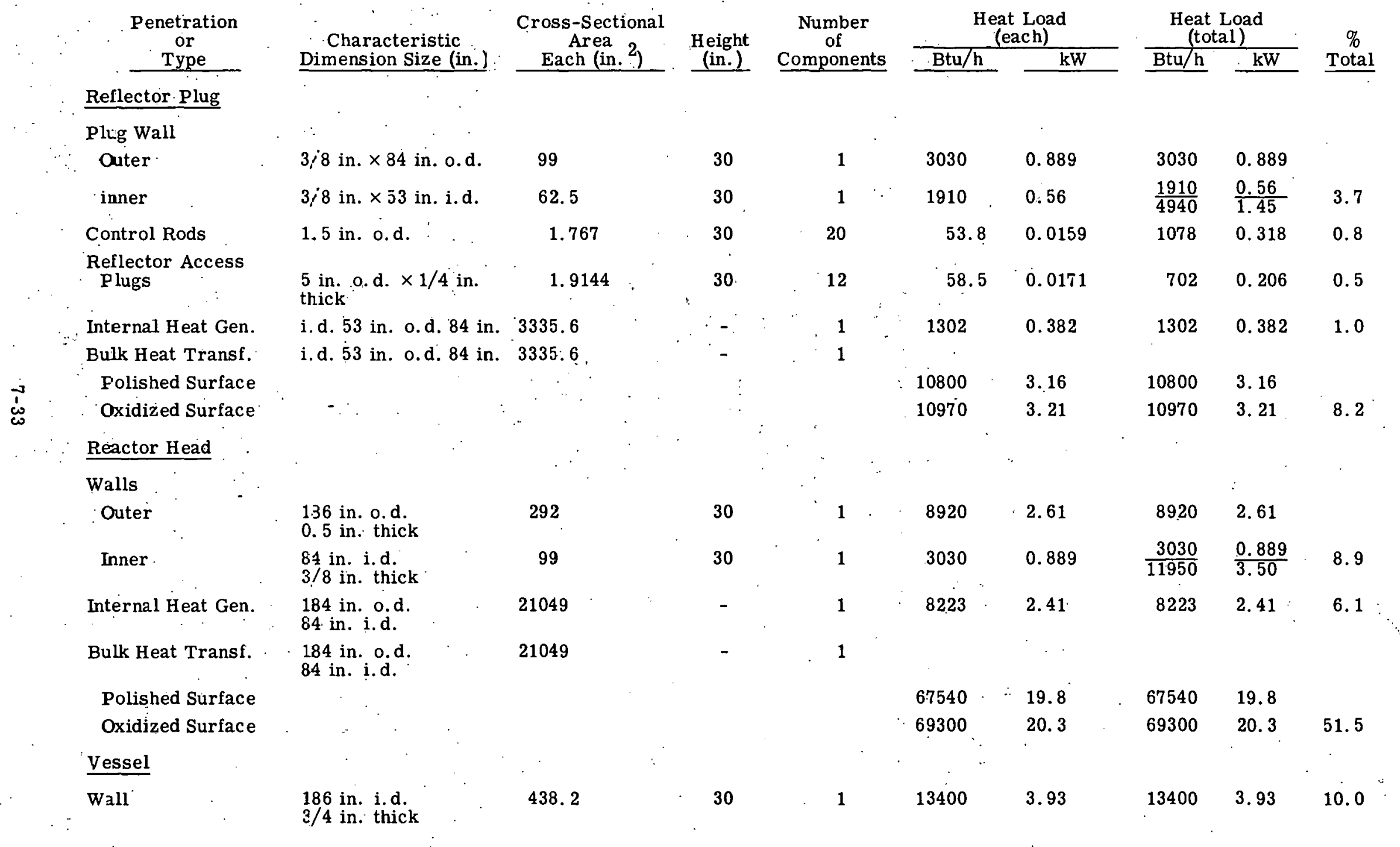


where:

$$
\begin{aligned}
& \mathrm{K}_{\mathrm{e}} \quad \text { = effective thermal conductivity } \\
& \mathrm{L} \quad=\text { thickness of the honeycomb core } \\
& \Delta \mathrm{T}_{\mathrm{f}}=\text { temperature difference across the panel face. }
\end{aligned}
$$

The effective thermal conductivity includes conduction and radiation modes of heat transfer.

The determination of the effective thermal conductivity in honeycomb panels is complicated by the fact that the heat transferred by radiation is a nonlinear function of temperature, and all of the modes of heat transfer are interrelated. Conduction heat transfer occurs through the gas filled spaces and honeycomb wall material. Radiation occurs between all cell surfaces and must be considered in an analysis. Convective heat transfer occurs in the gas spaces within the panel cells and between sections of the panel. Fortunately, the amount of heat flux transferred by the argon gas by conduction and convection is estimated to be a small fraction of the heat transferred and may be considered independently of the heat transmitted by the other modes.

The faces of the honeycomb panels are constructed of thin metal sheets; therefore, the temperature drop through sheets is so small that the thermal resistance can be neglected. In addition, since the side walls of the honeycomb core are also normally thin (assuming hollow cores), a one-dimensional analysis is permissible. To simplify the analysis further, the following assumptions were made: (a) The emissivities throughout the panel are equal; (b) The bonding material contributes a negligible amount to the effective thermal conductivity since a diffusion-bonding process is to be used; (c) The core conductivity, $\mathrm{K}_{\mathrm{e}}$, is evaluated at a mean temperature. The effective thermal conductivity of a honeycomb panel ${ }^{(4)}$ is expressed as

$$
\begin{aligned}
\mathrm{K}_{\mathrm{e}}=\frac{\mathrm{K}_{\mathrm{c}} \mathrm{A}}{\mathrm{A}_{\mathrm{F}}}+ & \mathrm{Ka}+1.78 \psi \mathrm{L}\left(\frac{\mathrm{Tm}}{1000}\right)\left(\frac{\Delta \mathrm{T}_{\mathrm{F}}}{1000}\right)^{2} \\
& +7.12 \psi \mathrm{L}\left(\frac{\mathrm{Tm}}{1000}\right)^{3} \mathrm{Btu} / \mathrm{h}-\mathrm{ft}-{ }^{\circ} \mathrm{R}
\end{aligned}
$$

$\mathrm{K}_{\mathrm{c}} \quad=$ Thermal conductivity of the core $\left(\mathrm{Btu} / \mathrm{h}-\mathrm{ft}-{ }^{\circ} \mathrm{R}\right)$

$\mathrm{Ka}=\mathrm{T}$ hermal conductivity of the argon $\left(\mathrm{Btu} / \mathrm{h}-\mathrm{ft}-{ }^{\circ} \mathrm{R}\right)$

$A=$ Cross-sectional area of conduction path through core material $\left(\mathrm{ft}^{2}\right)$

$A_{F}=$ Area of the face $\left(\mathrm{ft}^{2}\right)$

$\mathrm{L} \quad=$ Core height $(\mathrm{ft})$.

$\mathrm{Tm}_{.,}=$Mean temperature $\left({ }^{\circ} \mathrm{R}\right)$

$\Delta \mathrm{T}_{\mathrm{F}}=$ Change in temperature of the face $\left({ }^{\circ} \mathrm{R}\right)$ 
The function $\psi$ is a function of honeycomb core geometry and the internal panel emissivity and absorptivity. If the absorptivity is assumed equal to the emissivity, then $\psi$ may be defined as varying with emissivity, $\epsilon$, and with the ratio of core height to cell size, $\phi$. The term $\phi$ is then defined as $\mathrm{L} / \mathrm{d}$ for a cylindrical cell which closely approximates a hexagonal cell. The relationship is defined ${ }^{(4)}$ as

$$
\psi=0.664(\phi+0.3)^{-0.69} \in 1.63(\phi+1)^{-0.89}
$$

The selection of the honeycomb panel size and core material were predicated on the compatibility of materials, operating temperatures, and behavior due to a design basis accident. Honeycomb panel of 321 stainless steel with hexagonal size of $3 / 8$ inch and 0.005 inch in material thickness that is capable of withstanding 500 psi crushable pressure was selected as a representative structure for preliminary calculation. The dimensions of the honeycomb and its correspunding crush resistance is determined from head bolt loading considerations due to the design basis accident. It is currently felt that the crush pressure should be greater than the burst pressure of the reactor vessel and less than the failure load of the head hold-down bolts.

The calculated effective thermal conductivity for two hexagonal sizes and two thicknesses of the parent core material are illustrated in Figure 7-17. The effects of emissivity on the effective thermal conductivity is also included in this figure. Fortunately, the conductivity is not very sensitive to the emissivity.

Figure 7-18 shows the effect of sodium vapor deposit on the effective thermal conductivity as a function of film thickness assuming pure sodium. The increased effective conductivity value indicate that enclosure of the panel to prevent vapor deposit should be considered. Experimental verification of the amount of sodium deposition should be determined and means of minimizing this effect should be determined.

\section{5 - BIOLOGICAL SHIELD DESIGN}

\subsubsection{Shielding Requirements for the Top Shield Plug}

The principal source of radiation to be attenuated by the top shield plug comes from the $\mathrm{Na}^{24}$ gamma activity in the primary coolant pool below the plug. The dose rate at the surface of this pool is $2.5 \times 10^{8} \mathrm{mR} / \mathrm{h}$. Core and sodium gamma attenuation are shown. in Figure 7-19. The dose rate due to neutron flux from the core is shown in Figures 7-20 and 8-4 to be about $1 \times 10^{7} \mathrm{nv}$ (or $1 \times 10^{5} \mathrm{mRem} / \mathrm{h}$ ), which neglects geometric attenuation. The presently conceived top head design will attenuate the gamma dose rate to less than $10 \mathrm{mR} / \mathrm{h}$. As shown by Figure 7-20, the neutron mass attenuation of the top head reduces the total neutron flux to about $300 \mathrm{nv}$, or $1 \mathrm{mRem} / \mathrm{h}$. The contribution, however, of radiation streaming through the many penetrations in the top head can increase the dose rate considerably in some areas. The results of a preliminary study to determine the dose rate at the upper surface of the top head caused by radiation streaming was described in GEAP-5684, the Fifth Quarterly Report. Some changes in the head design were made since this radiation streaming study was completed. Hence, the results from an evaluation of the revised top head design are summarized in the following paragraphs. 


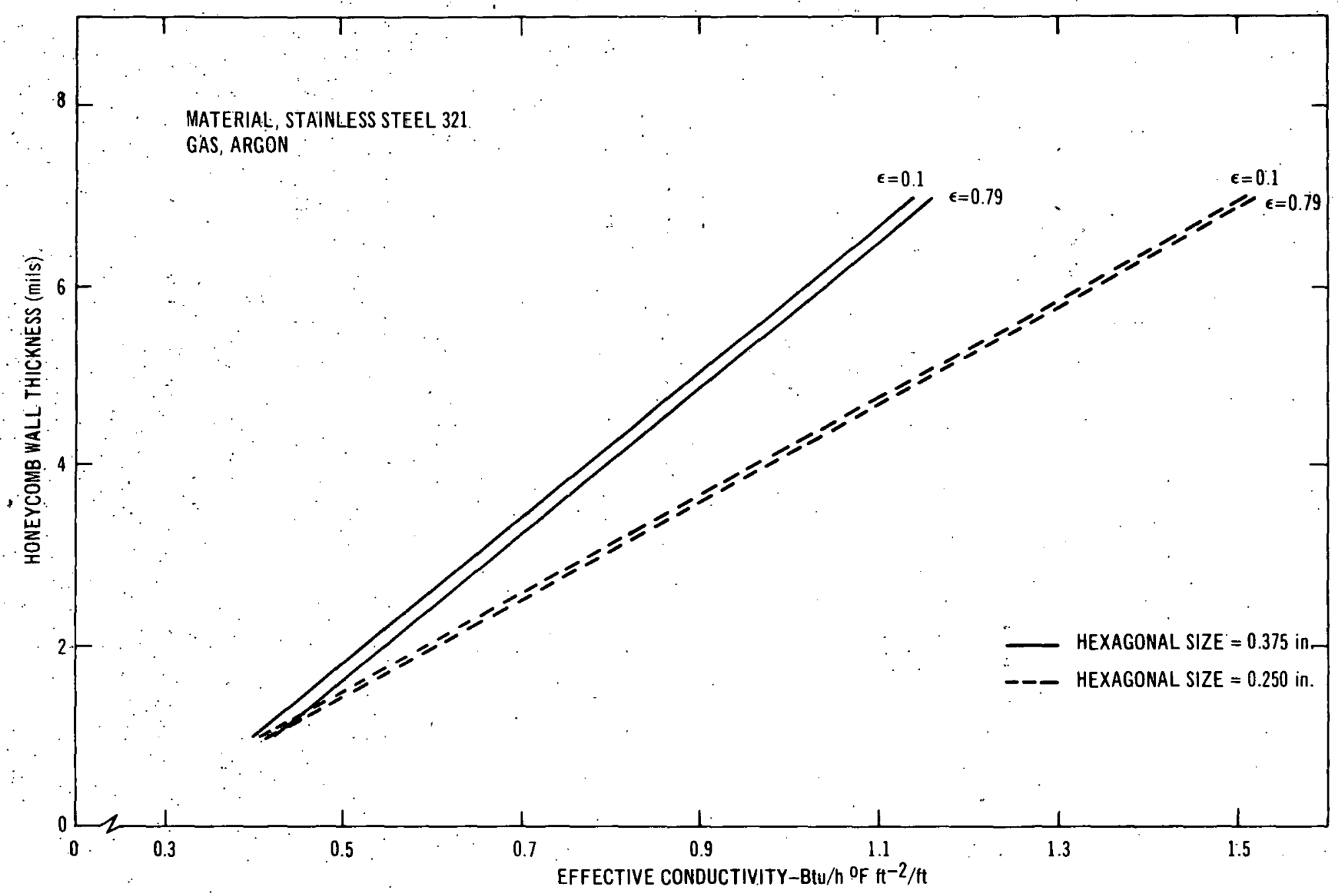




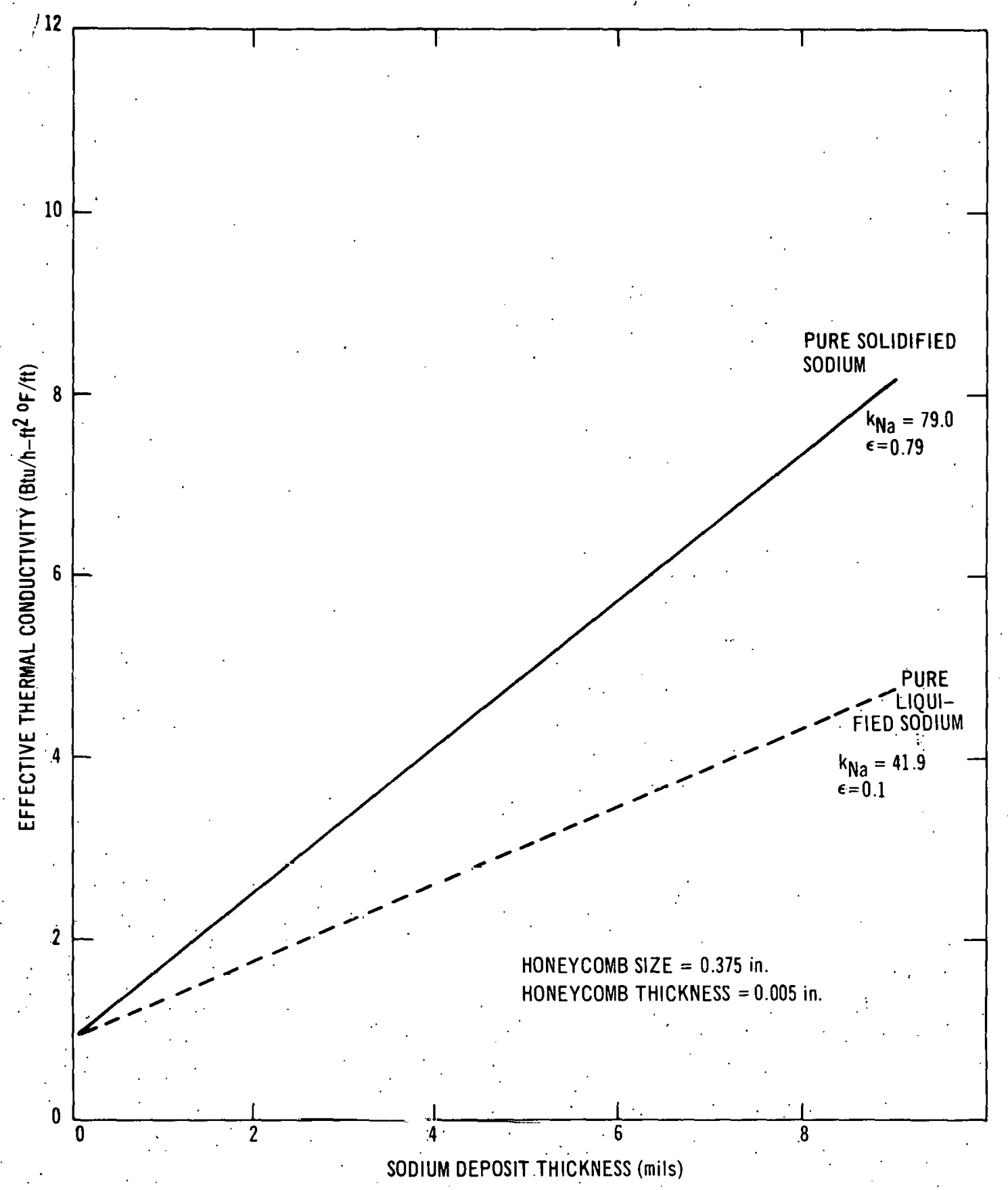




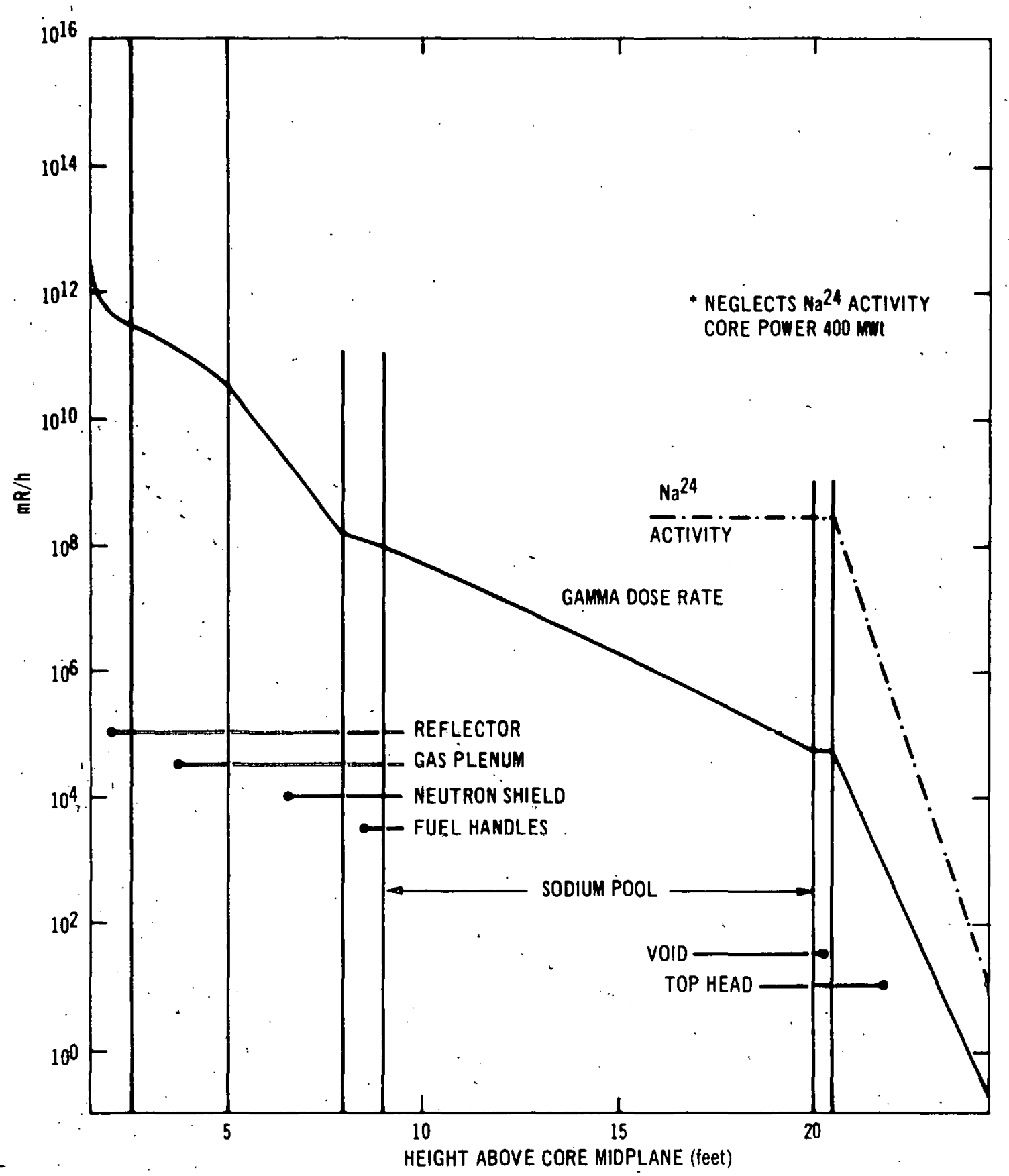

FIGURE.7-19. GAMMA DOSE RATE. VERSUS HEIGHT ABOVE CORE MIDPLANE 


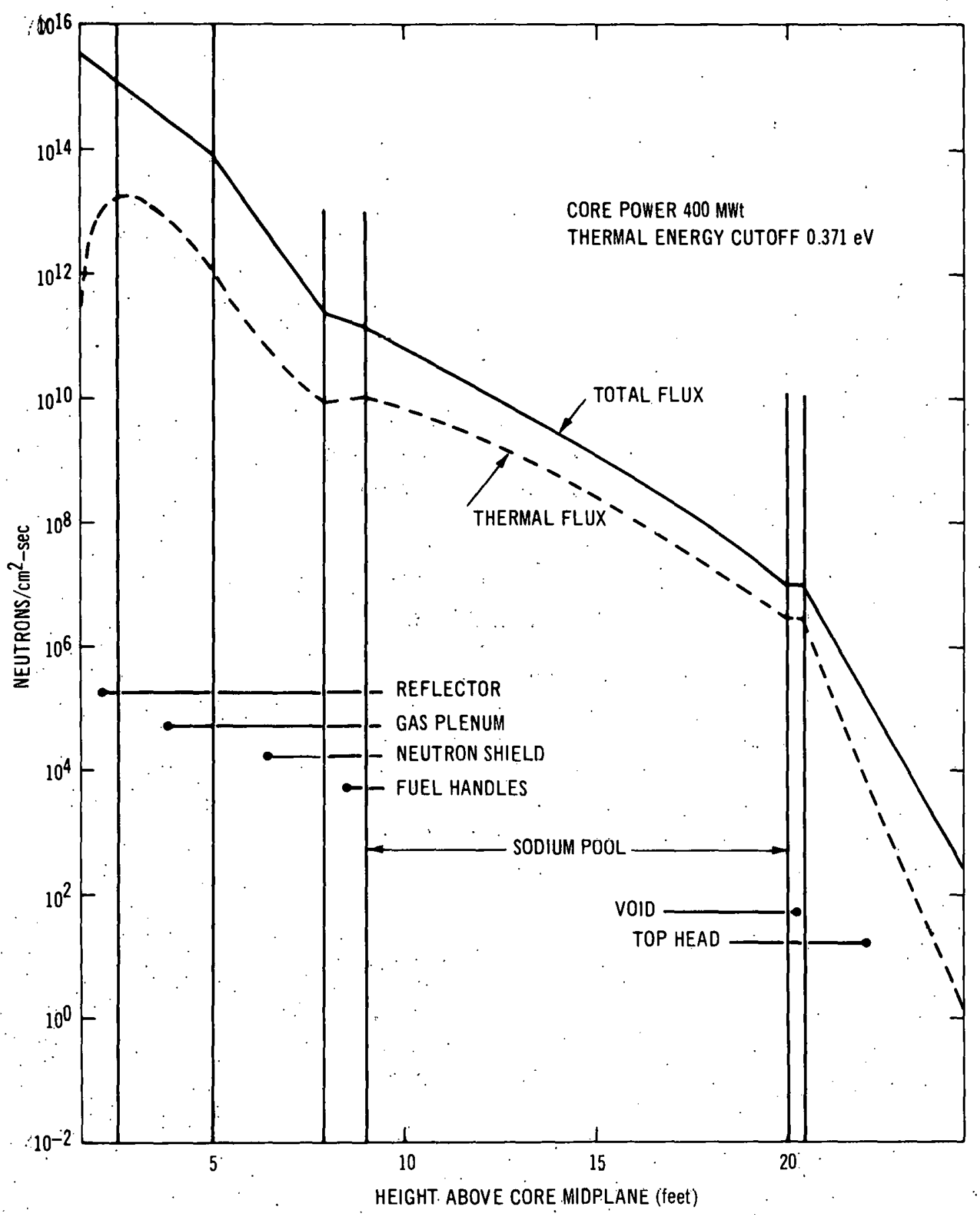

FIGURE - 1-20. TOTAL NEUTRON FLUX AND THERMAL NEUTRON FLUX VERSUS HEIGHT ABOVE CORE MIDPLANE 
7.5.2 Radiation Streaming through Annular Gaps in the Refueling, Reflector, and Main Heads

No significant changes were made in the design of the top head which affect the radiation streaming through the annular gaps at the following interfaces:

- Refueling Plug - Reflector Plug

- Reflector Plug - Main Head

As illustrated by Figures 7-2 and 7-3, however, the design was modified to reduce radiation streaming at the vessel wall, main head interface. The results of calculations to estimate the dose rate from radiation streaming at these three annular interfaces are shown in Table 7-3. Steel shot, preferably borated, is required in the void spaces of the main head in order to attenuate both the neutron and gamma flux. The density of the void spaces should be equal to, or exceed, 0.6 times the normal density of iron or steel or such that all head components have an equivalent of 24 inches of steel.

In summary, Table 7-3 indicates that the dose rate at no point on the upper surface of the top head is expected to exceed $300 \mathrm{mRem} / \mathrm{h}$, nor is the average dose rate expected to exceed $50 \mathrm{mRem} / \mathrm{h}$ to personnel performing maintenance operations to equipment in the refueling cell during full power operation.

\subsubsection{Radiation Streaming through Gaps in the Top Head Penetrations for Instrument Leads, Closed Loops, Open Loops, and Control Rods}

Hand calculations were performed to estimate the dose rate at the exit of each specific type of top head penetration. Table 7-4 illustrates the results of these estimates. This table indicates that the peak dose rate and average dose rate in the vicinity of the top head is not expected to exceed design criteria (300 $\mathrm{mRem} / \mathrm{h}$ and $50 \mathrm{mRem} / \mathrm{h}$, respectively). However, design margins are less than a desired factor of 10 . Further analysis is required to assure that the criteria will be met. The following paragraphs describe the results of this evaluation for each specific type of top head penetration.

\subsubsection{Instrument Lead Penetration}

An evaluation of the shielding required around the instrument sheath tubes indicates that a material having about $1 / 2$ the density of iron (preferably borated) is required to limit the dose rate to less than $50 \mathrm{mRem} / \mathrm{h}$ at the exit of the top head penetration. The geometry assumed for this evaluation is illustrated by Figure 7-21.

\subsubsection{Closed and Open Loop Penétrations}

Referring to Figures 4-8 and 4-11, it is apparent that the shielding design of the open loop is less complete than for the closed loop.. Accordingly, only the shielding for the closed loop was evaluated. It was assumed that the test loop sodium would never rise above the pool sodium level. For both loop types, steel shot (preferably borated). fills the space around the instrument leads. For the closed loop, an additional shielding annulus (like a pipe) must be welded to the nominal 3-inch o.d. closed loop pipe at the vertical height in the top head where the nominal 
TABLE $7-3$

DOSE RATES AT THE UPPER SURFACE OF. THE TOP HEAD:

RADIATION STREAMING THROUGH ANNULAR PLUG GAPS

\begin{tabular}{|c|c|c|c|c|}
\hline \multirow{2}{*}{\multicolumn{2}{|c|}{ Streaming Path }} & \multirow[b]{2}{*}{ Dimensions } & \multicolumn{2}{|c|}{ Dose Rate } \\
\hline & & & $\mathrm{Na}^{24}$ (Peak) & Neutron Flux (Peak) \\
\hline \multicolumn{2}{|c|}{ Refueling Head - Reflector Head } & $\begin{array}{l}\text { 50-in. diam, } \\
\text { *0.1-in. annular }\end{array}$ & & \\
\hline & Annular Duct & slot (1 step) & $40 \mathrm{mR} / \mathrm{h}$ & $<25 \mathrm{mRem} / \mathrm{h}$ \\
\hline \multirow[t]{2}{*}{ Reflector Hea } & d - Main Head & $\begin{array}{l}\text { 84-in. diam, } \\
* 0.15 \text {-in. annular }\end{array}$ & & \\
\hline & Annular Duct & slot (1 step) & $80 \mathrm{mR} / \mathrm{h}$ & $<50 \mathrm{mRem} / \mathrm{h}$ \\
\hline \multirow[t]{3}{*}{ Main Head } & - Vessel Wall & $\begin{array}{l}\text { 190-in. diam, } \\
* 1.0 \text {-in. annular }\end{array}$ & & \\
\hline & Annular Duct & slot (1 main step) & $<10 \mathrm{mR} / \mathrm{h}$ & $10 \mathrm{mRem} / \mathrm{h}$ \\
\hline & & & & 1.. \\
\hline
\end{tabular}

TABLE $7-4$

DOSE RATES AT THE UPPER SURFACE OF THE TOP HEAD: RADIATION STREAMING THROUGH SPECIFIC TYPES OF TOP HEAD PENETRATIONS

Type of Penetration

Instrument Lead

Closed and Open Loops

Control Rod
Dimensions

4- $1 / 4$ in. i.d. tube, filled with 72 instrument sheath tubes and a material having a density of about 0.5 times the density of iron, preferably borated.

$25 \mathrm{mR} / \mathrm{h} \quad<50 \mathrm{mRem} / \mathrm{h}$

Refer to Figures 4-8 and

4-11. Modify closed loop as described in Section

7.5.5.

$220 \mathrm{mR} / \mathrm{h} \quad<10 \mathrm{mRem} / \mathrm{h}$

Refer to Figure 5-3.

Modify as described in

Section 7.5.6.
Dose Rate

$\widehat{\mathrm{Na}^{24} \text { (Peak) Neutron Flux (Peak) }}$ 


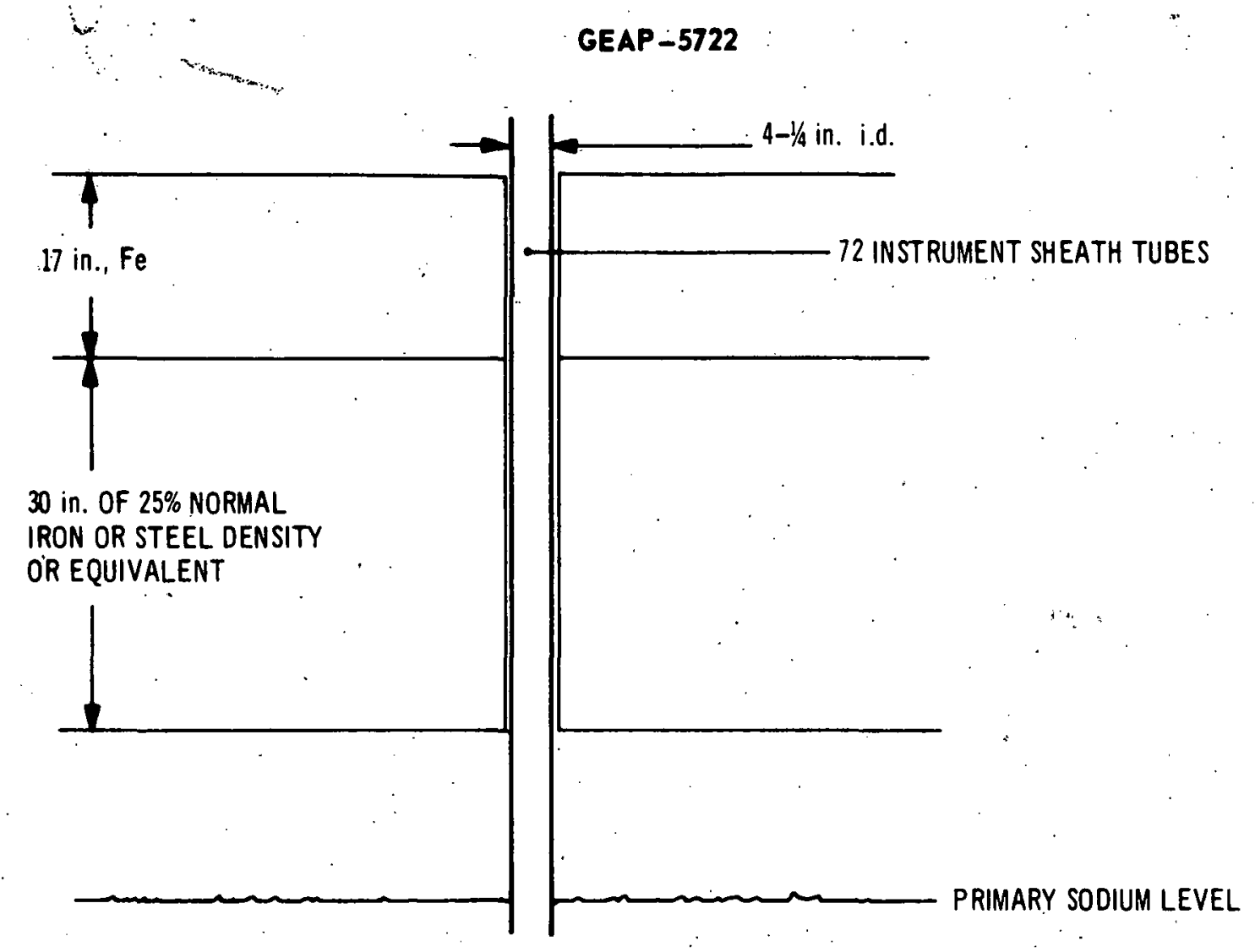

SHEATH TUBE WITH 2 INSTRUMENT LEADS

304 STAINLESS STEEL

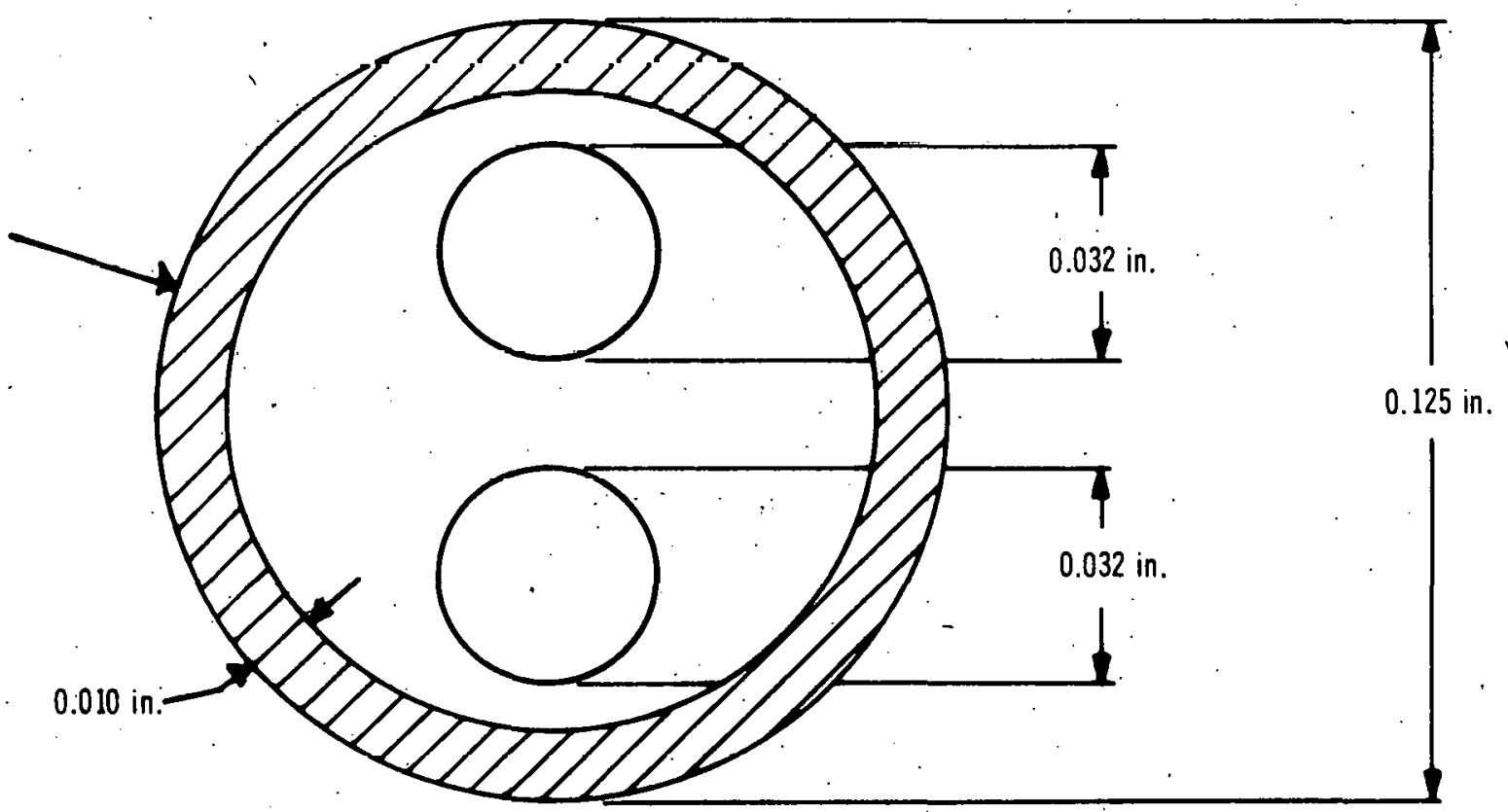

FIGURE 7-21. INSTRUMENT LEAD PENETRATION IN THE TOP HEAD 
4.5-inch o.d. penetration enlarges to a 6 -inch o.d. penetration. With this modification, the peak gamma and neutron flux levels calculated at the upper surface of the top head are as follows:
Gamma Dose Rate:
$216 \mathrm{mR} / \mathrm{h}$
Neutron Dose Rate:
$8.6 \mathrm{mRem} / \mathrm{h}$

To provide an additional design margin, it is also recommended that a borated stainless steel collar surround the pipe which extends above the upper surface of the top head.

Estimates have been made on the shielding required for the closed loop coolant piping that penetrates and is located above the head. These sources result from (a) activation of the sodium and (b) possible fission product release into the sodium. Limits on the sodium activity can be made ranging from a low of $0.05 \mathrm{Ci} / \mathrm{cm}^{3}$ to a high of $0.5 \mathrm{Ci} / \mathrm{cm}^{3}$. Assuming a log mean average of $0.16 \mathrm{Ci} / \mathrm{cm}^{3}$, shielding calculations show that an 11 -inch thick lead shield will attenuate the dose rate from the 3 pipes having a 2 -inch $0 . d$. to a level of $15 \mathrm{mR} / \mathrm{h}$. The contribution from fission products is less than from the $\mathrm{Na}^{24}$ activity (except for several days after reactor shutdown). Hence, the dose contribution from fission products is believed to be negligible outside of this shield.

\subsubsection{Control Rud Penetrations}

Refer to Figure 7-21. Assuming that the outer surface of the tube which holds the labryinth seal is modified and that a shielding annulus is installed inside the assembly outer tube, peak gamma and neutron dose rates: at the upper surface of the top head were calculated to be:

\begin{tabular}{|c|c|}
\hline $\begin{array}{l}\text { Gamma Dose Rate: } \\
\text { Neutron Dose Rate: }\end{array}$ & $\begin{array}{l}31.2 \mathrm{mR} / \mathrm{h} \\
1.3 \mathrm{mRem} / \mathrm{h}\end{array}$ \\
\hline
\end{tabular}

\subsection{PLUG GUIDANCE CONCEPTS}

A mechanical guidance system is provided for locating and orienting the annular reflector plug and the refueling plug. This system is utilized during both removal and replacement of the plugs. The following system description and step by step operating procedures are spectficully for the refueling plug but in most cases also apply to the annular plug. The two plugs are nested such that the reflector plug has to be in place before the refueling plug is returned to the head. No hardship should result from this sequencing because of the anticipated monthly removal frequency for the refueling plug and the annual or less frequent removal of the annular reflector plug. The refueling plug should be removed anyway when the reflector plug is replaced so that mechanical assistance can be provided for relatching (and checking) the reflector control extension rods. The annular head structure would only be removed for complete core structure modification or the most thorough vessel inspection or both. Location and orientation of the head would occur so infrequently that special procedures and fixtures would be required for each transfer and are very dependent on the operation to be performed. Thus, no guidance concepts for the head have been included. The overhead bridge crane in the refueling cell can lift the head structure. 


\subsubsection{System Description}

The plug guidance system consists of a segmented centering ring supported about 11 feet above the plugs by three vertical members (see Figure 7-22). After assembling the vertical members in " $\mathrm{T}$ " slots in the head structure and completing the segmented ring, the assembly is guyed by three cables fastened to the ring and to the periphery of the head. This structure protects the twenty reflector control drive units and provides a visual guide to the location of the plug as it is lowered. Each of the vertical supports has a guide bar that can be moved radially. After the plug is lowered far enough, these guide bars are moved inward until they engage the slot in the (empty) closed loop guide tubes. Dimensional and guide load sensors will permit centering of the (instrument structure and) refueling plug.

As the plug is lowered further, engagement between the instrument structure guide tubes and the open and closed loop stalks will be made. All experimental stalks should have guide tubes. Remote visual observation will be provided and minor location adjustments can be made by the movable guides and/or the plug guides located near the reflector plug opening. Remote manipulators will be able to adjust the location of individual stalks. As the plug is lowered, all of the stalks (18) will guide the instrument rack toward the proper location in the fuel subassembly handles. The plug structure will be located during the last 40 to 60 inches of travel by the plug guides located near the lower end of the guide structure.

Initial consideration has indicated that the annular reflector plug guidance system will consist of head mounted centering guides similar to the lower refueling plug guides. Final positioning will be provided by taper pins in the head and mating rings on the plug.

\subsubsection{Procedural Steps for Removing and Installing Head Plugs}

NOTE : Downtime would probably be reduced if procedure 7.6.2.2a described below were performed before the guide structure was assembled. If it is assembled, start with procedures 7.6.2.2.

\subsubsection{Guide Structure Assembly}

a. Remove each guide post from storage and position in the " $T$ " slots, in the head, as shown.'

b. Tie the 3 posts together at the top by means of the segmented guard ring.

c. Engage the sway cable hooks with the rings on the head and actuate the load binders to center and tighten.

d. Connect power leads (electrical or pneumatic) to each post.

e. Install or check any plug position indicators or visual aids. 

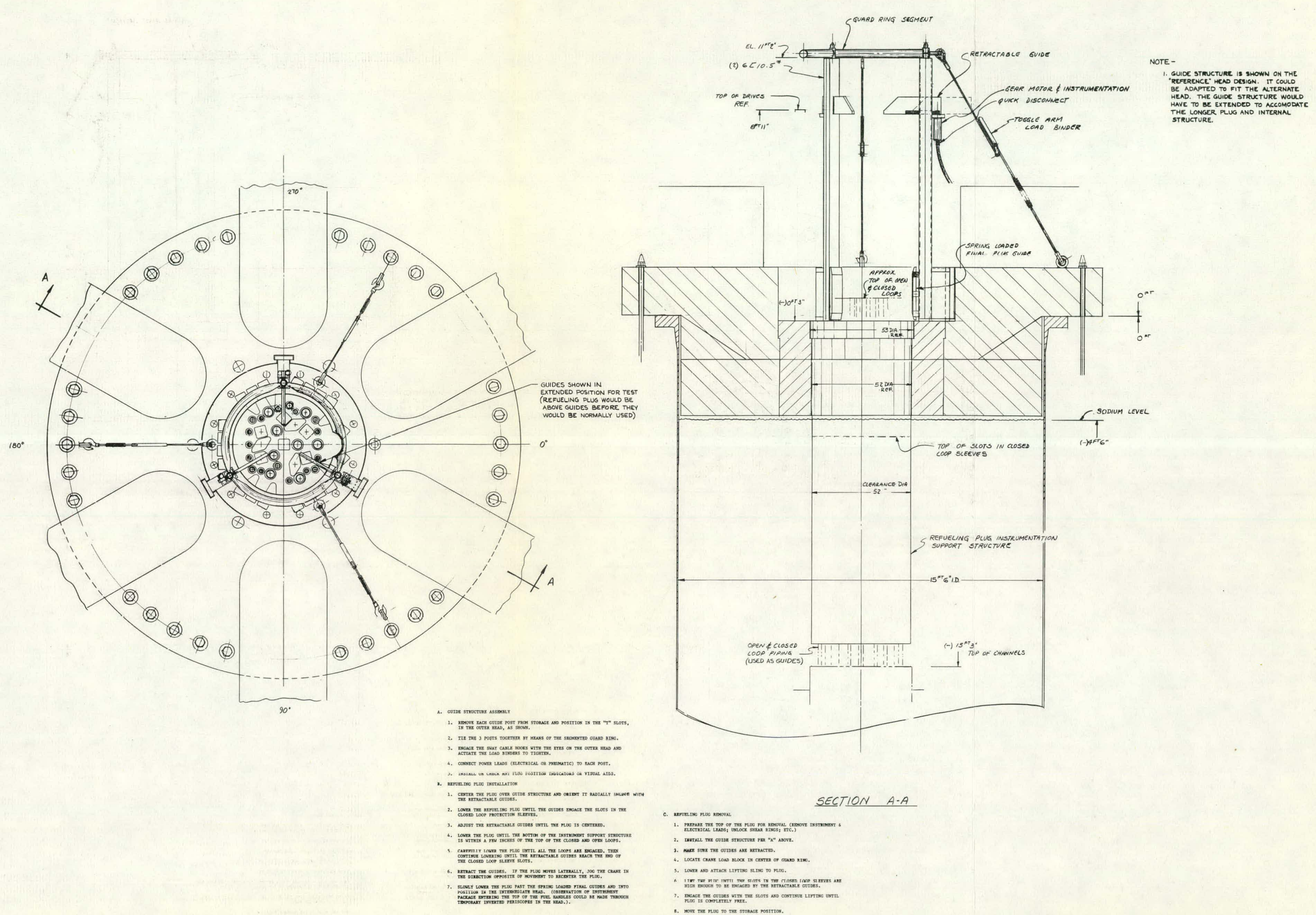


\subsubsection{Refueling Plug Removal}

a. Prepare the top of the plug for removal (remove instrument and electrical leads; unlock shear rings; etc.)

b. Check the guide structure assembly per paragraph 7.6.2.1.

c. Make sure the guides are retracted.

d. Locate crane load block or lifting sling or both in center of guard ring.

e. Lower and attach lifting sling to plug.

f. Lift the plug 3 inches and stop. Check that discorinects have released.

g. Lift the plug until the slots in the closed loop sleeves are high enough to be engaged by the retractable guides (about 14 feet). The closed and open loop stalks will guide the instrument structure. .

h. Engage the guides with the slots and continue lifting until plug is completely free.

i. Move the plug to the storage position.

j. The plug guide structure may be removed by reversing the procedures in paragraph 7.6.2.1. It is normally desirable to leave the structure assembled for refueling operations to protect the control drives.

\subsubsection{Refueling Plug Reinstallation}

a. Install or check the guide structure assembly per paragraph 7.6.2.1.

b. Center the plug over guide structure and orient it radially in line with the retractable guides.

c. Lower the refueling plug until the guides engage the (empty) slots in the closed loop sleeves.

d. Adjust the retractable guides until the plug is centered.

e. Lower the plug until the bottom of the instrument support structure is within a few inches of the top of the closed and open loops.

f. Carefully lower the plug until all the loops are engaged. Visual observation of loop engagement is possible through mirrors, TV cameras, or periscopes in the refueling cell.

g. Continue lowering until the retractable guides reach the end of the closed loop sleeve slots. 
h. Retract the guides. If the plug moves laterally, recenter the plug.

i. Slowly lower the plug past the spring loaded final guides and into position in the annular reflector plug. (Observation of instrument packages entering the top of the fuel handles can be made after the sodium is lowered to the inspection level with temporary, inverted periscopes through the head.)

j. Lock plug in place with the shear rings and reconnect instrument, control, plug, and test loop leads.

\subsection{CONCLUSIONS AND RECOMMENDATIONS ON HEAD DESIGN}

a. It is possible to provide a cold vessel flange and head structure for the backup FFTF.

b. The conceptual design provides integrity of the head during a DBA. This design anticipates release of some reaction products, cover gas; and sodium to the inert gas filled refueling cell under the severe DBA conditions. Distortion or vertical movement of the head structure during operation is small compared with thermal expansion differences of the vessel, test facilities, and control rod extension pieces.

c. Accessibility to three concentric regions of the vessel are provided by a nested cover and two plugs: the head, the annular reflector plug, and the refueling plug. The anticipated interval between head and plug removals are $60^{\circ}, 18$, and 1 months respectively.

d. Cooling is provided in the three head components at about 3 feet above the sodium level. The required cooling capacity is from $1.71 \times 10^{5}$ to $3.41 \times 10^{5} \mathrm{Btu} / \mathrm{h}(50$ to $100 \mathrm{~kW}$ thermal), which.is supplied by a circulating NaK system. The temperature of the structure above the coils is less than $200^{\circ} \mathrm{F}$, the freezing point of sodium. A slightly higher temperature may be required for plug removal.

e. Biological shielding is provided in the cool structural region to attenuate the gamma radiation from the activated sodium coolant. The design dosage in accessible regions of the head is $50 \mathrm{mRem} / \mathrm{h}$.

f. All 12 leads from each driver fuel assembly instrument package are continuous from the package to the plug connector and are frequently supported by the instrument structure.

g. All open loop (12) and closed loop (6) electrical leads penetrate the refueling plug vertically above the test facility. Connectors are provided above the plug surface. Closed loop facilities to remove the test fuel and contact instrumentation without removing the refueling plug are provided as part of thc closcd loop stalk that penetrates the plug. 
h. Closed loop coolant pipes and driver fuel FEDAL system sodium piping are located in the instrument structure below the refueling plug and are routed radially outward under the plugs and penetrate the head region. At this larger radius there is adequate space to biologically shield these radioactive pipes.

i. Reflector control rod drives are attached to the annular reflector plug. The extension pieces between the drives and the control rods penetrate the annular plug.

j. It is recommended that the design of this vessel cover with or without open vessel refueling features be pursued based on the practical conceptual design results to date. In order to proceed with the preliminary design, the following components or parts would have to be defined in more detail.

- Design of the plug penetrations and their operational requirements.

- Resolution of the amount and requirements of energy absorbing material (or thermal insulation), if any, to be applied between the head structure and the sodium.

- More sophisticated definition and analysis of the DBA and its effects on the head structure. Preferably experimental model data.

- More information on the reactor vessel, foundation, and surrounding structures. 


\section{SHIELDING AND RADIATION LEVELS}

\subsection{INTRODUCTION}

Basic shielding criteria are summarized in the following statements:

a. The shielding design will be sufficient to limit personnel radiation dosages and dose rates to the levels specified in 10 CFR 20.

b. Limited personnel access into the refueling cell will be possible at any time all top head shield plugs are in place. During full power operation, the average dose rate for personnel working in the vicinity of the top head will not exceed $50 \mathrm{mRem} / \mathrm{h}$. At no location in the refueling cell will the dose rate exceed $300 \mathrm{mRem} / \mathrm{h}$.

c. The fast neutron fluence limit at the reactor vessel is:

$$
\text { nvt }\left(E_{n}>0.1 \mathrm{MeV}\right)=5 \times 10^{20}
$$

(The preliminary nature of the fast neutron fluence limit should be emphasized since the mechanism for fast neutron damage is not well known; nor is there a sufficiently large amount of fast neutron irradiation experimental results for austenitic stainless steels that a specific damage limit can be determined. The above limit is considered to represent a low safety risk.)

d. The heat generation load from the reactor vessel shell, including heat generation in the shield, will not exceed $500 \mathrm{~kW}$. This load assumes heat generation axially below the reactor vessel, as well as radially external to the reactor vessel.

Subsequent paragraphs illustrate the results of bulk shielding analyses completed in the radial and upper and lower axial directions from the core. A limited number of streaming calculations were completed for penetrations in the top head. The net result of this preliminary shielding analysis is an indication that the FFTF backup shield design as described represents a feasible means of meeting shielding criteria.

\subsection{PRIMARY SHIELDING}

The neutron shielding immediately surrounding the core and reflector consists predominantly of stainless steel cooled by sodium. Neutron shielding within the vessel is required to protect the vessel, grid plate, and other critical core components from excessive fast neutron irradiation damage. The geometry of the FFTF Backup reactor core, shielding and vessel is illustrated by the elevation schematic, Figure 8-1. The compositions and thicknesses of the primary shielding and other regions surrounding the core in the radial direction are given in Talule $8-1$. The shiclding above the core and helow the core is listed in Tables 8-2 and 8-3. 


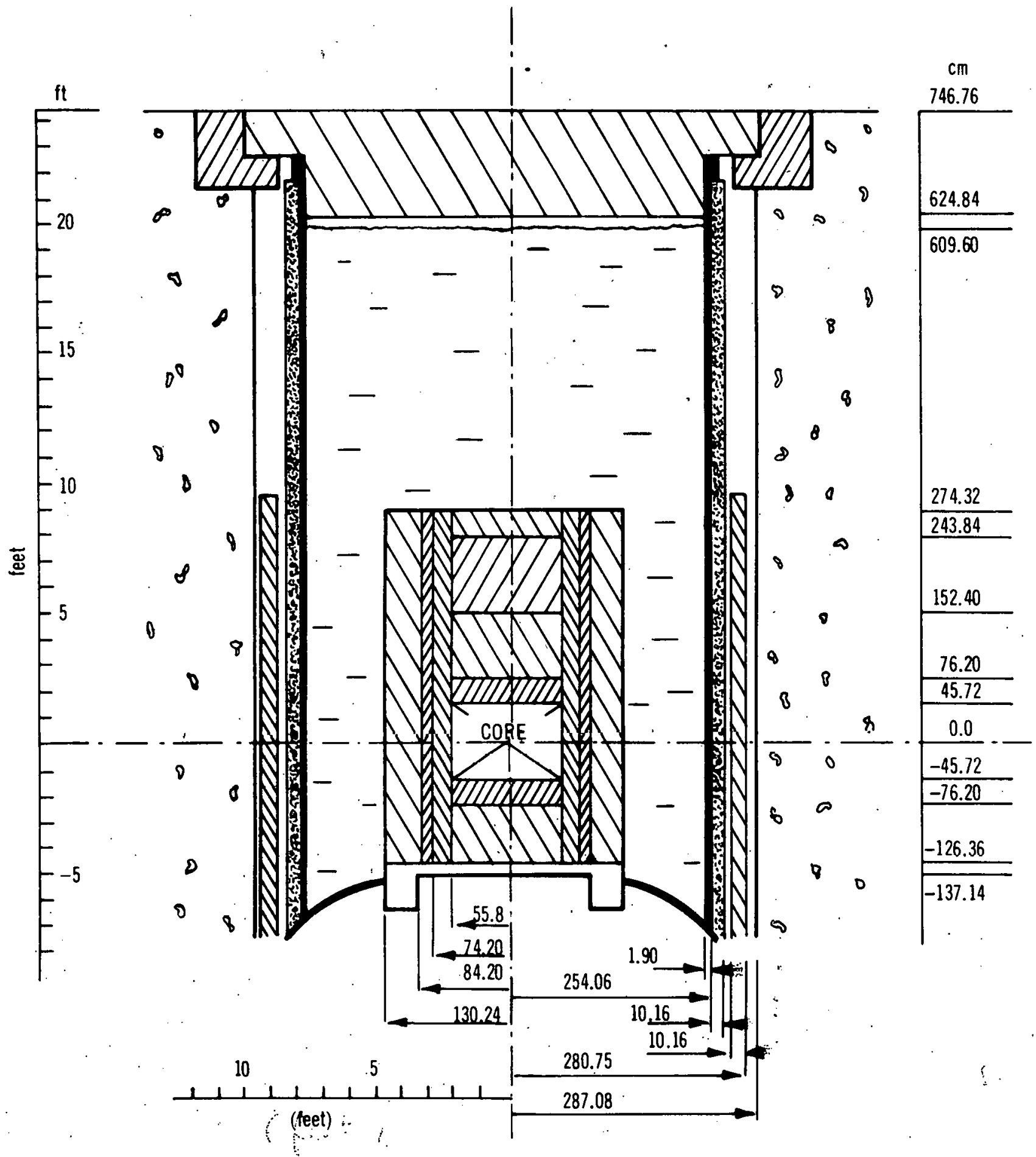

FIGURE '8-1. CORE SHIELDIMG SCHEMATIC-ELEVATION 


\subsubsection{Fast Neutron Fluence}

Figures 8-2, 8-3, and 8-4 illustrate the calculated fast neutron fluence in the radial, upper axial, and lower axial directions. In the radial direction, Figure 8-2 indicates that the fast neutron fluence $\left(E_{n}>0.1 \mathrm{MeV}\right)$ at the reactor vessel will be about $3 \times 10^{19} \mathrm{nvt}$, or more than a factor of 10 under the design limit. In the upper axial direction, Figure 8-3 shows that the design limit is not exceeded above the fuel handles. Below the fuel handles, the materials are changed with fuel bundle changes. In the lower axial direction, Figure 8-4 shows that the higher energy $\left(E_{n}>1 \mathrm{MeV}\right)$ fluence at the lower grid plate was calculated to be about $9 \times 10^{19}$ nvt. By ratioing the $E_{n}>0.1 \mathrm{MeV}$ neutron fluence to the $E_{n}>1 \mathrm{MeV}$ fluence, using Figure 8-3, the fast neutron fluence $\left(E_{n}>0.1 \mathrm{MeV}\right)$ at the grid plate is predicted to be $3 \times 10^{21} \mathrm{nvt}$. This is a factor of 6 in excess of the design limit. However, as noted before, this fast neutron fluence limit is preliminary. There is considerable experimental data which indicates no significant losses in stainless steel ductility for fast neutron $\left(E_{n}>1 \mathrm{MeV}\right)$ fluences exceeding $1 \times 10^{21}$ nvt. Figure 8-4 shows that the calculated fluence at the grid plate is more than a factor of 10 under this level. Hence, significant radiation damage to the grid plate, with the materials listed in Table 8-3 separating the core and grid plate, is not expected.

TABLE 8-1

MATERIAL COMPOSITIONS

FOR THE RADLAL SHIELD

\begin{tabular}{|c|c|c|c|c|c|}
\hline \multirow[t]{2}{*}{ REGION } & \multicolumn{2}{|l|}{ WWTH } & \multicolumn{3}{|c|}{$\begin{array}{c}\text { VOLUME FRACTION } \\
\text { AND DENSITY } \\
\end{array}$} \\
\hline & $55.8 \mathrm{~cm}$ & $\begin{array}{l}\text { Fuel } \\
\text { Na } \\
\text { SS-304 } \\
\text { I-800 }\end{array}$ & $\begin{array}{l}0.303 \\
0.468 \\
0.127 \\
0.102\end{array}$ & $\begin{array}{l}@ 9.85 \\
@ 0.8512 \\
@ 7.93 \\
@ 8.02\end{array}$ & $\mathrm{gm} / \mathrm{cm}^{3}$ \\
\hline Reflector & $18.72 \mathrm{~cm}$ & $\begin{array}{l}\mathrm{Na} \\
\mathrm{Ni} \\
\mathrm{SS}-304 \\
\mathrm{I}-800\end{array}$ & $\begin{array}{l}0.22 \\
0.60 \\
0.06 \\
0.12\end{array}$ & $\begin{array}{l}@ 0.8512 \\
8.90 \\
@ 7.93 \\
@ 8.02\end{array}$ & $\mathrm{gm} / \mathrm{cm}^{3}$ \\
\hline Support Structure & $10.0 \mathrm{~cm}$ & $\begin{array}{l}\mathrm{Na} \\
\mathrm{SS}-304\end{array}$ & $\begin{array}{l}U .5 \dot{U} \\
0.50\end{array}$ & $\begin{array}{l}0.8512 \\
@ 7.93\end{array}$ & $\sin / \mathrm{cin}^{3}$ \\
\hline Neutron Shield & $45.72 \mathrm{~cm}$ & $\begin{array}{l}\mathrm{Na} \\
\mathrm{SS}-304\end{array}$ & $\begin{array}{l}0.30 \\
0.70\end{array}$ & $\begin{array}{l}0.8512 \\
@ 7.93\end{array}$ & $\mathrm{gm} / \mathrm{cm}^{3}$ \\
\hline Sodium Annulus & $121.92 \mathrm{~cm}$ & $\mathrm{Na}$ & 1.0 & (a) 0.8512 & $\mathrm{gm} / \mathrm{cm}^{3}$ \\
\hline Reactor Vessel & $1.90 \mathrm{~cm}$ & SS- 304 & 1.0 & @ 7.93 & $\mathrm{gm} / \mathrm{cm}^{3}$ \\
\hline Blast Shield & $10.16 \mathrm{~cm}$ & $\mathrm{Fe}$ & 1.0 & (6) 7.70 & $\mathrm{gm} / \mathrm{cm}^{3}$ \\
\hline Thermal Insulation & $15.24 \mathrm{~cm}$ & SS-304 & 1.0 & @ 0.793 & $\mathrm{gm} / \mathrm{cm}^{3}$ \\
\hline Concrete Retainer & $1.90 \mathrm{~cm}$ & $\mathrm{Fe}$ & 1.0 & @ 7.7 & $\mathrm{gm} / \mathrm{cm}^{3}$ \\
\hline Concrete (Magnetite) & & Conc. & 1.0 & (4) 3.5 & $\mathrm{gm} / \mathrm{cm}^{3}$ \\
\hline
\end{tabular}




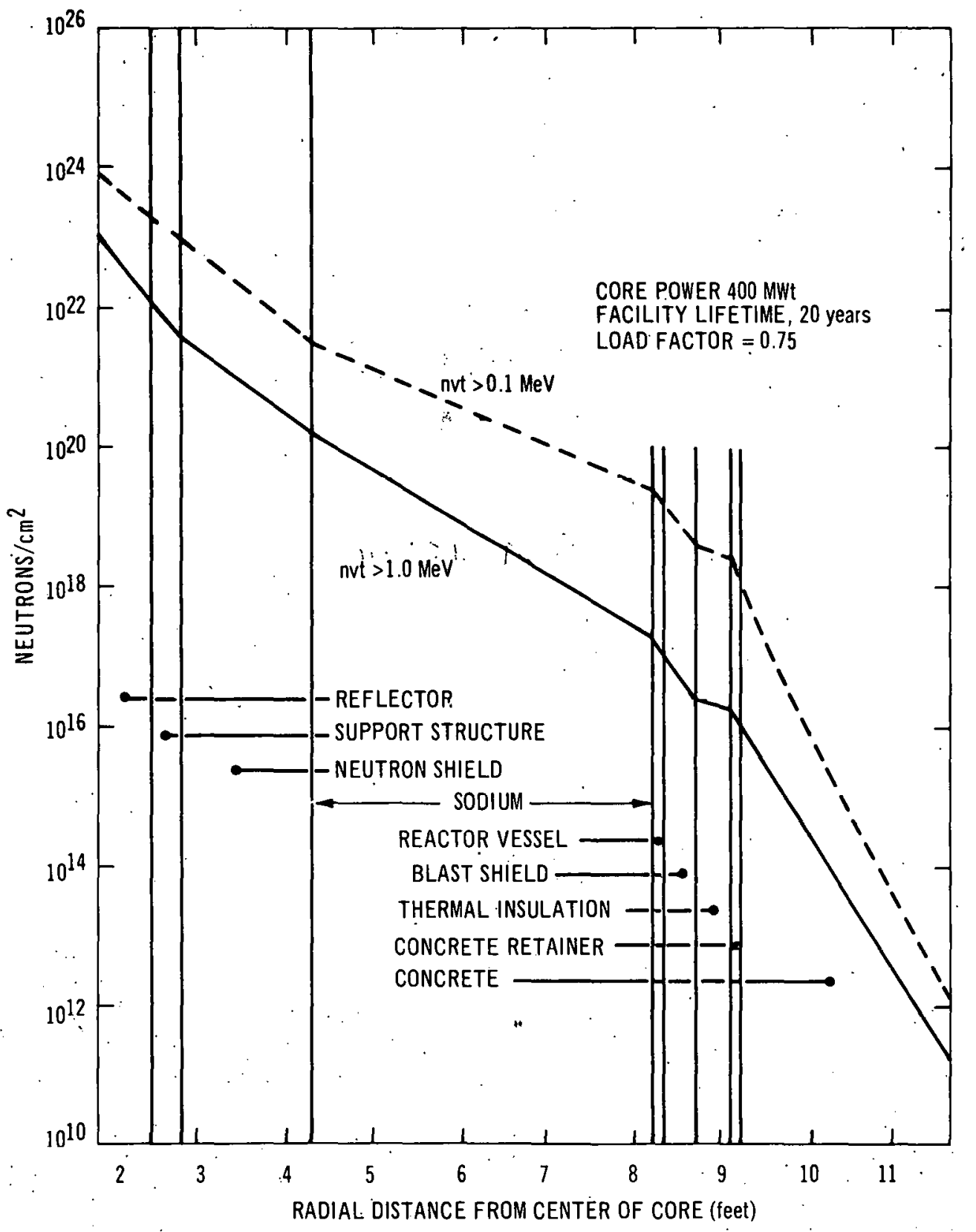

FIGURE 8-2. FAST NEUTRON FLUUENCE: $n v t>1.0 \mathrm{MeV}$ AND $n v t>0.1 \mathrm{MeV}$ VERSU'S RADIAL DISTANCE FROM CENTER OF CORE 


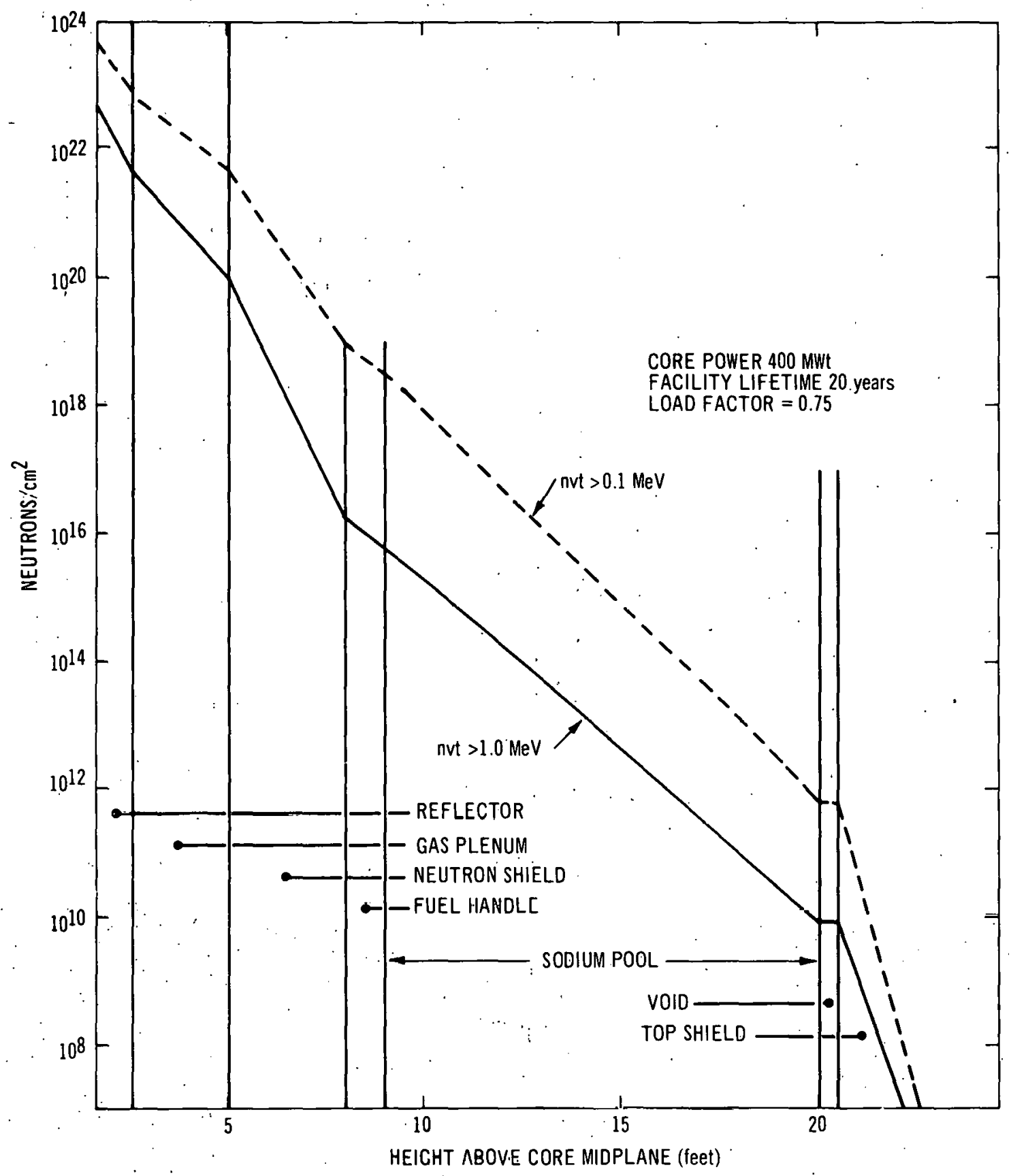

FIGURE 8-3. FAST NEUTRON FLUENCE: $n v t>1.0 \mathrm{MeV}$ AND $n v t>0.1 \mathrm{MeV}$ VERSUS HEIGHT ABOVE CORE MIDPLANE 
GEAP-5722

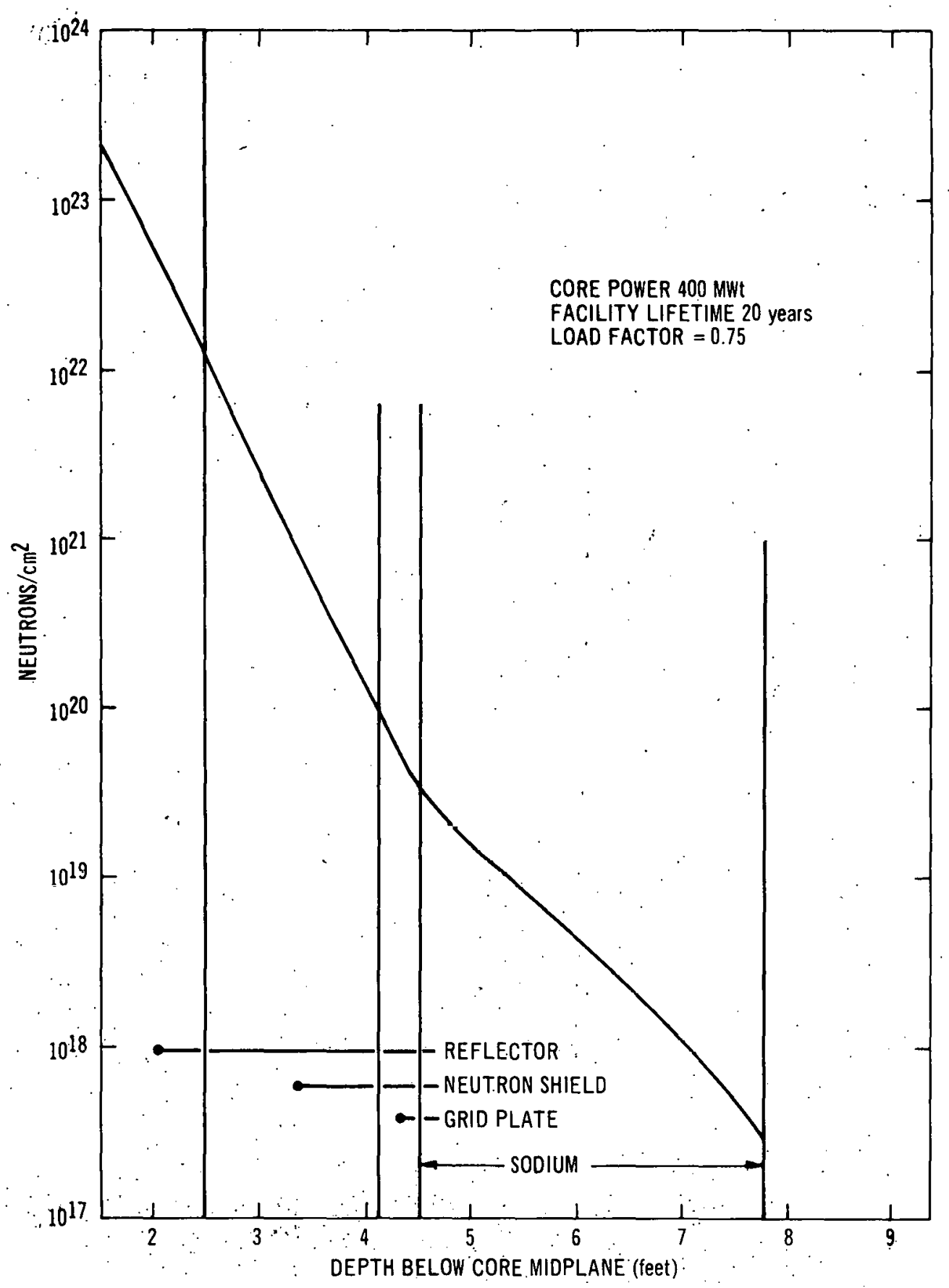

FIGURE 8-4. FAST NEUTRON FLUENCE: AnVt >1.0 MeV VERSUS DEPTH BELOW CORE MIDPLANE 
TABLE 8-2 MATERIAL COMPOSITIONS FOR THE UPPER AXIAL SHIELD MATERIAL,

REGION

1 Core

2 Reflector

3 Gas Plenum

4 Neutron Shield

5 Fuel Handles

6 Sodium Pool

7 Void

8 Top Shield

REGION

1 Core

2 Reflector

3 Neutron Shield

4 Grid Plate

:5 Sodium
WDTH

$45.72 \mathrm{~cm}$

$30.48 \mathrm{~cm}$

$$
\begin{aligned}
& \text { Fuel } \\
& \mathrm{Na} \\
& \text { SS-304 } \\
& \text { I-800 }
\end{aligned}
$$

$\mathrm{Na}$

$\mathrm{Ni}$

SS-304

I -800

$76.20 \mathrm{~cm}$

$\mathrm{Na}$

SS-304

I-800

Void

$91.44 \mathrm{~cm}$

$\mathrm{Na}$

SS-304

I -800

$30.48 \mathrm{~cm}$

$\mathrm{Na}$

SS-304

$335.28 \mathrm{~cm}$

$\mathrm{Na}$

$15.24 \mathrm{~cm}$
VOLUME FRACTION AND DENSITY

\section{$121.92 \mathrm{~cm}$ \\ $\mathrm{SS}-304$
(equivalent to 24 inches of steel) \\ TABLE 8-3 \\ MATERIAL COMPOSITIONS \\ FOR THE LOWER AXIAL SHIELD}

$\begin{array}{ll}0.303 @ 9.85 & \mathrm{gm} / \mathrm{cm}^{3} \\ 0.468 @ 0.8512 \\ 0.127 @ 7.93 \\ 0.102 @ 8.02\end{array}$

$0.499 @ 0.8512 \mathrm{gm} / \mathrm{cm}^{3}$

$0.359 @ 8.90$

$0.079 @ 7.93$

$0.113 @ 8.02$

$0.499 @ 0.8512$

$0.079 @ 7.93$

$0.113 @ 8.02$

0.359 क 0.0

$0.498 @ 0.8512$

$0.389 @ 7.93$

0.113 @ 8.02

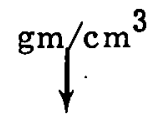

$0.800 @ 0.8512 \mathrm{gm} / \mathrm{cm}^{3}$

$1.0 @ 0.8512 \mathrm{gm} / \mathrm{cm}^{3}$

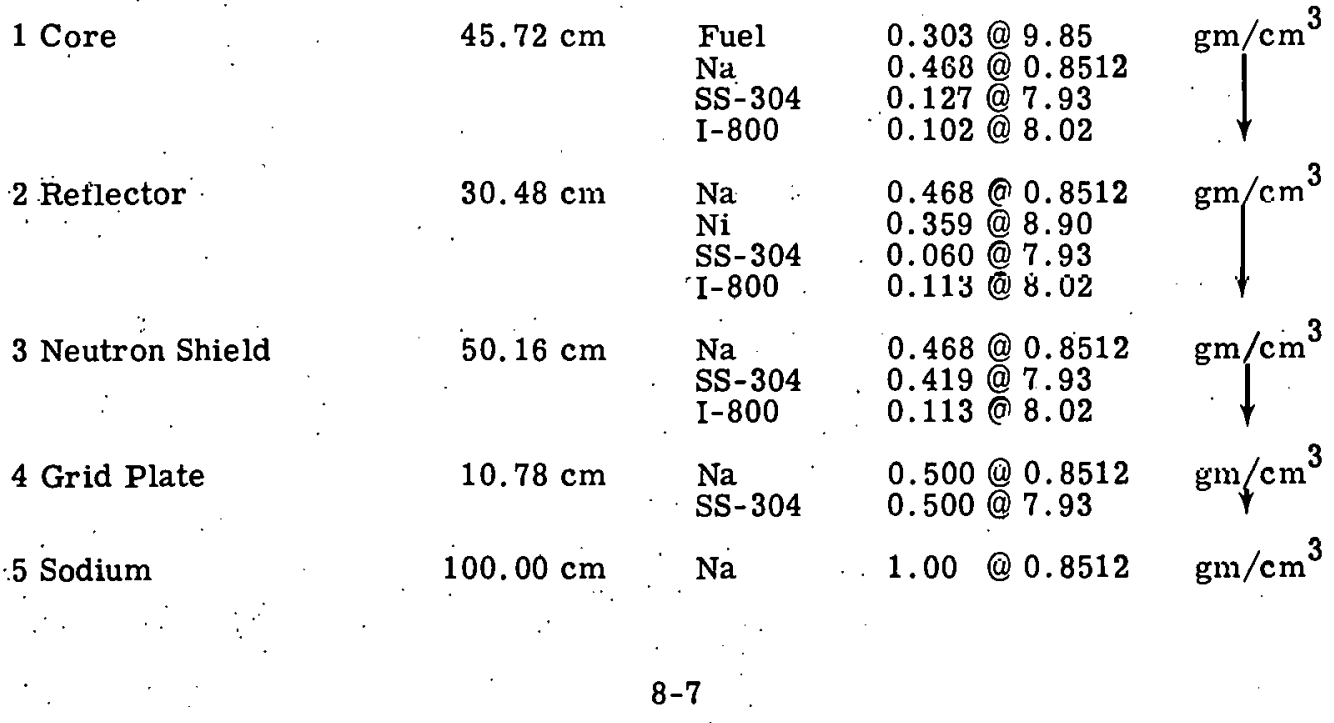

MATERIAL,

WIDTH.

$45.72 \mathrm{~cm}$ 


\subsection{TOTAL NEUTRON FLUX AND THERMAL NEUTRON FLUX}

The radiation level in spaces with personnel access is due both to gamma and neutron radiation. For the Backup core, the shielding in the upper axial direction is designed to limit the average dose rate to personnel working in the vicinity of the top head to $50 \mathrm{mRem} / \mathrm{h}$. In the radial and lower axial directions, the Backup core shielding is designed to limit fast neutron irradiation damage and the heat load external to the reactor vessel shell. In the latter two dimensions, external to the vessel shell, the Backup design will use the shielding provided for the reference design.

Figure 8-5 illustrates the total and thermal neutron flux levels in the radial direction. These results are included for reference purposes.

Figure 7-20 indicates that shield compositions in the upper axial direction (Table 8-2) will attenuate the neutron flux to $250 \mathrm{nv}$, or about $1 \mathrm{mRem} / \mathrm{h}$, at the upper surface of the top head. Since this calculation neglects geometric attenuation, this level is at least a factor of 10 less than would occur if geometric attenuation were included. It must be noted, however, that this calculated neutron flux level does not include the contribution from streaming paths. The latter was considered in Section 7.5.

\subsection{GAMMA DOSE RATE}

As noted for neutron attenuation, the gamma shielding radially external to and axially below the reactor vessel is being designed for the reference concept. The Backup core and reactor internals must be designed to utilize the reference design shielding in these two dimensions. The principal concern is to assure that the heat generation load external to the vessel does not exceed $500 \mathrm{~kW}$ as discussed in Section 8.8. However, in the upper axial direction, gamma shielding must be designed specifically for the Backup concept.

Figures 8-6 and 7-19 illustrate the calculated gamma dose rate in the radial and upper axial dimensions. The radial distribution is included for reference purposes and is used in determining the heat load external to the reactor vessel. Figure 7-19 indicates that the gamma dose rate at the upper surface of the top head is determined by $\mathrm{Na}^{24}$ decay activity in the primary sodium coolant. Neglecting streaming contributions, the gamma dose rate at the upper surface of the top head will be less than $10 \mathrm{mR} / \mathrm{h}$.

\subsection{REFUELING CELL SHIELD DESIGN}

Referring to Section 8.2 it should be noted that the refueling cell utilizes open head refueling in an inert gas atmosphere. Personnel access either during power operation or after shutdown requires "suiting up." Since the radiation sources are different during power operation than after shutdown-especially during refueling-the shielding requirements during power operation are discussed independently from those after shutdown in the following paragraphs. 


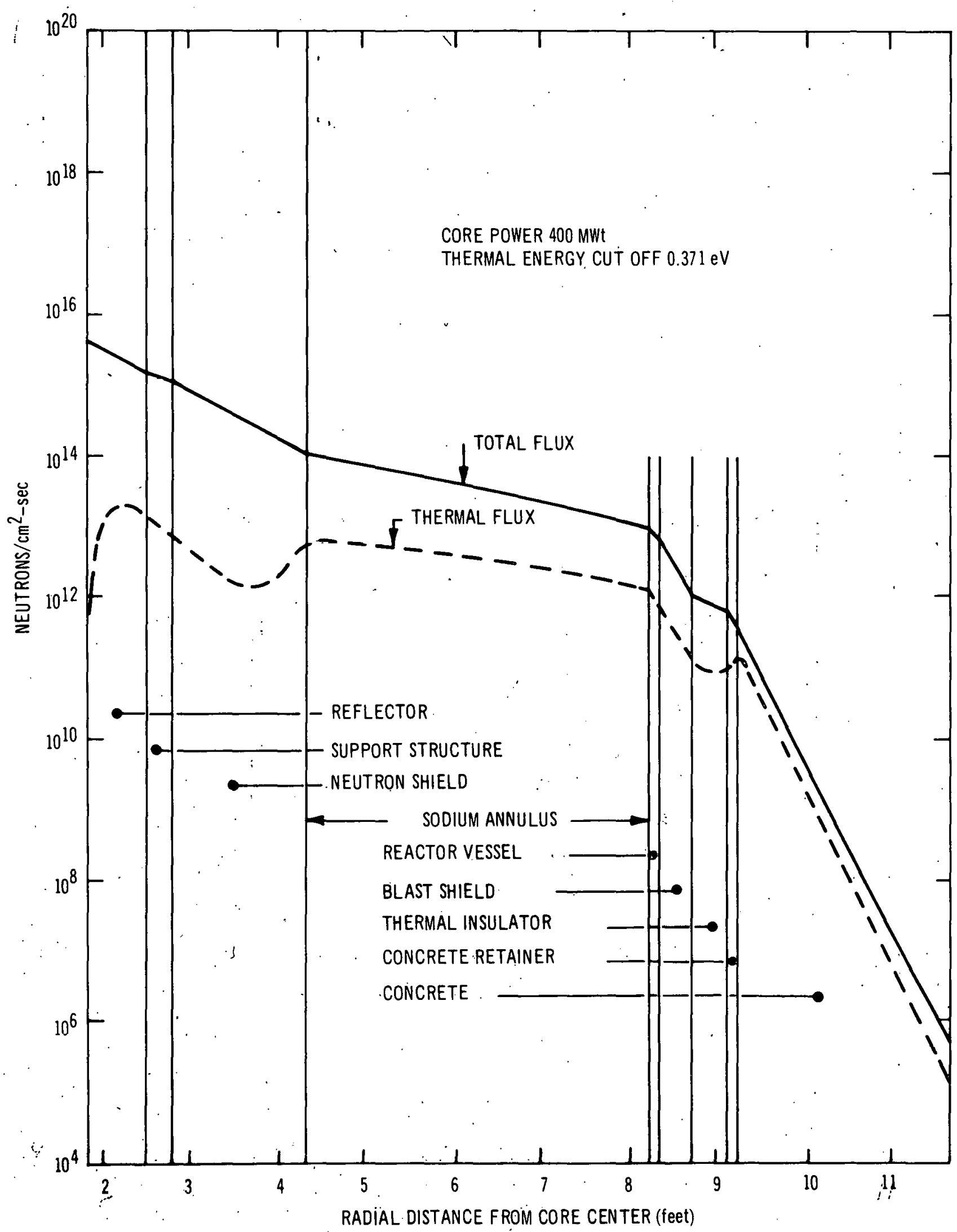

FIGURE 8-5. TOTAL NEUTRON FLUX AND THERMAL NEUTRON FLUX VERSUS RADIAL DISTANCE FROM CORE CENTER. 
GEAP-5722

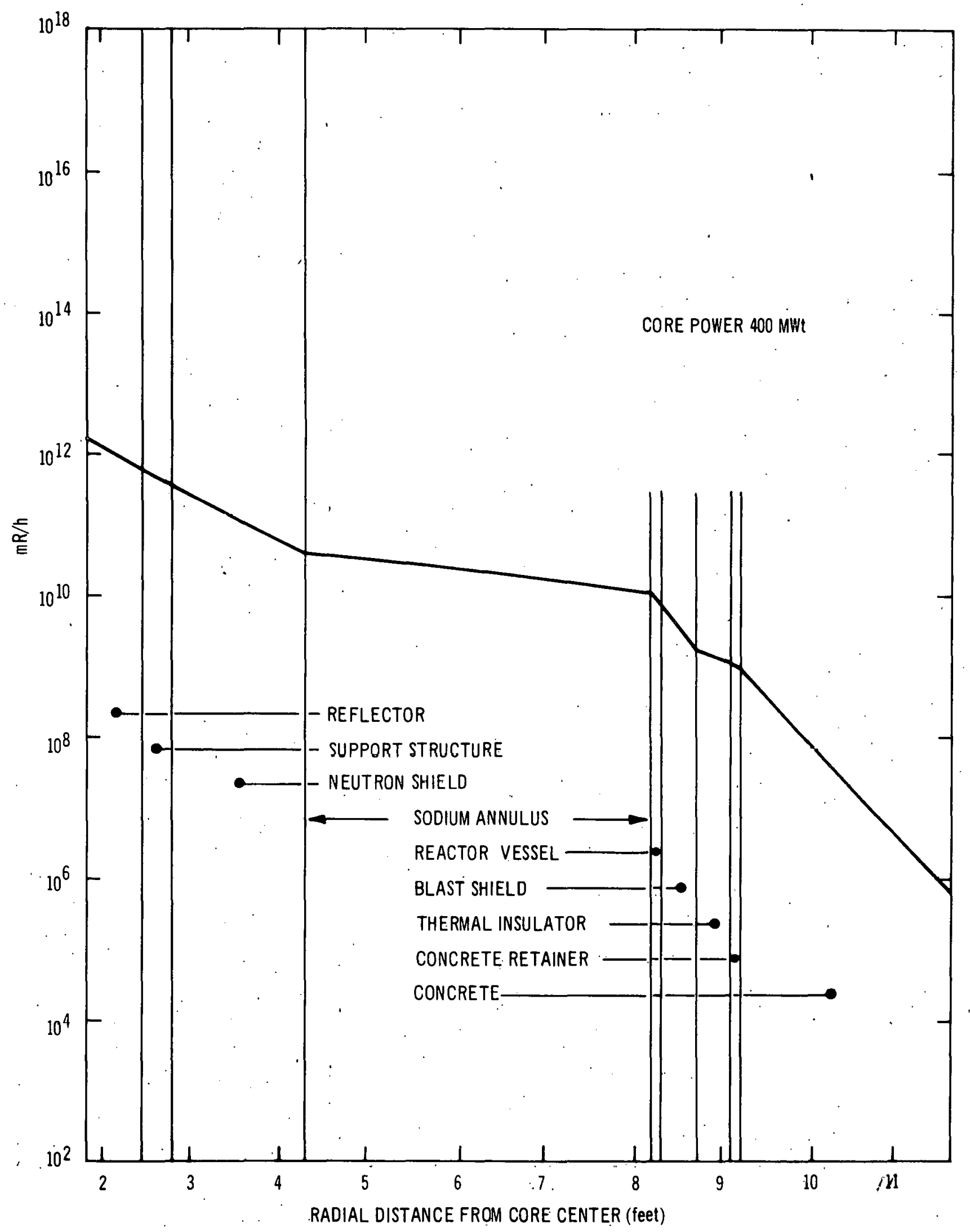

FIGURE 8-6. GAMMA DOSE RATE VERSUS RADIAL DISTANCE FROM CORE CENTER 


\subsubsection{Radiation Levels in the Refueling Cell During Full Power Operation}

The design criterion for the top head and upper axial shielding permits limited personnel access into the refueling cell at any time that all top head shield plugs are in place. (This assumes that no spent fuel or other highly radioactive sources are in the cell, unless adequately șielded.) During full power operation, the average dose rate for personnel working in the vicinity of the top head will not exceed $50 \mathrm{mRem} / \mathrm{h}$. At no location will the dose rate exceed $300 \mathrm{mRem} / \mathrm{h}$.

During full power operation, the principal radioactive sources and their calculated dose rates averaged over the surface of the top head are:

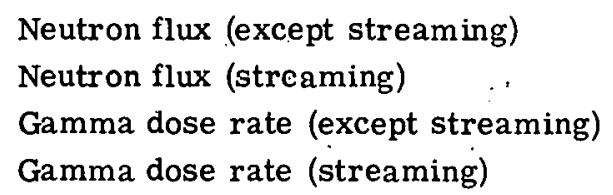

TOTAL
$1 \mathrm{mRem} / \mathrm{h}$ $\sim 15 \mathrm{mRem} / \mathrm{h}$ $10 \mathrm{mR} / \mathrm{h}$ $\sim 15 \mathrm{mR} / \mathrm{h}$ $<50 \mathrm{mRem} / \mathrm{h}$

The above numbers were obtained from Sections $8.2,7.5$, and 8.7 . It is seen that the peak radiation level in the vicinity of the top head is not expected to exceed design criteria.

\subsubsection{Radiation Levels in the Refueling Cell After Shutdown}

With the reactor shutdown and all top head shield plugs in place, the principal radiation source at shutdown will be the 15 -hour half-life $\mathrm{Na}^{24}$ decay activity in the primary sodium coolant. The average radiation level over the surface of the top head will decay at the rate of a factor of 3 per day until it is no longer significant. As noted in Section 7. 5, the peak radiation level from this source is not expected to exceed $25 \mathrm{mR} / \mathrm{h}$, averaged over the upper surface of the top head.

With the top shield plug removed, the dose rate in the refueling cell will be due to either the $\mathrm{Na}^{24}$ decay activity or the $\mathrm{Na}^{22}$ decay activity in the primary sodium coolant. As noted in Section 8.7 , the peak $\mathrm{Na}^{24}$ dose rate at the surface of the pool was calculated to be $240,000 \mathrm{R} / \mathrm{h}$, whereas the $\mathrm{Na}^{22}$ dose rate will be only about $10 \mathrm{R} / \mathrm{h}$. However, because of its very long half-life (2.6 years), the $\mathrm{Na}^{22}$ activity remains essentially constant during reactor shutdown periods. In 9 to 10 days following reactor shutdown, the $\mathrm{Na}^{24}$ dose rate decays to a lower level than that due to $\mathrm{Na}^{22}$. With the head removed and assuming a 10-day decay time following a long ( 3 days or more) period of operation, the scattered radiation level from $\mathrm{Na}^{22}$ decay inside the refueling cell is expected to be in the range of 10 to $100 \mathrm{mR} / \mathrm{h}$, unless looking directly into the sodium pool.

Of course, the largest radiation source in the refueling cell will come from the irradiated fuel assemblies during refueling operations. A gross calculation indicates a dose rate of $10^{7} \mathrm{R} / \mathrm{h}$ near a fuel assembly, decreasing to 100,000 (or $10^{5}$ ) $\mathrm{R} / \mathrm{h}$ ten feet away. Personnel access into the cell during refueling operations is clearly prohibited. 
During refueling operations a peak dose rate of $4 \mathrm{mR} / \mathrm{h}$ in the operations room was calculated for an unshielded fuel assembly located 4 feet from a 4-foot thickness magnetite concrete refueling cell wall. This is a peak value and occurs only directly opposite an FFTF fuel așembly which has generated 4.5 MWt over a long irradiation period. A decay time of 1 day is assumed. It is expected that refueling operations will contribute a dose rate of less than $0.5 \mathrm{mRem} / \mathrm{h}$ averaged over the working space in the operations room if 4-foot thickness magnetite concrete walls (or gamma equivalent) are used for the refueling celis. Of course, these wall thicknesses may be decreased in the upper levels of this cell where slanted radiation paths provide greater radiation attenuation.

\section{6 PRIMARY HEAT EXCHANGER AND PUMP CELL}

The principal radiation source in the primary heat exchanger and pump cells is the $\mathrm{Na}^{24}$ activity in the primary coolant. As noted in Section 8.7 , this 15 -hour half-life activity is estimated to reach $2.6 \times 10^{9}$ disintegrations $/ \mathrm{cm}^{3}$-sec (or $0.071 \mathrm{Ci} / \mathrm{cm}^{3}$ ) during $400 \mathrm{MWt}$ FFTF operation. The thicknesses of gamma shielding materials (equivalent to $450 \mathrm{gm} / \mathrm{cm}^{2}$ ) required to assure a dose rate of less than $1 \mathrm{mR} / \mathrm{h}$ in adjacent spaces are as follows:

$\begin{array}{lll}\text { Shielding Material } & \frac{\text { Density }}{\text { Thickness }} \\ \text { Regular Concrete } & 2.33 \mathrm{gm} / \mathrm{cm}^{3} & 6.3 \text { feet } \\ \text { Magnetite Concrete } & 3.69 \mathrm{gm} / \mathrm{cm}^{3} & 4.0 \text { feet } \\ \text { Iron } & 7.7 \mathrm{gm} / \mathrm{cm}^{3} & 2.0 \text { feet }\end{array}$

The principal source of the $\mathrm{Na}^{24}$ activity in the primary sodium coolant is the 5 -footdiameter hemispherical part of the primary to secondary heat exchanger. During operation the dose rate in this space is expected to reach $100,000 \mathrm{R} / \mathrm{h}$. However, after shutdown, the $\mathrm{Na}^{24}$ will decay on a 15 -hour half-life until, in about 9 days, the $\mathrm{Na}^{22}$ activity predominates. With the heat exchanger filled with sodium, the $\mathrm{Na}^{22}$ is expected to contribute an average dose rate of about $1 \mathrm{R} / \mathrm{h}$ in the working area inside the cell. At the upper and lower heads this dose rate will be about $5 \mathrm{R} / \mathrm{h}$.

With the heat exchanger drained, (both primary and secondary sides), $\mathrm{Na}^{22}$ activity is expected to give a dose rate of about $0.3 \mathrm{R} / \mathrm{h} 1$ foot from the, surface of the heat exchanger, assuming a 10-mil thickness of primary coolant clings to the inner surface of all tubes. All of these calculations involving the primary to secondary heat exchanger assume:

- The primary coolant is on the tube side of the heat exchanger

- There are 10401 -inch-outside-diameter tubes (42-mil wall)

- Tubes are 20 feet in length

- Total volume of the primary coolant sodium is $7400 \mathrm{ft}^{3}$ (or $2.1 \times 10^{8} \mathrm{~cm}^{3}$ )

- Heat exchanger diameter is 5 feet

- Non-radioactive secondary sodium coolant is on the shell side of the heat exchanger.

Fission products in the primary coolant are not expected to present a radiation problem during normal operation. Calculations were made which assumed the complete disintegration of one $50-\mathrm{kW}$ fuel pin followed by the homogeneous distribution of its fission products in the 
total primary coolant system volume. Resulting dose rates from these fission products, as a function of time after fuel pin disintegration, will be about:

\section{$\underline{\text { Time After Disintegration (Irradiation) }}$}
1 day
$\underline{5 \text { days }}$
10 days
Dose Rate from the Heat Exchanger =
$4.0 \mathrm{R} / \mathrm{h}$
$2.8 \mathrm{R} / \mathrm{h}$
$2.2 \mathrm{R} / \mathrm{h}$

With the heat exchanger drained (both primary and secondary sodium), except for a 10-mil thickness of primary coolant clinging to the inner surface of all tubes, the dose rate from fission products is expected to be less than $1 \mathrm{R} / \mathrm{h}, 10$ days after fuel pin disintegration.

The effect of radioactive mass transport has not been included in these estimates. However, based on the results of approximate calculations ${ }^{(5)}$, it is clear that this effect cannot be neglected. Dose rates in the range of 0.1 to $100 \mathrm{R} / \mathrm{h}$ from the heat exchanger are possible due to deposits of radioactive materials transported from the core.

\section{7 CLOSED LOOP CELLS}

The assumption is made for estimating closed loop cell shielding requirements that the experiment will be cooled by sodium. Hence, one of the primary radiation sources in this type of cell will be the coolant activity itself, both $\mathrm{Na}^{24}$ and $\mathrm{Na}^{22}$. Because of the experimental nature of the fuel being. irradiated in loops of this type, one must also assume significant fission product release into the coolant due to fuel cladding ruptures. Order of magnitude estimates ${ }^{(6)}$ indicate $\mathrm{Na}^{24}$ specific activities $\left(\mathrm{Ci} / \mathrm{cm}^{3}\right)$ in the closed loop coolants to be 2 to 5 times those in the main core primary coolant system. Of course, pipe sizes and heat exchanger volumes are much smaller. For shielding purposes, dose rates exceeding $10,000 \mathrm{R} / \mathrm{h}$ within the closed loop cells from $\mathrm{Na}^{24}$ activity are expected.

Should the fission products from a single $100 \mathrm{~kW}$.experimental fuel pin be homogenously distributed in a closed loop primary sodium coolant volume of $74 \mathrm{ft}^{3}$, the resulting contribution to the dose rate within the closcd loop cell from fission products only is estimated to be between 1,000 and $10,000 \mathrm{R} / \mathrm{h}$. Hence, it is seen that fission products may make a significant (although not overriding) contribution to the radiation sources which must be shielded during closed loop operation. Compared to the core primary heat exchanger cell shield requirements, only a factor of 5 to 10 (reduction) exists in the closed loop cell shield walls. This is equivalent to a reduction of about $54 \pm 10 \mathrm{gm} / \mathrm{cm}^{2}$ of gamma shielding, which results in the following estimated shield whll thickness for the closed lonp cells.

Shlelding Material
Regular Concrete
Magnetite Concrete
Iron

Shlelding Material

Regular Concrete

Iron
Density

$$
\begin{aligned}
& 2.33 \mathrm{gm} / \mathrm{cm}^{3} \\
& 3.69 \mathrm{gm} / \mathrm{cm}^{3} \\
& 7.7 \mathrm{gm} / \mathrm{cm}^{3}
\end{aligned}
$$

Thickness

5.7 feet

3.6 feet

1.7 feet

After reactor shutdown, the $\mathrm{Na}^{24}$ activity will decay with its characteristic 15-hour halflife until, in about 9 days the $\mathrm{Na}^{22}$ activity predominates. The latter is expected to contribute 
less than $1 \mathrm{R} / \mathrm{h}$ to the radiation level inside the closed loop cell. Draining the sodium would reduce the dose rate to an estimated $0.3 \mathrm{R} / \mathrm{h}$. The latter is due to an assumed 10 -mil thickness of primary loop coolant which clings to the pipes of the loop heat exchanger and other pipes associated with the given loop:

With fission products in the closed loop primary sodium cooling, however, the radiation level inside the closed loop cell originating from these fission products may be expected to decay no more than a factor of 2 in about 10 days. If draining the system reduces a dose rate of up to $10,000 \mathrm{R} / \mathrm{h}$ by no more than the factor of 3 calculated for the core primary coolant, then it would appear necessary to flush the closed loop primary system to permit personnel access to this space.

\section{8 SODIUM COOLANT ACTIVATION}

As noted in the preceding discussion, activation of the sodium coolant is the major concern in evaluating FFTF activation levels. The calculated dose rate at the pool surface of the FFTF primary sodium is $240,000 \mathrm{R} / \mathrm{h}$ during $400 \mathrm{MWt}$ operation. This dose rate is due only to the radioactive decay of $\mathrm{Na}^{24}$ at equilibrium conditions. Having a 15-hour half-life, equilibrium is effectively reached in less than 3 days. While $\mathrm{Na}^{24}$ constitutes the major activity in the sodium coolant during full-power operation, it is the lesser $\mathrm{Na}^{22}$ activity [resulting from high-energy $\left(>12.4 \mathrm{MeV}\right.$ ) neutron $(\mathrm{n}, 2 \mathrm{n})$ reactions with $\mathrm{Na}^{23}$ nuclei] which predominates 10 days after. reactor shutdown. Because of its very long half-life (2.6 years), the $\mathrm{Na}^{22}$ activity remains essentially constant during reactor shutdown periods. The calculated dose rate at the surface of a large pool of primary sodium coolant is expected to reach $10 \mathrm{R} / \mathrm{h}$ at equilibrium conditions due to $\mathrm{Na}^{22}$ activity only. A reactor operating time approaching 10 years is required to effectively reach equilibrium conditions. However, 50 percent of equilibrium $\mathrm{Na}^{22}$ activity is reached in only one half-life, or 2.6 years.

In Table 8-4, the rates of $\mathrm{Na}^{24}$ and $\mathrm{Na}^{22}$ formation are indicated as a function of core location.

TABLE 8-4

CALCULATED FORMATION RATE IN FFTF PRIMARY COOLANT SODIUM

\begin{tabular}{|c|c|c|}
\hline \multirow[b]{2}{*}{ Region } & \multicolumn{2}{|c|}{ Formation Rate (nuclei/sec) } \\
\hline & $\mathrm{Na}^{24}$ & $\mathrm{Na}^{22}$ \\
\hline & $0.8 \times 10^{17}$ & $6.3 \times 10^{13}$ \\
\hline Reflectors & $2.7 \times 10^{17}$ & $1.1 \times 10^{13}$ \\
\hline Gas Space & $2.0 \times 10^{17}$ & negligible \\
\hline & $5.5 \times 10^{17}$ & $7.4 \times 10^{13}$ \\
\hline
\end{tabular}

The above results are in quite good agreement with values quoted in Reference 5 . The above $\mathrm{Na}^{22}$ activity is a factor of 2 less than quoted in Reference 5 . However, this is not a large effect, considering the expected accuracy of the $\mathrm{Na}^{23}(\mathrm{n}, 2 \mathrm{n}) \mathrm{Na}^{22}$ cross section. 
Assuming a total primary sodium coolant volume of $7400 \mathrm{ft}^{3}$ (or $2 / 1 \times 10^{8} \mathrm{~cm}^{3}$ ), the above activation rates result in the saturated specific activities of the primary sodium coolant given in Table 8-5.

TABLE 8-5

SATURATED SPECIFIC ACTIVITY OF SODIUM IN THE PRIMARY COOLANT SODIUM $\left(7400 \mathrm{ft}^{3}\right)$

$\frac{\text { FFTF Power Level }}{400 \mathrm{MWt}} \quad \frac{\mathrm{Ci} \mathrm{Na}^{24} / \mathrm{cm}^{3}}{0.071} \quad \frac{\mathrm{Ci} \mathrm{Na}^{22} / \mathrm{cm}^{3}}{9.5 \times 10^{-6}}$

The specific activities given in Table $8-5$ result in dose rates of $240,000 \mathrm{R} / \mathrm{h}$ and $8.8 \mathrm{R} / \mathrm{h}$, respectively, for the $\mathrm{Na}^{24}$ and $\mathrm{Na}^{22}$. The $\mathrm{Na}^{22}$ dose rate ignores the annihilation radiation of positron decay, which will probably increase the dose rate from $8.8 \mathrm{R} / \mathrm{h}$ to about $10 \mathrm{R} / \mathrm{h}$.

\section{9 HEAT GENERATION OUTSIDE OF THE REACTOR VESSEL}

The radial shielding inside the reactor vessel is required to limit the heat generation load in the shielding external to the reactor vessel to $500 \mathrm{~kW}$ or less. This load assumes heat generation axially below the reactor vessel, as well as radially external to the reactor vessel. The shielding compositions inside the vessel are designed primarily to limit fast neutron irradiation damage to the reactor vessel itself. Hence, any optimization study must consider both fast neutron fluence at the vessel and the heat generation load external to the vessel.

A radial shield optimization study was completed with the results reported in Reference 7 . The specific goals of the analysis were to minimize the fast neutron fluence at the reactor vessel and to minimize gamma heating external to the reactor vessel. This study showed that, in all cases, where the $\mathrm{B}_{4} \mathrm{C}$ content of the 18-inch thickness neutron shield was varied from $60 \%$ down to $0 \%$, the fast neutron fluence $\left(E_{n}>0.1 \mathrm{MeV}\right)$ was well below the design limit $\left(5 \times 10^{20} \mathrm{nvt}\right)$.

This study indicated, however, that the gamma heat generation rate varied from $0.278 \mathrm{~W} / \mathrm{cm}^{2}$ $\left(0 \% \mathrm{~B}_{4} \mathrm{C}\right)$ down to $0.042 \mathrm{~W} / \mathrm{cm}^{2}\left(60 \% \mathrm{~B}_{4} \mathrm{C}\right)$, which is in excess of the $0.035 \mathrm{~W} / \mathrm{cm}^{2}$ recommended by PNL. The cooling system for components located externally adjacent to the reactor vessel has been, however, tentatively sized by PNL in the range of 100 to $500 \mathrm{~kW}$. If one assumes that this heating rate occurs over a 15 -foot height, the total gamma heating rates illustrated by Table 8-6 are generated. Table 8-6 shows that the gamma heat load varies from a low of $26 \mathrm{~kW}$ to a high of $201 \mathrm{~kW}$. Thus, in all cases, this total heat load is well under the tentative limit of $500 \mathrm{~kW}$. Therefore, considering the cost of $\mathrm{B}_{4} \mathrm{C}$, the decision has been made to recommend elimination of $\mathrm{B}_{4} \mathrm{C}$ from the core radial shielding. This decision, following as it does the study reported in Reference 8 , where it was shown to be both feasible and acceptable to remove all $\mathrm{B}_{4} \mathrm{C}$ from the upper axial neutron shield, results in the removal of all $\mathrm{B}_{4} \mathrm{C}$ from the Backup core shielding which is located inside the reactor vessel. 
TABLE 8-6

FFT F BACKUP DESIGN, $400 \mathrm{MW}$ THERMAL GAMMA HEAT GENERATION RATE IN THE COMPONENTS LOCATED EXTERNALLY ADJACENT TO THE REACTOR VESSEL

\begin{tabular}{|c|c|c|c|c|c|}
\hline \multicolumn{3}{|c|}{ Neutron Shield Composition } & \multicolumn{2}{|c|}{ Gamma Heat Generation Rate } & \multirow{3}{*}{$\begin{array}{c}\text { Total Heat Over } \\
\text { 15-Foot Height } \\
\mathrm{kW}\end{array}$} \\
\hline \multicolumn{3}{|c|}{ Volume Percent } & MAC $\infty$ Slab * & $1 / \mathrm{r}$ Correction * & \\
\hline $\mathrm{B}_{4} \mathrm{C}$ & SS-304 & $\mathrm{Na}$ & $\mathrm{W} / \mathrm{cm}^{2}$ & $\mathrm{~W} / \mathrm{cm}^{2}$ & \\
\hline 0 & 70 & 30 & 1.169 & 0.278 & 201 \\
\hline 10 & 60 & 30 & 0.168 & 0.057 & 41 \\
\hline 20 & 50 & 30 & 0.104 & 0.043 & 31 \\
\hline 40 & 30 & 30 & 0.072 & 0.036 & 26 \\
\hline 60 & 10 & 30 & 0.097 & 0.042 & 30 \\
\hline
\end{tabular}

\footnotetext{
* Includes $0.026 \mathrm{~W} / \mathrm{cm}^{2}$ due to $\mathrm{Na}^{24}$ decay activity. (Absorption in the reactor vessel was neglected.)
}

\section{10 FISSION PRODUCT DECAY ENERGY}

\subsubsection{Reference Data}

A very large amount of work has been done on other projects to measure the decay energy from U-235 fission products. Essentially all of these products result from fission reactions with thermal neutrons. In the FFTF core, however, fission products are formed from high energy, or fast, neutron $\left(E_{n}>0.1 \mathrm{MeV}\right)$ reactions with $\mathrm{Pu}-239$. The question being asked is, "How does the fission-product decay energy from the fast neutron fission of Pu-239 differ from the thermal neutron fission of U-235?"

A preliminary study indicates that measurements of the fission product decay energy from the fast fission of Pu-239 are as yet quite limited. A relatively old reference notes that within the limits of experimental error (10\%), there is no perceptible difference between the results for U-235 and Pu-239 as to the dependence on time after fission, mean energy of the gamma radiation, and total yield of gamma energy per fission. ${ }^{(9)}$ It should be noted that the latter reference refers to gamma energy only. Two relative recent References, 10 and 11 , indicate very good agreement when the total (gamma and beta) fission-product decay power from U-235 thermal neutron fission is compared to the total fission-product decay power from $\mathrm{Pu}-239$ fast neutron fission. The latter references, however, include measurements for only relatively long times after fission, i.e:, 40 to 150 days. Quite recently, Reference 12 was issued which indicates, for infinite irradiation periods, that the absorbable energy emitted by the fission fragments from the fast fission of $\mathrm{Pu-239}$ is in the range of 0.90 to 1.00 times the absorbable energy emitted by the fission fragments from the thermal fission of U-235.

In summary, a comparison of the limited measurements of fast-neutron-induced Pu-239 fission product decay energy to the relatively extensive measurements of thermal neutron U-235 fission-product decay energy indicates that differences are not large. Some experimental 
and analytical data indicate lower decay energy from $\mathrm{Pu}-239$ fast fission than from U-235 thermal fission. In view of the consistency of the available data, the use of fission-product decay curves based on measurements of U-235 thermal fission is recommended for estimating the decay power versus time after reactor shutdown from $\mathrm{Pu-239}$ fast fission for preliminary FFTF design work.

Figures 8-7 and 8-8 illustrate the recommended total (as well as gamma and beta only) fission product decay power versus cooling time (or time after reactor shutdown). These figures assume infinite reactor operating time. Table 8-7 and Figures 8-9 and 8-10 illustrate fission product decay power versus cooling time for irradiation times varying from 1 hour to infinite time.

In using these curves, it must be noted that there are other important sources of power generation in the FFTF core following reactor shutdown. During the first minute after scram, the fission power due to delayed neutron emission exceeds fission product decay power by a factor of 2 or more. At times ranging from 2 hours to 30 hours after shutdown, $\mathrm{Np}-239$ decay may contribute up to one-half of the heat generated by fission product decay (the former is additional to fission product decay energy). Details and graphs are given in Reference 13.

\section{10.2 Decay Heat Generation in a Fuel Bundle Following Reactor Shutdown}

During fuel bundle transfer from the FFTF core to the decay storage pool, heat will be generated in the fuel bundle and transfer thimble because of the absorption of radiation emitted from radioactive fission products and $\mathrm{Np}-239$ decay. To evaluate fuel bundle cooling requirements during such transfers, it is necessary to know the heat generation rate at the time of the transfer.

For purposes of this study, it was assumed that fuel transfers would take place in the interval of 8 to 24 hours following reactor shutdown. It was further assumed that the full power irradiation period would not be less than 6 months nor greater than 16 months. (To simplify the evaluation, the assumption was also made that the fuel was irradiated continuously for the stated period, with no intermediate shutdowns or operation at reduced power levels. This assumption is conservative.) Finally, the heat generation rates are based on fission pruduct decay heat measurements from the thermal neutron fission of U-235. As noted previously, a preliminary evaluation indicates this data may be used to estimate fission product decay heat rates from the fast fission of Pu-239.

Figure 8-11 and Table 8-8 summarize the results of this evaluation, which shows a range of heat generation rates from a high of $22.9 \mathrm{~kW}$ to a low of $15.4 \mathrm{~kW}$. The real significance of these heat generation rates is the subject of a thermal-hydraulics analysis.

The geometry assumed in calculating the amount of gamma radiation which escapes from the bundle and thimble is a cylindricized fuel bundle and flow channel surrounded by a 1.238 -inch annulus of sodium and a 0.333 -inch wall thickness of stainless steel (thimble). The cylindricized fuel assembly itself has an equivalent diameter of 3.524 inches. 


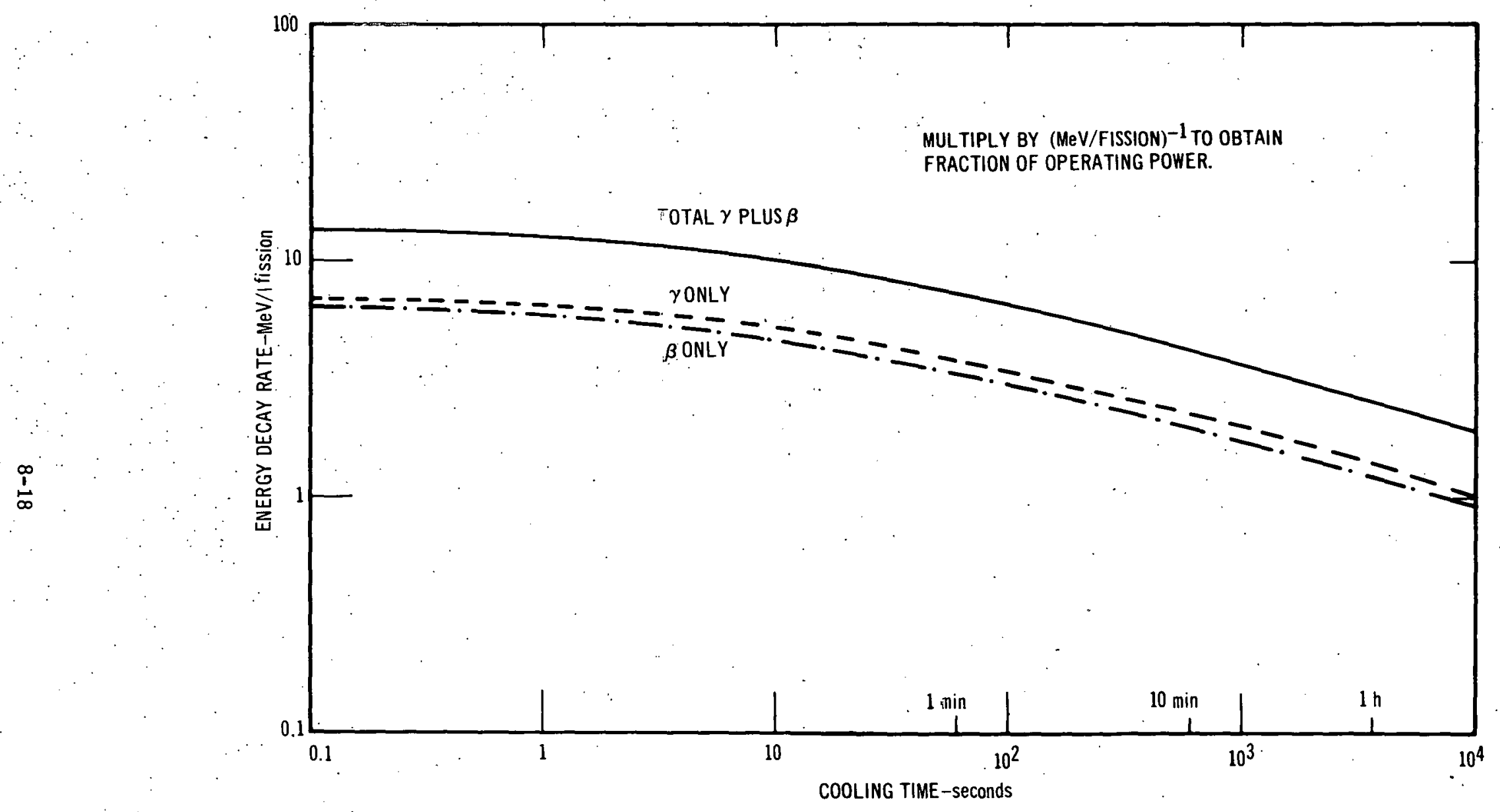




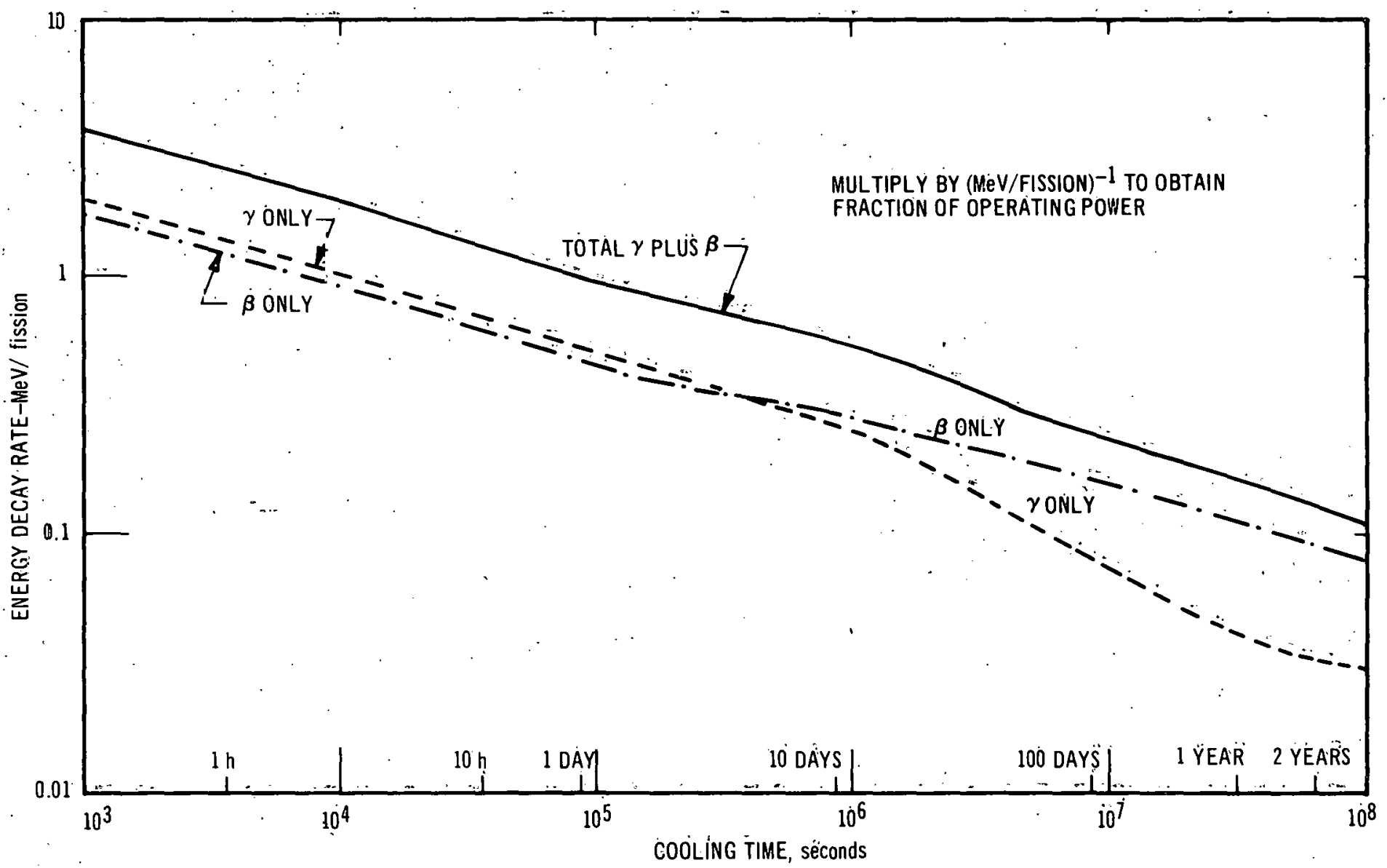




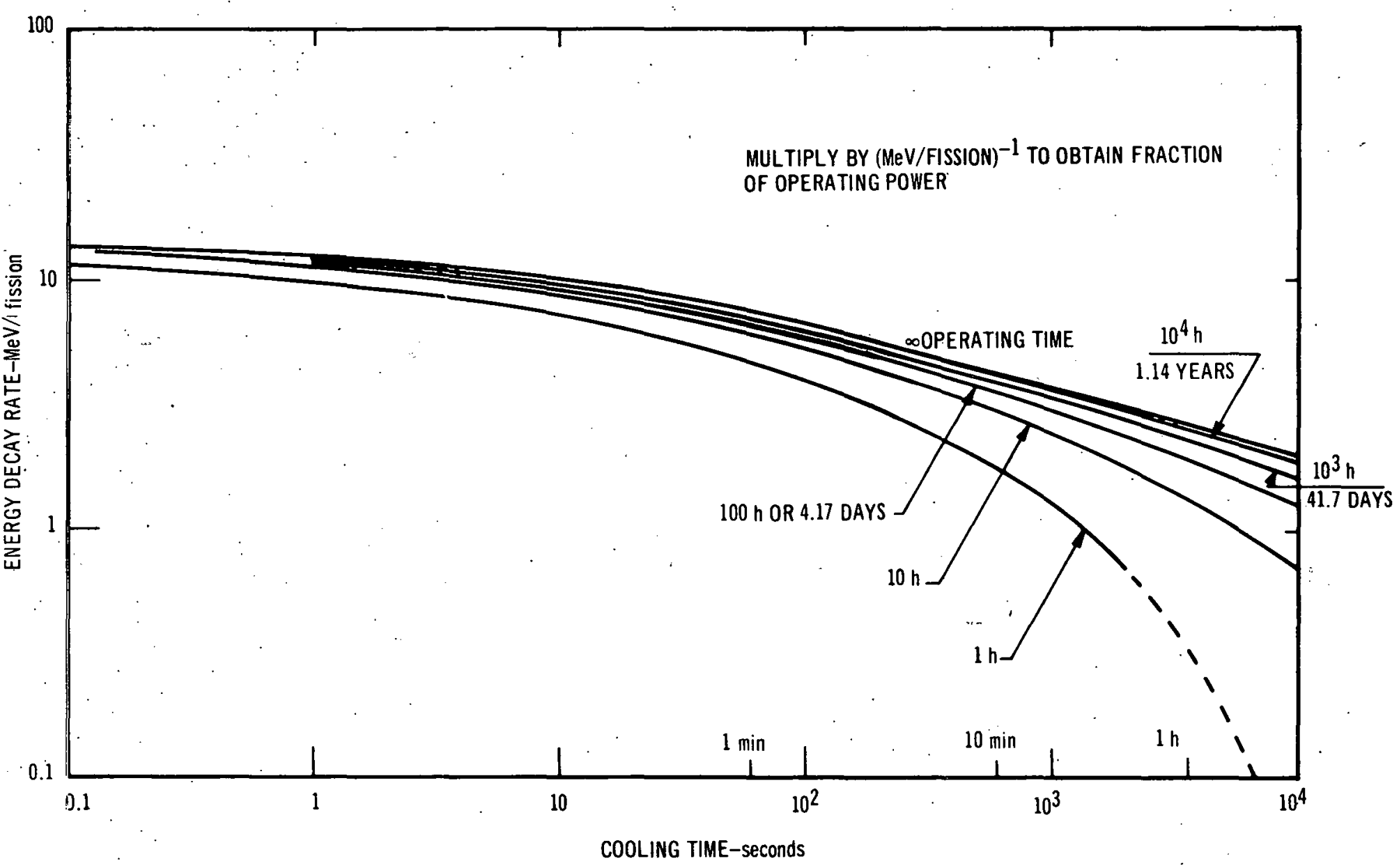




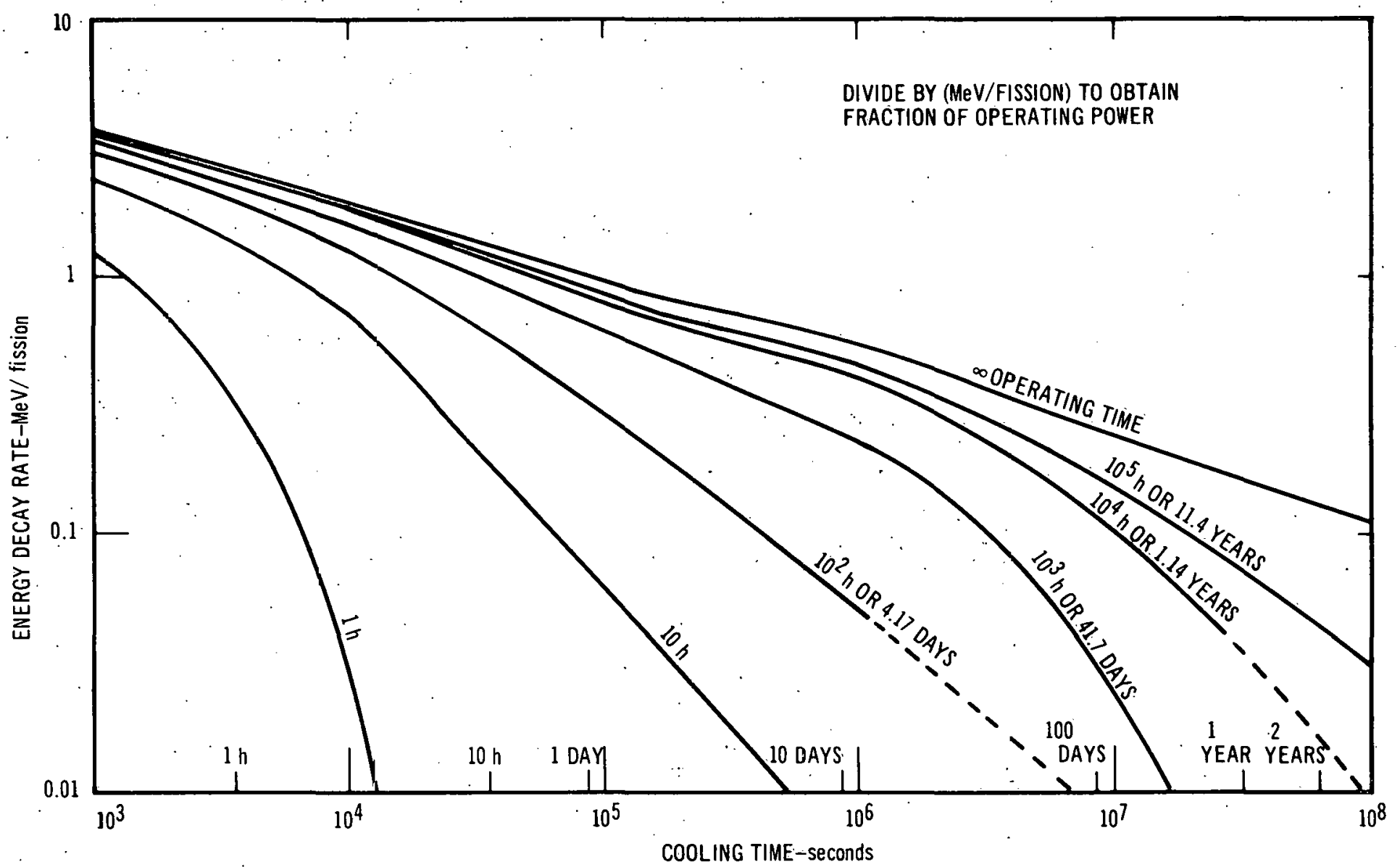

EIGURE 8-10. ABSORBABLE ENERGY RELEASED BY FISSION PRODUCTS FOR OPERATING TIMES VARYING FROM ONE HOUR TO $\infty$ VERSUS COOLING TIME 


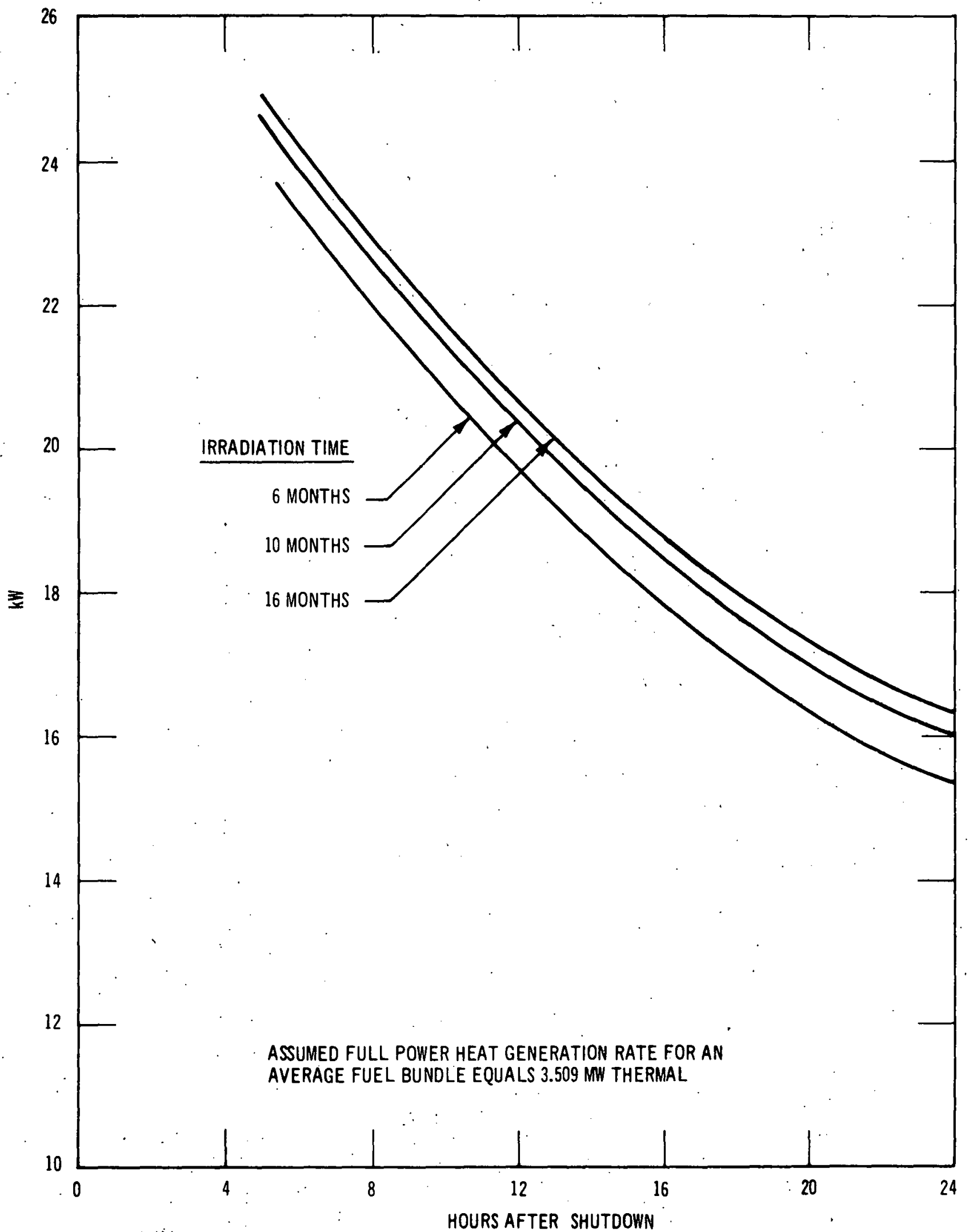

FICURE 8-11. FFTF HEAT GENERATION RATE IN A FUEL BUNDLE AND TRANSFER THIMBLE YERSUS (1) TIME AFTER SHUTDOWN (8 TO 24 hours)

(2) IRRADIATION TIME (6 TO 16 months) 
TABLE 8-7 ENERGY RELEASE RATE FROM FISSION PRODUCT DECAY

IN A U-235 - FUELED REACTOR AFTER SHUTDOWN

\begin{tabular}{|c|c|c|c|c|c|c|c|c|}
\hline & & & & $:$ & & & $\mathrm{MeV}-\mathrm{sec} / \mathrm{fiss}$ & \\
\hline Operating & Shutdown & & & $\mathrm{V} /$ fission & ** & & $\int^{\mathrm{t}} s_{-}$ & \\
\hline$\underset{\text { (h) }}{\operatorname{Time}, t_{0}}$ & $\underset{\text { (sec) }}{\text { Time, }}{ }^{t}$ & & $\mathbf{P}_{\gamma}$ & $\mathbf{P}_{\beta}$ & $\mathrm{P}_{\gamma+\beta}$ & & $\int_{0}{ }^{\mathrm{D}} \mathrm{P}_{\gamma+\beta^{\mathrm{dt}}}$ & \\
\hline . . & $\begin{array}{l}1 \\
10 \\
10^{2} \\
10^{3} \\
10^{4} \\
10^{5}\end{array}$ & & $\begin{array}{l}5.06 \\
3.90 \\
2.12 \\
0.68 \\
0.02 \\
-\end{array}$ & $\begin{array}{c}4.70 \\
3.40 . \\
.1 .86 \\
0.58 \\
0.01 \\
-\end{array}$ & $\begin{array}{l}9.76 \\
7.30 . \\
3.98 \\
1.25 \\
0.03 \\
-\end{array}$ & . & $\begin{array}{r}12 \\
110 \\
500 \\
2,260 \\
6,300 \\
9,900\end{array}$ & \\
\hline 10 & $\begin{array}{c}1 \\
10 \\
10^{2} \\
10^{3} \\
10^{4} \\
10^{5} \\
10^{6}\end{array}$ & . & $\begin{array}{l}5.80 \\
4.64 \\
2.84 \\
1.32 \\
0.40 \\
0.046 \\
0.005\end{array}$ & $\begin{array}{l}5.36 \\
4.06 \\
2.48 \\
1.10 \\
0.30 \\
0.014 . \\
-\end{array}$ & $\begin{array}{l}11.16 \\
8.70 \\
5.32 \\
2.42 \\
0.70 \\
0.06 \\
0.005\end{array}$ & & $\begin{array}{r}12 \\
110 \\
800 \\
3,760 \\
14,800 \\
32,400 \\
17,200\end{array}$ & \\
\hline $10^{2}$ & $\begin{array}{l}1 \\
10 \\
10^{2} \\
10^{3} \\
10^{4} \\
10^{5} \\
10^{6} \\
10^{7} \\
10^{8}\end{array}$ & & $\begin{array}{l}6.08 \\
4.92 \\
3.14 \\
1.62 \\
0.66 \\
0.176 \\
0.032 . \\
\quad- \\
-\end{array}$ & $\begin{array}{l}5.68 \\
4.38 \\
2.78 \\
1.42 \\
0.60 \\
0.120 \\
0.018 \\
\because- \\
\therefore-\end{array}$ & $\begin{array}{c}11.76 \\
9.30 \\
5.92 \\
3.04 \\
1.26 \\
0.296 \\
0.050 \\
- \\
-\end{array}$ & & $\begin{array}{r}12 \\
110 \\
800 \\
4,960 \\
19,200 \\
67,000 \\
172,000 \\
400,000 \\
460,000\end{array}$ & \\
\hline $10^{3}$ & $\begin{array}{l}1 \\
10 \\
10^{2} \\
10^{3} \\
10^{4} \\
10^{5} \\
10^{6} \\
10^{7}\end{array}$ & & $\begin{array}{l}6.34 \\
5.18 \\
3.40 \\
1.86 \\
0.88 \\
0.37 \\
0.136 \\
0.014\end{array}$ & $\begin{array}{l}5.78 \\
4.48 \\
2.88 \\
1.52 \\
0.72 \\
0.246 \\
0.088 \\
0.010\end{array}$ & $\begin{array}{c}12.12 \\
9.63 \\
6.28 \\
3.38 \\
1.60 \\
0.616 \\
0.224 \\
0.024\end{array}$ & & $\begin{array}{r}12 \\
110 \\
800 \\
4,960 \\
27,200 \\
103,000 \\
406,000 \\
1,542,000\end{array}$ & $\therefore$ \\
\hline $10^{4}$ & $\begin{array}{c}1 \\
10 \\
10^{2} \\
10^{3} \\
10^{4} \\
10^{5} \\
10^{6} \\
10^{7} \\
10^{8}\end{array}$ & & $\begin{array}{l}6.44 \\
5.28 \\
3.50 \\
1.96 \\
0.984 \\
0.472 \\
0.220 \\
0.044 \\
-\end{array}$ & $\begin{array}{l}5.88 \\
4.58 \\
2.98 \\
1.62 \\
0.824 \\
0.344 \\
0.176 \\
0.056 \\
\quad-\end{array}$ & $\begin{array}{c}12.32 \\
9.86 \\
6.48 \\
3.58 \\
1.808 \\
0.816 \\
0.396 \\
0.100 \\
-\end{array}$ & . & $\begin{array}{r}12 \\
110 \\
800 \\
4,960 \\
27,200 \\
137,000 \\
520,000 \\
2,180,000 \\
2,270,000\end{array}$ & \\
\hline $10^{5}$ & $\begin{array}{l}1 \\
10 \\
10^{2} \\
10^{3} \\
10^{4} \\
10^{5} \\
10^{6} \\
10^{7} \\
10^{8}\end{array}$ & & $\begin{array}{l}6.44 \\
5.28 \\
3.50 \\
1.98 \\
0.994 \\
0.480 \\
0.226 \\
0.050 \\
0.006\end{array}$ & $\begin{array}{l}5.94 \\
4.64 \\
3.04 \\
1.66 \\
0.872 \\
0.394 \\
0.226 \\
0.098 \\
0.024\end{array}$ & $\begin{array}{c}12.38 \\
9.92 \\
6.54 \\
3.64 \\
1.866 \\
0.874 \\
0.452 \\
0.148 \\
0.030\end{array}$ & • & $\begin{array}{r}12 \\
110 \\
800 \\
4,960 \\
27,200 \\
137,000 \\
740,000 \\
2,840,000 \\
8,300,000\end{array}$ & \\
\hline$\infty$ & $\begin{array}{c}1 \\
10 \\
10^{2} \\
10^{3} \\
10^{4} \\
10^{5} \\
10^{6} \\
10^{7} \\
\therefore \quad 10^{8}\end{array}$ & . & $\begin{array}{l}6.48 \\
5.32 \\
3.44 \\
2.00 \\
1.02 \\
0.508 \\
0.254 \\
0.076 \\
0.030\end{array}$ & $\begin{array}{l}5.98 \\
4.68 \\
3.08 \\
1.74 \\
0.93 \\
0.450 \\
0.284 \\
0.158 \\
0.080\end{array}$ & $\begin{array}{c}12.46 \\
10.00 \\
6.62 \\
3.74 \\
1.95 \\
0.958 \\
0.538 \\
0.234 \\
0.110\end{array}$ & & $\begin{array}{r}12 \\
110 \\
800 \\
4,960 \\
27,200 \\
137,000 \\
740,000 \\
3,645,000 \\
16,105,000\end{array}$ & \\
\hline
\end{tabular}

* Multiply by (MeV/fission) $)^{-1}$ to obtain fraction of operating power.

** Multiply results of (a) by power to obtaln units of puwer.

*** Multiply by power $\times(\mathrm{MeV} /$ fission) -1 to obtain units of energy, i.e., power-sec. 
TABLE 8-8

\section{FISSION PRODUCT AND Np-239 DECAY HEAT ABSORBED (kW) IN AN FFT F FUEL} BUNDLE AND FUEL TRANSFER THIMBLE VERSUS IRRADIATION PERIOD

$$
\text { AND SHUTDOWN TIME }
$$

Assumed Power Generation Rate in Fuel Bundle:

3.509 MW Thermal (Approximate Core Average) Fission Product

\begin{tabular}{|c|c|c|c|c|c|c|c|}
\hline \multirow[b]{2}{*}{$\begin{array}{l}\text { Irradiation } \\
\text { Period }\end{array}$} & \multirow[b]{2}{*}{$\begin{array}{c}\text { Shutdown } \\
\text { Time } \\
\text { (h) }\end{array}$} & \multicolumn{2}{|c|}{ Decay Heat } & & \multirow{2}{*}{$\begin{array}{c}\text { Np-239 } \\
\text { Decay Heat } \\
\begin{array}{c}\text { Total } \\
\text { (Beta }+ \text { Gamma) } \\
(\mathrm{kW})\end{array} \\
\end{array}$} & \multirow{2}{*}{$\begin{array}{c}\text { F. P. Gamma } \\
\text { Radiation Escaping } \\
\frac{(\text { or Leakage Rate) }}{(\mathrm{kW})}\end{array}$} & \multirow{2}{*}{$\begin{array}{c}\text { Total } \\
\text { Absorption } \\
\text { Rate } \\
(\mathrm{kW}) \\
\end{array}$} \\
\hline & & $\begin{array}{l}\text { Decay } \\
\text { Beta } \\
(\mathrm{kW})\end{array}$ & $\begin{array}{l}\text { Gamma } \\
(\mathrm{kW})\end{array}$ & $\begin{array}{r}\text { Torated } \\
(\mathrm{kW})\end{array}$ & & & \\
\hline 6 months & $\begin{array}{r}8 \\
16 \\
24\end{array}$ & $\begin{array}{l}8.63 \\
6.38 \\
5.16\end{array}$ & $\begin{array}{r}10.95 \\
8.80 \\
7.73\end{array}$ & $\begin{array}{l}19.58 \\
15.18 \\
12.89\end{array}$ & $\begin{array}{l}3.92 \\
3.59 \\
3.26\end{array}$ & $\begin{array}{l}1.49 \\
0.94 \\
0.78\end{array}$ & $\begin{array}{l}22.01 \\
17.83 \\
15.37\end{array}$ \\
\hline 10 months & $\begin{array}{r}8 \\
16 \\
24\end{array}$ & $\begin{array}{l}9.02 \\
6.77 \\
5.58\end{array}$ & $\begin{array}{r}11.22 \\
9.06 \\
7.97\end{array}$ & $\begin{array}{l}20.24 \\
15.83 \\
13.55\end{array}$ & $\begin{array}{l}3.92 \\
3.59 \\
3.26\end{array}$ & $\begin{array}{l}1.53 \\
0.96 \\
0.81\end{array}$ & $\begin{array}{l}22.62 \\
18.46 \\
16.00\end{array}$ \\
\hline 16 months & $\begin{array}{r}8 \\
16 \\
24\end{array}$ & $\begin{array}{l}9.26 \\
6.99 \\
5.79\end{array}$ & $\begin{array}{r}11.30 \\
9.17 \\
8.08\end{array}$ & $\begin{array}{l}20.56 \\
16.16 \\
13.87\end{array}$ & $\begin{array}{l}3.92 \\
3.59 \\
3.26\end{array}$ & $\begin{array}{l}1.54 \\
0.97 \\
0.82\end{array}$ & $\begin{array}{l}22.94 \\
18.77 \\
16.32\end{array}$ \\
\hline
\end{tabular}

In making the calculations, seven energy groups of fission product decay gammas were considered. No beta radiation was assumed to escape. Concerning the $\mathrm{Np}-239$ decay heat generation, none of the beta or gamma radiation was assumed to escape.

\section{11 SHELDING DESIGN METHODS}

Shielding methods are summarized in Appendix G. 
GEAP-5722

\section{SECTION IX}

\section{VESSEL}

\subsection{VESSE L-TO-CLOSURE INTERFACE LOADING ANALYSES}

A basic premise for the conceptual studies of the vessel closure has been that the head of the vessel can be cooled to nearly ambient temperature of the sodium pool and the head accommodated by flexure in the vessel walls between the head and pool. To support this premise, some basic review of the problem indicates that while this solution is not easy to accomplish, it is possible.

The loadings considered in this investigation include pressure, weight, and axial thermal gradient in the vessel. It is tacitly assumed that radial gradients are reduced to negligible values by insulation or preferential cooling. It also appears that the goal of operation at $1200^{\circ} \mathrm{F}$ is very"difficult with any cyclic operation and 304 stainless steel material because of the great degradation of creep properties at this temperature which appear to make ratcheting inevitable and the danger of low cycle fatigue failure prohibitive.

The cover gas design pressure has been assumed as $30 \mathrm{psig}$, and the weight of the vessel and contents estimated as 820,000 pounds, The axial gradients considered are those due to operation at steady state, scram, and heatup. The steady state thermal gradient is estimated as $1000^{\circ} \mathrm{F}$ in the 30 inches between the top of the sodium pool and a point 3 inches below the hub of the flange. Computer solution of the heat transfer indicates a round-off of the abrupt change of slope at the sodium surface, but this has been neglected in the stress computation.

The scram transient originates about 10 feet below the surface of the sodium pool and the thermal stratification of the sodium inhibits natural convection so that conductive heat transfer is the principal mechanism for changing the surface temperature and the gradient in the structure. The scram transient does not appear to affect the temperature near the surface of the pool until about 2 hours after scram and then has a moderating effect upon the abrupt change of slope of the gradient at this location. It does not appear that this transient will be significant in this location.

The startup transient results in a steady rise in temperature of the pool with convective currents furnishing good mixing. The ramp above the pool will follow with considerable delay as conductive and radiative transfer of heat must be relied upon in this region.

A thickness of 3/4-inch for the vessel wall was chosen as ample for the support of the weight of vessel and the internal pressure and to deform during the DBA to minimize head damage. The requirement for vacuum testing can be fuifilled by internally supporting the vessel.

The steady state temperature gradient of $1000^{\circ} \mathrm{F}$ in a 30 -inch length of vessel produces an axial thermal stress of $21,900 \mathrm{psi}$ and, when added to the dead load and pressure stresses, a combined stress of 25,600 psi. This stress is limited by the ASME Code-allowable of $3 . \mathrm{S}_{\mathrm{m}}$ to $26,100 \mathrm{psi}$ at a temperature of $1100^{\circ} \mathrm{F}$. To extend the ramp sufficiently to reduce the stresses to levels allowable at $1200^{\circ} \mathrm{F}$ appears prohibitive at this time and insulation or selective cooling to round off the abrupt change of slope in the gradient at the surface of the sodium would appear required for high temperature operation. 
The startup transient will accentuate the abrupt change of slope at the level of the pool surface and therefore severely limit the rate at which safe startup can be achieved. Preliminary investigation indicates that this limitation of the startup rate will not be severe in the early stages of the startup, when material properties are not degraded to a large extent, but will become progressively more limiting as the pool temperature rises. A startup rate of $100^{\circ} \mathrm{F} / \mathrm{h}$ is indicated safe to a temperature of $850^{\circ} \mathrm{F}$, but a $50^{\circ} \mathrm{F} / \mathrm{h}$ rate between $850^{\circ} \mathrm{F}$ and $900^{\circ} \mathrm{F}$ is marginal. Time has not permitted further investigation. Figures 9-1 to 9-5 illustrate the gradients considered.

\section{2 VESSEL HEIGHT CONSIDERATIONS}

The vessel description emphasizes the design requirements for the vessel support, flange, and coolant service nozzles as well as the length (or depth) of the major components within the vessel. It was noted that the vessel could be over 8 feet shorter if refueling of driver assemblies under the closed loop branch piping was performed when the involved closed loop was removed from the vessel. This $20 \%$ saving on vessel length appeared warranted. To fully utilize the advantages of the open head refueling (and top of the reactor viewing) concept of the Backup Design, facilities for safely lowering the sodium level in the vessel are required.

As the reference and Backup reactor designs are both being developed, it appears that the Backup Design has the same or slightly smaller vessel diameter requirements, thus diametrical inconsistencies can be filled up or utilized when the Backup Design is installed in the vessel. At this stage in conceptual development the depth of the vessel (or elevation of the core support plate) and other pertinent component elevations should be noted.

Attached are two drawings indicating the longest (deepest) length, Figure 9-6, and the minimum length, Figure 9-7, vessels for the backup design. The vessel diameter, bottom head, molten fuel containment high pressure plenum (except the grid plates) and the inlet and outlet coolant nozzles are identical to PNL drawing SK-3-14332, Revision 0 on these figures. The "maximum" length vessel is 8 feet 9 inches deeper than the minimum depth vessel. This additional depth is utilized to permit driver fuel (and grapple) movement beneath the closed loop branch piping and to store more sodium above the core in case of a casualty to the primary coolant system. The "minimum" length vessel provides the minimum of 2 feet of fuel submergence during refueling of the driver fuel. The shorter vessel in addition to being smaller and probably requiring a smaller containment building requires shorter:

- Extension rods on the control rod drives

- Closed loop lead stalks and coolant system

- Driver fuel instrument leads and structure

- Operators for core clamping devices

- Or less seismic restraint

- Or improved visibility of reactor components

For these reasons a short vessel design was pursued in the conceptual design period. 


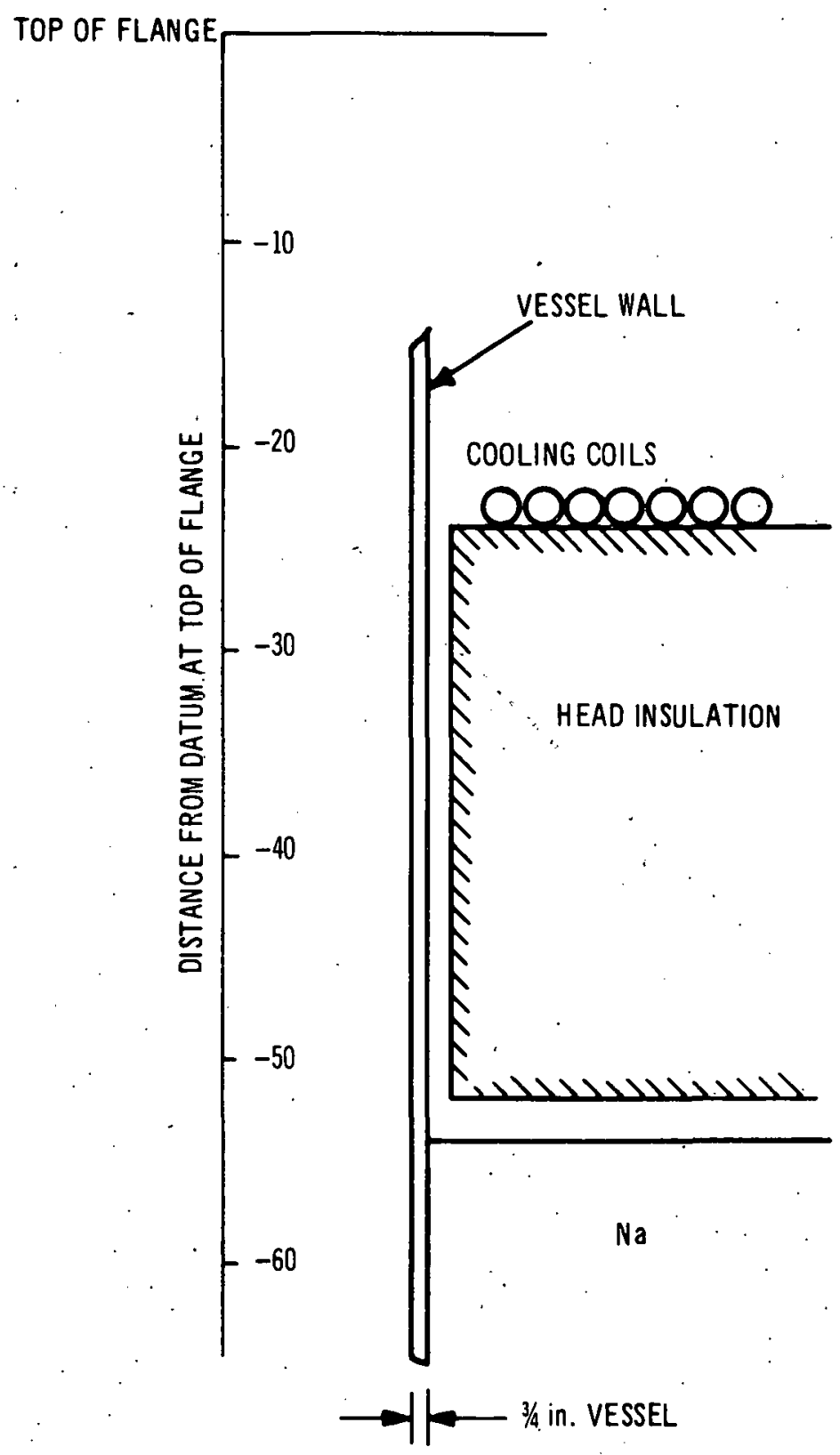




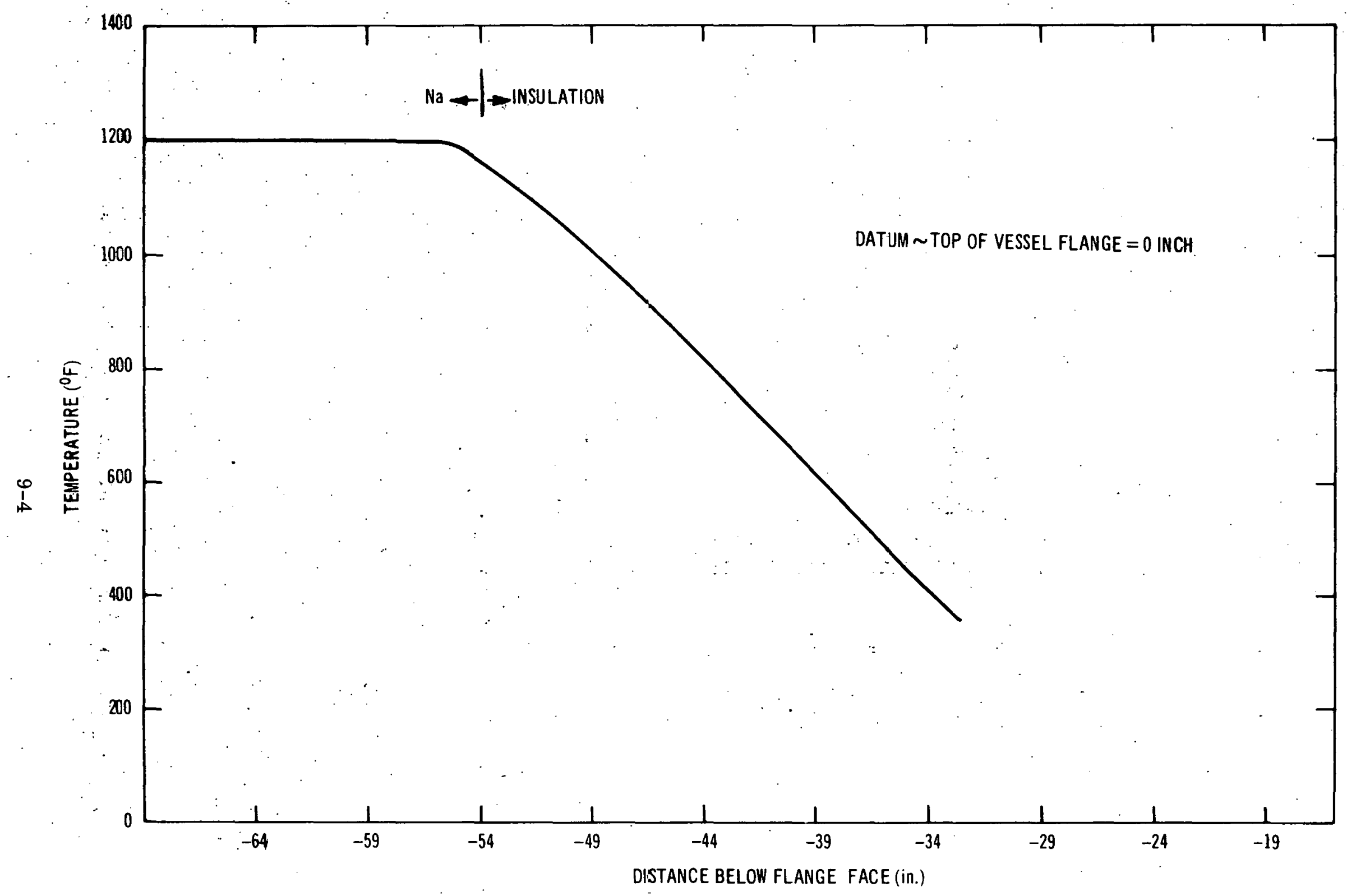




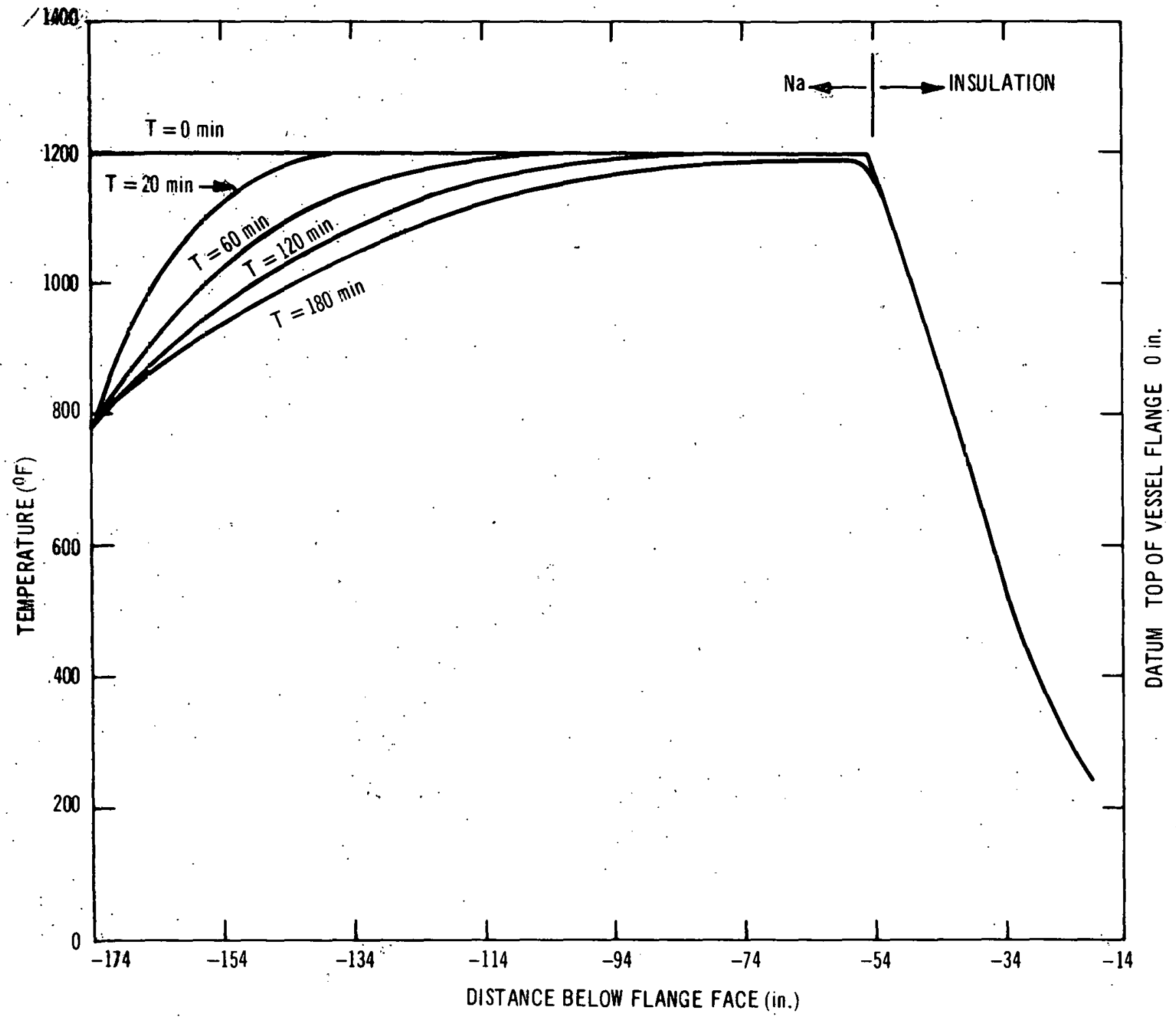

ֻٕ

FIGURE 9-3. TEMPERATURE GRADIENT AFTER SCRAM-VESSEL

UPPER WALL BETWEEN SODIUM OUTLET AND FLANGE 


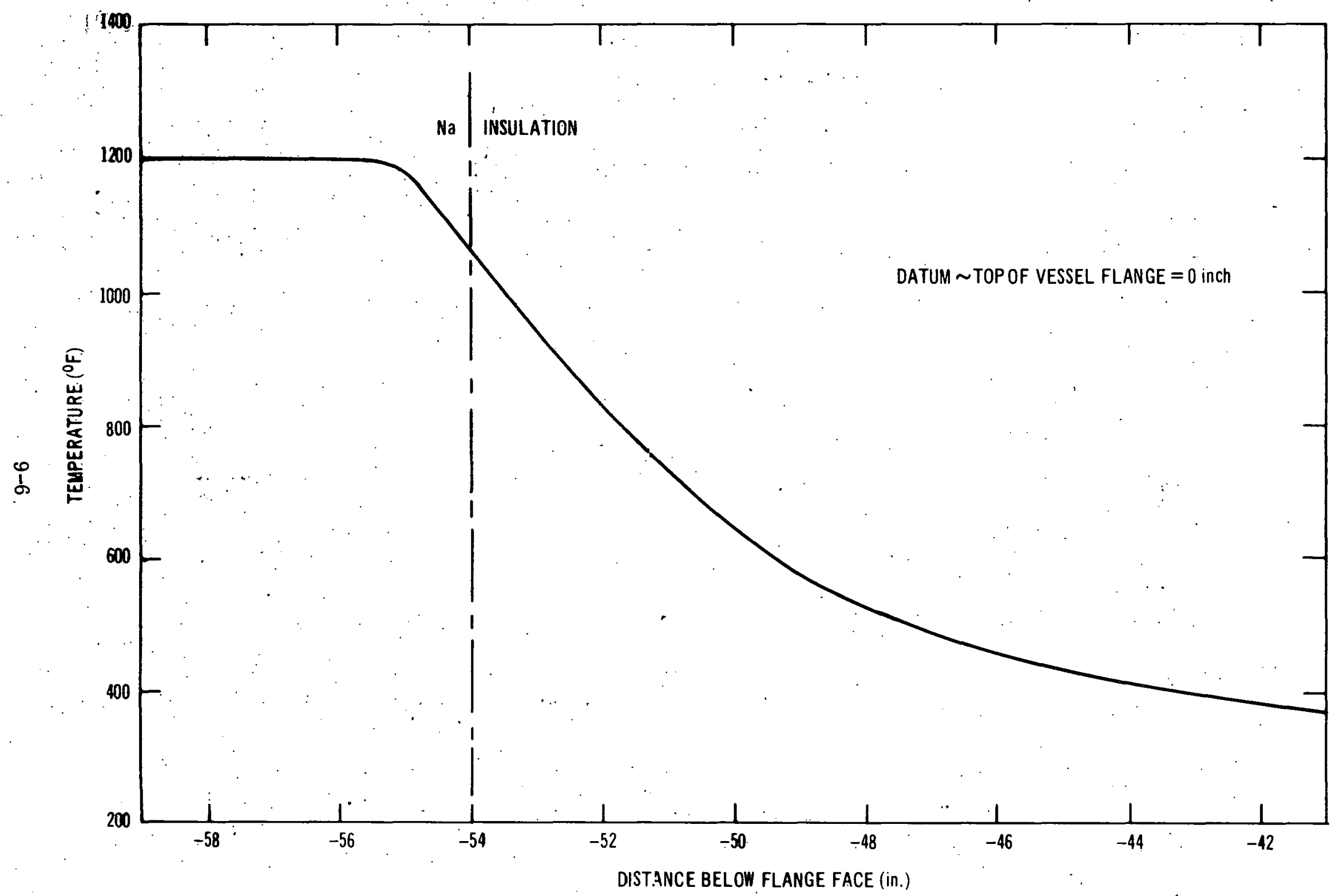

FIGURE 9-4. VESSEL FLANGE TRANSIENT TEMPERATURES $\left(50^{\circ} \mathrm{F} / \mathrm{h}\right)$, SODIUM

TEMPERATURE TRANSIENT $450^{\circ} \mathrm{F}-1200^{\circ} @ 50^{\circ} \mathrm{F} / \mathrm{h}$, TIME $=900 \mathrm{MINUTES}$ 


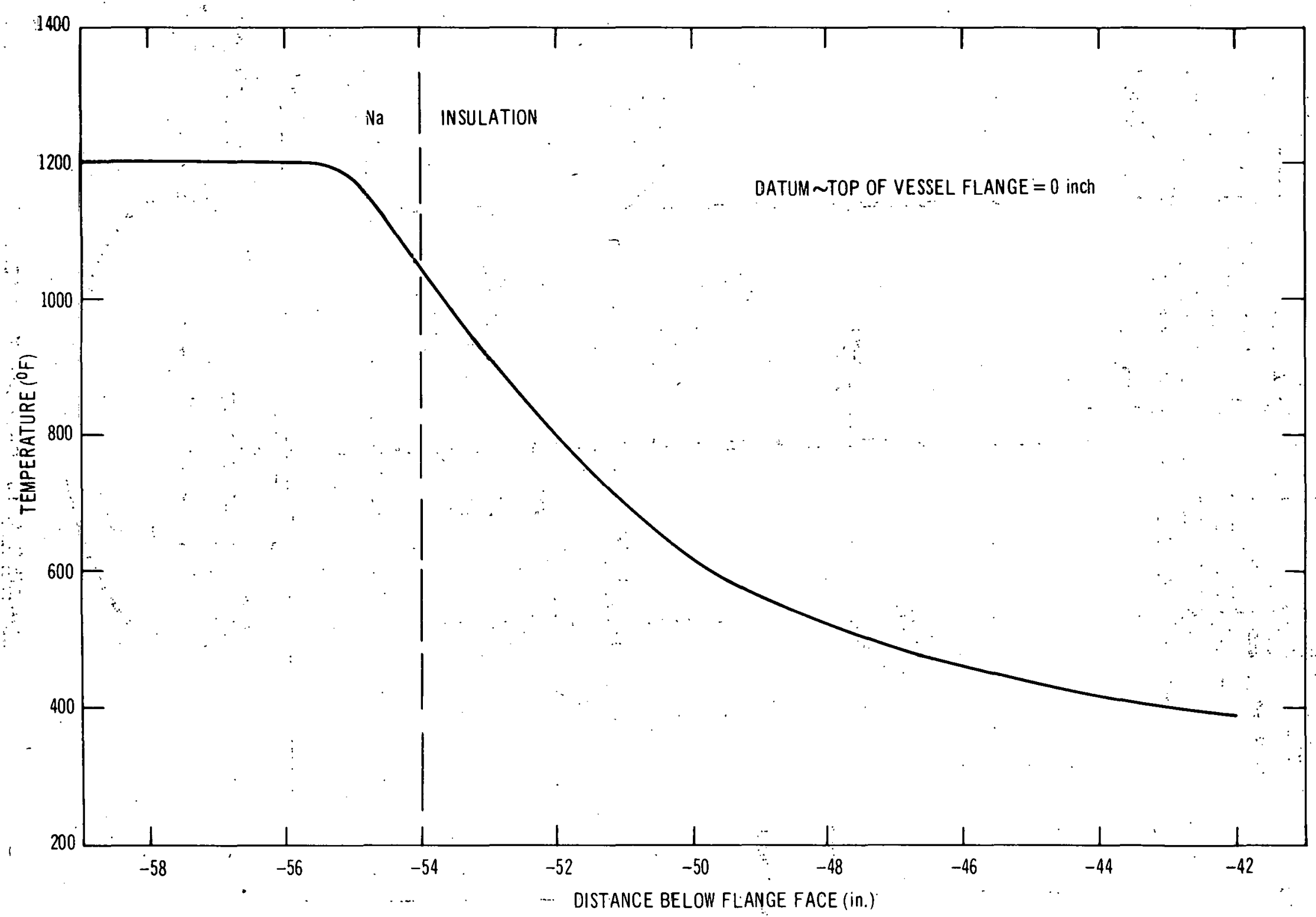

FIGURE 9-5. VESSEL FLANGE TRANSIENT TEMPERATURES $\left(100^{\circ} \mathrm{F} / \mathrm{h}\right)$, SODIUM TEMPERATURE TRANSIENT $450^{\circ}-1200^{\circ} @ 100^{\circ} \mathrm{F} / \mathrm{h}$, TIME $=450$ MINUTES 


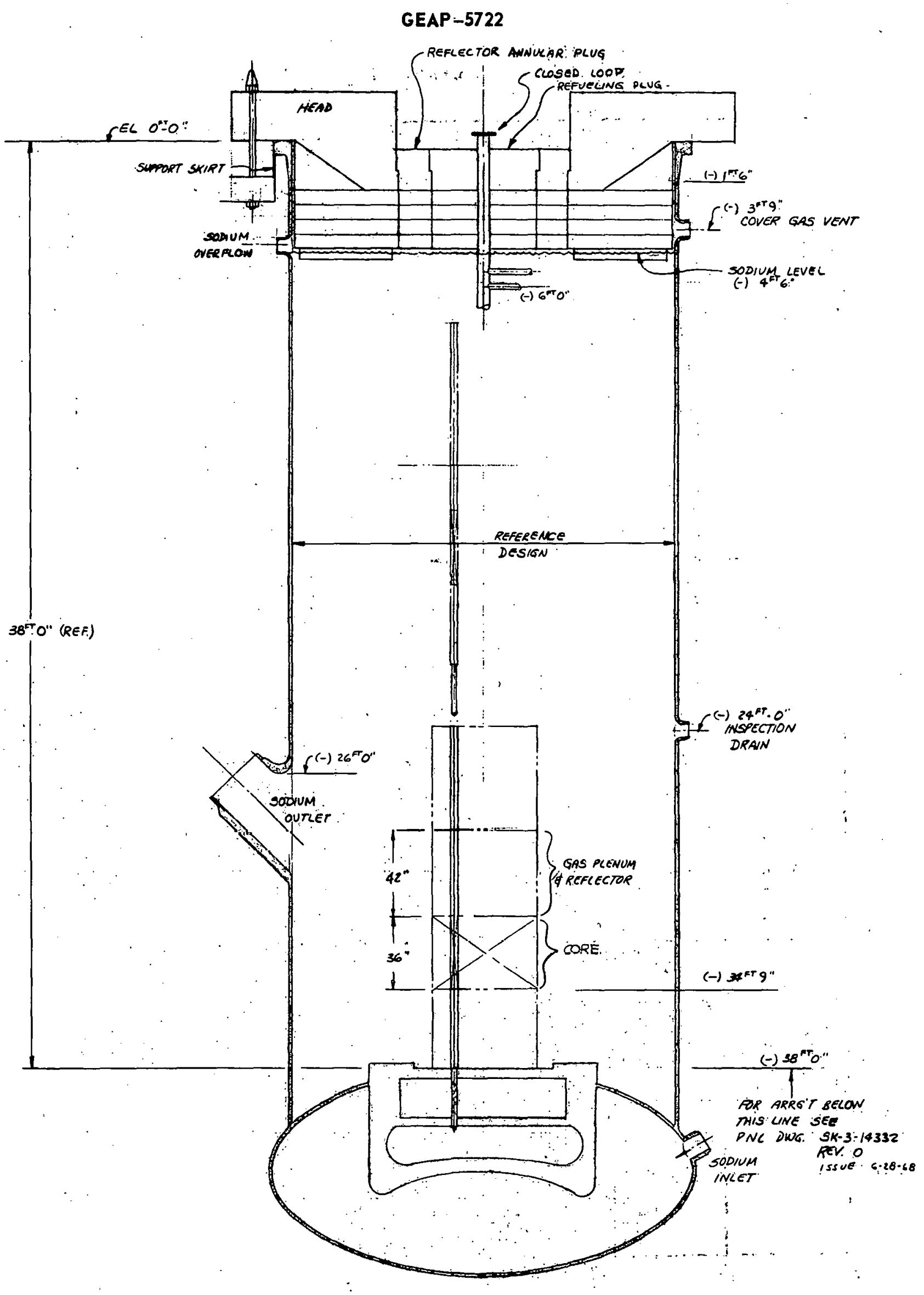

FIGURE 9-6. MAXIMUM LENGTH VESSEL 


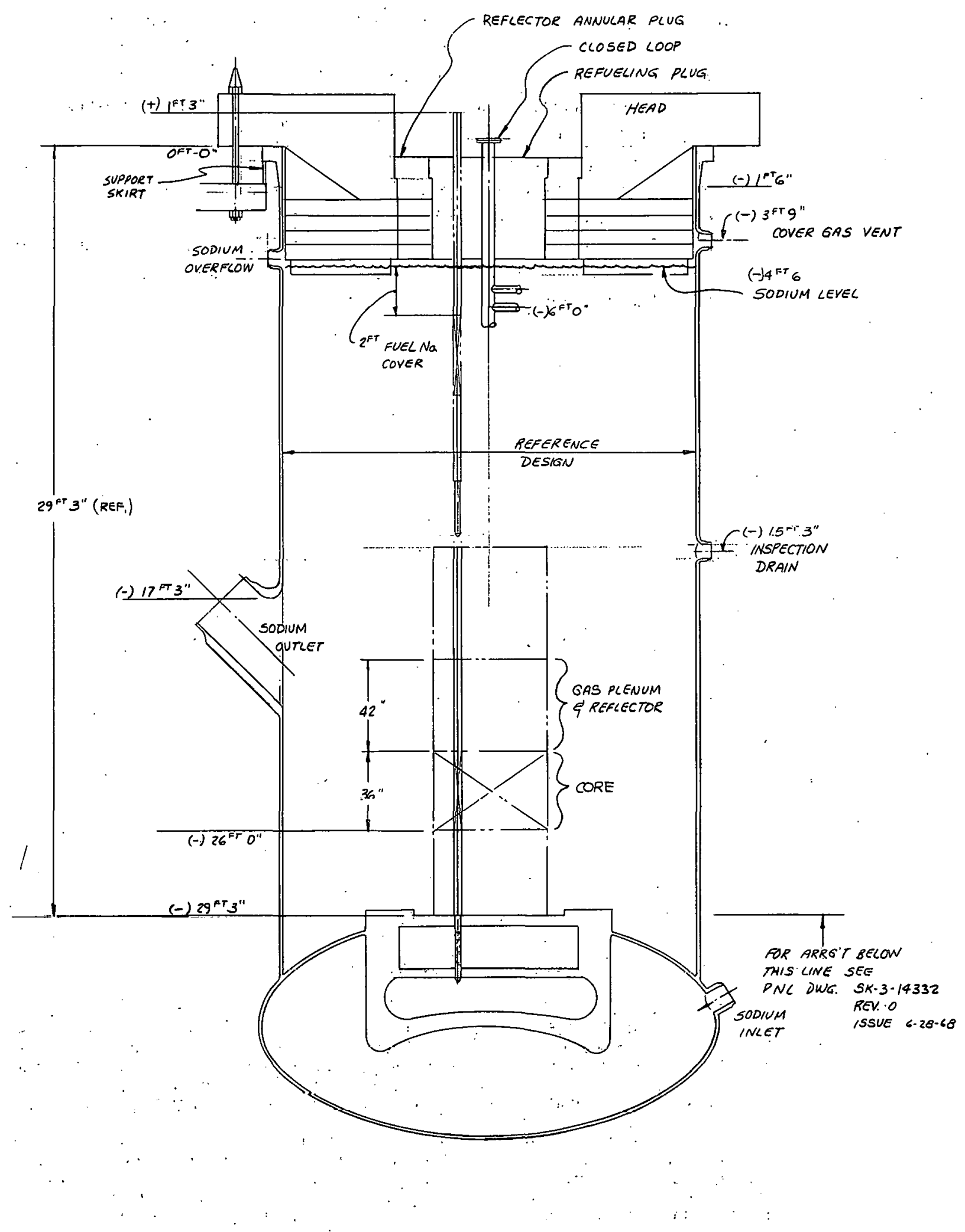

FIGURE 9-7. MINIMUM LENGTH VESSEL 
The following tentative reference elevations are noted on both drawings:

- Vessel flange face (elevation datum)

- Vessel flange connection to vessel (-) 1 foot 6 inches, limit of cool structure temperature

- Cover gas and sodium overflow pipes*

- Sodium level (maximum height of outlet temperature).

- Inspection level drain**

- Maximum coolant outlet nozzle height (2-foot submergence during inspection)

- Bottom of core elevation (reference design datum)

- Reactor support plate level (core datum)

* A two duct-multiple nozzle gravity overflow and extended cover gas reservoir system is recommended to provide constant sodium level in the vessel. The overflow sodium will flow by gravity to the drain tank. A service refill pump is required to return the sodium to the vessel. Actually the nozzles should. be located at a slightly lower level than shown with the sodium overflowing into a wier box and then to the drain tank.

** The inspection level drain can be provided as a dip tube with the actual nozzle near the top of the vessel. If these lines penetratc the head, additional shielding and space will be required above and near the head. This drain is sized to lower the sodium level in the vessel to the driver fuel handle level in about 1 hour. Inspection draining and handle observation may be required each time the refueling plug is replaced. 


\section{SECTION X}

\section{SYSTEM DYNAMIC ANALYSIS}

\section{1 INTRODUCTION}

The FFTF backup system must be designed for stress fatigue and thermal shock resulting from thermal transients. The short term (20 seconds) transient response of the sodium temperatures primarily between the core outlet and vessel outlet to selected mild and severe transients was investigated for the FFTF backup design.

Since the objectives of this study were limited and the analys is was applied during the conceptual stage of the FFTF backup design, the dynamics model that was developed is simplified and model development of each part of the system, such as the IHX, was considerably less than that required for detailed design.

The transients analyzed were divided into two categories, designated "mild" transients and "severe" transients. Mild transients are associated with events for which the total design number of cycles is of the order of $10^{3}$ during the plant lifetime. Severe transients are associated with low probability events, which may occur one to a few times.

\subsubsection{Transients Analyzed}

Mild transients studied included the following:

- Loss-of-site power

- Reactor overpower scram

- Reactor high temperature scram

- Primary pump startup in standby loop

- Loss of primary flow in one loop without scram

Severe transients analyzed included:

- Reactor scram with all pumps running

- Reactivity ramp of $10 \% / \mathrm{sec}$ without scram

- All pumps trip without scram

\subsubsection{Parameters Varied}

The effects of several parameters on the temperature responses above the core and at the vessel outlet were studied. These parameters included (1) pump coastdown characteristics, (2) outlet mixing time constant, (3) pump coastdown delay time, and (4) time between scram signal and start of rod drop. 


\subsection{MODEL OF TRANSIENT SYSTEM}

A schematic flow diagram of the FFTF backup system as mocked up by the dynamic model is shown in Figure 10-1. A short summary of the model is given in Table 10-1. (For a complete description of the model see GEAP-5660, Reference (14). The sodium temperatures of principal interest for the present studies were core outlet, channel outlet, and vessel outlet. The system external to the vessel was not included in the transient analyses reported, except for the fifth mild transient-loss of flow in one loop without scram. For all other transients, the vessel inlet is input to the calculations. Excluding the IHX and secondary system is a satisfactory approximation for the first 20 seconds of all of the mild (except for the fifth) and severe transients analyzed. The reason for this is that, for constant flow cases, the effect of the IHX is felt only after the transit time of the primary sodium outside the vessel, which is 17 seconds. For cases with pump coastdown, the effect of the IHX is felt after the transit time from the IHX to the vessel, which is $\mathbf{5}$ seconds at full flow but increases rapidly during the coastdown.

At the start of all transients which begin at full flow, the vessel outlet was $30^{\circ} \mathrm{F}$ below the channel outlet temperature due to the assumption of $10 \%$ bypass flow which mixes with the core flow before leaving the vessel.

\subsubsection{Pump Coastdown Characteristics}

The responses to two pump coastdown characteristics were examined (see Figure 10-2). Pump coastdown curve 1 corresponds to the FERMI pumps and represents only the inertia of the pump; it is the characteristic which is being recommended for the FFTF backup design. Curve 2 represents the EBR-II pump which coasts down more slowly because of additional inertia added to the pump. The pump coastdown curves 1 and 2 are shown in Figure 10-2. The solid curves represent the analytical expressions used for the transient analysis, where $w_{0}$ is the initial flow rate and $t_{0}$ is the starting time of the coastdown. The dashed lines represent the coastdown curves for FERMI and EBR-II.

\subsubsection{Control Rod Scram.Curve}

For the present analysis, the control rod scram worth as a function of time, $t$, since start of rod drop, $t_{0}$, was approximated by the following equation up to a total control worth of $\$ 10$ :

$\Delta \mathrm{k}(\mathrm{t})=\mathrm{a}\left(\mathrm{t}-\mathrm{t}_{\mathrm{o}}\right)+\beta\left(\mathrm{t}-\mathrm{t}_{\mathrm{o}}\right)^{2}+\gamma\left(\mathrm{t}-\mathrm{t}_{\mathrm{o}}\right)^{3}$

where

$$
\begin{aligned}
& \alpha=0 \\
& \beta=-6.085 \$ / \sec ^{2} \\
& \gamma=-187.35 \$ / \sec ^{3} .
\end{aligned}
$$

Sensitivity of the results to the shape of the scram curve has not been evaluated. For sufficient design margins, it may be important to design for a more conservative scram curve. 


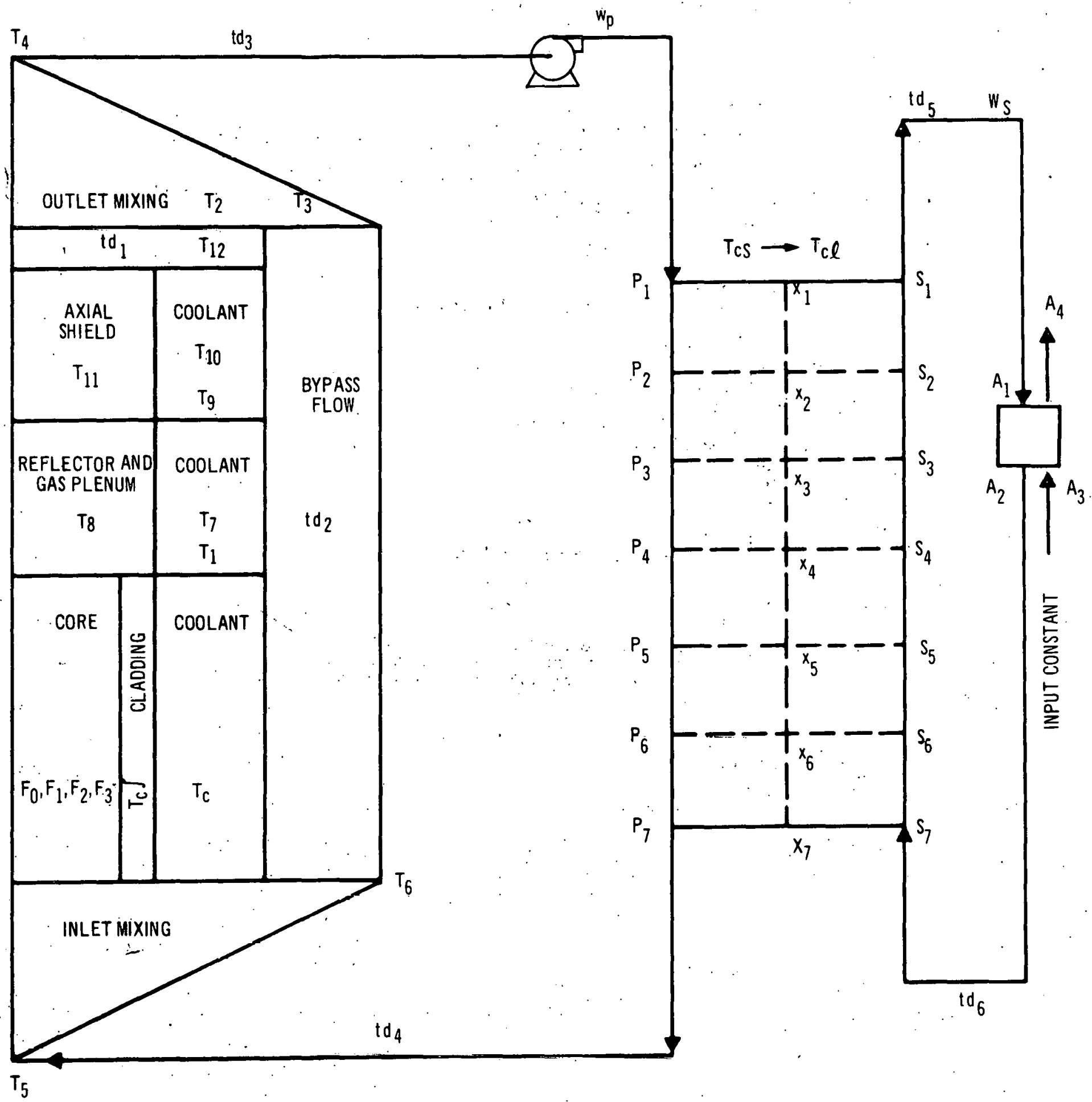

EIGURE 1O-1.' FLOW. DIAGRAM 
TABLE 10-1

\section{SUMMARY OF FFTF BACKUP SYSTEM DYNAMICS MODEL}

\section{INITIAL VALUES (STEADY STATE) CALCULATED}

\section{TRANSIENT MODEL:}

CORE

Point Kinetics

6 Delayed Neutron Groups

Distinguish Between Power Production and Material Dependent Power Absorption Rates

Fission Product Decay Power Calculated

Doppler, Fuel Expansion, and Coolant Reactivity Feedbacks Calculated Scram and Reactivity Input Included

Fuel at Average Power Density

\section{Radial Nodes}

1 Axial Node

Temperature Dependent Thermal Conductivity

1 Cladding Node

1 Core Coolant Node

\section{VESSEL INTERNALS}

Axial Reflector and Plenum Heat Sink

Axial Shield Heat Sink

Bypass Flow

Outlet Mixing

Inlet Mixing

VARIABLE PURE TIME DELAYS

Included in All Primary and Secondary Piping

IHX

Countercurrent Flow

Primary, Tube Wall, Secondary

Central Difference Approximation for Internal Points

Backward Difference Approximation at Primary and Secondary Outlets

6 Axial Nodes

HEAT SINK

Secondary Sodium Heat Sink

1 Node

Constant Sink Temperature

\section{FLOW OPTIONS}

Ramp Changes

Flow Coastdowns 


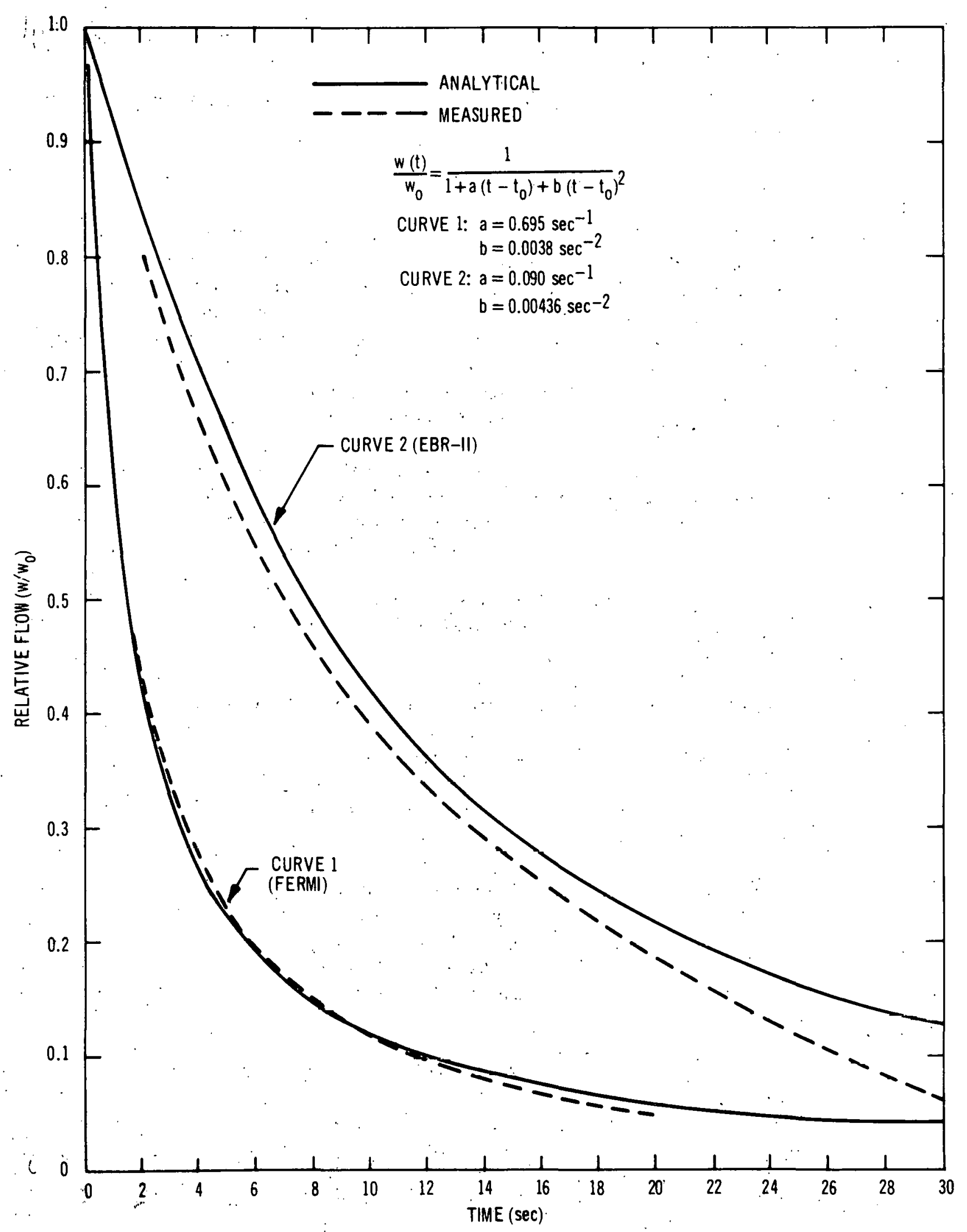

FIGURE 10-2. FLOW COASTDOWN CHARACTERISTICS 


\subsubsection{Decay Heat Curve}

Fission product decay heat was approximated by an exponential lag of the prompt power with a $30-$ second time constant.

\section{3 SUMMARY OF MILD TRANSIENTS RESULTS}

For the 20 second period following normal scram, the pump coastdown curve 1 (similar to FERMI) is preferable to curve 2 (similar to EBR-II). The sodium temperature gradients (and, hence, thermal stresses) at the core outlet, channel outlet, and vessel outlet are significantly steeper for curve 2 than for curve 1. These gradients are now available to the stress analyst to judge the relative merits of the two coastdown curves, though curve 1 looks more attractive than curve 2 for the first 20 seconds after a transient. No conclusion is yet available concerning the sodium temperature overshoot before natural convection takes over or the ultimate feasibility of transition to natural convection for either coastdown curve.

The sodium temperature gradient at the vessel outlet is strongly sensitive to the outlet mixing time constant. Although the gradient with no mixing for curve 1 does not appear to be prohibitive, sufficient reduction in the gradient is obtained for mixing the core outlet sodium with $20 \%$ of the sodium in the tank that an effort to achieve such mixing may be warranted.

Curve 1 leads to an initial rapid increase in sodium core outlet temperature for some conditions, but this rise is limited to $\sim 30^{\circ} \mathrm{F}$ which is probably acceptable. This rise practically disappears. for curve 2 .

Delays of the order of 1 second in starting the pump coastdown after scram produce large initial negative sodium temperature gradients. Hence, this consideration indicates the desirability for minimizing the time delay before starting the pump coastdown.

Little difference in temperature gradients outside the core appeared between values of 0.15 second and 0.25 second for the time between scram signal and start of rod drop.

No important differences in temperature gradients in the regions above the core were observed between the four scram situations investigated. The highest temperatures and positive temperature gradients were reached with the high temperature scram, but these temperatures and gradients do not appear excessive. The largest negative gradients occurred with the pump startup in the standby loop, but again these gradients were not significantly greater than for the other scram situations.

\section{4 SUMMARY OF SEVERE TRANSIENTS RESULTS}

The principal results for each of the three severe transients analyzed are given below:

Reactor scram with all pumps runing - the core and channel outlet temperatures drop $\sim 250^{\circ} \mathrm{F}$ in 6 seconds. The vessel outlet (for $20 \%$ mixing) drops by $\sim 200^{\circ} \mathrm{F}$ in 10 seconds. 
Reactivity ramp of $10 \alpha^{\prime} / \mathrm{sec}$ without scram-the core and channel outlet temperatures increase at a rate of $17^{\circ} \mathrm{F} / \mathrm{sec}$ and the vessel outlet increases at $13^{\circ} \mathrm{F} / \mathrm{sec}$. The hottest fuel would melt early during the transient. Sodium boiling would commence at $\sim 50$ seconds.

All pumps trip and coastdown. without scram-the core and channel outlet temperatures rise rapidly while the vessel outlet (for $20 \%$ mixing) rise slowly. For caostdown curve 1 (FERMI), sodium boiling at the core outlet starts in 8 seconds. For coastdown curve 2 (EBR-II) sodium boiling starts in 30 seconds.

\subsection{SODIUM TEMPERATURE RESPONSE TO MILD TRANSIENTS, RESULTS FOR PARAMETER STUDY}

\subsubsection{Comparison of Pump Coastdown Characteristics}

The comparison of pump coastdown curves 1 and 2 is best shown by comparison of transients following simultaneous flow coastdown and scram. The results from this scram condition are typical of all the scram conditions studied.

We assume both the start of coastdown and the start of control rod drop occur at time, $t=0$. Total control rod worth is $10 \$$.

Plots of sodium temperature versus time are shown in Figure 10-3. The solid lines are for coastdown curve 1; the dashed lines are for coastdown curve 2 . The results at the vessel outlet assume an outlet mixing time constant based on $20 \%$ mixing of the core outlet sodium with the sodium in the tank. For no outlet mixing the temperature response at the vessel outlet would be congruent with the channel outlet temperature.

Maximum negative temperature gradients at various system positions are listed in Table 10-2.

TABLE $10-2$

MAXIMUM NEGATIVE SODIUM TEMPERATURE GRADIENTS FOR SIMULTANEOUS COASTDOWN AND SCRAM GRADIENT ( ${ }^{\circ} \mathrm{F} / \mathrm{SEC}$ )

Location

Core Outlet Plcnum Outlet Channel Outlet Vessel Outlet (20\% Mixing)

\section{Coastdown Curve 1}

27

20

9

1
Coastdown Curve 2

87

80

62

15

The significantly lower temperature gradients for curve 1 make this coastdown characteristic more attractive than curve 2 . 
The difference in temperature response for the two coastdown curves can be explained qualitatively. For the rapid coastdown curve 1, the outlet temperature rises initially because the flow drops off rapidly (to $55 \%$ in 1 second) while the power stays up for a fraction of a second. Even after scram and rapid power reduction, the energy content of the fuel rod is high enough, the fuel time constant long enough, and the flow low enough to keep the sodium outlet temperature up for several seconds. The sodium outlet then falls because of the loss of power but eventually rises again since both the fission product decay power and the power generated from delayed neutrons are still high after the flow has coasted down to a small fraction of the initial value. At 30 seconds, the fission product power is $2.3 \%$ of the original power and the delayed neutron power is $1.4 \%$ while the flow rate is $4 \%$ of the original value; hence, the sodium outlet temperature has returned to nearly its original value. (Inclusion of natural circulation would increase the flow rate and reduce the sodium outlet temperature at 30 seconds.) The channel outlet lags the core outlet because of the heat capacity of the axial reflector, plenum, and shield, and the transit time from core outlet to channel outlet. For the coastdown curve 1, together with $20 \%$ mixing, the vessel outlet hardly changes temperature.

For coastdown curve 2, the flow rate remains sufficiently high during the first few seconds while the power is dropping rapidly. This essentially eliminates the initial rise in core outlet temperature which existed for curve 1. All coolant temperatures fall more rapidly for curve 2 since the flow rate remains higher. The core outlet does not rise back to a high value as was the case for curve 1 because the flow rate at 30 seconds is still $13 \%$ of the original flow rate.

\subsubsection{Effect of Outlet Mixing}

The results plotted in Figure 10-3 show the advantage of mixing of the sodium from the : channels with a significant fraction of the sodium in the tank before leaving the vessel. The vessel outlet curves on f'igure 1U-3 assumed that the channel outlet sodium mixed with $20 \%$ of the tank sodium before leaving the vessel. For no mixing, the gradient at the vessel outlet would be equal to the gradient at the channel outlet.

\subsubsection{Effect of Delay in Pump Coastdown}

The effects on channel outlet temperature of delays in the pump coastdown of 1 and 2 seconds after initiation of scram (i. e., start of rod drop) are shown in Figure 10-4. Since scram starts at $\mathrm{t}=0 \mathrm{sec}$, the power starts to drop almost immediately. Hence, all sodium temperatures drop rapidly until the pump coastdown starts. Therefore, based on consideration of initial temperature gradients, long delay times for pump coastdown are undesirable.

\subsubsection{Effect of Time Between Scram Signal and Start of Rod Drop}

The effects on channel outlet temperature of the time delays up to 0.25 second between the scram signal and start of rod motion are shown in Figure 10-5. The sodium lemperature response above the core is not very sensitive to this parameter for normal scram conditions. 
GEAP-5722

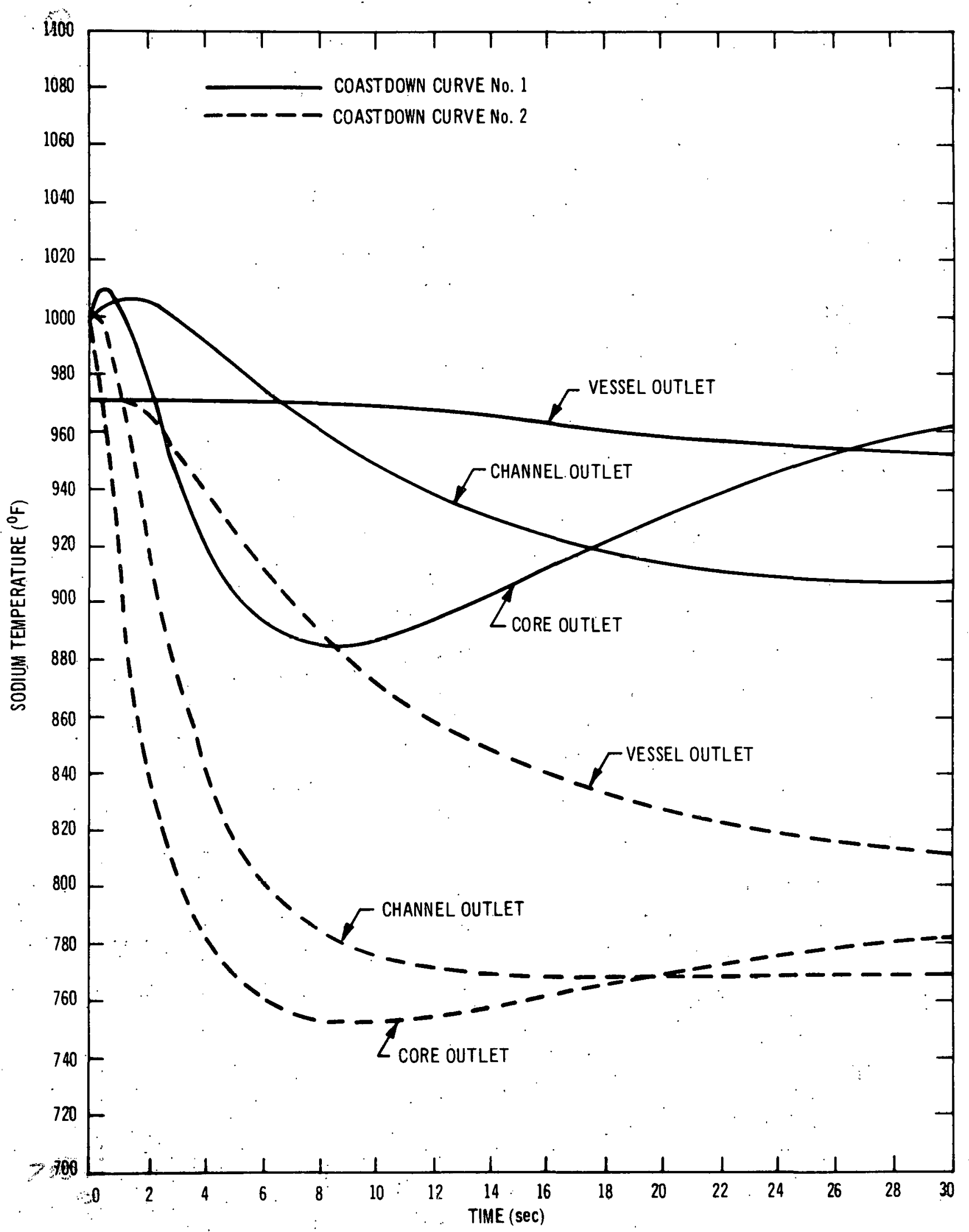

FIGURE, 10-3. COMPARISON OF. THE EFFECT OF THE COASTDOWN CURVES ON THE SODIUMTEAPPERATURE RESPONSE. CONDITIONS: SCRAM AND COASTDOWN AT TIME, $\uparrow=0$ 
GEAP -5722

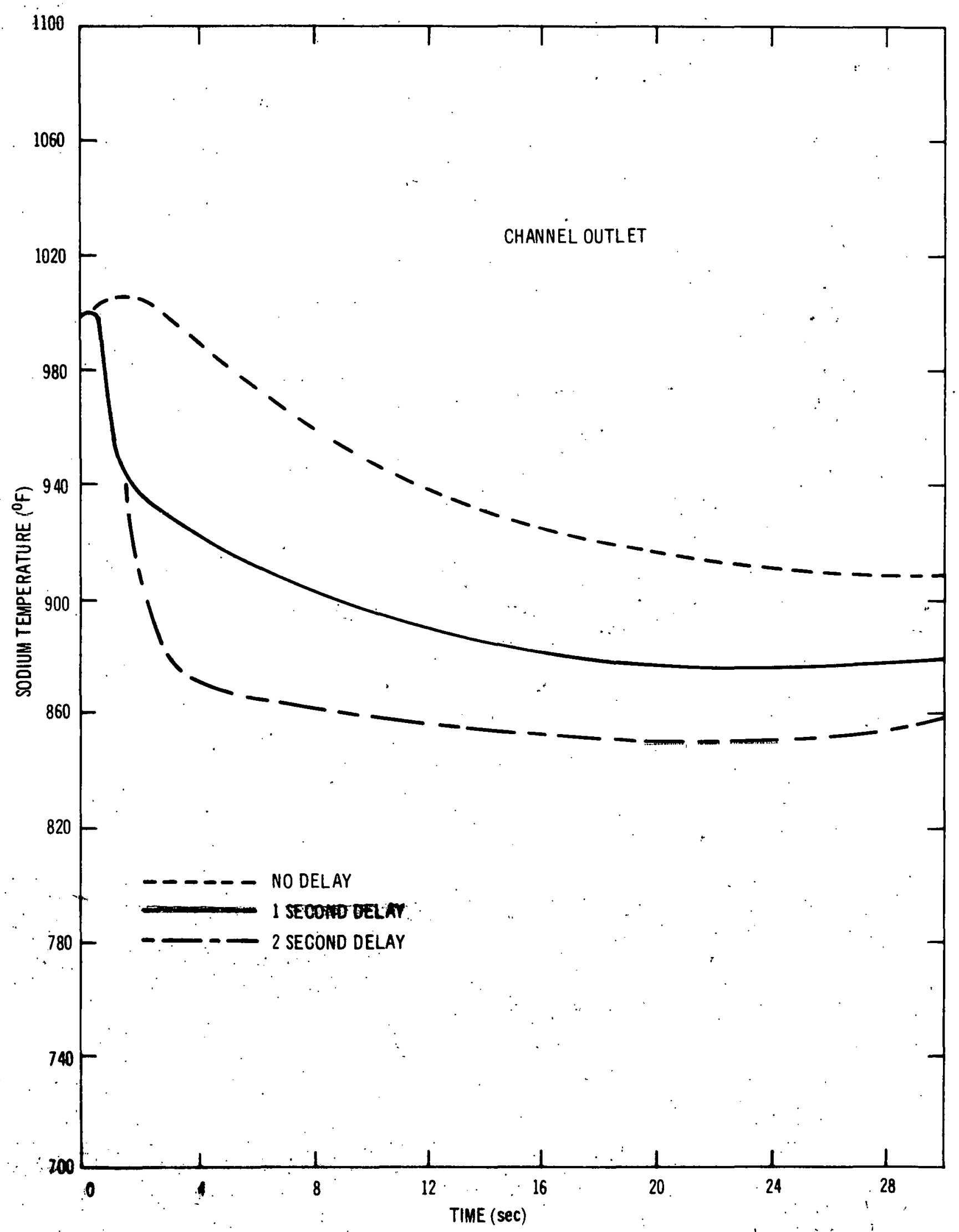

FIGURE 10-4. EFFECT OF DELAY IN PUMP COASTDOWN. CONDITIONS: SCRAM AT TIME, $+=0$, COASTDOWN WITH CURVE No. I CHANNEL OUTLET SODIUM VERSUS TIME.

$$
10-10 !
$$




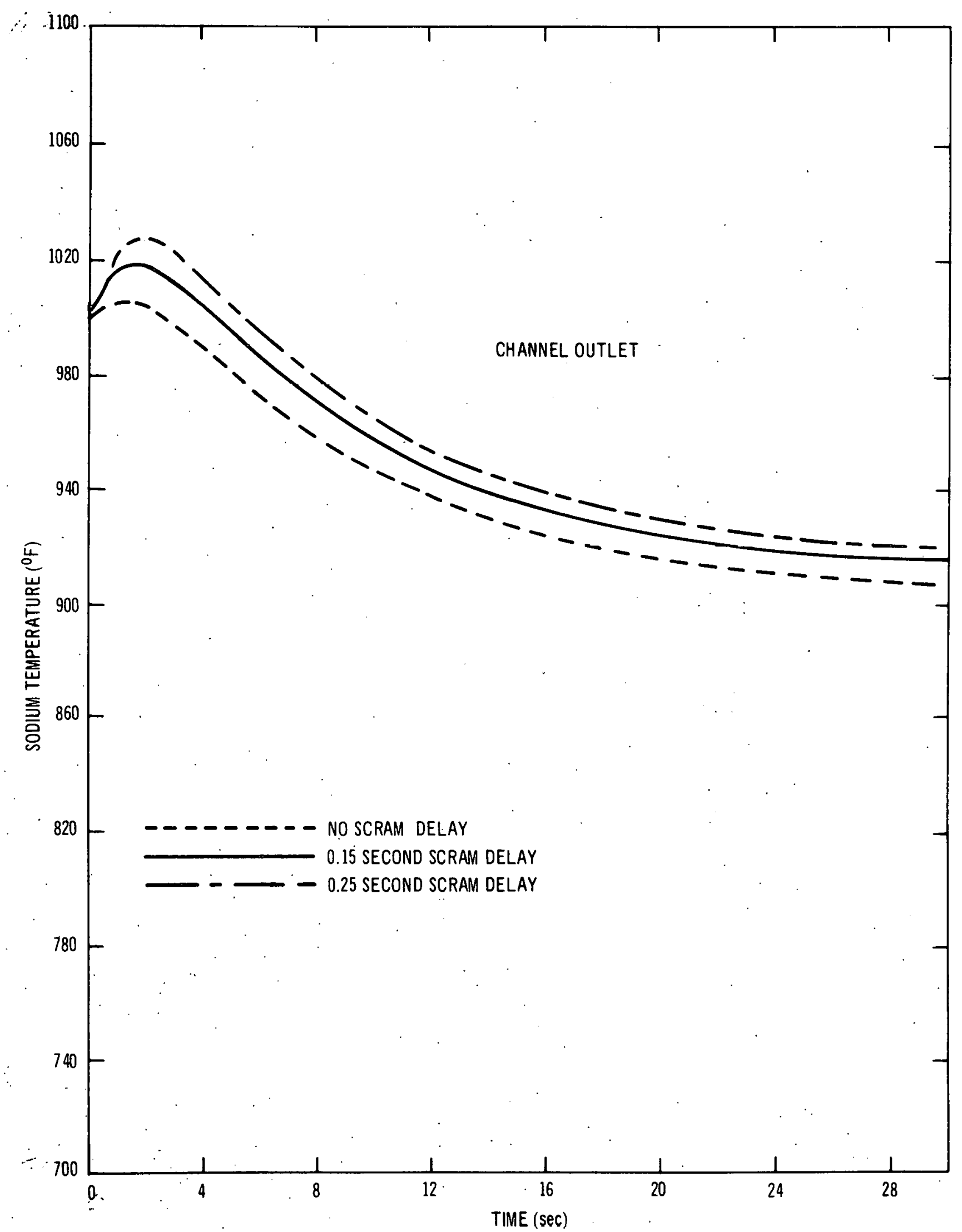

FIGURE 10-5. EFFECT OF TIME BETWEEN SCRAM SIGNAL AND START OF ROD DROP, SCRAM SIGNAL AT TIME; $T=0$; COASTDOWN WITH CURVE No. 1 AT TIME, $t=0$, CHANNEL OUTLET SODIUM VERSUS TIME 


\section{6 RESULTS FOR RESPONSE TO SPECIFIC ACCIDENTS FOLLOWED BY NORMAL SCRAM AND COASTDOWN CURVE 1}

\subsection{Four Mild Accidents}

The sodium temperature response at the core outlet, channel outlet, and vessel outlet (for 20\% mixing) are plotted in Figures 10-6 through 10-8 for the following four cases. All cases shown are compared for coastdown curve 1. The fifth mild accident studied-loss of flow in one loop without scram-is described in Section 10.6.2.

a. Loss-of-site power:

Coastdown starts at $\mathrm{t}=0$.

Rods start to drop at $t=0.15 \mathrm{sec}$.

b. Overpower scram:

Scram signal at $110 \%$ overpower from $10 \%$ /second ramp.

Rods start to drop $0.15 \mathrm{sec}$ after $110 \%$ power is reached.

Coastdown starts at the same time that rods start.

c. High temperature scram:

Scram signal at $30^{\circ} \mathrm{F}$ increase in temperature at channel outlet.

Temperature increase is caused by instantaneous flow decrease to $80 \%$ of normal

flow. Rods start to drop and flow coastdown starts 0.15 second after scram signal.

d. Pump startup in standby loop:

Standby loop (sodium at $500^{\circ} \mathrm{F}$ ) starts up at $t=0$. Flow in standby loop increases stantaneously to $0.75 \mathrm{w}_{\mathrm{o}}$. Flow in the other three loops (vessel inlet at $700^{\circ} \mathrm{F}$ ) drops instantaneously to $0.75 \mathrm{w}_{\mathrm{o}}$. Scram signal at $t=0$, rods start to drop and flow coastdown starts at $t=0.15$ second.

Variation in sodium temperature gradients between the four scram conditions is not large. The high temperature scram leads to the highest sodium temperatures, with the channel outlet rising an additional $20^{\circ} \mathrm{F}$ after the $30^{\circ} \mathrm{F}$ over-temperature scram is initiated. The core outlet rises a total of $70^{\circ} \mathrm{F}$. The high temperature scram is the only case that leads to a significantly positive gradient at the vessel outlet, although this maximum gradient is only $3^{\circ} \mathrm{F} / \mathrm{sec}$.

The lowest sodium temperatures and largest negative temperature gradients result from the pump startup in the standby loop. The difference in gradient, however, between this and the other transients shown is small. The maximum negative gradient at the vessel outlet is $-2^{\circ} \mathrm{F} / \mathrm{sec}$ for this scram condition.

The first two scram conditions-loss-of-site power and overpower scram-look similar except for a time delay to reach overpower in the latter case. Small differences in the sequencing 
GEAP-5722

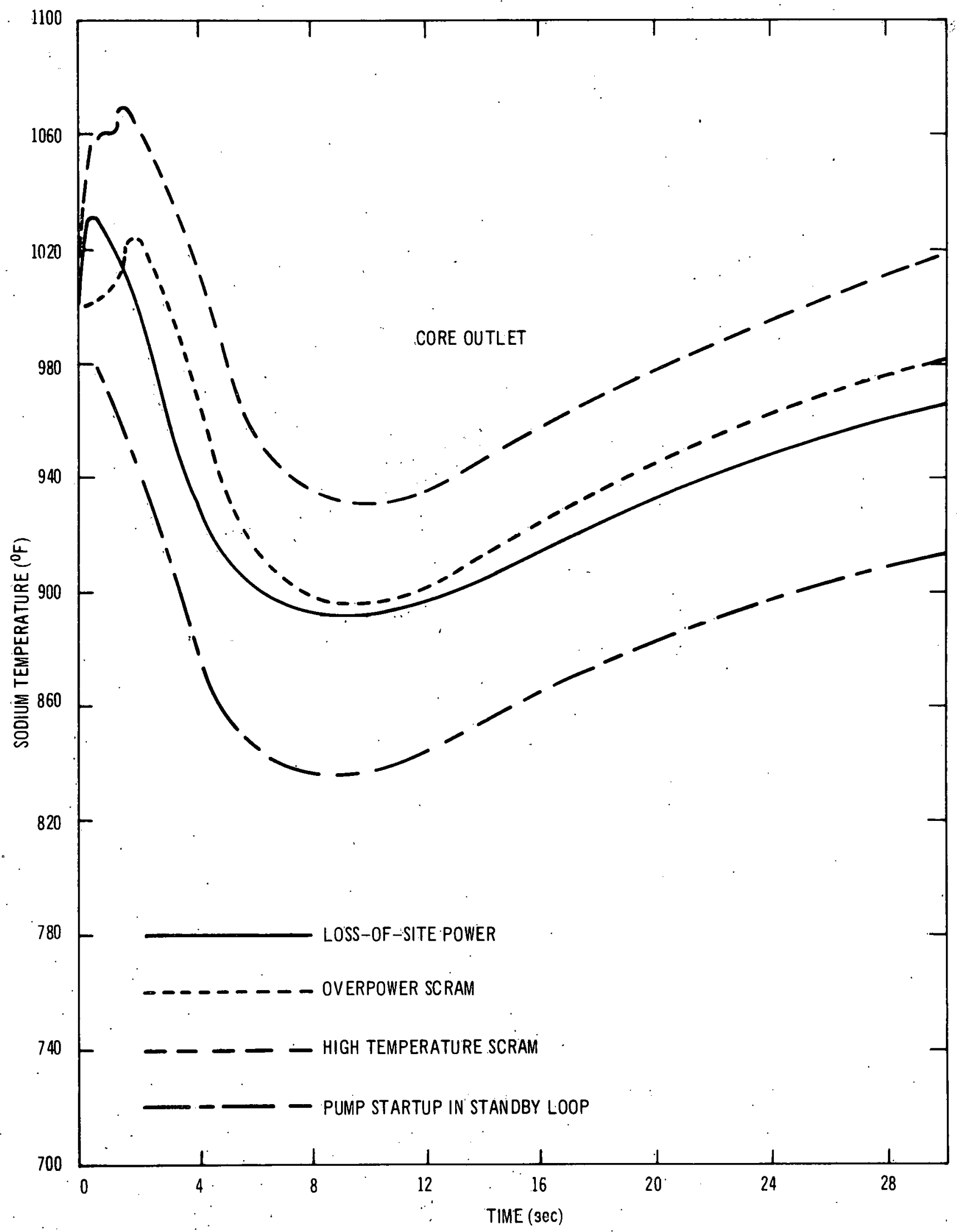

FIGURE 10-6: MILD ACCIDENT SODIUM TEMPERATURE RESPONSE AT CORE OUTLET 
GEAP-5722

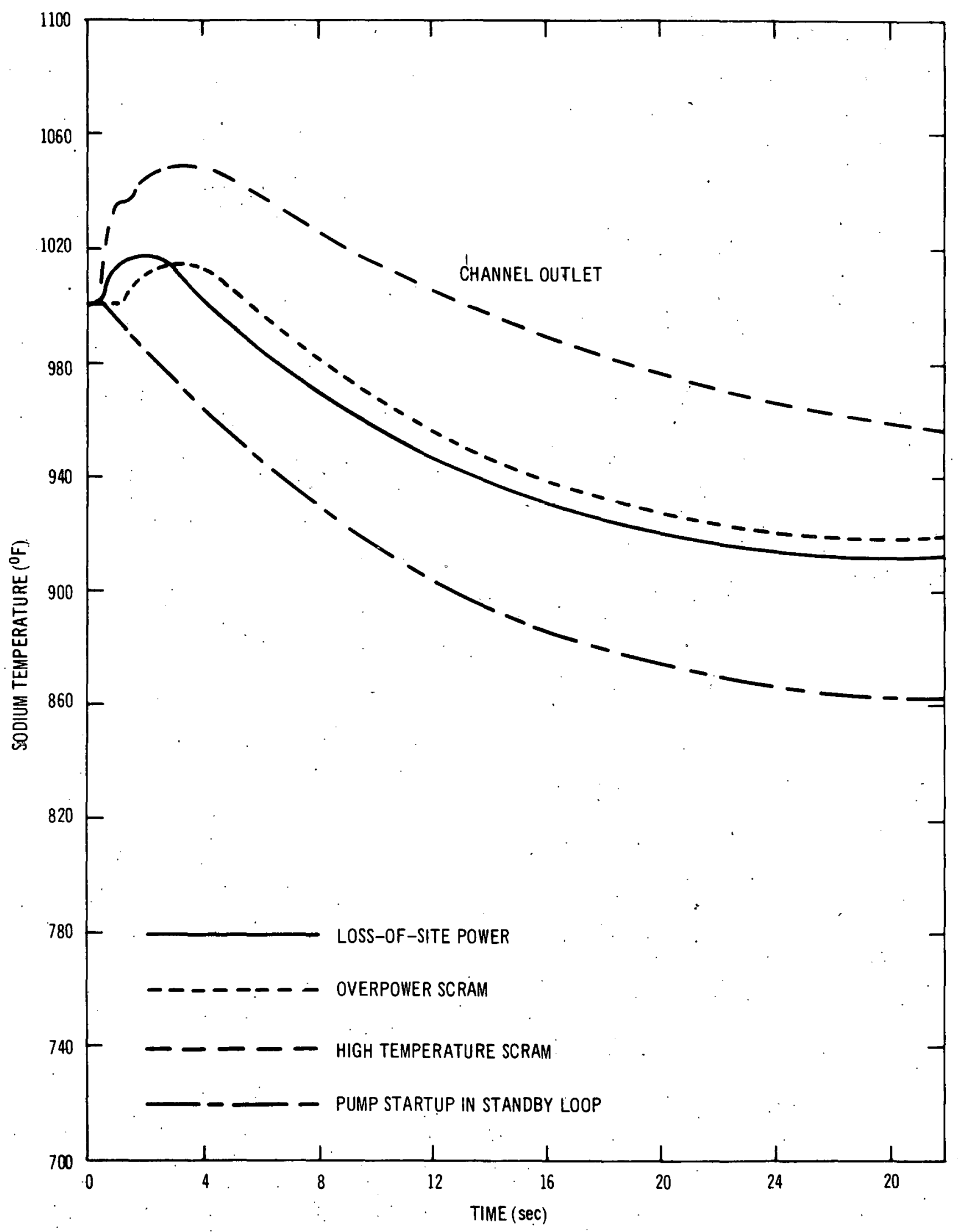

FIGURE 10-7. MILD ACCIDENT SODIUM-TEMPERATURE RESPONSE AT CHANNEL OUTLET 


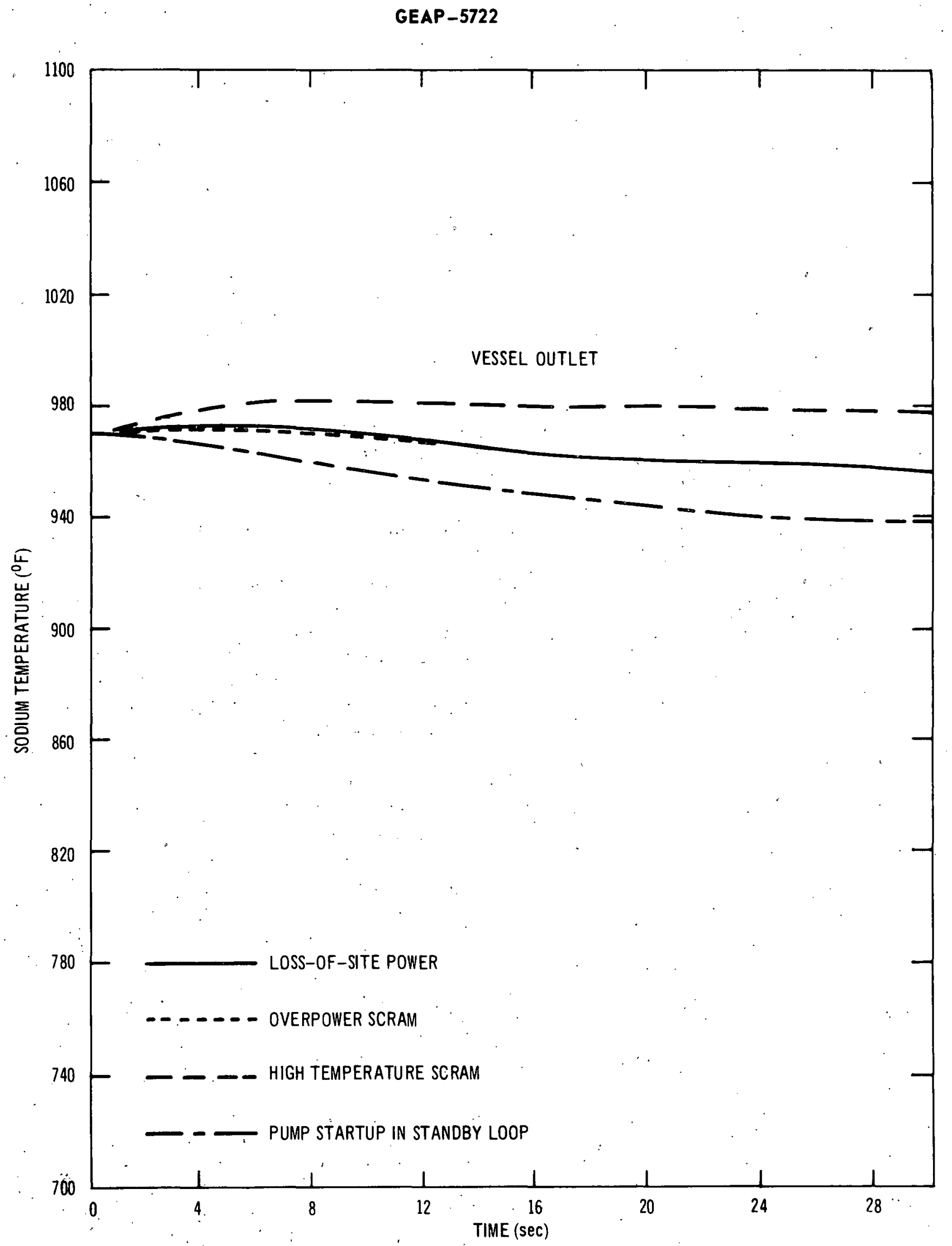

FIGURE 10-8: MHD ACCIDENT SODIUM TEMPERATURE RESPONSE AT VESSEL OUTLET 
of pump coastdown and scram and differences in the time dependence of the power between the two cases account for the small differences shown in the shape of sodium temperature response curves.

\subsubsection{Loss of Flow in One Loop Without Scram}

A fifth mild accident was calculated in which it was assumed that flow stops in one loop while operation continues without scram and with the other two loops in service. The flow in the failed loop goes to zero linearly in 2 seonds, while the flow in the two operating loops increases linearly to 1.16 normal flow in 2 seconds.

The response to this.transient was calculated for 80 seconds with the entire FFTF Backup system mocked up. The IHX, heat sink, and external piping time delays were included. Hence, temperature responses beyond the transit times of the primary and secondary systems were tested accurately.

System and temperature responses are plotted in Figures 10-9 and 10-10.

In the early part of the transient (first 2.5 seconds), the negative feedback from the rising core sodium temperature dominates the core power response and forces the core power down rapidly. Although the total core coolant flow has decreased, the fuel temperature (Figure 10-10) drops since the drop in power over compensates for the loss of heat transfer to the coolant. The resulting positive reactivity feedback from the fuel dominates the core power response from 2.5 to 4 seconds. After 4 seconds, the net effect of the positive fuel expansion and Doppler feedback and the negative coolant feedback is about constant at $\sim-3 \not \varnothing$.

The core inlet sodium temperature (Figure 10-9) shows the effect of time-delayed system responses outside of the vessel. The primary IHX outlet sodium temperature starts rising as the primary loop flow increases. This rise is first seen in the core inlet after 4 seconds, which is the transit time from IHX outlet to core inlet. The small increase in the rate of change of the core inlet temperature beyond 45 seconds results from the propagation of the effect of the change in vessel outlet temperature all the way around the secondary sodium system. The time after the start of the transient for this effect to appear at the core inlet includes the time for the vessel outlet to start changing temperature ( $\sim 2$ seconds), the time lag from the vessel outlet to the IHX primary inlet ( $\sim 8$ seconds), then the transit time through the entire secondary piping $(\sim 30$ seconds), and finally the time lag from the IHX primary outlet back to the core $(\sim 4$ seconds).

\section{7 SODIUM TEM PERATURE RESPONSE TO SEVERE TRANSIENTS}

This section describes the short term sodium temperature response of the FFTF system to various more-severe transients. These transients are associated with low probability accidents which the system must be designed to withstand should they occur one to a few times over the lifetime of the plant.

The temperature responses of the sodium at the top of the active core, at the channel outlet, and at the vessel outlet are presented for the four accidents listed in Section 10.1.1. 


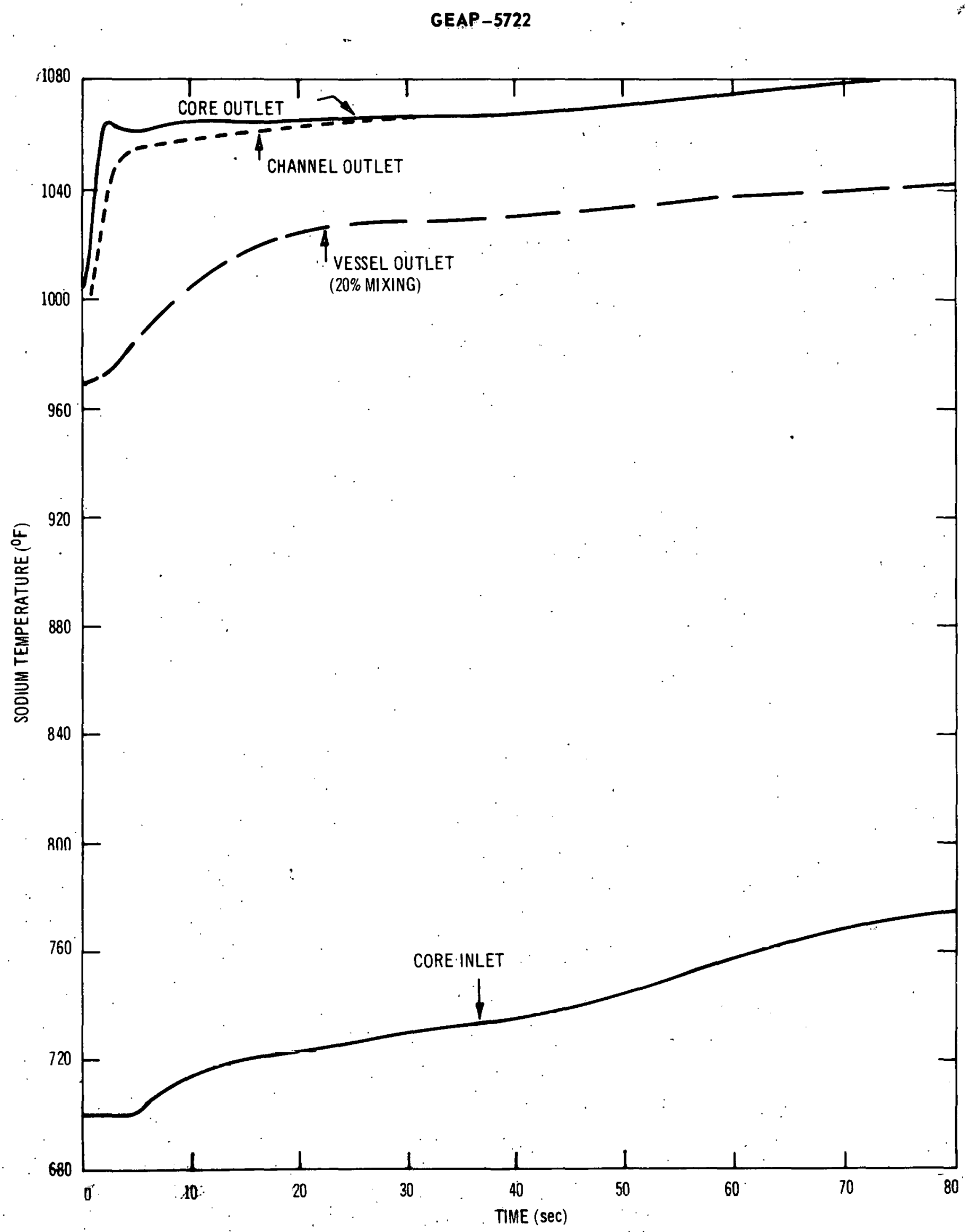

FIGURE 10-9. SODIUM TEMPERATURES ABOVE CORE-LOSS OF FLOW IN ONE LOOP WITHOUT SCRAM 


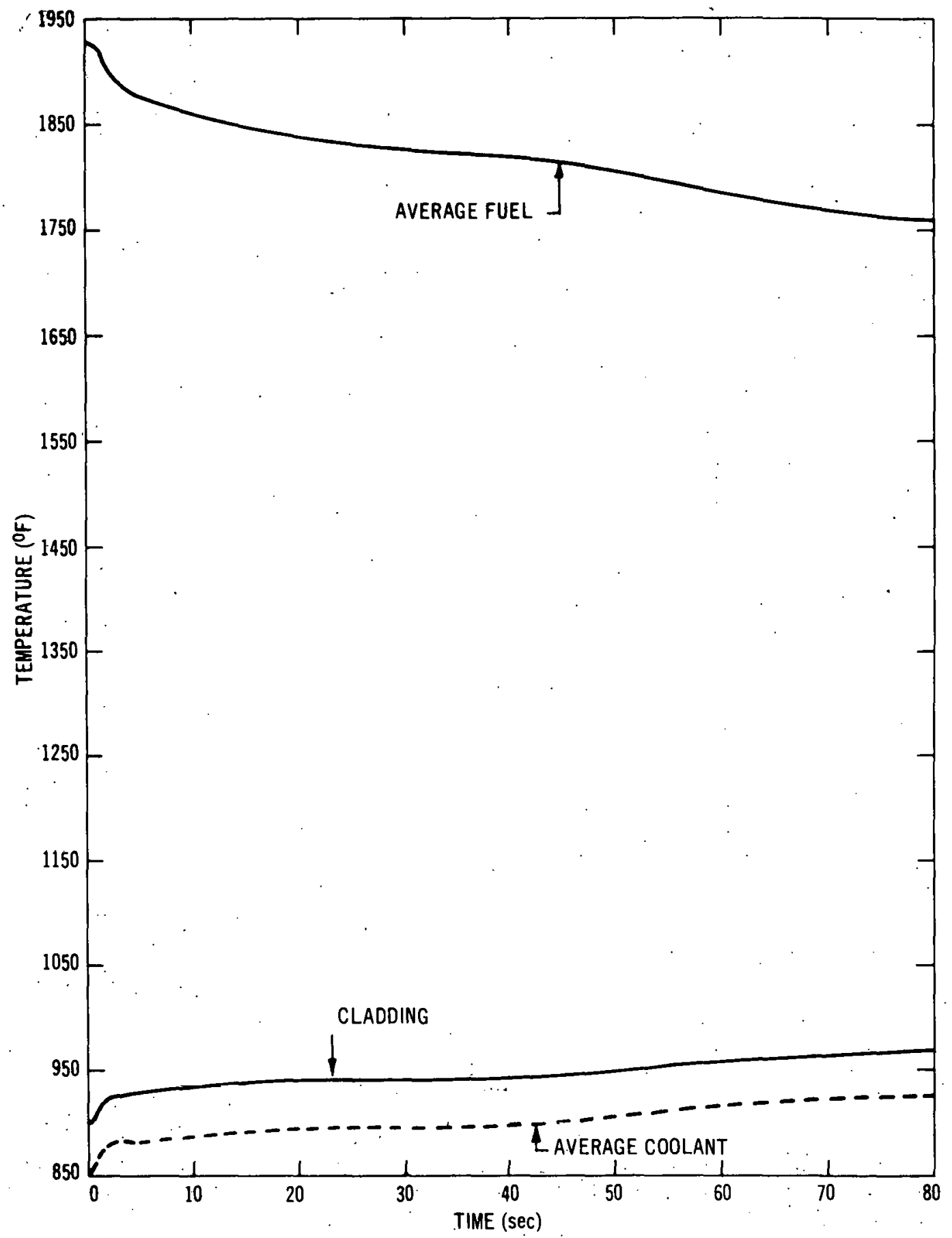

FIGURE 10-10. CORE TEMPERATURES_LOSS OF FLOW IN ONE LOOP WITHOUT SCRAM 10-18 


\subsubsection{Reactor Scram with All Pumps Running}

The following events lead to the sodium temperature response at the core outlet, channel outlet, and vessel outlet (for 20\%-mixing) shown in Figure 10-11:

Scram rods start to drop at time, $t=0$ ( $\$ 10$ scram worth inserted). Sodium coolant remains at full flow.

The negative temperature gradients are large, and equal to the values for the delayed coastdown following scram shown in Figure 10-4. However, the present accident is more serious since the total drop in coolant temperature above the core and at the vessel outlet are so large. Figure 10-11 shows a drop of $\sim 250^{\circ} \mathrm{F}$ in 6 seconds for the core and channel outlets and a drop of $\sim 200^{\circ} \mathrm{F}$ over a 10 second period for the vessel outlet.

Figure 10-12 shows the core temperatures associated with this transient.

As stated in Section 10.3, the inlet temperature was held constant throughout the calculation. For this transient, the assumption of constant inlet is exact for 17 seconds at full flow because 17 seconds is the transit time of the primary sodium around the system external to the vessel.

\subsubsection{Reactivity Ramp of $+\$ 0.10 / \mathrm{Sec}$ w.ithout Scram}

The second arcident analyzed was a $10 \phi / \mathrm{sec}$ ramp reactivity insertion without scram, starting at full power and full flow. The ramp is assumed to continue throughout the duration of. the transient while the coolant flow is assumed to remain constant. The results are shown in Figures $10-13$ and $10-14$.

The sodium temperature gradients at the core and channel outlets eventually reach a magnitude of $17^{\circ} \mathrm{F} / \mathrm{sec}$, and extrapolation of Figure 10-13 indicates that sodium boiling at the core outlet would commence at 50 seconds. The sodium temperature gradient at the vessel outlet (with $20 \%$ mixing and with $10 \%$ bypass flow) reaches $13{ }^{\circ} \mathrm{F} / \mathrm{sec}$.

The average fuel temperature (Figure 10-14) increases significantly as it follows the rising' power level. The peak fuel would have melted during the early part of this transient. (The details of the peak fuel behavior are best analyzed by a special purpose computer code.) The reactivity ramp increasc is strongly dampened by the compensating negative reactivity feedbacks. The net reactivity is quite small, therefore, and the power level rise is relatively slow.

\subsubsection{All Pumps Trip and Coast Down without Scram}

The accident in which all pumps coast down but scram fails to occur was examined for two pump coastdown characteristics. The two coastdown curves 1 and 2 are shown in Figure 10-2 and are characteristic of the FERMI and EBR-II pumps. The FERMI characteristics has been recommended for the FFTF backup design despite some advantage to the slower EBR-II coastdown in the accident considered in this section.

The results for coastdown curve 1 (FERMI) are shown in Figures 10-15 and 10-16. The results of curve 2 are shown in Figures 10-17 and 10-18. For both cases, the core outlet 
and channel outlet sodium temperatures rise rapidly. For curve 1, sodium boiling (boiling point $\approx 1600^{\circ} \mathrm{F}$ ) starts at 8 seconds; for curve 2 , boiling is delayed until 30 seconds. The effects of sodium boiling on reactivity and on heat transfer for curve 1 coastdown transient were not taken into account. The vessel outlet temperature (for $20 \%$ mixing) does not rise rapidly since the mixing time constant is increasing because of the flow coastdown. 


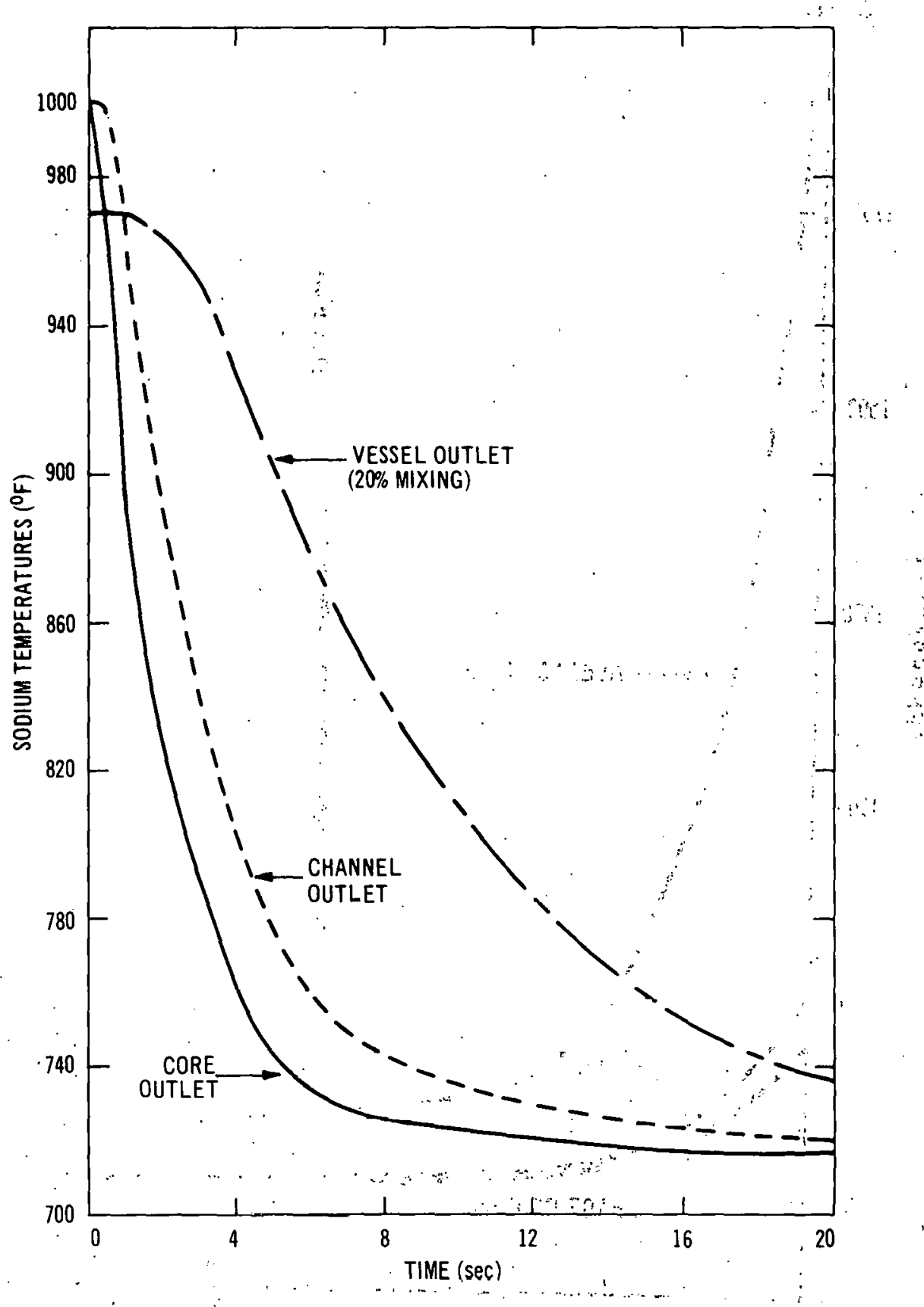

FIGURE 10-11.: SODUIUMMITEMPERATURES ABOVE CORE_REACTRR SCRAM WITH ALL PUMPS RUNNING 
GEAP -5722

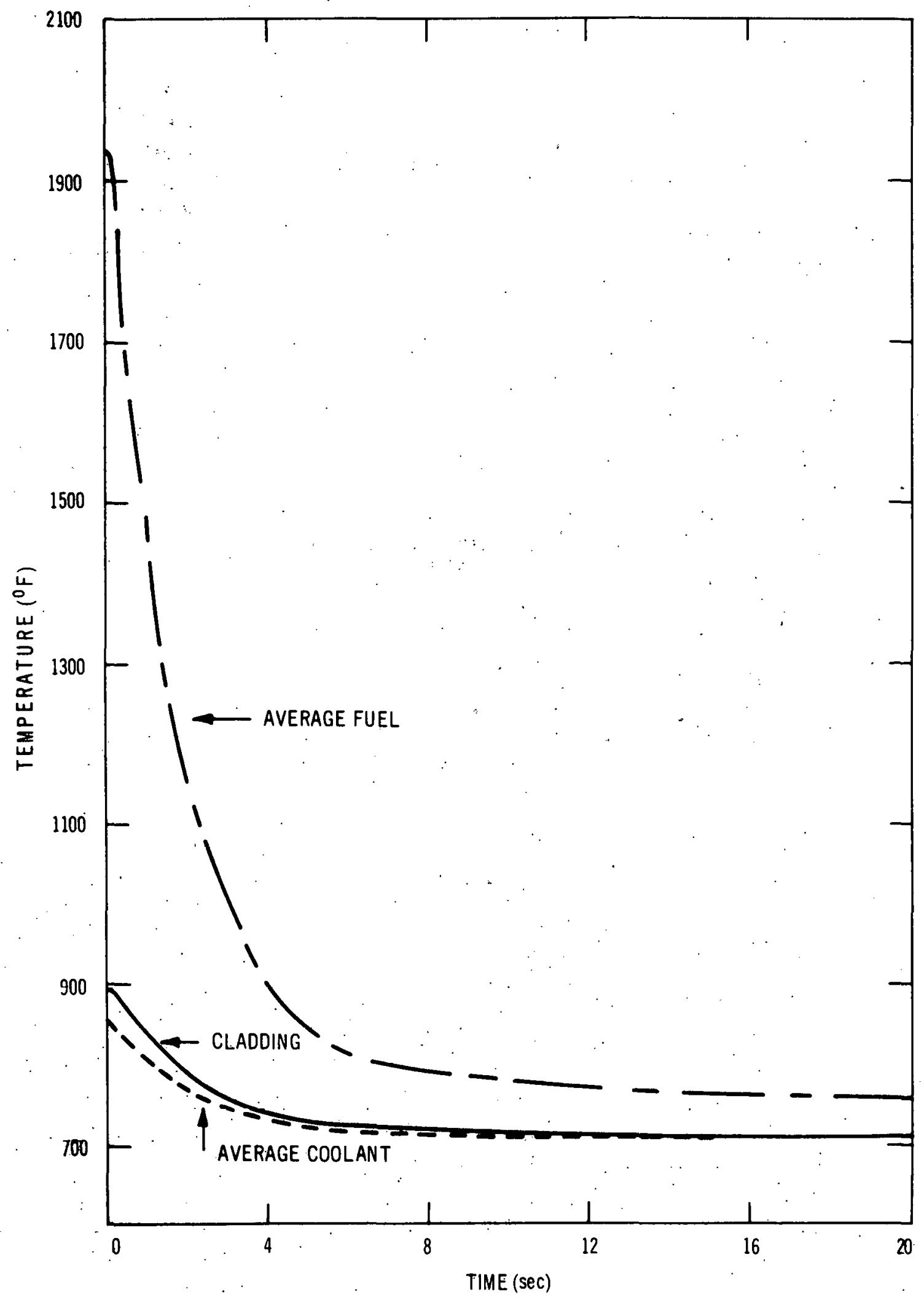

FIGURE. 10-12. CORE TEMPERATURES-REACTOR SCRAM WITH ALL PUMPS RUNNING 


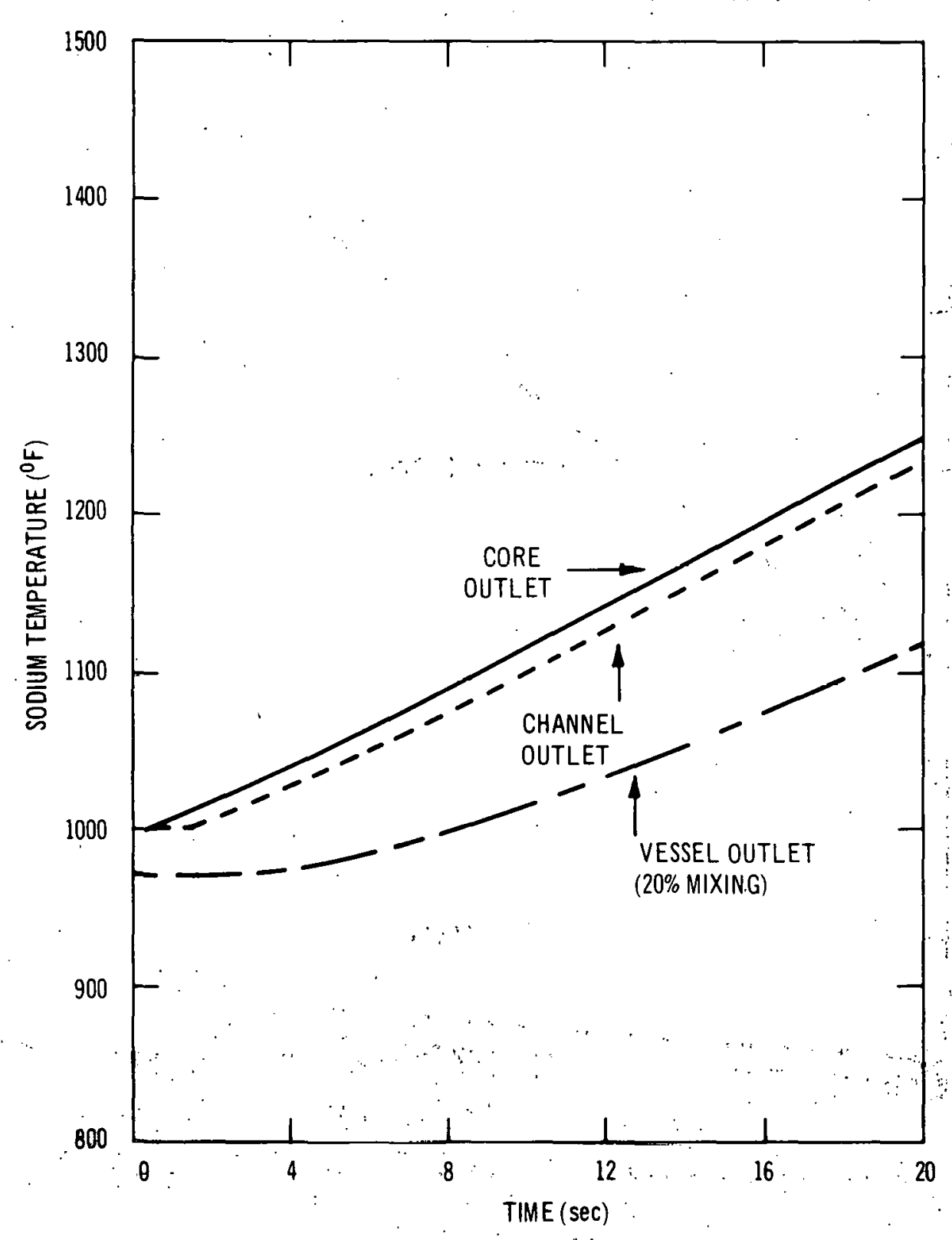

FIGORE 10-13: SODHM TEMPERATURE ABOVE CORE- + \$0.10/sec REACTIVITTRAMP, NO SCRAM-FULL FLOW.

$10-23$ 


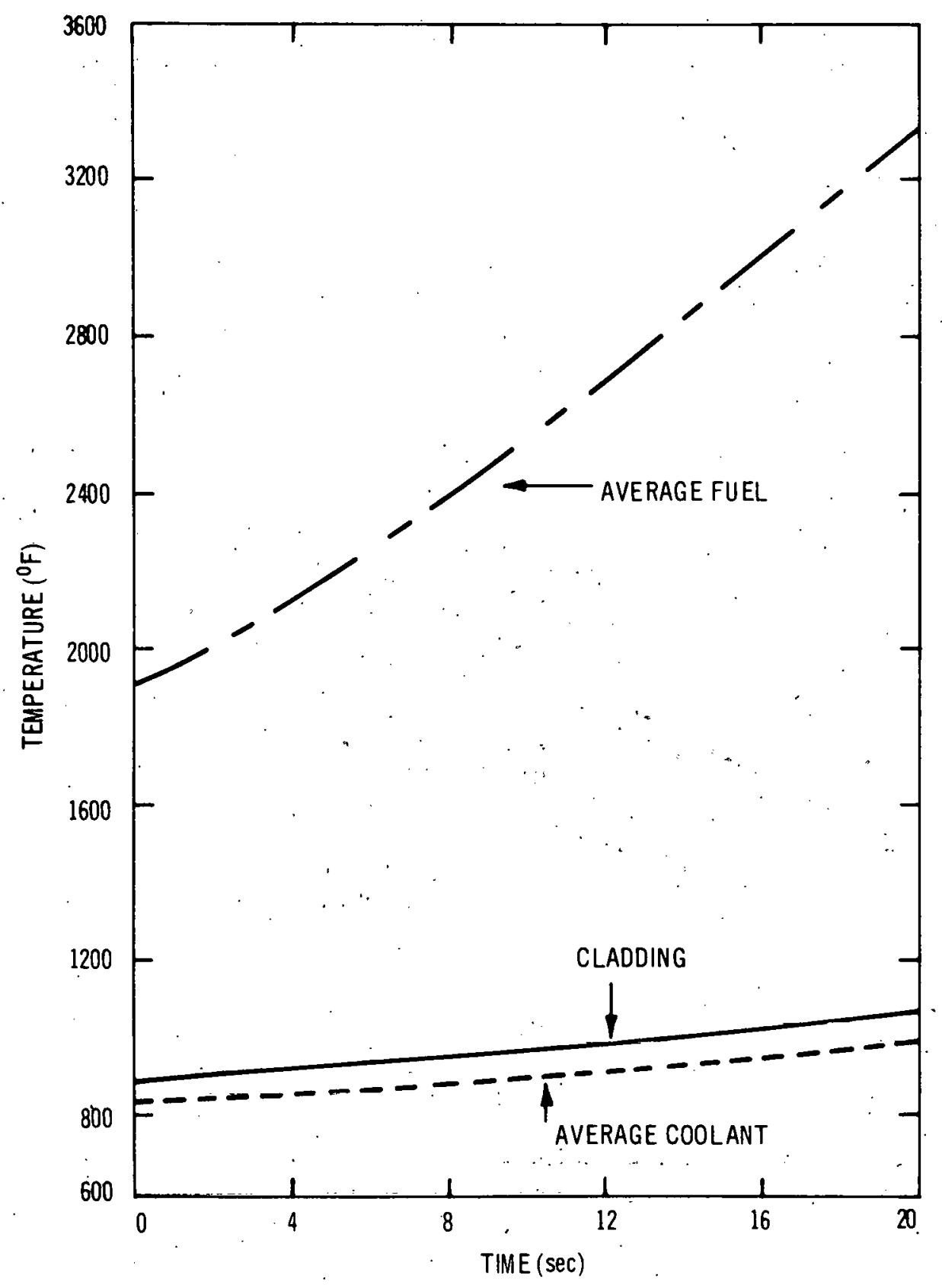

FIGURE 10-14: CORE TEMPERATURES - +\$0.10\% seC REACTIVITY RAMP, NO SCRAM - FULL FLOW 


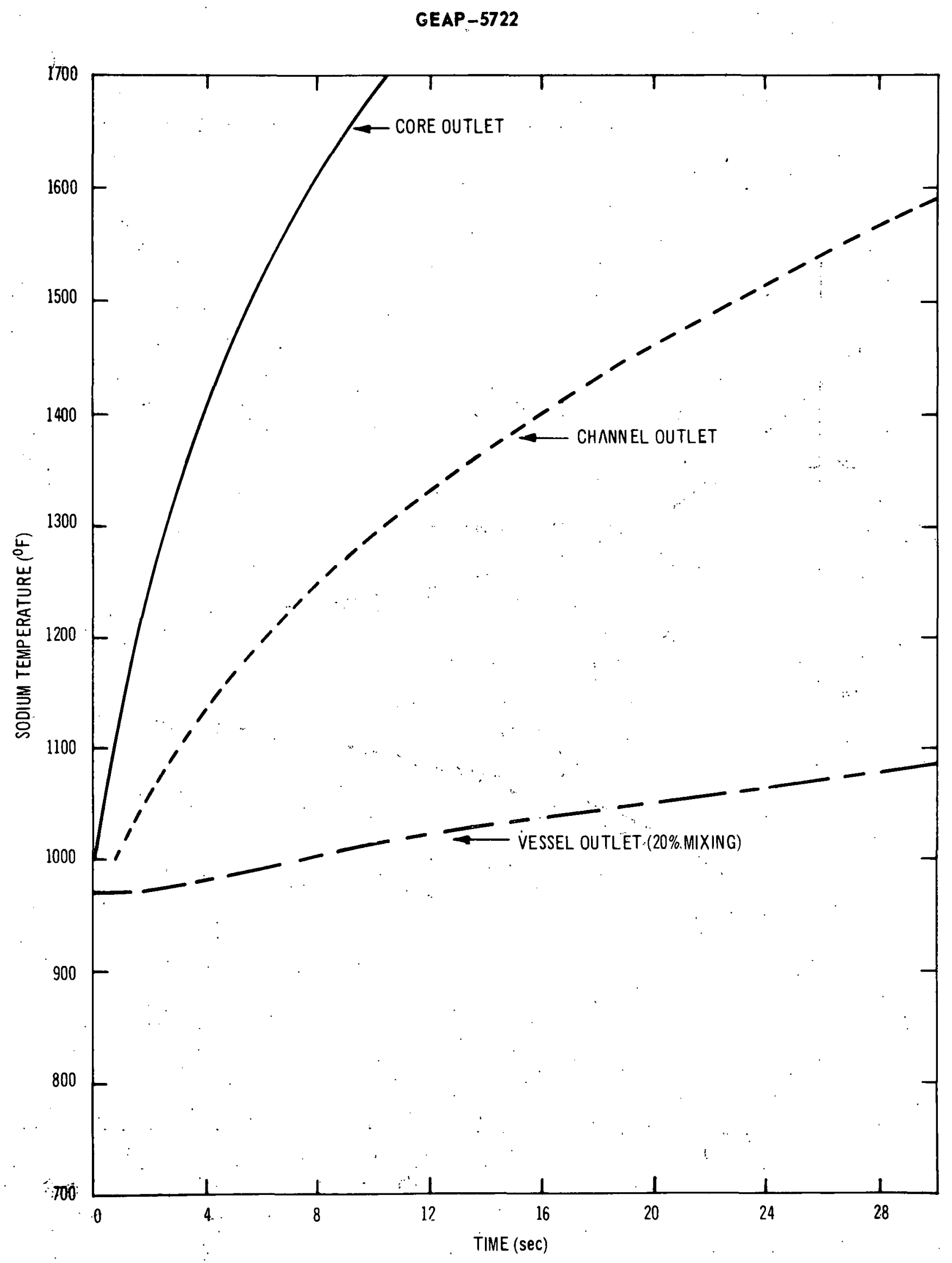

FIGURE 10-15. SODIUM TEMPERATURE ABOVE CORE-ALL PUMPS TTRIP WITHOUT SCRAM. COASTDOWN CUR VE No. I 
GEAP -5722

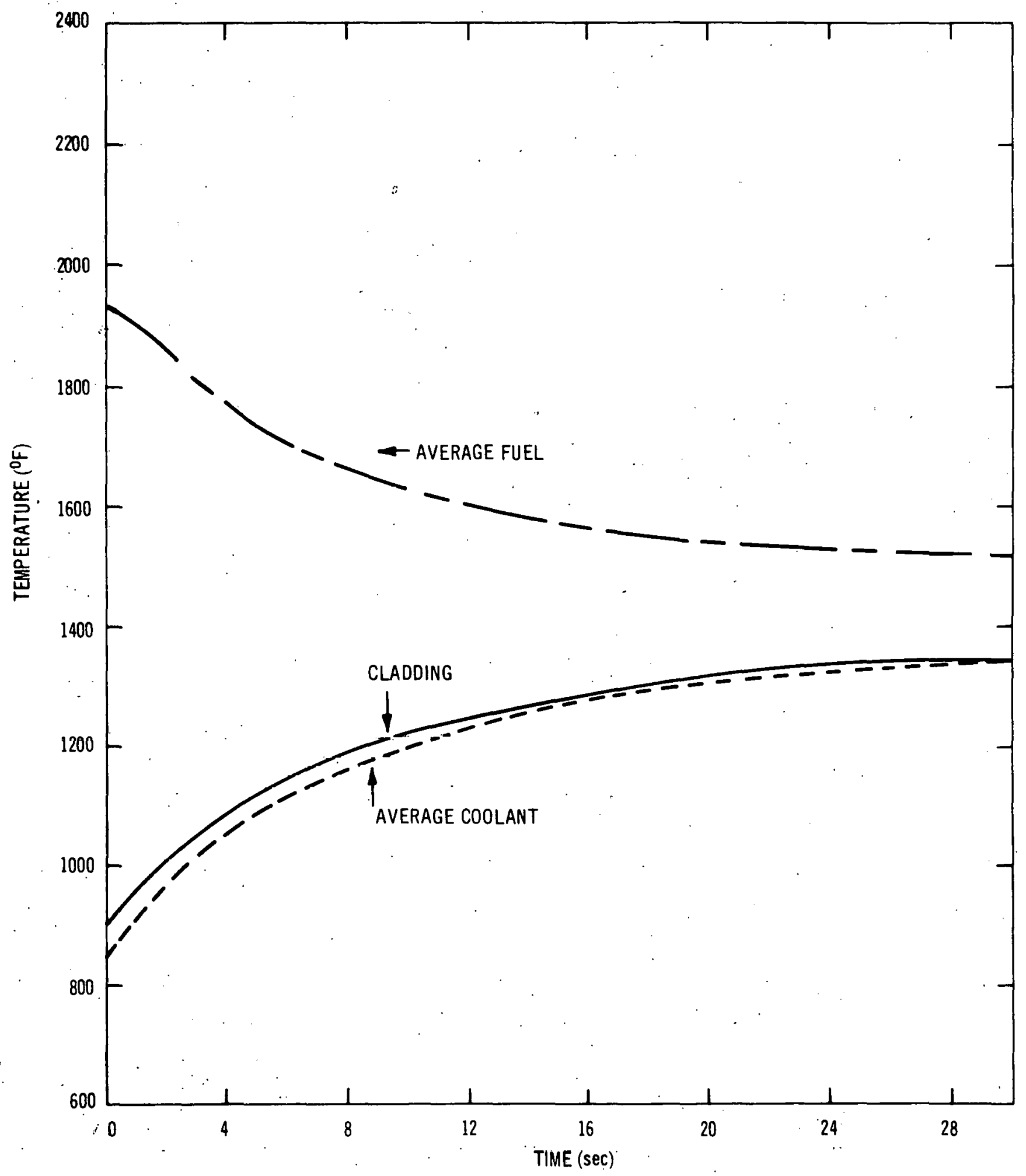

FIGURE 10-16. CORE TEMPERATURES-ALL PUMPS TRIP WITHOUT SCRAM. COASTDOWN CURVE No. 1 
GEAP-5722

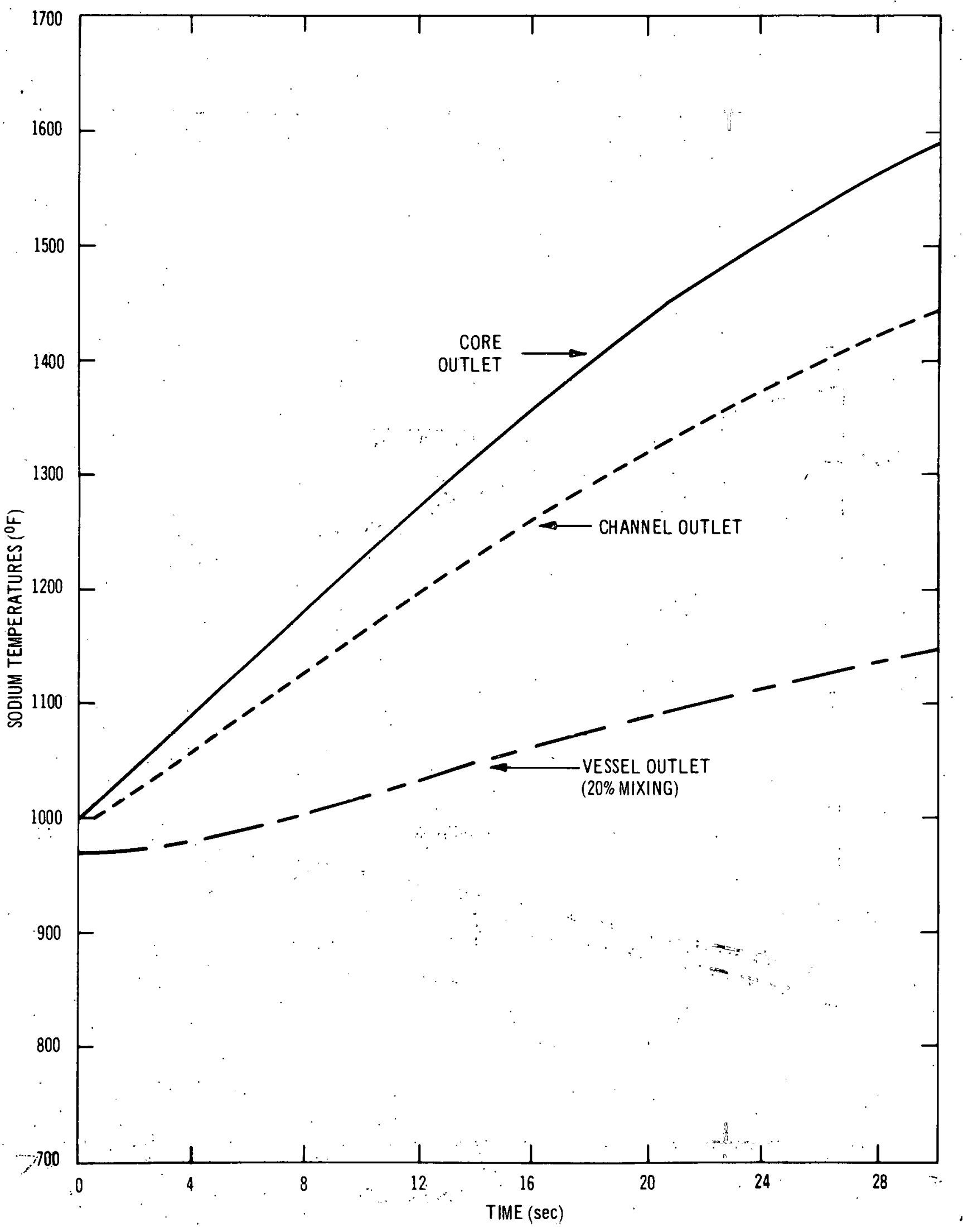

FIGURE 10-17. SODIUM TEMPERATURES ABOVE CORE-ALL PUMPS TRIP WITHOUT SCRAM. COASTDOWN CURVE No. 2 . 
GEAP-5722

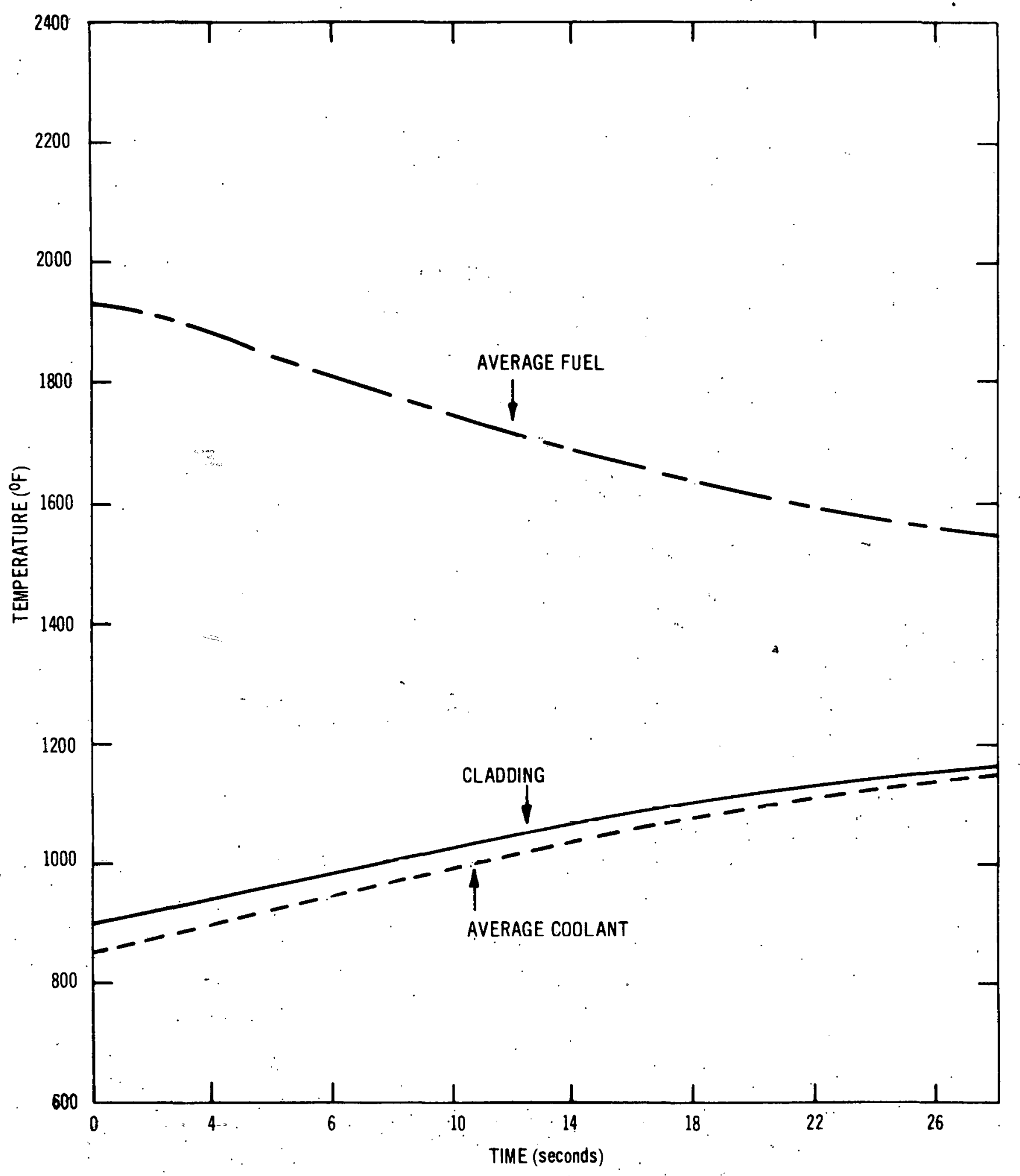

FIGURE 10-18. CORE TEMPERATURES-ALL PUMPS TRIP WITHOUT SCRAM. COASTDOWM CURVE No. 2 
GEAP-5722

\section{SECTION XI}

\section{SA FEGUARDS}

\subsection{SUMMARY}

Safeguards effort for the FFTF Backup Project is summarized in three main categories, general safety criterion, accident analysis,' and DBA definition. Other efforts included in the safeguards summary are the subcriticality analysis and the interface definitions. In the safety and design criterion, guidelines for comporients included in the original scope of FFTF work, but not in the Backup phase are included. Criterion are presented for the primary coolant system, emergency coolant, sodium fires, reactivity worth, vessel design;. and fuel. and.cladding damage limits. Accident analysis includes studies of the core and coolant transient behavior during loss of flow and reactivity insertion accidents, using assumed control rod insertion and pump coastdown characteristics. DBA work was limited to defining the postulated series of events which might result in a catastrophic accident and to forming a preliminary estimate of the explosive energy release.

\subsection{CRITERION FOR SAFEGUARDS FEATURES}

\subsubsection{Primary Coolant System}

Five accidents have been identified with the primary coolant system of the FFTF for which adequate safeguards must be provided. The accidents which have been identified are:

- Loss of site power.

- Loss of a single coclant loop without sodium leakage.

- Sodium leakage from a single loop.

- Guillotine piping failure.

- Vessel leakage.

The consequences of these accidents should be limited by the built-in capabilities of the primary coolant system coupled with a reactor scram. Reactor scram following an accident will be initiated by at least one of the following:

- Loss of main electrical power.

- Loss of coolant flow rate in the primary system.

- Low coolant level in the reactor vessel.

- High coolant temperature at vessel outlet.

- High coolant temperature at 'än intermediate heat exchanger outlet.

- High reactor power level or short reactor period.

With scram and a suitable system arrangement, ' it will be possible to limit the accidents as described in the following paragraphs. 


\subsubsection{Loss of Site Power}

With the power off the main pumps, a flow coastdown must be provided to remove the power produced before scram is completed and the energy stored in the fuel. The capability to remove decay heat is also required. No coolant boiling or cladding damage shall occur.

\subsubsection{Loss of a Single Coolant Loop Without Sodium Leakage}

The heat removal capacity of a single loop is lost by mechanical damage to the pump or IHX or by a failure in the secondary loop. The capability to remove the power produced before scram is completed and the energy stored in the fuel with the remaining loop(s) must be provided. The removal of the decay heat load with one loop inoperative is required. No coolant boiling or cladding damage shall occur.

\subsubsection{Sodium Leakage From a Single Loop}

A low leakage rate resulting from the loss of an appendage or a small hole in the piping will lower the coolant level in the vessel. The sodium level should be maintained above the outlet nozzles unless an emergency coolant loop is provided. No siphoning of sodium from the vessel or blowdown expulsion should occur. The power produced before the scram is completed and the energy stored in the fuel must be removed. No coolant boiling or cladding damage shall occur.

\subsubsection{Guillotine Piping Failure}

The consequences are the same as a small pipe break except that the coolant level will be lowered faster, so that more heat will be stored in the remaining coolant. No release of fuel from the cladding shall occur.

\subsubsection{Vessel Leakage}

The loss of sodium should be limited so that the main nozzles are not uncovered. Lowering of sodium level will result in more heat being stored in the coolant than occurs during the smallpipe-break accident. No fuel shall be released from the cladding.

To assure that the accidents do not exceed the recommended protection levels, the following design features and engineered safeguards will be incorporated into the coolant system.

a. Provide flow coastdown capability so that the power produced before a scram (based on power trip or flow rate decrease) and the energy stored in the fuel can be removed when one loop is inoperative. The coastdown characteristic can be obtained by inertia built into the pumps or by installing flywheels or pony motors:

b. Provide capability of removing decay heat load by natural circulation in primary loops with one loop inoperative. If natural circulation capability cannot be provided, then pony motors or the equivalent must be installed.

c. Ensure that sodium leakage ariywhere in the primary coolant system, including the vessel, does not.lower the sodium level in the vessel below the main nozzles so that 
natural circulation cooling flow can be maintained. The following design features are used to maintain sodium level:

- Safety tank around the vessel.

- Dip tubes on vessel outlet nozzles.

- Equipment arranged so that leakage anywhere drains into safety.tank.

- Sufficient sodium in vessel above nozzle dip tubes to fill safety tank.

- Cooling of safety tank.

d. Maintain vessel cover gas pressure near 1 atmosphere during normal operation and during accident conditions when the sodium level is changing rapidly. A pressurized cover gas system is not recommended since it would tend to expel sodium at a faster rate in the cvent of a leak in the primary coolant system. The cover gas pressure must be sufficient, however, to provide adequate suction.pressure for the main pumps. With the pumps placed upstream of the main heat exchangers;' 1 atmosphere cover gas pressure should be adequate.

In the event of a guillotine piping failure in the vessel inlet line, the gas volume in the vessel will expand rapidly. The cover gas system should be capable of maintaining sufficient pressure so that gas is not induced into the vessel.. Any gas thăt would be induced into the vessel because of the partial vacuum in the cover gas space could blanket the core, which would result in significant fuel damage.

\subsubsection{Emergency Cooling}

Review of the "General Design Criteria for Nuclear Power Plant Construction Permits" (No. 44) led to a recommendation for the minimum number of main heat transport loops in operation. Since elevated cooling locps have been recommended so that emergency cooling can be obtained by natural circulation in the main loops, the number of these loops enters into the redundancy requirements of the emergency cooling criteria. It was decided to recommend that a minimum of three main loops be capable of removing decay heat whenever the reactor is in a power operating mode. This would then provide a minimum of two loops capable of removing decay heat following loss of heat removal capability in a primary loop by any cause. This was considered to meet the redundancy requirement of Criterion No. 44 and provide adequate reliability of emergency cooling without introducing the complexity and associated safeguards' problems of a separate èmergency cooling system.

\subsubsection{Fuel Damage Limit C riteria}

This criteria established tentative temperature limits for fuel and cladding to be used in Safeguards Evaluations of the FFT F Backup Core as given in Tables 11-1 and 11-2. Two types of off-normal conditions must be considered:

a. Accident power transients in which both fuel and cladding temperatures may rise above the normal rated power conditions.

b. Accidental flow transients in which clädding temperatures rise above the normal rated powor conditions but fuel temperatures are lower than normal power operation. 
TABLE 11-1

FUEL OVERPOWER DAMAGE SEVERITY CRITERIA

\begin{tabular}{|c|c|c|c|c|c|c|}
\hline . & & . & New & Fuel** & $\begin{array}{r}(100 \\
\text { High B } \\
\end{array}$ & $\begin{array}{l}\mathrm{d} / \mathrm{kg}) \\
\mathrm{dp} \text { Fuel }\end{array}$ \\
\hline & Reactor Power & Description & $\begin{array}{l}\text { Fuel } T_{\text {max }} \\
\left({ }^{\circ} \mathrm{F}\right) \\
\end{array}$ & $\begin{array}{c}\text { Area Molten* } \\
(\%)\end{array}$ & $\begin{array}{l}\text { Fuel } T_{\max } \\
\left({ }^{\circ} \mathrm{F}\right)\end{array}$ & $\begin{array}{l}\text { Area Molten** } \\
\quad(\%)\end{array}$ \\
\hline Catastrophic Threshold & Danger Threshold & $\begin{array}{l}\text { Potential DBA initiated } \\
\text { by molter. fuel injection } \\
\text { into sodicm. }\end{array}$ & - & $70^{\dagger}$ & - & $50^{\dagger}$ \\
\hline Improbable Accident & $\begin{array}{l}\text { Safety Limit } \\
\text {. }\end{array}$ & $\begin{array}{l}\text { Moderate fuel damage, } \\
\text { threshold of cladding } \\
\text { rupture, some fission } \\
\text { product release. }\end{array}$ & - & $40^{\dagger}$ & - & $30^{\dagger}$ \\
\hline Credible Accident Limit & $\begin{array}{l}\text { Design Limit } \\
\cdot(1.2 \times \text { normal } \\
\text { S.S. power) }\end{array}$ & $\begin{array}{l}\text { No damage, incipient } \\
\text { fuel melt:ng }\end{array}$ & 5200 & $\therefore$ & 4930 & .0 \\
\hline Normal Operation & Normal Operation & Normal Cperation & 4450 & 0 & 4200 & 0 \\
\hline
\end{tabular}

* Based on PA10, Task C.

** These values are to be used for current evaluations but are subject to reevaluation as additional test data become available.

$\dagger$. The areas molten are recommendations for a rapid power transient, i. e., a rise and fall in overpower over a period of 1 second or less. 
TABLE 11-2

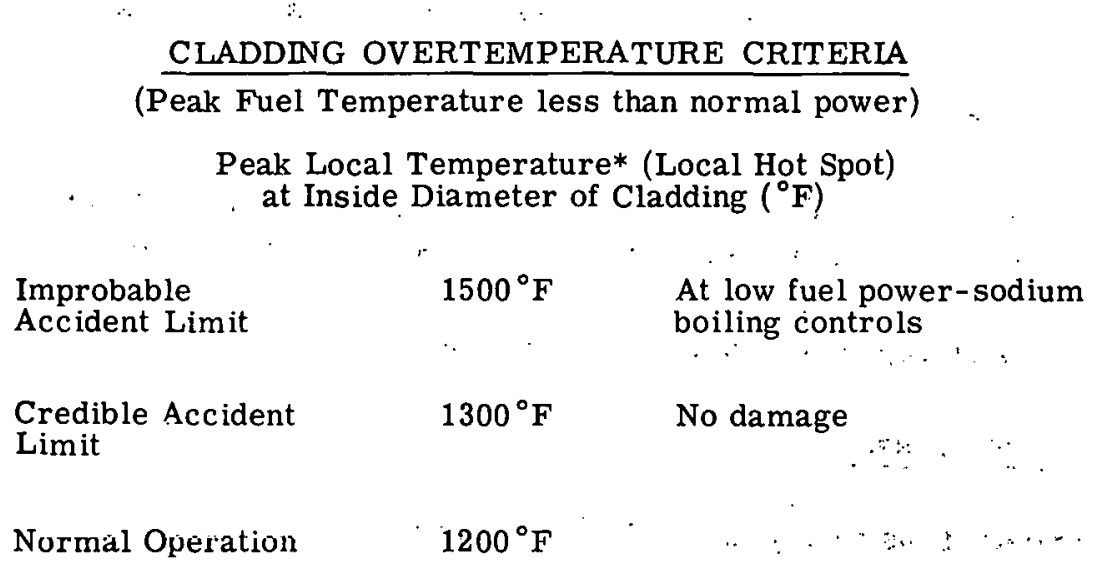

* These are tentative values subject to change as irradiated cladding damage test data becomes available.

Transients can be considered in the following categories:

a: A credible accident is herein defined as one in which the probability of occurrence is sufficiently high that it is desired that'no reduction in fuel life shall occur as a consequence of such an accident and the fuel temperatures are limited.such that a margin of safety against cladding rupture exists.

b. An improbable accident is one in which the probability of occurrence is sufficiently low that some fuel damage may be tolerated but the damage is limited such that a catastrophic condition is not approached.

c. A catastrophic accident is one in which damage is sustained by the permanent structure of the reactor. The conservative upper bound on such accidents is the "Design Basis Accident."

The following list of accidents has heen identified to date:

a. Credible

1. Power Transients (with scram)

(a) Control rod withdrawal

(b) Single bundle meltdown

2. Flow Tränsients (with scram):

(a) 'Loss of' site power

(b) Loss of one primary loop - pump seizure.

(c) Loss of one secondary loop 
(d) Small leak on one loop

(e) Non-shut off of pumps following a scram signal

b. Improbable

1. Power Transients - Control rod ejection at maximum credible rate with scram

2. Flow Transients - Guillotine pipe failure in one primary loop with scram

c. Catastrophic - Loss of flow without scram

\subsubsection{Safety Vessel}

A review of the conceptual design of the safety tank resulted in the following conclusions.

a. Tank should be backed up by concrete since it may have to resist high transient pressure during DBA - (SEFOR 200 psi).

b. Should have clearance behind it to permit vapor driven off from concrete to be vented.

c. Requirements (a) and (b) will require a slotted surface, a small gap, or both.

d. Tank should be made in factory and given ASME Code Class B requirements on fabrication and inspection. Testing to nominal pressure and hydrostatic leak test prior to installation is recommended.

e. The above, a. through $d$., result in a.free-standing tank with small clearance between tank and core wall (say 1 inch nominal). Flanges will be required for testing and connection to equipment cell liners.

f. Leaks-Accidental leaks cannot be positively precluded from causing some sodium to get into cavity. A pure cavity atmosphere (probably argon) is recommended so that corrosive products are not formcd in cavity because of a leak with a diaphragm seal at penetrations from cavity to $\mathrm{N}_{2}$ cells. This diaphragm also minimizes probability of sodium leaks in equipment cells getting into cavity and requiring cleanup.

g. Auxiliary NaK cooling coils, vertical coils on inside of tank protected from crushing because of excessive expansion of blast shield.

h. To ensure that the reactor vessel fails before the head, further layout work must be done in locating the blast shield and sodium deflector.

\subsection{ACCIDENT ANALYSIS}

A design objective is provision of test locations in the reactor core with a peak neutron flux level of $1.0 \times 10^{16} \mathrm{n} / \mathrm{cm}^{2}$-sec. To attain this with ceramic fuel $\left(\mathrm{UO}_{2}-\mathrm{PuO}_{2}\right)$ requires that fuel be operated so that its peak temperature is close to the fuel melting point. From safety considerations one of the primary requirements is the assurance that fuel pin failure (cladding rupture) is highly improbable. The design consequently becomes a trade-off between safety requirements 
and flux requirements. The nuclear and safety parameters of the Backup core have been selected to permit a reasonably conservative approach to be taken to safety evaluation and still meet the design requirement on neutron flux. Because of time and manpower limitations, the analyses conducted do not represent an exhaustive parametric study of all variables over their full range but provide a set of reference calculations to demonstrate the general safety characteristics of an unzoned core. A change to a two-zone core with the same fuel design criteria is not expected to change the results of the analysis appreciably since the only significant change is an increase in power density by $\sim 8 \%$.

\title{
11.3.1 Accident Transients
}

The potential accident transients that have been identified for further consideration are listed in Table 11-3.

As a partial evaluation of this list of accidents, the following scram-transient analyses of the core have been performed:

- Reactivity insertion from single bundle meltdown

- Reactivity insertion from contröl rod "ejection"

- Reduction of primary conlant flow corresponding to primary coolant system failures and fuel channel blockage

\subsubsection{Analytical Procedure}

The analytical procedure followed uses the FORE II computer code to generate the temperature and power distribution in the core during a transient.

The following summary is reprinted from GEAP-5273, the FORE II program manual.

\begin{abstract}
"FORE II is a coupled thermal hydraulics - point kinetics digital computer code designed to calculate significant reactor parameters under steady-state conditions, or as functions of time during transients. The transient may result from a programmed reactivity insertion or a power change. Variable inlet coolant flow rate and temperature are considered. The code calculates the reactor power, the individual reactivity feedbacks, and the temperature of coolant, cladding, fuel, structure, and additional material for up to seven axial positions in three channel types which represent radial. zones of the reactor. The heat of fusion accompanying fuel melting, the liquid metal voiding reactivity, and the spatial and the time variation of the fuel cladding gap coefficient due to changes in gap size are considered. FORE II is valid only while the core retains its initial geometry."
\end{abstract}

The significant material properties are specified in the input as functions of temperature or pressure, and the external effects as a function of time by tables. The feedback reactivity includes contributions due to the Doppler effect, density changes, dimensional changes (including bowing and deformation), coolant voiding, and control rods.' Any single phase coolant may be used. Although the code is biased toward fast reactors, it can be used for a thermal spectrum reactor as a steady-state heat transfer code and as a transient point kinetics code. 
TABLE 11-3

\section{DESIGN TRANSIENTS FOR CONSIDERATION}

\begin{aligned} Number & \\ \cline { 1 - 1 } 1.0 & $\quad$ Core Disassembly Transient \\ 2.0 & Ejection of Control Assembly with Scram \\ 3.0 & Single Fuel Assembly Meltdown \\ 4.0 & Fuel Assembly Drop-In \\ 5.0 & Control Assembly Withdrawal \\ 6.0 & Moderator Addition \\ 7.0 & Cold Sodium Addition \\ 8.0 & Sodium Voiding by Entrained Gas \\ 9.0 & Sodium Fire in Closed Inner Containment \\ 10.0 & Sodium Fire in Outer and Inner Containment \\ 11.0 & Sodium Spray Fire \\ 12.0 & Large Leak in Primary Coolant System \\ 13.0 & Large Leak in Secondary Coolant System \\ 14.0 & Reductions of Primary Coolant Loop Flow \\ 15.0 & Reductions of Secondary Coolant Loop Flow \\ 16.0 & Reductions of Forced Air Cooler Flow \\ 17.0 & Loss of Generated Electrical Power \\ 18.0 & Large Leak in Closed Test Loop Primary Coolant System \\ 19.0 & Large Leak in Closed Test Loop Secondary Coolant System \\ 20.0 & Reductions of Closed Test Loop Primary Coolant Flow \\ 21.0 & Reductions of Closed Test Loop Secondary Coolant Flow \\ 22.0 & Reductions of Cloocd Tcat Louj Furced Alr Cooler Flöw \\ 23.0 & Reductions of Open Test Loop Coolant Flow \end{aligned}

The programming language is FORTRAN IV. A computer with a $32-\mathrm{K}$ storage capacity is required for the operation of FORE II.

For the analyses conducted, the three channel types represented were:

- Central channel including local power peaking caused by nonuniformities and tolerances

- Central channel excluding local power peaking

- Average power channel

\subsubsection{Fuel Damage Limits}

These were presented in the Table 11-1 and 11-2 in detail and can be summarized as follows:

- Peak fuel temperature to be less than fuel melt temperature except for ultra-low probability accidents such as control rod shoot-out.

- Peak cladding temperature limit $1300^{\circ} \mathrm{F}$ except for ultra-low probability events such as rod shoot-out and guillotine pipe failure. 
Peak fuel temperature for rod shoot-out to be such that less than $40 \%$ of crosssectional area of a new fuel pin becomes molten."

\subsubsection{Trip Setting}

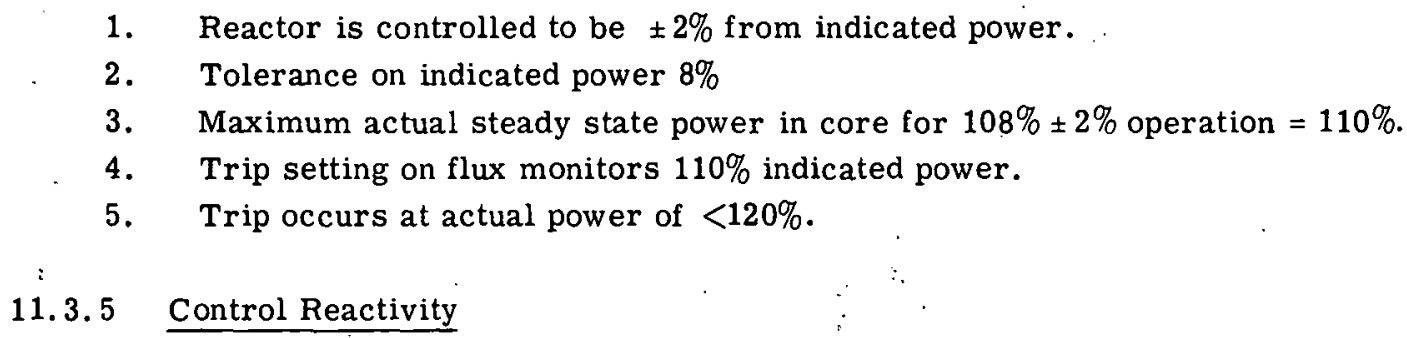

1. Reactor is controlled to be $\pm 2 \%$ from indicated power.

2. Tolerance on indicated power $8 \%$

3. Maximum actual steady state power in core for $108 \% \pm 2 \%$ operation $=110 \%$.

4. Trip setting on flux monitors $110 \%$ indicated power.

5. Trip occurs at actual power of $<120 \%$.

11.3.5 Control Reactivity

Figure 11-1 shows the delay time, control worth, and insertion rate used in the analyses. A control system with a $10 \$$ scram worth at $1 \mathrm{~g}$ acceleration and 0.150 second delay is the current reference for drive design. The curve used for analysis is conservative to allow for possible variations between anticipated and real drive behavior.

\subsubsection{Flow Coastdown}

Figure 11-2 shows the curve assumed." It is taken from the FERMI pump characteristics, since transient systems analyses have indicated its suitability.

\subsubsection{Reactivity Transients}

Figures 11-3, 11-4, and 11-5 show the percent melting at core hot spot, peak cladding temperature, and outlet sodium temperature as a function of ramp rate for an insertion of $1.5 \$$ and $0.5 \$$. The $1.5 \$$ was selected as the approximate maximum worth of the pair of elements in a reflector control drive assembly, and $0.5 \$$ as the worth associated with a single bundle meltdown. Cálculations were performed for Doppler feedback coefficient ( $\mathrm{T} \mathrm{dk} / \mathrm{dT}$ ) values of -0.006 and -0.004 . The Doppler coefficient is currently estimated to be about -0.006 but because of uncertainties in this estimate -0.004 is selected for reference calculations.

From these curves it can be seen that a reactivity ramp up to $2 \$$ per second can be tolerated without any fuel melting and $1 \$$ per second causes about $40 \%$ of the fuel pin to be molten at the core hot spot. The amount of over-temperature that can be tolerated on the cladding is difficult to define with precision. The capability of cladding to withstand the fission gas pressure is decreasing rapidly with temperature. It is anticipated that $100^{\circ} \mathrm{F}$ over-temperature would result in a negligible cladding damage. Figure 11-4 shows the peak cladding temperature raising very rapidly with ramp rate, and to reduce the probability of cladding rupture and the consequent problems assuciated with this, such as fuel sodium interactions, the ramp rate associated with accidents such as rod shoot-out should be limited to $2.5 \$ / \mathrm{sec}$ even though the fuel melting criteria would allow up to $4 \$$ / second.

\subsubsection{Rud Shoot-Out}

The control drive assembly shall be designed so that rod shoot-out is a virtually incredible event requiring at least two independent failures, however, the mechanism used to raise the rod 


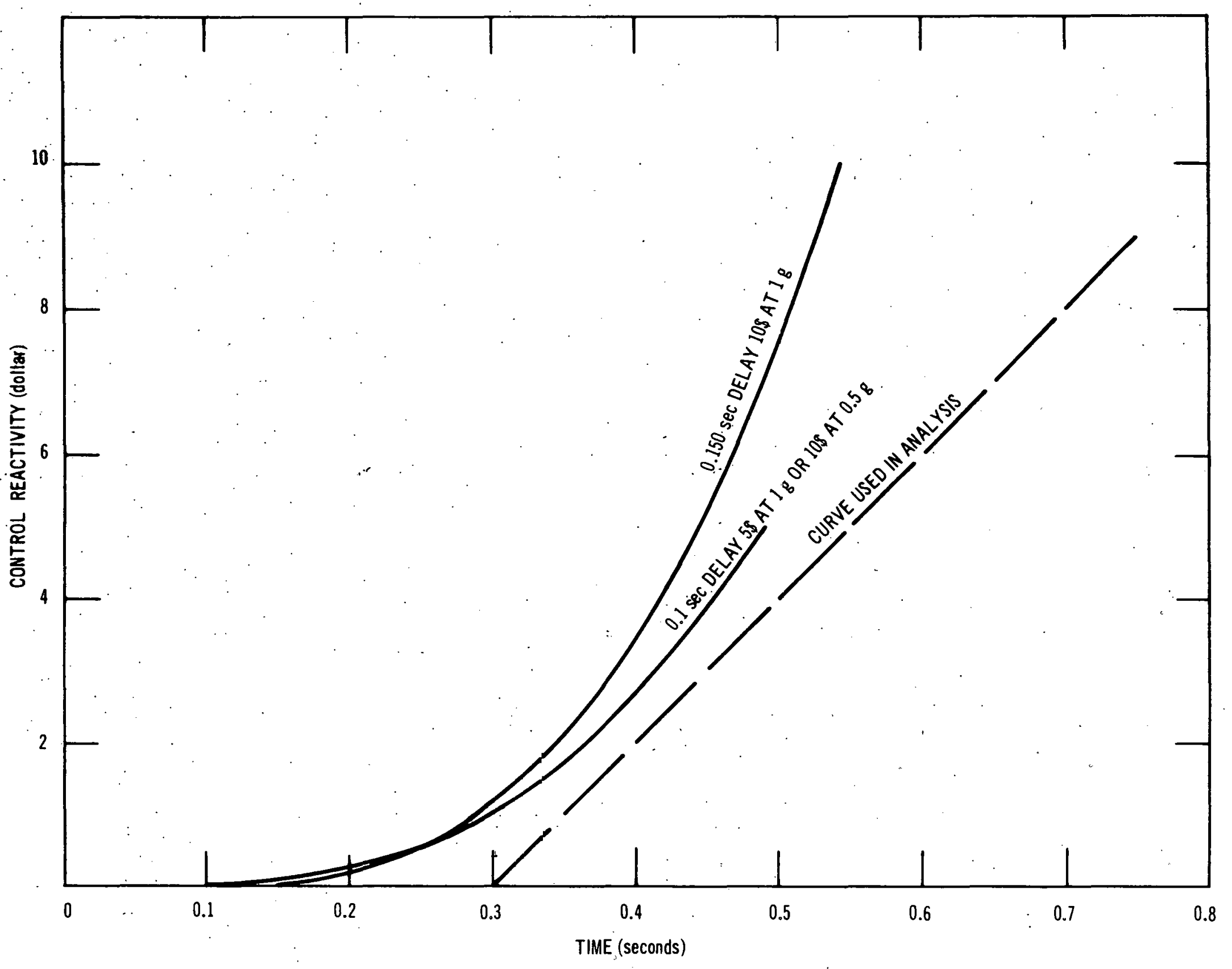

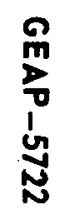

FIGURE 11-1. CONTROL REACTIVITY 


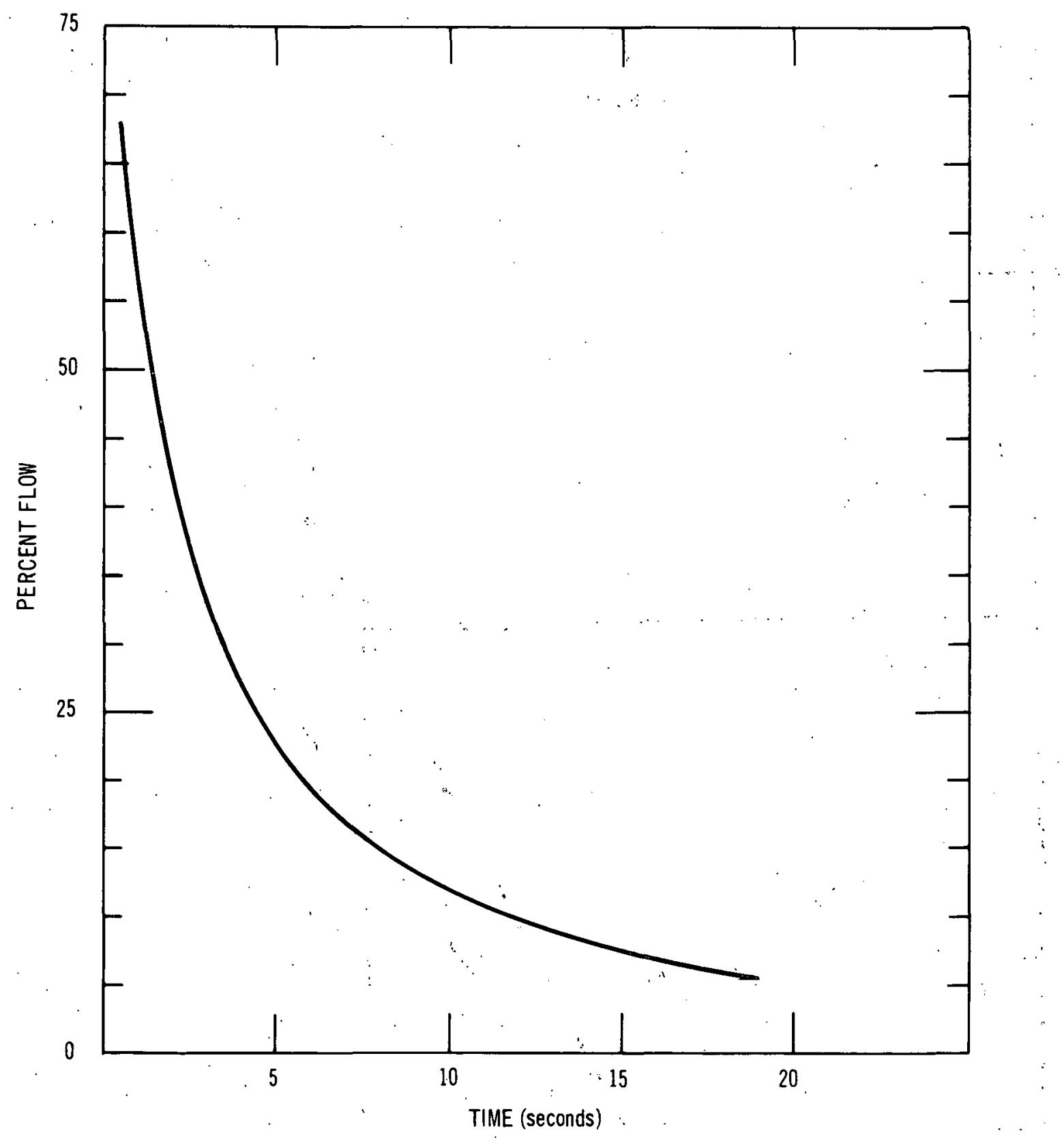

EIGURE 11-2. PUMP COASTDOWN (FERMI-12000 gpm) $11-11$ 
GEAP-5722

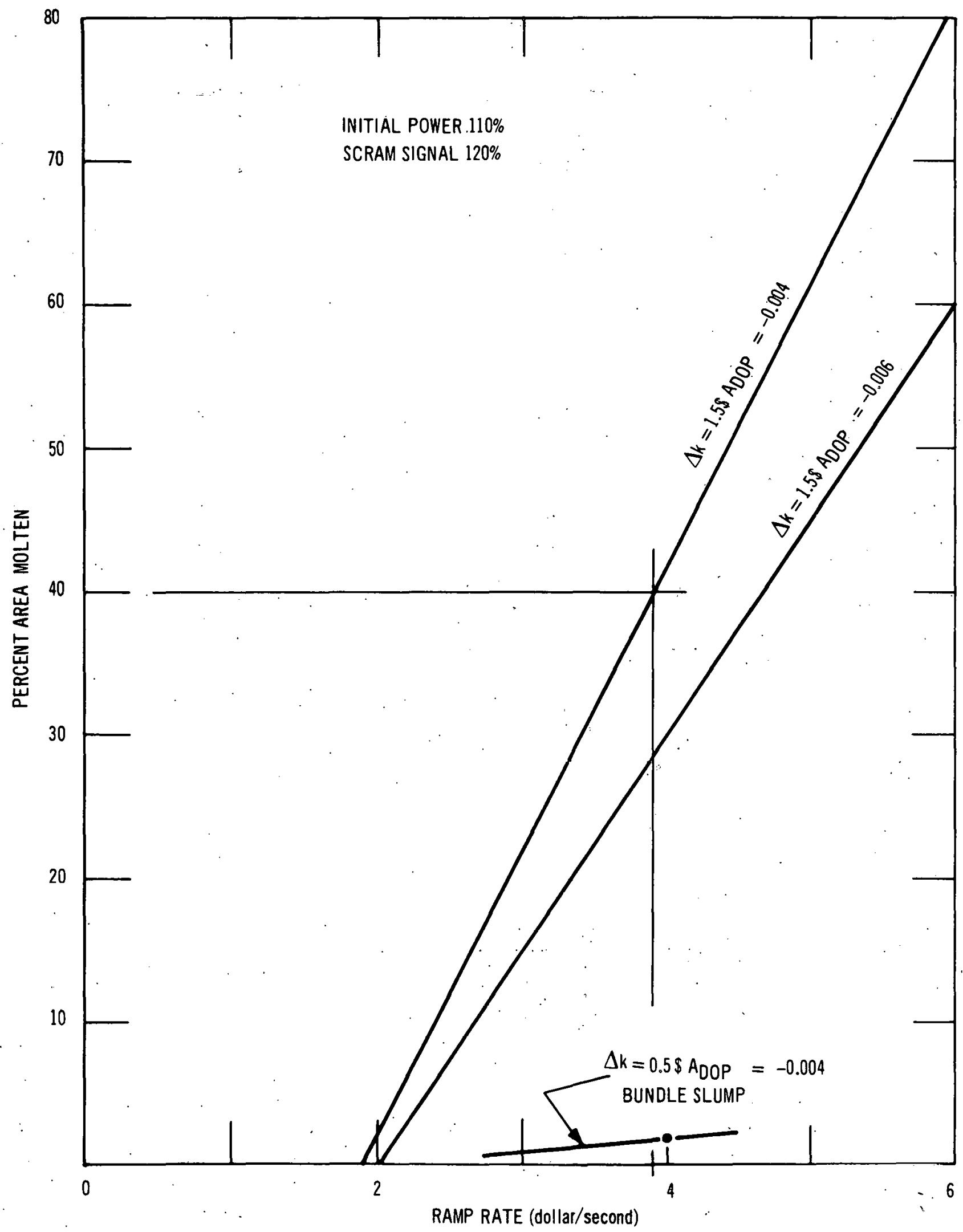

FIGURE 11-3. PERCENT MELTING AT CORE HOT SPOT REACTIVITY TRANSIENTS 


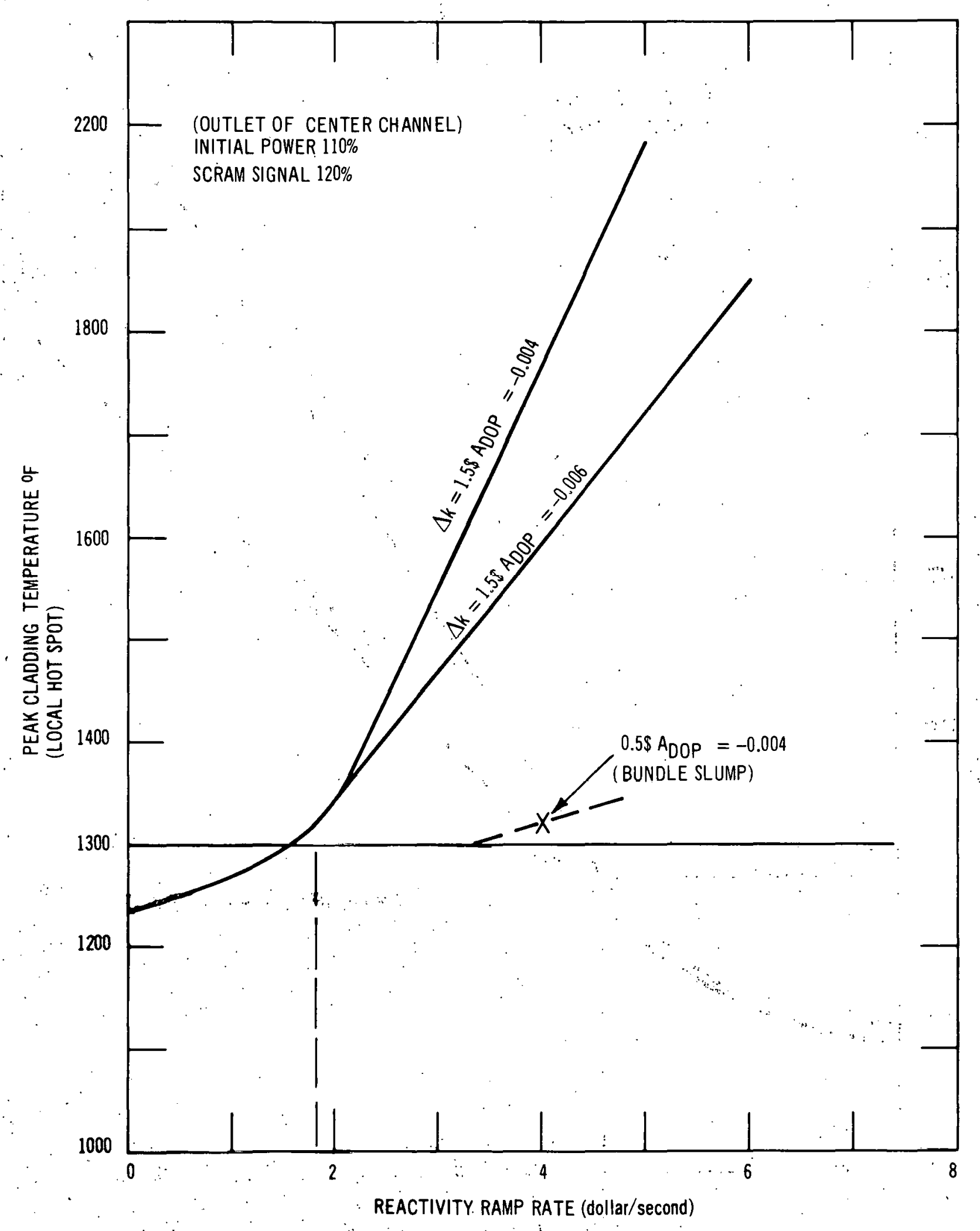

$1 ;-4$

FIGURE 11-4. PEAK CLADDING TEMPERATURE DURING REACTIVITY TRANSIEN TS 


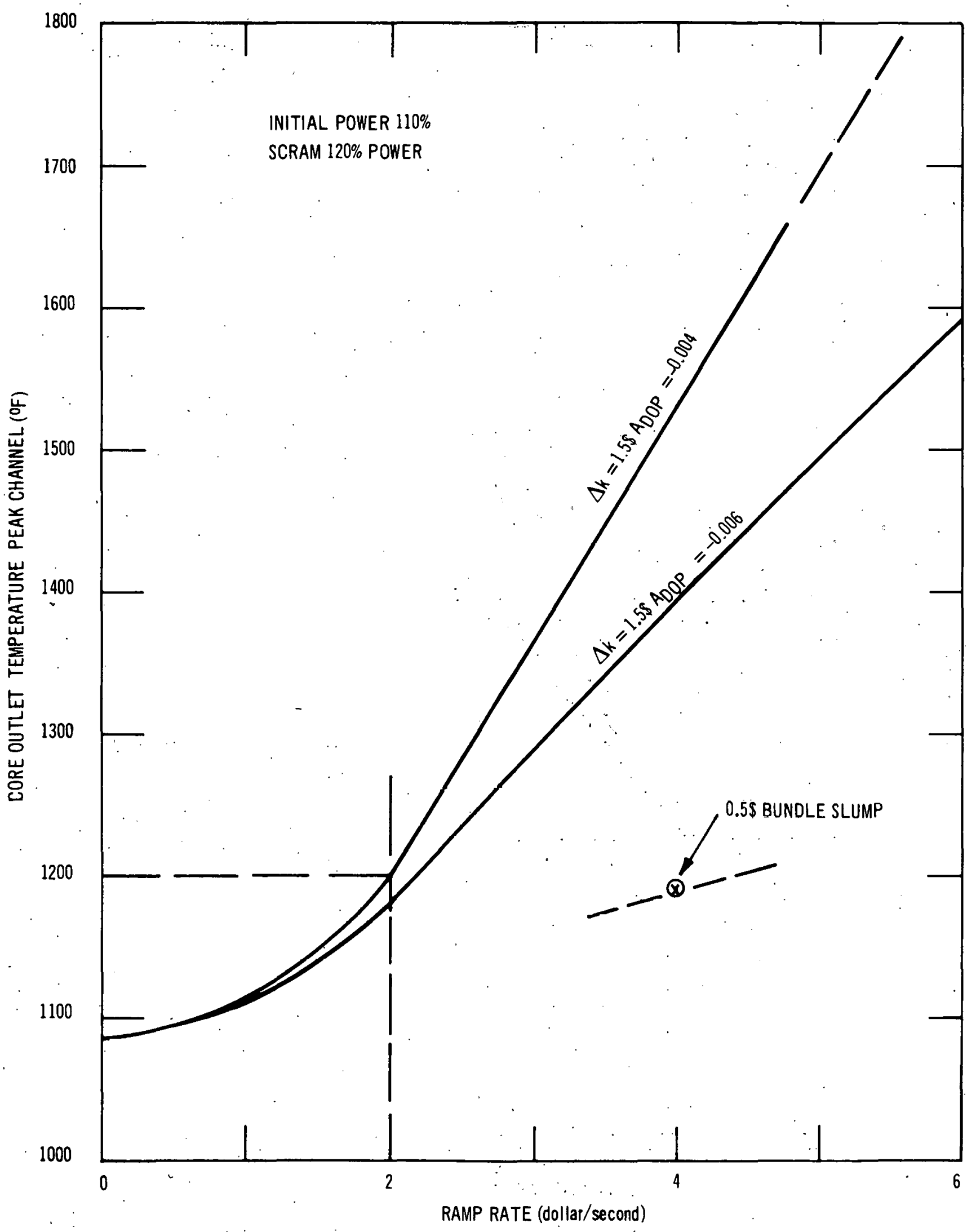

FIGURE 11-5. PEAK COOLANT OUTLET TEMPERATURE REACTIVITY TRANSIENTS 
is a potential energy source, and also the hydraulic forces on the element are in an upward direction. The hydraulic forces will be less than the element weight due to orificing of the coolant at the bottom of the channels.

For the current reference, the worth of a double reflector control rod in the most reactive geometrical arrangement is approximately $1.5 \$$, with a 3 -foot stroke.

To keep the average ramp rate at $2 \$ /$ second, the time for ejection should not be less than 0.75 second. Assuming a constant acceleration, $\mathrm{a}<25 / \mathrm{t}^{2}=6 / 0.75^{2}=10.6 \mathrm{ft} / \mathrm{sec}^{2} \sim 1 / 3 \mathrm{~g}$. The upward forces on the moving subassembly in the control drive assembly must be limited to $4 / 3$. times the weight of the moving assembly, for any credible failure or malfunction.

\subsubsection{Bundle Slump}

The reactivity worth of single bundle meltdown is estimated at $50 \notin$ for a slumping of the upper third of the fuel into the middle third. The rate is determined by free fall under gravity resulting in an average ramp rate of $2 \$ /$ second, which results in no fuel melting. A conservative reference point is plotted on the figures for a $4 \$ /$ second ramp rate.

\subsubsection{Flow Transients .}

Figure 11-6 shows the outlet temperature of a hot channel and the peak cladding hot spot temperature for a normal scram 'initiated at $110 \%$ power. This would cover the case of a scram signal from loss of site power, secondary system failures, etc. For an accidental overpower trip at $120 \%$ power, the dotted curves of Figure 11-6 show the temperature response of hot channel outlet coolant and local cladding hot spot. The peak cladding temperature of less than $1300^{\circ} \mathrm{F}$ is considered acceptable during a transient.

Figure 11-7 and 11-8 show the temperature response of the reactor coolant to varying degrees of rapid blockage of a single central fuel subassembly and the time for the event to be sensed by the channel outlet temperature instrumentation. These indicate the response time on outlet thermocouples need not be very fast and flux will be the fast signal for power transients.

\subsubsection{Safeguards During Refueling .}

A series of FORE II runs were made in which a bundle of nominal worth (2.20\$) and above nominal worth $(3.00 \$)$ were inserted into a just subcritical core at refueling temperature without scram. A range of Doppler coefficient from -0.004 to -0.008 was used along with a core coolant flow rate of $5 \%$ and $10 \%$. A $1 \mathrm{~g}$ and $1 / 2 \mathrm{~g}$ drop rate was assumed, and sodium boiling occurred in 1 to 3 seconds for all cases. The analysis was not taken to the point of a core slumping energy release but since coolant boiling occurs, an explosion of some magnitude induced by the reactivity insertion of sodium voiding and fuel slumping is quite probable. It is felt that the consequence to the design requirements on the refueling cell would be sufficiently severe that engineered safeguards to avoid criticality during refueling is the approach which should be followed. 


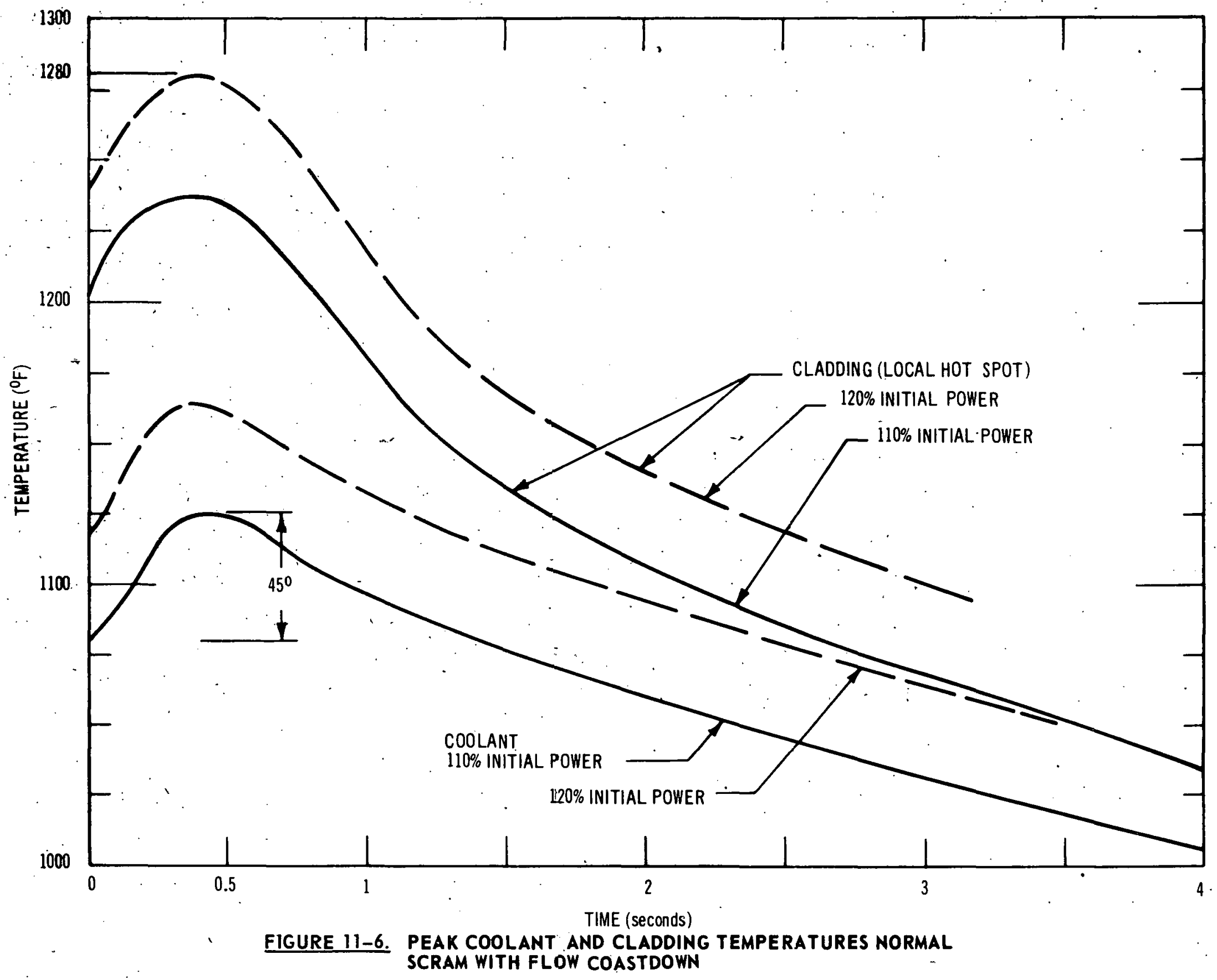




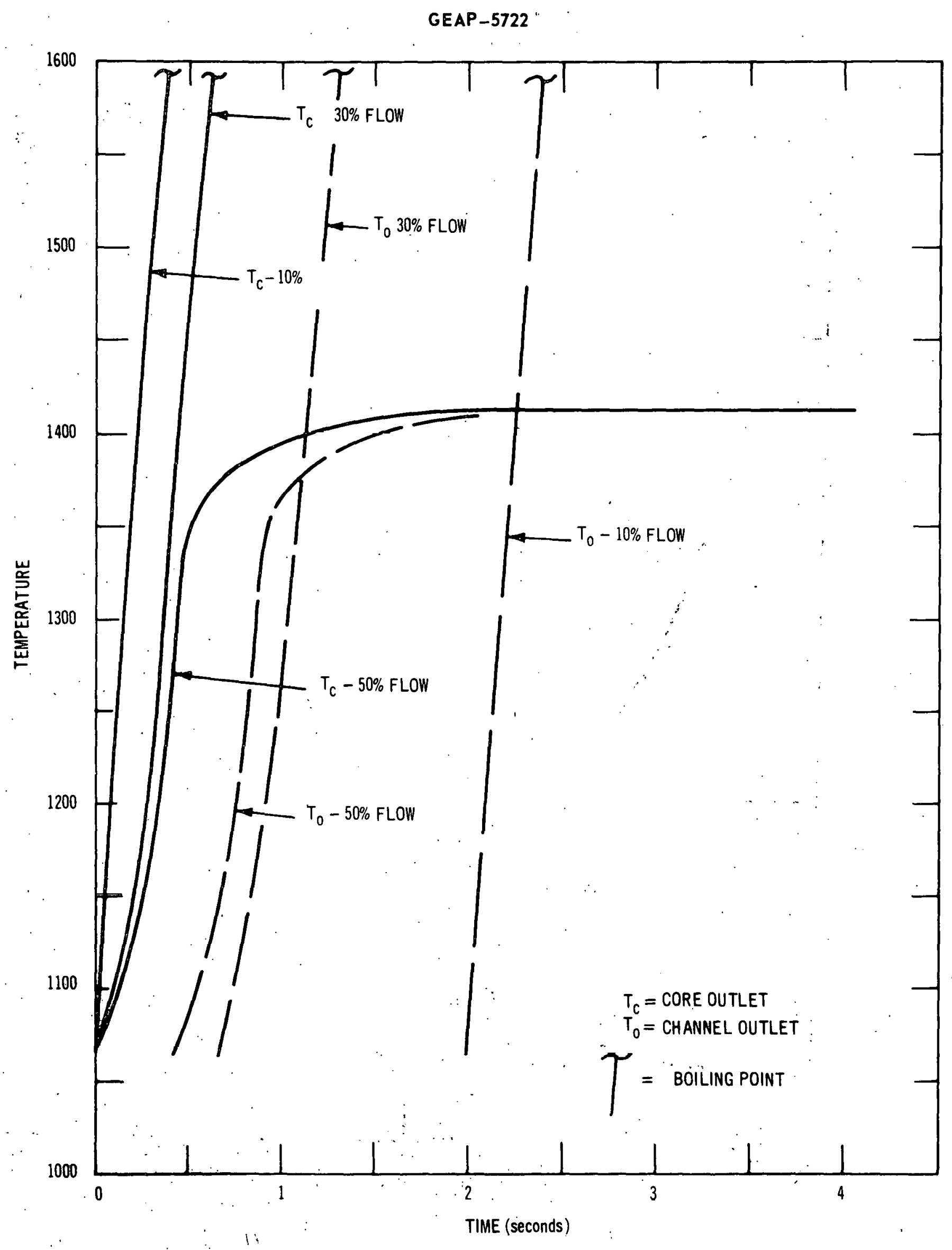

FIGURE 11-7. COOLANT TEMPERATURE RESPONSE TO BLOCKAGE 


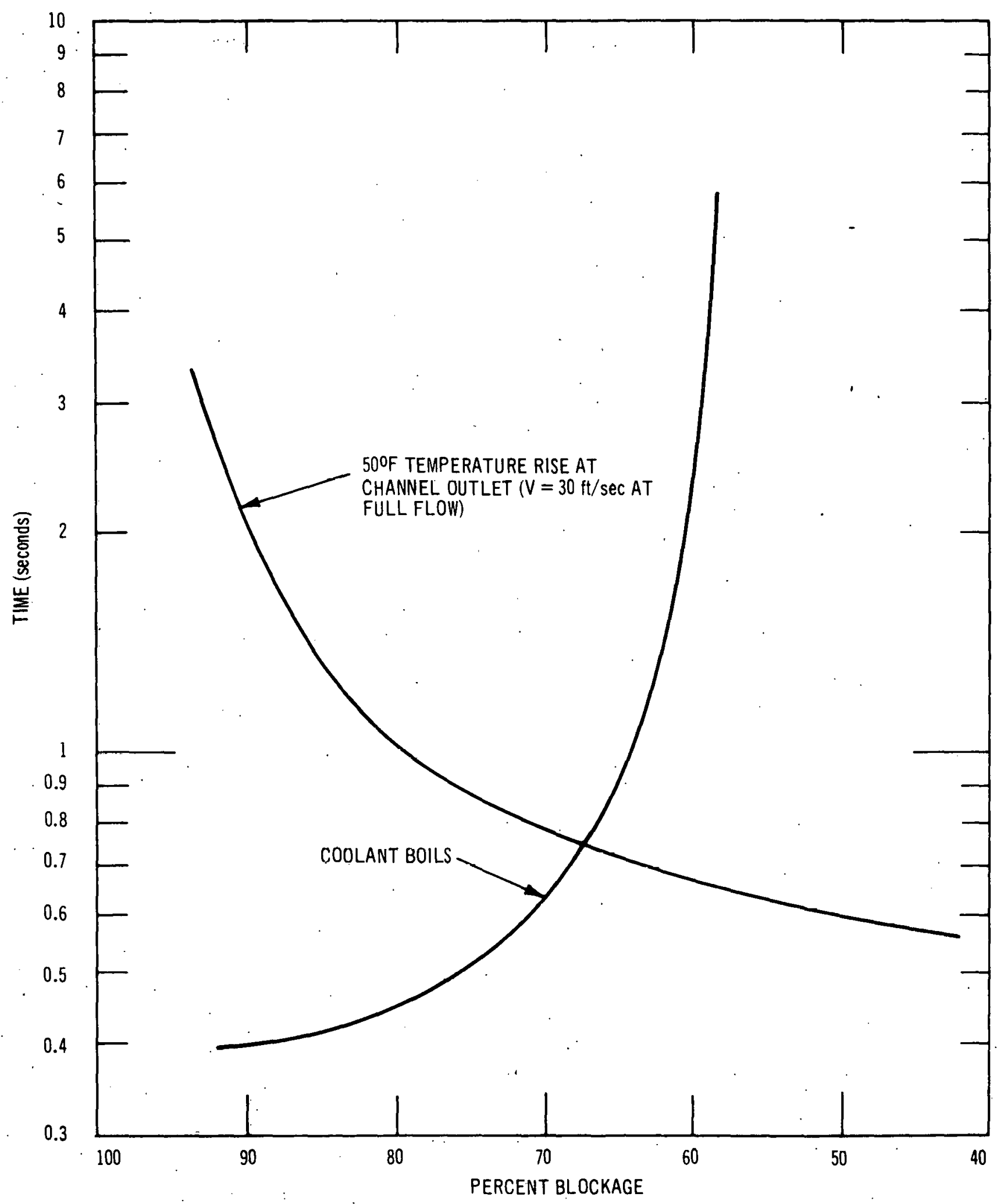

FIGURE 11-8. TIME TO REACH BOILING IN HOT CHANNEL AS FUNCTION OF BLOCKAGE 


\subsection{DESIGN BAASIS ACCIDENT *}

\section{$\therefore$}

The reactor system will be designed to limit and control the consequences of low - i probability nuclear excursions which may result from multiple independent failures: in:the system.

A set of design conditions referred to as the design basis accident (DBA) will be established and the design consequence of these will be that radiological release limits specified in. $10 \mathrm{CFR} 100$ will not be exceeded. These design conditions will identify the dynamic and static mechanical loadings and temperatures to be applied through the system.

Analytical studies will be made of various conditions which result in fuel melting and compaction. Using conservative as sumptions with regard to rate of change of reactivity, volume of sodium in that core, fuel slumping mechanism, power and flow conditions, and Doppler reactivity feedback coefficient, the mechanical êney release associated with uncontrolled fuel melting accidents will be determined. The analytical procedure uses the FORE II digital computer code (to establish initial conditions on fuel slumping) and a modified Bethe-Tait analysis ${ }^{(16)}$ which has also been programmed on the digital computer.

The sequence of events that are postulated for the DBA àre the following:

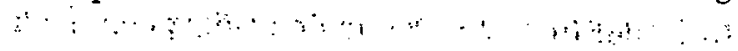

- Complete flow blockage results in coolant boiling, and the scram system does not

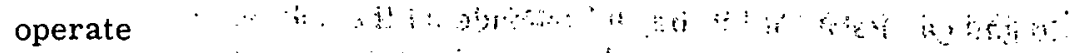

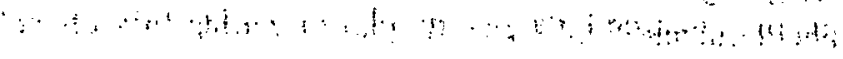

- . The positive reactivity effect because of preferential sodium voiding results in a power transient, and fuel melting occurs.

- The fuel melting results in core slumping and compaction.

- The reactivity insertion due to the fuèl cơmpaction cásés á power pulse which produces high internal pressure because of partial fuel vaporization, and an explosive

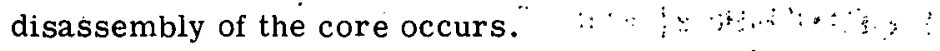

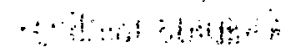

Studies are being conducted to establish an upper bound on the energy release. The magnitude of the release is dependent upon the initial conditions at the time that the core begins to compact. The variables affecting energy release include" coré power 'ávérage' and peak fuel temperatures, amount of sodium voiding, rate and radial distribution of compaction, and the magnitude of the Doppler coefficient. The core design is sufficiently well known so that various sets of initial conditions resulting from the sodium blockage initiating mechanism can be determiried using the FÖR computer code.

The mechanical loads of the DBA, i.e., shock wave loading and the following blast pressure, have been assumed to date as equivalent to 750 -pound (1500 $\mathrm{MW}-\mathrm{sec})$ TiN explosion, in which the energy partition between the shock wave and compressed explosion products is approximately 50/50. No moderation of the resulting blast pressure due to cooling by the hinks in the reactor vessel has been included. The TNT-equivalent rationale is the basis used for establishing a design concept. Further studies and analysis are required on potential energy transfer mechanism of the vaporized and liquid fuel, during and following a nuclear excursion, to establish design pressure and temperature levels in the reactor, reactor cavity and equipment cells, refueling cell, and containment shell. 
The estimated value of $1500 \mathrm{MW}-\mathrm{sec}$ for the DBA explosive energy release is based upon a series of conservative approximations to a very complex problem. These approximations, and results of previous calculations for the SEFOR plant and the 1000 MWe conceptual studies conducted by GE, indicate that the $1500 \mathrm{MW}-\mathrm{sec}$ value represents a conservative upper bound on the explosive energy release. Detailed studies on the FFTF configuration are being performed, but sufficient cases have not been completed to determine the degree of conservatism in the $1500 \mathrm{MW}-\mathrm{sec}$ value.

A review of explosion test data and a discussion of the explosive loadings and containment design requirements was made. To summarize, the main features recommended are:

a. The reactor vessel wall be of minimum practical thickness.

b. Blast cylinders should surround the vessel wall with a gap between the vessel and the cylinders to permit volume to be created by vessel deformation. This minimizes the water-hammer effects on the head from vapor bubble expansion and reduces the equilibrium pressure in the vessel.

c. Internal structure should be designed such that its radial rigidity is minimized, again to moderate water-hammer loadings on the head.

d. No gas gap between the impact surface on the bottom of the head. Variations in level accommodated by a porous plate forming this impact surface.

e. The head is held down by bolts tying directly into the foundation structure.

f. The holddown bolts are sized such that they do not fail under:

1. The dynamic loadings of the "explosion"

2. The quasi-static equilibrium pressure in the vessel following the initial dynamic loading.

g. Crush structure by provided beneath the vessel to absorb down-acting dynamics loads which would most probably fail the bottom of the vessel.

h. Last ditch core cooling be provided by a meltdown pan below the crush pan.

Appendix $H$ discusses the quantitative implications on the DBA on the vessel, head, and containment.

\subsection{SUBCRITICALITY ANALYSIS - SAFEGUARDS}

\subsubsection{Introduction}

The purpose of this study was to evaluate the feasibility of using neutron noise analysis techniques to measure subcritical reactivity in the FFTF backup design. Accurate knowledge of 
the system reactivity is desirable during shutdown and refueling procedures. Traditional reactivity measuring techniques are restricted in the desired application by accuracy limits, perturbations that must be applied to the system, or the length of time required to acquire sufficient data. Sheff has summarized the arguments for a continuous indication of shutdown reactivity. ${ }^{(17)}$ Neutron noise analysis techniques offer the possibility of nearly continuous reactivity measurement in far subcritical systems with no perturbation to the system. A "noise" system is not a prerequisite for FFT F licensing, normal procedural controls being considered ;totally adequate to eliminate consideration of a refueling accident. However, the successful development of this technique would be a valuable backup to procedural controls.

This section summarizes the preliminary evaluation of the feasibility of using noise analysis for the FFTF backup design. This section also outlines a simplified theory of the most promising noise analysis technique, indicates the areas that must be studied to evaluate this technique, and quantitatively discusses the application to the FFTF backup design.

\subsubsection{Basic Theory}

The basis idea of reactivity measurement by neutron noise analysis is as follows: the neutrons released in fission events provide a noise source of known frequency distribution (Poisson) that is modified by the reactor transfer function to provide a neutron flux noise spectrum related to the reactivity. state of the system. Spectral analysis of the output signal from conventional neutron detectors provides the basis for measúrement of the reactivity. The derivation (based on Reference 18) of the revelant equations for the most promising method, two-dectector twochannel cross correlation, is outlined below:

The generating function for the detector outputs, $\gamma_{1}$ and $\gamma_{2}$, is defined as

$$
\mathbf{f}\left(\mathrm{U}_{1}, \mathrm{U}_{2}\right) \equiv \int_{0}^{\infty} \int_{0}^{\infty} \mathrm{p}\left(\gamma_{1}, \gamma_{2}\right) \exp \left(\mathrm{U}_{1} \gamma_{1}+\mathrm{U}_{2}, \gamma_{2}\right) \dot{\mathrm{d}} \mathrm{d} \gamma_{1} \mathrm{~d} \gamma_{2}
$$

where $\mathrm{p}\left(\gamma_{1}, \gamma_{2}\right) d \gamma_{1} \mathrm{~d} \gamma_{2}$ is the probability that the signal from detector 1 is within $\mathrm{d} \gamma_{1}$ about the value $\gamma_{1}$ and the signal from detector 2 is within $d \gamma_{2}$ about the value $\gamma_{2}$. Thls genteraling function is useful since the time averaged signals from the detectors and the time averaged product of the signals may be expressed as simple derivatives of the generating function, evaluated at $\mathrm{U}_{1}=\mathrm{U}_{2}=0$ :

$$
\gamma_{1}(\mathrm{t})=\frac{\partial \mathrm{f}\left(\mathrm{U}_{1}, \mathrm{U}_{2}\right)}{\partial \mathrm{U}_{1}}\left|\begin{array}{l}
\mathrm{U}_{1}=0 \\
\mathrm{U}_{2}=0 . \ldots, \ldots . \quad \gamma_{2}(\mathrm{t})=\frac{\partial \mathrm{f}\left(\mathrm{U}_{1}, \mathrm{U}_{2}\right)}{\partial \mathrm{U}_{2}} \mid
\end{array}\right| \begin{aligned}
& \mathrm{U}_{1}=0 \\
& \mathrm{U}_{2}=0
\end{aligned}
$$

and, 


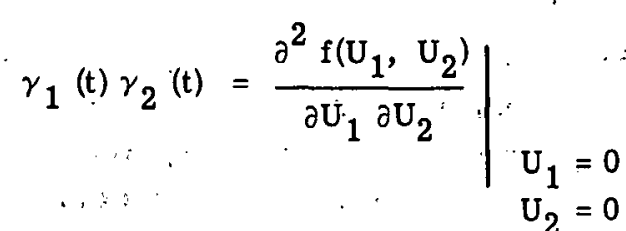

The notation indicates that the derivatives are evaluated at the point $U_{1}=U_{2}=0$. As shown below, the derivatives of the generating function, $f\left(U_{1}, U_{2}\right)$, are directly related to the system reactivity. Thus by measuring the time averaged signals, the reactivity may be measured. The generating function for the distribution of detector signals due to all nuclear events, $f\left(U_{1}, U_{2}\right)$, may be related to the generating function for signals due to the introduction of a single particle, a. ( $\left.t, U_{1}, U_{2}\right)$, to provide the following relations:

$$
\begin{aligned}
& \overline{\gamma_{1}}=\left.\lim _{\mathrm{T} \rightarrow \infty} \mathrm{S}_{0} \int_{0}^{\mathrm{T}} \frac{\partial \mathrm{a}\left(\mathrm{t}, \mathrm{U}_{1}, \dot{U}_{2}\right)}{\partial \mathrm{U}_{1}}\right|_{\mathrm{U}_{1}=0} \mathrm{dt} \\
& \text { - } \mathrm{U}_{2}=0 \text {. } \\
& \frac{a}{\gamma_{1} \gamma_{2}}=\overline{\gamma_{1}} \frac{1}{\gamma_{2}}+\left.\left.2 \mathrm{~F} \alpha_{2} \lim _{\mathrm{T}-\infty} \int_{0}^{\mathrm{T}} \frac{\partial \mathrm{a}\left(\mathrm{t}, \mathrm{U}_{1}, \mathrm{U}_{2}\right)}{\partial \mathrm{U}_{1}}\right|_{\substack{\mathrm{U}_{2}=0 \\
\mathrm{U}_{2}=0}} \frac{\partial \mathrm{a}\left(\mathrm{t}, \mathrm{U}_{1}, \mathrm{U}_{2}\right)}{\partial \mathrm{U}_{2}}\right|_{\substack{\mathrm{U}_{1}=0 \\
\mathrm{U}_{2}=0}} ^{\mathrm{dt}}
\end{aligned}
$$

where

$$
\begin{array}{ll}
\mathrm{S}_{0} & \text { the neutron source rate due spontaneous fission, } \\
\mathrm{F} & =\text { the fission rate, } \\
\alpha_{2}\left(\mathrm{t}, \mathrm{U}_{1}, \mathrm{U}_{2}\right)= & \text { the generating function for signals at time t due to the introduction of } \\
& \text { one particle at time zero. } \\
\alpha_{2} & =\text { is the average number of neutron pairs per fission }
\end{array}
$$

These expressions are simplified by noting that

$$
\frac{\partial \mathrm{a}\left(\mathrm{t}, \mathrm{U}_{1}, \mathrm{U}_{2}\right)}{\partial \mathrm{U}_{1}} \mid \begin{aligned}
& \\
& \mathrm{U}_{1}=0 \\
& \mathrm{U}_{2}=0
\end{aligned}
$$

is the expected signal from detector 1 at time $t$ due to a unit neutron source at time zero. Accordingly, 


$$
\left.\frac{\partial \mathrm{a}\left(\mathrm{t}, \mathrm{U}_{1}, \mathrm{U}_{2}\right)}{\partial \mathrm{U}_{1}}\right|_{\substack{\mathrm{U}_{1}=0 \\ \mathrm{U}_{2}=0}}=\frac{\mathrm{w}_{1} \mathrm{k}}{\ell \nu} \int_{0}^{\mathrm{t}} \mathrm{n}(\mathrm{t}) \mathrm{g}(\mathrm{t}-\tau) \mathrm{d} \tau
$$

where :

$\mathrm{w}=$ the detector efficiency in detections per fission

$\mathbf{k}=$ the syștem multiplication constant

$\ell=$ the prompt neutron lifetime

$\nu=$ the average number of neutrons emitted per fission

$\mathrm{n}(\tau)=$ the neutron population at time $\tau$ due to a unit source at time zero, i: e.; the solution to the point kinetics equation with a delta source at time zero.

$g(t-\tau)=$ the response of the detector and associated electronics at time $t-\tau$ due to a detection event at time $\tau$.

Equations 11-3 and 11-4 are manipulated to obtain more useful forms:

$$
\begin{aligned}
& \overline{\gamma_{1}}=\mathrm{w}_{1} \mathrm{~F} \lim _{\mathrm{T} \rightarrow \infty}^{\mathrm{T}} \int_{0}^{\mathrm{T}} \mathrm{g}_{1}(\mathrm{t}) \mathrm{dt} \\
& \overline{\gamma_{2}}=\mathrm{w}_{2} F \lim _{\mathrm{T} \rightarrow \infty} \int_{0}^{\mathrm{T}} \mathrm{g}_{2}(\mathrm{t}) \mathrm{dt} \\
& \overline{\gamma_{1} \gamma_{2}}=\overline{\gamma_{1}} \overline{\gamma_{2}}+\left(\mathrm{FW}_{1} \mathrm{w}_{2} \frac{\overline{\nu(\nu-1)} \mathrm{k}^{2}}{(\ell \nu)^{2}}\right) \times \\
& \left(\lim _{T \rightarrow \infty} \int_{0}^{T} \int_{0}^{t} n(\tau) g_{1}(t-\tau) d t \int_{0}^{t} n(\tau) g_{2}(t-\tau)(d \tau d t)\right)
\end{aligned}
$$

The Fourier transform forms of these equations are

$$
\begin{gathered}
\overline{\gamma_{1}}=\mathrm{w}_{1} \mathrm{~F} \mathrm{G}_{1}(0) \\
\overline{\gamma_{1}}=\mathrm{w}_{2} \mathrm{~F} \mathrm{G}_{2}(0) \\
\overline{\gamma_{1} \gamma_{2}}=\overline{\gamma_{1}} \overline{\gamma_{2}}+\mathrm{F} \mathrm{\textrm {w } _ { 1 }} \mathrm{w}_{2} \frac{\overline{\nu(\nu-1)} \mathrm{k}^{2}}{(l \nu)^{2} 2 \pi} \int_{0}^{\infty} \mathrm{G}_{1}(\omega) \mathrm{G}_{2}(-\omega)|\mathrm{H}(\omega)|^{2} \mathrm{~d} \omega \\
\ddots
\end{gathered}
$$


where

$$
\begin{aligned}
\dot{G}_{1}(\omega) & =\int_{0}^{\infty} e^{i \omega t} g,(t) d t \\
& =\int_{0}^{\infty} e^{i \omega t} n(t) d t
\end{aligned}
$$

From equation 11-6 we note that spectral analysis of the product signed $\gamma_{1} \gamma_{2}$ combined with knowledge of the transfer function of the detector and associated electronics, $G(\omega)$, will provide a measurement of the square modulus of the reactor transfer function, $H(\omega)$.

In the two detector two channel cross correlation technique the signal from each detector is passed through a wide band amplifier and a tuned bandpass filter with the transfer function B $(\omega)$. The signals are then multiplied and integrated as shown in Figure 11-9.

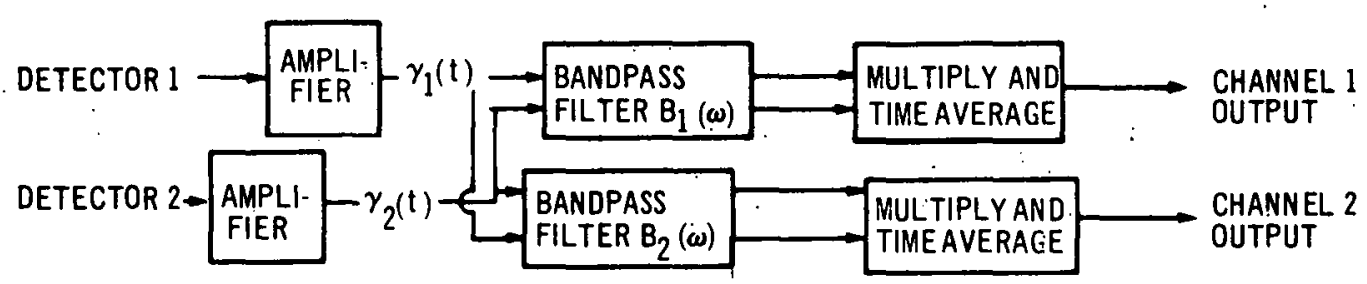

FIGURE 11-9.SCHEMATIC DIAGRAM OF TWO DETECTOR TWO CHANNEL CROSS CORRELATION MEASUREMENT

If the average charge at the amplifier output per detection event is $q$ and the detectors and amplifiers have essentially flat responses in the frequency range of interest then $G_{1}(\omega)=q_{1} B(\omega)$ and $G_{2}(\omega)=q_{2} B(\omega)$. The output signal from this system will be

$$
\begin{aligned}
\mathrm{S}_{1}= & \mathrm{q}_{1} \mathrm{q}_{2} \mathrm{~W}_{1} \mathrm{~W}_{2} \mathrm{~F}^{2} \mathrm{~B}_{1}(0) \mathrm{B}_{2}(0)+\mathrm{q}_{1} \mathrm{q}_{2} \mathrm{~W}_{1} \mathrm{~W}_{2} \mathrm{~F} \frac{\overline{\nu(\nu-1)} \mathrm{k}^{2}}{(\ell \nu)^{2} 2 \pi} \\
& \times\left.\operatorname{Re} \int_{0}^{\infty} \mathrm{B}_{1}\left(\omega^{\prime}\right) \mathrm{B}_{2}\left(\omega^{\prime}\right)\right|_{\left.\mathrm{H}\left(\omega^{\prime}\right)\right|^{2} \mathrm{~d} \omega^{\prime}}
\end{aligned}
$$

The bandpass filters are tuned so that only signals in a narrow frequency range are transmitted, that is

$$
\mathrm{B}_{1}\left(\omega^{\prime}\right) \mathrm{B}_{1}\left(-\omega^{\prime}\right)=0 \text {, if } \omega^{\prime} \text { is not within } \Delta \omega_{1} \text { about } \omega_{1} \text {. }
$$


The band width, $\Delta \omega$, is chosen so that $|\mathrm{H}(\omega)|^{2}$ is essentially constant over $\Delta \omega$ and therefore may be taken outside the integral in equation 11-7. The output signal may now be expressed as

$$
\mathrm{S}_{1}\left(\omega_{1}, \Delta \omega_{1}\right)=\mathrm{q}_{1} \mathrm{q}_{2} \mathrm{~F} \mathrm{w} \mathrm{w}_{1} \mathrm{w}_{2} \frac{\overline{\nu(\nu-1)} \cdot \mathrm{k}^{2}}{(\nu \ell)^{2}}|\mathrm{H}(\omega)|^{2} \Gamma_{1}\left(\omega_{1}, \Delta \omega_{1}\right)
$$

where

$$
\Gamma_{1}\left(\omega_{1}, \Delta \omega_{1}\right)=\operatorname{Re}\left(\frac{1}{2 \pi} \int_{0}^{\infty} \mathrm{B}_{1}\left(\dot{\omega}^{\prime}\right) \mathrm{B}_{2}\left(-\omega^{\prime}\right) \mathrm{d} \omega^{\prime}\right)
$$

To relate the output $S(\omega, \Delta \omega)$ to the system parameters we note that at sufficiently high frequencies, the effect of delayed neutrons may be ignored, and the zero power reactor transfer function is given by

$$
\mathrm{H}(\omega)=\frac{1}{\alpha+\mathrm{i} \omega},|\mathrm{H}(\omega)|^{2}=\frac{1}{\alpha^{2}+\omega^{2}}
$$

where

$$
\alpha=\frac{1-k(1-\beta)}{\ell}
$$

The ratio of the compensated signals from the two channels is thus

$$
\frac{\mathrm{S}_{1}\left(\omega_{1}, \Delta \omega_{1}\right) / \Gamma_{1}\left(\omega_{1}, \Delta \omega_{1}\right)}{\mathrm{S}_{2}\left(\omega_{2}, \Delta \omega_{2}\right) / \Gamma_{2}\left(\omega_{2}, \Delta \omega_{2}\right)}=\frac{\alpha^{2}+\omega_{1}^{2}}{\alpha^{2}+\omega_{1}^{2}}
$$

If the $\omega$ 's are chosen so that $\omega_{1}^{2}>>\alpha^{2}$ and $\omega_{2}^{2}<<\alpha^{2}$, then the ratio of the chantul signals is

$$
\frac{\mathrm{s}_{1}\left(\omega_{1}, \Delta \omega_{1}\right) / \Gamma_{1}\left(\omega_{1}, \Delta \omega_{1}\right)}{s_{2}\left(\omega_{2}, \Delta \omega_{2}\right) / \Gamma_{2}\left(\omega_{2}, \Delta \omega_{2}\right)}=\left[\frac{1-\mathrm{k}(1-\beta)}{\omega_{1} \ell}\right]^{2}
$$

The restrictions on the frequencies $\omega_{1}$ and $\omega_{2}$ are simply that $\omega_{1}$ is well above the break frequency of the reactor transfer function and $\omega_{2}$ is well below this frequency. The break frequency,

$$
\omega_{0}=\frac{\beta}{\ell}\left(1-\frac{\mathrm{k}-1}{\beta}\right),
$$

and the dependence on reactivity of this frequency are shown in Figure 11-10. The following data were used to construct Figure 11-10: $\beta=0.0032 *, \ell=3 \times 10^{-7}$ second. Introducing the definition

* This value was chosen before the work reported in Section III for the 2 zone core was completed, giving $\beta=0.0028$. 


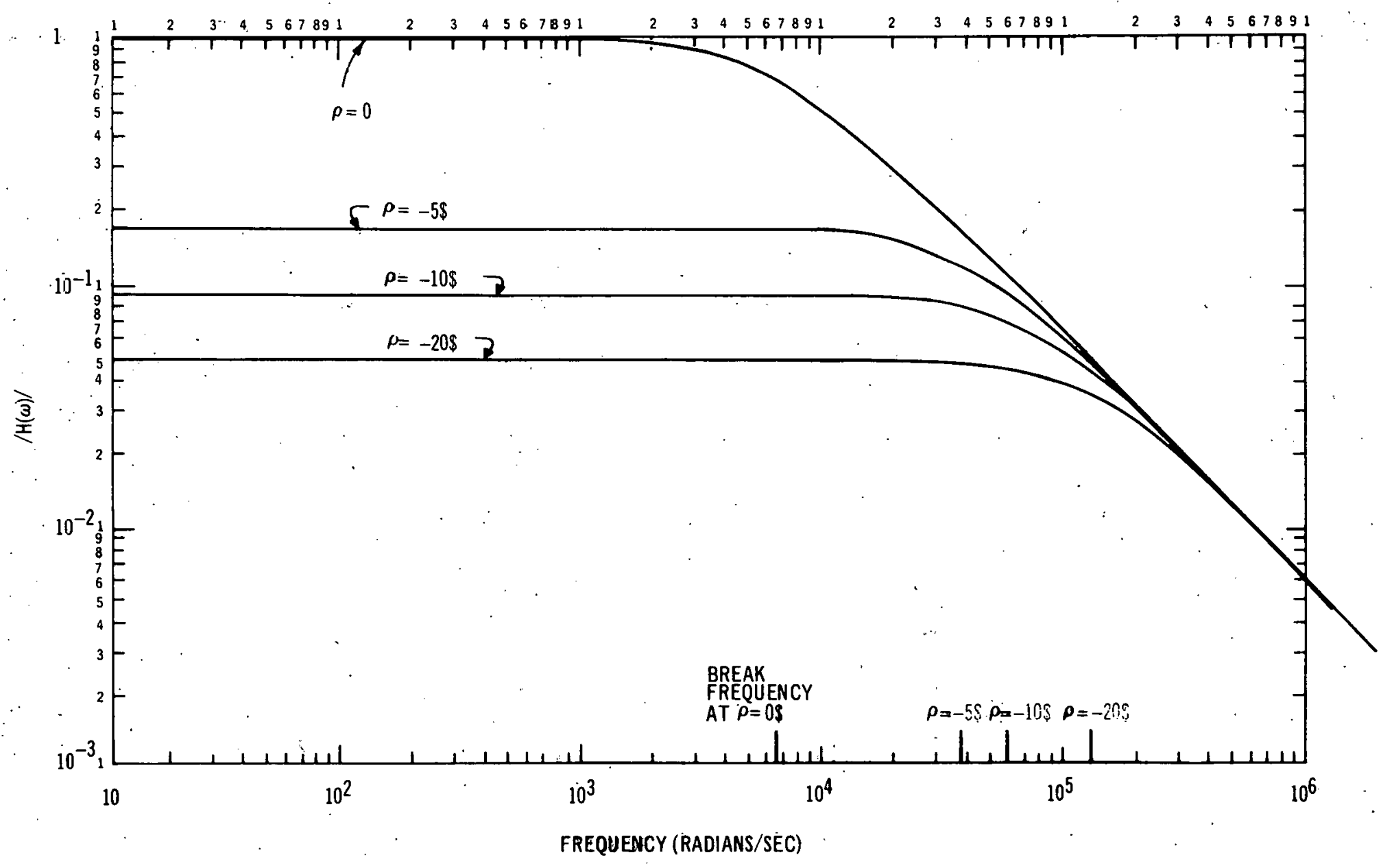

FIGURE 11-10. MODULUS OF ZERO POWER TRANSFER FUNCTION FOR FFTF AS A FUNCTION OF SUBCRITICAL!TY 
of reactivity in dollars $\rho \triangleq \frac{\mathrm{k}-1}{\beta}$ and noting that $\beta \ll 1$, we obtain the desired equation for evaluating the two detector two channel cross correlation technique:*

$$
\text { Reactivity in Dollars }=\rho=\frac{\mathrm{k}-1}{\beta}=1-\frac{\ell \omega_{1}}{\beta}, \sqrt{\frac{\mathrm{S}_{1}\left(\omega_{1}, \Delta \omega_{1}\right) \Gamma_{2}\left(\omega_{2}, \Delta \omega_{2}\right)}{\mathrm{S}_{2}\left(\omega_{2}, \Delta \omega_{2}\right) \Gamma_{1}\left(\omega_{1}, \Delta \omega_{1}\right)}}
$$

Equation 11-12 provides a means for determining reactivity by a simple analog processing of the output of the two frequency channels shown in Figure 11-9.

\subsubsection{Accuracy Limitations of Measured Reactivity}

The error in the measured reactivity obtained using the two detector two channel cross correlation method stems from several sources:

1. Statistical uncertainty due to finite sampling time ..

2. Error in measured constants $\left(\Gamma_{1}, \Gamma_{2}, \frac{\ell}{\beta}\right)$

3. Errors due to approximations made in theoretical derivation such as the use of the point kinetics model

4. Errors due to hardware such as amplifier drift or detector burnout.

The accuracy of this technique does not critically depend on the following data as do other familiar techniques:

1. Accurate knowledge of source strength and distribution

2. Spatial flux distribution

3. Absolute value of detector output

4. Accurate knowledge of material (i.e., control rod) worth far from operating conditions.

Only the accuracy limitations due to the finite sampling time and the stochastic nature of the process have been considered here.

The statistical error in the measured reactivity is dependent on the ratio of the correlated to uncorrelated noise. It has been shown in References 19 and 20 that this ratio is given by the expression,

$$
\mathrm{Q}(\omega)=\frac{\mathrm{W} \overline{\nu(\nu-1)}}{(\nu \beta)^{2} \mathrm{RD}}\left[\frac{1}{(1-\rho)^{2}+\left(\frac{\omega \ell}{\beta}\right)^{2}}\right]
$$

* Reactivity in dollars is usually defined as $\rho^{\prime}=\frac{\mathrm{k}-1}{\mathrm{k} \beta}$, thus $\rho^{\prime}=\frac{\rho}{1+\beta \rho^{\prime}}$, and for a subcritical system, $\left|\rho^{\prime}\right|>|\rho|$. The use of $\rho^{\prime}$ rather than $\rho$ would slightly modify the error analysis in the following sections but would not change the qualitấtive conclusions. 
where:

$$
\begin{aligned}
& \mathrm{R}=\overline{\mathrm{q}^{2}} / \overline{\mathrm{q}}^{2} \\
& \mathrm{D}=1+\frac{\phi_{\gamma}}{\phi \mathrm{n}} \mathrm{Z} \\
& \phi_{\gamma}=\text { gamma flux at detector }\left(\frac{\mathrm{R}}{\mathrm{h}}\right) \\
& \phi_{\mathrm{n}}=\text { neutron flux at detector }\left(\frac{\text { neutron }}{\mathrm{cm}^{2}-\text { sec }}\right) . \\
& \mathrm{Z}=\text { relative gamma effectiveness in detector }\left(\frac{\text { current } / \mathrm{R} / \mathrm{h}}{\text { current/neutron } / \mathrm{cm}^{2}-\mathrm{sec}}\right)
\end{aligned}
$$

The factor $R$ in Equation 11-13 accounts for the signal fluctuations due to randomness in the detection process. The factor $\mathrm{D}$ accounts for the uncorrelated noise due to gamma ray interaction with the detector. The relative standard deviation in the cross spectral density, assuming independent errors, ${ }^{(19)}$ is

$$
{ }^{\epsilon} \mathrm{CSD}^{(\omega, \Delta \omega)}=\frac{{ }^{\sigma} \mathrm{CSD}(\omega, \Delta \omega)}{\mathrm{S}(\omega, \Delta \omega)} \simeq\left\{\frac{1.5+2[\mathrm{Q}(\omega)]^{-1}+[\mathrm{Q}(\omega)]^{-2}}{\frac{\Delta \omega}{2} \mathrm{~T}}\right\}^{1 / 2}
$$

where $T$ is the measuring time in seconds. The relative standard deviation of the reactivity is found from Equation 11-12, again assuming Gaussian error propagation,

$$
\frac{\sigma \rho}{\rho}=\frac{1-\rho}{2|\rho|}\left[\epsilon \operatorname{CSD}^{2}\left(\omega_{1}\right)+\epsilon \operatorname{CSD}^{2}\left(\omega_{2}\right)\right]^{1 / 2}
$$

where $\omega_{1}$ and $\omega_{2}$ are the center frequencies of the two bandpass filters shown in Figure 11-9.

Equations 11-14 and 11-15 have been used to determine the achievable reactivity measurement accuracy under reasonable conditions in the FFTF backup design and to investigate the dependence of the accuracy limitation on the measurement system parameters.

\subsubsection{Analysis of Statistical Uncertainty in Measured Reactivity for FFTF Backup Design, No Gamma Background}

A simple FFT F backup design schematic core arrangement and nominal dimensions are shown in Figure 11-11. The statistical uncertainty in the measured reactivity was determined for detectors moved along the axial and radial lines shown in Figure 11-11. The following assumptions and data were used in the analysis:

\section{Assumptions}

1. The two detectors are identical and are placed next to each other so that the efficiencies are assumed to be equal. 


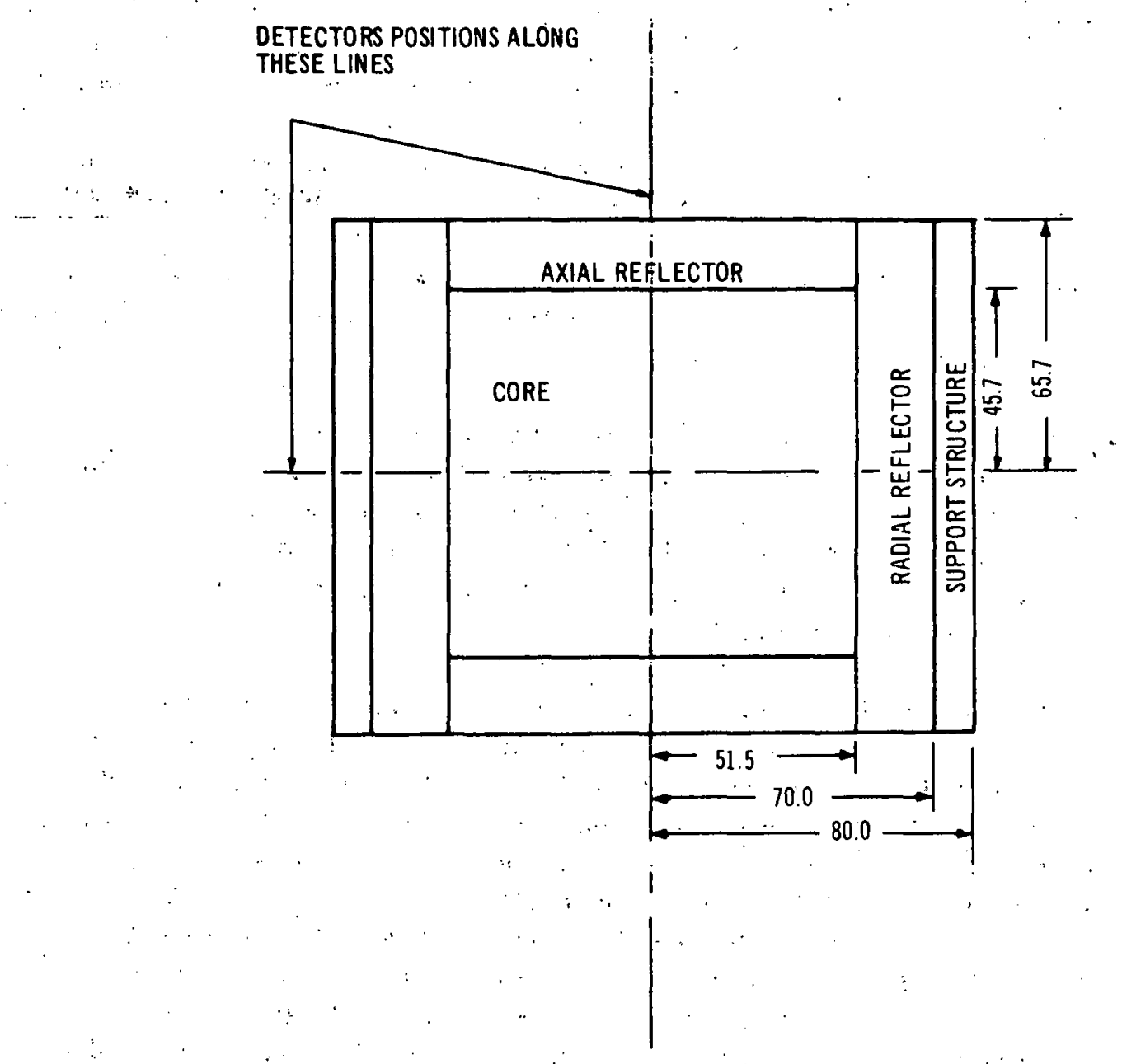

FIGURE 11-11: FFTF BACKUP DESIGN CORE AND REFLECTOR ARRANGEMENT $(\mathrm{cm})$

2. E'ach detector contains 1 gram of $\mathrm{B}^{10}$

3. The gamma ray interaction with the detectors is negligible, i.e., $D=1.0$. (The effect of gamma ray interaction is shown later in Figure 11-16.

4. Measuring time $=30$ minutes

$\overline{\frac{i(\nu-1)}{\nu^{2}}}=0.815$

$\mathrm{R} \quad=1.20$

$\beta \quad=0.0032$ (This value was chosen before the work reported in Section III for

८. $\quad=3 \times 10^{-7} \mathrm{ser}$

$\omega_{1}=3 \omega_{0}$. where $\omega_{0}(\rho)=\frac{\beta}{\ell}:(1-\rho)$

$\omega_{2}=1 / 3 \omega_{0}$

$\Delta \omega_{1} / \omega_{1}=\Delta \omega_{2} / \omega_{2}=0.5$. 
The detectors assumed for this analysis could be multiple plate Boron coated detectors $\sim 1$ inch in diameter and $\sim 18$ inches long. The type of detectors recommended for actual use will depend on the particular size and environment limitations and sensitivity to gamma flux that would be determined during a development program. A development program would also consider the use of pulse mode detectors and multiple detectors to determine the type of detection system that best meets the overall requirements in the specified environment.

The selection of channel frequencies and filter band widths indicated above does not represent an optimum choice but rather a reasonable estimate that will be modified as an optimum strategy for use of this technique is developed.

The detector efficiency was determined using the assumed detector composition $(1 \mathrm{gm}$ of $\mathrm{B}^{10}$ in each detector) and the flux and fission distributions from the FFT F backup nuclear design and shielding analyses. The average detector efficiency as a function of radial and axial position is shown in Figures 11-12 and 11-13. Since $B^{10}$ is a $\frac{1}{V}$ absorber the detector efficiency curves

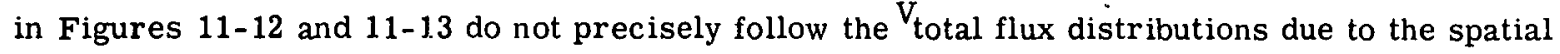
variation in neutron energy spectrum.

The statistical uncertainty in the measured reactivity obtained by using the data and assumptions stated above is shown in Figures 11-14 and 11-15 to be a function of detector location and reactivity. The uncertainties shown correspond to $2 \sigma$ variations which represents a $95 \%$ confidence level. A measuring time of 30 minutes has been used in these calculations. This measuring time was chosen as a nominal estimate of the minimum time available to measure reactivity while a fuel bundle is being removed from the core area to storage and a new fuel bundle is being transferred to the core area. The system reactivity during refueling will be between $15 \$$ and $25 \$$, assuming most control rods are inserted, and the worth of a bundle will be less than $4 \$$ as reported in Section III. Thus, the information in Figures 11-14 and 11-15 indicates, with respect to the statistical limitations of the method, subcriticality may be adequately (i.e., within much less than a fuel bundle worth) demonstrated during refueling with detectors located in the core, in radial reflector and support area, or in axial reflector and gas space. The actual uncertainty requirements will be determined by the strategy used and the additional information required in addition to the assurance of adequate subcriticality during refueling. This requirement when combined with the equipment uncertainty and the statistical uncertainty will define further limitations of the areas acceptable for detector location.

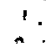

11.5.5 Effect of Gamma Interference on Accuracy

The calculations described in Section 11.5.4 assumed that the detection system is essentially insensitive to the gamma flux due to the detector design, compensating chambers, or shielding of the detector (e.g. many inches of lead). The results are therefore representative of the best results that could be achieved with this approach. From practical considerations such a perfect system has not been developed. In actual practice the gamma flux interference will degrade the statistical accuracy of the reactivity measurement. This occurs, because in a substantially subcritical reactor, the gamma flux near the core results from fission product decay and is completely uncorrelated with the neutron flux. Accordingly, the gamma flux contributes an uncorrelated noise signal to the detector output. The effect of this additional uncorrelated signal is shown in Figure 11-16. The gamma and neutron fluxes at about 10 hours after shutdown have been estimated from operating condition calculations. The increase in uncertainty becomes more 
GEAP -5722

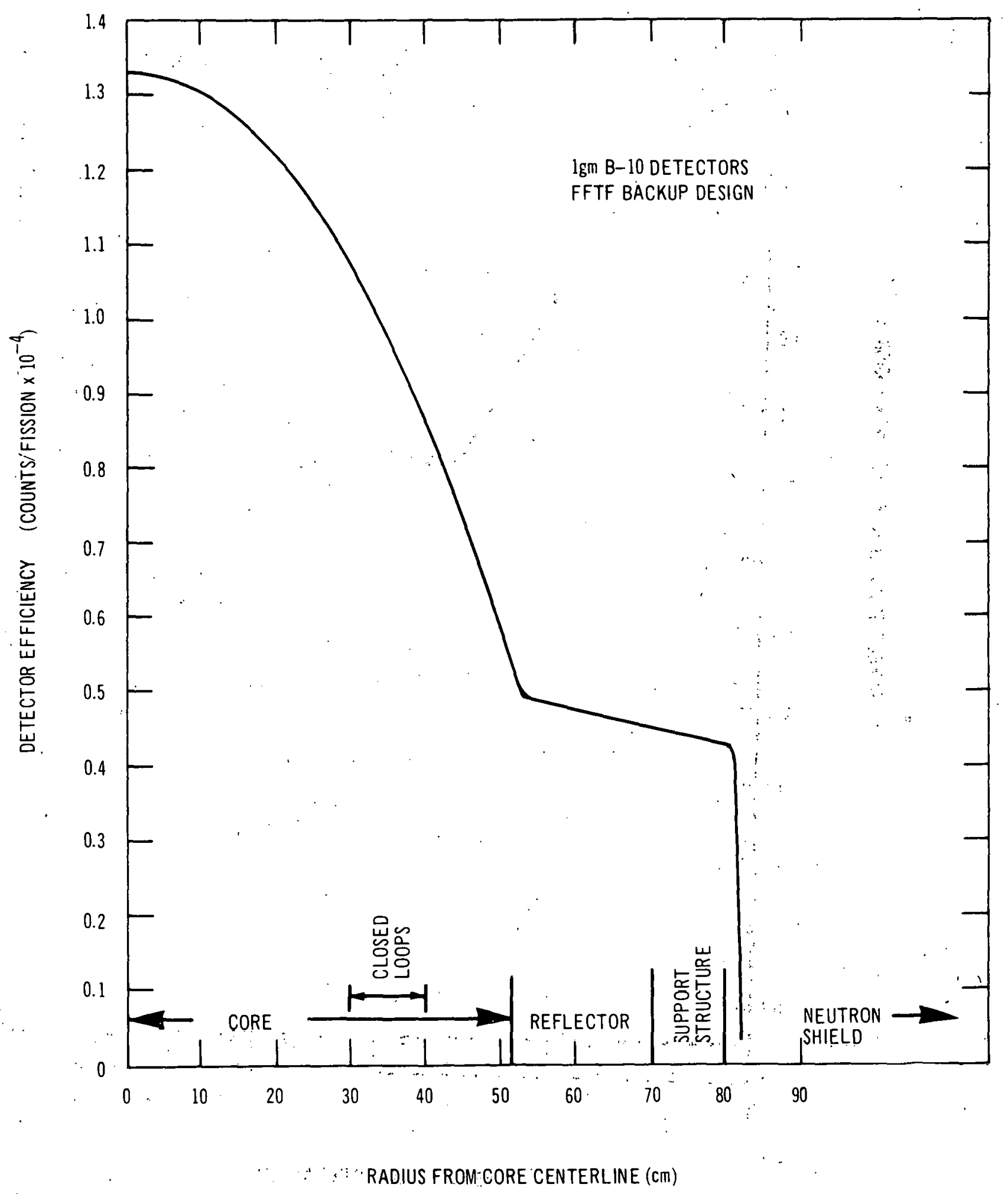

FIGURE 11-12. DETECTOR EFFICIENCY VS RADIAL DISTANCE 
GEAP-5722

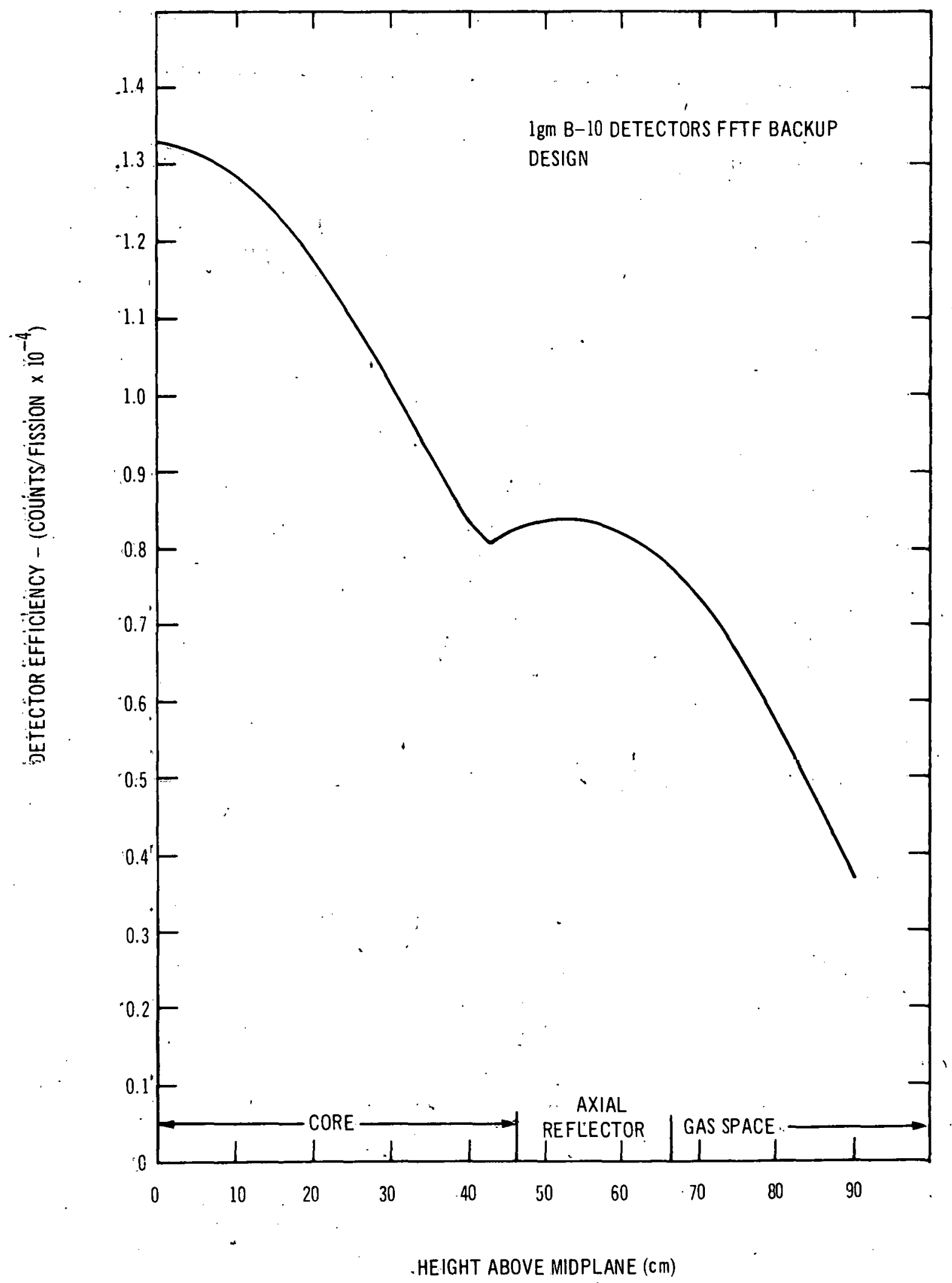

FIGURE 11-13. DETECTOR EFFICIENCY vS. HEIGHT 


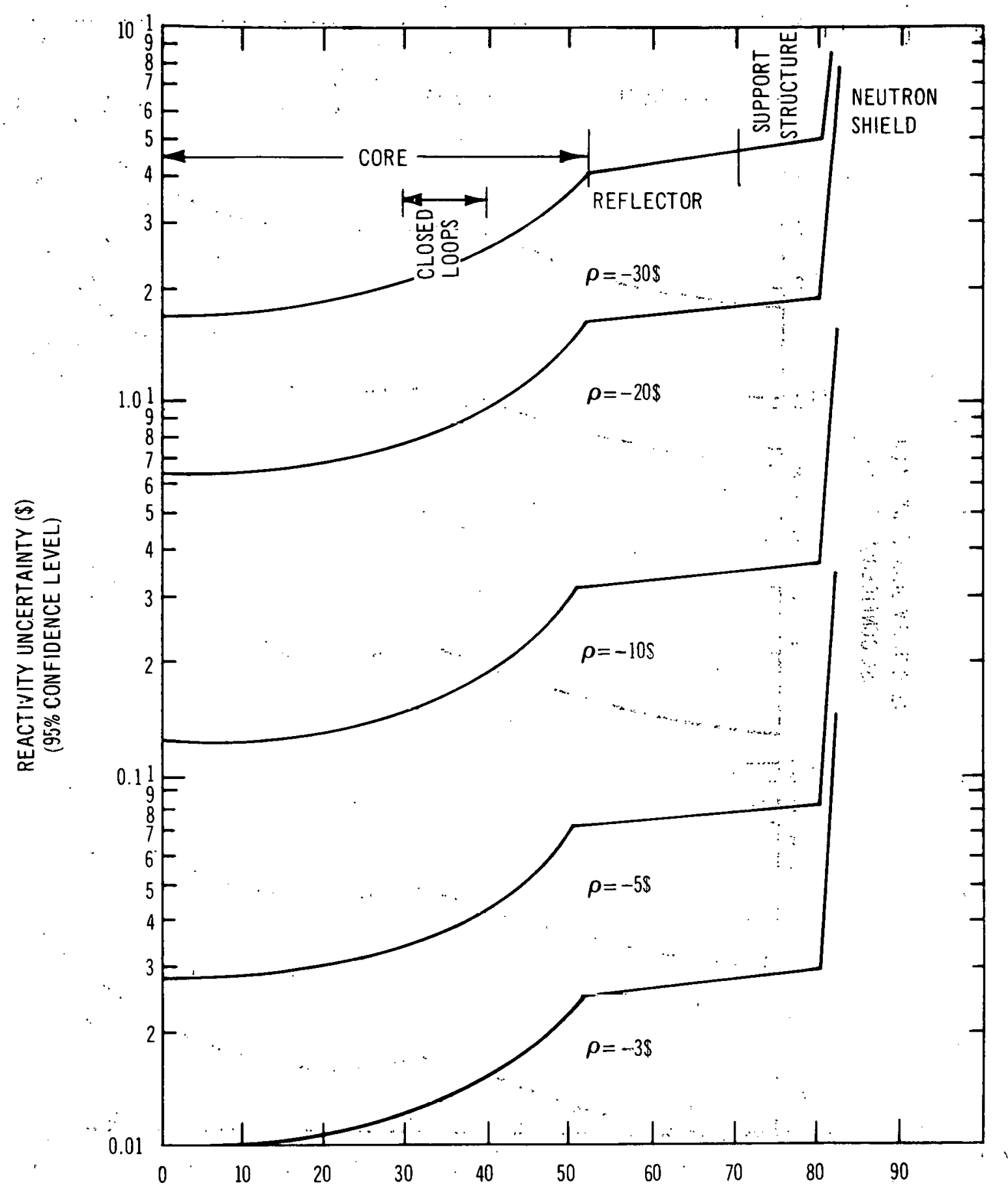

RADIUS FROM CORE CENTERLINE (cm) 


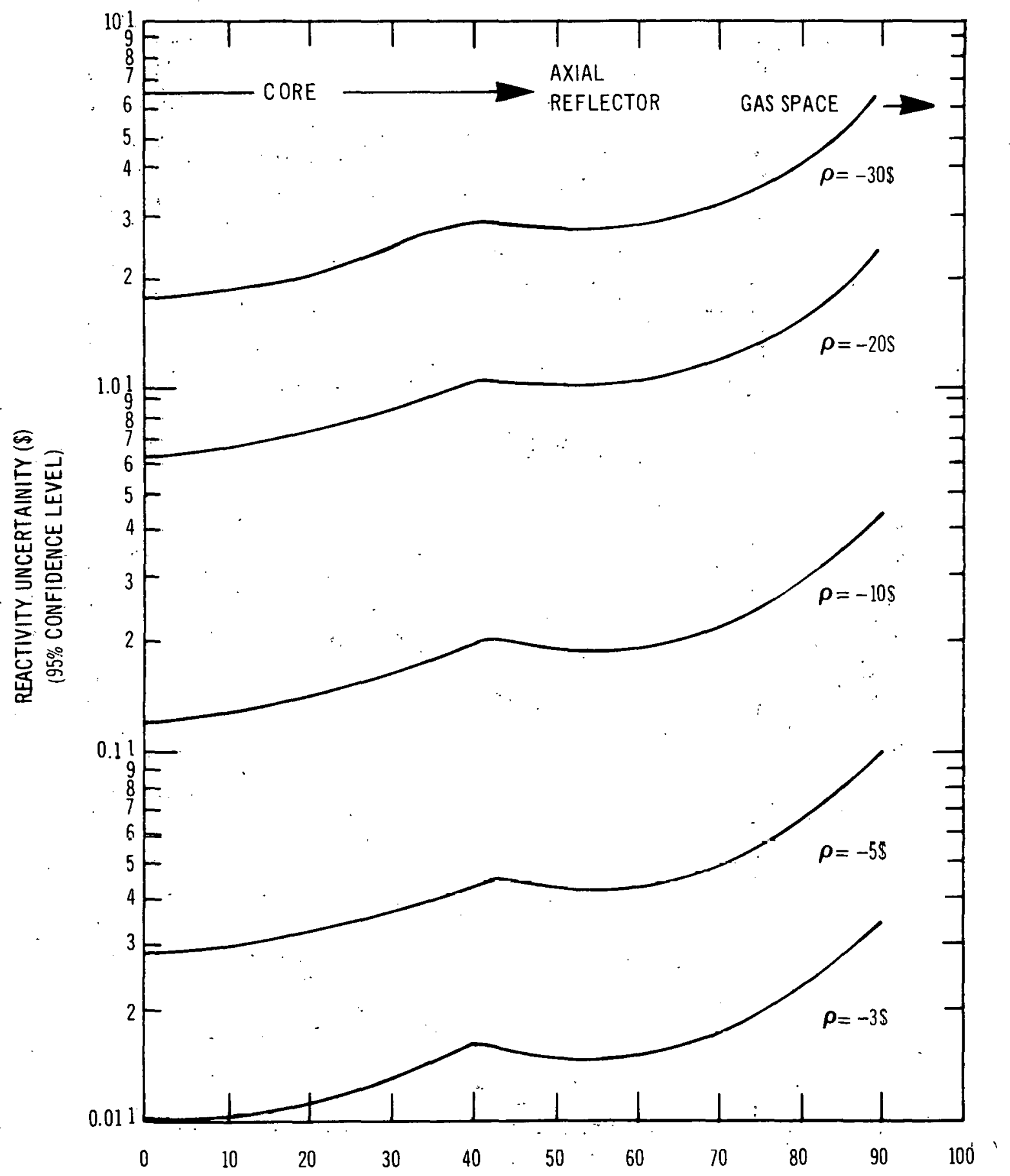

HEIGHT ABOVE CORE MIDPLANE (cm) 
pronounced as the system becomes more subcritical since the neutron flux is approximately inversely proportional to reactivity. For this example it has been assumed that the two detectors, each containing one gram of $\mathrm{B}^{10}$, are located at the radial reflector-support structure boundary $(\mathrm{r} \approx 70 \mathrm{~cm})$. The detectors (and required associated shielding) may be enclosed in a stainless steel capsule to prevent reactions with the sodium. This capsule could be inserted into a vacant channel of the outer row of reflector bundles at the start of refueling operations. The gamma flux from the core at the detector location is approximately $5 \times 10^{5} \mathrm{R} / \mathrm{h}$ with no detector shielding. The gamma flux from the radioactive sodium (assuming 50 volume percent of the reflector and radial core shielding region is sodium) is approximately $1.25 \times 10^{5} \mathrm{R} / \mathrm{h}$. With no detector shielding the total gamma flux at the detector is $6.5 \times 10^{5} \mathrm{R} / \mathrm{h}$. Each inch of lead shielding around the detector reduces the gamma flux by a factor of ten. Thus, the gamma flux at the detector is approximately $6.25 \times 10^{5} \mathrm{R} / \mathrm{h}$ with no shielding, $6.25 \times 10^{4} \mathrm{R} / \mathrm{h}$ with one inch of lead, and $6.25 \times 10^{3} \mathrm{R} / \mathrm{h}$ with two inches of lead.

Two types of detectors have been considered, an "optimized" ${ }^{(20)}$ detector with a relative gamma effectiveness in the detector, $\mathrm{Z} \approx 2 \frac{\text { neutron } / \mathrm{cm}^{2}-\mathrm{sec}}{\mathrm{h} / \mathrm{h}}$ (see Equation $6-13$ ) and a "conventional" detector with the same gamma to neutron sensitivity, $Z \approx 20$, as the Reuter Stokes RSN-5-S Boron Triflouride detector. For each detector, a shielded and an unshielded condition have been calculated. The shielded condition uses the equivalent of one inch of solid lead shielding around each detector. Note that two inches of lead shielding on the conventional detector is equivalent to the optimized detector with one.inch of lead. The detector design would consider the ambient sodium temperature during refueling, $400 \rightarrow 500^{\circ} \mathrm{F}$, the gamma induced heating of lead, the melting point of lead (if lead were used), and the allowable detector temperature $\left(300^{\circ} \mathrm{C}\right)$. Figure 11-16 illustrates that the gamma interference severely affects the measurement uncertainty. In fact it renders the unshielded "conventional" detector useless under the assumed conditions.

The shielded conventional detector and unshielded optimized detector lead to uncertainties much larger than those with no gamma interference. However, these two systems appear to reliably indicate whether or not the system is subcritical by at least the maximum bundle worth. Although these systems do not provide all the possible benefits of noise analysis, they do perform the basic safeguards function, namely to assure sufficient subcriticality during refueling.

The shielded optimized detector provides more information but is still considerably less certain than a gamma insensitive system. 


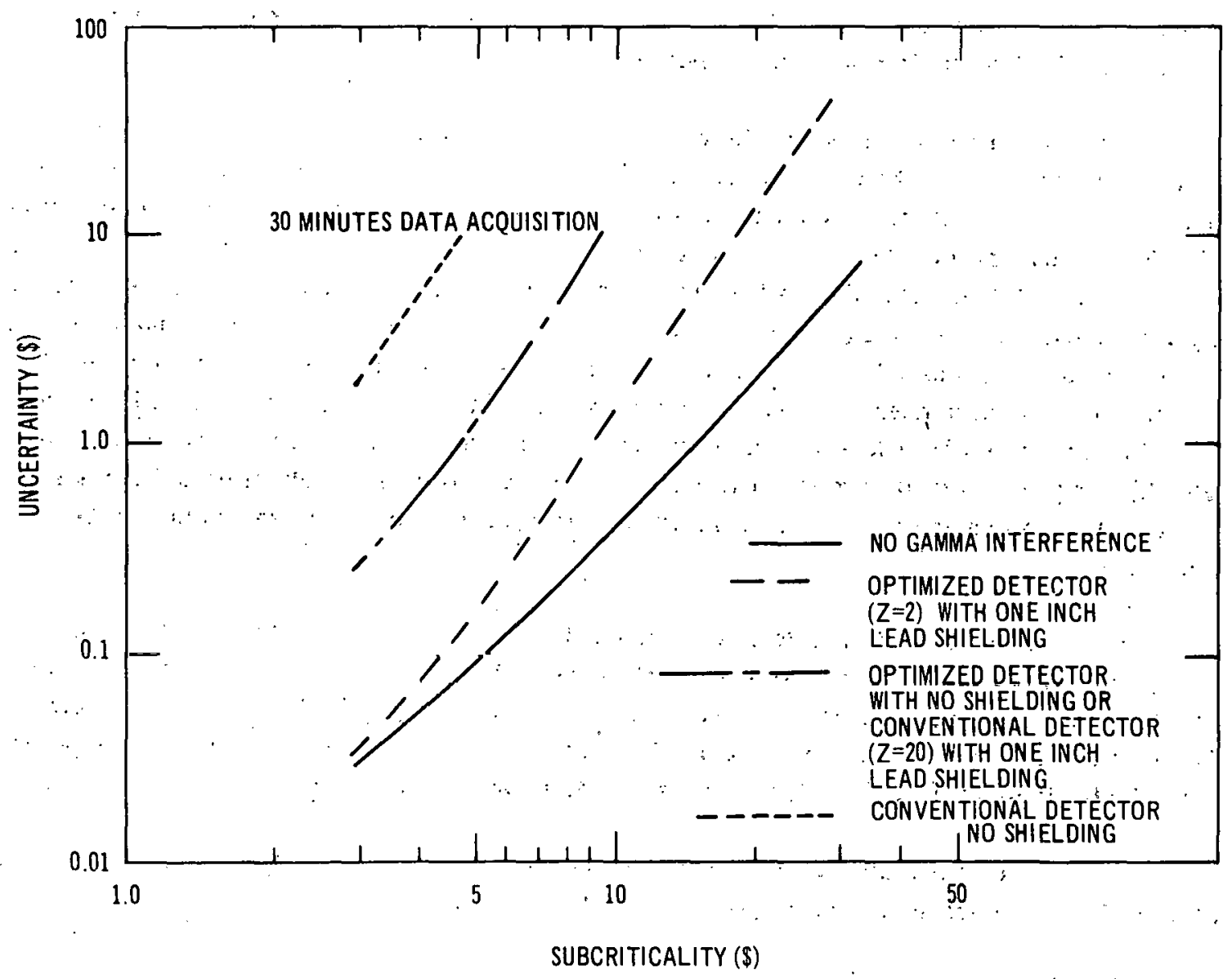

FIGURE 11-16. REACTIVITY UNCERTAINTY VERSUS REACTIVITY FOR SEVERAL DETECTORS (DETECTORS WITH $1 \mathrm{gm}$ B 10 AT RADIAL REFLECTOR-SUPPORT STRUCTURE BOUNDARY) 


\section{SECTION XII}

\section{REFUELING CELL AND FUEL HANDLING}

\subsection{GENERAL PHILOSOPHY}

The design of the refueling cell and fuel handling methods have been based upon an open pool reactor, hot cell concept, similar to that used in the SEFOR reactor. The refueling method may be described as visual, remote-manual since refueling operations are performed remotely by operators having visual contact with the upper end of the reactor vessel and internals. Emphasis has been placed on the use of a number of easily maintainable, general purpose hoists capable of handling specialized grapples; rather than the use of one multipurpose machine. All component transfers and servicing which involve exposure of radioactive materials will be carried out remotely while utilizing visual confirmation of events to as great a degree, as possible. Shielding applied over the reactor vessel and primary coolant lines makes direct access to the refueling cell possible to service any equipment during reactor operation.

\section{2:2 REFUELING CELL ARRANGEMENT}

\subsubsection{General Description}

The refueling cell illustrated in Figures $12-1$ and $12-2$ is a steel-lined concrete vault directiy over the reactor vessel within the primary containment building. It encloses a rectangular volume approximately 22 feet in width, 72 feet in length, and 78 feet in height, resulting in a total cell volume of approximately $124 ; 000$ cubic feet. The cell is connected to an external peripheral building outside the containment building by the "fuel transfer lock.".

The refueling cell structure has 4-foot thick reinforced wall sections utilizing a natural aggregate of magnetite which, in the "as cured" condition, less re-bar, weighs not less than $230 \mathrm{lb} / \mathrm{ft}^{3}$. This limits radiation exposure levels in the air zone around the cell to less than $2.5 \mathrm{mR} / \mathrm{h}$ during normal refueling operations. It is important that this be maintained at all work deck levels where unrestricted operator access is desired. The proposed design designates standard concrete "as cured" density of $145 \mathrm{lb} / \mathrm{ft}^{3}$ for the cell ceiling slab thickness of 6 feet. The assumption is that a premium in material costs is justified to conserve, space by reducing cell wall thickness with magnetite concrete while a few additional feet in overall height resulting from standard concrete for ceiling slabs will reduce shielding costs.

\subsection{2: Refueling Cell Containmenl Liner .}

The control of out-leakage of cell argon cover gas, sodium vapors, fission products, and other particulates depends upon the integrity of a continuous steel membrane within the cell and upon the leak tightness of any features which penetrate this liner. In-leakage rates will also be important to preserve the high-purity inert gas atmosphere of the cell. That portion which forms the floor pan is $1 / 4$-inch-thick, 300 -series stainless steel and would continue 12 inches up the ccll walls as a splash pan. The balance of the wall and ceiling surfaces are $1 / 4$-inch-thick mild steel to which has been applied an epoxy or modified phenolic white coating. Bare stainless steel is used on wall areas where equipment is stored or where other operations are performed that would leind to chip and ecuff a coated surfare. 
General purpose viewing and manipulating equipment, as well as equipment for specific tasks, is provided within the refueling cell. This equipment is operated remotely from outside the refueling cell and the operation is viewed through dense glass windows and other supplementary viewing aids. All controls and readout devices associated with this equipment are mounted in portable controllers outside the refueling cell. This permits the operators to move from window to window as necessary, thereby facilitating both operation and observation of the activity within the cell.

\subsubsection{Cell Penetrations}

A feature common to all floor, wall, and ceiling penetrations is that they are formed by steel cavity liners cast into the concrete and welded gas tight to the cell liner. Wall and ceiling penetration sleeves are mild steel as is the liner in these areas, while floor penetrations or wells with sealed bottoms are of 300 -series stainless steel consistent with the stainless steel floor pan. Gamma radiation attenuation is provided by either high-density inserts, shield plugs, dense glass, or by indirect " $\mathrm{S}$ "- and " $\mathrm{L}$ "-path piping. All closures are to reflect the design requirements of design basis accident conditions. Those which are to be used frequently will require buffer seals so that individual leak tests by application of either pressure or vacuum can be accomplished following reclosure. Infrequently opened or more permanently sealed penetrations may be leak tested when the total cell structure is periodically elevated in internal pressure and total outleakage rate is monitored.

Electrical service and instrumentation is carried within the cell either in gutter box or in rigid conduit, depending on the necessity to service and, in all cases, is carried through the cell structure within "S"- or "L"-path piping. A final gas-tight seal coupling will be located at the air side of the cell barrier where it can be serviced and monitored for leakage. The removal of seal elements from the in-cell environment will result in a greater selection of acceptable materials.

Pressurized gas service for various in-cell tools and cooling systems will penetrate the cell structure as " $\mathrm{S}$ "- and " $\mathrm{L}$ "- path piping to avoid radiation streaming. This piping, by operational procedure, shall never provide an open path between the cell interior and outside the containment building. Manually operated isolation valves for each such line would be installed immediately outside the refueling cell. All gas service into the refueling cell shall be argon gas to be compatible with the cell atmosphere. All valving and other controls which can reasonably be located in the air zone outside the cell will be panel mounted near the cell to reduce in-cell servicing.

Multipurpose wall ports are included around three of the four cell walls to make possible future installation of through-wall periscopes, manipulators, or other services which may be required. When not in use, these ports house concrete shield plugs and are capped at both ends.

\subsubsection{Man-Access}

Man-access panel is provided along one wall of the refueling cell for access onto the cell floor by two suited persons at a time. The arrangement includes an outer gas tight chamber which serves as a part of the cell containment during suited entry when the reactor is operating. This chamber is entered via a standard oval marine hatch and normally may contain air to support four 


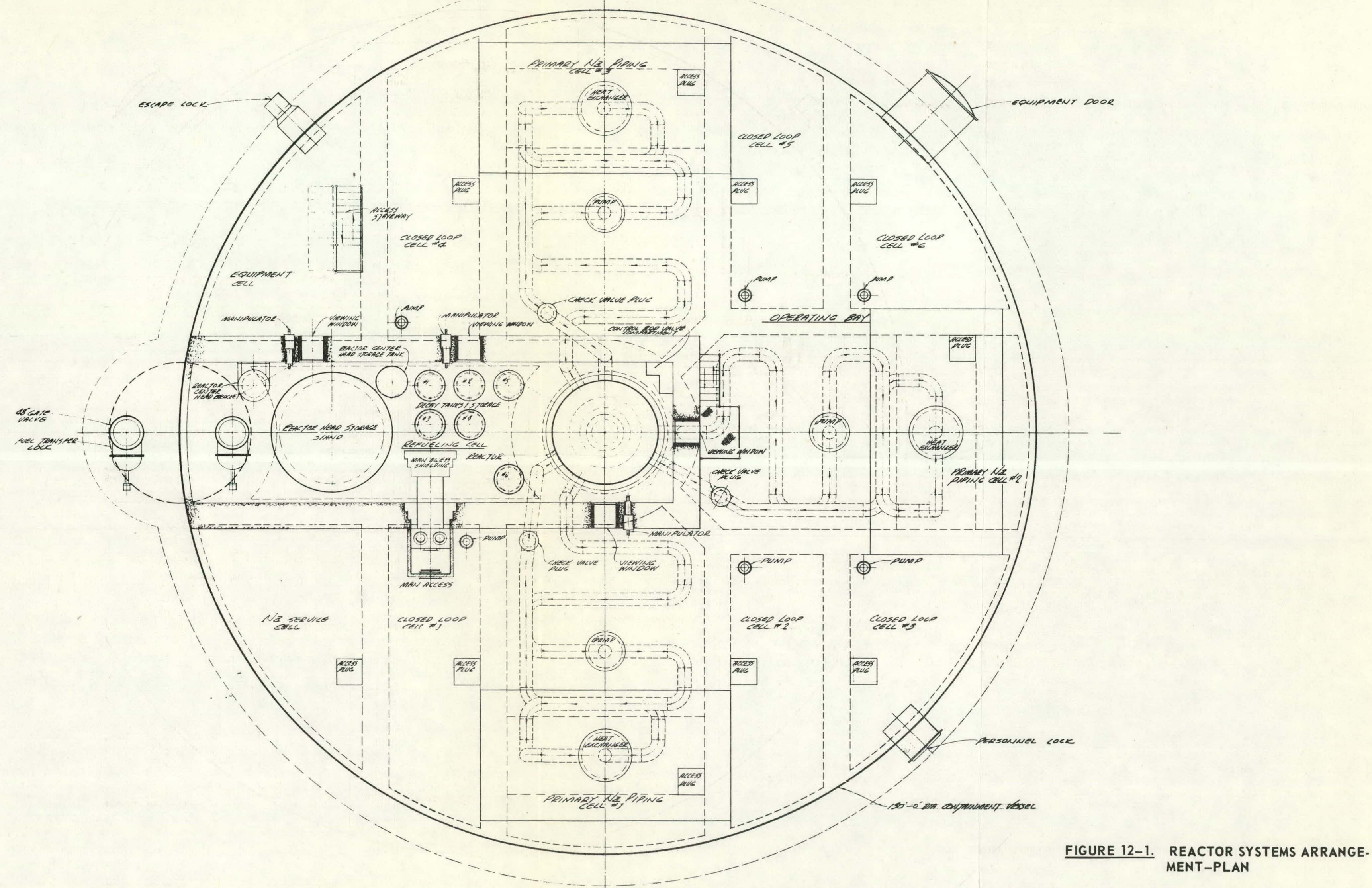




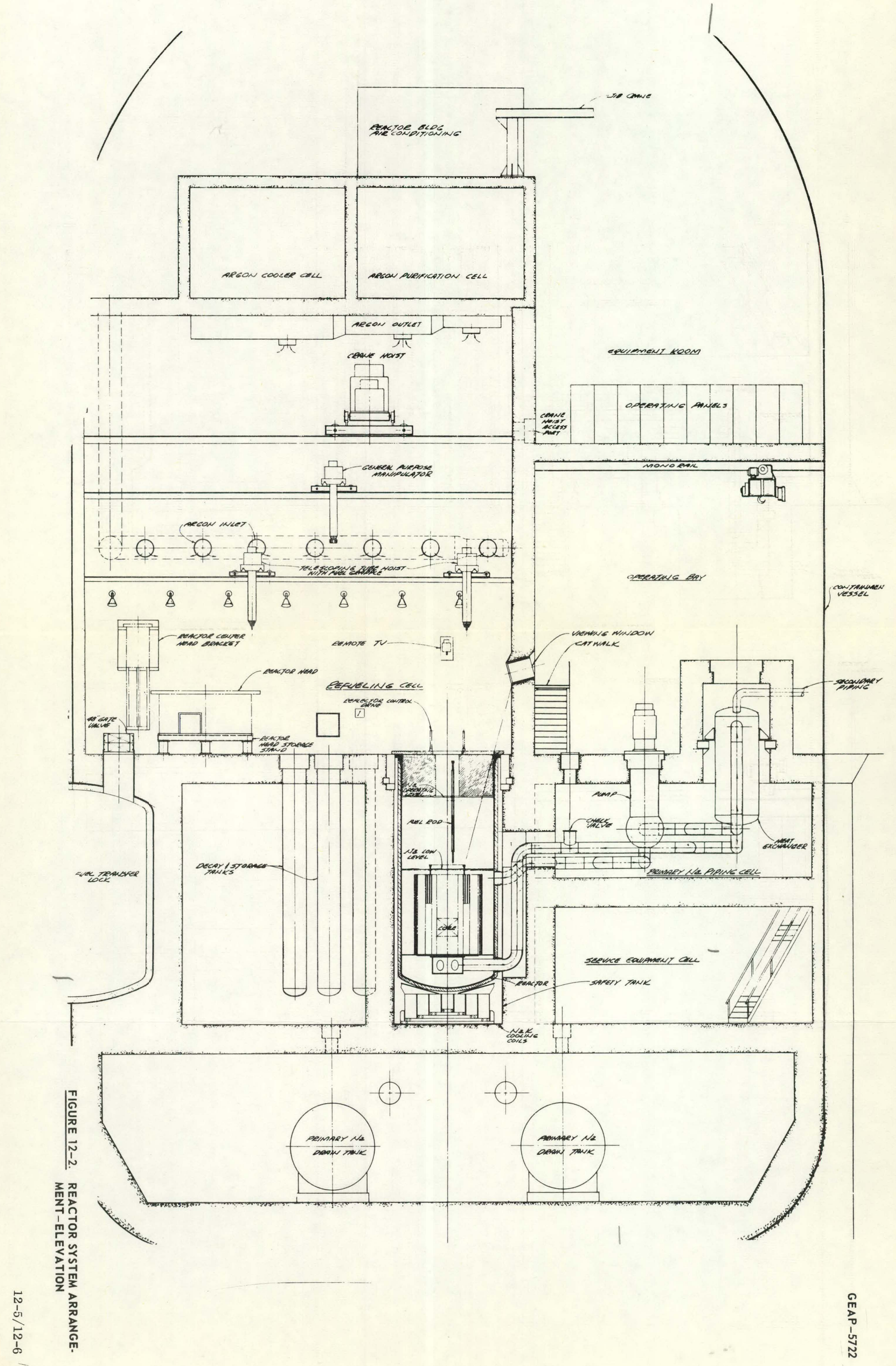


or five operators within. Two gas tight suits are mounted on the cell side of a special panel which contains a double-helmet assembly: This system allows cell entry without loss of cell gas. Breathing and cooling air is provided to and from the suits by supply and exhaust hoses. Voice communication is also provided between the various operators inside and outside the cell.

A quick-entry marine hatch is included to provide emergency ingress and egress.

While the entry suits remain stored within the cell, they are protected from radiation damage by being behind a section of roll-away biological shielding.

Tunnel suit entry provisions exist for less frequent one-man access at other levels to service the bridge manipulators and overhead bridge cranes. These are double closures using an inward-swinging, handwheel-operated seal door and an outer, removable, seal cover. The space between serves to house a plastic tunnel suit. Also, by pressurizing this zone, a local leak test of the penetration may be performed.

\subsubsection{Dense Glass Viewing Windows}

Dense glass windows have been located along three walls to provide direct viewing of all cell areas by operators standing on elevated work decks outside. The occurrence of events within the cell over a wide range of elevations and the desire to provide direct line-of-sight viewing from one window into the reactor results in window locations well above the cell floor. The window design incorporates construction details currently applied to the SEFOR cell windows. Successive slabs of radiation-resistant and high-density lead glass with mineral oil interfaces are housed in a steel tank sealed at both ends and inserted into a stepped steel wall cavity which is welded gas tight to the cell liner. The hot and cold face of the wall cavity liner includes a cover glass seal. Under accident conditions the cold face cover glass is considered to be the final containment barrier should other glass elements become damaged. The windows closest to the reactor head is oriented to optimize viewing into the reactor interior during refueling. Other windows are oriented for general cell viewing.

\subsubsection{Periscopes}

Periscopes located adjacent to refueling, inspection, and maintenance windows provide operators with "close-up" viewing of remotely performed tasks as well as providing scanning capability over the lower regions of the cell. A series of magnifications between $4 \times$ and $30 \times$ are available to the operator.

\subsubsection{Master-Slave Manipulators}

Manipulators are located near viewing windows serving the decay storage tanks and head storage locations to facilitate inspection and maintenance tasks. Multipurpose wall ports provided near other windows allow relocation of these manipulators or the addition of extra equipment, if necessary. 


\subsubsection{Bridge Crane Mounted Telescoping Tube Hoists}

Bridge and trolley mounted tube hoists are provided at $\sim 20$ and $\sim 40$-foot elevations. The lower hoist mounting is used for in-vessel and in-storage tank handling, whereas the higher hoist is used for the vessel-to-tank transfer. Two tandem 2-speed motors for each positioning drive provide 4 speeds in each direction. The hoist rating of approximately 1 ton gives a lift capacity of approximately 10 times the fuel element weight. This provides adequate load indicating sensitivity during normal handling operations as well as surplus lift capability for unforeseen circumstances.

\subsection{FUEL GRAPPLE}

An offset fuel grapple, illustrated on Figure 12-3, is semipermanently attached to the telescoping tube hoist used for in-vessel fuel handling operations. Major design features of this grapple and associated tube hoist include the following:

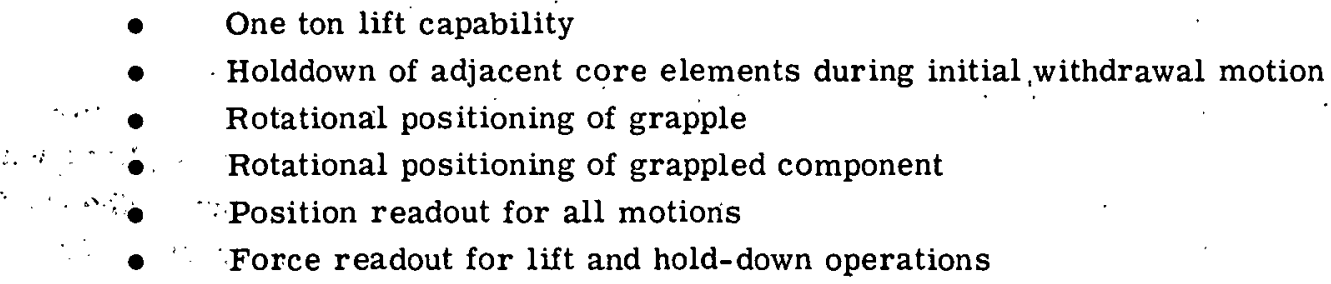

The 1-inch offset provided at the lower end allows manipulation of core elements adjacent to the experimental facility stalks. It does not, however, allow access to core elements positioned under closed loop piping. Refueling these locations will be coordinated with experimental facility changeout since residence time in the reactor is essentially the same for the two components.

The general procedure for a typical fuel handling cycle is itemized below to aid in understanding the grapple features and motions:

a. The grapple (tube hoist mounting) is angularly positioned. This step is particularly important when grappling a fuel element adjacent to an experimental facility. The holddown ring relief (outboard in the offset direction of the grapple head) allows the experiment to be held down while providing clearance for the stalk.

b. The grapple head is angularly positioned to properly orient a key on the grapple head for engagement into a keyway in the handle of the element. The keyways in the core elements (all facing in the same direction) allow positive angular positioning of the element for insertion into the core.

c. The tube hoist lowers the grapple into the element handle. This operation is terminated by load cell signal and confirmed by load and position readout.

d. A gearmotor and ballscrew arrangement drives the locking cam down, forcing the balls out into the locked position. 


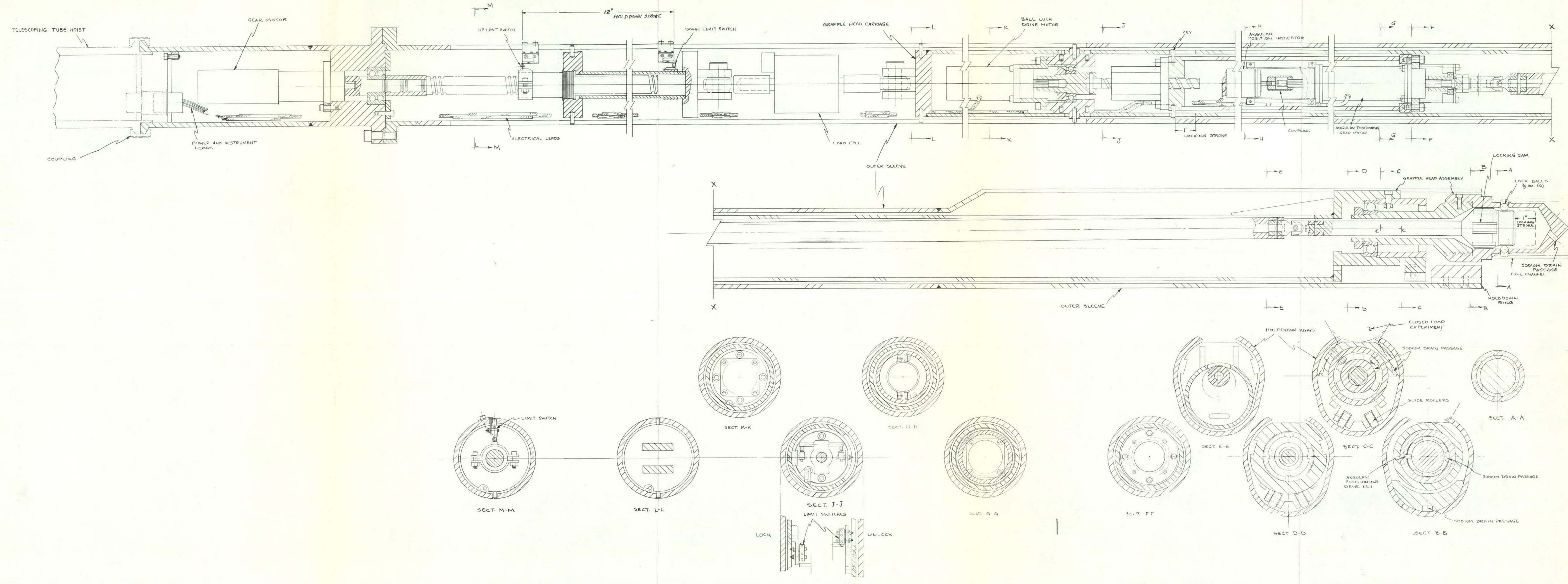


e. A second gearmotor and ballscrew combination lifts the grapple head within the holddown sleeve for a distance of 12 inches. This 12 -inch hold-down stroke is provided to break free any core element sticking to adjacent elements while raising the element from a close tolerance fit into a free condition. The hold down force is monitored by the load cell mounted in the fuel grapple and limit switches indicate the full up and down positions of the grapple head.

f. The tube hoist raises the fuel element to a position just above the channel tops leaving the active core region submerged in primary coolant.

g. The element is moved over and lowered into the transfer container. The hold-down motion is reversed near the end of the hoist downward motion in preparation for unlocking the grapple.

h. After bottoming the element out in the transfer thimble, the grapple is unlocked and the hoist raised in preparation for the next handling cycle.

\subsection{GENERAL PURPOSE BRIDGE MANIPULATORS}

Two telescoping bridge manipulators provide operators with remotely operated right and left hand handling capability usable in conjunction with other hoist and grapple slung devices. The articulated arm at the end of the telescoping bridge and trolley mounted boom provides tong grip or torque capability to use for such tasks as instrumentation and experimental loop connections. Each of the two telescoping manipulators operates on a separate trolley, but the two trolleys are mounted on a common traveling bridge at the 20-foot elevation. Articulated arm swing, tong, motion, and rotation utilize single two-speed motors. The telescoping tube, trolley, and bridge drives utilize two tandem 2 -speed motors to yield 4 speeds in.each direction. The lateral coverage within the cell for the tong or torque tool end of these devices is wall to wall. Vertical coverage is from 6 feet below the cell floor to 14 feet above floor level.

\subsection{5/25-TON BRIDGE CRANE}

This general purpose transport system consists of a remotely operated bridge crane and the associated grapples. This crane can traverse the length of the cell on rails 55 feet above the cell floor. It provides general handling capabilities from within the reactor to a maximum load block elevation 50 feet above the cell floor, having lateral coverage to within 3 feet of the cell walls. Two hoists one 5-ton and one 25-ton capacity, are to operate from a single trolley structure on the bridge. Remote control for the crane, its related grapples and the integral positioning and load readout devices, is available to an operator outside the cell. A smaller hand held controller is available to suited personnel within the cell, but control here is limited to bridge, trolley, and hoist motions only.

Some of the handling tasks for this system are:

- Transfer of center head and shielding, including the fuel holddown and instrumentation package

- Transfer of experimental loops within the cell. 
- Backup device for telescoping fuel lift devices

- Handling of miscellaneous shield plugs, tools, etc., which weigh less than 25 tons

To increase the versatility of the bridge crane and to provide backup for other in-cell equipment, each hoist is equipped with remotely operable grapples. Also, to more effectively utilize the bridge crane for light-weight objects, these grapples will be used to remotely attach to and make electrical connections with other specialized grapples.

\section{$12.6 \quad 100-$ TON HOIST}

A 100-ton hoist and trolley assembly is mounted on tracks near the top of the refueling cell. The primary function of this hoist is to handle the large annular reactor vessel shield plug. The trolley moves along the length of the cell to provide cell end to end handling capability. No movement is required across the width of the cell and, therefore, no bridge motion is provided since both the vessel location and the annular head storage location are on the centerline down the length of the cell.

\subsection{SPENT FUEL TRANSFER THIMBLES}

Fuel elements are moved from the reactor vessel to the fuel storage tanks using the spent fuel transfer thimble illustrated in Figure 12-4. This transfer thimble is a relatively simple finned container designed to dissipate the decay heat load by natural circulation. This amounts to approximately $25 \mathrm{~kW}$ after a 24 -hour decay time following reactor shutdown. Analysis for the thimble is given in section 4.9 .

During normal refueling operations, temperature rise of the thimble will not present a serious vapor generation problsm. For the abnormal condition, with the thimble suspended in the argon atmosphere for a prolonged time, there would be large amounts of sodium vapor generated. However, in this situation, the normal operating temperature of the fuel would not be exceeded. This potential sodium vapor problem could be eliminated by introducing forced convection cooling of the thimble surfaces.

The proposed method of dealing with the sodium vapor problem if it becomes a serious concern is to use a transfer cylinder into which the thimble is withdrawn. This transfer cylinder would incorporate use of a blower to circulate cell gas up past the thimble and then through a replaceable mist separator before dumping the gas back into the refueling cell. This cylinder could be incorporated into the spent-fuel transfer thimble handling equipment design.

A secondary consideration is to prevent freezing the sodium in the transfer container in the event a fuel element with low-level decay heat is being removed from the cell. This would require the use of radiant heating elements in the transfer cylinder and cooling gas flow control to maintain the desired temperaturc.

\subsection{FUEL STORAGE}

Below floor storage is provided for new fuel-spent fuel requiring decay heat removal-and activated equipment. New and spent fuel storage tanks will accommodate at least one core load, 


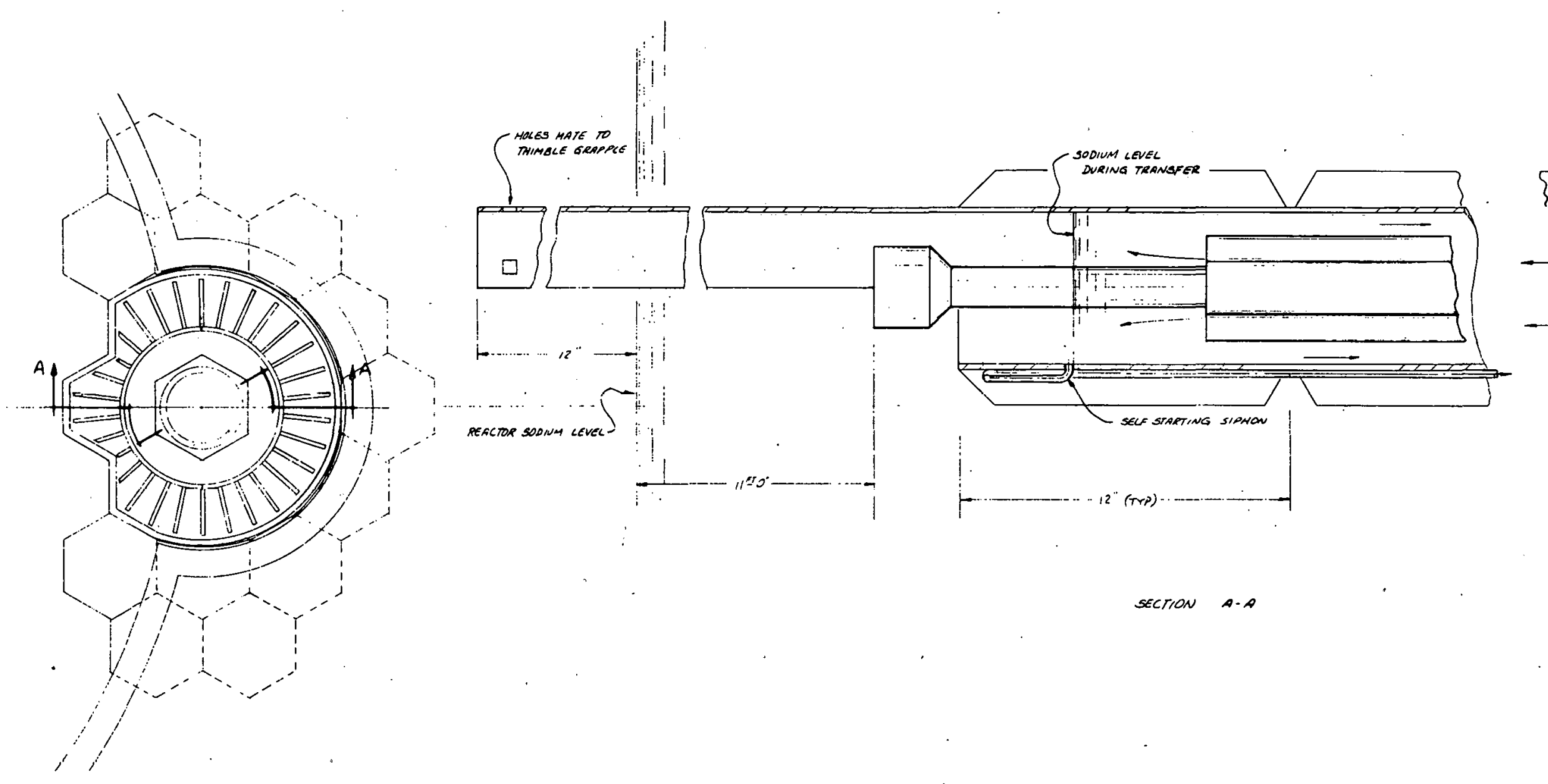


thereby providing long term decay storage space plus new and spent fuel storage space sufficient for one refueling load. This will allow the entire refueling operation to proceed without additional operations involved in transferring fuel in and out of the cell.

Spent-fuel storage tanks are required to permit removal of the decay heat which is generated after irradiation. Two tanks, with internal arrangement.as illustrated in Figure 12-5, will be used for quick removal of the spent fuel. These tanks have.the capacity to hold one entire refueling ( $~ 30$ elements). After reactor startup following the refueling outage, elements from these tanks will be transferred to the long-term decay tanks; - No. .2, No. $: 3$ and No. 4 the internal arrangement, of which is also illustrated in Figure 12-5. These tanks have the capacity for an entire core of spent fuel.

Secondary cooling to remove the decay heat will be provided for each tank along with a shield plug or cap to be placed at the top of each tank to. lower radiation levels in the cell.

Additional storage facilities will be provided within the refueling cell to accommodate small activated tools and yessel internals.

In-vessel storage facilities will be provided within the outer annular region between the neutron shielding and vessel wall. This storage area is located in the primary sodium and will be accessible only when the outer annular shield plug has been removed... The purpose of this storage area is to provide long-term storage for miscellaneous in-core equipment and to provide for emergency storage during complete core disassembly:

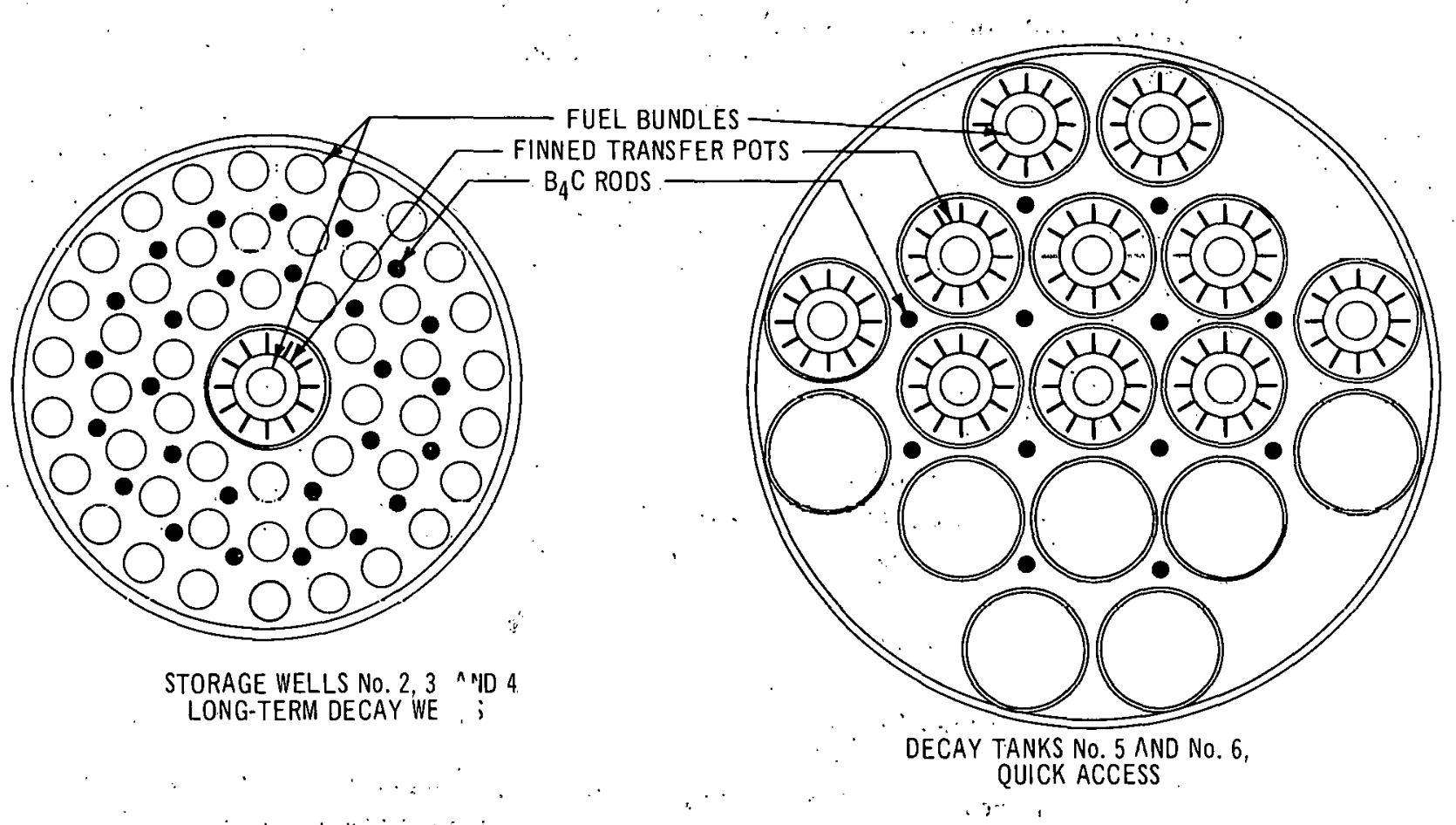

FIGURE 12-5. FUEL STORAGE TANKS 


\subsection{OTHER CELL EQUIPMENT}

\subsubsection{Remotely Operated TV}

A TV system is utilized to supplement direct viewing by window and periscope and to provide viewing of events in those locations where direct viewing is not possible. The TV camera mount provides pan and tilt and is situated on a motor-driven boom which may also be driven the length of the cell along one wall just below the bridge manipulator rails. A cart-mounted mobile monitor and control for the various remote drives is available to the operator on the elevated work deck outside the cell. The operator may thus position this equipment adjacent to any of the viewing windows.

\subsubsection{Remotely Positioned Mirrors}

A further supplement of direct window viewing is provided by convex and flat mirrors mounted on remotely operated pan and tilt drives. These are attached to a tripod and fitted with a grapple handle so that the operator can relocate the assembly using the in-cell $5 / 25$-ton bridge crane. Controls are portable to enable the operator to move from one window location to the next.

\subsubsection{In-Cell Lighting}

Mercury-vapor lamps located around the cell periphery and below the bridge manipulator rails are to result in a minimum illumination level of 50 -foot candles over the entire cell floor. Additional mercury-vapor lamps are required on the three remotely driven bridge structures to elevate illumination locally to $100 \mathrm{ft}$-c. The operator is to have on-off control of each lamp from the elevated work deck outside the cell in order to establish lighting patterns as may be required and yet enable varying the lamp heat load within the cell. Wall-mounted units may be serviced remotely with a bridge manipulator.

Emergency lighting will be incandescent units on emergency power to provide local illumination on the traveling bridge structures. The instantaneous startup characteristic of this type of lamp is necessary to overcome the cooldown time required to restart an interrupted mercury vapor lanip.

\subsubsection{In-Cell Audio Monitoring}

in-cell sounds occurring during remote operations are to be transmitted to operators on the elevated work deck outside the refueling cell. This will aid the operator in monitoring incell events and in the detection of potential mechanical power train failures.

\subsection{FUEL HANDLING}

\subsubsection{Driver Fuel Handling}

Following reactor shutdown, the primary coolant temperature will be lowered to 350 $400^{\circ} \mathrm{F}$ after which the center shield plug, which includes the fuel holddown and driver fuel instrumentation, will be removed and placed in a storage pit in the cell floor. The primary 
coolant may be lowered to expose the core component handles, thus enabling visual inspection within the vessel and confirmation of the handling equipment positioning and readout.

During fuel handling, the primary coolant level is maintained approximately 11 feet above the top of the fuel handles. This ensures that the fuel region of the element will remain immersed in sodium during the refueling operation. The refueling will then proceed as illustrated in Figure 12-6. Spent fuel transfer thimbles are placed, as needed during refueling in the special refueling position where they accept spent fuel elements to be removed from the core. A driver fuel element is removed from the core with the appropriate fuel grapple and either is moved to another core location or is placed in the spent fuel transfer thimble. The thimble containing the spent fuel is then lifted out of the core and located in one of the quick-access decay storage pools located near the reactor vessel.

After resumption of reactor operation the fuel is transferred from the quick-access decay pools to the long-term decay pools where it is removed from the transfer thimbles. After a suitable decay period, transfer from the reactor building takes place. At this time the decay heat load allows the use of either forced-convection gas cooling or an extremely simple sodium-filled thimble.

New fuel is introduced into the reactor by the reverse of the above sequence. After removal of the first spent fuel element, the transfer thimbles are used to bring in one new fuel element and remove the next spent fuel element for each transfer cycle. Heating of the new fuel elements before placing them in the transfer thimbles can be done in the cell if necessary.

Removal and insertion of fuel, if any, under vertical obstructions, such as the closed loops, will require special handling procedures, but the basic refueling sequence will remain unchanged. The use of dummy elements and/or vessel modifications to eliminate any special handling procedures which are necessary dus to these vertical obstructions should be considered.

Driver refueling time has been estimated to be approximately 67 minutes per bundle. This estimate is based on refueling time estimates published in GEAP-5422 which were developed for a tank-type arrangement but are considered to be valid since much of the basic operations remain the same.

Considering the fixed-time jobs which must precede each refueling, and using a 36-bundle refueling schedule, results in an approximate driver refueling time of 42 hours. 

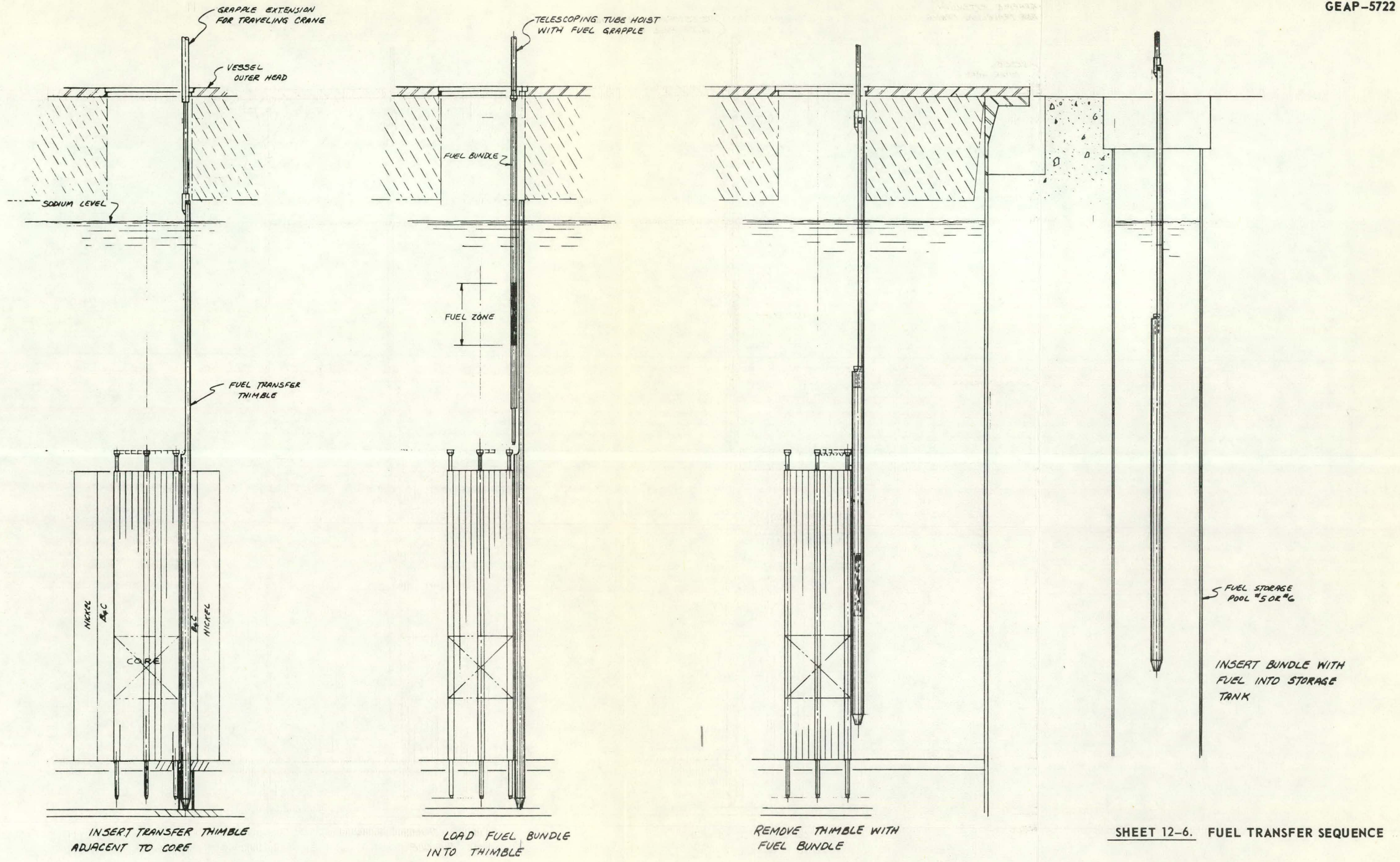


\section{SECTION XIII}

\section{REFERENCES}

1. Greebler, P., et al, "BISYN-A Two Dimensional Synthesis Program, "July 15, 1965, (GEA P-4922).

2. "Fast Ceramic Reactor Development Program," 26th and 27th Quarterly Reports, (GEAP-5631 and 5677).

3. Keepin, G. R., "Physics of Nuclear Kinetics, "Addison-Wesley, 1965.

4. Elann, B. F., "Heat Tranșfer in Honeycomb-Core Sandwich Panels, " August 1965, (ASME 65-HT-13).

5. Brehm, W. F., "Radioactive Mass Transport in FFT F Primary Piping, " August 1968, (BNW L-808).

6. Bunch, W. L., and Shaver, R. E., "Shielding Calculations for Conceptual Design of FFTF Sodium Systems, "April 1967, (BNWL-388, UC-80, Reactor Technology).

7. Riley, D. R. , et al, "Fast Flux Test Facility Backup Design Project Second Quarterly Report," April 1968, (GEAP-5614).

8. Riley, D. R., et al, "Fast Flux Test Facility Backup Design Project Third Quarterly Report, "July 1968, (GEAP-5641).

9. Shure, K., "Fission Product Decay Energy," Bettis Technical Review, December 1961, (WAPD-BT-24), pp. 1-17 which, in turn, references: Petrov, Yu. I. , "Gamma Radiation from U-235 and Pu-239 Fission Fragments, "J. Nuc. Energy, Part A, Reactor Science 12, 129-32 (1960).

10. Johnston, K., "A Calorimetric Determination of Fission Product Heating in Fast Reactor Plutonium Fuel, "J. Nuc. Energy, Parts A/B, 19, 527 (1965).

11. Battat, M. E., Dudziak, D. J., and Hicks, H. R. , (LASL), "Fission Product Decay from Fast Fission of Pu-239," pp. 524-525, Transactions of the American Nuc lear Society 1967 Winter Meeting, 10, No. 2

12. Battat, M. E., Dudziak, D. J., and Hicks, H. R., "Fission Product Energy Release and Inventory from Pu-239 Fast Fission," LA-3954, UC-80 Reactor Technology, TID-4500, (October 1968).

13. Riley; D. R., et al, "Fast Flux Test Facility Backup Design Project Fourth Quarterly Report, "July 1968, (GEA P-5650).

14. Reynolds, A. B., and Vaughan, P. C., "Sodium Temperature Response to Transients in the FFTF Conceptual Backup Design and Description of Dynamics Model, "September 1968, (GEA P-5660).

15. Fox, J. N., Lawler, B. E., and Butz, H. R., "FORE II, A Computational Program for the Analysis of Steady State and Transient Reactor Performance, "September 1966, (GEAP-5273).

16, Meyer, R. A., Wolfe, B., Friedman, N., F., and Seifert, R., "Fast Reactor Meltdown Accidents Using Bethe-Tait Analysis, "January 1967, (GEAP-4809).

17. Sheff, J. R., "Arguments for Continuous Direct On-Line Monitoring of Shutdown Reactivity, "Battelle-Northwest, 1967, (BNWL-cc-1458).

18. Borgweldt, H. and Stegemann, D. , "A Common Theory for Neutronic Noise Analysis Experiments in Nuclear Reactors," Nukleonick, 7,6 , (1965).

19. Seifritz, W., et al, "Two Detector Cross Correlation Experiments in the F'ast Thermal Argonaut Reactor (STARK),"' 1967, (CONF- 860206).

20. Roux, D. P., "Optimization of Reactor Shutdown Margin in High Gamma Fluxes," ANL'Trans, 9 , 2, (1966). 
APPENDIX A

BASIC NUCLEAR DESIGN DATA FOR ZONED CORE

TABLE A-1

ASSUMED TEM PERATURES FOR EXPANSION EFFECTS AND LINEAR EXPANSION FROM ROOM TEMPISRATURE

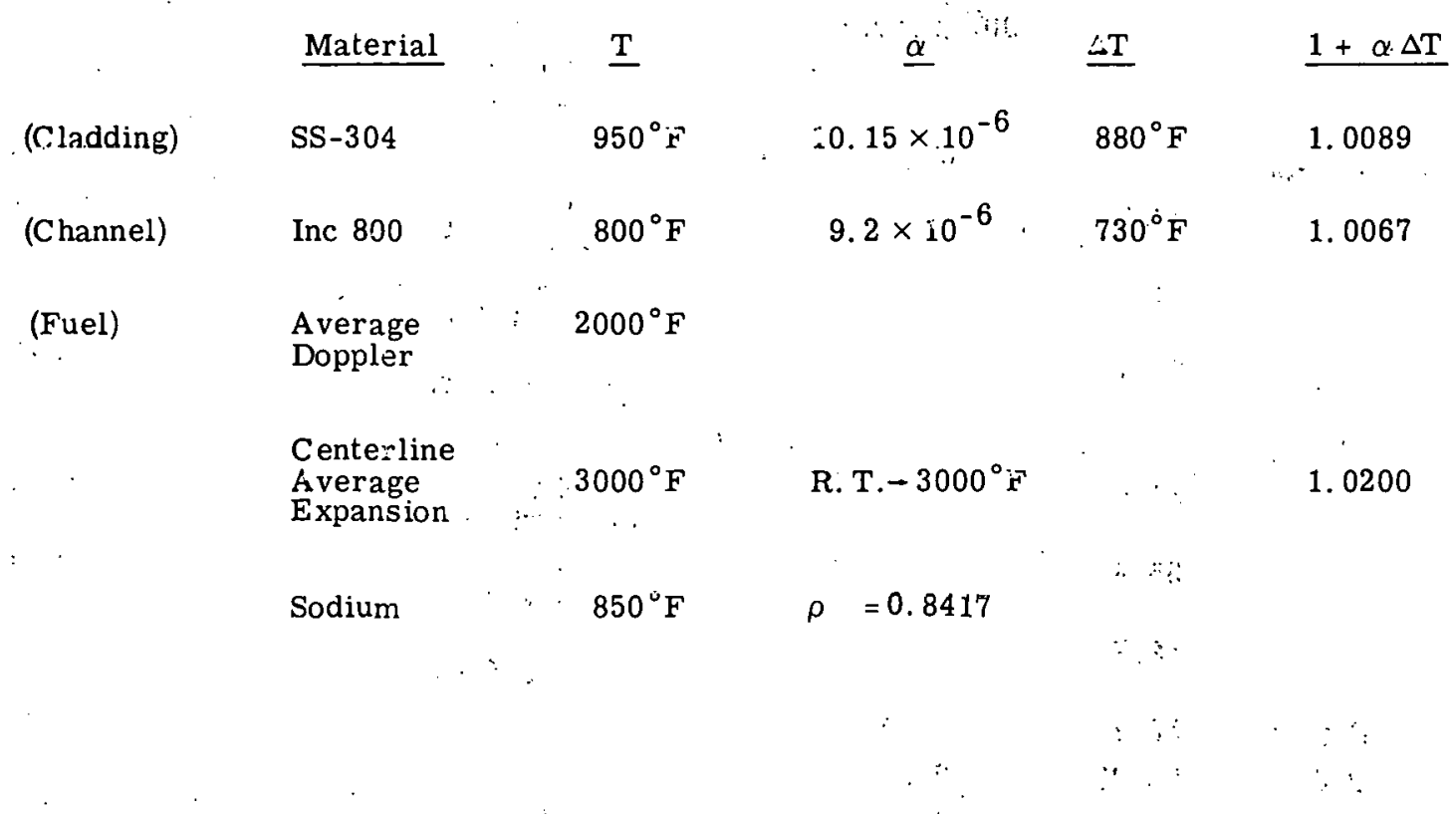


GEA P-5722

TABLE A-2

\section{CALCULATION OF ATOM DENSITIES}

\begin{tabular}{|c|c|c|c|c|c|c|}
\hline Material & $\begin{array}{c}\text { Molecular } \\
\text { Weight } \\
\end{array}$ & $\rho^{\rho_{\text {Theoretical }}}$ & $\rho_{\text {Hot }}$ & Atom & Temperature & $\begin{array}{c}\text { Hot Operation } \\
\text { Atoms/Barn }(\mathrm{cm}) \\
\end{array}$ \\
\hline \multirow[t]{2}{*}{ Sodium } & 22.89 & & & & & \\
\hline & & & .8417 & & $850^{\circ} \mathrm{F}$ & 0.0220383 . \\
\hline \multirow[t]{4}{*}{ Fuel } & 270.0 & 11.06 & 9.587 & & & \\
\hline & & $\begin{array}{c}9.954 \\
(90 \% \text { oTheo })\end{array}$ & & & . & \\
\hline & & & & $\mathrm{U}+\mathrm{Pu}$ & . & 0.0213927 \\
\hline & & & & ox & & 0.0427854 \\
\hline \multirow[t]{4}{*}{ Inc- -800} & & 8.02 & 7. 861 & & & \\
\hline & 52.0 & .. & & $\begin{array}{c}\mathrm{Cr} \\
(0.2075 \text { wt } \%)\end{array}$ & . & 0.0188984 \\
\hline & 55.8 & & & (0.457 wt \%) & & 0.0387876 \\
\hline & 58.7 & $\therefore$ & & $\frac{N i}{(0.3355 \text { wt } \%)}$ & & 0.0270685 \\
\hline \multirow[t]{4}{*}{ SS-304 } & & 7.93 & 7.721 & & & \\
\hline & 52.0 & & & $\begin{array}{c}\mathrm{Cr} \\
(0.19 \mathrm{wt} \%)\end{array}$ & & 0.0169978 \\
\hline & 55.8 & & & $\begin{array}{c}\mathrm{Fe} \\
(0.7 .0 \mathrm{wt} \%)\end{array}$ & & 0.0583590 \\
\hline & 58.7 & & & $\left(0.11^{\mathrm{Ni}} \mathrm{wt} \%\right)$ & & 0.0087176 \\
\hline Nickel & 58.71 & 8. 90 & & & & 0.0913345 \\
\hline \multirow{3}{*}{$\mathrm{B}_{4} \mathrm{C}$} & 55.29 & 2.5 & & & & \\
\hline & . & $\begin{array}{c}2.0 \\
(80 \% \text { p.Theo) }\end{array}$ & & B & & 0.0871766 \\
\hline & & & & $\mathrm{C}$ & & 0.02 .17942 \\
\hline
\end{tabular}


TABLE A-3

BUNDLE TYPE VOLUME FRACTIONS

Driver Fuel

Room Temperature $\quad \because \quad$ Hot Operating

Fuel:

$\mathrm{Na}$

Inc -800

0.326

0.406

0.328

SS -304

0.154

0.403

0.114

Open Loops ( $75 \%$ Driver Fuel)

Fuel

$\mathrm{Na}$.

Inc -800

SS-304.

Closed Loops (15\% of Driver Fuel)

Fuel

$\mathrm{Na}$

SS-304

In Core Control

$\mathrm{Na}$

SS-304

Axial Reflector Above Closed Loop

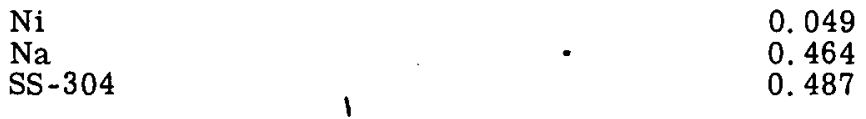

Axial Reflector Above Driver

$\begin{array}{ll}\mathrm{Na} & 0.406 \\ \mathrm{Inc}-800 & 0.114 \\ \mathrm{SS}-304 & 0.154 \\ \mathrm{Ni} & 0.311 \\ \text { Void } & 0.015\end{array}$

Axial Plenum

$$
\begin{aligned}
& \mathrm{Na} \\
& \text { Inc-800 } \\
& \text { SS-304 }
\end{aligned}
$$$$
\text { Void }
$$

0.245

0.466

0.174

0.115

0.246

0.464

0.174

0.116

0.049

0.464

0.487

0.667

0.333

0.464

0.487

0.406

154

0.015

0.112

0.216

0.248

Fixed Radial Reflector

$\begin{array}{ll}\mathrm{Ni} & 0.70 \\ \mathrm{Na} & 0.18 \\ \mathrm{Inc}-800 & 0.12\end{array}$

$\underline{\text { Radial Structure }}$
$\mathrm{Na}$
0.5

SS-304

\begin{tabular}{c}
$\mathrm{Na}$ \\
$\mathrm{SS}-304$ \\
Movable Radial Reflector \\
\hline $\mathrm{B}_{4} \mathrm{C}$ \\
$\mathrm{Na}$ \\
$\mathrm{SS}-304$ \\
Inc-800 \\
$\mathrm{Ni}$
\end{tabular}

0.5

Nickel In

Control In

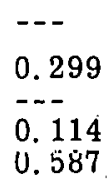

0.292

0.328

0.266

0.114

-.. 
TABLE A-4

MATERIAL DENSITIES AND DIMENSIONS

MATERIAL DENSITIES

Cold

8. 02.

7.93

9.954

Fuel

DIMENSIONS

Hex Area

Height

Axial Reflector Thickness

Plenum Thickness

Fixed Radial Reflector Thickness.

Radial Structure Thickness
Hot

$64.77 \mathrm{~cm}^{2}$

$93.27 \mathrm{~cm}$

$15.24 \mathrm{~cm}\left(6^{\prime}\right.$ in. $)$

$30.0 \mathrm{~cm}$

$20.0 \mathrm{~cm}$

$20.0 \mathrm{~cm}$ $\underline{\text { Hot }}$

7.86

7. 72

9. 587
Cold

$63.91 \mathrm{~cm}^{2}$

$91.44 \mathrm{~cm}$

1 
TABLE A-5

\section{VOLUME FRACTIONS BY COMPOSITION*}

\begin{tabular}{|c|c|c|c|c|c|c|c|}
\hline & Composition & Fuel & Sodium & SS-304 & Inc -800 & Nickel & $\underline{B}_{4} \mathrm{C}$ \\
\hline . & 1,2 & 0.328 & 0.403 & 0.155 & 0.114 & -- & -- \\
\hline \multirow[t]{2}{*}{$\therefore$} & . 3,4 & 0.229 & 0.448 & 0.247 & 0.076 & -- & -- \\
\hline & 5,6 & 0.328 & 0.403 & 0.155 & 0.114 & -- & -- \\
\hline \multirow[t]{2}{*}{. } & $7 ; 8$ & 0.300 & 0.424 & 0.142 & 0.134 & -- & -- \\
\hline & 9,10 & 0.049 & 0.462 & 0.489 & -- & -- & - \\
\hline (nickel in) & 11,12 & - & 0.299 & -- & 0.114 & 0.587 & -- \\
\hline \multirow[t]{8}{*}{ (control in) } & 11 & -. & 0.280 & 0.255 & 0.114 & -- & 0.351 \\
\hline & 13 & - & 0.18 & -- & 0.12 & 0.70 & -- \\
\hline & 14 & -- & 0.5 & 0.5 & -- & -- & -- \\
\hline & 15 & -- & 0.464 & 0.487 & .- & 0.049 & -- \\
\hline & 16 & -- & 0.406 & 0.154 . & 0.114 & 0.311 & 0.015 Void \\
\hline & 17 & -- & 0.451 & 0.246 & 0.076 & 0.217 & 0.010 Void \\
\hline & 18,19 & -- & 0.406 & 0.154 & 0.114 & 0.311 & 0.015 Void \\
\hline & 20 & -- & 0.424 & 0.216 & 0.112 & -- & 0.248 Void \\
\hline
\end{tabular}

*Refer to Figure 3-2 for region description corresponding to compositions listed. 
TABLE A- 6

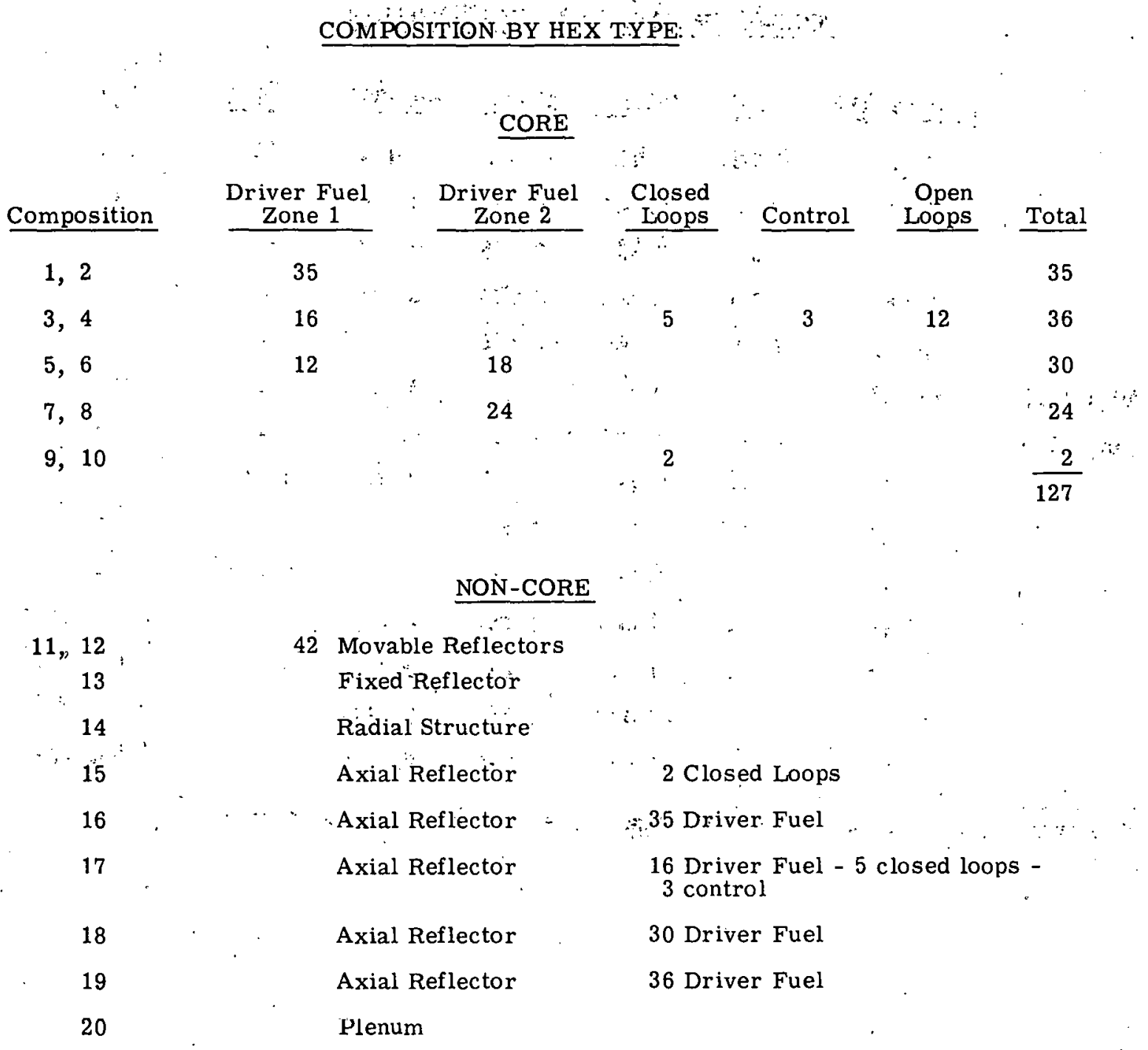


GEAP-5722

\section{A PPENDIX B \\ CIRCUMFERENTIAL TEMPERATURE DISTRIBUTION FOR CORNER AND SIDE FUEL PINS}

\section{B. 1 SUMMARY}

The theoretical background and numerical methods being used in a digital computer code (now in the debugging stage) to be used in the determination of the circumferential temperature distribution for the outer row of fuel pins in the FFTF fuel subassembly are described. A detail description and users manual is in preparation, GEAP-5725.

Emphasis is placed on the development of the velocity profile around a corner pin. The computer code being developed to perform this analysis will with slight modifications be appliable for analysis of the fuel pins along the channel wall: The geometry allowed in the computer model is restricted to a multiple fuel-pin triangular array. The nomenclature is defined in Section B-7.

\section{B. 2 INTRODUCTION}

The FFT F Backup Design and the reference design call for multiple fuel pins in triangular arrays within hexagonal channels. Figure B-1 shows a schematic plan view of a Backup Design bundle.

A considerable amount of thermal hydraulic analysis has been performed on interior pins by considering them to be in an infinite array, notably the analysis done by Bender, Switick and Field. ${ }^{(B-1)}$ The circumferential velocity distribution and associated eddy diffusivities have been analyzed by Nijsing, Gargantini, and Eifler. ${ }^{(B-2)}$

In comparison, very little analytical or experimental work has been performed on the outer row of fuel pins. The outer row of fuel pins is of particular interest due to the nonsymmetrical cooling which exists. The presence of the channel on one side of the pins will disturb the velocity profile and will change the heat transfer through circumferential heat transfer in the wall. Nonsymmetrical cooling also results because, the flow area between the fuel pin and channel wall is normally larger than the flow area on the interior' side of the fuel pins:

The nonsymmetrical cooling will cause a circumferential temperature distribution in the fuel pin. This nonuniform temperature distribution introduces the following possibilitiès:

1. Thermal bowing can occur if the fuel pins are loosely supported:

2. High stresses can occur at the points of support if the fuel pins are rigidly supported.

3. High circumferential thermal stresses may develop.

The purposes for developing this digital code is to determine the temperature distribution for a corner fuel pin in a triangular array. The corner fuel pin was chosen since its temperature distrihution should be more severe than a fuel pin along one of the hexagonal flats. The computer code which is being developed will also be applicable for analyzing a side rod by replacing the geometry subroutines. 


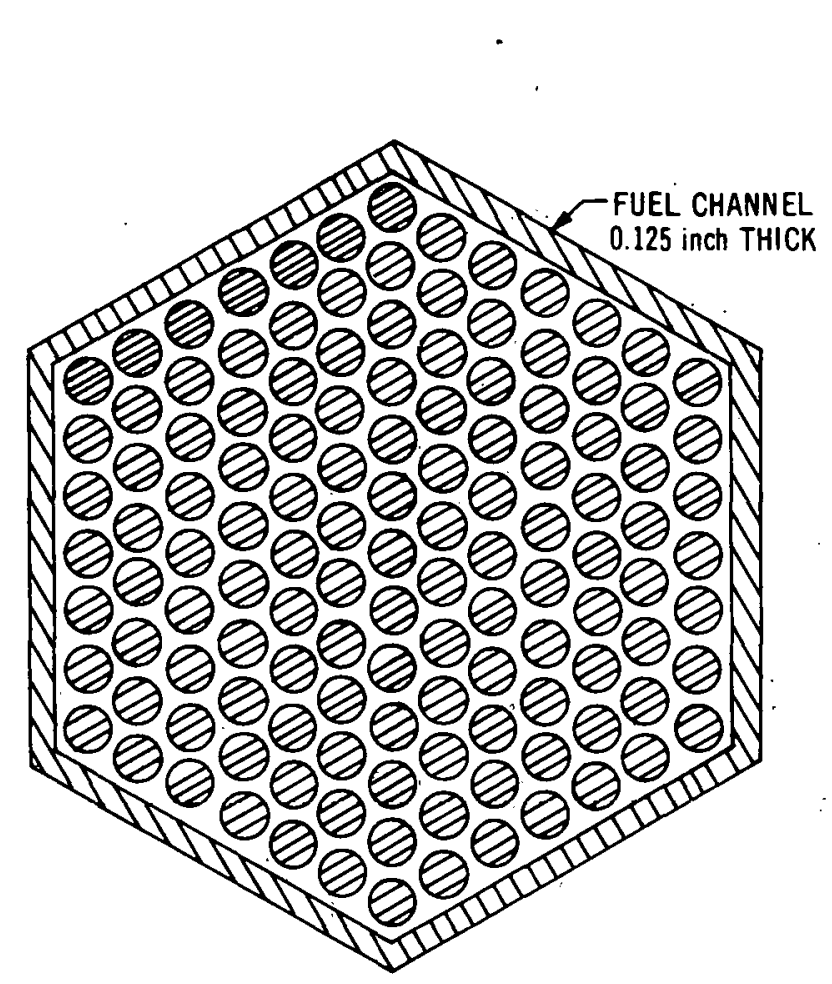

PITCH-DIAMETER RATIO OF 1.20

PIN DIAMETER OF 0.250 in.

FIGURE B-1. TYPICAL 127-PIN FUEL BUNDLE

The temperature distribution analysis can be done in two steps. First, it will be assumed that momentum and energy equations arerseparable (coolant properties will be evaluated at the coolant bulk temperature). The resulting velocity distribution will be based on bulk fluid properties. Secondly these results will be used in a general heat transfer code, such as THTD, ${ }^{(B-3)}$ to generate the circumferential pin temperature profile.

The circumferential variation of the velocity and circumferential eddy diffusivity for momentum will be determined using a modification of the procedure of Nijsing, Gangantini, and Eifler. This procedure was developed for the case of a rod in an infinite array, but by modifying the equations to include the channel wall, it can be used for corner or side rods. This procedure will yield values for the local mean velocity and average circumferential eddy diffusivity for momentum as a function of circumferential position.

The radial variation of the velocity and radial eddy diffusivity for momentum will be based upon an annular model proposed by S. Levy. ${ }^{(B-4)}$ By using this model with the average velocity 
equal to the local mean velocity (from circumferential analysis) and considering each circumferential segment as an equivalent annulus, the radial variations can be determined.

The superposition of the results of these two procedures will yield a complete nodal velocity field and each nodal position will have circumferential and radial components of the eddy diffusivity for momentum associated with it.

The accuracy of this approach will depend upon several factoris:

1. Number of circumferential segments: This will directly effect the accuracy of the local mean velocities distribution and average circumferential diffusivities. It will also determine the amount of deviation from an annular section, effecting the radial distributions.

2. Number of radial segments: Since the annular solution is not a nodal solution but is a continuous function, the number of radial segments will not have a large bearing on the results. It will, however, effect the heat transfer portion significantly.

Therefore, from an accuracy standpoint a large number of radial and circumferential segments is desirable.

The use of an average value for the circumferential eddy diffusivity. (for each radial position) is not expected to cause significant errors. Since the pitch-to-diameter ratios under consideration are in the range of $1.20-1.30$, the use of an annular model at each circumferential position is not expected to cause large errors.

The assumption of superposition of the radial and circumferential solutions has been examined. Although some inaccuracy is expected, the radial distribution is of secondary importance to the heat transfer analysis. The ratio of eddy diffusivities (circumferential/radial) should be greater than unity. Thus, heat transfer in the circumferential direction should predominate and the radial distribution will have only a second order effect on the circumferential transfer. Since the circumferential temperature distribution in the cladding ị the desired result, small errors in the radial distribution can be tolerated.

The errors which result from assuming no circumferential or radial velocity components (unidirectional velocity) and neglecting mixing from the spiral wire spacers should be small. For wire wrap pitches, of the order of twelve inches, the flow direction can be considered vertical without introducing. significant error. The amount of gross mixing should also be small. Nomenclature for the derivations appears at the end of this Section.

\section{B. 3 VELOCITY DISTRIBUTION DERIVATIONS}

\section{B. 3.1 Assumptions}

The major assumptions involved in the derivation of the velocity distribution are as follows:

1. Fully developed, single phase, steady-state turbulent flow .

2. Coolant is incompressible. 
3. No momentum flux across the boundaries of the channel.

4. Temperature differentials are not severe so that material properties may be evaluated at the bulk fluid temperature and considered constant across the flow cross section.

Additional assumptions will be required in the analysis and will be discussed as they.appear.

\section{B. 3.2 Equation of Motion}

Since there is no momentum flux across the boundaries and the flow is incompressible, the radial and circumferential velocities must be zero,

$$
u_{r}=u_{\phi}=0
$$

where $u$ is the time averaged velocity.

:The equation of continuity in cylindrical coordinatcs is:

$$
\frac{1}{r} \frac{\partial}{\partial r}\left(r u_{r}\right)+\frac{1}{r} \frac{\partial u_{\phi}}{\partial \phi} \frac{\partial u_{z}}{\partial z}=\dot{0}
$$

Application of equation (B-1) reduces equation (B-2) to,

$$
\frac{\partial \cdot u_{z}}{\partial z}=0
$$

which implies that $u_{z}$ is constant in the axial direction:

$$
u_{\mathrm{z}}=u_{\mathrm{z}}(\mathrm{r}, \phi)
$$

From the $r, \phi$ components of the momentum equation,

$$
\mathbf{P} \neq \mathbf{P}(\mathbf{r}, \phi)
$$

Therefore, the axial pressure gradient; $\partial \mathrm{P} / \partial \mathrm{z}$, is constant across the flow section.

The governing flow equation thus becomes the $\mathrm{z}$ component of the momentum equation. If one assumes that the molecular and turbulent momentum transport effects are additive, the momentum equation becomes

$$
\left(\nu+\epsilon_{\mathrm{mr}}\right) \frac{\partial \mathbf{2}_{\mathrm{u}}}{\partial \mathrm{r}^{2}}+\frac{(\nu+\epsilon \mathrm{mr})}{\mathrm{r}} \frac{\partial \mathrm{u}}{\partial \mathrm{r}}+\frac{\left(\nu+\epsilon_{\mathrm{m} \phi}\right)}{\mathrm{r}^{2}} \frac{\partial \mathbf{2}_{\mathrm{u}}}{\partial \phi^{2}}=\frac{\mathrm{g}_{\mathrm{c}}}{\rho} \frac{\partial \mathrm{P}}{\partial \mathrm{z}}
$$

where

$$
\mathrm{u}=\mathrm{u}_{\mathrm{z}}(\mathrm{r}, \phi)
$$


The quantities $\epsilon_{\mathrm{mr}}$ and $\epsilon_{\mathrm{m} \phi}$ are the eddy diffusivities of momentum in the radial and circumferential directions, respectively.

The solution of Equation (B-6) for a nonsymmetrical geometry is very difficult and no methods. have been developed at this time. The method used by. Bender, Switick and Field (B-1) cannot be applied for the corner rod geometry (Figure B-2) due to the presence of the channel wall. It is therefore necessary to look for a simpler approach to the problem.

The first and second terms in Equation (B-6)account for the transfer of momentum normal to the rod surface. Near the surface the transfer mechanism is largely molecular in nature and therefore the molecular coefficient $\nu$ is much larger than the eddy diffusivity. As the distance from the wall increases, the eddy diffusivity predominates. Therefore, the radial transfer rate is determined primarily by the conditions in the immediate vicinity of the surface.

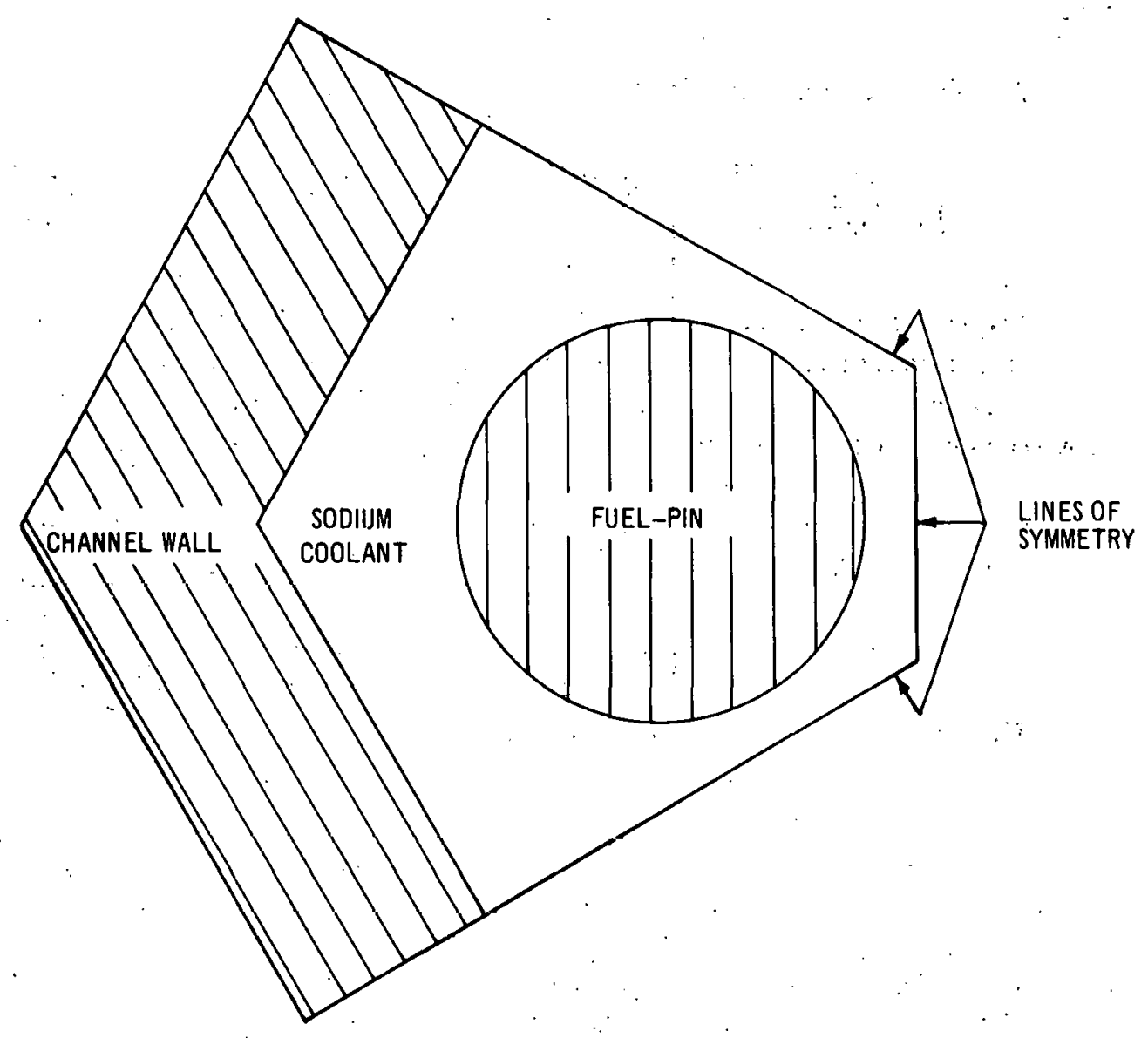

FIGURE B-2. TYPICAL CORNER FUEL. PIN GEOMETRY 
The third term in Equation (B-6) accounts for transfer of momentum around the rod periphery. Peripheral transfer will occur due to the variation in flow area (and thus velocity gradients) around the rod. Peripheral transfer is determined by the conditions in the central portion of the flow where molecular diffusivities are small. Experimental observations and analytical predictions have shown that $\epsilon_{\mathrm{m} \phi}$ is larger than $\epsilon_{\mathrm{mr}}$.

Considering the foregoing characteristics of the transfer phenomena, the radial and circumferential transfer of momentum may be considered independently of each other.

\section{B. 3.3 Circumferential Velocity Distribution}

The model to be considered is shown in Figure B-3. This model is obtained by taking advantage of the symmetry in the entire geometry (Figure B-2).

Consider a volume element $\mathrm{dA} \cdot \mathrm{dz}$ such as that shown in Figure $\mathrm{B}-4$. In this Figure, $\mathrm{dA}$ is the flow area for the region between the rod surface and the outer boundary for a differential segment $d \phi$. Let $y_{o}$ be the distance from the rod surface to the outer boundary at a given angle $\phi$.

The momentum balance can be written in the form:

$$
\left\{\begin{array}{c}
\text { rate of } \\
\text { momentum } \\
\text { accumulation }
\end{array}\right\}=\left\{\begin{array}{c}
\text { rate of } \\
\text { momentum } \\
\text { in }
\end{array}\right\}-\left\{\begin{array}{c}
\text { rate of } \\
\text { momentum } \\
\text { out }
\end{array}\right\}+\left\{\begin{array}{c}
\text { sum of forces } \\
\text { acting on } \\
\text { system }
\end{array}\right\}
$$

The rate of momentum accumulation for a steady-state system is zero. Since the radial and circumferential velocities are zero and the flow is fully developed, the net rate of momentum by convection will also be zero. 'Therefore, the net change of momentum is due to molecular and eddy transport by the stresses on the bounding surfaces of the element.

Neglecting gravity effects, the forces acting on the system are the pressure forces $\mathrm{C}$ and $D$ in Figure B-4. Using the notation of Figure B-4, the momentum balance equation becomes:

$$
A+B-C+D+E-F=0 \quad:
$$

The momentum flux A can be expressed in terms of the shear stress along the rod surface by

$$
A=\tau_{\phi} R \mathrm{R} \phi \mathrm{dz}
$$

where:

$$
\begin{aligned}
& \tau_{\phi_{1}}=\text { Shear stress at rod surface at position } \phi . \\
& \mathrm{R} \quad \text { = Radius of fuel rod. }
\end{aligned}
$$

In a similar manner

$$
B=\alpha \tau_{\phi 2} \mathrm{~d} \ell \mathrm{dz}
$$




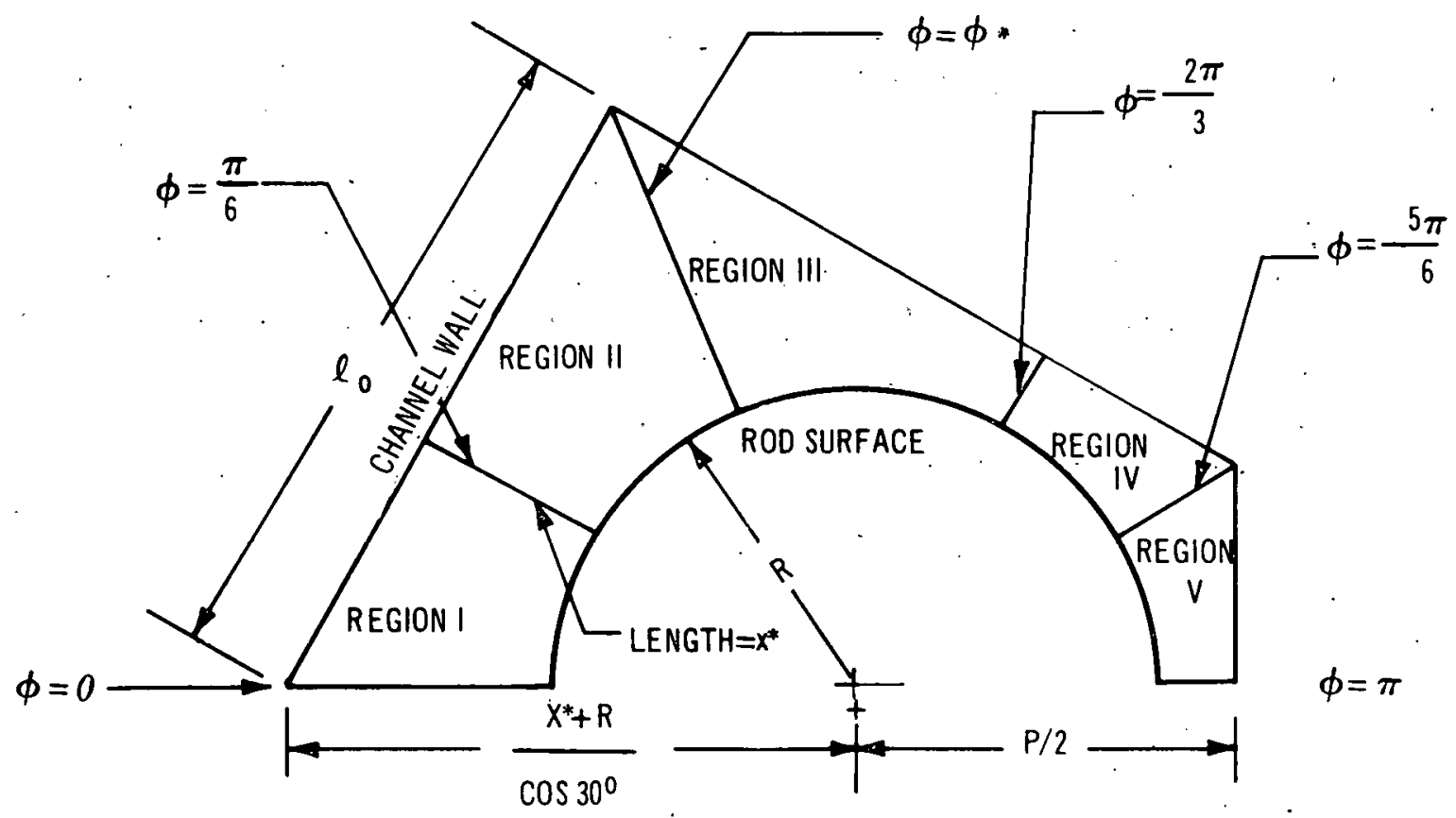

FIGURE B-3. MODEL FOR VELOCITY DISTRIBUTION CALCULATIONS

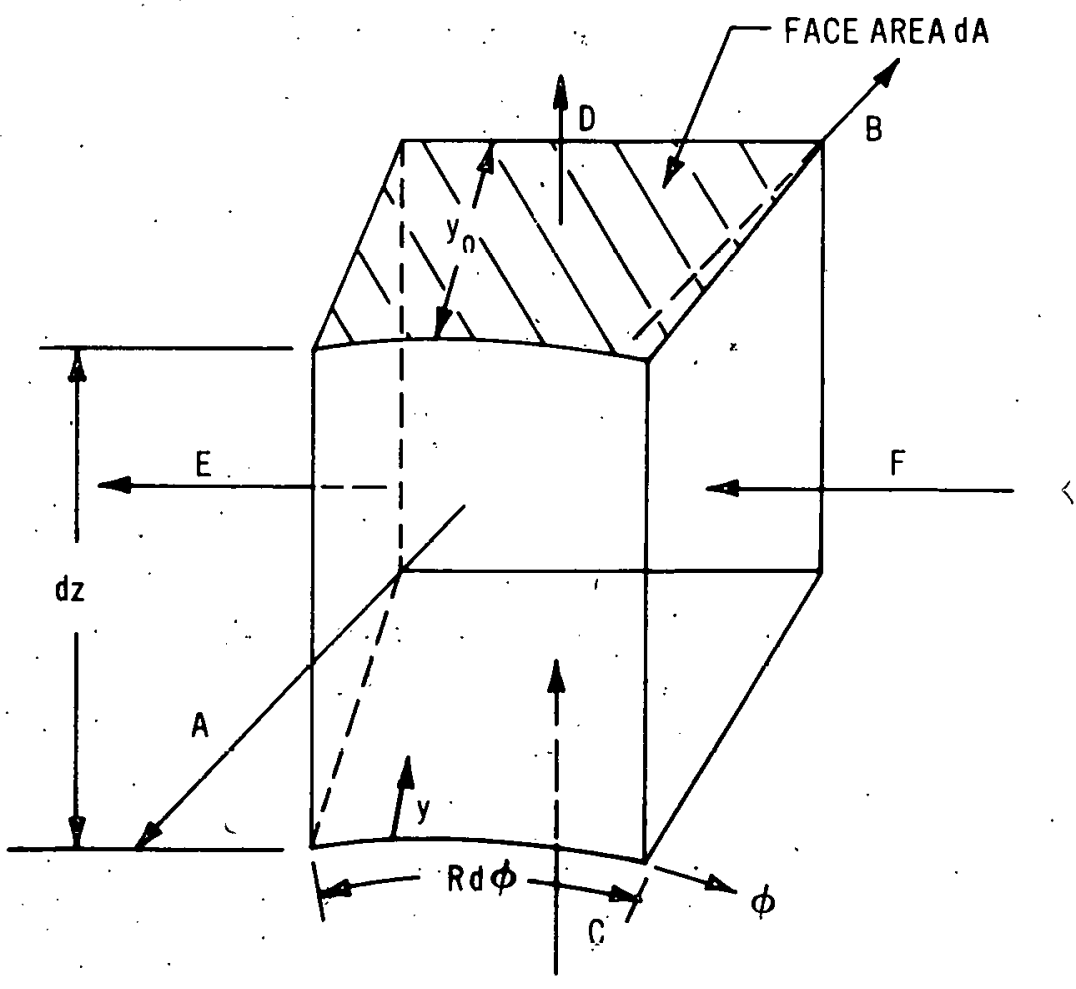

FIGURE B-4. MOMENTUM BALANCE ON ELEMENTAL VOLUME dA $\cdot d z$ 
where:

$$
\begin{aligned}
& \tau_{\phi_{2}}=\text { Shear stress at channel wall at position } \phi . \\
& d \ell=\text { Length of channel for differential angle } d \phi .
\end{aligned}
$$

The variable $\alpha$ serves the following purpose: When the outer boundary is the channel wall, (Regions I and II of Figure B-3), $\alpha$ has a value of unity. When the outer boundary is a line of symmetry (Regions III-V in Figure B-3). it carries the value of zero. Therefore, the term may be included in the general formulation and is valid for any circumferential position.

The pressure force $\mathrm{C}$ is simply

$C=\operatorname{Pd} \mathbf{A}$

where:

$\mathbf{P}=$ Pressure.

In a similar manner

$D=\left[P+\frac{d P}{d z} d z\right] d A$

The momentum flux E can be expressed in terms of the circumferential shear stress by

$$
E=\tau_{\phi \phi} \mathrm{y}_{\mathrm{n}} \mathrm{dz}
$$

where:

$\tau_{\phi \phi}=$ Circumferential shear stress at position $\phi$.

Assuming the molecular and eddy effects are additive:

$$
\tau_{\phi \phi}=\frac{\rho}{\mathrm{g}_{\mathrm{c}}}\left(\nu+\epsilon_{\mathrm{m} \phi}\right) \frac{1}{\mathrm{r}} \frac{\mathrm{du}}{\mathrm{d} \phi}
$$

Since the circumferential transfer occurs predominately in the central region where molecular effects are small, one may assume an average value of $\epsilon \mathrm{m \phi}$ acting at a mean radius. One may also neglect the molecular diffusivity $\nu$. This also requires that a mean velocity be considered for the differential segment.

Then:

$$
\tau_{\phi \phi}:=\frac{\rho}{g_{c}} \bar{\epsilon}_{m \phi} \frac{1}{r} \frac{d u}{d \phi} .
$$


Let the mean radius be defined by:

$\overline{\mathrm{r}}=\mathrm{R}+\mathrm{y}_{\mathrm{o}} / 2$

Therefore, Equation (B-12) can be expressed by:

$E=\frac{\rho}{\mathrm{g}_{\mathrm{c}}}\left(\bar{\epsilon}_{\mathrm{m} \phi}\right) \frac{\mathrm{y}_{\mathrm{o}} \mathrm{dz}}{\mathrm{R}+\mathrm{y}_{\mathrm{o}} / 2} \frac{\mathrm{d} \overline{\mathrm{u}}}{\mathrm{d} \phi}$

Then in a similar manner:

$$
F=\frac{\rho}{\mathrm{g}_{\mathrm{c}}}\left(\bar{\epsilon}_{\mathrm{m} \phi}\right)\left(\frac{\mathrm{y}_{\mathrm{o}} \mathrm{dz}}{\mathrm{R}+\mathrm{y}_{\mathrm{o}} / 2}\right) \frac{\mathrm{d} \overline{\mathrm{u}}}{\mathrm{d} \phi}+\frac{\rho}{\mathrm{g}_{\mathrm{c}}}\left(\bar{\epsilon}_{\mathrm{m} \phi}\right) \mathrm{dz} \frac{\mathrm{d}}{\mathrm{d} \phi}\left(\frac{\mathrm{y}_{\mathrm{O}}}{\mathrm{R}+\mathrm{y}_{\mathrm{o}} / 2} \frac{\mathrm{du}}{\mathrm{d} \phi}\right) \mathrm{d} \phi
$$

Substitution of the preceding equations into equation (B-7) yields:

$$
\begin{aligned}
\tau_{\phi_{1}} \mathrm{Rd} \phi \mathrm{dz} & +\alpha \tau_{\phi_{2}} \mathrm{~d} \ell \mathrm{dz}-\mathrm{PdA}+\left[\mathrm{P}+\frac{\mathrm{dP}}{\mathrm{dz}} \mathrm{dz}\right] \mathrm{dA}+\frac{\rho}{\mathrm{g}_{\mathrm{c}}} \bar{\epsilon}_{\mathrm{m} \phi}\left(\frac{\mathrm{dz} \mathrm{y}_{\mathrm{o}}}{\mathrm{R}+\mathrm{y}_{\mathrm{o}} / 2}\right) \frac{\mathrm{d} \overline{\mathrm{u}}}{\mathrm{d} \phi} \\
& -\left[\frac{\rho}{\mathrm{g}_{\mathrm{c}}}\left(\bar{\epsilon}_{\mathrm{m} \phi}\right)\left(\frac{\mathrm{dz} \mathrm{y}_{\mathrm{o}}}{\mathrm{R}+\mathrm{y}_{\mathrm{O}} / 2}\right) \frac{\mathrm{d} \overline{\mathrm{u}}}{\mathrm{d} \phi}+\frac{\rho}{\mathrm{g}_{\mathrm{c}}}\left(\bar{\epsilon}_{\mathrm{m} \phi}\right) \mathrm{dz} \frac{\mathrm{d}}{\mathrm{d} \phi}\left(\frac{\mathrm{y}_{\mathrm{o}}}{\mathrm{R}+\mathrm{y}_{\mathrm{o}} / 2} \frac{\mathrm{d} \overline{\mathrm{u}}}{\mathrm{d} \phi}\right) \mathrm{d} \phi\right]=0
\end{aligned}
$$

Equation (B-18) can be reduced directly to:

$$
\tau_{\phi_{1}} \mathrm{Rd} \phi+\alpha \tau_{\phi_{2}} \mathrm{~d} \ell+\frac{\mathrm{dP}}{\mathrm{dz}} \mathrm{dA}-\frac{\rho}{\mathrm{g}_{\mathrm{c}}} \bar{\epsilon}_{\mathrm{m} \phi} \frac{\mathrm{d}}{\mathrm{d} \phi}\left(\frac{\mathrm{y}_{\mathrm{o}}}{\mathrm{R}+\mathrm{y}_{\mathrm{o}} / 2} \frac{\mathrm{du}}{\mathrm{d} \phi}\right) \mathrm{d} \phi=0
$$

Dividing by $d \phi$ :

$$
\tau_{\phi_{1}} \mathrm{R}+\alpha \tau_{\phi_{2}} \frac{\mathrm{d} \ell}{\mathrm{d} \phi}+\frac{\mathrm{dP}}{\mathrm{dz}} \frac{\mathrm{dA}}{\mathrm{d} \phi}-\frac{\rho}{\mathrm{g}_{\mathrm{c}}} \bar{\epsilon}_{\mathrm{m} \phi} \frac{\mathrm{d}}{\mathrm{d} \phi}\left(\frac{\mathrm{y}_{\mathrm{o}}}{\mathrm{R}+\mathrm{y}_{\mathrm{o}} / 2} \frac{\mathrm{d} \overline{\mathrm{u}}}{\mathrm{d} \phi}\right)=0
$$

Consider a momentum balance on an elemental volume $\Delta A \cdot d z$ as shown in Figure B-5. As in the elemental volume $d A \cdot d z$ the rate of accumulation of momentum and net rate of momentum by convection will he zero. Then the momentum balance becomes:

$$
A^{\prime}-B^{\prime}+C^{\prime}+D^{\prime}=0
$$

The pressure forces $\mathrm{A}^{\prime}$ and $\mathrm{B}^{\prime}$ are:

$$
A^{\prime}=-P \Delta A
$$




\section{GEAP-5722.}

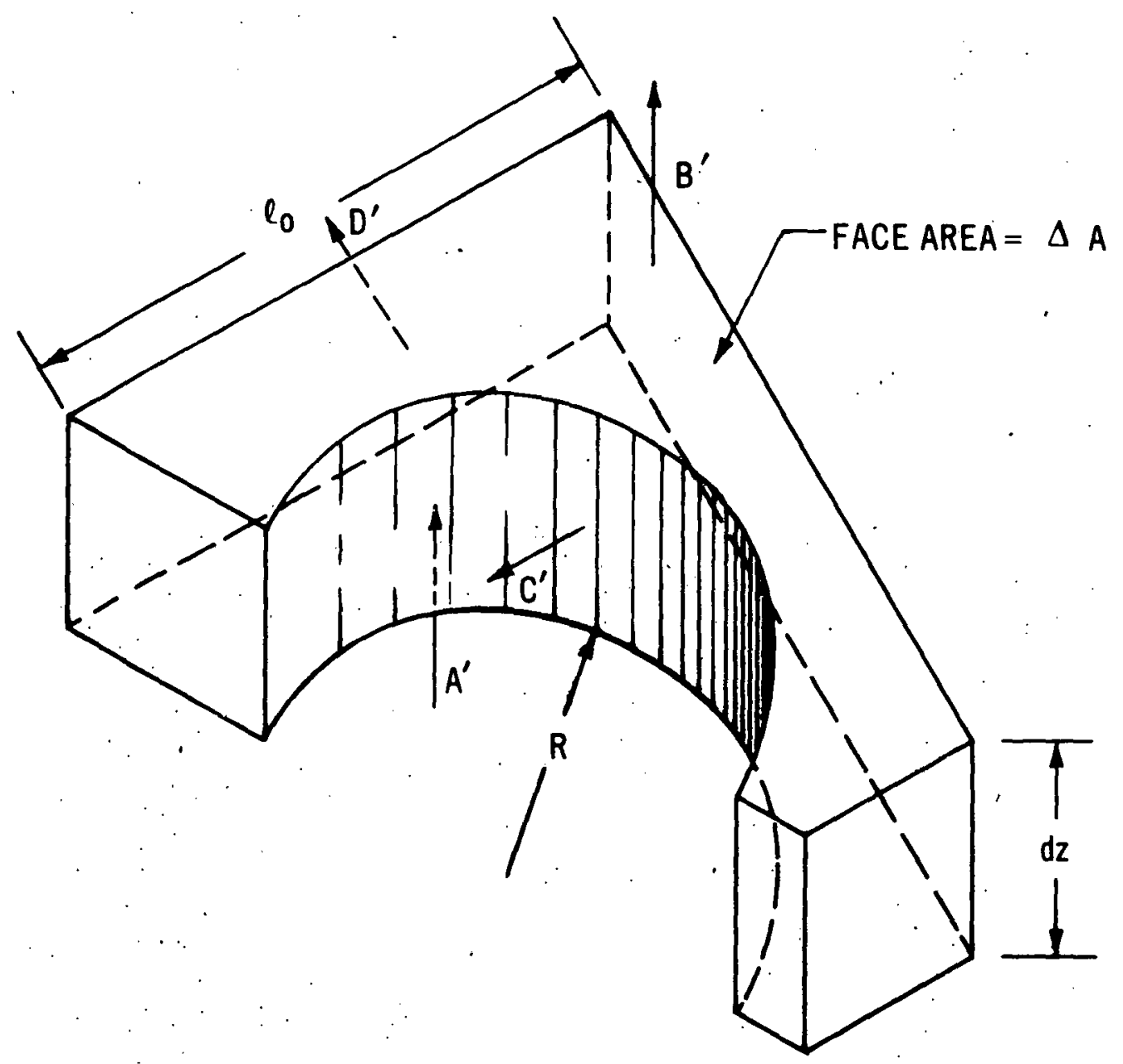




$$
B^{\prime}=-\left[P+\frac{d P}{d z} d z\right] \Delta A
$$

The momentum flux $C^{\prime}$ can be expressed in terms of the average shear stress along the rod surface by

$$
\mathrm{C}^{\prime}=\tau_{\mathrm{av}_{1}} \pi \mathrm{Rdz}
$$

where:

$\tau_{\mathrm{av}_{1}}=$ Average shear stress at rod surface.

In a similar manner

$$
\mathrm{D}^{\prime}=\tau_{\mathrm{av}_{2}} \ell_{\mathrm{o}} \mathrm{dz}
$$

where:

$\tau_{\mathrm{av}_{2}}=\cdot$ Average shear stress at channel wall.

$\ell_{0} \quad=$ Length of channel wall.

Omitting details of the derivation given in the Fifth Quarterly Report, GEAP-5684, the desired result is obtained

$$
\begin{aligned}
& \frac{\mathrm{d}^{2} \eta}{\mathrm{d} \phi^{2}}+\frac{\mathrm{R}}{\mathrm{y}_{\mathrm{o}}\left(\mathrm{R}+\mathrm{y}_{\mathrm{o}} / 2\right.} \frac{\mathrm{dy}_{\mathrm{o}}}{\mathrm{d} \phi} \frac{\mathrm{d} \eta}{\mathrm{d} \phi}-\frac{13.7565}{\mathrm{~d}_{\mathrm{e}}^{2}}\left(\frac{\mathrm{d}_{\mathrm{e}}}{\mathrm{y}_{\mathrm{e}}}\right)^{0.875} \mathrm{R}_{\mathrm{e}}^{-0.125} \frac{\mathrm{dA}}{\mathrm{d} \phi}\left(\frac{\mathrm{R}+\mathrm{y}_{\mathrm{o}} / 2}{\mathrm{y}_{\mathrm{o}}}\right) \\
& {\left[\eta^{0.875}\left(\frac{\mathrm{d}_{\mathrm{e}}}{\mathrm{y}_{\mathrm{e}}}\right)^{1.25}-\frac{\mathrm{Q}}{\eta^{0.875}}\right]=0}
\end{aligned}
$$

The boundary conditions may be transformed directly to:

$$
\begin{aligned}
& \left.\frac{\mathrm{d} \eta}{\mathrm{d} \phi}\right|_{\phi=0}=0 . \\
& \left.\frac{\mathrm{d} \eta}{\mathrm{d} \phi}\right|_{\phi=\pi}=0 .
\end{aligned}
$$

The continuity relation yields:

$$
\int_{0}^{\Delta \mathrm{A}} \eta \frac{\mathrm{dA}}{\Delta \mathrm{A}}=1 .
$$


Solution of Equation (B-26) subject to the boundary conditions, continuity equation and shear stress ratio $Q$ will yield a dimensionless velocity profile. This profile when multiplied by the bulk velocity $u_{b}$ will give the circumferential distribution of the local mean velocity $\bar{u}$. The use of this distribution will be described in the following section.

\section{B. 4 RADIAL VELOCITY DISTRIBUTION}

In Section B. 3, the methods for determining the circumferential distribution of the local mean velocity $\overline{\mathrm{u}}$ were discussed. The results of that analysis can be used to determine the radial distribution of velocity and eddy diffusivity for mómentum.

The method to be used is to consider each circumferential segment separately. Each circumferential segment is assumed to be adequately approximated by an annulus with mean velocity equal to the local mean velocity $\overline{\mathrm{u}}$ for that segment from the circumferential analysis.

For the segments in Regions I and II (Figure B-3), the annulus is assumed to be defined by an inner radius equal to the fuel pin radius and an outer radius equal to the radial distance from the pin center to the channel wall at the midpoint of the segment. For the segments in Regions III-V, a fictitious annulus is defined such that the zero shear plane in this annulus is at the same radius as the average radius of the actual outer boundary.

The technique advanced by Levy, ${ }^{(B-4)}$ which is a semi-empirical procedure, is then used for each equivalent annulus:

\section{B. 5 CIRCUM FERENTIAL DIF FUSIVITY DISTRIBUTION}

The eddy diffusivities of momentum in the radial and circumferential directions are assumed to act according to a mixing length model. Following the procedure of Bender, Switick and Field, ${ }^{(B-1)}$ the following expressions can be written:

$$
\begin{aligned}
& \epsilon_{\mathrm{mr}}=\ell_{\mathrm{c}}^{2} \frac{\partial \mathrm{u}}{\partial \mathrm{r}} \\
& \epsilon_{\mathrm{m} \phi}=\ell_{\mathrm{c}}^{2} \frac{1}{\mathrm{r}} \frac{\partial u}{\partial \mathrm{d}}
\end{aligned}
$$

where:

$$
\ell_{c}=\text { Turbulent characteristic mixing length. }
$$

One could attempt to obtain an expression for the mixing length using the method of Hooper. $(\mathrm{B}-5)$ However, the complexities caused by the nonsymmetrical geometry make this infeasible. Since the radial diffusivity components are known, a simpler procedure is available. 
Assuming that the mixing lengths in the radial and circumferential directions are equal, one may write:

$$
\epsilon_{\mathrm{m} \phi}=\frac{\epsilon_{\mathrm{mr}}}{\mathrm{r}} \frac{\partial \mathrm{u} / \partial \phi}{\partial \mathrm{u} / \partial \mathrm{r}}
$$

Therefore once the velocity profiles in the radial and circumferential directions and the radial components of diffusivity are known, the circumferential diffusivity components can be determined by Equation (B-32). The derivatives are evaluated by using a first order central difference scheme.

\section{B. 6 METHOD FOR CALCULATION OF HEAT TRANSFER INPUT PARAMETERS}

\section{B.6.1 Determination of Eddy Diffusivities of Heat}

It is assumed that the heat transfer by turbulent mixing is proportional to the momentum transfer by turbulent mixing. Then,

$$
\epsilon_{H}=\bar{\psi} \epsilon_{M}
$$

where:

$\bar{\psi} \quad$ = Constant of proportionality

$\epsilon_{\mathrm{H}}=$ Eddy diffusivity of heat

$\epsilon_{M}=$ Eddy diffusivity of momentum .

Using the correlation of Dwyer ${ }^{(B-6)}$ the constant of proportionality in the radial direction is:

$$
\bar{\psi}_{\mathrm{r}}=1-\frac{1,8 ?}{\mathrm{P}_{\mathrm{R}}\left(\frac{\epsilon \mathrm{mr}}{\nu}\right)_{\max }^{1.4}}
$$

where:

$\dot{\mathrm{P}}_{\mathrm{R}}=$ Prandtl number.

In a similar analogy, the constant of proportionality for the circumferential heat transfer is:

$$
\bar{\psi}_{\phi}=\left[1-\frac{1.82}{\mathrm{P}_{\mathrm{R}}\left(\frac{\epsilon \mathrm{m} \phi}{\nu}\right)_{\max }^{1.4}}\right]
$$


Therefore the equations for the radial and eddy diffusivities for heat are:

$$
\begin{aligned}
& \epsilon_{\mathrm{Hr}}=\left[1-\frac{1.82}{\mathrm{P}_{\mathrm{R}}\left(\frac{\epsilon_{\mathrm{mr}}}{\nu}\right)_{\max }^{1.4}}\right]{ }^{\epsilon \mathrm{mr}} \\
& \epsilon_{\mathrm{H} \phi}=\left[1-\frac{1.82}{\mathrm{P}_{\mathrm{R}}\left(\frac{\epsilon_{\mathrm{m} \phi}}{\nu}\right)_{\max }^{1.4}}\right]{ }^{\epsilon} \mathrm{m \phi} .
\end{aligned}
$$

The maximum values of $\epsilon_{\mathrm{mr}} / \nu$ and $\epsilon_{\mathrm{m} \phi} / \nu$ are determined from the calculated values from the velocity distribution analysis.

\section{B. 6.2 Effective Sodium Conductivity}

An effective conductivity for the sodium coolant can be defined by:

$$
\mathrm{K}_{\mathrm{eff}}=\mathrm{K}_{\mathrm{viscous}}+\mathrm{K}_{\text {turbulent }} .
$$

Since the thermal diffusivity $(\alpha)$ is defined by

$$
\alpha=\frac{\mathrm{K}_{\text {viscous }}}{\rho \mathrm{C}_{\mathrm{p}}}
$$

and defining $\mathrm{K}_{\text {turbulent }}$ by

$$
\epsilon_{\mathrm{H}}=\frac{\mathrm{K}_{\text {turbulent }}}{\rho \mathrm{C}_{\mathrm{p}}}
$$

yields an expression for $\mathrm{K}_{\mathrm{eff}}$ of:

$$
\cdot \mathbf{K}_{\text {eff }}=\rho \mathbf{C}_{\mathbf{p}}\left(\alpha+\epsilon_{\mathrm{H}}\right)
$$

Since the assumption of additive diffusivities is commonly used, this expression should be adequate.

\section{B. 6.3 Temperature Calculations}

The calculations of temperature distributions will be accomplished by use of the generalized nodal heat transfer computer code "THTD." (B-3) 
The input to "THTD" will be the nodal velocity.field as well as an effective conductivity for both radial and circumferential directions for each node.

The "THTD" computer code is basically a two-dimensional, transient, and-steady state-heat transfer code. This code allows each node to have a different conductivity between.adjacent nodes. This code does not allow for axial conduction; however, axial variations can be considered as the code allows for heat addition between axial segments.

The basic geometry is as.shown in Figure B-6.

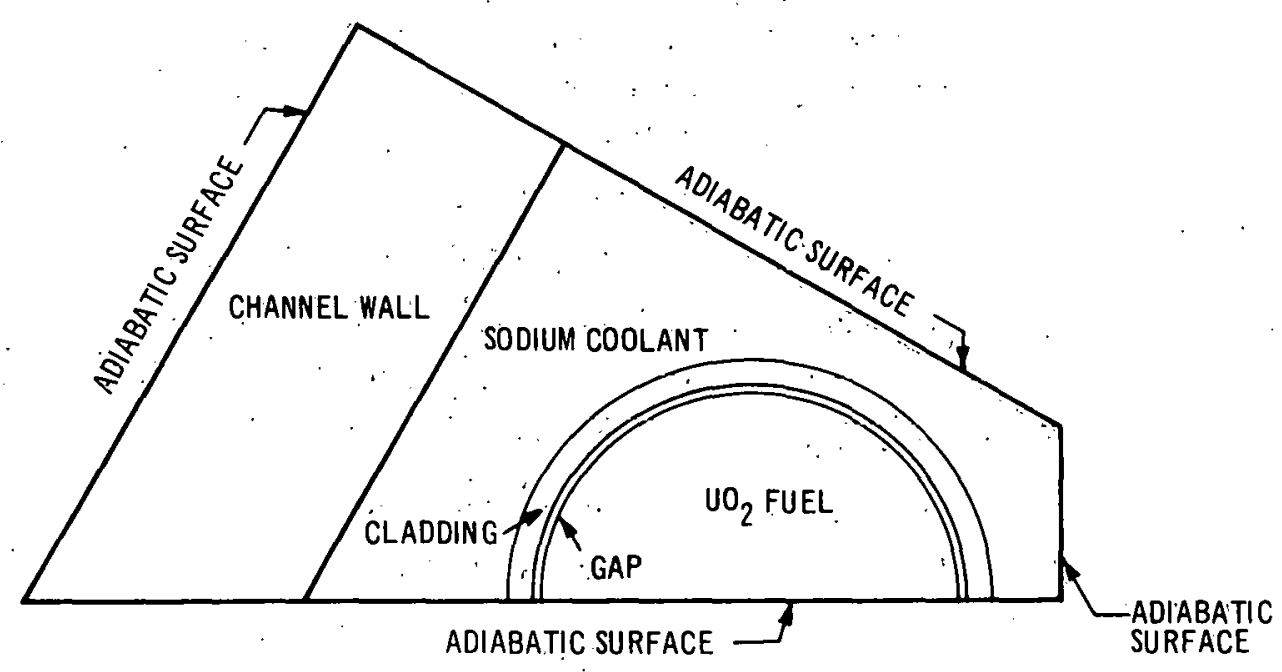

FIGURE B-6. MODEL FOR TEMPERATURE DISTRIBUTION CALCULATIONS 


\section{B. 7 NOMENCLATURE}

\section{ENGLISH SYMBOLS}

\section{DESCRIPTION}

\section{SYMBOL}

$\Delta \mathrm{A}$

$C_{p}$

d

$\mathrm{dA}$

$d_{e}$

$\mathrm{d} \ell$

$\mathrm{dz}$

$\mathrm{d} \phi$

$f$

$\mathrm{g}_{\mathrm{c}}$

$\mathrm{K}_{\text {eff }}$

$\mathrm{k}_{\mathrm{i}}$

$\mathrm{k}_{\mathrm{o}}$

$\ell_{c}$

$\ell_{0}$

$\mathrm{N}_{\mathrm{Re}}$

$\mathrm{p}$

$\mathrm{P}$

$\mathbf{P}_{\mathrm{R}}$

Q

$\mathbf{r}$

$r_{m}$

$\mathrm{R}$

$\mathrm{R}_{\mathrm{e}}$

$\mathrm{R}_{\mathrm{i}}$

$\mathrm{R}_{\mathrm{o}}$

$\mathrm{S}_{\mathrm{i}}$

$\mathrm{S}_{0}$

$\overline{\mathrm{u}}$

$\mathrm{u}_{\mathrm{b}}$

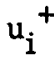

$u_{0}+$

$u_{r}$

Total flow area $\left(\mathrm{ft}^{2}\right)$

Specific heat of coolant $\left(\mathrm{Btu} / \mathrm{lb} \mathrm{b}-{ }^{\circ} \mathrm{F}\right)$

Diameter of fuel pin (ft)

Flow area of circumferential segment $\left(\mathrm{ft}^{2}\right)$

Hydraulic diameter of total section ( $\mathrm{ft}$ )

Differential length of channel wall

Differential distance in axial direction

Differential distance in circumferential direction

Fanning friction factor

Gravitational constant $\left(\mathrm{lb}_{\mathrm{m}}^{*}-\mathrm{ft} / \mathrm{lb}_{\mathrm{f}}-\mathrm{sec}^{2}\right)$

Effective coolant conductivity $(\mathrm{Btu} / \mathrm{h}-\mathrm{ft})$

Nondimensional mixing length in inner region of annulus.

Nondimensional mixing length in outer region of annulus

Turbulent characteristic mixing length (ft)

Length of channel wall (ft)

Reynolds number for equivalent annulus

Pitch or rod to rod center distance ( $\mathrm{ft}$ )

Pressure (psia)

Prandtl number of coolant

Ratio of shear stresses $-\tau_{\mathrm{av}} / \tau_{\mathrm{u}}$

Radial position ( $\mathrm{ft}$ )

Radius of zero shear ( $\mathrm{ft}$ )

Radius of fuel pin ( $\mathrm{ft}$ )

Reynolds number of total section

Inner radius of annulus ( $\mathrm{ft}$ )

Outer radius of annulus (ft)

Ratio of zero shear radius to inner radius of annulus

Ratio of zero shear radius to outer radius of annulus

Coolant velocity in axial direction $(\mathrm{ft} / \mathrm{sec})$

Local mean coolant velocity in circumferential segment $(\mathrm{ft} / \mathrm{sec})$

Bulk coolant velocity (ft/sec).

Nondimensional coolant velocity in. inner region of annulus

Nondimensional coolant velocity in outer region of annulus

Radial component of coolant velocity (ft/sec) 


$\mathrm{u}_{\phi}$
$\mathrm{u}_{\mathrm{z}}$
$\mathrm{x}^{*}$
$\mathrm{y}$
$\mathrm{y}_{\mathrm{e}}$
$\mathrm{y}_{\mathrm{o}}$
$\mathrm{y}_{\mathrm{i}}^{+}$
$\mathrm{y}_{0}^{+}$
$\mathrm{z}^{+}$

GREEK SYMBOLS

$\underline{\text { SYMBOL }}$

$\alpha$

$\beta_{\mathrm{i}}$

$\beta_{0}$

${ }^{\epsilon} \mathrm{Hr}$

${ }^{\epsilon} \mathrm{H} \phi$

${ }^{\epsilon} \mathrm{mr}$

${ }^{\epsilon} \mathrm{m} \phi$

$\eta$

$\nu$

ค

$\tau$ av

$\tau_{\mathrm{av}_{1}}$

$\tau^{\mathrm{av}_{2}}$

$\tau_{1}$

${ }^{\tau} \mathbf{r}_{0}$

${ }^{\top} \mathbf{R}_{\mathbf{i}}$

${ }^{\tau} \mathbf{R}_{0}$

$\tau_{\mathrm{u}}$

$\tau_{\phi_{1}}$
Circumferential component of coolant velocity $(\mathrm{ft} / \mathrm{sec})$

Axial component of coolant velocity (ft/sec)

Distance from rod surface to channel wall at angle of $30^{\circ}$ (ft)

Distance from rod surface to position $r$ (ft)

Local equivalent hydraulic diameter (ft)

Distance from rod surface to outer boundary at position $\phi$. (ft)

Nondimensional distance from rod surface in annulus

Nondimensional distance from outer wall in annulus

Axial position

\section{DESCRIPTION}

Zero when outer boundary is line of symmetry-1.0 when outer boundary is channel wall.

Defined by $r_{m}-r / r_{m}-R_{i}$

Defined by $r-r_{m} / R_{o}-r_{m}$

Radial component of eddy diffusivity of heat $\left(\mathrm{ft}^{2} / \mathrm{sec}\right)$

Circumferential component of eddy diffusivity of heat $\left(\mathrm{ft}^{2} / \mathrm{sec}\right)$.

Radial component of eddy diffusivity of momentum ( $\mathrm{ft}^{2} / \mathrm{sec}$ )

Circumferential component of eddy diffusivity of momentum $\left(\mathrm{ft}^{2} / \mathrm{sec}\right)$

Nondimensional ratio of local mean velocity to bulk velocity of coolant Kinematic viscosity of coolant $\left(\mathrm{ft}^{2} / \mathrm{sec}\right)$

Density of coolant $\left(\mathrm{lb}_{\mathrm{m}^{\prime}} / \mathrm{ft}^{3}\right)$

Shear stress averaged over rod surface and channel wall $\left(\mathrm{lb}_{\mathrm{f}} / \mathrm{ft}^{2}\right)$

Shear stress averaged over rod surface $\left(\mathrm{lb}_{\mathrm{f}} / \mathrm{ft}^{2}\right)$

Shear stress averaged over channel wall $\left(\mathrm{lb}_{\mathrm{f}} / \mathrm{ft}^{2}\right)$

Shear stress at position $r$ in inner region of annulus $\left(\mathrm{db}_{\mathrm{f}} / \mathrm{ft}^{2}\right)$

Shear stress at position $r$ in outer region of annulus $\left(\mathrm{lb}_{\mathrm{f}} / \mathrm{ft}^{2}\right)$

Shear stress on inner surface of annulus $\left(\mathrm{lb}_{\mathrm{f}} / \mathrm{ft}^{2}\right)$

Shear stress on inner surface of annulus $\left(\mathrm{lb}_{\mathrm{f}} / \mathrm{ft}^{2}\right)$

Average shear ștress in uniform geometry - annulus $\left(\mathrm{lb}_{\mathrm{f}} / \mathrm{ft}^{2}\right)$

Local shear stress on rod surface $\left(\mathrm{lb}_{\mathrm{f}} / \mathrm{ft}^{2}\right)$ 
$\tau_{\phi_{2}}$

$\tau_{\phi \phi}$

$\phi$

$\phi^{*}$

$\bar{\psi}_{\mathrm{r}}$

$\bar{\psi}_{\phi}$
Local shear stress on channel wall $\left(\mathrm{lb}_{\mathrm{f}} / \mathrm{ft}^{2}\right)$.

Circumferential shear stress due to eddy diffusivity $\left(\mathrm{lb}_{\mathrm{f}} / \mathrm{ft}^{2}\right)$

Circumferential position

Circumferential position at which channel wall ends (radians)

Ratio of eddy diffusivity of heat to eddy diffusivity of momentum radial component

Ratio of eddy diffusivity of heat to eddy diffusivity of momentum circumferential component 


\section{REFERENCES FOR APPENDIX B}

B. 1 Bender, D.J., Switick, D.M., and Field, J.H., "Turbulent Velocity Distribution in a Rod Bundle," October 1967, (GEAP-5411).

B. 2 Nijsing, R., Gargantini, I., and Eifler, W., " Fundamental Studies of ,Fluid Flow and Heat Transfer in Fuel Element Geometries I. Analysis of Fluid Flow and Heat Transfer in a Triangular Array for Parallel Heat Generating Rods, "1964, (EUR-2913.E).

B. 3 "Users Manual for the THTD Computer Program," P.O. No. 036926052 T0602, Nuclear Materials and Propulsion Operation, Nuclear Technology Dept., General Electric Company, Cincinnati, Ohio, 1966, (45215).

B. 4 Levy, S., "Turbulent Flow in an Annulus," October 1965, (GEAP-4976).

B. 5 Hooper, G.T.J., "Turbulent Momentum Diffusivity Within a Circular Tube, "Int. J. Heat and Mass Transfer, 6, (1963).

B. 6 Dwyer, O. E., "Eddy Transport in Liquid-Metal Heat Transfer," A.I. Ch. 'E Journal, $\underline{9}$, 2, pp 261-268, March (1963). 


\title{
APPENDIX C
}

\author{
RESULTS OF THERMAL HYDRAULIC \\ PARAMETER STUDY-CORE CHARACTERISTICS
}

\section{1 ANALYSIS}

The variations in core pressure drop (plenum to plenum) and core linear power for FFTF were investigated as functions of core height, fuel pin diameter, fuel cladding thickness and pitch to diameter ratio. The results of this study influenced the reference thermal hydraulic characteristics given in Section 4. 7 .

The plenum to plenum pressure drop was calculated for the "hot" fuel bundle shown in Figure C-1. Two driver fuel pin lengths of 36 inches and 33 inches with gas plenum lengths equal to fuel pin lengths were investigated. The wire spacers have a pitch of 1 wrap per foot. The sodium coolant velocity through the core is shown in Figure C-2.

The reactor power distribution has $95 \%$ of the rated power (400 MWt) generated by the core. The linear power results for the following conditions are shown in Figure C-3. Only the results for the 36-inch fuel pins are shown as fuel linear power did not change noticeably for the 33-inch pins. The fuel pellet density is $95 \%$ of theoretical and the pellet-to-clad radial gap is 0.002 inches. The melt temperature for new fuel is taken as $5200^{\circ} \mathrm{F}$. The curve of the $\int \mathrm{Kd} \theta$ is shown in Figure C-4. The axial and radial peak-to-average power factors chosen are 1.20 and 1.40 , respectively, and the core overpower factor is 1.20 . The peaking factor due to all secondary effects is 1.09 . The overall peak-to-average $(1.2 \times 1.4 \times 1.2 \times 1.09)$ is 2.19 .

The plenum to plenum pressure drop is a composite of fuel, reflector, and entrance-exit region pressure drop. The pressure loss inventory may be summarized as follows:

a. Expansion loss from circular hydraulic hold down area to the hexagonal fuel bundle area

b. Extrance and exit losses in the axial blankets

c. Frictional losses in the axial blanket

d. Entrance and exit losses to fuel and gas plenum section

e. Frictional losses in fuel and gas plenum section (including wire wrap losses)

Figure C-5 summarizes the total pressure loss from plenum to plenum. Figure C-6 presents the frictional, entrance, and exit losses for the fuel and gas plenum sections only (Items d. and e.). 


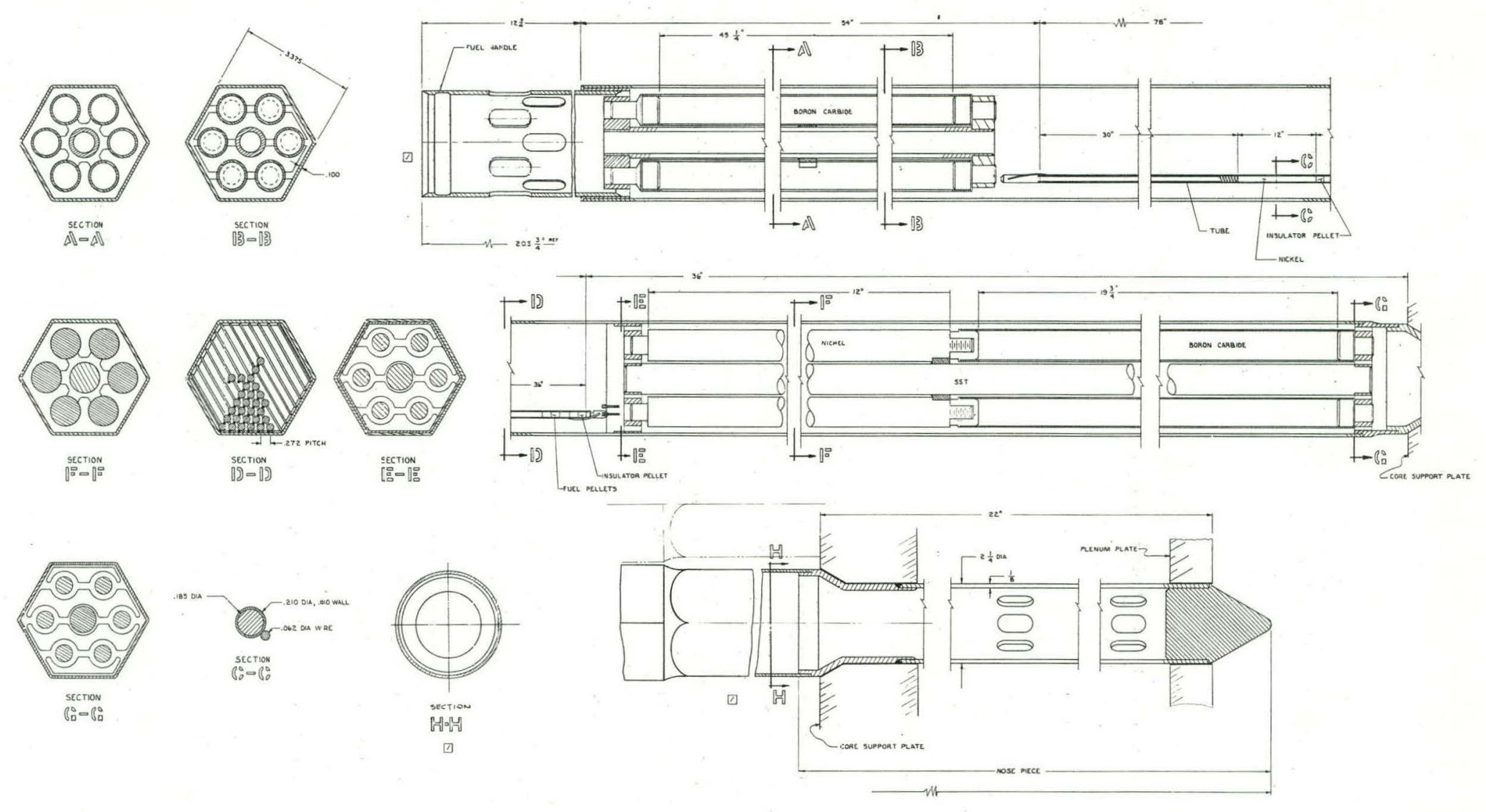

FIG. SK 2 DRIVER FUEL ELEMENT 


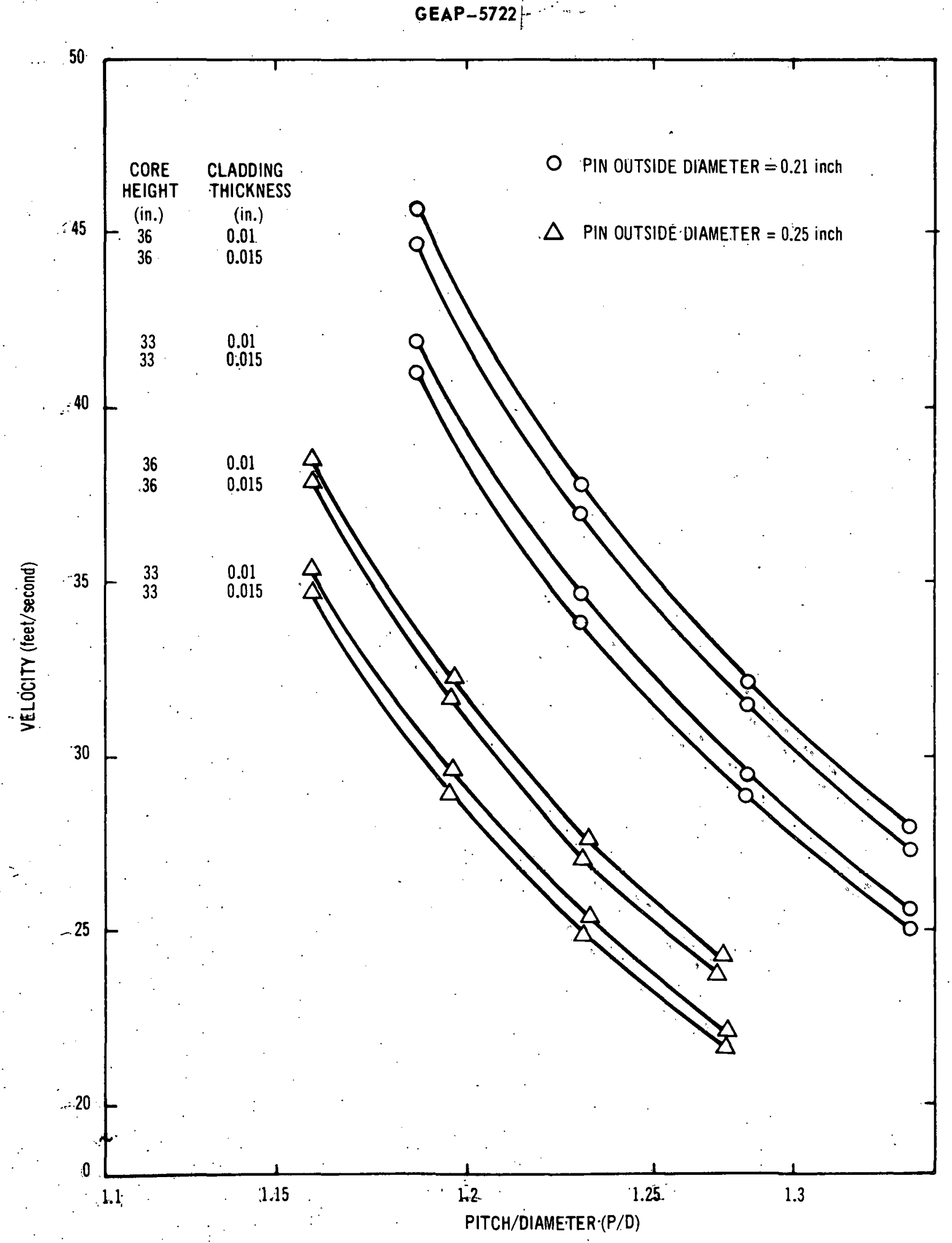

FIGURE C-2. VELOCITY OF SODIUM COOLANT THROUGH THE FUEL BUNDLE $\because$

$C-3$ 


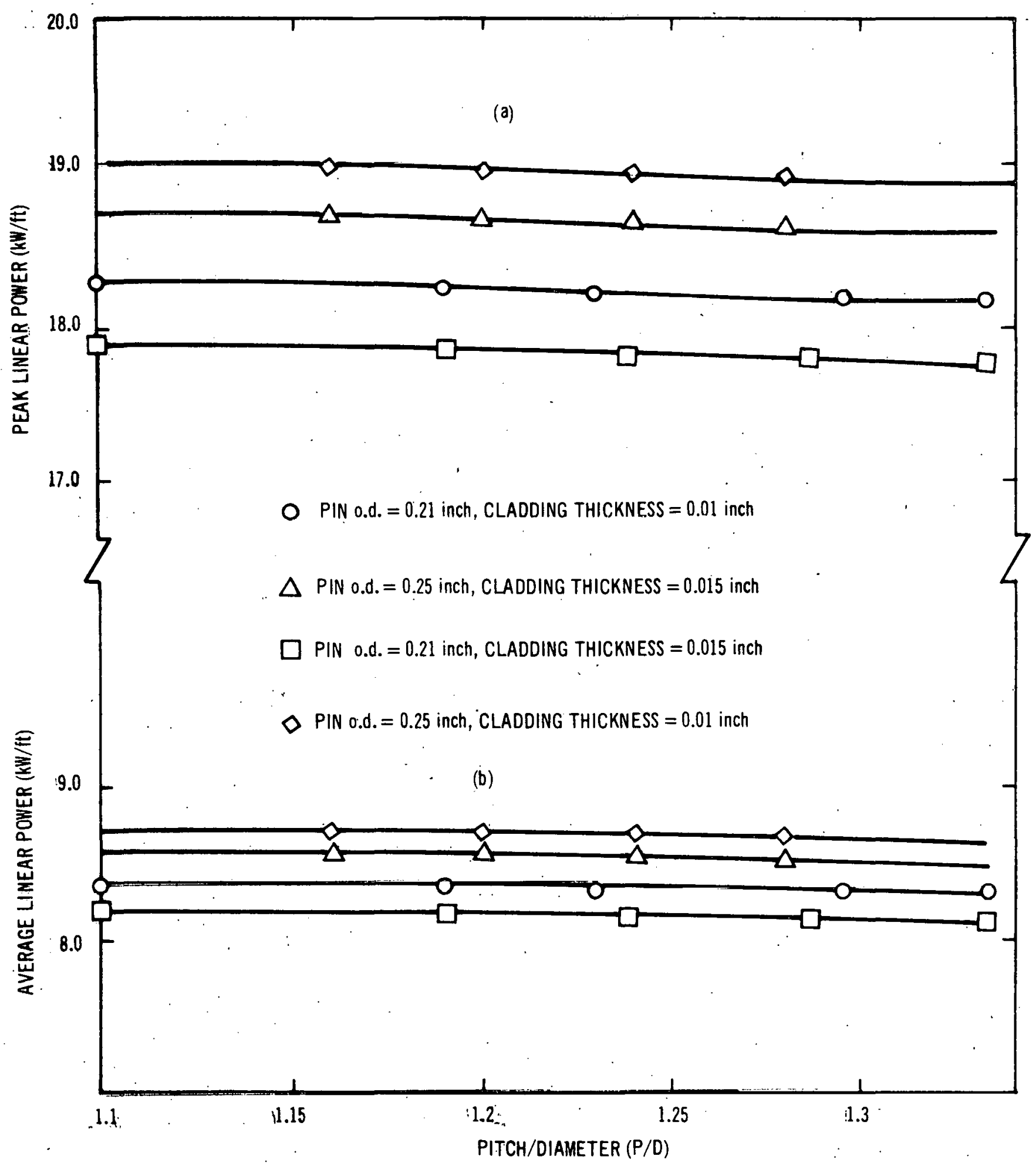




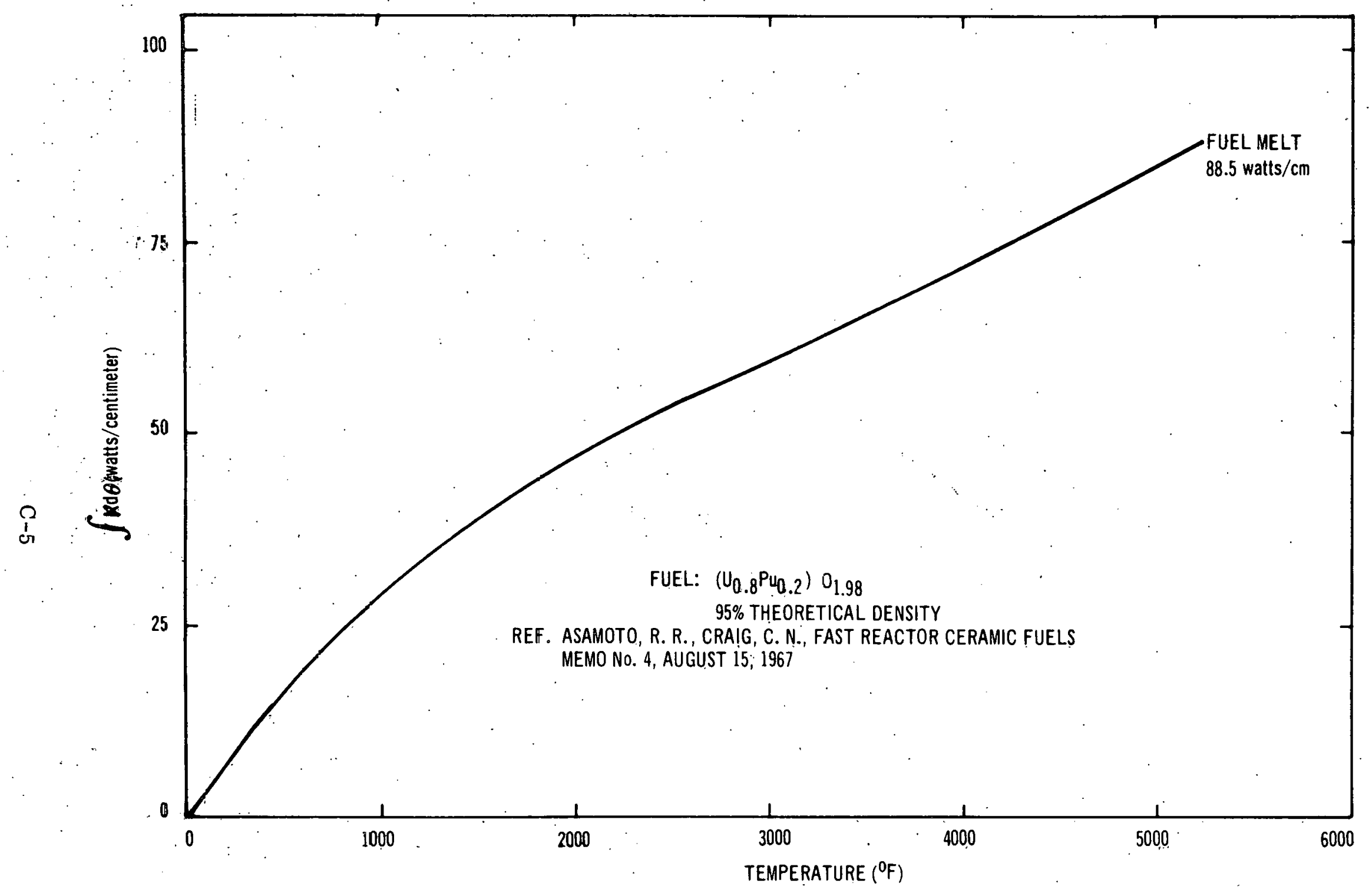




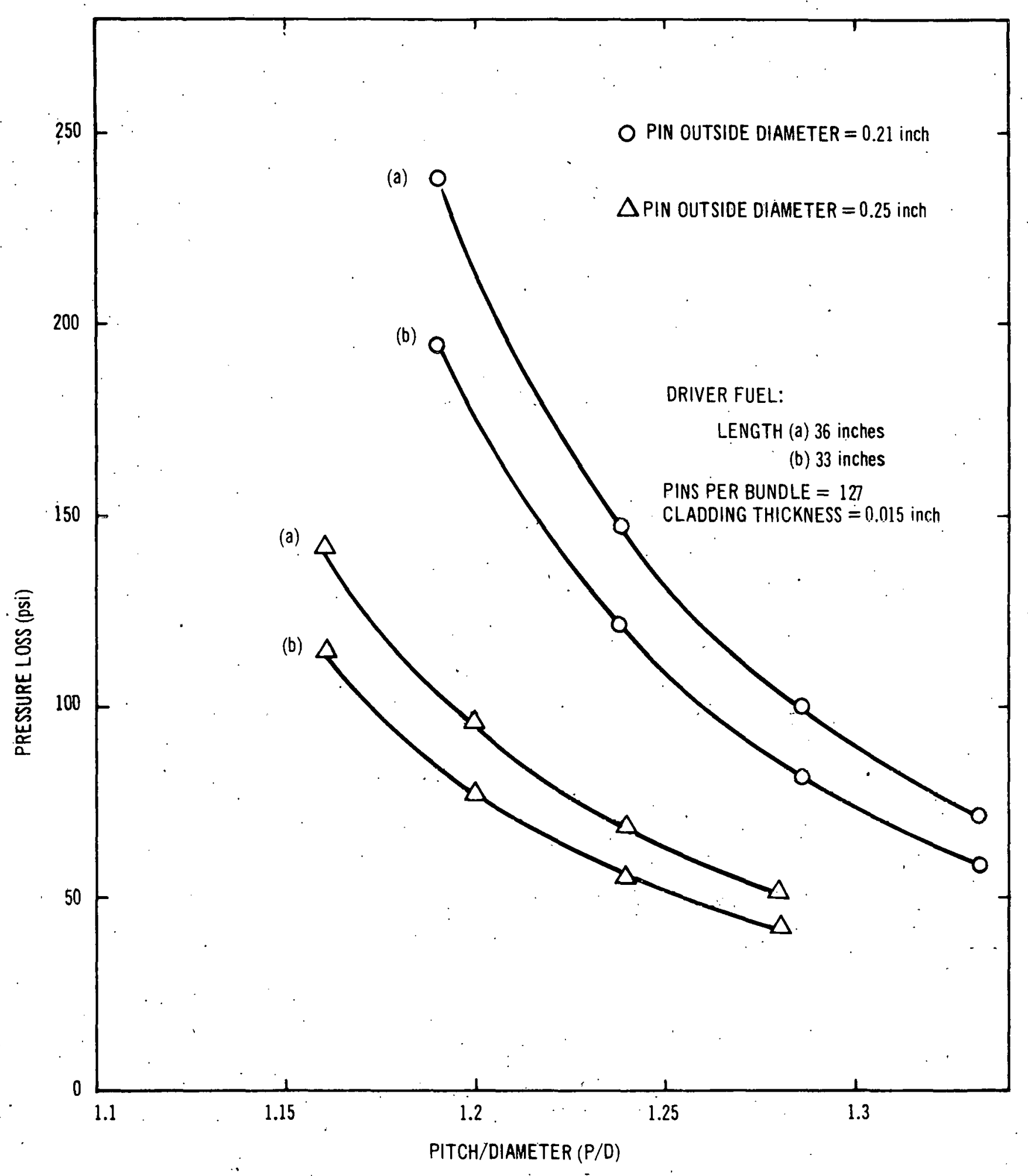

F.IGURE C-5. TOTAL PRESSURE LOSS FROM PLENUM TO PLENUM

$$
\therefore \quad C-6
$$




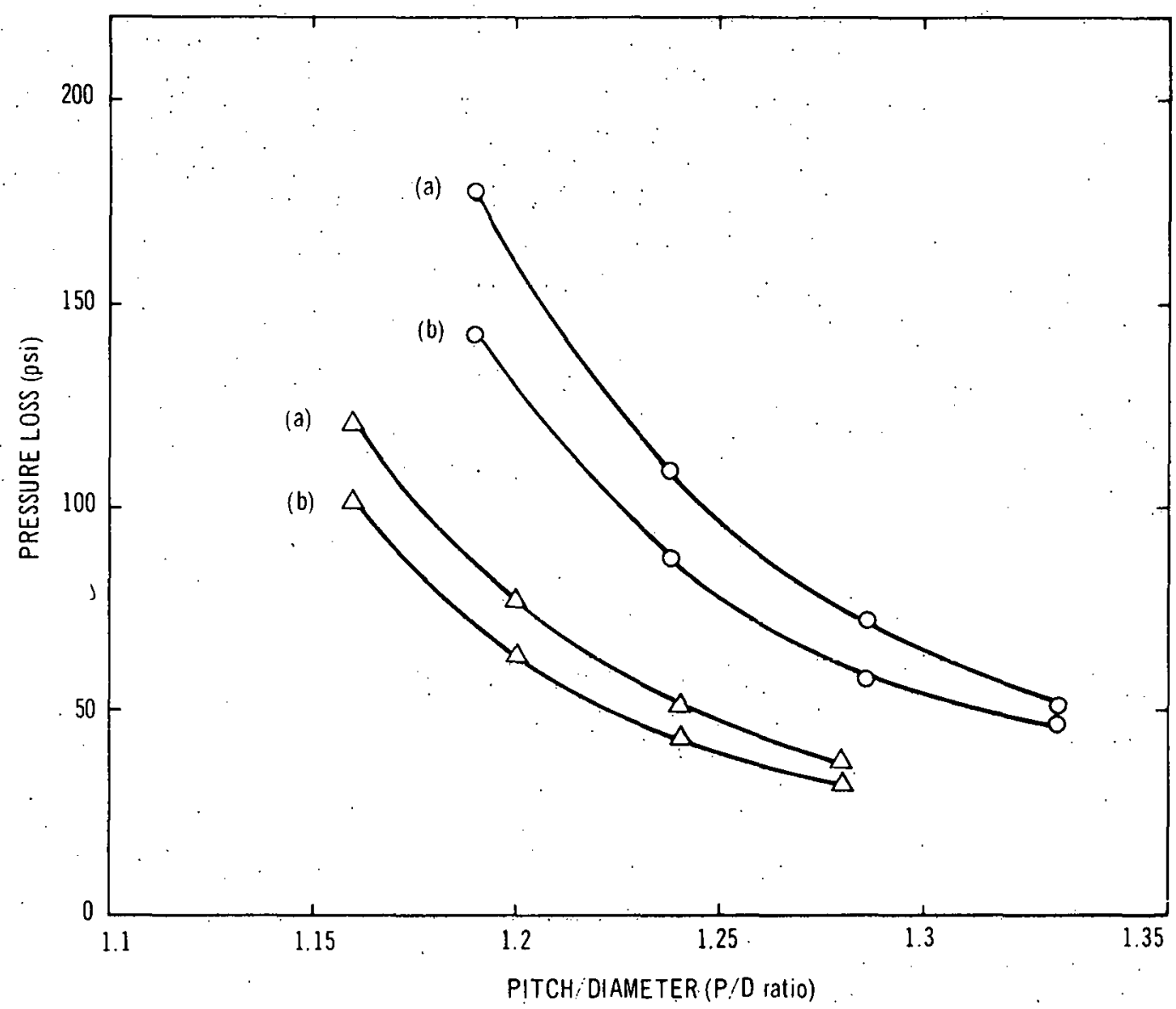

PINS PER BUNDLE $=127$

CLADDING THICKNESS $=0.015$ inch
FUEL LENGTH (a) 36 inch TOTAL PIN LENGTH

(b) 33 inch

(a) 84 inch

(b) 78 inch

O PIN o.d. $=0.21$ inch

$\Delta$. PIN o.d. $=0.25$ inch 


\section{APPENDIX D}

\section{SINGLE PISTON MODEL FOR CONTROL BUNDLE DECELERATION}

\section{1 NOMENCLATURE USED IN DERIVATION}

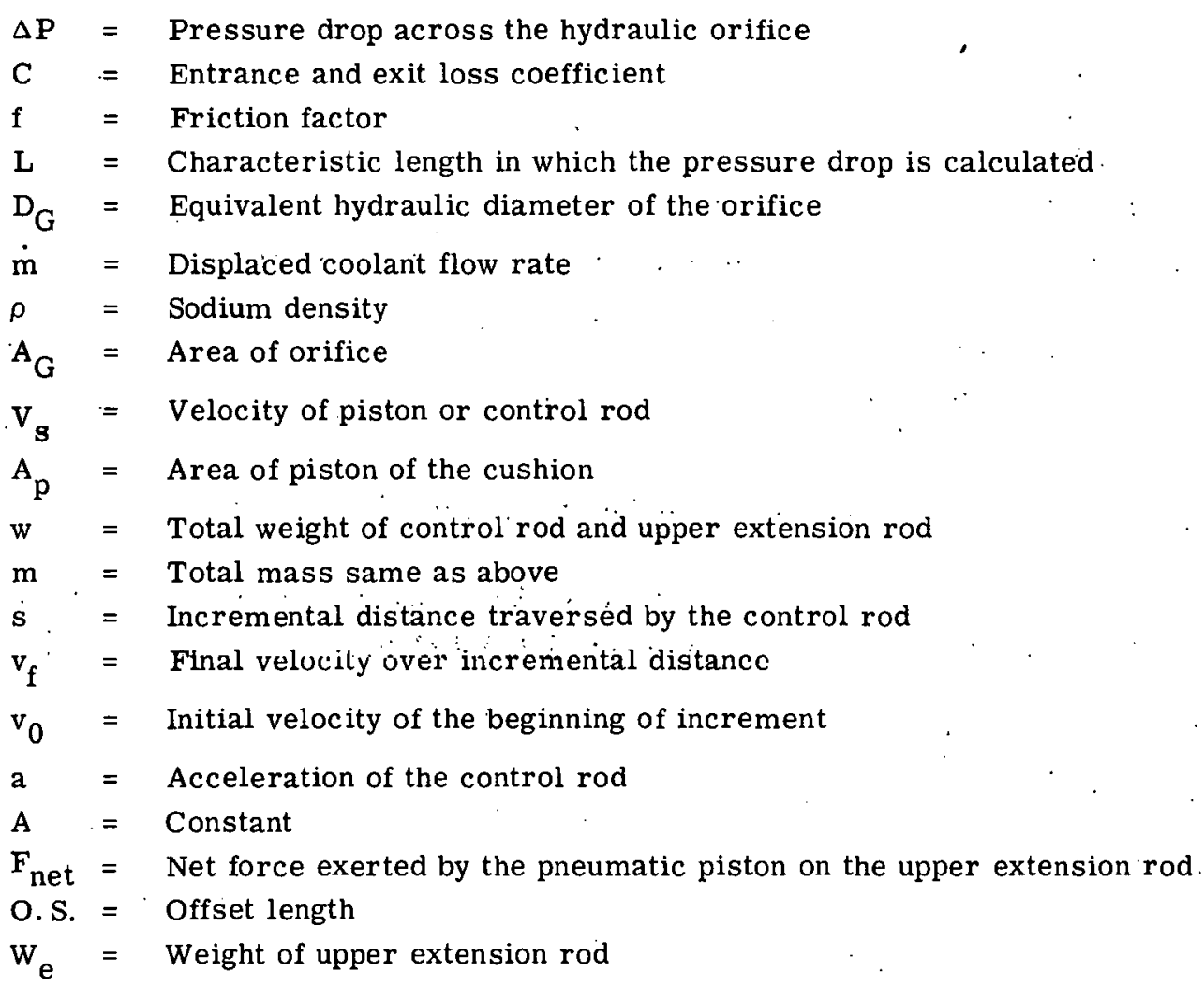

\section{2 ZERO SCRAM FORCE}

\section{.. - ...}

The pressure drop across the hydraulic snubber can be expressed as

$\Delta P=\left(c+f \frac{L}{D_{G}}\right) \frac{\dot{m}^{2}}{2 g_{c} \rho A_{G}^{2}}$

The coolant flow, $\dot{\mathrm{m}}$, is defined as the displaced coolant

$$
\dot{\mathrm{m}}=\rho \mathrm{VpAp}
$$

The hydraulic force exerted on the snubber piston is

$$
F=\Delta P A_{p}
$$

Combining Equations (D-1, D-2, and D-3) the following relationship is obtained 


$$
F=\left(c+f \frac{L}{D_{G}}\right) \rho \frac{V_{p}{ }^{2} A_{p}^{3}}{2 g_{c} A_{G}{ }^{2}}
$$

which is the hydraulic force exerted on the piston.

From the equations of linear motion

$F-W=m a$

$v_{f}^{2}=v_{0}^{2}+2 a s$

Equating Equations (D-5) and (D-6), the resultant force of motion is

$$
F=W\left(1+\frac{v_{0}^{2}-v_{f}^{2}}{2 s g}\right)
$$

which is the force required to decelerate the control rod.

The hydraulic force and the force of motion are equated to determine the velocity of the control rod. Equating Equations(D-4) and (D-7), rearranging, and defining

$$
\begin{aligned}
& k=\left(c+f \frac{L}{D_{G}}\right) \\
& v_{p}=\frac{v_{0}+v_{f}}{2} \\
& A=\frac{\operatorname{sgk} \rho A_{p}^{3}}{4 w_{c} A_{G}^{2}}
\end{aligned}
$$

and implicitly expressing in terms of $v_{\mathbf{f}}$,

$$
v_{f}^{2}(1+A)+\left(2 A v_{0}\right) v_{f}+\left[v_{0}^{2}(A-1)-2 s g\right]=0
$$

Transient analysis is approximated from Equation (D-8) by calculating the incremental velocity change for an incremental distance change.

\section{3 SCRAM FORCE NOT EQUAL TO ZERO}

The hydraulic force exerted on the piston is equation (D-4). The equation of linear motion is now

$$
F-w+F_{\text {net }}=- \text { ma }
$$


Combining Equations (D-9) and (D-6), and solving for the force,

$$
F=\frac{v_{0}^{2}-v_{f}^{2}}{2 s}\left(\frac{w}{g}\right)+w-F_{n e t}
$$

And again defining

$$
\begin{aligned}
& v_{p}=\frac{v_{0}+v_{f}}{2} \\
& k=\left(c+f \frac{L}{D_{G}}\right) \\
& A=\frac{k s g \rho A_{p}^{3}}{4 g_{c} A_{G}^{2}}
\end{aligned}
$$

and solving for $v_{f}$ implicitly after equating Equations (D-4) and (D-10),

$$
(1+A) v_{f}^{2}+\left(2 A v_{0}\right) v_{f}+\left[v_{0}^{2}(A-1)-2 s g+\frac{2 s g}{w} F_{n e t}\right]=0
$$

Transient analysis is simulated by Equation (D-11) to obtain the velocity profile. The force. is calculated by equation (D-10).

The moment exerted on the offset is determined by

$$
M=0 . S \times\left[w_{e}\left(1-\frac{a}{g}\right)-F_{n e t}\right]
$$




\section{APPENDIX E}

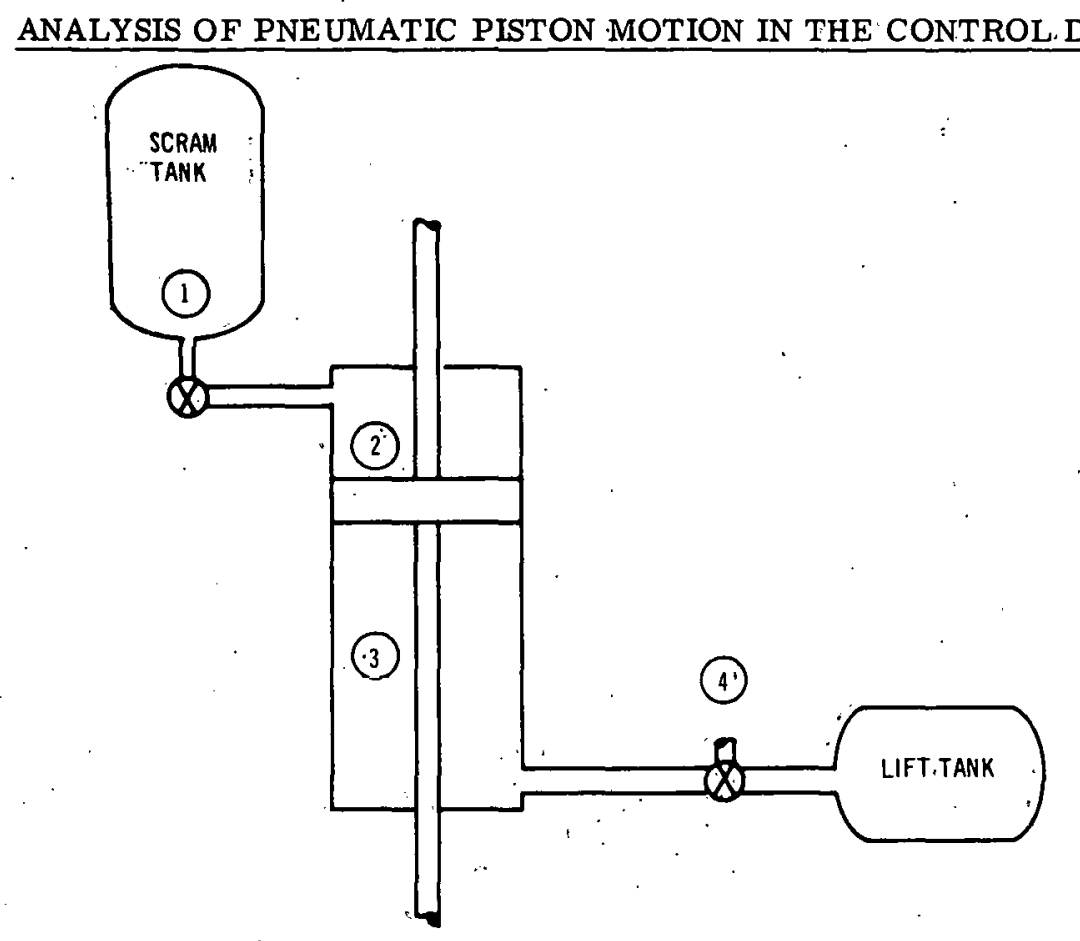

FIGURE E-1. DYNAMIC CONTROL: DRIVE MODEL SCHEMATIC

Figure E-1 shows the model of the drive used in the analysis of the drive dynamics. The following was assumed:

a. Gas flow is adiabatic and reversible

b. No gas leakage from the system

c. Friction and viscous forces are constants

d. Perfect gas law can be used to calculate pressure in each chamber

e. Gas compression in cylinder is an.adiabatic process.

The energy equation assumes an adiabatic process:

$$
\left(\frac{v^{2}}{2 g}+z+E_{n}\right)_{1}+\left(E_{a}-E_{g}\right)=\left(\frac{v^{2}}{2 g}+z+E_{n}\right)_{2}
$$

Neglecting elevation and energy added or subtracted:

$$
\frac{v_{2}^{2}}{2 g}-\frac{v_{1}^{2}}{2 g}=E_{n_{1}}-E_{n_{2}}
$$


From the thermodynamic relationship of steady flow adiabatic process:

$$
\begin{aligned}
& \mathrm{W}=\mathrm{h}_{1}-\mathrm{h}_{2}=\mathrm{C}_{\mathrm{po}}\left(\mathrm{T}_{1}-\mathrm{T}_{2}\right) \\
& \mathrm{C}_{\mathrm{po}}=\frac{\mathrm{kR}}{\mathrm{k}-1} \\
& \quad \mathrm{E}_{\mathrm{n}_{1}}-\mathrm{E}_{\mathrm{n}_{2}}=\frac{\mathrm{k}}{\mathrm{k}-1}\left(\frac{\mathrm{P}_{1}}{\gamma_{1}}-\frac{\mathrm{P}_{2}}{\gamma_{2}}\right)=\frac{\mathrm{kR}}{\mathrm{k}-1}\left(\mathrm{~T}_{1}-\mathrm{T}_{2}\right)
\end{aligned}
$$

Combining Equations (E-2) and $(E-3)$ :

$$
\begin{gathered}
\frac{\mathrm{v}_{2}^{2}}{2 \mathrm{~g}}-\frac{\mathrm{v}_{1}^{2}}{2 \mathrm{~g}}=\frac{\mathrm{k}}{\mathrm{k}-1}\left(\frac{\mathrm{P}_{1}}{\gamma_{1}}-\frac{\mathrm{P}_{2}}{\gamma_{2}}\right)=\frac{\mathrm{k}}{\mathrm{k}-1} \mathrm{R}\left(\mathrm{T}_{1}-\mathrm{T}_{2}\right) \\
\frac{\mathrm{P}_{1}}{\gamma_{1}^{\mathrm{k}}}=\frac{\mathrm{P}_{2}}{\gamma_{2}^{\mathrm{k}}}=\mathrm{constant} \\
\frac{\mathrm{v}_{2}^{2}}{2 \mathrm{~g}}-\frac{\mathrm{v}_{1}^{2}}{2 \mathrm{~g}}=\frac{\mathrm{P}_{1}}{\gamma_{1}} \frac{\mathrm{k}}{\mathrm{k}-1}[\vdots \\
\vdots
\end{gathered}
$$

In the scram tank, $v_{1}=0$

$$
\frac{v_{2}^{2}}{2 g}=\frac{P_{1}}{\gamma_{1}}\left(\frac{k}{k-1}\right)\left[1-\left(\frac{P_{2}}{P_{1}}\right)^{\frac{k-1}{k}}\right]
$$

From the continuity equation:

$$
\dot{\mathrm{m}}=\mathrm{A}_{1} \mathrm{v}_{1} \dot{\gamma}_{1}
$$

and:

$$
\begin{aligned}
& \frac{\mathrm{P}_{1}}{\gamma_{1}^{\mathrm{k}}}=\frac{\mathrm{P}_{2}}{\gamma_{2}^{\mathrm{k}}} \\
& \frac{\dot{\mathrm{m}}}{\mathrm{A}_{1}}=\mathrm{v}_{1} \gamma_{1}=\left\{2 \mathrm{~g} \mathrm{P}_{1} \frac{\gamma_{2}^{2}}{\gamma_{1}} \cdot\left(\frac{\mathrm{k}}{\mathrm{k}-1}\right)\left[1-\left(\frac{\mathrm{P}_{2}}{\mathrm{P}_{1}}\right)^{\frac{\mathrm{k}-1}{\mathrm{k}}}\right]\right\}^{\frac{1}{2}} \\
& \frac{\dot{\mathrm{m}}}{\mathrm{A}_{1}}=\mathrm{v}_{1} \gamma_{1}=\left\{2 \mathrm{~g} \mathrm{P}_{1}\left(\frac{\mathrm{k}}{\mathrm{k}-1}\right) \gamma_{1}\left[\left(\frac{\mathrm{P}_{2}}{\mathrm{P}_{1}}\right)^{2 / \mathrm{k}}-\left(\frac{\mathrm{P}_{2}}{\mathrm{P}_{1}}\right)^{\frac{\mathrm{k}+1}{\mathrm{k}}}\right]\right\}^{\frac{1}{2}}
\end{aligned}
$$


Ideal gas relationship:

$$
\gamma_{1}=\frac{\mathrm{P}_{1}}{\mathrm{RT}_{1}},
$$

The flow equation is:

$$
\dot{\mathrm{m}}_{1-2}=\mathrm{A}_{1} \mathrm{P}_{1}\left[\frac{2 \mathrm{gk}}{\mathrm{k}-1} \frac{1}{\mathrm{RT}_{1}}\left\{\left(\frac{\mathrm{P}_{2}}{\mathrm{P}_{1}}\right)^{2 / \mathrm{k}}-\left(\frac{\mathrm{P}_{2}}{\mathrm{P}_{1}}\right)^{\frac{\mathrm{k}+1}{\mathrm{k}}}\right\}\right]^{-\frac{1}{2}}
$$

Maximum discharge is:

$$
\left(\frac{P_{2}}{\mathrm{P}_{1}}\right)=\left(\frac{2}{k+1}\right)^{k / k-1}
$$

For argon, $\mathrm{k}=1.668$

$$
\left(\frac{\mathrm{P}_{2}}{\mathrm{P}_{1}}\right)_{\mathrm{C}}=\left(\frac{2}{2.668}\right)^{\frac{1.668}{0.668}}=(0.75)^{0.25}=0.487
$$

Rewriting Equation (E-11) in terms of critical pressure ratio:

$$
\left(\frac{\dot{m}}{A_{1}}\right)_{\max }=\sqrt{\frac{2 g k}{k-1}\left(P_{1} \gamma_{1}\right)\left(\frac{2}{k+1}\right)^{2 / k-1}\left(\frac{k-1}{k+1}\right)^{\frac{k+1}{2}}}
$$

The mass of the gas in the chamber:

$$
\begin{aligned}
& \mathrm{m}_{2}=\mathrm{m}_{02}+\int_{0}^{t} \dot{\mathrm{m}}_{1-2} \mathrm{dt} \\
& \mathrm{m}_{3}=\mathrm{m}_{03}-\int_{0}^{\mathrm{t}} \dot{\mathrm{m}}_{3-4} \mathrm{dt}
\end{aligned}
$$

Gas Pressure required to calculate the flow rate:

$$
\begin{aligned}
& \mathrm{P}_{2}=\frac{\mathrm{m}_{2} \mathrm{RT}_{2}}{\mathrm{~V}_{2}} \\
& \mathrm{P}_{3}=\frac{\mathrm{m}_{3} \mathrm{RI}_{3}}{\mathrm{~V}_{3}}
\end{aligned}
$$

The mass calculated in the previous incremental step is used:

$$
Q=c p \cdot m_{2}\left(T_{2}-T_{02}\right) J
$$




$$
\begin{aligned}
& T_{2}=T_{02}-\frac{m_{c r} \ddot{x} x}{m_{2} c p J} \\
& V_{2}=v_{02}+A_{2} x \\
& V_{3}=v_{03}-A_{3} x \\
& Q=c p m_{3}\left(T_{3}-T_{03}\right) J \\
& T_{3}=T_{03}+\frac{m_{c r} \ddot{x} x}{m_{3} c p J}
\end{aligned}
$$

From Equations (E-16), (E-19), and (E-20):

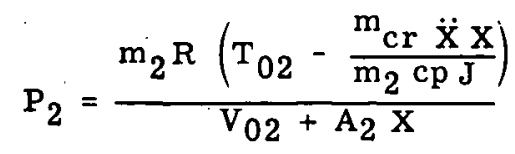

Mass flow exiting out the bottom of cylinder:

$$
\begin{gathered}
\frac{\mathrm{v}_{4}^{2}}{2 \mathrm{~g}}-\frac{\mathrm{v}_{3}^{2}}{2 \mathrm{~g}}=\mathrm{E}_{\mathrm{n} 3}-\mathrm{E}_{\mathrm{n} 4} \\
\mathrm{~W}=\mathrm{h}_{3}-\mathrm{h}_{4}=\mathrm{cp}\left(\mathrm{T}_{3}-\mathrm{T}_{4}\right) \\
\mathrm{E}_{\mathrm{n} 1}-\mathrm{E}_{\mathrm{n} 2}=\frac{\mathrm{kR}}{\mathrm{k}-1}\left(\mathrm{~T}_{3}-\mathrm{T}_{4}\right)=\frac{\mathrm{k}}{\mathrm{k}-1}\left(\frac{\mathrm{P}_{3}}{\gamma_{3}}-\frac{\mathrm{P}_{4}}{\gamma_{4}}\right) \\
\frac{\mathrm{v}_{4}^{2}}{2 \mathrm{~g}}-\frac{\mathrm{v}_{3}^{2}}{2 \mathrm{~g}}=\frac{\mathrm{k}}{\mathrm{k}-1}\left(\frac{\mathrm{P}_{3}}{\gamma_{3}}-\frac{\mathrm{P}_{4}}{\gamma_{4}}\right) \\
=\frac{\mathrm{P}_{4}}{\gamma_{4}},\left(\frac{\mathrm{P}_{3}}{\mathrm{P}_{4}} \frac{\gamma_{4}}{\gamma_{3}}-1\right) \frac{\mathrm{k}}{\mathrm{k}-1} \\
\frac{\mathrm{P}_{3}}{\gamma_{3}^{\mathrm{k}}}=\frac{\mathrm{P}_{4}}{\gamma_{4}^{\mathrm{k}}},\left(\frac{\gamma_{4}}{\gamma_{3}}\right)=\frac{\mathrm{P}_{4}}{\mathrm{P}_{3}} \\
\frac{\gamma_{4}}{\gamma_{3}}=\left(\frac{\mathrm{P}_{4}}{\mathrm{P}_{3}}\right) \frac{1}{\mathrm{k}}
\end{gathered}
$$




$$
\frac{\mathrm{V}_{4}^{2}}{2 \mathrm{~g}}-\frac{\mathrm{V}_{3}^{2}}{2 \mathrm{~g}}=\frac{\mathrm{P}_{4}}{\gamma_{4}} \frac{\mathrm{k}}{\mathrm{k}-1}\left[\left(\frac{\mathrm{P}_{3}}{\mathrm{P}_{4}}\right)^{\frac{\mathrm{k}-1}{\mathrm{k}}}-1\right]
$$

$\mathrm{V}_{4}=0$ atmospheric

$$
\begin{aligned}
& \frac{\mathrm{v}_{3}^{2}}{2 \mathrm{~g}}=-\frac{\mathrm{P}_{4}}{\gamma_{4}} \frac{\mathrm{k}}{\mathrm{k}-1}\left[\left(\frac{\mathrm{P}_{3}}{\mathrm{P}_{4}}\right)^{\frac{\mathrm{k}-1}{\mathrm{k}}}-1\right] \\
& \dot{\mathrm{m}}_{3-4}=\mathrm{A}_{4} \mathrm{v}_{4}{ }_{4}=\mathrm{A}_{3}\left\{2 \mathrm{~g} \frac{\mathrm{P}_{4}}{\gamma_{4}} \gamma_{3}^{2}\left(\frac{\mathrm{k}}{\mathrm{k}-1}\right)\left[\left(\frac{\mathrm{P}_{3}}{\mathrm{P}_{4}}\right)^{\frac{\mathrm{k}-1}{\mathrm{k}}}-1\right]\right\}^{\frac{1}{2}} \\
& \left(\frac{\gamma_{3}}{\gamma_{4}}\right)^{2}=\left(\frac{\mathrm{P}_{3}}{\mathrm{P}_{4}}\right)^{\frac{2}{\mathrm{k}}} \cdot\left(\frac{1}{\dot{\mathrm{m}}_{3-4}}=\mathrm{A}_{4} \mathrm{P}_{4}\left\{\frac{\mathrm{k}}{\mathrm{RT}}\right)\left[\left(\frac{\mathrm{P}_{3}}{\mathrm{P}_{4}}\right)^{\frac{\mathrm{k}+1}{\mathrm{k}}}-\left(\frac{\mathrm{P}_{3}}{\mathrm{P}_{4}}\right)^{\frac{2}{\mathrm{k}}}\right]\right\}^{\frac{1}{2}}
\end{aligned}
$$

Flow equation out of the lower section of the cylinder:

$$
\begin{aligned}
& \left(\frac{\mathrm{P}_{3}}{\mathrm{P}_{4}}\right)^{\frac{\mathrm{k}+1}{\mathrm{k}}}=\left(\frac{2}{\mathrm{k}+1}\right)^{\frac{\mathrm{k}}{\mathrm{k}-1} \frac{\mathrm{k}+1}{\mathrm{k}}}=\left(\frac{2}{\mathrm{k}+1}\right)^{\frac{\mathrm{k}+1}{\mathrm{k}-1}}\left(\frac{\mathrm{P}_{3}}{\mathrm{P}_{4}}\right)^{2 / \mathrm{k}}=\left(\frac{2}{\mathrm{k}+1}\right)^{\frac{2}{\mathrm{k}} \frac{\mathrm{k}}{\mathrm{k}-1}}=\left(\frac{2}{\mathrm{k}+1}\right)^{\frac{2}{\mathrm{k}-1}} \\
& \frac{2}{\mathrm{k}+1}^{\frac{\mathrm{k}+1}{\mathrm{k}-1}}-\left(\frac{2}{\mathrm{k}+1}\right)^{\frac{2}{\mathrm{k}+1}}=\left(\frac{2}{\mathrm{k}+1}\right)^{\frac{2}{\mathrm{k}-1}}\left[\left(\frac{2}{\mathrm{k}+1}\right)^{\frac{\mathrm{k}+1}{2}}-1\right] \\
& =\left(\frac{2}{k+1}\right)^{\frac{2}{k-1}}\left(\frac{2-k-1}{k+1}\right)^{\frac{k+1}{2}}=\left(\frac{2}{k+1}\right)^{\frac{2}{k-1}}\left(\frac{1-k}{k+1}\right)^{\frac{k+1}{2}} \\
& \mathrm{P}_{3}=\frac{\mathrm{m}_{3} \mathrm{RT}_{3}}{\mathrm{~V}_{3}} \\
& \mathrm{~T}_{3}=\mathrm{T}_{03}+\frac{\mathrm{m}_{\mathrm{cr} \ddot{\mathrm{x}} \mathrm{x}}}{\mathrm{m}_{3} \mathrm{cpJ}} \\
& \mathrm{v}_{3}=\mathrm{v}_{03}-A_{3} \mathrm{x} \\
& P_{3}=\frac{m_{3} R}{V_{3}}\left[T_{03}+\frac{m_{c r} \ddot{x} x}{m_{3} c p J}\right] \\
& \mathbf{P}_{3}=\frac{\mathrm{m}_{3} R \mathrm{~T}_{\mathrm{U3}}+\frac{\mathrm{R} \mathrm{m}_{\mathrm{cr} \ddot{\mathrm{X}} \mathrm{X}}}{\mathrm{cpJ}}}{\mathrm{V}_{03}-\mathrm{A}_{3} \mathrm{X}}
\end{aligned}
$$


Force equation:

$$
\begin{aligned}
& F=m \frac{d v}{d t} \\
& P_{2} A_{2}-P_{3} A_{3}+W-F_{f}-F_{v i s}=\frac{W}{g} \frac{d v}{d t}=m_{c r} \ddot{X}
\end{aligned}
$$

Combine with Equation (E-27):

$\mathrm{P}_{2}$ Equation (E-24)

$P_{3}$ Equation (E-26)

$$
\begin{gathered}
\frac{A_{2} m_{2} R\left(T_{02}-\frac{m_{c r} \ddot{x} x}{m_{2} c p ~ J}\right)}{\left(V_{02}+A_{2} X\right)}-\frac{A_{3} m_{3} R\left(T_{03}+\frac{m_{c r} \ddot{x} X}{m_{3} c p J}\right)}{\left(V_{03}-A_{3} X\right)}- \\
+W-F_{f}-F_{v i s}=m_{c r} \ddot{x}
\end{gathered}
$$

$\frac{A_{2} m_{2} R T_{02}}{\left(V_{02}+A_{2} X\right)}-\frac{A_{2} R m_{c r} \ddot{X} X}{c p J\left(V_{02}+A_{2} X\right)}-\frac{A_{3} m_{3} R T_{03}}{\left(V_{03}-A_{3} X\right)}-\frac{A_{3} R m_{c r} \ddot{x} x}{c p J\left(V_{03}-A_{3} X\right)}$

$$
+W-F_{f}-F_{v i s}=m_{c r} \ddot{x}
$$

$\ddot{x} m_{c r} R\left[\frac{1}{R}+\frac{X_{2}}{c p J\left(V_{02}+A_{2} X\right)}+\frac{X_{3}}{c p J\left(V_{03}-A_{3} X\right)}\right]$

$$
+R\left[\frac{A_{3} m_{3} T_{03}}{V_{03}-A_{3} X}-\frac{A_{2} m_{2} T_{02}}{V_{02}+A_{2} X}\right]=W-F_{f}-F_{v i s}
$$

$$
\ddot{\mathrm{x}}=\frac{R\left[\frac{\mathrm{m}_{2} \mathrm{~T}_{02} \mathrm{~A}_{2}}{\mathrm{cpJ}\left(\mathrm{V}_{02}+\mathrm{A}_{2} \mathrm{X}\right)}-\frac{\mathrm{m}_{3} \mathrm{~T}_{03} \mathrm{~A}_{3}}{\mathrm{cpJ}\left(\mathrm{V}_{03}-\mathrm{A}_{3} \mathrm{X}\right)}\right]+\mathrm{W}-\mathrm{F}_{\mathrm{f}}-\mathrm{F}_{\text {vis }}}{\frac{\mathrm{m}_{\mathrm{cr}} \mathrm{R}}{\mathrm{cp} \mathrm{J}}\left[\frac{\mathrm{cpJ}}{\mathrm{R}}+\frac{\mathrm{XA_{2 }}}{\left(\mathrm{V}_{02}+\mathrm{A}_{2} \mathrm{X}\right)}+\frac{\mathrm{X} \mathrm{A}_{3}}{\left(\mathrm{~V}_{03}-\mathrm{A}_{3} \mathrm{X}\right)}\right]}
$$




\section{APPENDIX' F \\ CORE TEMPERATURE, FLOW AND BOILING DETECTION}

\section{F. 1 INTRODUCTION}

The instrumentation evaluation was divided into the following four parts:

- Temperature measurements

- Flow measurement

- Acoustic measurements

- Conceptual probe design

The state-of-the-art of temperature measurements in reactors is well advanced and a variety of vendor hardware is available. Therefore, the analysis can be very specific. Flow instrumentation for liquid sodium is, in general, available; however, it is not suited to the unique requirements of FFTF.' Therefore, the analysis consists of review and selection of the most promising techniques for further evaluation.

The measurement of acoustic noise to detect boiling is again not new; however, the unique requirements of this application necessitates a feasibility study to determine the applicability of this technique. The work described below reflects this degree of development of each of the tasks.

\section{F. 2 TEMPERATURE MEASUREMENTS}

Thermocouple instrumentation is needed to measure the subassembly outlet sodium temperature. Nominal instrumentation requirements are shown in Table F-1.

Based on this evaluation, the recommended alloy combination is chromel-alumel in an ungrounded sheathed configuration. The sheath material should be 304 stainless steel with a minimum wall thickness of $0.010 \mathrm{inch}$ and a diameter of between $0.050 \mathrm{inch}$ and $0.065 \mathrm{inch}$. The insulating material should be densely compacted magnesium oxide or equivalent heat conductor. The thermocouple should be no sinaller than 30 gauge.

In the First Quarterly Report, GEAP-5550, a preliminary recommendation to use ChromelConstantan was made based primarily on the high sensitivity of this combination over the temperature range of interest. The chromel-alumel (type $\mathrm{K}$ ) thermocouple is now recommended even though it is less senisitive. Chromel-alumel has better stability especially to radiation effects.

Special grade thermocouples and pre-aging are recommended for this application. One such special grade is the type $3 \mathrm{G}-187$, by Hoskins Manufacturing Company. This special grade chromel-P and alumel wire was developed to meet the requirements of sheathed thermocouples . used for nuclear reaclur auplications operating at temperatures up to $100 n^{\circ} \mathrm{F}$. It is especially selected and processed to minimize emf drift during the long time aging treatment prior to actual service. 
GEAP-5722

TABLE. F-1

NORMA L INSTRUMENTA TION REQUIREMENTS

Temperature range:

Accuracy:

Resolution:

Response time:

Length of leads:

Life:

Environment:

Location:

Number of units:

Wall thickness:

Radiation Environment: $700^{\circ} \mathrm{F}$ to $1200^{\circ} \mathrm{F}\left(1000^{\circ} \mathrm{F}\right.$ nominal $)$

$\pm 5^{\circ} \mathrm{F}$ over range desirable $\pm 15^{\circ} \mathrm{F}$ over range tolerable

$3^{\circ} \mathrm{F}$

1. 0 second time constant

21 feet to top of reactor cover 50 from $\mathrm{T} / \mathrm{C}$ to amplifier

12,000 hours with possible recalibration at 2,000 hours intervals

Liquid sodium at above temperature, flow rates from 11 to 22 feet per second.

Thermocouples extend through wall near bottom end of 1. 7-inch diameter instrument tube

$4 \mathrm{~T} / \mathrm{C}$ per instrument unit ( 3 for measurement, plus 1 spare)

0.010 inch minimum wall thickness exposed to liquid sodium

Fast neutrons ( $) \mathrm{MeV})=2 \times 10^{11} \mathrm{n}$ per $\mathrm{cm}^{2} / \mathrm{sec}$

Thermal neutrons $\quad=3 \times 10^{9} \mathrm{n}$ per $\mathrm{cm}^{2} / \mathrm{sec}$

Total neutrons $\quad=3 \times 10^{11} \mathrm{n}$ per $\mathrm{cm}^{2} / \mathrm{sec}$

Gamma

The factors leading to a short response time of a sheathed thermocouple are (a) the mass of the thermocouple and sheath should be small and the (b) thermal path from the sheath to the thermocouple should be short.

Sheathed thermocouples as small as 0.010 inch in diameter are commercially available and would be very fast for this application. They would, however, present mechanical problems because of their small size and wall thickness. Thus, a compromise must be made between response time and mechanical size considerations.

Grounded thermocouples have a direct thermal path between the sheath and thermocouple element and thus are most desirable from the standpoint of response time. However, because of noise effects to be discussed later, ungrounded thermocouples are preferred in this application.

Many factors can contribute small errors in the thermocouple system. The ISA standard limit of error for chromel-alumel thermocouples over a temperature range of $530^{\circ} \mathrm{F}$ to $1400^{\circ} \mathrm{F}$ is $\pm 3 / 4 \%$ (by special order, ISA standard $\pm 3 / 8 \%$ ). These standard limits of error refer to replaceability and represent a worse case where a length of chromel-P wire of maximum 
deviation might be paired with a length of alumel wire also of maximum deviation and opposite polarity. Thus, it is reasonable to expect a replacement thermocouple to match the temperatureemf values of the previous thermocouple to a better degree than the limit of error. The limit of error takes into account such things as non-homogeneity and non-uniformity of the wires and of variations in the junction between thermocouples.

Aging affects the accuracy, because the calibration tends to change as a function of time at elevated temperatures. A typical aging pattern of a standard thermocouple is to drift 4 or $5^{\circ} \mathrm{F}$ upwards in temperature over the first several hours and then stabilizing. While both wires change in emf, most changes take place in the chromel- $P$ wire at temperatures between $700^{\circ} \mathrm{F}$ to $1000^{\circ} \mathrm{F}$. Thus the aging process during use can be minimized if the thermocouple is pre-aged at a temperature of $1000^{\circ} \mathrm{F}$ or more before calibration.

It is difficult to predict the actual amount of aging because mechanisms would be involved in the FFTF application:

- evaporization-changes in alloy composition result from evaporization of some constituants at high temperature

- diffusion-emf drift can result from diffusion of alloying element from one leg to the other

Diffusion effects will be small or negligible because the temperature gradient is small near the thermocouple junction. Thus, we can predict the main cause of aging in this application to be caused by evaporation effects which are largely non-reversible and can be effectively minimized by pre-aging.

The instrument unit containing the thermocouples extends about 12 feet into the liquid sodium at a nominal uniform temperature of $1000^{\circ} \mathrm{F}$. A total of about 20 feet of thermocouple is used up to the multipin connector located near the cover. The top of the connector is exposed to ambient air. Extension wires also of chromel-alumel are used for some 25 feet between the connector and the amplifier.

The connector will contain a number of materials other than chromel and alumel which will produce local thermal emfs, some positive and some negative. However, as long as the connector is at a uniform temperature between the incoming and outgoing conductors, which are of the same thermocouple materials, there will be no net emf error measured at the amplifier. A temperature difference of $2^{\circ} \mathrm{F}$ or $3^{\circ} \mathrm{F}$ across the connector will produce no more than $1^{\circ} \mathrm{F}$ error in reading and is tolerable within the accuracy requirements of the system. Note, this does not mean that the absolute temperature of the connector has to be maintained, only that the difference in temperature at points around the connector be kept to a minimum.

The cold junction is most conveniently located at the amplifier. The input terminals of the amplifier are maintained at constant temperature by use of a temperature controller. A commercially available cold junction reference may be suitable or a special temperature reference unit could be built in the integrated circuit amplifier section of the electronics. The cold junction temperature is typically controlled to $32^{\circ} \mathrm{F}$, but another temperature, such as $+100^{\circ} \mathrm{F}$, is also satisfactory, provided the calibration is corrected accordingly. Temperature control to $\pm 1 / 2^{\circ} \mathrm{F}$ should be feasible. 


\section{F.2.1 Electrical Circuit Considerations for Temperature Measurement}

\section{F.2.1.1 Lead Resistance}

A simplified electrical circuit is shown in Figure F-1.

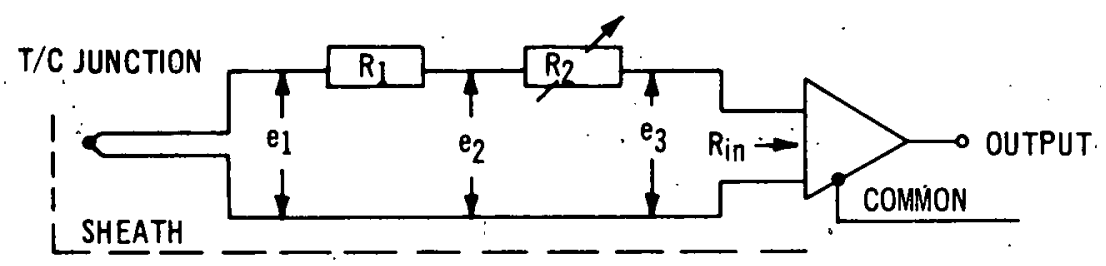

FIGURE F-1. SIMPLIFIED THERMOCOUPLE ELECTRICAL CIRCUIT

The thermocouple emf, $e_{1}$, does not appear at the input terminals of the amplifier because of IR drops in the leads. However, if the input resistance, $R_{i n}$, to the amplifier is very large, the thermocouple current can be kept to a minimum so as to make the IR drops negligible. $R_{1}$ and $R_{2}$ represent the thermocouple lead resistance over the entire distance from the $T / C$ junction to the amplifier. The fixed resistance $R_{1}$ is the lead resistance at the lower range temperature of $700^{\circ} \mathrm{F}$. Resistance $R_{2}$ represents the additional resistance as a function of temperature over the measurement range of $700^{\circ} \mathrm{F}$ to $1200^{\circ} \mathrm{F} . \quad R_{2}$ is zero at $700^{\circ} \mathrm{F}$. as follows:

The resistances $R_{1}$ and $R_{2}$ can be calculated to determine the requirements on $R_{\text {in }}$

$$
\begin{aligned}
& \mathbf{R}=\frac{\rho \mathrm{L}}{\mathrm{A}} \\
& \rho=\text { resistivity } \\
& \text { (chromel } 425 \mathrm{ohm} / \mathrm{cmf} \text { at } 68^{\circ} \mathrm{F} \text { ) } \\
& \text { (alumel 177. ohm } / \mathrm{cmf} \text { at } 68^{\circ} \mathrm{F} \text { ) } \\
& L=\text { length (ft) } \\
& A=\text { area (circular mils) }
\end{aligned}
$$

Calculation of wire resistance at $68^{\circ} \mathrm{F}$ :

Total length: 21 feet No. 30 ( 100.5 circular mils) plus 25 feet No. 26 extension (254. 1 circular mils)

$68^{\circ} \mathrm{F}$ chromel resistance $=425\left[\frac{21}{100.5}+\frac{25}{254.1}\right]=130 \mathrm{ohms}$

$68^{\circ} \mathrm{F}$ alumel resistance $=177\left[\frac{21}{100.5}+\frac{25}{254.1}\right]=54.3 \mathrm{ohms}$

Total resistance at $68^{\circ} \mathrm{F}$ is $184.3 \mathrm{ohm}$. 
As an approximation, assume that only the 12 -foot portion of thermocouple wire emersed in the liquid sodium is at high temperature and that the rest remains at $68^{\circ} \mathrm{F}$.

Therefore, the total resistance at $700^{\circ} \mathrm{F}$ is:

$$
R_{1}=184.3+9.2+13.1=206.6 \mathrm{ohms}
$$

Next, the maximum value of $R_{2}$ for a temperature of $1200^{\circ} \mathrm{F}$ can be estimated to be $9.3 \mathrm{ohms}$.

Knowing resistances $R_{1}$ and $R_{2}$, the amplifier input resistance can be specified. First, consider how large $R_{\text {in }}$ must be to make $R_{1}+R_{2}$ negligible so that $e_{3}=e_{1}$. The temperature error should not be greater than 1 to $3^{\circ} \mathrm{F}$ at $1000^{\circ} \mathrm{F}$ so that $R_{\text {in }}=1000 \times\left(R_{1}+R_{2}\right)=207$ kilomh. Thus, if $R_{\text {in }}$ can be as large as 207 kilohm, the thermocouples will not have to be calibrated to compensate for lead errors since the thermocouple emf will appear at $e_{3}$ within an allowable error of $1^{\circ} \mathrm{F}$. Since it is desirable to keep the ratio of $R_{\text {in }}$ to $R_{1}+R_{2}$ at 1000 or greater to avoid having to re-calibrate the thermocouples, the high input impedance of the amplifier should be one of its requirements. If an amplifier cannot be found with $R_{\text {in }}$ large enough, $R_{1}+R_{2}$ might be lowered by the choice of a larger thermocouple wire, say a No. 28.

If the ratio of $R_{\text {in }}$ to $R_{1}+R_{2}$ cannot be made high enough to satisfy the above requirements then $R_{\text {in }}$ can be reduced to a minimum of $R_{\text {in }} / R_{2}=1000$ or

$$
\quad R_{\text {in }}=10 \text { kilohms. }
$$

In this case, the thermocouple will have to be calibrated to determine the proper values of $e_{3}$ versus temperature since the lead resistance $R_{1}$ is not neglibible. $R_{\text {in }}$ must be large compared to $R_{2}$ so that $e_{3}=e_{2}$ within the allowable error over the range of $700^{\circ} \mathrm{F}$ to $1200^{\circ} \mathrm{F}$.

\section{F.2.1.2 Amplifier Stability}

Another requirement of the amplifier is its gain stability. Since drift in the amplifier contributes directly to measurement errors, the gain stability must be consistant with the system requirements. Voltage gain stability of $0.1 \%$ with $27 \mathrm{mV}$ input would be equivalent to $1^{\circ} \mathrm{F}$ (at $1000^{\circ} \mathrm{F}$ liquid sodium temperature) measurement error and should be adequate for the application.

In addition, the actual gain of all the amplifiers must be matched to one another within $0.1 \%$. If this later requirement cannot be met, it may be necessary to calibrate each thermocouple circuit before or after installation by trimming the gains of each amplifier.

Gain and stability are not required over a wide temperature range, however. Since the amplifier also is the cold junction for the thermocouple circuit, its temperature will remain constant and the gain and stability requirements are with reference to that temperature only.

\section{F.2.1.3 Noise Effects}

It is impossible to completely isolate the thermocouple circuits from adjacent instrumentation and other effects that produce electrical noise. This, coupled with the fact that the 
thermocouple is inherently a low output device makes noise an important design consideration. The thermocouple output is only $23 \mathrm{mV}$ at a temperature of $1000^{\circ} \mathrm{F}$. A resolution of $1^{\circ} \mathrm{F}$ or 23 microvolts is desirable in the system. Assuming the amplifier has an input impedance of $200 \mathrm{kilohm}$, this corresponds to a current resolution of only 0.21 nano amps.

Because of the noise consideration, we recommend the ungrounded type of shielded thermocouple where the two thermocouple wires are electrically isolated from the sheath. Others, such as either the grounded sheath or the coaxial type, would be unsatisfactory from a noise standpoint. The sheath of the thermocouple is in direct contact with the liquid sodium. Since liquid sodium is a good electrical conductor, all the thermocouple sheaths and many other parts of the reactor which come in contact with the sodium are electrically shorted together. Under this condition some ground loop currents can be expected because of differences in ground potential at various points in the system. These $d-c$ potential differences will be effectively isolated from the thermocouple in an ungrounded sheath type configuration.

A-C induced voltages are not completely eliminated even in an ungrounded configuration because of capacitance between the sheath and the thermocouple wires. It is recommended that two steps be taken to further reduce the effects of these a-c induced voltages. First, the electrical response of the circuit should be limited by putting a low pass filter in the amplifier. The amplifier should attenuate beyond $5 \mathrm{~Hz}$. Second, the amplifier should be a differential input type having common mode rejection. Common mode rejection is important because the a-c induced voltage will appear as a common mode potential at both wires of the thermocouple.

The effect of nuclear radiation on the electrical cable is an important factor that must be accounted for in the detailed design evaluations.

\section{F.2.2 Thermocouple Design Recommendation Summary}

The following is a summary of the design requirements for the sodium temperature measuring system. These conclusions are a result of the design specifications and considerations for all of the factors discussed above.

a. Thermocouple (approximately 21 feet, inside reactor to connector)

Type: chromel-alumel (Omega; Conax; or equivalent)

Configuration: sheath type, ungrounded

Sheath diameter: $0.062 \mathrm{inch}$ (or between $0.050 \mathrm{inch}$ and $0.065 \mathrm{inch}$ )

Sheath wall thickness: 0.010 inch minimum

Sheath material: 304 stainless steel

Inductor: density compacted MgO

Thermocouple wire type: Hoskins type 3G-187 or equivalent. Special wire for reactor application, pre-aged to $1000^{\circ} \mathrm{F}$ (prefer pre-aging to $1200^{\circ} \mathrm{F}$ )

Wire size: 30 gauge (prefer 28 gauge if it can be assembled in sheath size and give fast response)

Mounting: Recommended approximately 0.3 inch of thermocouple extend into liquid sodium environment through wall of instrument tube. Four thermocouples per instrument tube. . Location selected per convenience.

Response time: Time constant of 1 second or less for specified mounting and size in liquid sodium at velocity of $11 \mathrm{fps}$. 
b. Connector (vessel head): Recommend separate connector for thermocouple wires. The temperature gradient across the connector must be low $\left(2^{\circ} \mathrm{F}\right.$ or less).

The thermocouple sheaths should be brought physically close to the connector but need not be electrically shorted to the connector.

c. Thermocouple extension (approximately 25 feet, connector to amplifier)

Type: chromel-alumel (Omega; Conax; or equivalent)

Wire size: 26 gauge

All extension thermocouples from each connector should be in a common shield referenced to amplifier 'common'.

d. Amplifier and cold junction reference

Cold junction reference at input to amplifiers: $\pm 1 / 2{ }^{\circ} \mathrm{F}$ temperature control at $32^{\circ} \mathrm{F}$ recommended (other reference point up to $100^{\circ} \mathrm{F}$ could be used if preferred).

Amplifier type: differential input with common mode rejection, single ended output Input impedance:

$207 \mathrm{kilohm}$ minimum if standard $\mathrm{T} / \mathrm{C}$ calibration is to be used

$10 \mathrm{kilohm}$ minimum if thermocouples are to be recalibrated

Gain: fixed gain, approximately 100

Gain stability: $0.1 \%$ at cold junction temperature, $\pm 1 / 2^{\circ} \mathrm{F}$

Gain conformity between amplifiers: $0.1 \%$ at cold junction temperature, $\pm 1 / 2^{\circ} \mathrm{F}$

(if gain varies between amplifiers, individual thermocouple calibration will be required.)

Frequency response: 0 to $5 \mathrm{~Hz}$

Input noise level: less than 10 microvolts.

The design recommendations given above are the result of an attempt to meet all of the specification requirements as stated earlier. These stringent specifications place burdens in several areas of the design.

The specification on response time determines the maximum thermocouple wire size, sheath diameter, thermocouple mounting, and amplifier bandwidth. Thermocouple wire size and temperature resolution determines the input impedance of the amplifier. Resolution and accuracy place additional design burdens on the entire temperature measurement system notably the thermucuuple itself and tho amplifier. Fnr instance, the design recommendations specify a combination of amplifier requirements that will be difficult to meet. If met, however, the system specifications for both resolution and response time are attainable. Since the question of system accuracy involves more detailed information about the performance of the system when built, such as aging under actual environmental conditions, one cannot say with conf idence at this time that the design will meet the specified accuracy.

\section{F. 3 FLOW MEASUREMENTS}

Present plans for the FFTF backup reactor program speclfy that the velocity of the sodium coolant flowing through each of the fuel channels be continuously monitored. An instrumentation section in the flow duct is provided just above the upper termination of the control rods within the hexagonal flow duct. This duct is circular in cross section, having a diameter of 2.7 inches and a length of 5-3/4 inches. An instrumentation probe (1.5 inches maximum diameter with a minimum wall thickness of $0.010 \mathrm{inch}$ ) is inserted into the outlet section of the fuel subassembly. The instrumentation probe, containing temperature and flow sensors, will be inserted into the 
instrumentation portion of the coolant flow duct as the reactor plug is placed into position. The flow sensor must be designed to function in an off-center position and with significant bypass flow.

The performance, environmental and physical requirements of the FFTF in-core flowmeter are listed in Table F-2.

TABLE F-2

\section{STATEMENT OF REQUIREMENTS FOR FFTF FUEL CHANNEL FLOWMETER}

Full Range:

Response:

Accuracy:

Life:

Physical:

Output:

Operating Temperature:

Maximum Pressure Loss $\left(P_{L}\right)$ : Static Head $\left(\mathbf{P}_{\mathrm{S}}\right)$ :

Static Pressure $\left(\mathrm{P}_{\mathrm{B}}\right)$ :

Total Static Pressure:

Radiation Environment:
Varies from 10.9 to $22.7 \mathrm{fps}$ depending on location within the reactor at rated power

Response time of 1.0 second or less

- Target $= \pm 5 \%$ full scale

Acceptable $= \pm 10 \%$ full scale

12,000 hours

Maximum diameter of 1.5 inches

Final signal to be electrical

$350^{\circ} \mathrm{F}$ to $1200^{\circ} \mathrm{F}$ (nominal $1000^{\circ} \mathrm{F}$ )

5 psi

12 to 15 feet of sodium.

At $300^{\circ} \mathrm{F}=4.8 \mathrm{psi}$ to $6.0 \mathrm{psi}$

At $1000^{\circ} \mathrm{F}=4.3$ psi to 5.3 psi

10 inches of water ( $0.36 \mathrm{psi}$; gas blanket)

Approximately 9.7 to $11.4 \mathrm{psi}\left(\mathrm{P}_{\mathrm{L}}+\mathrm{P}_{\mathrm{S}}+\mathrm{P}_{\mathrm{B}}\right)$

Fast neutrons $(>1 \mathrm{MeV})=2 \times 10^{11} \mathrm{n}$ per $\mathrm{cm}^{2} / \mathrm{sec}$

Thermal neutrons $\quad=3 \times 10^{9} \mathrm{n}$ per $\mathrm{cm}^{2} / \mathrm{sec}$

Total neutrons . $=3 \times 10^{11} \mathrm{n}$ per $\mathrm{cm}^{2} / \mathrm{sec}$

Gamma $\quad=8.6 \times 10^{7} \mathrm{per} \mathrm{mR} / \mathrm{h}$

Nine different principles of fluid flow sensing which appear appropriate, have been selected for discussion and evaluation for FFTF in-corè application. These are as follows:

- Drag Plate

- Eddy Current

- Magnetic - Permanent Magnet

- Magnetic - Electromagnet (dc)

- Moving Vane

- Restriction (Variable Head).

- Rotameter

- Stagnation Pressure 


- Thermal - Differential Thermocoúple
- Thermal - Resistance Bridge
- Turbine

\section{F.3.1 Drag Plate Flowmeter}

For the drag plate flowmeter, a bonded strain gauge bridge translates fluid forces into an electrical output which is proportional to the square of fluid velocity. The describing equation is $\mathrm{E}=\mathrm{K}_{1} \mathrm{~F}=\mathrm{K}_{2}$ Ap $\frac{\mathrm{V}^{2}}{2 \mathrm{~g}}$, where $\mathrm{E}=$ volts output, $\mathrm{K}_{1}=$ calibration constant, $\mathrm{F}=$ force on plate, $\mathrm{K}_{2}=$ drag coefficient, $\mathrm{A}=$ area, $\rho=$ fluid density, $\mathrm{V}=$ fluid velocity, and $\mathrm{g}$. = acceleration of gravity.

a. Advantages:
1. Simple.design
2. Low maintenance
3. Fast response
4. Unaffected by system static pressure variations
5. Requires two leads.

b. Disadvantages:
1. Output varies as the square of fluid velocity
2. Unreliable with currently available strain gauges
3. Target can be readily damaged during insertion and withdrawal of instrument tubes
4. Calibration depends on spring rate of flexure tube, which will vary with temperature.

Flow transducers using this principle are commercially available for application at temperatures up to $600^{\circ} \mathrm{F}$. Lack of suitable strain gauges limits higher temperature ratings. The Liquid Metal Engineering Ccnter is developing a gauge for $1200^{\circ} \mathrm{F}$ application. Evaluation tests show promise for this unit.

A drag plate flowmeter using an " $E$ " core and armature design for transduction has proved to be suitable for measuring fluid velocity transients $(10 \mathrm{msec})$ in a high pressure and high temperature $\left(625^{\circ} \mathrm{F}\right)$ water system. ${ }^{(\mathrm{F}-1)}$ Development may be required to obtain a radiation hardened ' $\mathrm{E}$ ' core and coil for $1200^{\circ} \mathrm{F}$ expnsure.

\section{F.3.2 Eddy Current Fluwmeter.}

The eddy current flow sensing principle is an adaptation of the Lehde and Lang induced field flowmeters. $(\mathrm{F}-2)$ It is cylindrical in form, consisting of a primary coil mounted on a tube with two simllar secondary coils mounted one on either end of this coil. The primary coil is energized by an a-c source of constant voltage and frequency. When immersed in a stationary liquid metal, symmetrical currents are generated in the liquid metal by the primary coil. These currents induce equal voltages into each of the secondary coils: Since the secondary 
coils are connected in series-bucking, their output is zero. When the liquid metal is moving, however, it adds an induced component into the eddy current distribution which disturbs the symmetry of the distribution about the primary coil. The field of this current then couples the two secondary coils unequally causing unequal voltages to be induced within them. The external field penetrates only a small distance into the liquid metal because of skin-depth effects. A large velocity gradient exists in the fluid near the surface of the flowmeter. Popper states, however, that empirical calibrations have shown that the output varies very nearly linearly with local mean fluid velocity. $(F-3)$ Shercliff states that exact theoretical analysis of output sensitivity is usually difficult and that empirical calibration is inevitable. $(F-2)$

A flow transducer using this principle has been applied to serve as a liquid sodium pump failure monitor in the British Prototype Fast Reactor on a go, no-go basis. Coils of this unit are wound on a ceramic form and the unit is "canned" in a stainless steel housing. No operating experience is known regarding this type of sensor.

a. Advantages:

1. No moving parts

2. Fast response

3. Requires no special materials (no ferromagnetic materials)

4. Low pressure loss

5. Sensor can be embodied within the instrumentation tube without contour discontinuities.

b. Disadvantages:

1. Calibration is sensitive to the electrical resistivity of sodium which varies frum 11 mlcruluns-cm al $284^{n} \mathrm{~F}$ lo 27 micruhms-cm at $932^{n} \mathrm{~F}^{(\mathrm{F}-\mathrm{f})}$ (cannor calibrate in a water system)

2. Coil alignment critical

3. Requires development of electronics

4. Requires four leads

\section{F. 3.3 Magnetic Flowmeter-Permanent Magnet}

The operating principle of the magnetic flowmeter is similar to that of a d-c generator. Liquid flowing through a pipe placed between the poles of a permanent magnet cuts the line of magnetic flux and generates a $d-c$ voltage in the pipe. The generated voltage is in a direction normal to both the direction of the flux and the fluid flow. The flow equation for this flowmeter is, $\mathrm{E}=\frac{\mathrm{Q} B \mathrm{~K}_{1} \mathrm{~K}_{2}}{3160 \mathrm{D}}$, where $\mathrm{E}=$ output $(\mathrm{mV}), \mathrm{Q}=$ fluid flow (gal $\left./ \mathrm{min}\right), \mathrm{B}=$ magnet flux density (gauss), $\mathbf{K}_{1}=$ pipe material and flowing fluid resistivity correction factor, $K_{2}=$ end loss correction factor, and $\mathrm{D}=$ pipe inside diameter (in.).

Permanent magnet flowmeters have now been successfully used for measuring fluid velocity in liquid metal systems for the past 20 years. Possible application of permanent magnet flowmeters for FFTF in-core sodium coolant velocity measurements has been reviewed in much detail by Popper, Weigand and Glass. $(\mathrm{F}-3)$ Their report indicates that suitable permanent magnets are 
available for $1000^{\circ} \mathrm{F}$ service, based on works reported by Kronenberg and Bohlman,. $(\mathrm{F}-7)$ and Tenzer. ${ }^{(F-8)}$ Data submitted by Tenzer lists various measurement of remnance at room temperature of Alnico $\mathrm{V}$ magnets after exposure to $1022^{\circ} \mathrm{F}$ for 1000 hours. In these tests, losses of remnance (primarily magnetic changes) of up to $4.5 \%$ were noted. Tenzer further states that when Alnico $\mathrm{V}$ has reached metallurgical equilibrium at $1022^{\circ} \mathrm{F}$; it is not necessarily stable at lower temperatures. Information regarding magnet stability after exposure to a $1200^{\circ} \mathrm{F}$ environment at high radiation levels would be of real interest.

Gordon ${ }^{(F-9)}$ reports that Alrico $V$ is suited for use in environmental temperatures of up to $932^{\circ} \mathrm{F}$ and is insensitive to nuclear radiation of up to $10^{17}$ fast neutrons $/ \mathrm{cm}^{2}$ (nvt) which is somewhat lower than FFTF's target radiation of $10^{19}$ fast neutrons $/ \mathrm{cm}^{2}$. He reports that this information has been obtained by studying these effects individually and that very little data are available on the combined environmental effects.

Popper ${ }^{(F-10)}$ and Knox ${ }^{(F-11)}$ report on an in-core permanent magnet flowmeter using Alnico V B magnets which will be investigated for in-core application in FFTF. It is 10-inches long and will be completely contained within a fuel assembly, hence its hexagonal cross section. Since it is not to be withdrawn with the reactor core plug as in the FFTF Backup Design, it is not subject to significant bypass flow. A flux density of approximately 340 gauss has been measured in the magnet gap. This flux provides an output signal of about $0.42 \mathrm{mV} \mathrm{per} \mathrm{ft} / \mathrm{sec}$. Equivalent in the FFTF "low-flow" channels (10.9 fps) to approximately $4.6 \mathrm{mV}$ output at full range flow. However; maximum length available in the FFTF flow channel is nominally 5 inches and the outputs would bc substantially less, Popper and.Knox did not report performance data for this flowmeter which is intended to operate at $1200^{\circ} \mathrm{F}$ in a high radiation environment.

A. prominent manufacturer of permanent magnet flowmeters (M.S. A.) believes that Alnico $\mathrm{V}$ can be stablized within $\pm 10 \%$ for $1200^{\circ} \mathrm{F}$ exposure but that the magnitude of flux density will be temperature sensitive. Of greater concern to this vendor is the effect on permanent magnets of simultaneous exposure to both high temperature and severe fast neutron radiation.

For application to FFTF, the flowmeter. must be designed to permit easy insertion into the reactor flow duct. The spacing provided for this purpose will permit unmetered coolant. flow to bypass the flow sensing element which will reduce measurement accuracy and will make it difficult to calibrate by calculation.

Calibration is also affected by variations in the electrical resistivity of sodium which varies considerably over the temperature range of interest.

\section{a. Advantages:}

1. No moving parts

2. Approach conditions of the fluid have small effect on the calibration

3. Fast response

4. Output signal is linear with fluid velocity -

5. No power required to energize

6. Callbration inay le possible by calculation

7. Requires two leads. 


\section{b. Disadvantages:}

1. Sodium must wet the flowmeter pipe wall for proper calibration

2. Calibration is sensitive to temperature variations

3. Output signal is small.

\section{F. 3. 4 Electromagnetic (d-c) Flowmeter (Saddle Coil Flowmeter)}

In an effort to reduce the size of the permanent magnet flowmeter, a d-c electromagnetic flowmeter was developed for use in the secondary circuit of the Prototype Fast Reactor. $(F-4)$ In this report, no information is given regarding application environment nor performance for this flowmeter. The principle of this flowmeter is the same as that of the permanent magnet flowmeter except that the magnetic field is supplied by coils energized with direct current.

These coils take the form of rectangular spirals and are curved to conform to the pipe section through which the fluid being measured is passed. When two of these "saddle" form coils, placed on opposite sides of the flow duct are energized, an essentially homogeneous magnetic field is generated within the duct.

a. Advantages:

1. Smaller size than permanent magnet flowmeters

2. Calibration can be calculated to better than $\pm 5 \%$

3. No moving parts

4. Fast response

5. Approach conditions of the fluid have small effect on the calibration

6. " Output signal varies linearly with fluid velocity.

b. Disadvantages:

1. Requires a large amount of power

2. Requires large coils

3. Requires four leads

4. Sodium must wet the inner wall of the flowmeter for proper calibration

5. Output signal is small

6. The flowmeter must be fastened as an appendage to the instrumentation tube.

\section{F. 3.5. Moving-Vane Flowmeter (Special Case of Drag Plate Flowmeter)}

General design of the moving vane flowmeter being considered for FFTF application consists of a " $U$ " shaped magnetic yoke provided with a coil and a magnetically permeable moving vane mounted in close proximity to the open end of the yoke. Flowing fluid exerting a force on the vane, moves it toward the yoke tips reducing the gap between them and thereby decreasing the reluctance of the magnetic circuit and hence changing both the magnitude and phase of the coil current.

For FFTF application the yoke and coil can be placed within the instrumentation tube with the moving vane fastened in close proximity but outside of the tube and in the path of the sodium 
flow stream. A number of different configurations are possible. For example, a force amplifying disc can be attached to a rectangular moving vane. Force exerted against the disc, having a comparatively large area, is transmitted to the moving vane causing a greater motion than is obtained without it. With the moving vane fastened at only one end, force-to-deflection sensitivity can be significantly increased, but stability may be reduced.

No known information exists regarding experimental or field experience for units of this type. FFTF application will require a review of suitable materials and material joining techniques.

a. Advantages:

1.'. Simple design (all welded, no bonding)

2. Unaffected by system static pressure

3. Can be calibrated in a water system

4. Fast response

5. Can determine reverse fluid flow

6. Requires two leads.

b. Disadvantages:

1. Output varies as the square of fluid velocity

2. Has external moving part

3. Calibration depends on spring rate of moving vanc, which will vary with temperature.

\section{F.3.6 Restriction Type Flowmeter (Variable Head)}

Restriction type flowmeters (variable head) are probably the oldest known and still most commonly used fluid flow sensors. Consequently, a great deal of experimental and analytical investigation have been devoted to determining the associated proper techniques, tolerances, and equations to permit calibration of fluid velocity by computation. As their name implies, they consist essentially of a restriction placed into the path of a flowing fluid whose velocity is to be measured. Orifice plates, nozzles, and venturi tubes are the common forms of this meter. The pressure differential across the restriction varies as the square of the fluid velocity.

Consideration of the venturi tube shows that serious problems exist in its application to the FFTF. Although awkward, pressure measurement at the venturi throat is possible. However, pressure measurement at the entry presents a very serious problem. Further, the fit of the venturi within the fuel channel flow duct cannot be snug, since it must be withdrawn with the reactor instrument tube-plug assembly. Variable bypass flow will preclude calibration by computation and will introduce uncertainties into the calibration.

An inverted venturi offers significant advantages over the conventional venturi since insertion and withdrawal of the flow sensor element in the flow channel are.no longer a problem.

a. Advantages:

1. . Simple design

2. No moving parts 

3. Low pressure loss
4. May be calibrated by computation
5. Can be calibrated in a water system.
6. Less sensitive to fluid velocity distribution.

\section{b. Disadvantages:}

1. Pressure transducers may be too large to fit available space

2. Can fail unsafe*

3. Requires four leads.

\section{F. 3. 7 Rotameter (Variable Area Flowmeter)}

The fluid enters at the bottom of a tapered meter tube and exits at the top. In the rotameter, fluid flow is restricted by the spacing between the float and the wall of the tube. Force exerted on the float by the flowing fluid is proportional to the fluid flow rate. The float holds a fixed position in the tube for any given flow rate. An increase in fluid flow rate will cause the float to rise higher in the tapered tube, and increases the area between the float and the tube wall, thus permitting a greater flow of fluid. The space between the float and tube wall varies proportionally with fluid flow rate, hence the calibration (float displacement versus rate of flow) is linear.

a. Advantages:

1. Linear calibration

2. Fluid approach characteristics have minor effect

3. Unaffected by system static pressure

4. Can be calibrated in a water system.

b. Disadvantages:

1. Unit is large

2. Pressure loss is high

3. Two close fitting moving elements are required

4. Deposits of foreign material can be critical and can fail unsafe

5. Requires five leads.

\section{F.3.8 Stagnation-Pressure Type Flowmeter}

Stagnation pressure is a measure of the energy represented by the velocity of a flowing fluid. The pitot tube is the most commonly used flow sensor to make use of this principle. The following relationship exists, $\mathrm{V}=\mathrm{C} \sqrt{\frac{2 \mathrm{~g}\left(\mathrm{P}_{\mathrm{T}}-\mathrm{P}_{\mathrm{S}}\right)}{\rho}}$, where $\mathrm{V}=$ fluid velocity, $\mathrm{g}=$ acceleration of gravity, $\mathrm{P}_{\mathrm{T}}=$ total pressure, $\mathrm{P}_{\mathrm{S}}=$ static pressure, $\rho$. = fluid density, $\mathrm{C}=$ calibration constant, and $P_{\text {stagnation }}=P_{T}-P_{S}$.

* Accumulation of foreign materials at or upstream of the point of constriction may cause an increase in pressure, erroneously indicating an increase in fluid flowrate. 
A number of possible configurations of such flow.sensors for application to FFTF exists. The sensor for these units is a pressure transducer of proper range. The nominal concept responds to total pressure (static plus dynamic) so variations in static pressure will introduce flow measurement error. In an effort to improve the output signal of. the transducer, a force disc may be added. The disc, being of larger area than the pressure transducer diaphragm, will tend to increase the transducer output response related to the dynamic pressure and hence reduce the effect of system static pressure on the output signal.

a. : Advantages:

1. Simple design

2. Can be calibrated in a water system

3. Not significantly affected by foreign material deposits

4. Fast response

5. Requires two leads.

b. Disadvantages:

1. Calibration is affected by system.static pressure

2. Calibration varies with system fluid temperature

3. Calibration sensitive to system fluid approach characteristics.

\section{F. 3.9 Thermal Flowmeter-Differential Thermocouple}

Two forms of the differential thermocouple type thermal flowmeter are considered. In one concept, the difference in temperature between a heated and unheated thermocouple; is affected by the rate of environmental fluid flow.

Using the thermal principle, two possibilities exist for flow measurement. - Either to hold the heat flow constant and permit the differential temperature to vary with changing fluid flow rates or to hold the differential temperature constant and vary the amount of power supplied to the heater for changing flow rates. If the former is chosen,. differential temperature is a decreasing function with increasing fluid velocity. In the latter. case, power supplied to hold differential pressure constant is an increasing function which soon responds.linearly with.fluid flow rate. The latter system appears preferable.

a. Advantages:

1. Small size

2. No moving parts

3. Not significantly affected by deposit of foreign materials

4. Low sensitivity to system temperature variations

5. Low pressure loss

6. Not affected by system static pressure. 
b. Disadvantages:

1. Requires substantial power

2. Output signal may be low

3. Measures point flow and is significantly affected by the fluid approach characteristics

4. Response is slow

5. Cannot be calibrated in a water system

6. Requires five leads.

\section{F. 3.10. Thermal Flowmeter-Heated Resistance Bridge}

The heated resistance bridge flowmeter consists essentially of resistance elements which are heated to a temperature slightly higher than the maximum temperature of the fluid whose flow rate is to be measured. All arms of the bridge do not have the same electrical resistance. With constant power supplied to the resistance element bridge, the temperature of the elements, hence resistance, vary differently with the velocity of the fluid into which they are immersed.

A manufacturer of this type of flowmeter believes that he can supply a flow sensing element suitable for FFTF application. The resistance grids of this flowmeter are made of platinum and are insulated from and fastened to the metal tube with ceramic and have an overlay of ceramic. This complete system includes compensation of output for system temperature variations in order to hold nonlinearity to a maximum of $8 \%$. A similar sensor is currently in use at the GeorgiaPacific Corporation to measure flow of molten sulphur and is performing satisfactorily.

a.. Advantages:
1. Simple design
2. No moving parts
3. Low pressure loss
4. Reasonably linear output
5. Moderately fast response
6. Not affected by system static pressure
7. Not significantly affected by deposit of foreign materials.

b. Disadvantages:

1. Flowing fluid must wet sensor wall

2. Cannot be calibrated in a water system

3. Cannot determine reverse flow

4. Requires four leads

5. Relatively insensitive to flow changes.

\section{F.3.11 Turbine Flowmeter}

A typical turbine flowmeter consists of a housing with a cylindrical bore which contains a hydraulically, self-positioned rotor. A permanent magnet is sealed within the rotor. The pick-up 
coil mounted on the housing does not penetrate the inner bore. Fluid passing through the flowmeter, spins the rotor. The speed of spin is a function of fluid velocity. As the rotor spins, an a-c voltage is generated in the pick-up coil by the magnets. The frequency of this voltage is a function of the fluid velocity. Typical ranges offered by manufacturers vary from $1 / 8$-inch $(1.4 \mathrm{gpm})$ size, to 12 -inch size $(26,000 \mathrm{gpm})$.

A turbine flowmeter has been used to measure liquid-metal flow rates in out-of-reactor systems operating at $800^{\circ} \mathrm{C}\left(1427^{\circ} \mathrm{F}\right) .(\mathrm{F}-10)$ Problems were encountered with the bearings and magnets.

A turbine flowmeter was designed to be completely contained within a FARET fuel assembly. $(\mathrm{F}-10)$. This flowmeter uses molydenum guide bearings, Hastelloy $\mathrm{C}$ shaft material, and Alnico-V B magnets. No tests were performed to the time of the reference report.

a. Advantages:

1. Linear output

2. Requires no power to energize

3. Frequency output

4. Not significantly affected by moderate deviations from straight-line flow of entry fluid

5. Fast response

6. Fails safe

7. Unaffected by system static pressure

8. Can be calibrated in a water system.

b. Disadvantages:

1. Design contains delicate parts

2. Rotor continually spins (suitable bearings are not available)

3. Pressure loss is high

4. Foreign material deposits can cause unit to fail.

$-$

\section{F.4. IN-CORE SODIUM BOILING DETECTION BASED ON ACOUSTIC MEASUREMENT}

With the development of fast flux liquid sodium cooled reactors, an increasing number of investigators are looking to boiling noise as a means of detecting dangerous coolant bolling conditions in the reactor. Groups both in this country and in England have reported some successes with boiling noiso detection, but invariably the research has been performed in the audible frequency range on nucleate boiling. - Numerous difficulties have arisen in practically all reports, the primary one being the high level of mechanical background noise, particularly from coolant pumps. Furthermore, the detection of fully developed nucleate boiling may be too late to prevent core damage.

With these problems in mind, a preliminary survey of the noise generated prior to the onset of nucleate boiling and an investigation of the frequency range above $20 \mathrm{kHz}$, where mechanical background noise would not play such a significant part, were made. An analytical 
prediction of the propagation characteristics of this noise from the boiling core to the instrumentation region in the top of the reactor was also attempted.

The following aspects have been considered with respect to the detection of boiling noise in a liquid sodium cooled reactor:

a. Boiling generates wide band noise which is in general indistinguishable from background noise in the reactor. The problem is to separate the boiling noise signal from noise generated by pump, hydraulic flow, etc.

b. Practical considerations require that the sensor be located far from the boiling source. How is the boiling noise affected as it is propagated toward the sensor location?

c. The sensor must withstand high temperature and radioactive environments. What sensors meet these requirements?

Other researchers have suggested that the high frequency components of boiling noise would have a better signal to noise ratio than the audible range sound which is mashed by background noise. Experiments in water have shown that the acoustic signature of boiling is strongest, in the regions above $1000 \mathrm{~Hz}$, before fully developed nucleate boiling exists. High frequency transients, between 20 and $60 \mathrm{kHz}$ were generated in water early in the pre-boiling stage and peaked at least a full minute before nucleate boiling oçcurred.

From an analytical standpoint, it appears that high frequency boiling noise will be propagated almost exclusively directly up the channel in which it originates. This will allow a single detector in the top of each channel to accurately localize the source of boiling and is another factor favoring the high frequency components of the noise. References F-12 to F-21 are pertinent to the discussion of sodium boiling and detection.

\section{F. 4.1 Correlation of Water Tests to Liquid Sodium Boiling}

While there is every reason to believe, based on the experiments performed here and elsewhere on boiling noise detection, that subcooled boiling noise in the high frequency range can be detected in the reactor core, there are many questions yet to be answered. Not the least of these is the question whether subcooled boiling can be expected under all circumstances of boiling occurrences. It is possible, given the high thermal conductivity of sodium, that no bubble collapse would occur until a large bubble had reached the cooler liquid above the channel.

Pump cavitation noise will be indistinguishable from boiling noise, where it exists. More study is needed to determine the level of cavitation generated by pumps and the effects on this noise by distance, geometry, and superheat.

The density and viscosity of warm water are comparable to those of liquid sodium. In terms of the propogation of sound, the warm water model is a fair approximation. The unique characteristics of liquid sodium make extrapolation from water difficult or questionable in the case of the mechanics and thermodynamics of nucleation. 


\section{F. 4.2 Noise Generated By Boiling in Water}

Our experiments with subcooled water have shown boiling noise to have very broad band. frequency characteristics. There are strong signals generated in the audible range associated with bubble oscillation, container resonances, and bubble collapse. As we look at increasingly higher frequencies, the intensity appears to drop off, but a significantly strong signal is still detected at $60 \mathrm{kHz}$. Off-setting this decrease in intensity is the corresponding decrease in intensity of the background noise, which in this application is due primarily to pump and flow noise. At frequencies between 20 and $60 \mathrm{kHz}$ there seems to be a much better signal to no ise ratio than at audible ranges.

An experiment was performed to determine the spectral characteristics of boiling noise in a column of water. Since the high frequency range above $20 \mathrm{kHz}$ was of particular interest, equipment was used which allowed the detection and recording of up to $100 \mathrm{kHz}$ signals. The column containing the boiling water was a glass tube $30 \mathrm{~cm}$ long and $3.5 \mathrm{~cm}$ in diameter. Heat was applied to the bottom of the tube by a gas flame. The water could be brought from room temperature to a full boil in about $2-1 / 2$ to 3 minutes.

In the first test performed, the output of the accelerometer was fed into a band pass filter with a range of $20 \mathrm{kHz}$ to $60 \mathrm{kHz}$. Intermittent spikes were observed 5 to 10 seconds after the heat was applied, even though no bubbles could be seen. The amplitude and rate of occurrence of these spikes increased to a maximum at about 30 to 45 seconds, then the amplitude decreased as the water approached a full boil. At full boil there were very few strong signals in this range.

The observed transient responses are attributed to the formation and subsequent immediate collapse of small bubbles as the liquid is heated at the container wall and cooled by the surrounding liquid. As the temperature of the surrounding liquid increases, the collapses are less severe and the peak amplitudes are observed to decline:

A second run was tape recorded, with, no filtering, and the tape was then used in subsequent analyses. The results of Figure F-2 were obtained by first rectifying and squaring the signal and then cumming the signal over a 5 second interval. A band pass filter gave a 1 octave range at $250,500,2000$, and $4000 \mathrm{~Hz}$ and a $1 / 3$ octave range at $20 \mathrm{kHz}$ and $40 \mathrm{kHz}$. The waves above $500 \mathrm{~Hz}$ show an increase in energy as bubbles form in the bottom of the tube and immediately collapse: The maximum occurs at about 70 seconds, where bubbles of about $3 \mathrm{~mm}$ in diameter are formed but collapse before they can be carried upward in the tube. The energy then decreases as the boiling becomes more vigorous in all but the $500 \mathrm{~Hz}$ range, which continues at a constant rate until about 110 seconds. Here bubbles of about $4 \mathrm{~mm}$ diameter are observed to remain intact several centimeters above the bottom of the tube. As more of these bubbles are formed, the low frequency energy increases, but the higher frequencies drop off.

Since relatively high peaked transients were observed in the initial test, it seemed desirable to obtain some indication of the intensities of these peaks for the different frequency bands. This was accomplished by triggering a pulse generator with the filtered noise signal and counting pulses in 1 second intervals on a digital counter. The pulse generator had a variable trigger sensitivity which permitted the peak amplitude threshold to be varied. Figure F-3 shows a large number of peaks above the threshold centered around the 60 second point. 
GEAP-5722

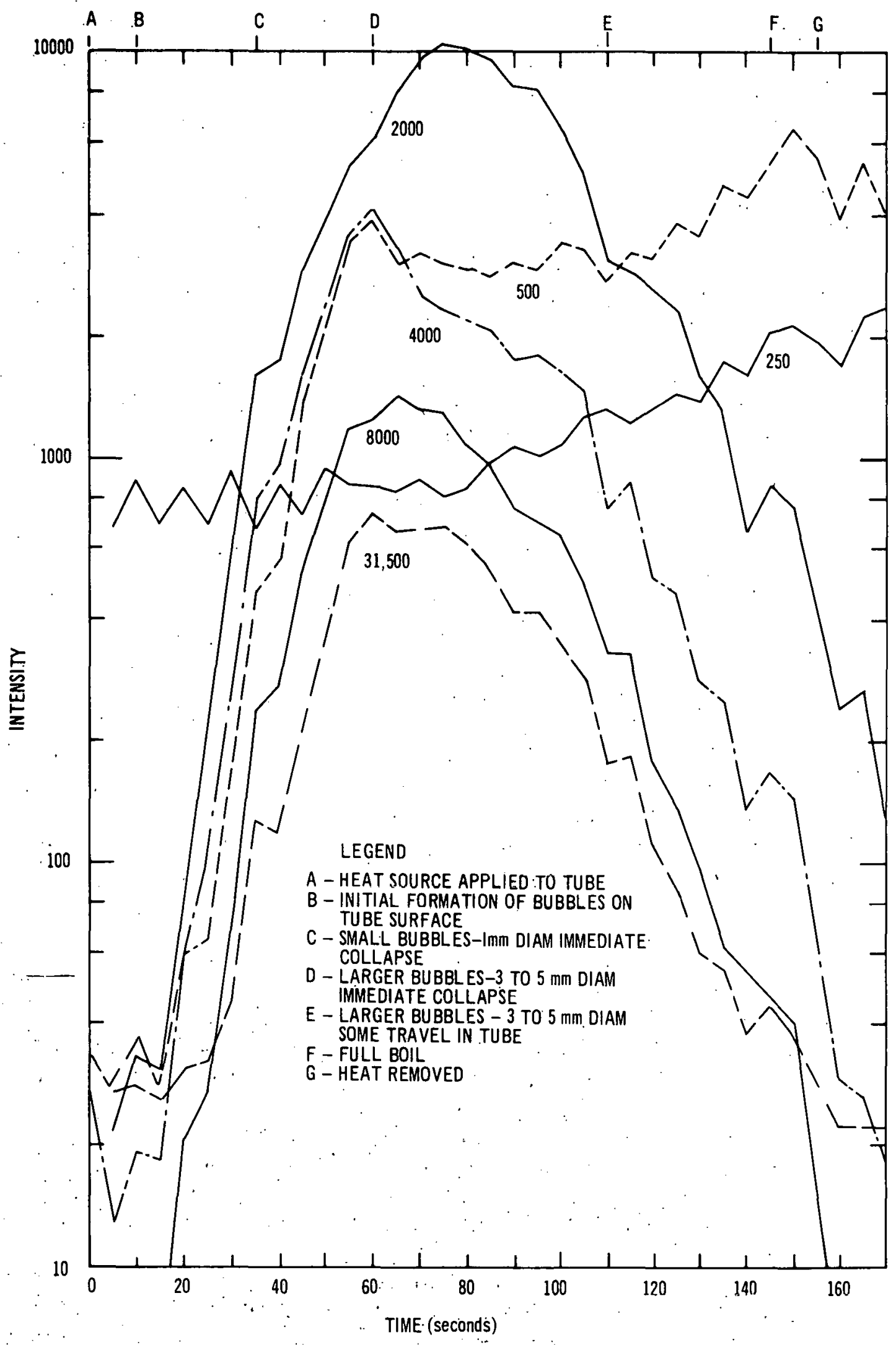

FIGURE F-2. POWER VERSUS TIME FOR WATER'BOILING WITH FREQUENCY; Hz, AS A PARAMETER 


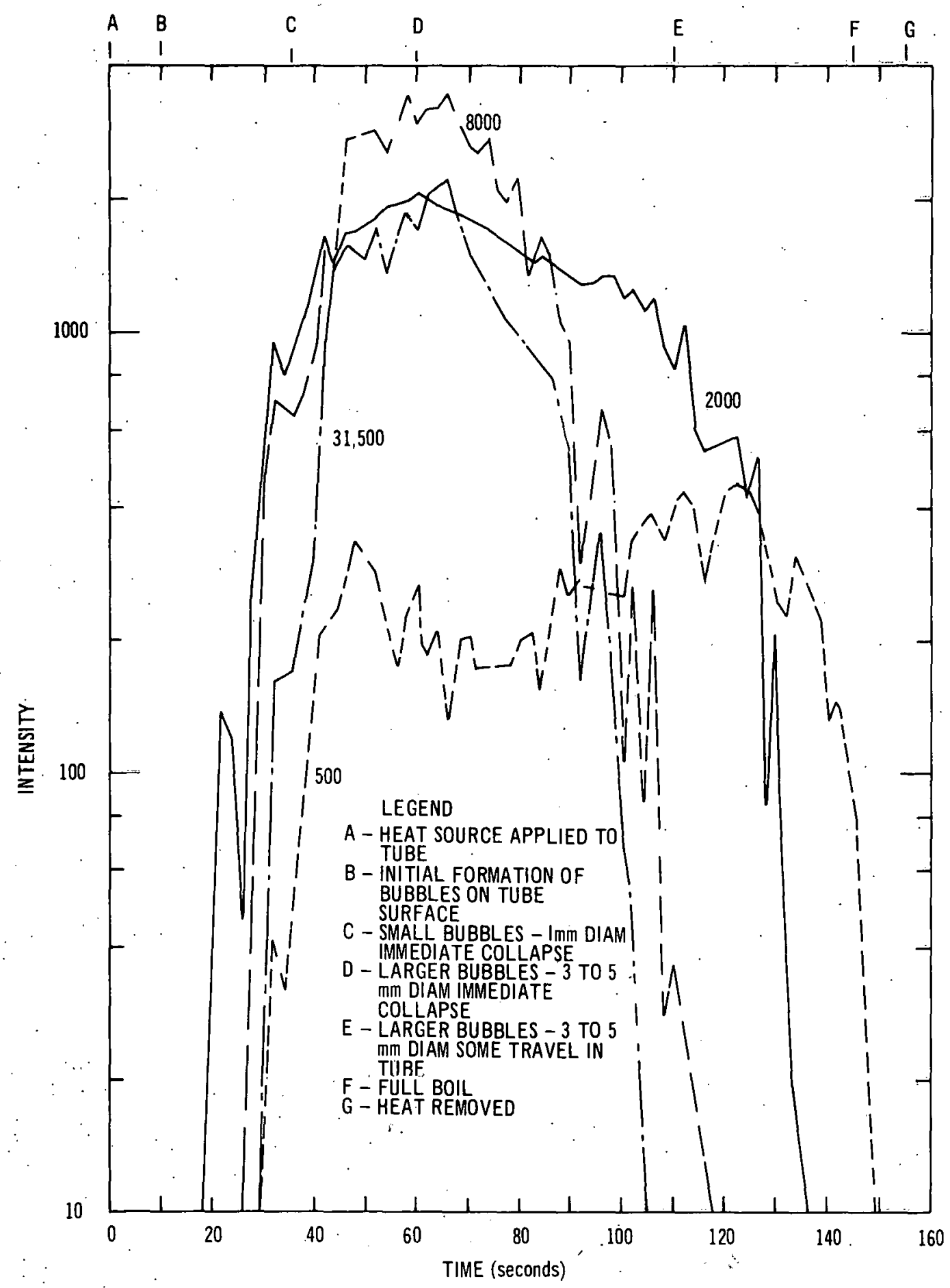


Raising the threshold eliminated the low frequency noise $(500 \mathrm{~Hz})$. It also decreased the $40 \mathrm{kHz}$ signal relatively more than the signals in the 2 to $8 \mathrm{kHz}$ range, illustrating the shortringing transient nature of the high frequency signal.

The results of this brief experiment suggest that a practical boiling detector might be designed on the principle of detection of high frequency.transient peaks. The threshold of a triggering input could be set well above the normal continuous noise level and would give a null readout except when sharp spikes cause the generation of a countable pulse. Observation of this characteristic would certainly indicate the onset of boiling.

\section{F.4.3 Transmission Characteristics of Liquid Sodium}

Liquid sodium, at reactor temperatures, has a density of approximately $8.11 \times 10^{-1} \mathrm{gm} / \mathrm{cm}^{3}$. The velocity of sound in sodium will be approximately $2.35 \times 10^{5} \mathrm{~cm} / \mathrm{sec}$ giving an acoustic impedance of $1.9 \times 10^{5} \mathrm{~g} / \mathrm{cm}^{2} \mathrm{sec}$. In contrast, the impedance of steel is $4.56 \times 10^{6} \mathrm{~g} / \mathrm{cm}^{2} \mathrm{sec}$.

The normal sound transmission coefficient from one hexagonal channel to an adjacent channel is given by: $(\mathrm{F}-22)$

$$
\alpha_{t}=\frac{4}{4 \cos ^{2} k_{2} l+\left(r_{12}+r_{21}\right)^{2} \sin ^{2} k_{2} l}
$$

where $r_{12}, r_{21}$, are ratios of acoustic impedances between sodium and steel, and steel and sodium respectively. The wall thickness between two channels is 1 .

For frequencies below $20 \mathrm{kHz}$, the walls are sufficiently thin to allow almost unobstructed passage of the sound throughout the reactor. But at frequencies between 20 and $60 \mathrm{kHz}, 91$ percent of the incident sound on the wall is reflected back into the coolant. Furthermore, in this range where the thin wall approximation is not valid, the critical angle, given by:

$$
\theta_{c}=\frac{\mathrm{C}_{1}}{\mathrm{C}_{2}}
$$

where $C_{1}$ and $C_{2}$ are velocities of sound in sodium and steel, is approximately $14^{\circ}$ from the line normal to the wall. Thus, it can be expected that almost all the boiling noise in this range will be propagated directly up the channel in which it originates. Absorption in the liquid sodium itself is expected to be extremely small over the short distances of propagation under consideration here.

\section{F. 4. 4 Sensor Location}

Taking advantage of the properties of the boiling sound in the 20 to $60 \mathrm{kHz}$ range, it appears most desirable to locate one sensor directly in the top of each channel in the reactor, coupled directly to the coolant. In this configuration, each sensor will detect boiling originating in its channel, allowing the location of the boiling source to be precisely pinpointed. Depending on the actual characteristics of structural members and other reflectors in the reactor, the sensors immediately surrounding a boiling channel may detect the boiling, but at a greatly reduced intensity. 


\section{F. 4.5 Sensor Type}

Currently, there is one sensor which appears to meet many of the requirements of the reactor environment and is commercially available. This is a pressure transducer manufactured by Kaman Nuclear Corporation, Model No. K-1900, designed to tolerate a $1000^{\circ} \mathrm{F}$ environment with high radiation and electromagnetic pulse fields. The sensor is 1.12 inches in diameter and 2.31 inches long, with a $5 / 8$-inch diameter diaphragm resonant at $50 \mathrm{kHz}$. The signal processing system and transducer design make this sensor usable up to the resonant frequency. At present, the sensitivity is somewhat less than might be desired, but modifications can be made.to increase the sensitivity.

\section{F. 5 SUMMARY AND CONCLUSIONS}

This study emphasizes key technical areas of the instrumentation probe for the GE backup FFTF system. Measurement systems for liquid sodium coolant temperature, flow, and acoustic noise were investigated, and design recommendations are included for each system. This preliminary information is presented so as to provide a basis for more detailed analysis and design leading toward the development of the complete instrumentation probe for the FFTF system.

The state-of-the-art in sensor systems for temperature, fluid flow, and acoustic noise measurements are not at equal levels of development for this application. Because of the unique requirements of this application and the degree of development in the past in similar applications, the order of development is temperature, flow, and acoustic noise. Thus it was possible to specify the thermocouple system design in more detail than the other two systems.

The three measurement areas appear, however, in the same order in terms of their weighted contribution to the present concept for reactor instrumentation. In this concept, the thermocouple outputs are the first to be considered in a decision to scram the reactor, with the flowmeter being second. Thus the overall instrumentation system is not being jeopardized now because of the differences in the state-of-the art in development for the three measurements.

Present plans call for the development of a:probe containing four thermocouples for temperature measurements, a flowmeter and, if practical, an acoustic sensor for boiling noise detection. A backup probe should also be developed for the measurement of temperature and flow only. This approach has several significant advantages. The acoustic sensor has the potential for adding instrumentation of advanced design. The alternate design containing only temperature and flow sensors can be developed in parallel with the first to give technical flexibility to the program. For instance, if size and configuration are important considerations in the final selection of a flow sensor, the alternate design may have a different choice of flowmeter since the packaging decign will be less stringent with only two measurements to consider. The program approach is a practical one of combining techniques that insure maximum likelihood of success with techniques for advanced measurement capabilities. 


\section{REFERENCES FOR APPENDIX F}

F-1 Hunter, J. J., McNulty, P. J., Ralston, T., "The Development of a Drag Plate Transient Flowmeter, "British Ministry of Technology, August 1966, (NEL Report No. 244.

F-2 Shercliff, J. A., "The Theory of Electromagnetic Flow-Measurement, " Cambridge University Press, 1962.

F-3 Popper, G. F., et al., "A Survey and Status Report on In-Core Flowmeters for Operation in the Fast Flux Test Facilitity, March 1967, (W P-0092-ANL).

F-4 Evans, P. B. F., et al., "Control and Instrumentation of the Prototype Fast ReactorProceedings, " of the London Conference on Fast Breeder Reactors, May 17 to 19, 1966, pp. 765-781.

F-5 Davidson, D. F. and Duncombe, E. , "Some Electromagnetic Transducer Techniques for. Use at Elevated Temperatures, "Transactions of the Society of Instrument Technology, June 1966, pp. 51-59.

F-6 Atomic Energy Commission - The Bureau of Ships, Department of the Navy, Washington, D. C., "Liquid Metals Handbook, "Sodium (NaK) Supplement TID 5277, July 1, 1955.

F-7 Kronenberg, K. J., and Bohlmann, M. A., "Long Term Magnetic Stability of Alnico V and Other Permanent Magnet Materials, "December 1958, (WADC-TR-58-535).

F-8 Tenzer, R. K., "Influences of Various Heat Exposures on Alnico V Magnets," J. Appl. Phys., Suppl. to 30, 4, 115s-116s, (April 1959).

F-9 Gordon, D. I. , "Magnetic Cores and Permanent Magnets in Hyper-Environments," Proceedings of the Institute of Environmental Sciences, Los Angeles, Calif., April 6 to $8,1960$.

F-10 Popper, G. F., and Knox, A. E., "FARET In-Core Instrument Development," July 1966, (ANL 7161).

F-11 Knox, A. E. and Popper, G. F., "ANL Participation in the FFTF Instrument Development Effort, "Argonns National Laboratory, Proceedings of the Symposium on Liquid Metal Instrumentation and Control, Idaho Falls, Idaho, March 1-2, 1967, (ANL 7380), pp. 9-15.

F-12 Hogan, J. M. and Boyd, L. R. "Joint Bettis-KAP. Nucleate Boiling Detection Experiment," February 1957, (WAPD-168).

F-13 Saxe, R. F., "Detection of Boiling In Water-Moderated Nuclear Reactors, "Nuclear Safety, 7 No. 4, pp. 452-456, (Summer 1966).

F-14 Osborne, M. F. M. and Holland, F. H., "The Acoustical Concomitants of Cavitation and Boiling, Produced by a Hot Wire (I \& II), "J. Acoust. Soc. Amer., 19, 13-29, (Jan. 1947).

F-15 Harrison, M. , "An Experimental Study Single Bubble Cavitation Noise, " J. Acoust. Soc. Amer., 776, 24 pp., (1952).

F-16" Mellen, R. H., "Ultrasonic Spectrum of Cavitation Noise in Water," J. Acoust. Soc. Amer., 26, pp. 356-60, (1954).

F-17 Babikov, O. I. , "Ultrasonics and Its Industrial Applications, " Consultants Bureau, New York (1960).

F-18 James, L. C. ,"Experiments on Noise as an Aid to Reactor and Plant Operation," Nuclear Engineering, Nuclear Engineering, (January 1965).

F-19 Anderson, T. T., "A Survey and Status Report on the Application of Acoustic Boiling Detection Techniques to Liquid Metal Cooled Reactors, "Argonne National Laboratory, (June, 1967). 
F-20. Hammitt, F. G., "Cavitation Phenomena in Liquid Metals," Dept. of Nuclear Engineering, University of Michigan, December 1967, (No. 01357-1-T).

F-21 Fitzpatrick, H. M., "Cavitation Noise, " Paper, 2nd Symposium in Naval Hydrodynamics, Washington, D. C., (1958).

F-22 Kinslur and Frey, "Fundamentals of Acoustics" Wiley and Sons, New York, (1950). 


\section{APPENDIX G}

\section{SHIELDING DESIGN METHODS}

The MAC ${ }^{(G-1, G-2)}$ removal-diffusion computer program was used almost exclusively for the survey calculations carried out in this preliminary shielding design analysis. A major limitation of this program is its provision to calculate only one-dimensional, infinite slab geometry. Approximate geometric corrections can be made to somewhat compensate for this limitations. Its principal advantage is its low computer cost. It is a good survey tool for evaluating the relative advantage of one shield composition over another. For deep neutron penetration, the results of neutron flux calculations are approximate. Transport theory and Monte Carlo programs, with higher computing costs, are required and should be used to verify results for deep penetration and streaming problems.

Corrections to the iron cross sections were received at the time the work reported here was nearing completion. Accordingly, check calculations were performed to estimate the direction and magnitude of this correction on calculated neutron flux and gamma dose rate distributions. At the same time, this check also provided a means of evaluating the effect of doing the shielding analyses with the 15 -group cross section set, as compared to the more costly 31 -group set. Figures G-1, G-2, G-3 and G-4 show that the magnitude of the difference was approximately a factor of 2, with the 31-group set giving results that are higher than obtained with the 15-group set. Hence, the effect of using the older cross section set and 15 in lieu of 31 groups is not large compared to the error that results from making all calculations in one-dimensional infinite slab geometry.

\section{REFERENCES}

G-1 Peterson, E.G., "MAC-A Bulk Shielding Code," April 1962, (HW-73381).

G-2 Greenborg, J., "Two Cross Section Libraries for Use With MAC Shlelding Code," January 1964, (HW-73381 Sup-1).

G-3 Pluta, P.R., etal., "Fast Flux Test Facility Backup Design Project, Fifth Quarterly Report," GEAP-5684, June - August 1968. 


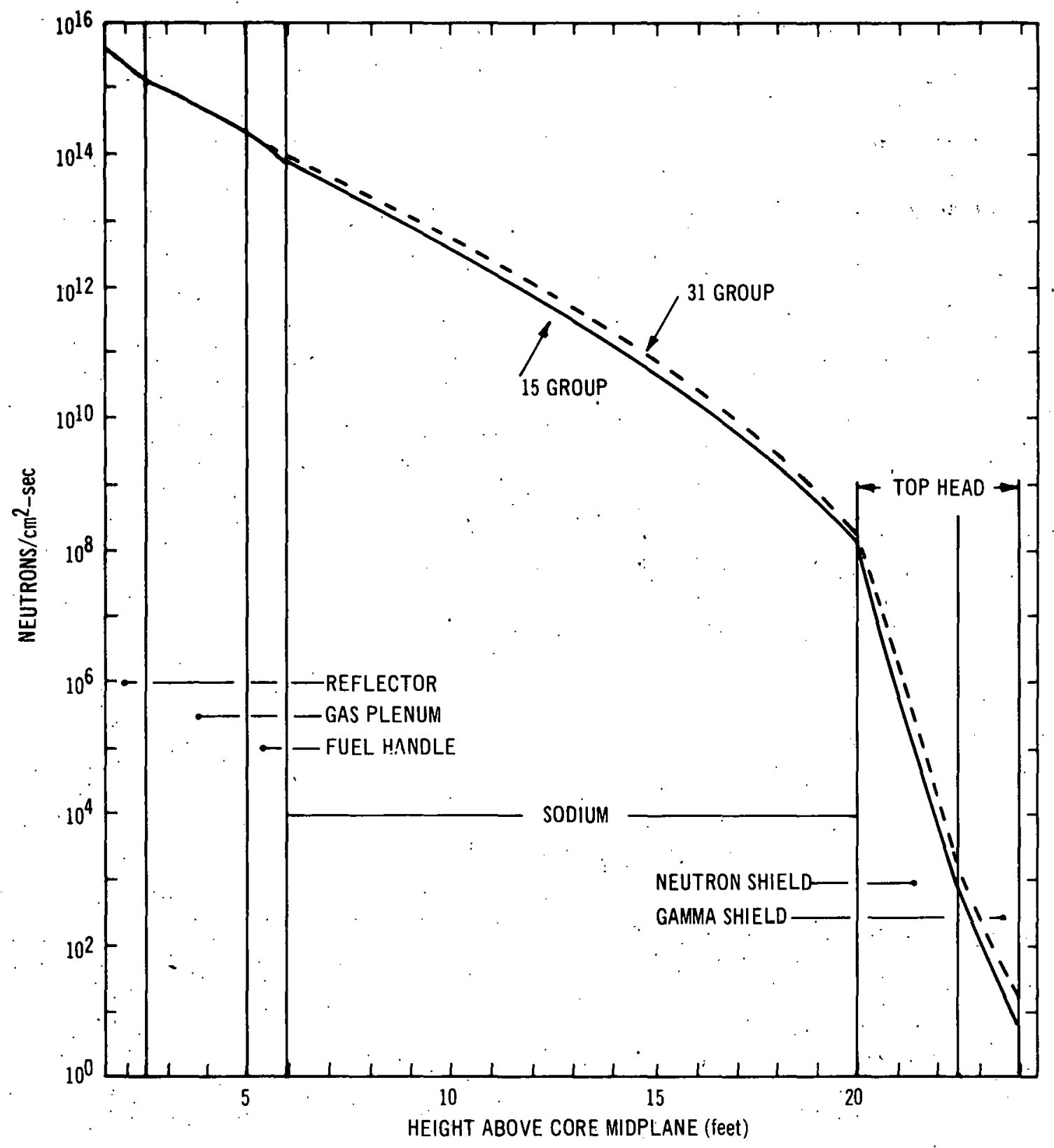

FIGURE G-1. COMPARISON OF THE.RESULTS FROM A 31 GROUP CALCULATION AND A 15 GROUP CALCULATION: TOTAL NEUTRON FLUX VERSUS HEIGHT ABOVE CORE MIDPLANE

$$
\text { G-2 }
$$




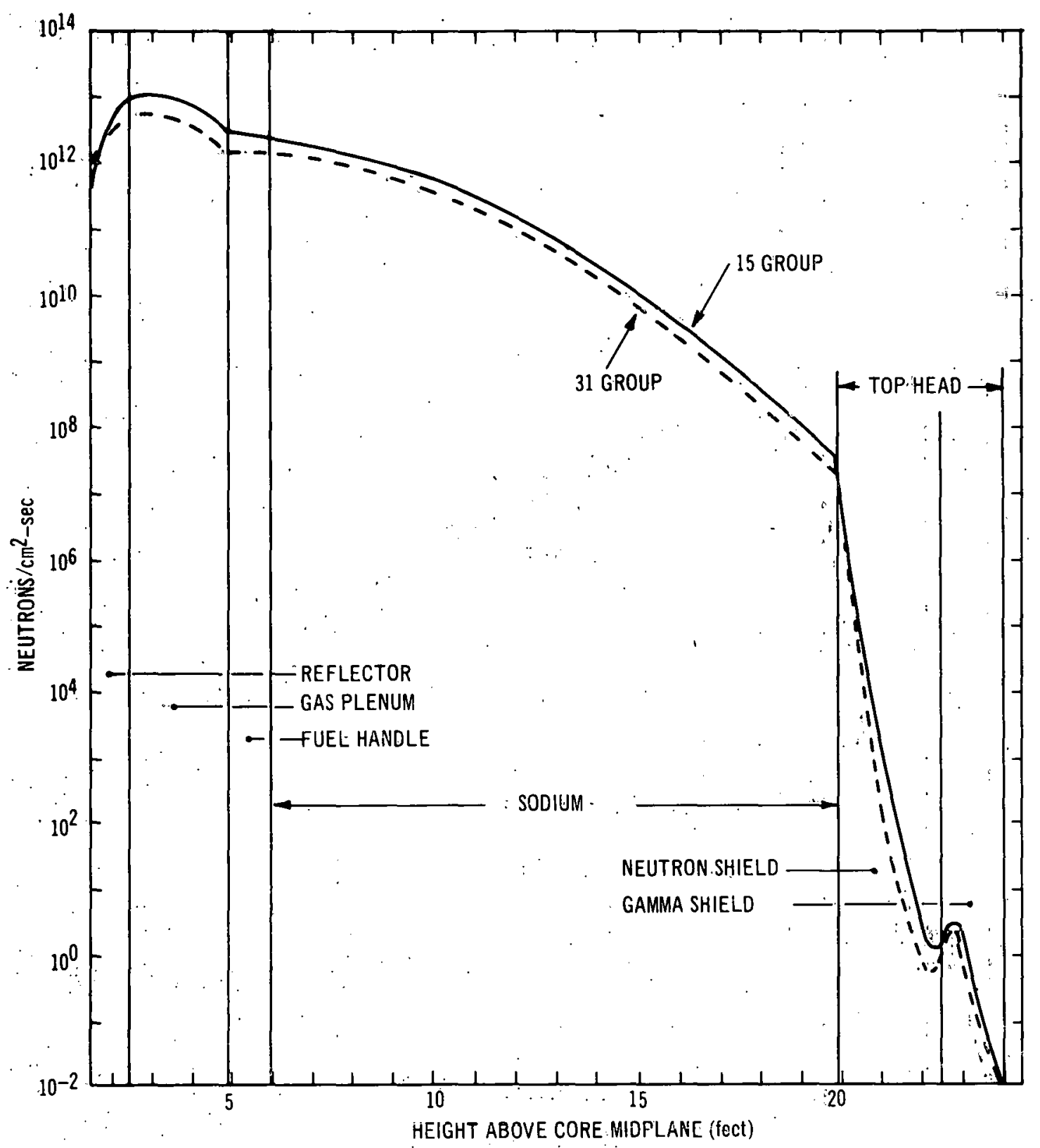

FIGURE G-2. COMPARISON OF THE RESULTS FROM A 31 GROUP. CALCULATION AND A 15 GROUP CALCULATION: THERMAL NEUTRON FLUX VERSUS HEIGHT. ABOVE CORE MIDP.LANE 


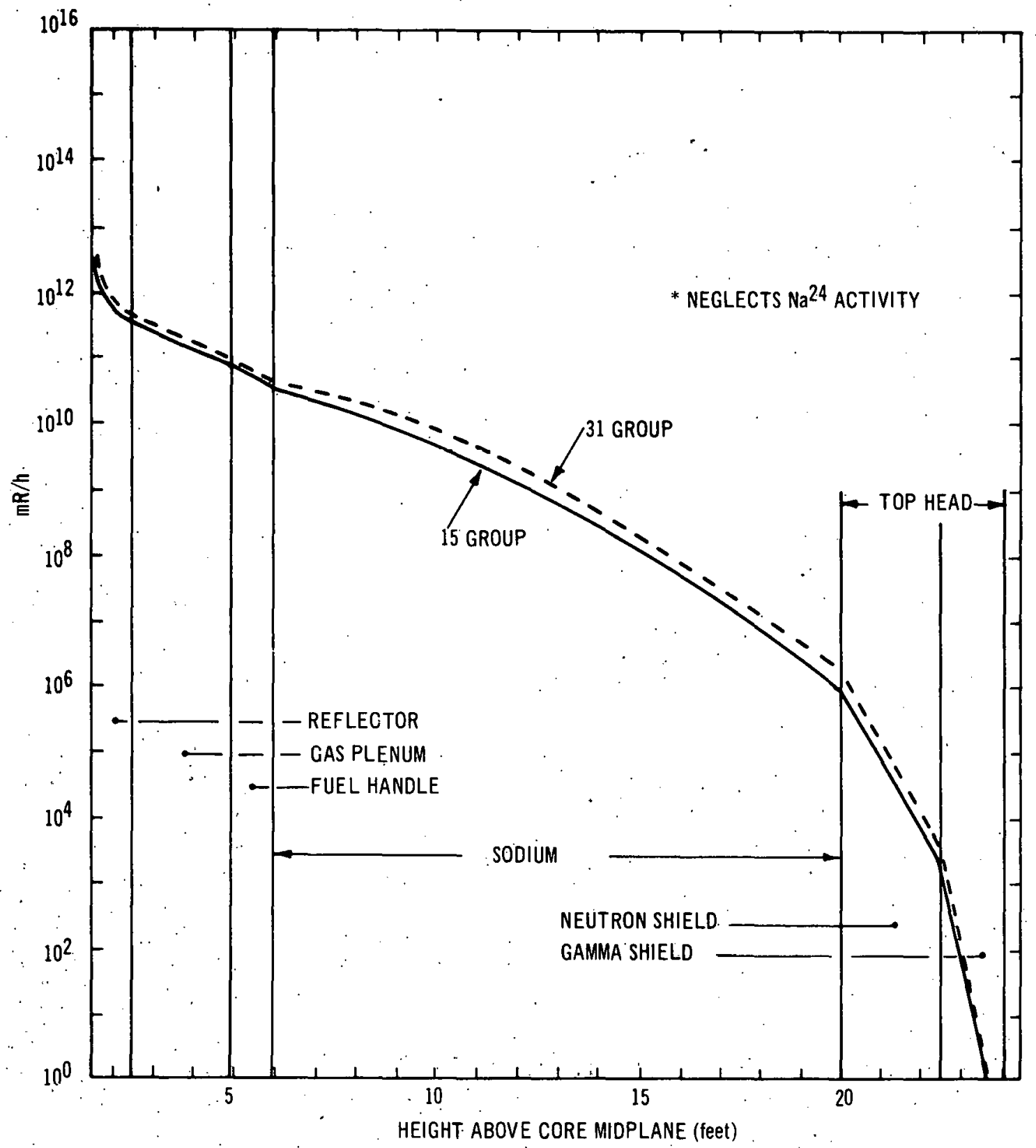

FIGURE G-3. COMPARISON OF THE RESULTS OF A 31 GROUP. CALCULATION AND A 15 GROUP CALCULATION: GAMMA DOSE RATE* YERSUS HEIGHT ABOVE CORE MIDPLANE

$\mathrm{G}-4$ 


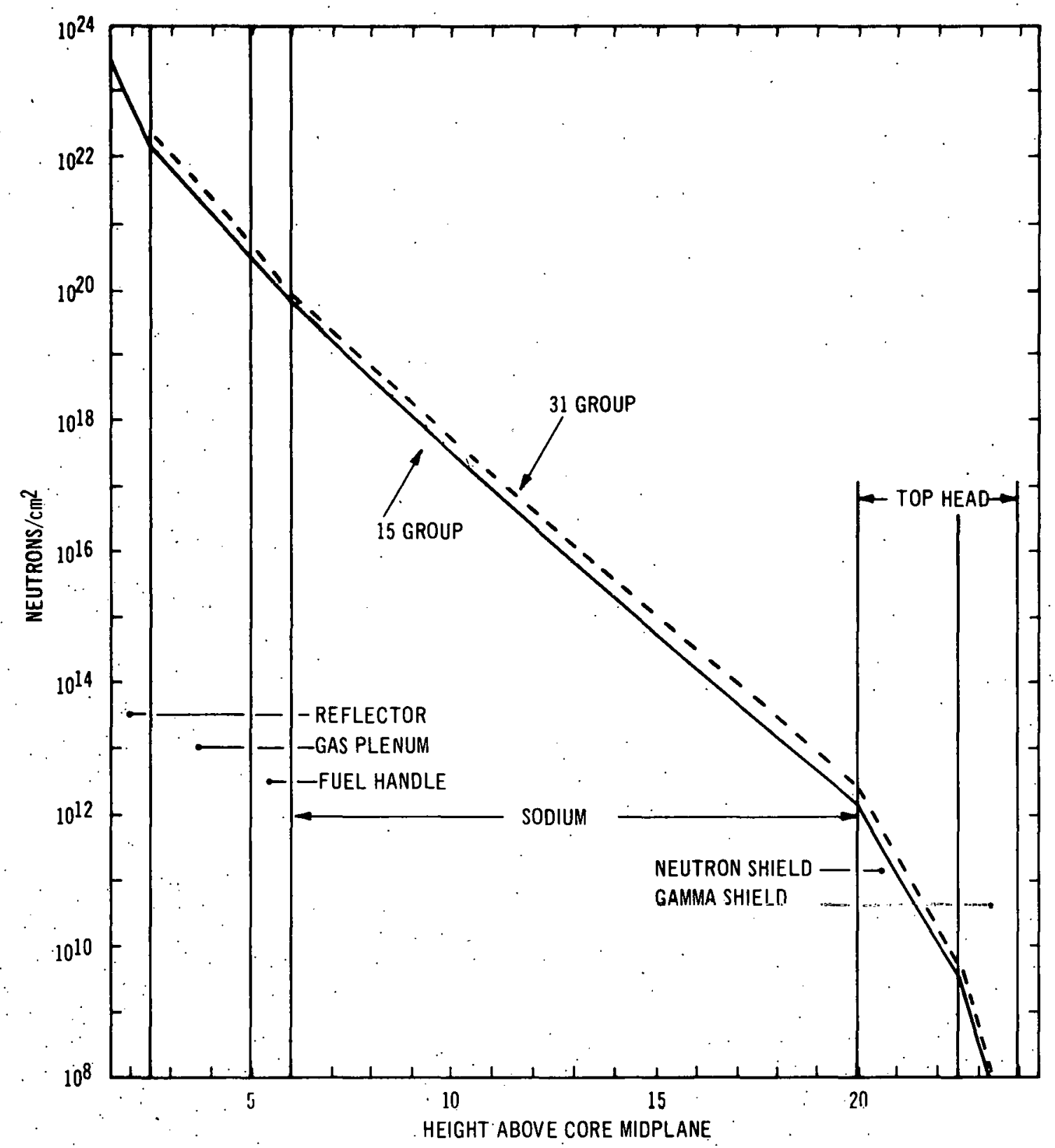

FIGURE G-4. COMPARISON OF THE RESULTS FROM A 31 GROUP CALCULATION VERSUS A 15 GROUP CALCULATION: nvt ( $\left.E_{n}>1.0 \mathrm{MeV}\right)$ VERSUS HEIGHT ABOVE CORE MIDPLANE

$$
\text { G-5/G-6. }
$$




\section{APPENDIX H}

\section{DBA CONTAINMENT}

To design the containment system, the quantitative methods to establish the following are required:

1. Energy absorption of head hold down mechanism

2. Static strength of head hold down mechanism

3. Thickness of reactor vessel and additional blast cylinders

4. Energy absorption of bottom of vessel and backup structure

5. Post-DBA cooling requirements

6. Radiological release to Equipment and Refueling Cell atmospheres

7. Pressure in Equipment Cell Atmospheres

During the DBA transient, a significant fraction of the fuel in the core may become vaporized. The resulting expansion is the source of mechanical loading. The analytical method used assumes an ideal expansion (isentropic) of the fuel in computing the mechanical work available. The following distribution of energy is assumed:

1. Energy is stored in vaporized fuel prior to its expansion (excluding heat of vaporization and heat required to raise fuel to its vaporization point).

2. Mechanical energy is extracted by isentropic expansion of vaporized fuel.

For mechanical loading it has been the accepted approach to define an equivalent chemical explosion for the energy release. The deficiencies of such an approach are the rate of energy release may be overestimated for the shock wave strength and the incondensibility of the vapors formed may be overestimated for the pressure loadings following the shock wave. However, in lieu of an acceptable alternative, it is assumed that the "TNT Rationale" is a requirement for mechanical loadings during the "explosion."

An ample margin between calculated energy release values and design values is recommended since potential energy extraction processes such as transfer of thermal energy to the sodium that generates a sodium vapor bubble is not included because of the complexity of defining the heat transfer processes which are highly geometry dependent.

Hicks and Menzies, Reference $\mathrm{H}-1$, indicate the secondary processes in which vapurized sodium becoming the working fluid may be explosive in nature and extract about $10 \%$ of the residual heat energy as expansion work of sodium vapor; in addition to the work of expanding fuel vapor. The following analysis illustrates an application of the TNT rationale.

\section{H. 1 RECOMMENDED DESIGN APPROACH}

To provide ani ample margin, the cnergy absorption requirements of the design for the equivalent TNT explosion is selected as 750 .pounds, which corresponds to $1500 \mathrm{MW}$ seconds mechanical energy release and defined as the present reference DBA. The discussion of available 
test data on explosive tests on similar designs resulted in making ultra-conservative assumptions to establish the head loading leads to very severe energy absorption requirements. By not including design features and configurätions which tend to reduce the head loading, it is possible to direct from $15 \%$ to $20 \%$ of the charge energy into the head. (For a $1500 \mathrm{MW}$ second, a mechanical energy release of $1 \%$ would require forty-eight $3-1 / 2$ inch diameter bolts to be 18 inches long. This gives a perspective of magnitude for holddown requirements.) Selecting a vessel wall thickness as small as practical and providing space between the vessel wall and additional external blast cylinders for the vessel to expand into is a recommended design feature. In addition to this the vessel internals should not be designed with more radial rigidity than necessary in the form of support cylinders. The mass of shielding will inevitably tend to direct energy upwards in the expanding bubble process. The above features will make it possible to reduce the design level of energy absorption on the head from about $15 \%$ to less than $10 \%$ of the charge energy.

Another major consideration is the effect of a gas gap between the sodium surface and the underside of the head. Tests ${ }^{(\mathrm{H}-2)}$ indicate the water hammer loading from the expanding gas bubble are more than the shock wave loading even when a "weak" tank is used. Unfortunately the only test data on a configuration with no gap was taken with a strong tank. It is probable that a combination of weak tank and no gap is the best configuration since (1) the shock-wave loading would be due to a direct reflection which is smaller than shock-wave loading due to the sprayimpact loading across a small gap, and (2) the water hammer loading should be small since the bubble pressure should be relieved by vessel deformation. This is a tentative conclusion since applicable test data is not available; it is probable that such an arrangement can limit the head loading to a small fraction ( 1 to $3 \%$ ) of the charge energy. The energy transmitted by a direct shock impact is calculated to be approximately $1 / 2 \%$ of the charge energy. The loading during the bubble expansion phase will be controlled by the hoop resistance of the vessel. Three percent $(3 \%)$ of charge energy is selected as a design value on total kinetic energy imparted to the head. The head must be able to withstand a static pressure loading equal to the pressure required to deform the vessel. The loading on the head during the expansion of the vessel will drop from an initial high value of about 20,000 psi (for TNT) down to about 400 psi. During this loading phase, yielding of the hold down will occur and kinetic energy will be imparted to the head. This yielding decreases as the yield strength of the hold down increases. A preliminary review indicates a numerical method of solution will be required. As a reference, it is recommended the head hold down be designed to absorb $3 \%$ of the energy released. A development program will be required to establish the adequacy of this recommendation. An analytical evaluation of the loading mechanisms of an expanding bubble of $\mathrm{UO}_{2}$ vapor will give an indication of the probable margin of safety in the design against a more realistic model of the accident.

\section{H. 2 DISCUSSION OF LOADING MECHANISMS}

\section{H. 2. 1 Shock Wave at Liquid-Solid Interface}

For no gap, the head acts essentially as a rigid boundary, and upon impact of the compression shock, a compressive wave is reflected back into the liquid, leaving the liquid essentially at rest. The loading on the head for a normal reflection is the impulse associated with the pressure across the shock front. This can be computed ${ }^{(\mathrm{H}-3)}$ : 


$$
I=1.46 \mathrm{~W}^{1 / 3}\left(\frac{\mathrm{W}^{1 / 3}}{\mathrm{R}}\right)^{0.89} \frac{\mathrm{lb}-\mathrm{sec}}{\text { sq. in }} \text { for TNT }
$$

where:

$$
\begin{aligned}
& \mathrm{W}=\text { Weight of charge- } \mathrm{lb} \\
& \mathrm{R}=\text { Distance from charge-ft }
\end{aligned}
$$

The velocity of the head associated with this is $V=A I / M$

where:

$$
\begin{aligned}
& M=\text { Mass of head } \\
& A=\text { Area of head }
\end{aligned}
$$

Kinetic energy of head $=1 / 2 \mathrm{MV}^{2}=1 / 2 \frac{(\mathrm{AI})}{\mathrm{M}}^{2}$.

\section{H.2.2 Shock Wave-Liquid Gas Interface}

For a design in which there is a gas gap between the surface and the head, the shock strength of the refracted wave through the gas is very small due to the gas compressibility. The reflected wave is a tensile wave, and the upward velocity behind the initial shock front is increased further by the reflected tension resulting in a layer of fluid leaving the surface with an upward velocity. A numerical evaluation of this effect has not been performed; it is dependent upon a reasonably precise knowledge of the cavitation pressure which is required to determine the depth of liquid which can be set in motion and transmit kinetic energy by impact on the head. Interpretation of measurements of Reference H-4 indicates this is $\sim 2.5$ times the energy transmitted by direct shock impact.

\section{H. 2.3 Bubble Expansion}

For no gas gap the loading from the expanding bubble will be initially very high.' Under such pressure, the head or the vessel or both will deform by plastic flow and create volume to relieve the pressure. If the static strength of the head and hold down is less than the vessel, the head hold-down will take most of the expansion, and some kinetic energy associated with the rate of the expansion will also be delivered from the sodium and head to the hold down.

For the situation in which a free volume exists for the gas to expand into the static pressure, loading is determined by this volume, but the transmittal of kinetic energy to the sodium ahead of of the expanding bubble provides a loading mechanism. The amount of energy in the sudium directed upward to impact the head is dependent upon the radial resistance to deformation of the vessel internals and the vessel wall. From the experimental data of Reference $\mathrm{H}-2$, the head loading in a rigid tank was much higher than in $a$ weak tank. Therefore, it appears that an expanding vapor bubble is a stronger loading source than the shock wave. From this discussion it is clear that an analytical approach which adequately predicts head loading must take into account several complex time-dependent interrelated mechanisms. 


\section{H. 3 PRELIMINARY HEAD LOADING ANALYSES}

\section{H. 3.1 Static Pressure Loading on Head}

The quasi-static pressure loading on the head will be limited by the hoop strength of the vessel.

Hoop strength of vessel,

$$
\sigma_{h}=\frac{p r}{t} \text { or } p=\frac{\sigma_{h} t}{r}
$$

For 304 stainless steel at $900^{\circ} \mathrm{F} \quad \sigma_{\mathrm{y}}=20,000$

$$
\sigma_{u}=60,000
$$

$$
\begin{aligned}
& r=100 \mathrm{in} . \\
& p=\frac{60,000 t}{100}=600 \mathrm{t}
\end{aligned}
$$

where $t$ is the vessel thickness. The $900^{\circ} \mathrm{F}$ was chosen to be representative of the minimum upper pool temperature at power and is conservative with respect to the head loadings (as related to vessel deformation).

For:

$$
\begin{array}{ll}
\mathrm{t}=3 / 4 \mathrm{in} . & \mathrm{p}=450 \mathrm{psi} \\
\mathrm{t}=1 \mathrm{in} . & \mathrm{p}=600 \mathrm{psi} \\
\mathrm{t}=2 \mathrm{in} . & \mathrm{p}=1200 \mathrm{psi} \\
\mathrm{t}=3 \mathrm{in} . & \mathrm{p}=1800 \mathrm{psi}
\end{array}
$$

\section{H.3.2 Shock Wave Loading on Head}

The mass of head was assumed to be 150,000 pounds for this analysis. Actually, the head and its appurtenances (lead shielding) are considerably heavier than this value. This is a conservative assumption with respect to the head-bolt specifications.

Free impulse at head $16 \mathrm{ft}$ from charge.

$$
\begin{aligned}
I_{s p} & =1.46 \mathrm{w}^{1 / 3}\left(\frac{\mathrm{W}^{1 / 3}}{\mathrm{R}}\right)^{0.89} \\
& =1.46 \times 750^{1 / 3}\left(\frac{750^{1 / 3}}{20}\right)^{0.89}
\end{aligned}
$$

$\cong 7.0 \mathrm{lb} \mathrm{sec} / \mathrm{in}^{2}$ 
where:

$$
\begin{aligned}
& \mathrm{W}=\text { Weight of } \mathrm{TNT}-\mathrm{lb} \\
& \mathrm{R}=\text { Distance from charge }-\mathrm{ft}
\end{aligned}
$$

Kinetic energy of head after impact,

$$
\mathrm{U}_{\mathrm{K}}=\frac{1}{2} \frac{\mathrm{W}}{2} \mathrm{v}^{2}=\frac{1}{2} \frac{\mathrm{W}}{\mathrm{g}}\left(\frac{\mathrm{IA}}{\mathrm{W} / \mathrm{g}}\right)^{2}=\frac{1}{2}\left(\frac{\mathrm{IA}}{\mathrm{W}}\right)^{2} \mathrm{~g} .
$$

$A=$ Area of head $=\pi \times 100^{2}=3.14 \times 10^{4} \mathrm{in}^{2}$

$$
\mathrm{U}_{\mathrm{K}}=\frac{1}{2} \frac{(7.0 \times 3.14)^{2} \times 386 \times 10^{8}}{150,000}=62.2 \times 10^{6} \mathrm{in}-\mathrm{lb}
$$

Percent of charge energy $\left(\alpha_{\mathrm{s}}\right)$

$$
\begin{aligned}
\alpha_{s}=\frac{62.2 \times 10^{6}}{1500 \times 8.85} \times 10^{6} & =0.47 \% \\
\text { Say } & =\underline{1 / 2 \%}
\end{aligned}
$$

\section{H. 4. HOLD DOWN BOLT REQUIREMENTS}

\section{H. 4.1 Static Pressure.}

For:

$$
\begin{aligned}
\text { Vessel thickness } \mathrm{t} & =0.75 \mathrm{in} . \\
\text { Static pressure } \mathrm{p}_{\mathrm{s}} & =450 \mathrm{psi} \\
\text { Design stress in bolt } & =\sigma \text { yield }=30,000 \mathrm{psi} \\
\text { Bolt area required } & =\frac{\mathrm{pA}}{\sigma}=\frac{450 \times 3.14 \times 10^{4}}{30 \times 10^{3}} \\
& =465 \mathrm{sq} \text { in. }
\end{aligned}
$$

Assume 48 bolts

$$
\begin{aligned}
& \mathrm{A}_{\mathrm{b}}=\frac{465}{48}=9.65 \mathrm{sq} \text { in. } \\
& \text { Bolt diameter }=\sqrt{\frac{4}{\pi} \times 9.65}=\sqrt{12.3}
\end{aligned}
$$

$=3.5$ in. diam 


\section{H.4.2 Length Required}

Energy absorption per inch with $20 \%$ elongation

Average stress $=50,000 \mathrm{psi} \quad$ Strain $=0.2$

$$
\begin{aligned}
U_{S} & =\sigma \epsilon A=50,000 \times 0.2 \times 9.65=96,500 \text { in. }-1 \mathrm{~b} . / \mathrm{ft} \text { bolt } \\
& =48 \times 96,500=4.65 \times 10^{6} \text { in. }-\mathrm{lb} . / \mathrm{ft}
\end{aligned}
$$

Energy delivered to head $3 \% \times 1500 \times 8.85 \times 10^{6}=396 \times 10^{6}$

Length $=\frac{396 \times 10^{6}}{4.65 \times 10^{6}}=85 \mathrm{in}$. Say, $7 \mathrm{ft}$

\section{H. 5 DISCUSSION OF AVAILABLE TEST DATA}

Reference $\mathrm{H}-2$ reports experimental information taken on model tests in a 24 -inch diameter tank 24 inches high with a central roof plug 7-3/4 inches in diameter and a weight of 50 pounds. Tests were performed using a bare charge and also a charge surrounded by a simulated core structure. From velocity measurements of the plug, the kinetic energy imparted to it is established.

$\mathrm{KE}$ of Plug
of Charge E
$\begin{array}{r}0.2 \% \\ 1.5 \% \\ 0.2 \% \\ 0.6 \%\end{array}$

The percentage of charge energy imparted to the plug from direct shock wave impact can be computed using Reference H-3 as follows:

Energy release quoted is $203,000 \mathrm{ft} \mathrm{lb}$

Corresponding weight of TNT, $\mathrm{W}=0.138 \mathrm{lb}$

Distance from charge to undersurface of head

$\cdot \mathrm{R}=16.6 \mathrm{in},=1.38 \mathrm{ft}$

Specific impulse $I_{\mathrm{sp}}=1.46 \mathrm{w}^{1 / 3}\left(\frac{\mathrm{w}^{1 / 3}}{\mathrm{R}}\right)^{0.89}$ $=0.32 \mathrm{lb} \mathrm{sec} / \mathrm{sq}$ in.

Head area $A=47$ in. ${ }^{2}$

Impulse on head $=I_{s p} \times A=15 \mathrm{lb}-\mathrm{sec}$. 
$\begin{aligned} \text { Kinetic energy of head } & =\frac{1}{2} \cdot \frac{\mathrm{W}}{\mathrm{g}} \mathrm{v}^{2}=\frac{1}{2} \frac{\mathrm{I}^{2}}{\mathrm{~W}} \mathrm{~g} \\ & =\frac{1}{2} \times \frac{15^{2}}{50} \times 32=72 \mathrm{ft}-\mathrm{lb}\end{aligned}$

Percent charge energy imparted to head by direct shock wave impulse $=\frac{7: 2}{203,000}=\underline{\underline{0.035 \%}}$.

Reference H-4 reports on similar tests in which the impulse on the head due to shock wave effects was separated out from the total loading. For tests using three different charge weights, the impulse on the head in which a gap existed between the surface and the bottom of the head was from two to three times the impulse obtained from the direct. impact as calculated above.using Reference H-3. So, for the tesțs of Reference H-2, the percentage of charge energy delivered to the plug by the shock wave is approximately $3 \times 0.035 \% \simeq 0.1 \%$.

The major part of the energy transmitted to the roof is associated with the expanding vapor bubble of explosion products and is strongly dependent upon the radial restraint by the rigidity of the vessel internals and vessel wall.

The area of the model plug is approximately $10 \%$ of the roof area. For the strong tank, the impulse on the roof was approximately $1.25 \times$ the impulse on the plug. The kinetic energy imparted to the roof is approximately $10 \times 1.25 \times$ energy imparted to the small central plug.

\section{Percent of Energy Given to Head}

\begin{tabular}{lrrrrr}
\cline { 1 - 1 } Tank-Charge & & Total & & Shock Wave & Gas Bubble \\
\cline { 1 - 1 } Strong-bare & $25 \%$ & & $1 \%$ & & $24 \%$ \\
Strong-enclosed & $17 \%$ & & $1 \%$ & $16 \%$ \\
Weak-bare & $2.5 \%$ & $1 \%$ & $1.5 \%$ \\
Weak-enclosed & $7.5 \%$ &. & $1 \%$ & & $6.5 \%$
\end{tabular}

Since $50 \%$ of the energy rclcaco is in the gas huhble 3 to $50 \%$ of this can be transmitted to the head depending upon the system geometry. For the FFTF the percentage of charge energy absorbed by the head and its hold-down structure will also depend upon the radial constraints to bubble growth. A weak tank with the radial stiffness of the core internals minimized is desired to minimize energy absorption requirements in the head:

In the above experiments, the internal structure included a mockup of a relatively massive graphite shield. It is not anticipated that the FFTF design would offer as much restraint. The height to diameter ratio of the reactor vessel is greater than in the tests quoted. The effect of this is not clear; however, it is most likely that if the vessel is designed to be relatively weak, the gun barrel effect will be offset by deformation of the vessel, creating a volume for the gases to expand into.

\section{H. 6 HEAD LOADING FROM SHOCK WAVE WITH A GAP BETWEEN SUR FACE AND HEAD}

Reference $\mathrm{H}-4$ reports the following initial impulse data associated with shock wave with a gap: 


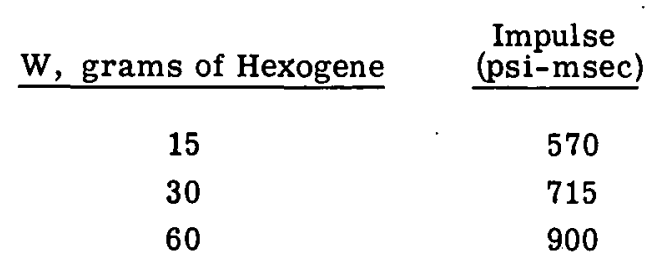

The charge energies were reported as $2 \times 10^{4}, 4 \times 10^{4}$ and $8 \times 10^{4}$ calories. Since TNT releases $1050 \mathrm{cal} / \mathrm{gm}$, the equivalent weights of TNT are 19,38 , and 76 grams or $0.042,0.084$ and 0.168 pounds. From Reference $\mathrm{H}-3$ the impulse is:

$$
I=1.46 \mathrm{w}^{1 / 3}\left(\frac{\mathrm{W}^{1 / 3}}{\mathrm{R}}\right)^{0.89} \mathrm{lb} \mathrm{sec} / \mathrm{in}^{2}
$$

$R$ is estimated to be 1.1 . Therefore,

$$
\begin{aligned}
\mathrm{I} & =1.35 \mathrm{w}^{0.63} \\
& =184 \mathrm{psi}-\mathrm{msec} \text { for } 15 \mathrm{gm} \text { Hexogene } \\
& =284 \mathrm{psi}-\mathrm{msec} \text { for } 30 \mathrm{gm} \text { Hexogene } \\
& =439 \mathrm{psi}-\mathrm{msec} \text { for } 60 \mathrm{gm} \text { Hexogene }
\end{aligned}
$$

$$
\left.\begin{array}{l}
570 / 184=3.1 \\
715 / 284=2.5 \\
900 / 439=2.1
\end{array}\right\} \begin{aligned}
& \text { ratio of measured im- } \\
& \text { pulse with a gap to } \\
& \text { calculated impulse based } \\
& \text { on no gap. }
\end{aligned}
$$

\section{H. 7 RADIAL BLAST SHIELD REQUIREMENTS}

For TNT the thickness of a single cylinder required to contain a charge without rupture (or to a prescribed maximum deformation) can be calculated using the method of Reference $\mathrm{H}-5$.

$$
\begin{aligned}
& W=\left[\frac{1.407 A\left(\sigma_{t}\right) \epsilon}{w^{-0.85} 10^{5}}\right]^{0.811} \\
& \sigma_{t}=\sigma_{y}+\frac{\epsilon}{\epsilon_{u}}\left[\sigma_{u}\left(1+\epsilon_{u}\right)-\sigma_{y}\right]
\end{aligned}
$$

where the geometry factor $\mathrm{A}$ is;

$$
\begin{aligned}
& A=\frac{\left(3.41+0.117 \mathrm{R}_{\mathrm{i}} / \mathrm{h}_{\mathrm{o}}\right)\left(\mathrm{R}_{\mathrm{e}}^{2}-\mathrm{R}_{\mathrm{i}}^{2}\right)^{1.85}}{\left(1.47+0.0373 \mathrm{R}_{\mathrm{i}} / \mathrm{h}_{\mathrm{o}}\right)^{0.15} \mathrm{R}_{\mathrm{i}}^{0.15}} \\
& \mathrm{~W}=\text { Weight of TNT }-\mathrm{lb} \\
& \sigma_{\mathrm{y}}=\text { Yield stress psi } \\
& \sigma_{\mathrm{u}}=\text { Ultimate stress psi } \\
& \epsilon=\text { Hoop strain, } \epsilon_{\mathrm{u}}=\text { Ultimate elongation } \\
& \mathrm{R}=\text { Cylinder radius, } \mathrm{i}=\text { inside, e }=\text { outside, } \mathrm{ft} \\
& \mathrm{h}=\text { Cylinder thickness, } \mathrm{ft} \\
& \mathrm{w}=\text { Material density, } \mathrm{lb} / \mathrm{ft}^{3}
\end{aligned}
$$




$$
\begin{aligned}
& \text { For } \mathrm{R}_{\mathrm{i}}=8, \mathrm{R}_{\mathrm{e}}=8+\mathrm{h} \\
& \text { SS } 304 \text { at } 900^{\circ} \mathrm{F} \quad \sigma_{\mathrm{y}}=16,000 ; \sigma_{\mathrm{u}}=60,000 ; \epsilon_{\mathrm{u}}=0.44 \\
& \mathrm{~A}=\frac{(3.41+0.936 / \mathrm{h}) 124.8 \mathrm{~h}^{1.85}}{(1.47+0.298 / \mathrm{h})^{0.15}} \\
& \frac{\sigma_{\mathrm{t}}}{10^{5}}=(0.16+1.6 \epsilon) \\
& \mathrm{w}^{+0.85}=(500)^{0.85}=197
\end{aligned}
$$

Maximum radial deflection $=U_{r}=R \epsilon=100 \epsilon$, in.

$$
\begin{aligned}
& \frac{1}{w^{0.811}}=750^{\frac{1}{0.811}}=3600 \\
& \epsilon \frac{\sigma_{t}}{10^{5}}=\left(0.16+0.016 U_{r}\right) \frac{U_{r}}{100}
\end{aligned}
$$

For $h=1,2,4$ in. $A=14.4,34.8$, and 89.4 , respectively.

$$
\begin{aligned}
& \left(0.16+0.016 U_{r}\right) \cdot \frac{U_{r}}{100}=\frac{3600}{1.407(197 A)} \\
& \left(0.16+0.016 U_{r}\right) U_{r}=\frac{1300}{A}
\end{aligned}
$$

Thus for. $h=1,2$, and 4 in., the radial expansion would be 73,44 , and 25.6 inches; respectively.

Figure. $\mathrm{H}-1$ shows this expansion as a function of vessel thickness.

It is clear that additional radial support will be required for the vessel to reduce the expansion.

\section{H. 8: DOWN BLAST REQUIREMENTS}

Down loads from the shock wave and bläst pressure may be absorbed by elongation of the vessel; however, the difficulty from theoretical calculations is showing that the stress levels at the knuckle region between the bottom head and the cylinders will not cause fracture. Tests will establish this; however; it is recommended that the assumption be made until test.data is available to indicate to the contrary that the knuckle does fail." "Erush strücture beneath the vessel is recommended as. a means of absorbing the kinetic energy imparted to the lower head. Preliminary 


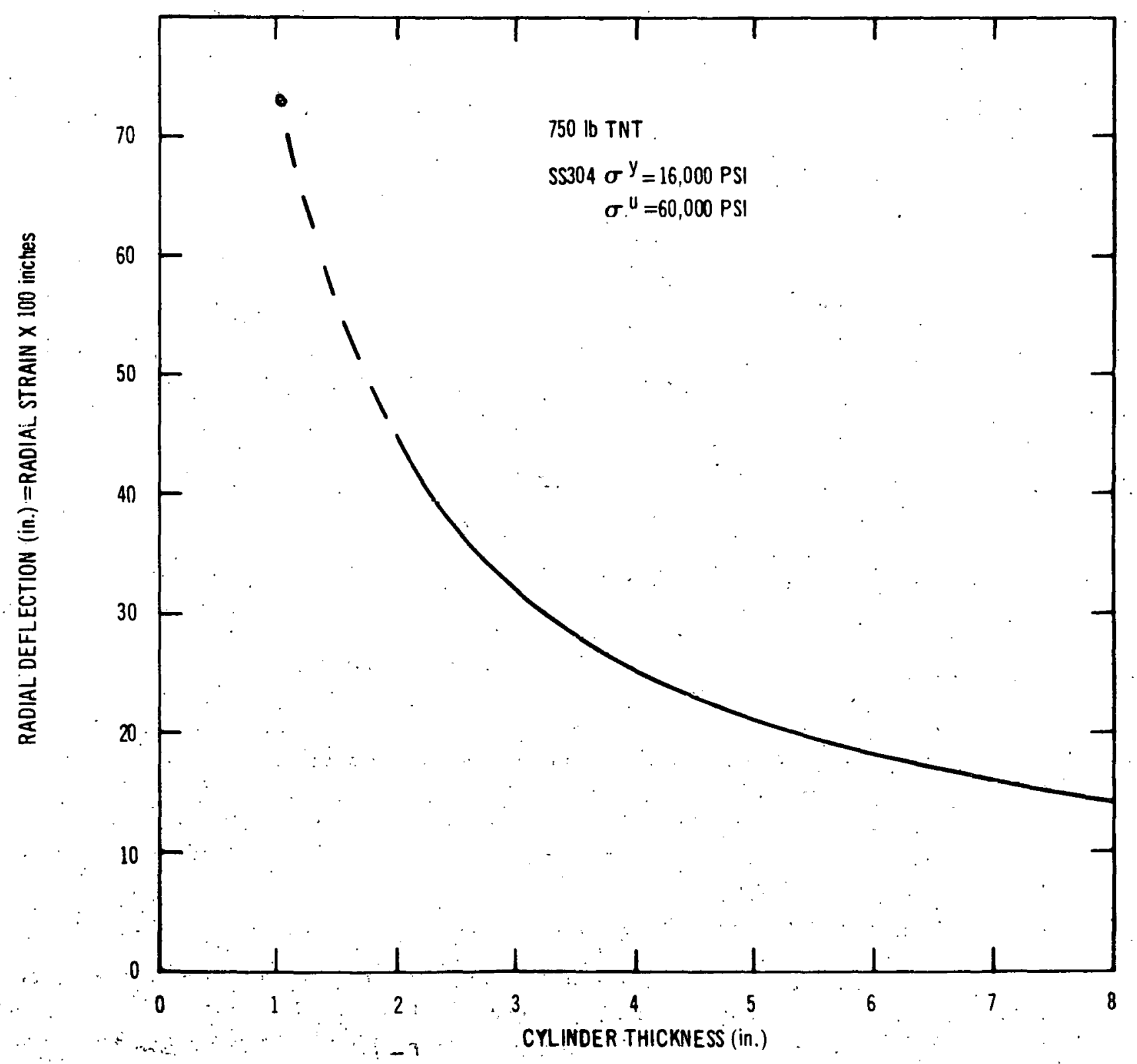

FIGURE H-1. DEFLECTION OF VESSEL AND BLAST CYLINDERS

$$
\text { I } \mathrm{H}-10
$$


calculations using the direct impulse of a shock wave on the grid plate of $20 \mathrm{lb}-\mathrm{sec} / \mathrm{sq}$.in. (based upon $6 \mathrm{ft}$ from $750 \mathrm{lb}$ charge) -show that the energy absorption requirements of the crush structure $=$ $1.4 \times 10^{9}$ in. $-1 b$.

\section{H. 9 POST DBA COOLING}

The agglomerate of material which accumulates in the bottom of the vessel following the DBA generate heat due to decay of fission products. The heat level is $20 \mathrm{MW}$ initially, decaying to $4 \mathrm{MW}$ after three hours, and about $1 \mathrm{MW}$ after one day. The temperature rise of the sodium in the reactor is approximately $350^{\circ} \mathrm{F}$ in the first three hours assuming no cooling. A decay. heat removal.system capable of removing $5 \mathrm{MW}$ would appear to be adequate. A $10 \mathrm{MW}$ system has been suggested to permit redundancy to be incorporated.

\section{H.9.1 Thermal-Hydraulic Analysis of Graphite Collection Pan}

In the analysis the following conditions were assumed.

1. The conglomerate consists of a homogeneous mixture of half the fuel and an equal volume of molten metal (i.e., $5 \mathrm{ft}^{3}$ of $\mathrm{UO}_{2}+5 \mathrm{ft}^{3}$ of stainless steel).

2. The decay power density of the conglomerate is $0.5 \mathrm{MWt} / \mathrm{ft}^{3}$ and the thermal conductivity of the conglomerate is $8 \mathrm{Btu} / \mathrm{h}-\mathrm{ft}-{ }^{\circ} \mathrm{F}$.

3. The conglomerate forms a pancake-shaped pool $0.5 \mathrm{ft}$ high on the catch pan.

4. The thermal conductivity of the graphite catch pan is $20 \mathrm{Btu} / \mathrm{h}-\mathrm{ft}-{ }^{\circ} \mathrm{F}$.

5. The cell cavity is fiooded with sodium and the temperature of the conglomerate at the sodium interface is $1700^{\circ} \mathrm{F}$.

6. The conglomerate is cooled by sodium boiling at its top surface and conduction through the catch pan on the bottom surface. (Figure $\mathrm{H}-2$ )

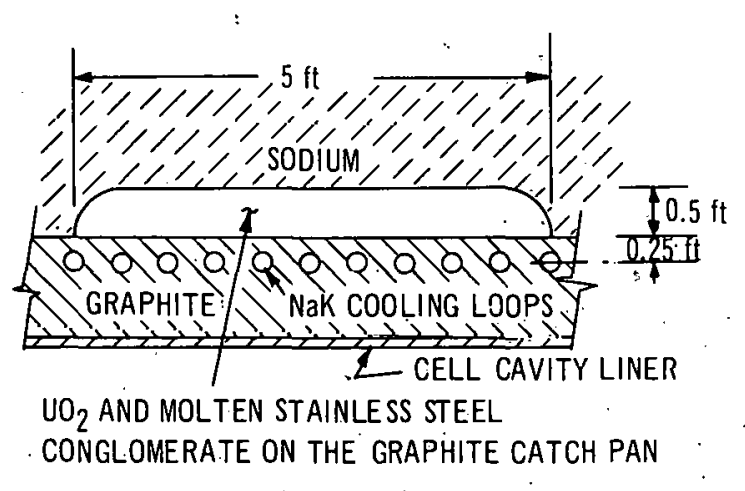

FIGURE H-2. FUEL-MELTDOWN THERMAL,MODEL 
Assuming steady state conditions, the temperature at the conglomerate-catch pan interface is given by:

$$
T_{0}=\frac{\frac{z_{g}^{\circ}}{2 U}+\frac{K_{c} T_{s}}{z U}+T_{W}}{1+\frac{K_{c}}{z U}}
$$

where;

$z \quad=0.5 \mathrm{ft}$ (height of conglomeration)

$\stackrel{\circ}{\mathrm{g}}=1.706\left(10^{6}\right) \mathrm{Btu} / \mathrm{h}-\mathrm{ft}^{3}$ (decay power density)

$\mathrm{U} .=80 \mathrm{Btu} / \mathrm{h}-\mathrm{ft}^{2}-{ }^{\circ} \mathrm{F}$ (Admittance of catch pan)

$\mathrm{K}_{\mathrm{c}}=8 \mathrm{Btu} / \mathrm{h}-\mathrm{ft}-{ }^{\circ} \mathrm{F}$ (thermal conductivity of conglomeration)

$\mathrm{T}_{\mathbf{S}}=1700^{\circ} \mathrm{F}$ (sodium-conglomeration interface temperature)

$\mathrm{T}_{\mathrm{W}}=.1600^{\circ} \mathrm{F}$ (catch pan temperature at level of NaK cooling coils) (Corresponds to bulk temperature of $400^{\circ} \mathrm{F}$ for the NaK.)

$\therefore \dot{\mathrm{T}}_{0}=6100^{\circ} \mathrm{F}$.

The level of the maximum temperature in the conglomeration is given by:

$$
\begin{aligned}
& \mathrm{z}_{\max }=\frac{\mathrm{z}}{\mathrm{L}}+\frac{\mathrm{K}_{\mathrm{c}}\left(\mathrm{T}_{\mathrm{O}}-\mathrm{T}_{\mathrm{S}}\right)}{\mathrm{zg}} \\
& \therefore \mathrm{z}_{\text {max }}=0.2913 \mathrm{ft} \text { below the sodium-conglomeration interface. }
\end{aligned}
$$

The maximum temperature in the conglomeration is given by:

$$
\begin{aligned}
& T_{\max }=T_{s}+\frac{\stackrel{\circ}{g}\left(z_{\max }\right)^{2}}{L_{c}} \\
& \therefore T_{\max }=10,750^{\circ} \mathrm{F}
\end{aligned}
$$

With the above temperature distribution, 2.9 MWt of decay heat is transferred to the boiling sodium and 2.1 MWt is conducted through the catch pan to the NaK cooling coils.

The two inch diameter NaK loops on four inch centers can easily handle the $2.1 \mathrm{MWt}$. In fact, the NaK loops can handle much greater. heat loads, but the graphite catch pan would not be able to stand the higher temperatures. 
All of the above results indicate the severity of the heat removal problem. The decay power density of $0.5 \mathrm{MWt} / \mathrm{ft}^{3}$ corresponds to the decay heat rate $10,000 \mathrm{sec}(2.78 \mathrm{~h})$ after the accident. This factor along with the height of the conglomerate pool have the greatest effect on the temperature distribution.

\section{H. 10 RE FERENCES}

H-1 .Hicks, E.P. and Menzies, D. C., "Theoretical Studies of Fast Reactor Maximum Accident, " (ANL-7120).

H-2 Rees, N.J.M., "A Model Investigation of Explosion Containment in Single Tank Fast Reactors," (ANL-7120).

H-3 Cole, R., "Underwater Explosions," Dover Pub. , p. 241.

H-4 Drevon, G. A. V., et al., "Comparison of Pressure Loading Produced by Containment Explosions in Water and Sodium," (ANL-7120).

H-5 Wise, W.R. and Proctor, J.F., "Explosion Containment Laws for Nuclear Reactor Vessels," (Equation 9-1), (NOLTR-63-140). 


\section{ACKNOWLEDGMENTS}

The following personnel made a substantial contribution to the work described in this report:

'Control System Design - W: Taft, F. Suckow*

Control System Analysis - A. Brown, T. Fukushima

Closed Loop Design - N. Hansen, T. Wilson*

Open Loop Design - W. Taft

Inlet Plenum and Core Support - N. Hansen, T. Wilson*

Core Clamping - N. Hansen, T. Wilson*

Instrumentation Layout - T. Gleason, W. Butler*, GE R\& DC Instrumentation

Physics - S. Stewart, P. Vaughan, A. Hartman

Shielding - M. Weiss, P. Vaughan, P. Hendricksz

Subcriticality Analysis - H. Bailey

Thermal Hydraulic Analysis - T. Fukushima, A. Brown, R. Murata

Safeguards - N. Friedman, G. May

Systems - G. Kruger, W. Kendall, D. Mitome

Reliability/Availability -- J. Fleck GE R\&DC

Sodium Boiling Detection - K. Smith GE R\& DC

Fuel Design - F. Young

Vessel and Head - R. Lockhart, J. Cole, F. Suckow*

DBA Containment - A. Brown

Refueling and Reactor Servicing - G. Brynsvold, G. Phipps

Circumferential Fuel Pin Temperature Distribution - K. Cook

In addition to these contributors, managerial and technical guidance were provided by:

T. Brownell, * P. Greebler, G. Gyorey, K. Hikido, L. Nemeth, F. Rally, D.R. Riley,

H. Rubinstein, B. Wolfe.

APO Drafting. 
$\underline{\text { Copies }}$

Pacific Northwest Laboratory

120

FFT F Project

P. O. Box 220

Richland, Washington 99352

Attn: Supervisor of Configuration Contract 